\title{
Waste Isolation Pilot Plant 1999 \\ Site Environmental Report
}

Roy B. Evans, Ph.D.

Amy Adams Luft

Don Martin

Randall C. Morris, Ph.D.

Timothy D. Reynolds, Ph.D.

Ronald W. Warren

September 2000

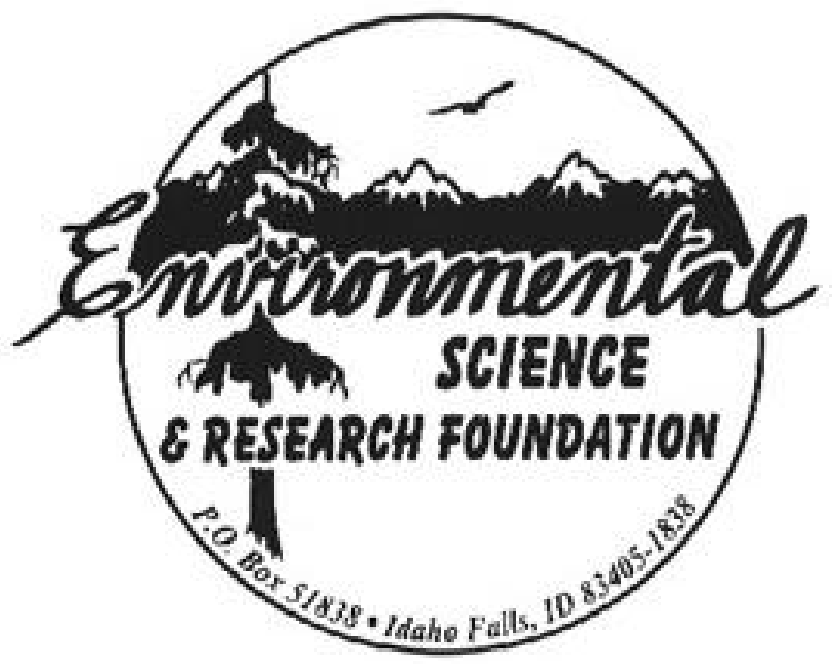

Dr. Roy B. Evans, Project Manager

Dr. O. Doyle Markham, Executive Director

Environmental Science and Research Foundation, Inc.

101 S. Park Avenue, Suite 2

P.O. Box 51838

Idaho Falls, ID 83405-1838

http://esrf.org 
This document has been reproduced directly from the best possible copy. It is available to DOE and DOE contractors from the following address:

Office of Scientific and Technical Information

P.O. Box 62

Oak Ridge, TN 37831

Prices available from (615) 576-8401

Available to the public from the National Technical Information Services

U.S. Department of Commerce 5285 Port Royal Road Springfield, Virginia 22161

Processing and final preparation of this report was performed by the Environmental Science and Research Foundation, Inc. for Waste Isolation Pilot Plant Management and Operating Contractor for the U.S. Department of Energy under Contract No. DE-AC01-86AL31950. 


\section{Acknowledgments}

The authors appreciate the reviews by Cynthia Zvonar of the U.S. Department of Energy Carlsbad Area Office (CAO), Joe Harvill of the CAO Technical Assistance Contractors (CTAC), and Marsha Beekman, Peter S. Damm, and Stewart Jones of Westinghouse Environmental Service Company, LLC, Waste Isolation Division (WID).

Stewart Jones served as the liaison between the WID and the Environmental Science and Research Foundation, Inc. and provided overall coordination between the two companies. Jim W. Kenney and Don Gray of the Environmental Evaluation Group provided radiological data for scientific comparisons in advance of releasing the data in their own report. Irene Joo provided assistance with ground-water monitoring data and was quick to respond to all queries.

Clerical and formatting work was done by Katie Dimick and Melissa Harwood of the Environmental Science and Research Foundation, Inc., and Carol Larsen and Shelly Greenhalgh of Executive Training Resources. Foundation Executive Director, Dr. Doyle Markham, provided thorough reviews. Randy Morris coordinated the writing of this report, and Amy Adams Luft supervised overall formatting, design, and editing. Greg Morgan of The Chartwell Group provided advice and assistance with the color figures.
Many WID groups contributed to this report, which would not have been complete and accurate without their assistance. WIPP laboratory personnel provided the gross alpha and gross beta results for the ambient air filters. Tony D. Donner reprocessed samples, as necessary, and provided information requested from the laboratory.

The WID Environmental Compliance Group was very helpful throughout the writing of this report: Rick R. Chavez, Koreen S. Guillermo, Jim R. Hollen, Jeff W. Knox, Steve C. Kouba, Wille A. Most, Carl S. Ortiz, Dan C. Robertson, Linda Frank-Supka, Miriam Whatley, and Cindy L. Woodin.

WIPP library staff Erin Bentley, Lata S. Desai, and Robin Wilson were very cooperative in locating any documents that were not available in the WIPP library.

The WID Environmental Monitoring Group implements U.S. DOE Order 5400.1, "General Environmental Protection Program," by providing the technical assistance to collect samples, analyze data, perform verification and validation, protect fauna and flora, implement land management activities, monitor ground water, and provide data for this report. 


\section{Executive Summary}

The U.S. Department of Energy's (DOE) Carlsbad Area Office and the Westinghouse Waste Isolation Division (WID) are dedicated to maintaining high quality management of Waste Isolation Pilot Plant (WIPP) environmental resources. DOE Order 5400.1, General Environmental Protection Program, and DOE Order 231.1, Environmental, Safety, and Health Reporting, require that the environment at and near DOE facilities be monitored to ensure the safety and health of the public and the environment. This Waste Isolation Pilot Plant 1999 Site Environmental Report summarizes environmental data from calendar year 1999 that characterize environmental management performance and demonstrate compliance with federal and state regulations.

This report was prepared in accordance with DOE Order 5400.1, DOE Order 231.1, the Environmental Regulatory Guide for Radiological Effluent Monitoring and Environmental Surveillance (DOE/EH- 0173T), and the Waste Isolation Pilot Plant Environmental Protection Implementation Plan (DOE/WIPP 96-2199). The above orders and guidance documents require that DOE facilities submit an Annual Site Environmental Report to DOE Headquarters, Office of the Assistant Secretary for Environment, Safety, and Health. The purpose of this report is to provide a comprehensive description of operational environmental monitoring activities, to provide an abstract of environmental activities conducted to characterize site environmental management performance to confirm compliance with environmental standards and requirements, and to highlight significant programs and efforts of environmental merit at WIPP during calendar year 1999.

WIPP received its first shipment of waste on March 26, 1999. In 1999, no evidence was found of any adverse effects from WIPP on the surrounding environment. Radionuclide con- centrations in the environment surrounding WIPP were not statistically higher in 1999 than in 1998.

\section{Introduction}

Located in southeastern New Mexico, WIPP is the world's first underground repository permitted to safely and permanently dispose of transuranic (TRU) radioactive and mixed waste generated through the research and production of nuclear weapons and other activities related to the national defense of the United States. TRU mixed waste is TRU waste mixed with hazardous waste regulated under the Resource Conservation and Recovery Act (RCRA). Transuranic waste consists of material contaminated with elements with atomic numbers greater than uranium, the heaviest natural element. Most TRU waste is contaminated industrial trash, such as rags, old tools, and rubbish from dismantled buildings.

WIPP's legislative mandate is to demonstrate the safe disposal of TRU wastes from national defense activities and programs. To fulfill this mandate, WIPP has been designed to safely handle, store, and dispose of TRU waste in a fully-operational disposal facility. When waste arrives at WIPP, it is placed in excavated storage rooms, carved from rock salt, $655 \mathrm{~m}(2,150 \mathrm{ft})$ below the earth's surface. The nature of the salt is such that after a storage room has been filled, the salt will slowly fill the remaining spaces, thus isolating the waste for thousands of years.

\section{Environmental Program Information}

It is DOE's policy to conduct its operations at WIPP in compliance with all applicable environmental laws and regulations, and to safeguard the integrity of the southeastern New Mexico environment. This is accomplished through radiological and nonradiological environmental monitoring programs and land management programs, which include wildlife 
monitoring and the WIPP Raptor Program. The purpose of these programs is to collect data needed to detect and quantify possible impacts WIPP may have on the surrounding environment and to provide technical support to DOE's Carlsbad Area Office in the fields of environmental science and land management.

Environmental activities at WIPP generally fall into four categories: collecting environmental samples and analyzing them for a variety of contaminants, preparing and publishing documents showing compliance with federal and state regulations, evaluating whether WIPP activities cause any environmental impacts, and taking corrective action when an adverse effect on the environment is identified.

WIPP's Environmental Monitoring Plan outlines the programs that monitor the environment on, and immediately surrounding, the WIPP site. It discusses major environmental monitoring and surveillance activities at WIPP and WIPP's quality assurance/quality control program as it relates to environmental monitoring.

WIPP's effluent monitoring and environmental surveillance programs are designed to determine adequate protection of the public and the environment during DOE operations, and to ensure that operations comply with DOE and other applicable federal and state radiation standards and requirements. The Environmental Monitoring Program monitors the pathways that radionuclides and other contaminants could take to reach the environment surrounding WIPP. Pathways monitored include air, ground water, surface water, soils, sediments, vegetation, and game animals. In addition, ground-water quality and environmental health are also monitored. The goal of the program is to determine if the local ecosystem has been impacted during the predisposal and disposal phases of WIPP, and, if so, to evaluate the severity, geographic extent, and environmental significance of those impacts. The Environmental Monitoring Program is conducted in compliance with DOE Orders 5400.1 and 5400.5 .
Southeastern New Mexico is home to an abundant array of wildlife. Wildlife species are monitored on the WIPP site to document any population changes that may occur as a result of WIPP activities. Species of special concern, including federally-listed threatened and endangered species, receive special consideration when planning WIPP activities that may impact wildlife habitat.

WIPP's Land Management Plan was created in accordance with the WIPP Land Withdrawal Act of 1992. This plan identifies resource values, promotes multiple-use management, and identifies long-term goals for the management of WIPP lands. In accordance with its Land Management Plan, WIPP follows a land reclamation program and a long-range reclamation plan. In 1999, reclamation on the Site Preliminary Design and Validation salt pile was initiated. WIPP also conducts oil and gas surveillances in the region surrounding the WIPP site to identify new activities associated with oil and gas exploration and production. In 1999, WIPP surveillance teams conducted 224 oil and gas surveillances in addition to routine bimonthly surveillances.

\section{Environmental Compliance}

WIPP is required to comply with all applicable federal and state laws and DOE orders. In 1999, WIPP maintained compliance with these laws and DOE orders.

\section{Comprehensive Environmental Response, Compensation, and Liability Act}

The Comprehensive Environmental Response, Compensation, and Liability Act (CERCLA) establishes a comprehensive federal strategy for responding to, and establishing liability for, releases of hazardous substances from a facility to the environment. No release sites have been identified at WIPP that would require cleanup under provisions of CERCLA. 


\section{Federal Acquisition, Recycling, and Pollu- tion Prevention}

In 1995, WIPP adopted a systematic and costeffective affirmative procurement plan for the promotion and procurement of products containing recovered materials. Affirmative procurement is designed to "close the loop" in the waste minimization recycling process by supporting the market for materials collected through recycling and salvage operations. In 1999, WID purchased 98 percent of items required by the Environmental Protection Agency (EPA) through its affirmative procurement program.

WIPP continued its recycling program in 1999. Increases of 100 to 300 percent above 1998 levels were realized for most recycled materials. In addition, a Pollution Prevention Opportunity Assessment was performed to address concerns of using an industrial cleaner containing a known carcinogenic compound, and process changes were made to reduce the leaded brine waste stream by 50 percent.

\section{Resource Conservation and Recovery Act}

The Resource Conservation and Recovery Act (RCRA) ensures that hazardous wastes are managed and disposed of in ways that protect human health and the environment. WIPP is subject to permitting requirements under RCRA and the New Mexico Hazardous Waste Act. Nonmixed TRU radioactive waste shipments began arriving at WIPP on March 26, 1999. Shipments were postponed after November 22, 1999, to address requirements of the Waste Isolation Pilot Plant Hazardous Waste Permit, which was issued on October 27, 1999, and went into effect on November 26, 1999.

WIPP is in compliance with permit reporting requirements. As required, a notice was sent on December 8, 1999, to inform individuals on the WIPP mailing list that DOE had established three repositories for information associated with corrective action activities at WIPP.

Currently, WIPP personnel are preparing a
WIPP Sampling and Analysis Plan for Solid Waste Management Units and Areas of Concern to comply with the RCRA permit. The Sampling and Analysis Plan has two objectives: to define the extent of concentrations of hazardous constituents that exceed background metal concentrations in soil at specific Solid Waste Management Units, and to perform a release assessment at specific Areas of Concern to determine if hazardous constituents are present above background concentrations.

\section{National Environmental Policy Act}

The National Environmental Policy Act (NEPA) requires the federal government to use all practicable means to consider potential environmental impacts of proposed federal projects as part of the decision-making process. NEPA dictates the public shall be allowed to review and comment on proposed projects that have the potential to significantly affect the environment. NEPA also directs the federal government to use all practicable means to improve and coordinate federal plans, functions, programs, and resources relating to human health and the environment.

Title 10 CFR $\S 1021.331$ requires that, following completion of each Environmental Impact Statement and its associated Record of Decision (ROD), DOE shall prepare a mitigation action plan that addresses mitigation commitments expressed in the ROD. DOE Order 451.1A requires DOE facilities to track and annually report progress in implementing a commitment for environmental impact mitigation. The 1998 Annual Mitigation Report for the Waste Isolation Pilot Plant was issued on June 28, 1999.

\section{Clean Air Act}

The Clean Air Act provides for the preservation, protection, and enhancement of air quality. Under section 109 of the Clean Air Act, the EPA established the National Ambient Air Quality Standards for six "criteria" pollutants. The initial WIPP hazardous air pollutant (HAP) emission inventory was developed as a baseline document to calculate maximum potential hourly 
and annual emissions of both hazardous and criteria pollutants. The HAPs inventory is conducted biennially and compared to baseline data to identify trends and potential emissions problems. The biennial inventory scheduled for calendar year 1998 was postponed because conditions at the site were unchanged from the previous inventory. The next inventory will be conducted in 2000. Based on the current HAPs inventory, WIPP operations do not exceed the 10ton-per-year emission limit for any individual pollutant or the 25-ton-per-year limit for any combination of pollutants.

Based on emission estimates generated in the HAPs inventory, the WIPP site is not required to obtain federal Clean Air Act permits. WIPP was required to obtain a New Mexico Air Quality Construction Permit for two primary backup diesel generators. During 1999, the generators were operated for approximately 31 of the 480 hours allowed by the permit. There were no malfunctions or abnormal conditions of operations that would cause a violation of the permit.

Title 40 CFR $\S 61$ requires WIPP to notify the EPA of its anticipated start date not more than 60 days and not less than 30 days before the actual start-up date. This notification was made on February 23, 1999; the actual start-up date was March 26, 1999. In addition, EPA required notification of the actual date of initial start-up be made within 15 days of actual start-up. The 15day notice of actual start-up was made on March 26, 1999.

\section{Clean Water Act}

Section 402 of the Clean Water Act established provisions for the issuance of permits for discharges into waters of the United States. WIPP has no pollutant discharges from point sources and is currently exempt from obtaining a National Pollutant Discharge Elimination System permit.

A permit for Storm Water Discharge Associated with Industrial Activity was issued in 1998. No sampling is required to demonstrate compliance with this permit unless a release occurs. Operational permit compliance activities are limited to quarterly inspections of retention basins, spill containment devices, reclamations sites, and site housekeeping practices. DOE submits quarterly discharge monitoring reports to the New Mexico Environment Department to demonstrate compliance with inspection, monitoring, and reporting requirements as identified in the WIPP Sewage System Discharge Plan.

\section{Safe Drinking Water Act}

The Safe Drinking Water Act provides the regulatory strategy for protecting public water supply systems and underground sources of drinking water. The WIPP water supply is categorized as a nontransient, noncommunity system for reporting and testing requirements. The water supply is sampled 10 times every three years for various chemical constituents. Samples were collected in July 1999 and the results were submitted to the New Mexico Environmental Department. All samples were below action levels as specified by New Mexico monitoring requirements for lead and copper in tap water. Bacterial samples were collected and reported monthly throughout 1999. All results were below Safe Drinking Water Act regulatory limits.

\section{National Historic Preservation Act}

The National Historic Preservation Act was enacted to protect the nation's cultural resources and establish the National Register of Historic Places. Federal agencies are required to ensure that historic and cultural properties are given proper consideration in the preparation of NEPArelated documents. No new archeological sites were discovered in 1999, nor were any WIPPrelated activities initiated that required archeological investigation.

\section{Hazardous Materials Transportation Act}

The Hazardous Materials Transportation Act is one of the major transportation-related statues that affects WIPP operations. It provides for the safe transportation of hazardous materials, including radioactive materials. DOE orders 
establish packaging and transportation criteria and require DOE field offices to conduct their operations in accordance with all applicable international, federal, state, local, and tribal laws, rules, and regulations governing materials transportation. These DOE orders also require the development of a transportation plan and use of the DOE TRANSCOM (transportation and tracking communications) system to monitor shipments.

\section{Packaging and Transporting Radioactive Materials}

The WIPP Land Withdrawal Act requires TRU waste containers shipped to WIPP be transported using packages which have had the design certified by the Nuclear Regulatory Commission (NRC) and which have been determined by the NRC to satisfied its quality assurance requirements. Contact-handled TRU waste will be shipped in TRUPACT-II and HalfPACT containers.

\section{Environmental Compliance Assessment Program}

The Environmental Compliance Assessment Program plays a major role in the overall program for environmental protection activities at WIPP. The program was developed to determine if facility activities protect human health and the environment and if these activities are in compliance with applicable federal, state, and local requirements; with permit conditions and requirements; and with best management practices. During 1999, six environmental compliance assessments were conducted. Fortysix improvements were identified and implemented as a result of these assessments.

\section{ISO 14000}

IS0 14001 is the specific section of the ISO 14000 standard devoted to Environment Management Systems. The WID Environmental Management System (EMS) received third-party registration on August 5, 1997. Two third-party registration surveillance audits were conducted in 1999. One minor nonconformance was identified during the March audit and the Environmental Policy was revised to include the EMS voluntary programs such as VPP and ISMS. No findings or observations were identified during the second surveillance conducted in August.

Several actions have been taken to more effectively implement the ISO 14001 Standard at WIPP. An ISO 14001 Integration Team has been formed and WIPP's ISO 14001 program is being integrated with other Westinghouse governmentowned, contractor-operated programs.

\section{Pollution Prevention Committee}

WIPP's Pollution Prevention Committee was formed in 1993. The committee celebrates Earth Day to promote awareness of waste minimization. In October 1999, Energy Month was celebrated by the committee with a display of solar powered equipment.

\section{Environmental Training}

Environmental training was provided to personnel associated with environmental operations at WIPP.

\section{Environmental Radiological Program Information}

Radionuclides present in the environment, whether naturally-occurring or from human-made sources, contribute to radiation doses to humans. Therefore, environmental monitoring around nuclear facilities is imperative for characterizing radiation conditions, and for detecting releases and determining their effects, should they occur. The WIPP Environmental Monitoring Program monitors air, surface and ground water, soils, and biota to characterize the radiation environment and to detect potential releases from WIPP activities.

\section{Effluent Monitoring}

If radionuclides are released into the environment from WIPP, they would first be detected in airborne effluents. Therefore, WIPP monitors airborne effluents from the facility at 
three locations. Station A samples underground exhaust air, Station B samples unfiltered underground exhaust air after HEPA filtration as well as unfiltered air during maintenance, and Station C samples air in the Waste Handling Building after HEPA filtration. Representative samples were composited each quarter and sampled for ${ }^{241} \mathrm{Am},{ }^{238} \mathrm{Pu}$, and ${ }^{239+240} \mathrm{Pu}$. Americium-241 was detected in composites from at least one station in each of the last three quarters. However, no values were over the decision level activity which represents background activity.

\section{Airborne Gross Alpha/Beta}

Gross alpha and beta measurements in airborne particulates are used as screening techniques to provide timely information on levels of radioactivity in the environment around the WIPP site. Airborne particulate samples were collected from seven locations around WIPP. Samples were collected weekly.

Weekly gross alpha activity concentrations measured in 1999 varied throughout the year at each location. Results from all of the sampling stations varied similarly throughout the year, indicating they were responding to the same environmental conditions. Only one measurement appeared to be an outlier. Analysis of Variance indicated no statistically significant differences between sampling stations.

The annual mean gross alpha activity concentrations found at each location in 1998 and 1999 were compared to determine whether gross alpha in air particulates had increased since waste has been stored at WIPP. A student's t-test was performed to determine if concentrations found in 1999 were statistically different from concentrations found in 1998 at each location. The concentrations were not found to be significantly different at any location.

In 1999, the weekly gross beta concentrations varied over almost an order of magnitude at each location. However, the annual concentrations of gross beta activities found at all locations were similar. The annual mean gross beta activity concentrations found at each location in 1999 were compared with those from 1998. No significant difference was found between years at any of the locations.

One duplicate sample was collected at a different location every quarter by rotating a portable sampler from one location to another. The samples were collected by two samplers in identical conditions at all four locations. Relative Error Ratios (RFR) were less than one in 96 percent of the weekly gross alpha and beta measurements, which indicates a good agreement between duplicates.

\section{Airborne Particulates}

The major pathways for the intake of radioactive materials in the human body are from the inhalation of dust particles and the ingestion of food and drinking water. Plutonium, the major constituent of TRU waste stored at WIPP, is mostly in an insoluble form. The uptake of insoluble materials through ingestion is very poor; therefore, inhalation is the major pathway for the intake of such radioactive materials. Accordingly, plutonium and other radionuclides of interest were determined in air particulate samples around WIPP.

Uranium-233+234 was detected in 64 percent of the samples, and in at least one sample from every location. Uranium-233+234 concentrations were not significantly different between locations or quarters. The concentration of ${ }^{235} \mathrm{U}$ in air particulate samples was lower than the minimum detectable concentration (MDC) throughout 1999. Uranium-238 was detected in 27 of the 28 composite air filters. There were not statistically significant differences in concentrations between sampling locations, but there were significant quarterly differences, with the second quarter having the highest ${ }^{238} \mathrm{U}$ concentration. Uranium$233+234,{ }^{235} \mathrm{U}$, and ${ }^{238} \mathrm{U}$ are all found naturally in the environment. The concentration of ${ }^{235} \mathrm{U}$ in the environment is much lower than the concentrations of ${ }^{233+234} U$ and ${ }^{238} U$.

Plutonium-238 was detected in composited air filters for the third quarter from one location and 
for the fourth quarter from another location. Detection is questionable for the third quarter result. The concentration of ${ }^{238} \mathrm{Pu}$ was below the MDC in each of the 26 other quarterly composites and the annual mean for every sampling location, including those closest to WIPP. Thus, the fourth quarter detection by itself does not indicate plutonium contamination of the environment.

Plutonium-239+240 was detected in quarterly composited air filters from the fourth quarter at one location. The concentration of ${ }^{239+240} \mathrm{Pu}$ was below the MDC in each of the 27 other quarterly composites and the annual mean for every sampling location. The one detection does not by itself indicate plutonium contamination of the environment. Concentrations of ${ }^{241} \mathrm{Am},{ }^{40} \mathrm{~K},{ }^{60} \mathrm{Co}$, ${ }^{90} \mathrm{Sr}$, and ${ }^{137} \mathrm{Cs}$ in each quarterly composite, and in annual means, were all below their MDC at all seven locations.

Duplicate samples were analyzed to check for reproducibility of the data. Relative error ratios were calculated to determine if the results from the duplicate samplers agreed with those from the regular samplers. For all results except two, the RERs were less than one, indicating a good agreement between regular and duplicate samples.

\section{Ground Water}

Ground-water samples were collected twice in 1999 from seven wells around WIPP and were analyzed for gamma-emitting radionuclides, ${ }^{90} \mathrm{Sr}$, uranium, plutonium, and americium. Isotopes of naturally-occurring uranium were detected in every well. The concentrations of ${ }^{233+234} U$ and ${ }^{238} \mathrm{U}$ were significantly different between wells, but no pattern related to WIPP activities could be determined. Uranium-235 did not differ between wells. The results for the concentrations of uranium isotopes in water samples collected in 1999 were compared with the results from 1998. There was no significant difference in concentrations of any uranium isotope between ground-water samples collected in 1998 and those collected in 1999.

Plutonium-238, ${ }^{239+240} \mathrm{Pu}$, and ${ }^{241} \mathrm{Am}$ were also analyzed. Plutonium-238 was detected in one sample from one well. However, the annual mean for ${ }^{238} \mathrm{Pu}$ levels for that well was below the detection limit for ${ }^{238} \mathrm{Pu}$. There was no statistical difference among ${ }^{238} \mathrm{Pu}$ concentrations between wells or between 1998 and 1999. Plutonium$239+240$ and ${ }^{241} \mathrm{Am}$ were nondetectable in all samples.

The results of measurements for ${ }^{40} \mathrm{~K},{ }^{60} \mathrm{Co}$, ${ }^{90} \mathrm{Sr}$, and ${ }^{137} \mathrm{Cs}$ were only reported by the laboratory for autumn sampling. Strontium-90 was detected in one well. All other concentrations of all four radionuclides were below the MDC.

\section{Surface Water}

Surface water samples were collected once from 12 locations around WIPP in 1999. In two cases where a surface water sampling location was dry, sediment at the location was collected instead. Uranium-238 was detected in surface water at every sampling location and ${ }^{235} \mathrm{U}$ was detected in 42 percent of the sampling locations. Uranium-233+234 was detected in 83 percent of the samples. There were no significant differences between concentrations of uranium isotopes between 1998 and 1999. Differences among sampling locations were detected for each uranium isotope. Large spatial variations in uranium concentrations in surface water are expected because of the different characteristics of the water bodies and the underlying sediments.

Plutonium-238, ${ }^{239+240} \mathrm{Pu}$, and ${ }^{241} \mathrm{Am}$ were also measured. Measured concentrations for all of these radionuclides were below the MDC. Additionally, no ${ }^{40} \mathrm{~K},{ }^{60} \mathrm{Co},{ }^{90} \mathrm{Sr}$, and ${ }^{137} \mathrm{Cs}$ were found in surface waters in 1999. A duplicate sample was collected at one sampling location. The results for uranium isotopes were compared between the original and the duplicate sample. The RER values were less than one, indicating no difference between samples.

\section{Soil Samples}

Soil samples were collected from six locations surrounding WIPP. Samples from each location were collected at three different depths. Measurements of radionuclides in depth profiles 
provide information about their vertical movements in soil systems.

Uranium-233+234 was detected in every soil sample in 1999 and ${ }^{238} \mathrm{U}$ was detected in all but one. Uranium-235 was detected in three of the 18 samples. The concentration of ${ }^{233+234} U$ varied significantly between sampling locations. However, all measured concentrations fell within the range of natural concentrations of uranium found in soils throughout the world. There was no statistically significant difference in the concentrations of any uranium isotope with depth. Uranium-233+234 and ${ }^{238} \mathrm{U}$ varied significantly between 1998 and 1999. For both isotopes, the mean concentration was higher in 1998 than in 1999. All of these results suggest a natural variability consistent with the existence of natural uranium.

Plutonium-238, ${ }^{239+240} \mathrm{Pu}$, and ${ }^{241} \mathrm{Am}$ were also measured in soil samples. Neither ${ }^{241} \mathrm{Am}$ nor ${ }^{238} \mathrm{Pu}$ were detected in any samples. Plutonium$239+240$ was detected in one sample at the intermediate depth. The absence of any other detectable $\mathrm{Pu}$ indicates this finding is likely not the result of releases from WIPP.

Potassium-40 was detected in every sample. This naturally-occurring radionuclide is ubiquitous in soils. The concentration of ${ }^{40} \mathrm{~K}$ did not vary significantly between depths or between 1998 and 1999. However, there were significant differences seen between sampling locations. The range of concentrations observed are consistent with average natural ${ }^{40} \mathrm{~K}$ concentrations around the world.

Neither ${ }^{60} \mathrm{Co}$ nor ${ }^{90} \mathrm{Sr}$ was detected in any soil sample. However, two human-made radionuclides, ${ }^{58} \mathrm{Co}$ and ${ }^{65} \mathrm{Zn}$, were detected. These detections are unusual because both radionuclides have short half lives and were detected in subsurface soils. This combination makes it very likely these were anomalous results. Short-lived radionuclides detected on the surface could be explained as accidental releases; shortlived radionuclides at depth cannot easily be explained. This interpretation is supported by the large analytical uncertainties associated with both of these measurements.

Cesium-137 was detected in 10 of 18 soil samples. Although ${ }^{137} \mathrm{Cs}$ is a fission product, and a potential component of waste stored at WIPP, it is ubiquitous in soils because of global fallout from atmospheric nuclear weapons testing. There was no significant difference in the concentration of ${ }^{137} \mathrm{Cs}$ in soils around WIPP between 1998 and 1999, nor were there significant differences in ${ }^{137} \mathrm{Cs}$ concentrations between sampling locations or soil depths.

\section{Sediments}

Sediment samples were collected from 12 locations around the WIPP site, mostly from the same water bodies from which the surface water samples were collected. Uranium-233+234 and ${ }^{238} \mathrm{U}$ were detected in every sediment sample in 1999. Uranium-235 was detected in 42 percent of the samples. None of the uranium isotopes varied significantly between sampling locations or between 1998 and 1999. All concentrations of uranium were within the range of natural concentrations found in soils throughout the world.

Neither ${ }^{238} \mathrm{Pu}$ nor ${ }^{239+240} \mathrm{Pu}$ were detected in any sediment sample in 1999. Americium-241 was detected in seven of the 12 samples. The concentration of ${ }^{241} \mathrm{Am}$ was not significantly different between sampling locations or between 1998 and 1999. Strontium-90 was detected in one sample, and ${ }^{137} \mathrm{Cs}$ was detected in 42 percent of the sediment samples. Cobalt- 60 was not detected in any of the samples. None of these radionuclides had sufficient detections to justify statistical comparisons between locations or years.

Potassium was detected in all sediment samples. Potassium-40 concentrations did not vary significantly between 1998 and 1999 , but ${ }^{40} \mathrm{~K}$ did vary significantly between locations. The concentration range measured in 1999 was similar to the average concentration of ${ }^{40} \mathrm{~K}$ found in soils throughout the United States. 
Duplicate samples were performed for all radionuclides in one sediment sample. The RER was less than one, indicating acceptable correspondence between the original and duplicate samples, for all radionuclides except for ${ }^{238} \mathrm{U}$.

\section{Biota}

The concentration of radionuclides in plants is an important factor in estimating the intake of individual radionuclides by humans through ingestion. Therefore, rangeland vegetation samples were collected from the same six locations where soil samples were collected. Also collected were muscle tissues from three roadkilled deer and a composite of several quail, both species commonly consumed by humans. Fish samples were taken from three different locations on the Pecos River. The whole fish and the muscle tissue from the deer and quail were analyzed for radionuclides.

Uranium-233+234 was detected in five of the six vegetation samples and ${ }^{238} U$ was detected in all vegetation samples. Uranium-235 was not detected in any of the vegetation samples. The concentrations of ${ }^{233+234} \mathrm{U}$ and ${ }^{238} \mathrm{U}$ did not vary significantly between locations, but they did vary significantly between 1998 and 1999. Average concentrations were higher in 1998 than 1999, which is consistent with what was seen in the soil. Concentrations of ${ }^{241} \mathrm{Am},{ }^{238} \mathrm{Pu}$, and ${ }^{239+240} \mathrm{Pu}$ were equal or less than the MDC in every sample. Potassium-40 was detected in five of the six vegetation samples and ${ }^{90} \mathrm{Sr}$ was detected in all vegetation samples. No other radionuclides of interest were detected in vegetation samples. Neither ${ }^{40} \mathrm{~K}$ nor ${ }^{90} \mathrm{Sr}$ varied significantly between locations. Strontium-90 did not vary between 1998 and 1999; however, the concentration of ${ }^{40} \mathrm{~K}$ in vegetation was significantly different between 1998 and 1999, with the 1999 mean being higher than the 1998 mean. As the primary source for potassium in plant tissues is the soil, the difference between soil results (no significant difference between 1998 and 1999) and plant results is difficult to explain. However, uptake of radionuclides and contamination by resuspension are highly species dependent and sometimes different between plants of the same species collected adjacent to one another. The difference may be related to a difference in the species mix sampled between years.

A duplicate analysis of one vegetation sample was performed. Concentrations of ${ }^{233+234} \mathrm{U},{ }^{238} \mathrm{U}$, ${ }^{40} \mathrm{~K}$, and ${ }^{90} \mathrm{Sr}$ were detected in the duplicate sample. The RER for ${ }^{90} \mathrm{Sr}$ was less than one, but the RERs for the remaining radionuclides were greater than one, indicating that laboratory results were not reproduceable.

Of radionuclides of interest, only the naturally-occurring radionuclide ${ }^{40} \mathrm{~K}$ was detected in deer tissue. The mean concentration of ${ }^{40} \mathrm{~K}$ was similar to that found in other mammals throughout the world. No radionuclides were found in the quail. Uranium-233+234 was detected in every fish sample and ${ }^{238} U$ was detected in two of the three fish samples. Strontium-90 was also detected in two of the three samples and ${ }^{40} \mathrm{~K}$ was detected in all fish. Americium-241, ${ }^{238} \mathrm{Pu}$, and ${ }^{239+240} \mathrm{Pu}$ were not detected in fish. Potassium-40 is present naturally in the environment, while ${ }^{90} \mathrm{Sr}$ is present in the environment worldwide as a result of fallout from above-ground nuclear weapons tests.

There were no statistically significant differences between concentrations of radionuclides in fish at any location. However, there was a significant difference between 1998 and 1999 for ${ }^{233+234} \mathrm{U}$ and ${ }^{40} \mathrm{~K}$. Uranium-233+234 was higher in 1998 and ${ }^{40} \mathrm{~K}$ was higher in 1999. This is attributable to natural variability because both radionuclides are naturally-occurring and are not major components of the waste stored at WIPP.

\section{Environmental Nonradiological Pro- gram Information}

Nonradiological environmental surveillance programs at WIPP include land management programs (including reclamation of disturbed lands, oil and gas surveillance, and wildlife population monitoring) and meteorological monitoring. In addition to nonradiological environmental surveillance programs, volatile 
organic compounds (VOCs) were monitored to comply with provisions of WIPP's hazardous waste permit, and liquid effluent monitoring was conducted in accordance to WIPP Sewage System Discharge Plan criteria.

The principal functions of the WIPP nonradiological environmental surveillance program are to:

- $\quad$ assess the impacts of WIPP construction and operations activities on the surrounding ecosystem;

- monitor ecological conditions in the Los Medaños region;

- investigate unusual or unexpected elements in the ecological databases;

- provide environmental data which are important to the mission of the WIPP project, but which have not or will not be acquired by other programs; and

- comply with applicable commitments identified with existing agreements.

\section{WIPP Raptor Program}

The WIPP Raptor Program was established in the early 1990s to monitor and protect raptors on the WIPP site, and to educate site workers and the public about these birds. The program presently serves four functions: wildlife monitoring, scientific research, community outreach, and interagency cooperation. In 1999, research continued on long-term studies of productivity and population demographics of the raptor community in and around WIPP. One study specifically targeted the behavioral ecology of the Harris' hawk, while another investigated breeding activity and nesting behavior of Swainson's hawks. In addition to ongoing studies, a pilot study was initiated in 1999 to evaluate methods for observing Swainson's hawks at the nest.

\section{Meteorology}

The annual precipitation at WIPP for 1999 was $200 \mathrm{~mm}$ (7.8 in). While precipitation in 1999 was greater than 1998, the total precipitation during 1999 was still below average. The mean annual temperature at WIPP was $18^{\circ} \mathrm{C}\left(64^{\circ} \mathrm{F}\right)$. Winds near WIPP blew predominantly from the southeast during 1999.

\section{Volatile Organic Compound Monitoring}

The volatile organic compound monitoring program is designed to measure VOC concentrations attributable to hazardous waste disposal units (panels) which are either open and are in the process of being filled or which are full and have been closed. Nine target compounds, which contribute approximately 99 percent of the calculated human health risks from RCRA constituents, are monitored. Sampling for target compounds is done at two air monitoring stations. One station monitors air found in the mine before it has passed through the panels containing the waste, while the other station monitors air that has passed through the waste panels. Differences measured between the two stations represent VOC contributions from the waste panels.

In 1999, only three (chlorobenzene, methylene chloride, and toluene) of the nine target compounds were measured above the detection limit. None of these compounds were found at an average concentration greater than 0.06 percent of the concentration of concern as listed in WIPP's hazardous waste permit. For each compound, 88 sample pairs (the difference between the first and second sampler) were compared. Positive sample pair differences were found in 12 of the 88 sample pairs for methylene chloride, 29 of 88 sample pairs for toluene, and one of 88 sample pairs for chlorobenzene, indicating there were differences in concentrations of these compounds between air samples collected before and after the waste panels.

\section{Seismic Activity}

Locations of 120 seismic events within 300 $\mathrm{km}(186 \mathrm{mi})$ of WIPP were recorded in 1999. The strongest recorded event (magnitude 4.0) was located about $80 \mathrm{~km}(50 \mathrm{mi})$ west-northwest of WIPP. These seismic events had no effect on WIPP structures. 


\section{Liquid Effluent Monitoring}

The WIPP sewage lagoon system is a zerodischarge facility. The entire facility is lined with 30-mil synthetic liners and is designed to dispose of domestic sewage as well as site-generated brine waters. The facility is operated under the WIPP Sewage System Discharge Plan and is managed in accordance with EPA sewage sludge regulations, New Mexico Solid Waste Management Regulations, New Mexico Water Quality Control Regulations, and applicable WIPP controlled procedures.

\section{Ground-water Monitoring}

Current ground-water monitoring activities at WIPP are outlined in the Groundwater Surveillance Program Plan. The objectives of the WIPP Ground-water Monitoring Program are to:

- determine the physical and chemical characteristics of ground water;

- maintain surveillance of ground-water levels surrounding the WIPP facility, both before and throughout the operational lifetime of the facility;

- document and identify effects, if any, of WIPP operations on ground-water parameters; and

- fulfill the requirements of the RCRA Part B Permit Application and DOE Order 5400.1.

Data obtained by the WIPP Ground-water Monitoring Program supports two major programs at WIPP: (1) the RCRA Detection Monitoring Program, and (2) performance assessments supporting the Compliance Certification Application.

Ground-water monitoring activities during 1999 included ground-water quality sampling and ground-water level surveillance. Ground-water quality data were gathered from six wells in the Culebra member of the Rustler Formation and one well in the Dewey Lake Formation. Field analyses for Eh (Intensity Factor: an indicator of oxidation or reduction of chemical species), specific gravity, specific conductance, acidity or alkalinity, chloride, divalent cations, and total iron were performed on a periodic basis during serial sampling.

Because no hazardous wastes were shipped to WIPP before or during 1999, the results of ground-water sampling from 1999 and all previous sampling will be used to calculate baseline data for ground-water quality for the New Mexico Environmental Department Hazardous Waste Permit.

Ground-water surface elevations in the vicinity of WIPP may be influenced by site activities, such as pumping tests for site characterization, water quality sampling, or shaft sealing. In October 1988, WIPP was tasked with conducting a Ground-water Level Surveillance Program. Ground-water surface elevation data were gathered from 70 well bores, five of which were equipped with production-inflated packers to allow ground-water level surveillance of more than one producing zone through the same well bore. These well bores were used to perform surveillance of eight water-bearing zones in the WIPP region. The two zones of primary interest were the Culebra and Magenta members of the Rustler Formation. Ground-water elevation measurements in the Culebra member indicated the generalized directional flow of ground water was north to south in the vicinity of WIPP.

Regional ground-water levels taken in Culebra observation wells with four or more data points for the year showed increasing trends in water levels in 49 wells and decreasing trends in nine wells. Total fluctuations of more than $0.6 \mathrm{~m}(2 \mathrm{ft})$ in ground-water levels occurred in six wells completed to the Culebra. The fluctuations in three of these wells may have been influenced by ground-water sampling activities. Two wells experienced water-level fluctuations due to maintenance activities. The water level in one well continued a rising trend, of unknown cause, dating back to its completion in 1977.

Ground-water modeling efforts for 1999 developed a particle-based flow simulation, estimating the minimum travel time from the center of WIPP to the farthest boundary to be about 880 years. To date, there is no indication 
WIPP operations have had a measurable impact on either the level or the quality of ground water underlying WIPP.

\section{Radiological Dose Assessment}

The potential radiation dose to members of the public from WIPP operations was calculated to demonstrate compliance with federal regulations and DOE's policies and objectives of keeping this dose as low as possible.

\section{Dose Limits}

For more than 50 years, extensive research has been conducted on the effects of radiation on humans and the environment. Much of this research used standard epidemiological and toxicological approaches to characterize the response of populations and individuals to high radiation doses. From this, a good understanding of the risks associated with high radiation doses was achieved. However, there is still uncertainty as to what risks are incurred from low radiation dose and dose rates, so models are used to predict these risks.

Regulatory dose limits are set well below where measurable health effects have been observed. Environmental radiation protection standards for the management and disposal of TRU radioactive wastes set limits on the total radiation dose to members of the public at 0.25 $\mathrm{mSv} / \mathrm{y}(25 \mathrm{mrem} / \mathrm{y})$ to the whole body and 0.75 $\mathrm{mSv} / \mathrm{y}(75 \mathrm{mrem} / \mathrm{y})$ to any critical organ. National standards for emissions of radionuclides from DOE facilities state that the maximum dose to any member of the public from air emissions must be no greater than $0.1 \mathrm{mSv} / \mathrm{y}(10 \mathrm{mrem} / \mathrm{y})$. The Safe Drinking Water Act states that average annual concentrations of beta- and gamma-emitting human-made radionuclides in drinking water shall not result in a dose greater than $0.04 \mathrm{mSv} / \mathrm{y}$ (4 $\mathrm{mrem} / \mathrm{y}$ ). It is important to note that all of these dose limits are set for doses due to radionuclides released to the environment from DOE operations. They do not include, but are limits in addition to, doses from natural background radiation or from medical procedures.

\section{Background Radiation}

Radiation is a naturally-occurring phenomenon that has been in the environment since the beginning of time. There are several sources of natural radiation: cosmic and cosmogenic radiation (from outer space and the earth's atmosphere), terrestrial radiation (from the earth's crust), and internal radiation (naturallyoccurring radiation in our bodies). In addition to natural radioactivity, small amounts of radioactivity from the 1986 Chernobyl nuclear accident and above-ground nuclear weapons tests that occurred from 1945 to 1980 are also present in the environment. Together, these sources of radiation are called "background" radiation. Every human is constantly exposed to background radiation. Exposure to radioactivity from weapons testing fallout is quite small compared to natural radioactivity and continually gets smaller as radionuclides decay. The average annual dose received by a member of the public from naturally-occurring radionuclides is about $3 \mathrm{mSv}$ (300 mrem).

\section{Dose from Air Emissions}

The National Emission Standards for Hazardous Air Pollutants issued by the EPA set limits for doses due to radionuclide emissions to air. To determine the potential radiation dose received by members of the public from WIPP, WID used the computer model CAP88-PC, version 2.0. CAP88 dose calculations are based on the assumption that exposed persons remain at home during the entire year and all vegetables, milk, and meat consumed are home produced. Thus, this dose calculation is a maximum potential dose which encompasses dose from inhalation, submersion, deposition, and ingestion of air emitted radionuclides.

For 1999, the CAP88 model predicted the highest dose to someone residing near WIPP to be at the Smith Ranch, approximately $4 \mathrm{~km}(2.5 \mathrm{mi})$ northwest of WIPP. Results showed the whole body dose potentially received by someone residing at this location to be about $2.2 \times 10^{-8} \mathrm{mSv}$ $\left(2.2 \times 10^{-6} \mathrm{mrem}\right)$ per year. The critical organ dose was less than $3.9 \times 10^{-7} \mathrm{mSv}\left(3.9 \times 10^{-5} \mathrm{mrem}\right)$ per 
year. This potential whole body dose is $2.2 \times 10^{-5}$ percent of the whole body dose limits of $0.1 \mathrm{mSv}$ (10 mrem) per year specified in 40 CFR $\S 61.92$. The dose to a hypothetical person residing yearround at the WIPP fence line was estimated to be $3.1 \times 10^{-7} \mathrm{mSv}\left(3.1 \times 10^{-5} \mathrm{mrem}\right)$ per year whole body and $5.3 \times 10^{-6} \mathrm{mSv}\left(5.3 \times 10^{-4} \mathrm{mrem}\right)$ per year to the critical organ.

\section{Total Potential Dose from WIPP Opera- tions}

The potential dose to an individual from the ingestion of WIPP-related radionuclides transported in water is estimated to be nonexistent. Drinking water for communities near WIPP comes from ground-water sources which are not expected to be affected by potential WIPP contaminants. Ground-water and surface water samples collected around WIPP during 1999 did not contain radionuclide concentrations different from those in samples collected prior to WIPP receiving waste.

Game animals sampled during 1999 were mule deer, quail, and fish. No radionuclides were detected in quail and those detected in deer and fish were not different from background levels measured prior to commencement of waste shipments to WIPP. Therefore, no dose from WIPP-related radionuclides is estimated to have been received by any individual from this pathway during 1999.

The only pathway for which a dose could be estimated was that of air emissions. Air emissions from WIPP were not considered above background ambient air levels. Estimated concentrations of radionuclides in air emissions accounted for the calculable dose from WIPP operations during 1999. The total dose from the air pathway (see "Dose from Air Emissions," above), was $8.8 \times 10^{-6}$ percent of the whole body dose limits of $0.25 \mathrm{mSv}$ ( 25 mrem) per year from all sources and $5.2 \times 10^{-5}$ percent of the dose limit of $0.75 \mathrm{mSv}$ ( $75 \mathrm{mrem}$ ) per year to the critical organ for all sources (40 CFR $\S 191.03$ ). The dose to a hypothetical person residing year-round at the WIPP fence line was estimated to be $1.2 \times 10^{-4}$ percent of the whole body dose limit of
$0.25 \mathrm{mSv}$ ( $25 \mathrm{mrem})$ per year from all sources and $7.1 \times 10^{-4}$ percent of the dose limit of $0.75 \mathrm{mSv}(75$ mrem) to the critical organ from all sources.

\section{Dose to non-human Biota}

DOE Order 5400.5 lists the environmental radiation protection requirements that WIPP must meet to protect aquatic animals. In addition, dose limits below which no deleterious effects on populations of aquatic and terrestrial organisms have been observed have been discussed by the National Counil on Radiation Protection and Measurements and the International Atomic Energy Agency. Those dose limits are:

- Aquatic Animals $10 \mathrm{mGy} / \mathrm{d}(1 \mathrm{rad} / \mathrm{d})$

- Terrestrial Plants $10 \mathrm{mGy} / \mathrm{d}(1 \mathrm{rad} / \mathrm{d})$

- Terrestrial Animals $1 \mathrm{mGy} / \mathrm{d}(0.1 \mathrm{rad} / \mathrm{d})$

DOE requires discussion of radiation doses to non-human biota in the Annual Site Environmental Report using the Interim Technical Standard, DOE-STD-XXXX-00, A Graded Approach for Evaluating Radiation Doses to Aquatic and Terrestrial Biota. The Interim Technical Standard uses a multi-phase approach, including an initial screening phase with conservative assumptions. In the initial screen, maximum concentrations of radionuclides detected in soil, sediment, and water during environmental monitoring are divided by Biota Concentration Guides (BCG), concentrations of radioactivity in the sampled media which would provide a radiation dose equal to the appropriate limits. These fractions are summed for each organism and, if the sum of fractions is less than 1 , the site is deemed to have passed the screen and no further action is required. This screening evaluation is intended to provide a very conservative evaluation of whether the site is in compliance with the recommended limits.

This guidance was used to screen radionucide concentrations observed around WIPP during 1999. The sum of fractions was less than one for all media, demonstrating compliance with the proposed rule. Radiation in the environment surrounding WIPP does not have a deleterious effect on populations of plants and animals. 


\section{Quality Assurance}

The fundamental objective of a quality assurance (QA) program is to ensure high-quality measurements are produced and reported from the analytical laboratory. The defensibility of data generated by laboratories must be based on sound scientific principles, method evaluations, and data verification and validation. Thermo NuTech, of Albuquerque, NM; Air Toxics, Ltd. of Folsom, CA; and Trace Analysis, of Lubbock, TX, were the contract laboratories that performed the radiological and nonradiological analyses for WIPP environmental samples. The WIPP laboratory performed the gross alpha and gross beta analyses on weekly air dust samples.

The WID Environmental Monitoring Section performed assessments and audits to ensure the quality of the systems, processes, and deliverables was maintained or improved in 1999. Along with these regulatory requirements, the Environmental Monitoring Section also implements DOE Order 414.1, Quality Assurance. The parameters for performance evaluations are completeness, reproducibility, accuracy, comparability, and representativeness.

\section{Completeness}

The completeness parameter was calculated as the ratio of the number of valid results to the total number of samples collected and analyzed. The Environmental Monitoring Program's overall data quality objective of 98 percent completeness for environmental samples was achieved during 1999.

\section{Reproducibility}

The reproducibility of the measurements was validated through analysis of duplicate samples. A low-volume air sampler was rotated in each quarter from location to location and sampled along with routine samples. The duplicate samples for other matrices were collected at the same time, same place, and under similar conditions as routine samples. These samples were analyzed in the same analytical batch and/or sample delivery group using similar methods for radiochemical separations and counting as original samples. The RER of the duplicate air samples was calculated. Of the 98 RER values calculated for duplicate air samplers, 95 had RER values equal or less than one, which are considered to demonstrate reproducibility.

\section{Accuracy and Comparability}

The accuracy of the analyses were assured/controlled by using National Institute of Standards and Technology-traceable standards for instrument calibration. Internal quality control is performed by using spiked laboratory control samples. Intercomparisons were performed with the DOE Environmental Measurements Laboratory to ensure the reliability of radiochemical separation methods and counting instruments. Accuracy is expressed in terms of percent bias.

Thermo NuTech participated in this program. The laboratory's percent bias in evaluating air filters was not acceptable for ${ }^{54} \mathrm{Mn},{ }^{239} \mathrm{Pu},{ }^{90} \mathrm{Sr}$, and ${ }^{238} \mathrm{U}$. The gross alpha and gross beta analyses for air filters were not acceptable.

The reported values for ${ }^{214} \mathrm{Bi},{ }^{214} \mathrm{~Pb},{ }^{212} \mathrm{~Pb}$, ${ }^{239} \mathrm{Pu}$, and ${ }^{234} \mathrm{Th}$ in the soil matrix were not acceptable. All the reported values for radionuclides in the vegetation samples were acceptable, and all but one of the reported values for radionuclides in the water samples were acceptable; the reported value for ${ }^{234} \mathrm{U}$ had a negative bias of 24.3 percent.

Thermo NuTech's failure of these laboratory intercomparisons is of concern. However, because of the low values being measured and the large uncertainties associated with them, this failure does not invalidate the conclusion that WIPP has not released radioactivity into the environment.

Environmental Resource Associates provides an interlaboratory assessment of the analysis for volatile organics. Air Toxics participated in this assessment and received a score of 100 percent and an overall assessment of "excellent." Environmental Resource Associates also provides an interlaboratory assessment of the analysis for 
water pollutants. Trace Analysis participated in this assessment and received a score of 80.8 percent and an overall assessment of "good."

\section{Representativeness}

The quality objective of representativeness was based on potential radiation exposure of the population through inhalation and ingestion. Samples of ambient air, surface water, sediment, ground water, and biota were collected from areas representative of potential pathways for intake.
The samples were collected using generally accepted methodologies for environmental sampling and approved procedures, ensuring they were representative of the media sampled. These samples were analyzed for natural radioactivity, fallout radioactivity from nuclear weapons tests, and other anthropogenic radionuclides. The reported concentrations at various locations were representative of the baseline information for radionuclides of interest at the WIPP facility. 


\section{Table of Contents}

Acknowledgments $\ldots \ldots \ldots \ldots \ldots \ldots \ldots \ldots \ldots \ldots \ldots \ldots \ldots \ldots \ldots \ldots \ldots$

Executive Summary $\ldots \ldots \ldots \ldots \ldots \ldots \ldots \ldots \ldots \ldots \ldots \ldots \ldots \ldots$

List of Tables $\ldots \ldots \ldots \ldots \ldots \ldots \ldots \ldots \ldots \ldots \ldots \ldots \ldots \ldots \ldots \ldots \ldots \ldots$

List of Figures $\ldots \ldots \ldots \ldots \ldots \ldots \ldots \ldots \ldots \ldots \ldots \ldots \ldots \ldots \ldots \ldots \ldots \ldots$

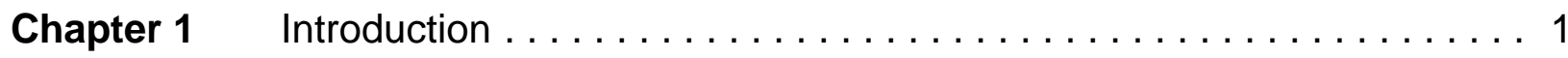

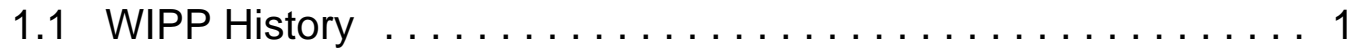

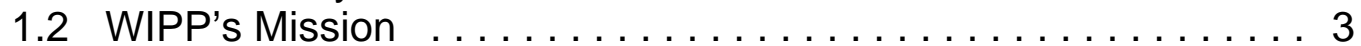

1.3 WIPP Location ........................ 3

1.3.1 WIPP Property Areas $\ldots \ldots \ldots \ldots \ldots \ldots \ldots \ldots$

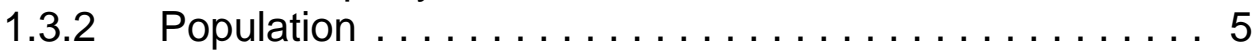

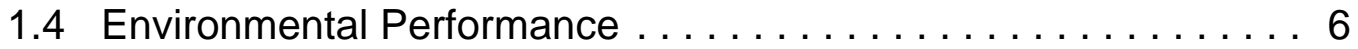

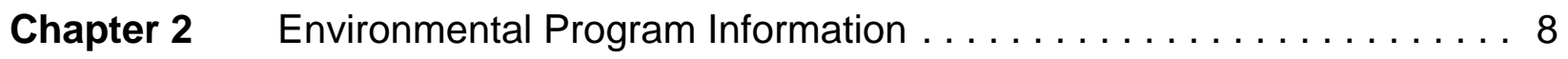

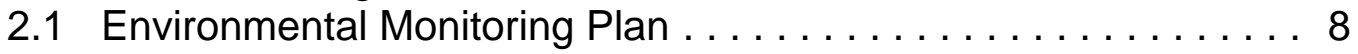

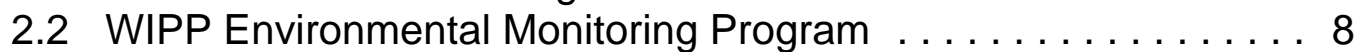

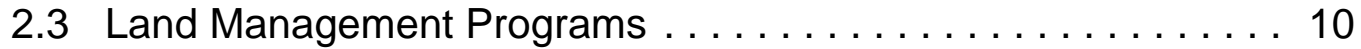

2.3.1 Land Use Requests . . . . . . . . . . . . . . . 11

2.3.2 Wildlife Population Monitoring ............. 11

2.3.3 Reclamation of Disturbed Lands ............. 13

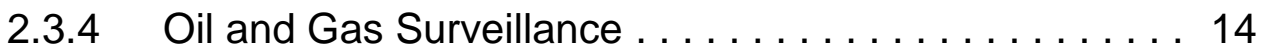

2.3.5 Aerial Photography .................. 15

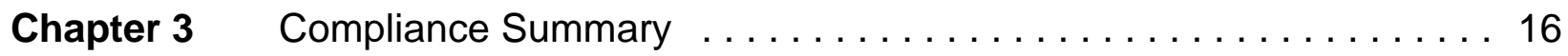

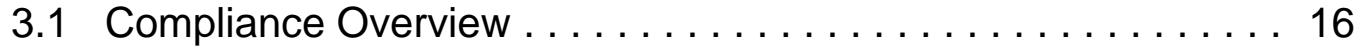

3.2 Compliance Status ................... 16

3.2.1 Comprehensive Environmental Response,

Compensation, and Liability Act ........... 16

3.2.2 Federal Acquisition, Recycling, and

Pollution Prevention ................. 17

3.2.3 Resource Conservation and Recovery Act ........ 18

3.2.4 National Environmental Policy Act . . . . . . . . . . 20

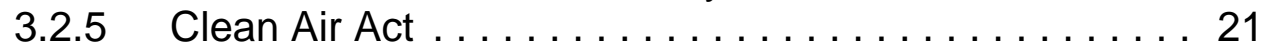


3.2.6 Clean Water Act . . . . . . . . . . . . . . . 22

3.2.7 Safe Drinking Water Act . . . . . . . . . . . . 23

3.2.8 National Historic Preservation Act . . . . . . . . . . . 24

3.2.9 Hazardous Materials Transportation Act . . . . . . . . . 24

3.2.10 Packaging and Transporting

Radioactive Materials .................... 24

3.3 Other Significant Accomplishments and Ongoing

Compliance Activities ..................... 25

3.3.1 Environmental Compliance Assessment Program . . . 25

3.3.2 ISO 14000 - Standards for Environmental

Management ..................... 25

3.3.3 Pollution Prevention Committee . . . . . . . . . . . 26

3.3.4 Environmental Training . . . . . . . . . . . . 26

Chapter $4 \quad$ Environmental Radiological Program Information $\ldots \ldots \ldots \ldots . .34$

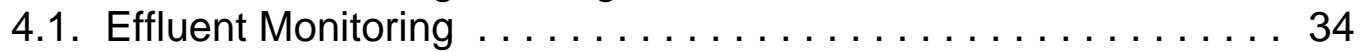

4.2 Airborne Gross Alpha/Beta . . . . . . . . . . . . . . . 36

4.3 Airborne Particulate ...................... 40

4.3.1 Sample Preparation ................. 41

4.3.2 Determination of Individual Radionuclides . . . . . . . . 41

4.3.3 Results and Discussions .................. 41

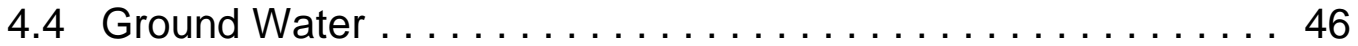

4.4.1 Sample Collection .................. 46

4.4.2 Determination of Individual Radionuclides . . . . . . . . 46

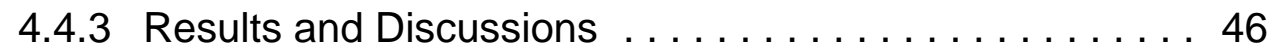

4.5 Surface Water .......................... 50

4.5.1 Sample Collection ................. 50

4.5.2 Determination of Individual Radionuclides . . . . . . . . 50

4.5.3 Results and Discussions . . . . . . . . . . . . . 51

4.6 Soil Samples ......................... 56

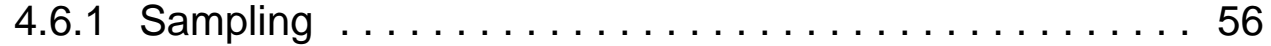

4.6.2 Sample Preparation ................... 56

4.6.3 Determination of Individual Radionuclides . . . . . . . . 56

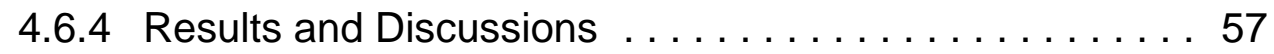

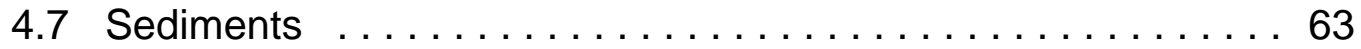

4.7.1 Sample Collection .................... 63

4.7.2 Sample Preparation .................. 63

4.7.3 Determination of Individual Radionuclides . . . . . . . . 63

4.7.4 Results and Discussions . . . . . . . . . . . . 63

4.8 Biota . . . . . . . . . . . . . . . . . . . . . . 69

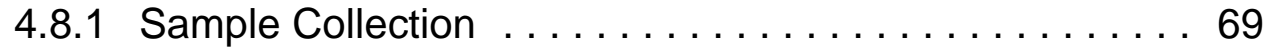

4.8.2 Sample Preparation ................... 69

4.8.3 Results and Discussions . . . . . . . . . . . . . . 69

4.9 Summary and Conclusion $\ldots \ldots \ldots \ldots \ldots \ldots \ldots \ldots$ 
Chapter $5 \quad$ Environmental Nonradiological Program Information . . . . . . . . 76

5.1 Principal Functions of Nonradiological Sampling . . . . . . 76

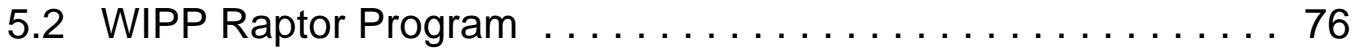

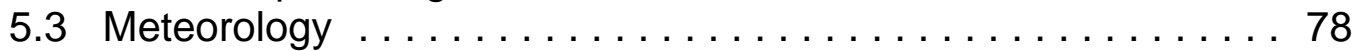

5.3.1 Climatic Data . . . . . . . . . . . . . . . . . 78

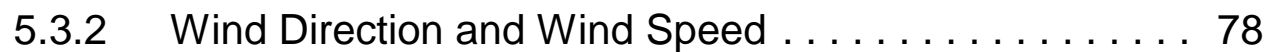

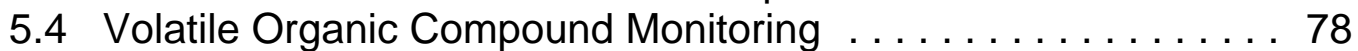

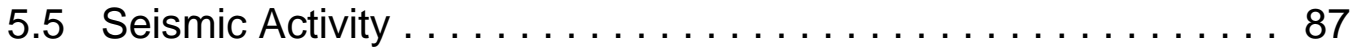

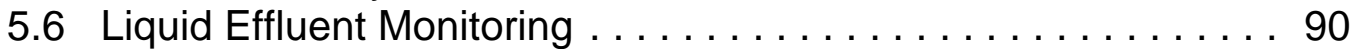

Chapter $6 \quad$ Ground-water Monitoring $\ldots \ldots \ldots \ldots \ldots \ldots \ldots \ldots \ldots \ldots \ldots$

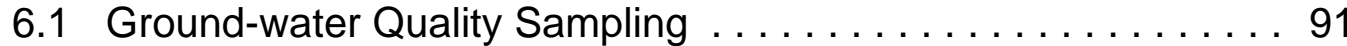

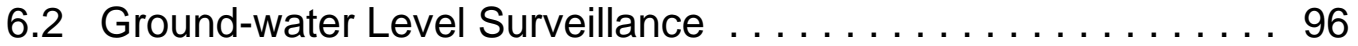

Chapter $7 \quad$ Radiological Dose Assessment . . . . . . . . . . . . . . 203

7.1 Introduction and Dose Limits . . . . . . . . . . . . . 203

7.2 Background Radiation ...................... 204

7.3 Dose from Air Emissions ..................... 205

7.3.1 Maximally Exposed Individual from Air

Emission Pathway .................... 205

7.4 Total Potential Dose from WIPP Operations ........... 206

7.4.1 Potential Dose from Water Ingestion Pathway ...... 206

7.4.2 Potential Dose from Wild Game Ingestion . . . . . . . . . 206

7.4.3 Total Potential Dose from All Pathways . . . . . . . . 206

7.5 Dose to non-human Biota . . . . . . . . . . . . . . 206

Chapter $8 \quad$ Quality Assurance . . . . . . . . . . . . . . . . . . . . . . . . . . 209

8.1 Completeness . . . . . . . . . . . . . . . . . . . . . . 209

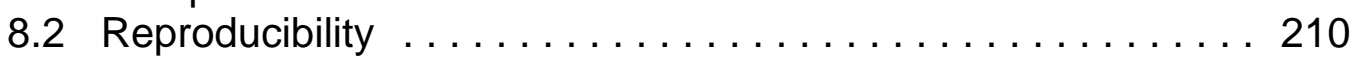

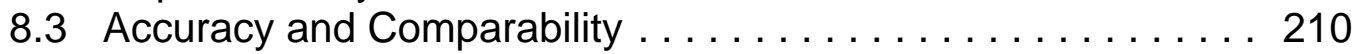

8.4 Representativeness ........................ 217

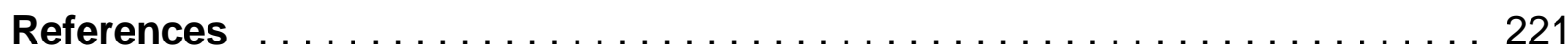

Appendix A Acronyms, Abbreviations, and Symbols . . . . . . . . . . . . 227

Appendix B Location Codes $\ldots \ldots \ldots \ldots \ldots \ldots \ldots \ldots \ldots \ldots \ldots \ldots \ldots \ldots \ldots$

Appendix D Equations ............................ 246 
Appendix E Air Sampling Data: Mass of Particulates and

Volumes of Air Samples . . . . . . . . . . . . . . . 248

Appendix $\mathbf{F} \quad$ Authors and Contributors $\ldots \ldots \ldots \ldots \ldots \ldots \ldots \ldots \ldots \ldots$ 


\section{List of Tables}

Table 2.1 The Environmental Monitoring Plan outlines the sampling schedule for the WIPP Environmental Monitoring Program ........ 9

Table $3.1 \quad$ Materials recycled at WIPP in $1999 \ldots \ldots \ldots \ldots \ldots \ldots \ldots$

Table $3.2 \quad$ WIPP's key RCRA permit deliverables and due dates $\ldots \ldots \ldots 21$

Table 3.3 Compliance status with major environmental regulations applicable to the WIPP project $\ldots \ldots \ldots \ldots \ldots \ldots \ldots \ldots \ldots 27$

Table 3.4 DOE orders affecting the WIPP environmental program $\ldots \ldots \ldots 29$

Table 3.5 Active environmental permits for the Waste Isolation Pilot Plant (does not include RCRA permits) $\ldots \ldots \ldots \ldots \ldots \ldots \ldots .31$

Table 4.1 Activity $(\mathrm{Bq})$ of quarterly composite air samples from effluent monitoring Stations $A, B$, and $C \ldots \ldots \ldots \ldots \ldots \ldots . \ldots \ldots$

Table 4.2 Annual minimum, maximum, and mean gross alpha activity concentrations $\left(\mathrm{Bq} / \mathrm{m}^{3}\right)$ found in air particulate samples collected weekly at various locations $\ldots \ldots \ldots \ldots \ldots \ldots \ldots \ldots$

Table 4.3 Annual minimum, maximum, and mean gross beta activity concentrations $\left(\mathrm{Bq} / \mathrm{m}^{3}\right)$ found in air particulate samples collected weekly at various locations $\ldots \ldots \ldots \ldots \ldots \ldots \ldots . \ldots . \ldots$

Table $4.4 \quad$ Uranium-233+234 concentration $\left(\mathrm{Bq} / \mathrm{m}^{3}\right)$ in air particulates . . . . . 42

Table $4.5 \quad$ Uranium-235 concentration $\left(\mathrm{Bq} / \mathrm{m}^{3}\right)$ in air particulates $\ldots \ldots \ldots . .42$

Table $4.6 \quad$ Uranium-238 concentration $\left(\mathrm{Bq} / \mathrm{m}^{3}\right)$ in air particulates $\ldots \ldots \ldots \ldots 42$

Table $4.7 \quad$ Plutonium-238 concentration $\left(\mathrm{Bq} / \mathrm{m}^{3}\right)$ in air particulates . . . . . . 43

Table $4.8 \quad$ Plutonium-239+240 concentration $\left(\mathrm{Bq} / \mathrm{m}^{3}\right)$ in air particulates . . . . . 43

Table 4.9 Americium-241 concentration $\left(\mathrm{Bq} / \mathrm{m}^{3}\right)$ in air particulates $\ldots \ldots \ldots 43$

Table 4.10 Potassium-40 concentration $\left(\mathrm{Bq} / \mathrm{m}^{3}\right)$ in air particulates $\ldots \ldots \ldots 44$ 
Table 4.11 Cobalt-60 concentration $\left(\mathrm{Bq} / \mathrm{m}^{3}\right)$ in air particulates $\ldots \ldots \ldots \ldots 44$

Table 4.12 Strontium-90 concentration $\left(\mathrm{Bq} / \mathrm{m}^{3}\right)$ in air particulates . . . . . . 44

Table 4.13 Cesium-137 concentration $\left(\mathrm{Bq} / \mathrm{m}^{3}\right)$ in air particulates . . . . . . . . . 44

Table 4.14 Concentration of radionuclides $\left(\mathrm{Bq} / \mathrm{m}^{3}\right)$ in duplicate

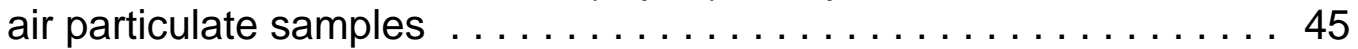

Table 4.15 Quarterly average radionuclide concentrations $\left(\mathrm{Bq} / \mathrm{m}^{3}\right)$ measured in air particulate samples by EEG in $1999 \ldots \ldots \ldots \ldots .46$

Table $4.16 \quad$ Uranium concentration $(\mathrm{Bq} / \mathrm{L})$ in ground water $\ldots \ldots \ldots \ldots \ldots$

Table 4.17 Plutonium and americium concentrations (Bq/L) in ground water .......................... 48

Table 4.18 Reported concentrations $(\mathrm{Bq} / \mathrm{L})$ of ${ }^{238} \mathrm{Pu}$ and ${ }^{241} \mathrm{Am}$ in ground-water samples from $1997-1999 \ldots \ldots \ldots \ldots \ldots . \ldots 49$

Table 4.19 Gamma-emitters and ${ }^{90} \mathrm{Sr}$ in ground water $(\mathrm{Bq} / \mathrm{L}) \ldots \ldots \ldots \ldots$

Table 4.20 Radionuclide concentrations $(\mathrm{Bq} / \mathrm{L})$ measured by

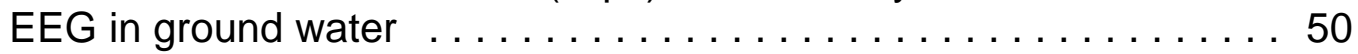

Table $4.21 \quad$ Uranium concentration in surface water $(\mathrm{Bq} / \mathrm{L}) \ldots \ldots \ldots \ldots \ldots$

Table 4.22 Surface water concentration $(\mathrm{Bq} / \mathrm{L})$ of transuranic elements $\ldots . .54$

Table 4.23 Surface water concentration $(\mathrm{Bq} / \mathrm{L})$ of gamma emitters $\ldots \ldots \ldots 55$

Table 4.24 Results of duplicate surface water sample analyses. . . . . . . . . 55

Table 4.25 Concentration $(\mathrm{Bq} / \mathrm{L})$ of radionuclides measured by EEG in surface water $\ldots \ldots \ldots \ldots \ldots \ldots \ldots \ldots \ldots \ldots \ldots$

Table 4.26 Uranium concentration $(\mathrm{Bq} / \mathrm{g}$ dry mass $)$ in soil . . . . . . . . . . . . 59

Table 4.27 Americium and plutonium concentration (Bq/g dry mass)

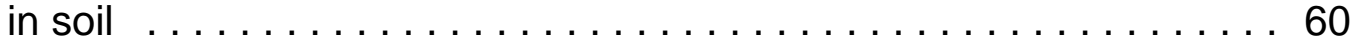

Table 4.28 Concentration $(\mathrm{Bq} / \mathrm{g})$ of beta and gamma emitters in soil . . . . . . 61

Table 4.29 Duplicate measurements of soil concentration $(\mathrm{Bq} / \mathrm{g}) \ldots \ldots \ldots 63$

Table $4.30 \quad$ Uranium concentration $(\mathrm{Bq} / \mathrm{g}$ dry mass) in sediment $\ldots \ldots \ldots \ldots 66$ 
Table 4.31 Americium and plutonium concentration (Bq/g dry mass) in sediments

Table 4.32 Concentrations (Bq/g dry mass) of beta- and gamma-emitters in sediments

Table 4.33 Duplicate analyses for radionuclide concentrations (Bq/g dry mass) in sediment . . . . . . . . . . . . . . 68

Table $4.34 \quad$ Uranium concentration $(\mathrm{Bq} / \mathrm{g}$ wet mass $)$ in vegetation $\ldots \ldots \ldots . .71$

Table 4.35 Concentration (Bq/g wet mass) of selected alpha-emitters

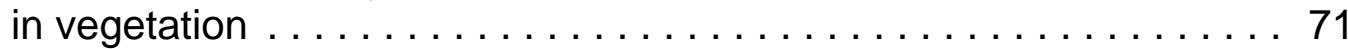

Table 4.36 Concentration (Bq/g wet mass) of beta- and gamma-emitters

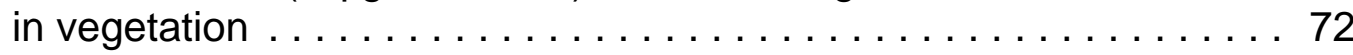

Table 4.37 Concentrations ( $\mathrm{Bq} / \mathrm{g}$ wet mass) of radionuclides from duplicate vegetation analyses $\ldots \ldots \ldots \ldots \ldots \ldots \ldots \ldots \ldots \ldots \ldots \ldots$

Table 4.38 Uranium concentration $(\mathrm{Bq} / \mathrm{g}$ wet mass) in animals $\ldots \ldots \ldots \ldots 73$

Table 4.39 Concentration (Bq/g wet mass) of selected alpha-emitters in animals

Table 4.40 Concentration $(\mathrm{Bq} / \mathrm{g})$ wet mass) of selected beta- and gammaemitters in animals

Table 5.1 A summary of 1999 temperature observations at 2-meter height

Table 5.2 A summary of 1999 temperature observations at 10-meter height 81

Table 5.3 A summary of 1999 temperature observations at 50-meter height

Table 5.4 1999 wind frequencies at 2-meter height, stratified by direction and speed (percent)

Table 5.5 1999 wind frequencies at 10-meter height, stratified by direction and speed (percent)

Table 5.6 1999 wind frequencies at 50-meter height, stratified by direction and speed (percent) 
Table 5.7 Concentrations of concern for volatile organic compounds, from attachment $\mathrm{N}$ of the Hazardous Waste Facility permit (No. NM489019088)

Table $5.8 \quad$ Volatile organic compound sample pair differences measured at WIPP in $1999 \ldots \ldots \ldots \ldots$

Table 6.1 Analytical parameters for which ground water was analyzed ..... 95

Table 6.2 Analytical results for ground water sampled from well WQSP-1

Table 6.3 Analytical results for ground water sampled from well WQSP-2 104

Table 6.4 Analytical results for ground water sampled from well WQSP-3

Table 6.5 Analytical results for ground water sampled from well WQSP-4

Table 6.6 Analytical results for ground water sampled from well WQSP-5

Table 6.7 Analytical results for ground water sampled from well WQSP-6

Table 6.8 Analytical results for ground water sampled from well WQSP-6A

Table 6.9 Ground-water surface elevations for 1999 182

Table 7.1 Annual estimated average radiation dose received by a member of the population of the United States from naturally-occurring radiation sources (adapted from NCRP-94) . . . . . . . . . 205

Table 7.2 General screening results for potential radiation dose to non-human biota

Table 8.1 Comparison of duplicate air monitoring results (first quarter of 1999) from WIPP Environmental Monitoring Laboratory data from WIPP Far Field (WFF)

Table 8.2 Comparison of duplicate air monitoring results (second quarter of 1999) WIPP Environmental Monitoring Laboratory data at WEE 
Table 8.3 Comparison of duplicate air monitoring results (third quarter of 1999) from WIPP Environmental Monitoring Laboratory data from WIPP South (WSS) . . . . . . 213

Table 8.4 Comparison of duplicate air monitoring results (fourth quarter of 1999) from WIPP Environmental Monitoring Laboratory data from Mills Ranch (MLR) . . . . . . . . 214

Table 8.5 Environmental Measurement Laboratory evaluation of Thermo NuTech (air) . . . . . . . . . . . . 215

Table 8.6 Environmental Measurement Laboratory evaluation of Thermo NuTech (soil) . . . . . . . . . . . . . . . . . . . . . . . 215

Table 8.7 Environmental Measurement Laboratory evaluation of Thermo NuTech (vegetation) $\ldots \ldots \ldots \ldots \ldots \ldots \ldots \ldots \ldots$

Table 8.8 Environmental Measurement Laboratory evaluation of Thermo NuTech (water) . . . . . . . . . . . . . . . . . 216

Table 8.9 Environmental Resource Associates assessment of

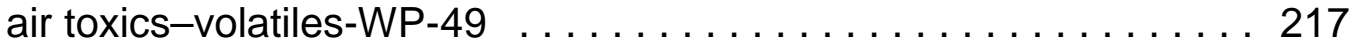

Table 8.10 Environmental Resource Associates assessment of trace analysis-InterLaB WatR ${ }^{\mathrm{TM}}$ Pollution WP-51 


\section{List of Figures}

Figure $1.1 \quad$ WIPP Stratigraph $\ldots \ldots \ldots \ldots \ldots \ldots \ldots \ldots \ldots \ldots \ldots \ldots \ldots \ldots \ldots \ldots$

Figure $1.2 \quad$ WIPP Location $\ldots \ldots \ldots \ldots \ldots \ldots \ldots \ldots \ldots \ldots \ldots \ldots$

Figure $1.3 \quad$ WIPP Property Areas $\ldots \ldots \ldots \ldots \ldots \ldots \ldots \ldots \ldots \ldots$

Figure 4.1 Air Sampling Locations on and near the WIPP Facility $\ldots \ldots \ldots 37$

Figure 4.2 Gross Alpha Activity Concentration Measured in Air Particulates Each Week in 1999 . . . . . . . . . . . . . . . . . . 38

Figure 4.3 Gross Beta Activity Concentration Measured in Air Particles Each Week in 1999 . . . . . . . . . . . . . . . . . . . . 40

Figure $4.4 \quad$ Surface Water Sampling Locations in $1999 \ldots \ldots \ldots \ldots \ldots$

Figure $4.5 \quad$ Soil and Vegetation Sampling Locations $\ldots \ldots \ldots \ldots \ldots$

Figure $4.6 \quad$ Sediment Sampling Sites $\ldots \ldots \ldots \ldots \ldots \ldots \ldots \ldots \ldots \ldots \ldots$

Figure $5.1 \quad 1999$ Precipitation at WIPP $\ldots \ldots \ldots \ldots \ldots \ldots \ldots \ldots \ldots \ldots$

Figure 5.21999 WIPP Site Temperature at 2-Meter Height $\ldots \ldots \ldots \ldots \ldots 80$

Figure 5.31999 WIPP Site Temperature at 10-Meter Height $\ldots \ldots \ldots \ldots .81$

Figure 5.41999 WIPP Site Temperature at 50-Meter Height $\ldots \ldots \ldots \ldots \ldots 82$

Figure 5.51999 WIPP Site Wind Rose at 2-Meter Height . . . . . . . . . . . 83

Figure 5.61999 WIPP Site Wind Rose at 10-Meter Height . . . . . . . . . . 84

Figure $5.7 \quad 1999$ WIPP Site Wind Rose at 50-Meter Height . . . . . . . . . . . 85

Figure $5.8 \quad$ WIPP Seismograph Station Locations $\ldots \ldots \ldots \ldots \ldots \ldots \ldots$

Figure 6.1 Water Quality Sampling Program Sample Wells ... . . . . . . 92

Figure 6.2 Ground-water Level Surveillance Wells ... . . . . . . . . 93 
Figure 6.3a Measured Ground-water Potentiometric Surface (feet) in the Culebra Member of the Rustler Formation . . . . . . . . . . . 98

Figure 6.3b Modeled Ground-water Potentiometric Surface (feet) in the Culebra Member of the Rustler Formation . . . . . . . . . . . . 99

Figure 6.4 Modeled Particle Movement in Ground-water Flow in the Culebra Member of the Rustler Formation . . . . . . . . . 100

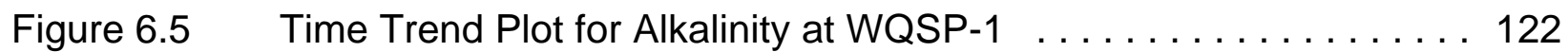

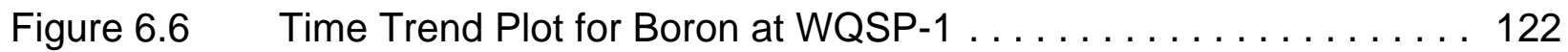

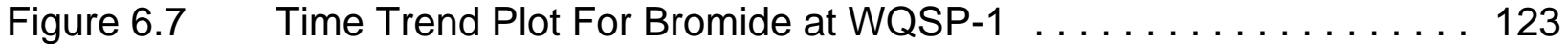

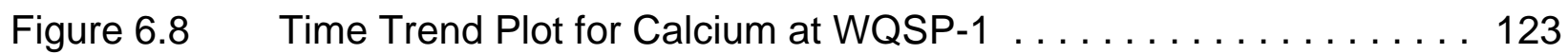

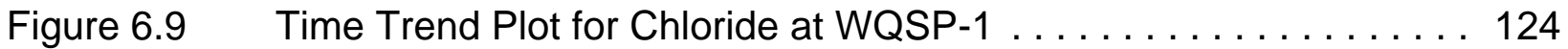

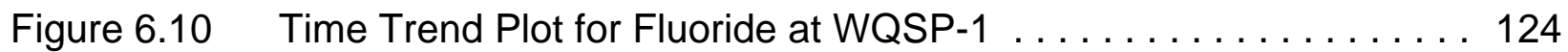

Figure 6.11 Time Trend Plot for Lithium at WQSP-1 . . . . . . . . . . . . 125

Figure 6.12 Time Trend Plot for Magnesium at WQSP-1 . . . . . . . . . . . 125

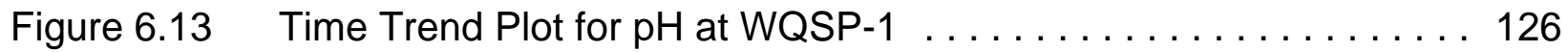

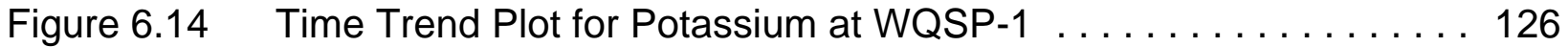

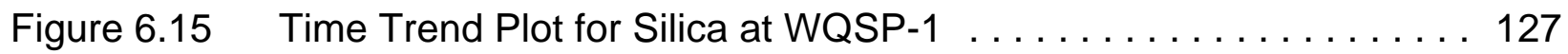

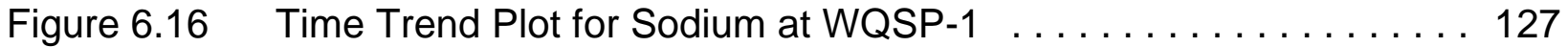

Figure 6.17 Time Trend Plot for Specific Conductance at WQSP-1 . . . . . 128

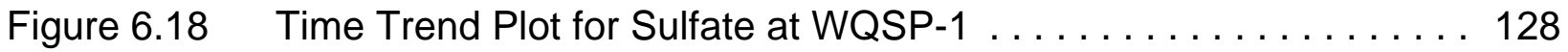

Figure 6.19 Time Trend Plot for Total Dissolved Solids at WQSP-1 . . . . . . . 129

Figure 6.20 Time Trend Plot for Total Organic Carbon at WQSP-1 . . . . . . 129

Figure 6.21 Time Trend Plot for Total Organic Halogens at WQSP-1 . . . . . . 130

Figure 6.22 Time Trend Plot for Alkalinity at WQSP-2 $\ldots \ldots \ldots \ldots \ldots \ldots$

Figure $6.23 \quad$ Time Trend Plot for Boron at WQSP $-2 \ldots \ldots \ldots \ldots \ldots \ldots \ldots \ldots 131$ 


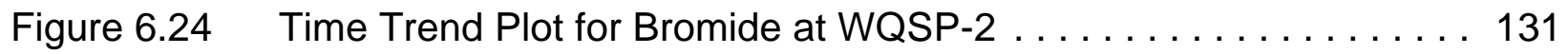

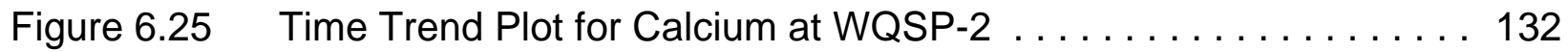

Figure 6.26 Time Trend Plot for Chloride at WQSP-2 . . . . . . . . . . . . 132

Figure 6.27 Time Trend Plot for Fluoride at WQSP-2 $\ldots \ldots \ldots \ldots \ldots \ldots \ldots$

Figure 6.28 Time Trend Plot for Lithium at WQSP-2 . . . . . . . . . . . . 133

Figure 6.29 Time Trend Plot for Magnesium at WQSP-2 . . . . . . . . . . 134

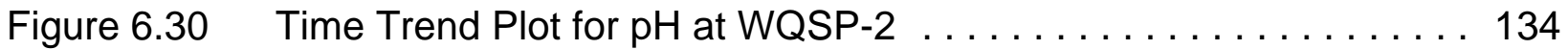

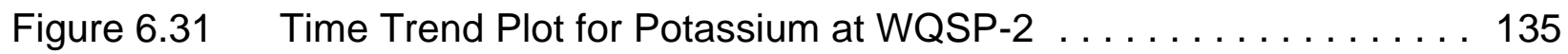

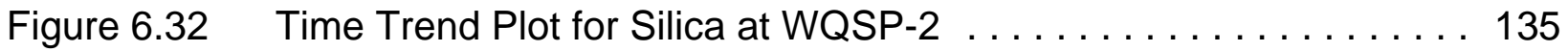

Figure 6.33 Time Trend Plot for Sodium at WQSP $-2 \ldots \ldots \ldots \ldots \ldots \ldots$

Figure 6.34 Time Trend Plot for Specific Conductance at WQSP-2 . . . . . . 136

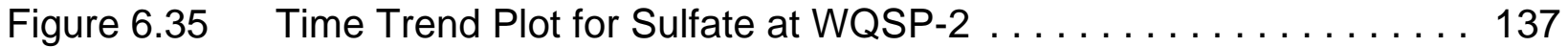

Figure 6.36 Time Trend Plot for Total Dissolved Solids at WQSP-2 . . . . . . . 137

Figure 6.37 Time Trend Plot for Total Organic Carbon at WQSP-2 . . . . . . 138

Figure 6.38 Time Trend Plot for Total Organic Halogens at WQSP-2 . . . . . . 138

Figure 6.39 Time Trend Plot for Alkalinity at WQSP-3 $\ldots \ldots \ldots \ldots \ldots \ldots$

Figure 6.40 Time Trend Plot for Boron at WQSP-3 . . . . . . . . . . . . . . . 139

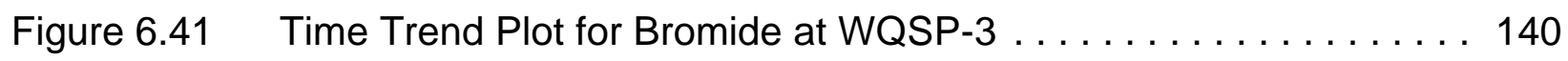

Figure 6.42 Time Trend Plot for Calcium at WQSP-3 . . . . . . . . . . . . . . 140

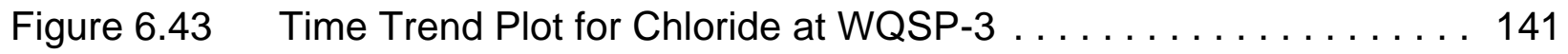

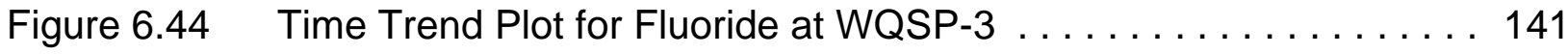

Figure 6.45 Time Trend Plot for Lithium at WQSP-3 . . . . . . . . . . . . . . 142

Figure 6.46 Time Trend Plot for Magnesium at WQSP-3 . . . . . . . . . 142

Figure 6.47 Time Trend Plot for $\mathrm{pH}$ at WQSP-3 . . . . . . . . . . . . . 143 


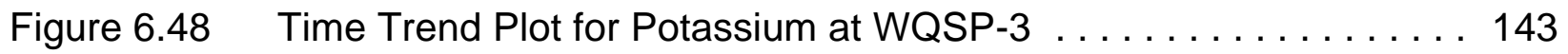

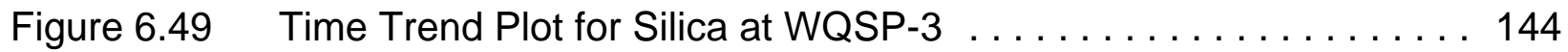

Figure 6.50 Time Trend Plot for Sodium at WQSP-3 . . . . . . . . . . . . . 144

Figure 6.51 Time Trend Plot for Specific Conductance at WQSP-3 . . . . . . 145

Figure 6.52 Time Trend Plot for Sulfate at WQSP-3 . . . . . . . . . . . . . 145

Figure 6.53 Time Trend Plot for Total Dissolved Solids at WQSP-3 . . . . . . 146

Figure 6.54 Time Trend Plot for Total Organic Carbon at WQSP-3 . . . . . . 146

Figure 6.55 Time Trend Plot for Total Organic Halogens at WQSP-3 . . . . . . 147

Figure 6.56 Time Trend Plot for Alkalinity at WQSP-4 $\ldots \ldots \ldots \ldots \ldots \ldots$

Figure 6.57 Time Trend Plot for Boron at WQSP $-4 \ldots \ldots \ldots \ldots \ldots \ldots \ldots$

Figure 6.58 Time Trend Plot for Bromide at WQSP $-4 \ldots \ldots \ldots \ldots \ldots \ldots \ldots$

Figure 6.59 Time Trend Plot for Calcium at WQSP-4 . . . . . . . . . . . 149

Figure 6.60 Time Trend Plot for Chloride at WQSP-4 . . . . . . . . . . . . 149

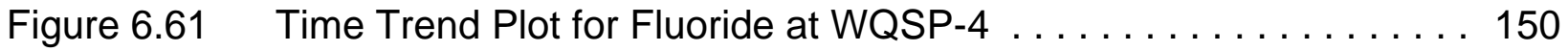

Figure 6.62 Time Trend Plot for Lithium at WQSP $-4 \ldots \ldots \ldots \ldots \ldots \ldots$

Figure 6.63 Time Trend Plot for Magnesium at WQSP-4 $\ldots \ldots \ldots \ldots \ldots 151$

Figure 6.64 Time Trend Plot for $\mathrm{pH}$ at WQSP $-4 \ldots \ldots \ldots \ldots \ldots \ldots \ldots \ldots$

Figure 6.65 Time Trend Plot for Potassium at WQSP-4 . . . . . . . . . . 152

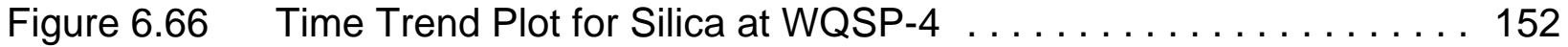

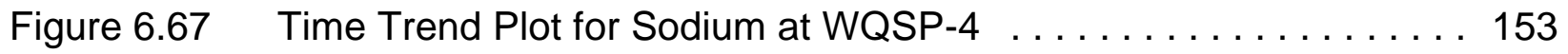

Figure 6.68 Time Trend Plot for Specific Conductance at WQSP-4 . . . . . . 153

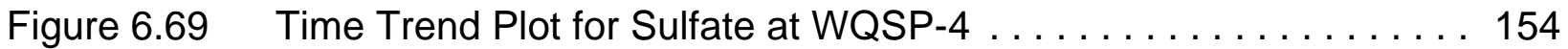

Figure 6.70 Time Trend Plot for Total Dissolved Solids at WQSP-4 . . . . . . . 154

Figure 6.71 Time Trend Plot for Total Organic Carbon at WQSP-4 . . . . . . 155 
Figure 6.72 Time Trend Plot for Total Organic Halogens at WQSP-4 . . . . . 155

Figure 6.73 Time Trend Plot for Alkalinity at WQSP-5 $\ldots \ldots \ldots \ldots \ldots \ldots$

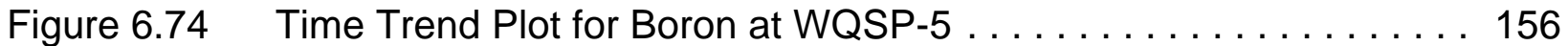

Figure 6.75 Time Trend Plot for Bromide at WQSP $-5 \ldots \ldots \ldots \ldots \ldots \ldots$

Figure 6.76 Time Trend Plot for Calcium at WQSP-5 . . . . . . . . . . . 157

Figure 6.77 Time Trend Plot for Chloride at WQSP $-5 \ldots \ldots \ldots \ldots \ldots \ldots$

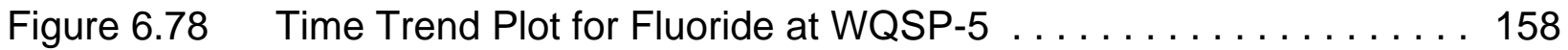

Figure 6.79 Time Trend Plot for Lithium at WQSP-5 . . . . . . . . . . . . 159

Figure 6.80 Time Trend Plot for Magnesium at WQSP-5 . . . . . . . . . 159

Figure 6.81 Time Trend Plot for $\mathrm{pH}$ at WQSP $-5 \ldots \ldots \ldots \ldots \ldots \ldots$

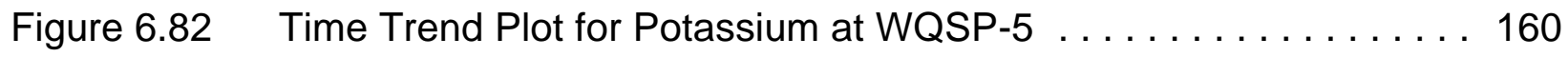

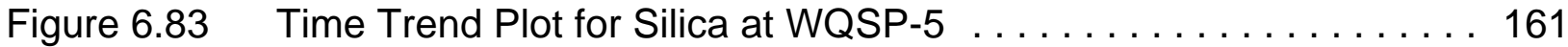

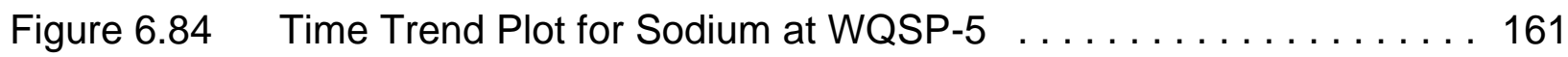

Figure 6.85 Time Trend Plot for Specific Conductance at WQSP-5 . . . . . . 162

Figure 6.86 Time Trend Plot for Sulfate at WQSP $-5 \ldots \ldots \ldots \ldots \ldots \ldots$

Figure 6.87 Time Trend Plot for Total Dissolved Solids at WQSP-5 . . . . . 163

Figure 6.88 Time Trend Plot for Total Organic Carbon at WQSP-5 . . . . . . 163

Figure 6.89 Time Trend Plot for Total Organic Halogens at WQSP-5 . . . . . . 164

Figure 6.90 Time Trend Plot for Alkalinity at WQSP $-6 \ldots \ldots \ldots \ldots \ldots$

Figure 6.91 Time Trend Plot for Boron at WQSP $-6 \ldots \ldots \ldots \ldots \ldots \ldots \ldots$

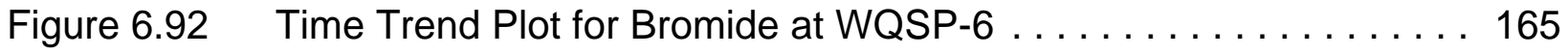

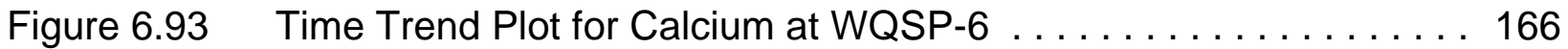

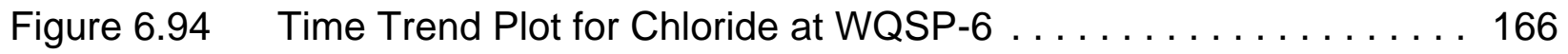

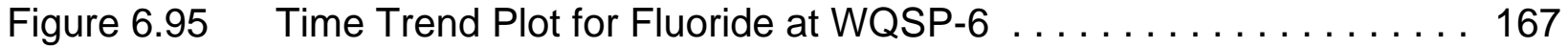


Figure 6.96 Time Trend Plot for Lithium at WQSP $-6 \ldots \ldots \ldots \ldots \ldots$

Figure 6.97 Time Trend Plot for Magnesium at WQSP-6 $\ldots \ldots \ldots \ldots \ldots$

Figure 6.98 Time Trend Plot for $\mathrm{pH}$ at WQSP-6 $\ldots \ldots \ldots \ldots \ldots \ldots \ldots$

Figure 6.99 Time Trend Plot for Potassium at WQSP $-6 \ldots \ldots \ldots \ldots \ldots$

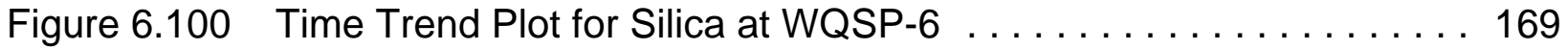

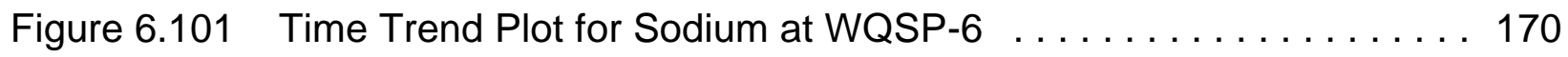

Figure 6.102 Time Trend Plot for Specific Conductance at WQSP-6 . . . . . . 170

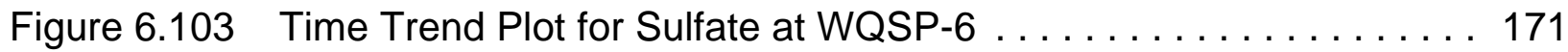

Figure 6.104 Time Trend Plot for Total Dissolved Solids at WQSP-6 . . . . . 171

Figure 6.105 Time Trend Plot for Total Organic Carbon at WQSP-6 . . . . . . 172

Figure 6.106 Time Trend Plot for Total Organic Halogens at WQSP-6 . . . . . . 172

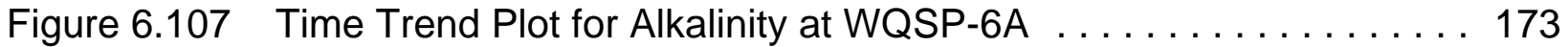

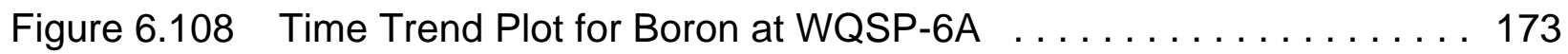

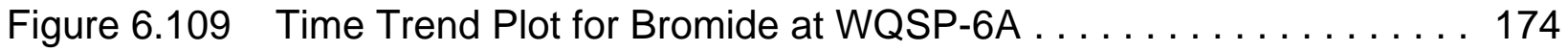

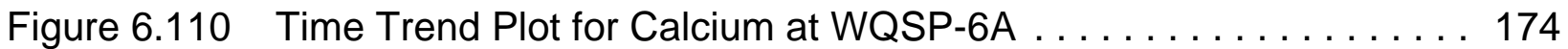

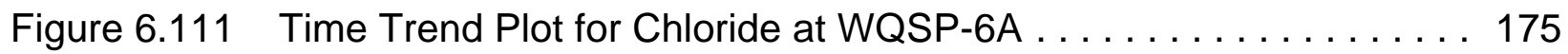

Figure 6.112 Time Trend Plot for Fluoride at WQSP-6A . . . . . . . . . . . 175

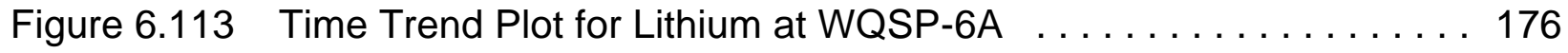

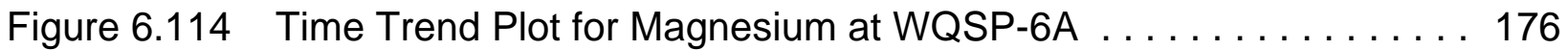

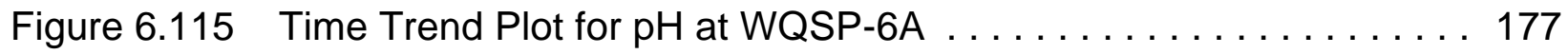

Figure 6.116 Time Trend Plot for Potassium at WQSP-6A . . . . . . . . . . 177

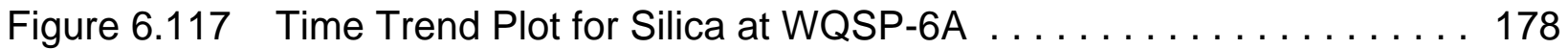

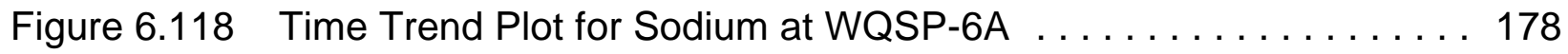

Figure 6.119 Time Trend Plot for Specific Conductance at WQSP-6A . . . . . . 179 


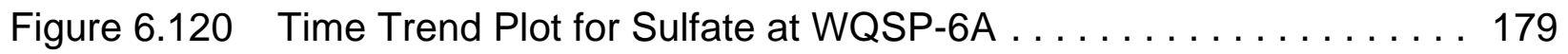

Figure 6.121 Time Trend Plot for Total Dissolved Solids at WQSP-6A . . . . . . 180

Figure 6.122 Time Trend Plot for Total Organic Carbon at WQSP-6A . . . . . 180

Figure 6.123 Time Trend Plot for Total Organic Halogens at WQSP-6A . . . . 181

Figure 7.1 Three General Models Used to Predict Risk from Radiation Dose . . . . . . . . . . . . . . . . . . . . . . . . . . 204 


\section{Chapter 1 Introduction}

The Waste Isolation Pilot Plant (WIPP) is the world's first underground repository with the necessary permits and certifications for safe and permanent disposal of transuranic (TRU) radioactive and mixed waste generated by defense-related activities. TRU waste consists of material contaminated with elements with atomic numbers greater than uranium. A TRU waste is eligible for disposal at WIPP if it has been generated in whole or part by one or more of the activities listed in section 10101(3) of the Nuclear Waste Policy Act of 1982, including: naval reactors development, weapons activities, verification and control technology, defense nuclear materials production, defense nuclear waste and materials by-products management, defense nuclear materials security and safeguards and security investigations, and defense research and development. TRU waste is defined in the WIPP Land Withdrawal Act of 1992 (PL 102579) as radioactive waste containing more than 100 nanocuries $(3,700 \mathrm{bq})$ of alpha-emitting TRU isotopes per gram of waste, with half-lives greater than 20 years. There are certain exceptions to this definition, including: high-level radioactive waste; waste that the Secretary of Energy has determined, with the concurrence of the Administrator of the Environmental Protection Agency, does not need the degree of isolation required by 40 CFR $\S 191$ disposal regulations; or waste that the Nuclear Regulatory Commission has approved for disposal on a case-by-case basis in accordance with $10 \mathrm{CFR} \S 61$. Most TRU waste is contaminated industrial trash, including used protective clothing, rags, old tools and equipment, and pieces of dismantled buildings.

The WIPP Project is authorized by the U.S. Department of Energy (DOE) National Security and Military Applications of Nuclear Energy Authorization Act of 1980 (PL 96-164). WIPP's legislative mandate is to demonstrate the safe disposal of TRU wastes from national defense activities and programs. To fulfill this mandate, WIPP has been designed to safely handle, store, and dispose of TRU waste in a fully-operational disposal facility. After more than 20 years of scientific study, public input, and regulatory struggles, WIPP received its first shipment of waste on March 26, 1999.

When TRU waste arrives at WIPP, it is transported into the Waste Handling Building. The waste containers are removed from the shipping containers, placed on the waste hoist, and lowered to the repository level of $655 \mathrm{~m}$ $(2,150 \mathrm{ft}$; approximately $0.5 \mathrm{mi})$ below the surface. During the disposal phase, the containers of waste are removed from the hoist and placed in excavated storage rooms in the Salado Formation, a thick sequence of salt beds deposited approximately 250 million years ago (Figure 1.1). Once a disposal area has been filled with waste, specially designed closures will be placed in the excavated disposal rooms, and seals will be placed in the shafts. Salt under pressure is relatively plastic, and mine openings will creep closed, encapsulating and isolating the waste.

\subsection{WIPP History}

Government officials and scientists initiated the WIPP site selection process in the 1950s. At that time, the National Academy of Sciences conducted a nationwide search for stable geological formations to contain wastes for thousands of years. In 1955, after extensive study, salt deposits were recommended as a promising medium for the disposal of radioactive waste.

Salt was chosen as the material for the planned disposal of nuclear waste for several reasons. Most deposits of salt are found in stable geological areas with very little earthquake activity, assuring the stability of a waste repository. Salt deposits also demonstrate the 


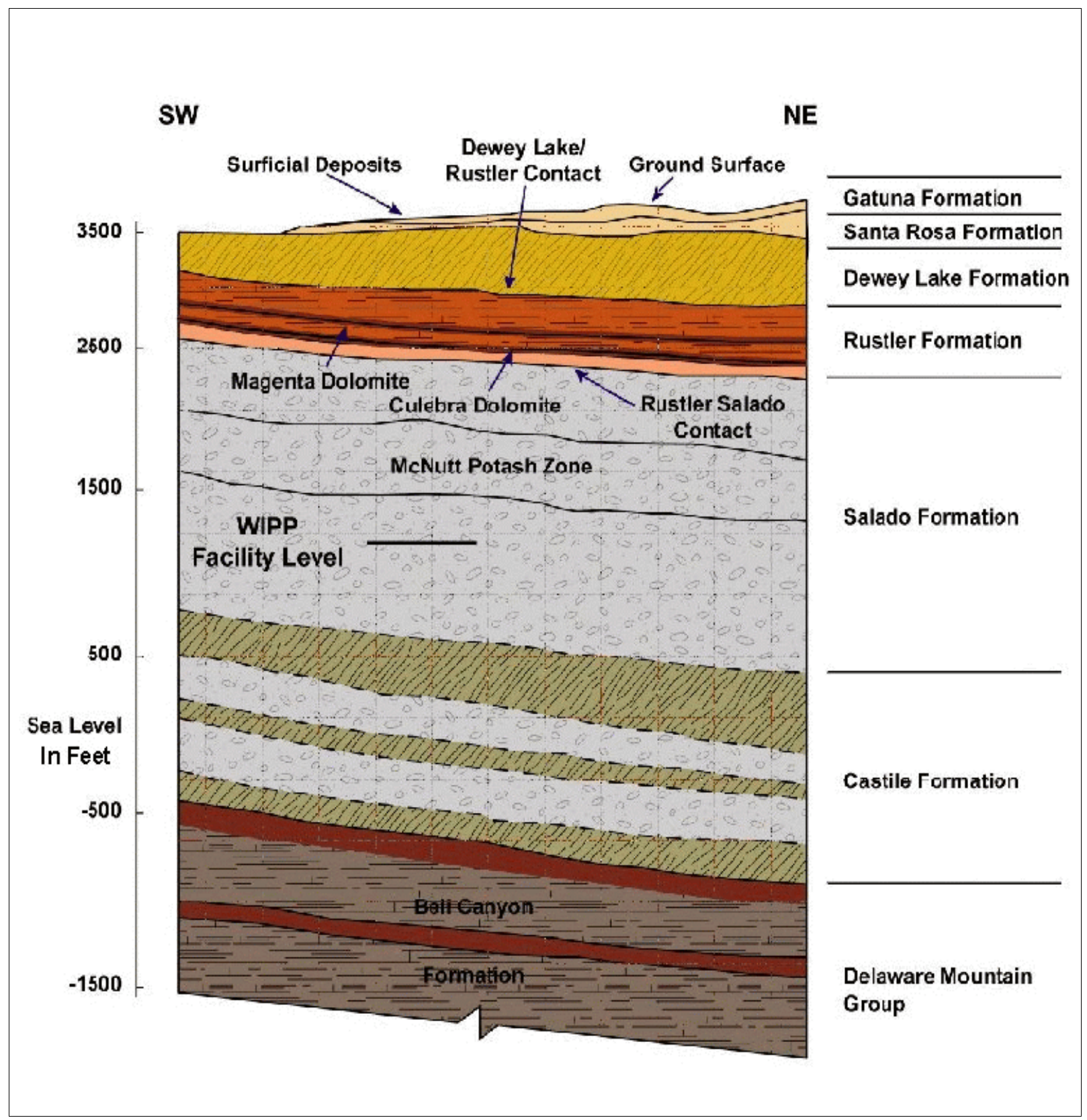

Figure 1.1 WIPP Stratigraph

absence of flowing fresh water that could move waste to the surface. Water, if it had been or were present, would have dissolved the salt beds. In addition, salt is relatively easy to mine. Finally, rock salt heals its own fractures because it is relatively plastic. This means salt formations will slowly and progressively move in to fill mined areas and will safely seal radioactive waste from the environment.
Government scientists searched for an appropriate site for the disposal of radioactive waste throughout the 1960s, and finally tested the area of south-eastern New Mexico in the early 1970s. Salt formations at WIPP were deposited in thick beds during the evaporation of an ancient ocean, the Permian Sea. These geologic formations consist mainly of sodium chloride, the same substance as table salt. However, at WIPP, the salt is not granular, but is in the form of solid 
rock. The main salt formation at WIPP is about $610 \mathrm{~m}(2,000 \mathrm{ft})$ thick, and begins $259 \mathrm{~m}(850 \mathrm{ft})$ below the earth's surface. Formed about 225 million years ago during the Permian Age, the large expanses of uninterrupted salt beds provide a repository that has been stable and free from the disturbances of large earthquakes for more than 200 million years. This proven stability over such a long time span offers the predictability that the salt will remain stable for the comparatively short 10,000 -year period that WIPP is mandated to isolate the waste from the human environment.

In 1979, Congress authorized the construction of WIPP, and DOE constructed the facility during the 1980s. In late 1993, DOE created the Carlsbad Area Office to lead the TRU waste disposal efforts. The Carlsbad Area Office coordinates the TRU program at waste-generating sites and national laboratories.

Several important milestones were reached in 1999. Most significantly, WIPP received its first waste shipments. On March 25, the first waste bound for WIPP departed Los Alamos National Laboratory in New Mexico; it arrived at WIPP the following morning, and the first wastes were placed underground later that day. On April 17, WIPP celebrated its official grand opening. Ten days later, on April 27, the first out-of-state shipment arrived at WIPP, from the Idaho National Engineering and Environmental Laboratory. Later in the year, on October 27, the Secretary of the New Mexico Environment Department issued a WIPP Facility Hazardous Waste Permit, which allows WIPP to manage, store, and dispose of contact-handled TRU mixed waste. Mixed waste is waste contaminated by both hazardous and radioactive substances. "Contact-handled mixed waste" is TRU mixed waste with a surface dose rate less than 200 millirem per hour.

\subsection{WIPP's Mission}

Current temporary radioactive waste storage facilities at 23 locations across the United States were never intended to provide permanent disposal. WIPP is the nation's first operating underground repository for defense-generated
TRU waste and is a critical step toward solving the nation's nuclear waste disposal problem. Its mission is to provide for the safe, permanent, and environmentally-sound disposal of TRU radioactive waste left from research, development, and production of nuclear weapons. Over the next 35 years, WIPP is expected to receive about 37,000 shipments of waste from locations across the U.S.

The mission of the Carlsbad Area Office is to protect human health and the environment by opening and operating WIPP for safe disposal of TRU waste and by establishing an effective system for management of TRU waste from generation to disposal.

\subsection{WIPP Location}

Located in Eddy County in the remote Chihuahuan Desert of southeastern New Mexico (Figure 1.2), the WIPP site encompasses approximately $41.1 \mathrm{~km}^{2}$, or $16 \mathrm{mi}^{2}$. The site is 42 $\mathrm{km}(26 \mathrm{mi})$ east of Carlsbad in a region known as Los Medaños. This part of New Mexico is relatively flat and is sparsely inhabited, with little surface water. The WIPP site boundary extends a minimum of $1.6 \mathrm{~km}(1 \mathrm{mi})$ beyond any of the WIPP underground developments. The WIPP Land Withdrawal Act was signed into law on October 30, 1992, transferring the land from the Department of the Interior to DOE. With the exception of facilities within the boundaries of the posted $5.7 \mathrm{~km}^{2}\left(2.2 \mathrm{mi}^{2}\right)$ Off-Limits Area, the surface land uses remain largely unchanged from pre-1992 uses, and are managed in accordance with accepted practices for multiple land use. However, mining and drilling for purposes other than those which support WIPP are prohibited within the WIPP site.

The majority of the lands outside the WIPP boundary are managed by the Department of the Interior's Bureau of Land Management (BLM). Land uses in the surrounding area include livestock grazing; potash mining; oil and gas exploration and production; and recreational activities such as hunting, camping, hiking, and bird watching. The region is home to a diverse population of animals and plants. 


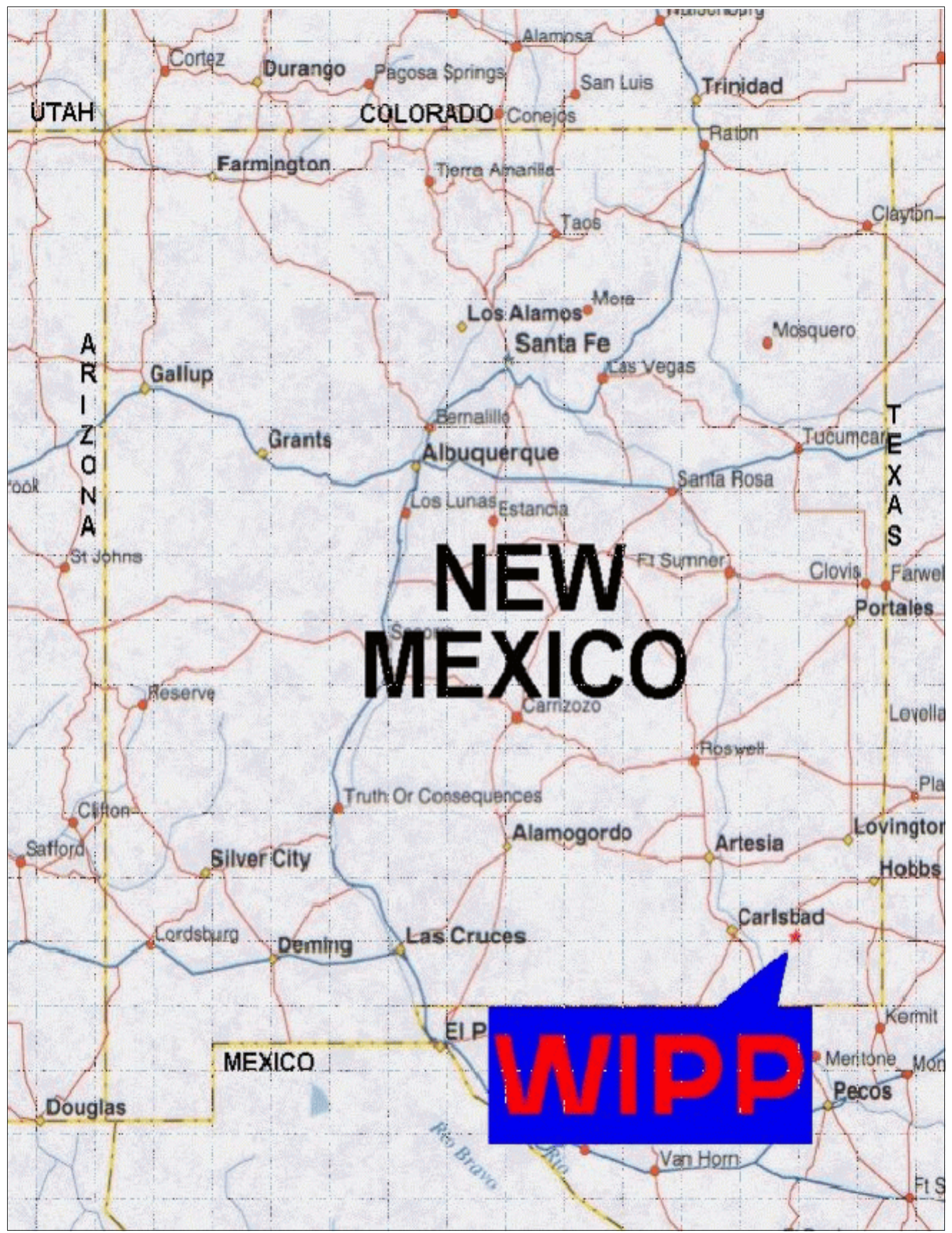

Figure 1.2 WIPP Location 


\subsubsection{WIPP Property Areas}

There are five types of property areas within WIPP's boundary (Figure 1.3).

\section{Property Protection Area}

The interior core of the facility encompasses approximately $0.129 \mathrm{~km}^{2}\left(0.05 \mathrm{mi}^{2}\right)$ surrounded by a chain link fence. This area is under tight security and uniformed security personnel are on duty 24 hours a day. It is underneath this core area where the TRU waste is stored in underground disposal rooms.

\section{Exclusive Use Area}

The Exclusive Use Area comprises $1.12 \mathrm{~km}^{2}$ $\left(0.432 \mathrm{mi}^{2}\right)$. It is surrounded by a five-strand barbed wire fence and is restricted exclusively for the use of the DOE and its contractors and subcontractors in support of the project. In addition, this area is defined as the point of closest public access for the purpose of analyzing accident consequences to the general public in the WIPP Safety Analysis Report (DOE/WIPP 952065). This area is marked by DOE "no trespassing" signs and is patrolled by WIPP security personnel to prevent unauthorized activities or uses.

\section{Off-Limits Area}

Managed as an area where unauthorized entry and introduction of weapons and/or dangerous materials is prohibited, the Off-Limits Area includes $5.7 \mathrm{~km}^{2}\left(2.2 \mathrm{mi}^{2}\right)$. Pertinent prohibitions are posted at consistent intervals along the perimeter. Grazing and public thoroughfare will continue in this area until such time that these activities present a threat to the security, safety, or environmental quality of WIPP. This sector is patrolled by WIPP security personnel to prevent unauthorized activity or use.

\section{WIPP Land Withdrawal Area}

The WIPP site boundary delineates the perimeter of the $41.4 \mathrm{~km}^{2}\left(16 \mathrm{mi}^{2}\right)$ WIPP Land Withdrawal Area. This tract includes properties outlying the Property Protection Area, the
Exclusive Use Area, and the Off-Limits Area. This sector is designated as a Multiple Land Use Area, and is managed accordingly.

\section{Special Management Areas}

Certain properties used in the operation of WIPP (e.g., reclamation sites, well pads, roads) are, or may be, identified as Special Management Areas (SMA). A SMA designation is made due to values, resources, and/or circumstances that meet criteria for protection and management under special management designations. Unique resources of value that are in danger of being lost or damaged, areas where ongoing construction is occurring, fragile plant and/or animal communities, sites of archaeological significance, locations containing safety hazards, or sectors that may receive an unanticipated elevated security status would be suitable for designation as a SMA. Accordingly, the subject sector would receive special management emphasis under this stipulation. Special Management Areas will be posted against trespass and will be safeguarded commensurate with applicable laws governing property protection. WIPP security personnel will patrol these areas to prevent unauthorized access or use.

\subsubsection{Population}

Approximately 26 residents live within $16 \mathrm{~km}$ (10 $\mathrm{mi})$ of the WIPP site. The majority of the local population within $80.5 \mathrm{~km}$ (50 mi) of WIPP is concentrated in and around the communities of Carlsbad, Hobbs, Eunice, Loving, Jal, and Artesia, New Mexico. The nearest community is the village of Loving (current estimated populated 1,977), $29 \mathrm{~km}$ (18 mi) west-southwest of WIPP. The nearest major populated area is Carlsbad, 42 $\mathrm{km}(26 \mathrm{mi})$ west of WIPP. The current estimated population of Carlsbad is approximately 26,315 . The population within $16 \mathrm{~km}(10 \mathrm{mi})$ of WIPP is associated with ranching, oil and gas exploration/production, and potash mining. There are two nearby ranch residences (Smith Ranch and Mills Ranch) which are continuously monitored as part of the Environmental Monitoring Program (DOE/WIPP 99-2194). 


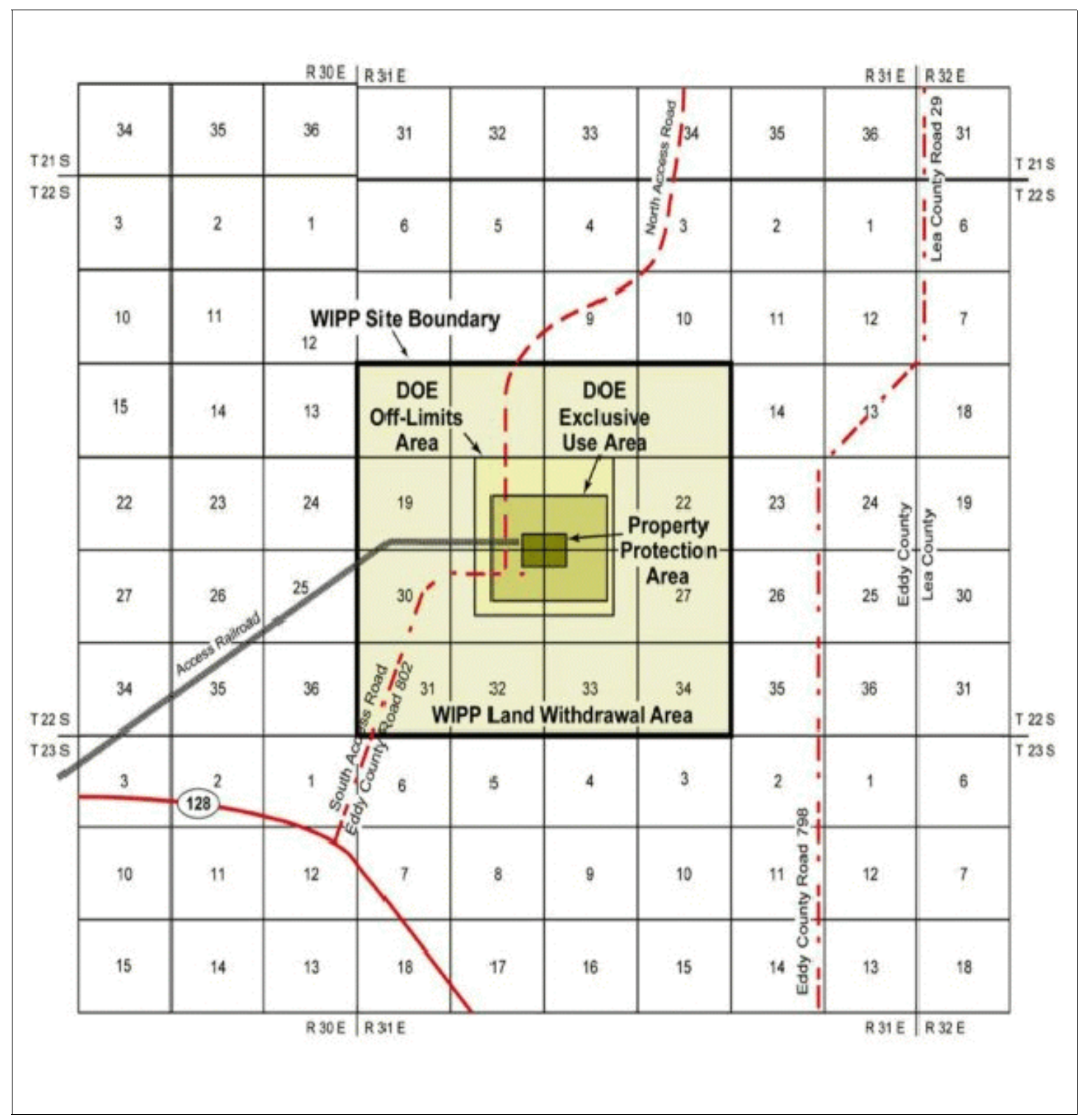

Figure 1.3 WIPP Property Areas

\subsection{Environmental Performance}

The Department of Energy's Environmental Policy Statement describes DOE's commitment to environmental protection and pledges to conduct operations "in an environmentally safe and sound manner. . . in compliance with the letter and spirit of applicable environmental statues, regulations, and standards" (DOE 1986). The Statement also affirms DOE's commitment to "good environmental management in all of its programs and at all of its facilities in order to correct existing environmental problems and to anticipate and address potential environmental problems before they pose a threat to the quality of the environment or public welfare." Additionally, it states, "It is DOE's policy that efforts to meet environmental obligations be carried out consistently across all operations and among all field organizations and programs. . ." (DOE 1986). 
DOE used laboratory tests, field tests, and computer models to demonstrate WIPP's validity as a permanent disposal site. The Environmental Protection Agency (EPA) certified in May 1998, WIPP's ability to protect the environment and human health, while assuring continued compliance through periodic recertification.

The Waste Isolation Division (WID) of Westinghouse Government Environmental Service Company conducts the Environmental Monitoring Program at WIPP to monitor for any potential radiological effects of WIPP on people and the environment. The Carlsbad Environmental Monitoring and Research Center conducts a supplementary environment monitoring program around WIPP. Numerous other organizations oversee the WIPP program, including the EPA, which is responsible for certifying whether radioactive material disposal requirements are met; the state of New Mexico, which regulates the handling of the hazardous components of mixed wastes; and the Environmental Evaluation Group, an independent technical oversight group that participates in and comments on various WIPP issues and activities. Several other agencies, committees, and panels monitor progress at WIPP and contribute to the project's development through regulation, review, and comment at the state and federal levels.

\section{This Waste Isolation Pilot Plant 1999 Site} Environmental Report has been prepared by the Environmental Science and Research Foundation, Inc. for WID in accordance with DOE Order 231.1. This report documents WIPP's radiological, nonradiological, and ground-water monitoring programs and their results; radiation dose estimates; and environmental compliance for calendar year 1999. 


\section{Chapter 2 \\ Environmental Program Information}

DOE's policy for the management of WIPP is to conduct its operations in a manner commensurate with all applicable environmental laws and regulations, and to safeguard the integrity of the southeastern New Mexico environment. This is accomplished through radiological and nonradiological environmental monitoring programs and land management programs, which include monitoring wildlife populations, the WIPP Raptor Program, and reclamation of disturbed lands. The purpose of these programs is to collect data needed to detect and quantify possible impacts WIPP may have on the surrounding ecosystem and, when necessary, provide technical support in the disciplines of environmental science and land management to DOE's Carlsbad Area Office.

Environmental monitoring activities at WIPP generally fall into four categories: collecting environmental samples from various matrices and analyzing them for specific radionuclides; preparing and publishing documents showing compliance with federal, state, and local regulations; evaluating whether WIPP activities cause any environmental impacts; and taking corrective action when an adverse effect on the environment is identified.

\subsection{Environmental Monitoring Plan}

WIPP's Environmental Monitoring Plan (EMP) outlines the programs that monitor the environment on, and immediately surrounding, the WIPP site (DOE/WIPP 99-2194). It discusses major environmental monitoring and surveillance activities at WIPP and reflects the importance of monitoring as a critical element of an effective environmental protection program. The EMP also discusses the WIPP quality assurance/quality control (QA/QC) program as it relates to environmental monitoring. The purpose of the EMP is to outline the programs that evaluate
WIPP's effect on the local ecosystem. Effluent and environmental monitoring also provide the data necessary to demonstrate compliance with applicable environmental protection regulations. The EMP sampling schedule is provided in Table 2.1 .

The EMP describes the monitoring of naturally-occurring and specific anthropogenic (human-made) radionuclides. This surveillance includes monitoring worldwide fallout from historic nuclear weapons tests. The geographic scope of radiological sampling is based on projections of potential release pathways from the waste stored at WIPP. Airborne radioactivity is also monitored at Carlsbad, NM and local ranches.

The EMP also describes monitoring of volatile organic compounds (VOCs), wildlife populations, meteorology, ground water chemistry, and other nonradiological environmental parameters. In general nonradiological monitoring is conducted within or near the WIPP boundary.

Results and discussions pertaining to the monitoring programs prescribed by the EMP are provided in Chapter 4, "Environmental Radiological Program Information," and Chapter 5, "Environmental Nonradiological Program Information." DOE Order 5400.1 requires the EMP to be reviewed internally every year and updated as required. The most recent EMP update was in September 1999.

\subsection{WIPP Environmental Monitoring Program}

It is the policy of DOE to conduct effluent monitoring and environmental surveillance programs that are appropriate for determining 
Table 2.1 The Environmental Monitoring Plan outlines the sampling schedule for the WIPP Environmental Monitoring Program.

\begin{tabular}{lcc}
\hline \multicolumn{1}{c}{ Type of Sample } & Number of Sampling Locations & Sampling Frequency \\
\hline Liquid effluent & 1 & Semiannual (oversight) \\
Liquid effluent & 1 & Quarterly (DP 831 permit) \\
Airborne effluent & 3 & Periodic/Confirmatory \\
Meteorology & 2 & Continuous \\
Atmospheric particulate & 7 & Weekly \\
Vegetation & 6 & Annual \\
Beef/Deer/Game Birds/Rabbits & 3 & Annual \\
Soil & 6 & Annual \\
Surface water & 14 & Annual \\
Ground water & 7 & Semiannual \\
Fish & 3 & Annual \\
Sediment & 12 & Annual \\
Aerial photography & Sitewide & Annual \\
Volatile organic compounds & 2 & Semiweekly \\
(VOCs) & &
\end{tabular}

adequate protection of the public and the environment during WIPP operations, and to ensure operations comply with DOE and other applicable federal or state radiation standards and requirements. It is DOE's objective that all DOE operations properly and accurately measure radionuclides in effluent streams and in the ambient environmental media. The goal of the WIPP Environmental Monitoring Program is to determine if the local ecosystem has been impacted during the predisposal and disposal phases of WIPP, and, if so, to evaluate the severity, geographic extent, and environmental significance of those impacts. The program fulfills DOE Orders 5400.1 (General Environmental Protection Program) and 5400.5 (Radiation Protection of the Public and the Environment).

The Environmental Monitoring Program monitors pathways by which WIPP-related radionuclides and other contaminants could reach the environment surrounding the WIPP site. The pathways measured include air, surface water, ground water, sediments, soils, and biota (e.g., vegetation, game birds, and fish). In addition, the program monitors ground-water quality and the overall health of the local environment. Nonradiological portions of the program focus on the area immediately surrounding the site while radiological surveillance generally covers a broader geographical area.

In addition to monitoring for radionuclides expected in WIPP wastes, background radiation (naturally-occurring radioactivity and radioactivity associated with worldwide fallout from historic weapons testing) is also monitored. The geographic scope of radiological sampling is based on projections of potential release pathways for the types of radionuclides in WIPP wastes. 
Also, Carlsbad, NM and local ranches are monitored, even though release scenarios involving radiation doses to residents of these population centers are improbable.

The atmospheric pathway, which can lead to the inhalation of radionculides, has been established as the most likely exposure pathway to the public from WIPP. Therefore, airborne particulate sampling for alpha-emitting radionuclides is emphasized. Air sampling results are used to trend environmental radiological levels and determine if there has been a deviation from established baseline concentrations.

Nonradiological environmental monitoring activities at WIPP consist of a comprehensive set of sampling programs designed to detect and quantify impacts of construction and operational activities. The ecological monitoring program focuses on nonradiological effects of WIPP, such as habitat disturbance.

WIPP has collected preoperational radiological and nonradiological environmental data. The environmental monitoring data collected prior to March 1999 are being compiled to broaden the radiological baseline in the WIPP vicinity and could be used as a confirmatory tool to quantify unplanned radiological occurrences. Baseline conditions were initially characterized by the Radiological Baseline Program. When the first shipment of waste arrived at WIPP, this program became an operational monitoring program.

Preoperational studies must be considered during environmental evaluations. These assessments have contributed to baseline data gathered during the construction phase and provided much of the foundation for long-term monitoring programs. Below are listed examples of such investigations.

- The WIPP Site Characterization Program was instituted in 1976 by Sandia National Laboratories to monitor air quality, background radiation levels, and groundwater quality.
- The WIPP Biology Program began in 1975 with site characterization studies of climate, soils, vegetation, arthropods, and vertebrates.

- Investigations of site geohydrology are conducted by the U.S. Geological Survey (USGS) at the request of the DOE. In addition, the Nuclear Regulatory Commission issued a contract to Columbia University to perform a study of radionuclide mobility in the highly saline ground waters of the Delaware Basin.

- Radiological monitoring of air, water, and biological media was conducted by the U.S. Atomic Energy Commission before and after the Project Gnome nuclear detonation in 1961.

\subsection{Land Management Programs}

On October 30, 1992, the WIPP Land Withdrawal Act (Public Law 109-579) became law. This act transferred the responsibility for the management of the WIPP Land Withdrawal Area from the Secretary of the Interior to the Secretary of Energy. In accordance with Sections 3(a)(1) and (3) of the act, these lands:

. . . are withdrawn from all forms of entry, appropriation, and disposal under the public land laws ... and are reserved for the use of the Secretary of Energy ... for the construction, experimentation, operation, repair and maintenance, disposal, shutdown, monitoring, decommissioning, and other activities associated with the purposes of WIPP as set forth in Section 213 of the DOE National Security and Military Application of the Nuclear Energy Act of 1980 (Public Law) 96-164; 93 Stat. 1259, 1265) and this Act.

DOE developed the Land Management Plan (DOE/WIPP 93-004) (LMP) as required by Section 4 of the Land Withdrawal Act. The LMP was developed to identify resource values, promote multiple-use management, and identify long-term goals for the management of WIPP lands until the culmination of the decommissioning phase. This plan was developed 
in consultation and cooperation with the BLM and the state of New Mexico. Changes or amendments to the plan require the involvement of the BLM, the state of New Mexico, and affected stakeholders, as appropriate.

Guidelines in the LMP provide for the management and oversight of WIPP lands under the jurisdiction of DOE. Lands outside the WIPP boundary used in the operation of WIPP (e.g., ground-water surveillance well pads outside the withdrawal area) are also included in the plan. Furthermore, the plan provides for multi-agency involvement in the administration of DOE land management actions. For example, the Bureau of Land Management is responsible for administering grazing leases through a Memorandum of Understanding. The LMP is available to anyone desiring to conduct activities on lands under the jurisdiction of WIPP in addition to those involved in developing or amending existing land management actions.

The LMP encourages direct communication among stakeholders, including federal and state agencies, involved in managing the resources within, or activities impacting the areas adjacent to, the WIPP Land Withdrawal Area. It sets forth cooperative arrangements and protocols for addressing WIPP-related land management actions. Commitments contained in current permits, agreements, or concurrent Memoranda of Understanding (MOUs) with other agencies will be respected when addressing and evaluating land use management activities and future amendments that affect the management of WIPP lands.

The LMP was reviewed in 1999. It is reviewed on a biennial basis to assess the adequacy and effectiveness of the document, or as may be necessary to address emerging issues potentially affecting WIPP lands. Affected agencies, groups, and individuals may be involved in the review process. Components of the LMP emphasize management protocols for the following issues: administration of the plan, environmental compliance, wildlife, cultural resources, grazing, recreation, energy and mineral resources, lands/realty, reclamation, security, industrial safety, emergency management, maintenance, and work control.

\subsubsection{Land Use Requests}

Parties who wish to conduct activities that may impact lands under the jurisdiction of WIPP, but outside the inner core of the facility designated as the Property Protection Area, are required to prepare a Land Use Request (LUR). A LUR consists of a narrative description of the project, a completed environmental review, and a map depicting the location of the proposed activity. The LUR is used to determine if applicable regulatory requirements have been met prior to the approval of a proposed project. A LUR may be submitted to the land use coordinator by any WIPP organization or outside entity wishing to complete any construction, right-of-way, pipeline easement, or similar action within the WIPP boundary or on lands used in the operation of WIPP, under the jurisdiction of the DOE. During 1999, 21 LURs were submitted for review and approval; all met applicable criteria and were approved.

\subsubsection{Wildlife Population Monitoring}

Southeastern New Mexico is home to diverse populations of plants and wildlife. Shrubs and grasses are the most prominent components of the local flora. Dominant trees include shinnery oak (Quercus havardii), honey mesquite (Prosopis glandulosa), and western soapberry (Sapindus drummondii). Much of the area is composed of combined dune and grassland aspects that include perennial grasses and shrubs.

According to the BLM's Resource Management Plan, 15 percent of the wildlife species identified in the area use the shinnery oak habitat, while 30 percent occupy areas consisting primarily of grasses. The juxtaposition of shinnery oak/dune habitat with grassland habitat has resulted in a diverse wildlife population.

This portion of New Mexico supports an abundant and diverse population of mammals, including black-tailed jackrabbits (Lepus californicus), desert cottontails (Sylvilagus audoboni), desert mule deer (Odocoileus 
hemionus), coyotes (Canis latrans), gray foxes (Urocyon cinereoargenteus), badgers (Taxidea taxis), and striped skunks (Mephitis mephitis).

The habitat heterogeneity of the Los Medaños region also accounts for a wide assortment of bird species. Scaled quail (Callipepla squamata), mourning doves (Zenaida macroura), loggerhead shrikes (Lanius ludovicianus), black-throated sparrows (Amphispiza bilineata), Chihuahuan ravens (Corvus cryptoleucus), and a unique desert subspecies of the northern bobwhite (Colinus virginianus) are but a few examples of the array of avian inhabitants. Due to a scarcity of surface waters in the immediate vicinity of WIPP, migrating or breeding waterfowl are not common.

In addition, this area supports a particularly abundant and diverse population of raptors, or birds of prey. Harris' hawks (Parabuteo unicinctus), Swainson's hawks (Buteo swainsoni), and great horned owls (Bubo virginianus) are species commonly found nesting in the area. Northern harriers (Cicus cyaneus), burrowing owls (Athene cunicularia), barn owls (Tyto alba), and American kestrels (Falco sparverius) are also found at the site.

Reptiles and amphibians are also found in great numbers in southeastern New Mexico. Representative of the no fewer than 10 native amphibians are the tiger salamander (Ambystoma tigrinum), green toad (Bufo debilis), plain's spadefoot toad (Spea bombifrons), red-spotted toad (Bufo punctatus), and New Mexico spadefoot toad (Spea muliplicata). Their significance is seldom recognized until spring or summer rains, at which time they appear in extraordinary numbers. Reptiles are more conspicuous due to their diurnal nature. Characteristic reptiles in the region include the ornate box turtles (Terrapene ornata), side-blotched lizards (Uta stansburiana), western whiptails (Cnemidophorus tigris), bullsnakes (Pituophis melanoleucus), prairie rattlesnakes (Crotalus viridis), and Texas horned lizards (Phrynosoma cornutum), a federal notice-of-review species listed under the Endangered Species Act.
Birds and mammals compose the upper levels of the food chain in the natural ecosystem around WIPP. These organisms may be affected by noise and human presence as well as by changes in habitat structure due to salt impacts. Population densities are monitored annually to define normal cycles of abundance and to detect major changes in populations or communities which may be due to activities at WIPP.

Beginning in 1985, population density measurements of birds and small nocturnal mammals were performed annually to assess the effects of WIPP surface activities (e.g., construction, salt piles) on wildlife populations. Customary protocol involved comparative data analyses between two outlying or "control" plots and two experimental plots near WIPP operations. A Hantavirus investigation during 1994 prompted the temporary postponement of small nocturnal mammal surveys. Previous years' investigations revealed no detectable detrimental impacts from salt encroachment on the peripheral environment; therefore, annual appraisals of small mammal populations were discontinued indefinitely.

WIPP personnel manage several wildlife research projects and conduct a number of general wildlife management activities. Specific wildlife populations are monitored and researched in accordance with applicable laws, agreements, and regulations. Each activity is mandated and/or supported by state and federal guidelines or by way of commitments created through interagency agreements and MOUs. Wildlife within the WIPP Land Withdrawal Area are given consideration by way of the WIPP LUR process during planning stages of projects that may disturb or encroach on wildlife habitat.

In 1979, DOE consulted with the United States Fish and Wildlife Service (USF\&WS) and was informed of the presence of threatened or endangered species at or near the WIPP site. However, no critical habitat for endangered species was identified at WIPP. In 1989, DOE again consulted with the USF\&WS and was advised of no status changes since 1979. 
In 1995, the USF\&WS provided an updated list of threatened and endangered species for Eddy and Lea Counties, New Mexico. Included were 18 species that occur or are likely to occur on WIPP lands. A comprehensive evaluation in support of the second Supplemental Environmental Impact Statement (SEIS-II) was conducted in 1996 to determine the presence or absence of threatened or endangered species in the vicinity of WIPP and WIPP's effect on these species. Results indicated that activities associated with the operation of WIPP had no impact on any threatened or endangered species. The protection of threatened and endangered species is taken into consideration when planning and administering projects on WIPP lands.

During 1989, DOE consulted with the New Mexico Department of Game and Fish (NMDG\&F) regarding state-listed endangered species in the vicinity of WIPP. NMDG\&F Regulation 657, dated January 9, 1988, listed seven birds and one reptile in one of two endangerment categories that occur or are likely to occur at the site.

WIPP, and the region surrounding it, is widely recognized for its concentration and diversity of raptors. The area is home to several raptor species of special concern, including Harris' hawks, Swainson's hawks, burrowing owls, and barn owls, as well as other species.

DOE, the BLM, and other government agencies are keenly aware of the value and importance of protecting and monitoring raptor populations. To assist in this effort at WIPP, the BLM and DOE established the WIPP Raptor Program (WRP) in the early 1990s to monitor, protect, and educate about raptors on the WIPP site. The WRP is administered by the WIPP Environmental Monitoring Program with input from the BLM and others. Scientific consultation, research direction, and field operations are conducted by scientists from Sonora Environmental Consultants, Inc., a private firm specializing in ecological research, wildlife inventory and monitoring, and environmental education programs (Dawson et al 2000).
In 1999, research continued on long-term studies of productivity and population demographics of the raptor community in and around WIPP. These studies are described in greater detail in Chapter 5.

\subsubsection{Reclamation of Disturbed Lands}

DOE recognizes its responsibility pursuant to federal, state, and local environmental regulations to enhance and restore areas affected by WIPP activities, including disturbed lands accepted as part of the land transfer from the BLM. WIPP reclamation activities are conducted in accordance with DOE Order 5400.1; the DOE Organization Act (42 U.S.C. § 7112); the Federal Land Policy and Management Act of 1976 (43 U.S.C. § 1751); the first Supplemental Environmental Impact Statement (SEIS-I); the Final Environmental Impact Statement (FEIS); and all applicable reclamation requirements by federal laws and regulations, executive orders, MOUs, DOE orders, and state and local laws. These commitments encompass any unforeseeable future mandates or amendments to existing regulations.

Without an active reclamation program, the establishment of stable ecological conditions in arid environments may require decades or centuries to achieve, depending on the disturbances and environmental conditions present. Reclamation activities are intended to reduce soil erosion, increase the rate of plant colonization and succession, and provide habitat for wildlife in disturbed areas. Reclamation ultimately serves to mitigate the effects of WIPP-related activities on affected plant and animal communities. The objective of the reclamation program is to return lands used in the operation of WIPP that are no longer commissioned for WIPP operations to a predisturbance ecological condition. DOE will also establish reclamation guidelines for land use requesters on a case-by-case basis.

In accordance with the LMP, WIPP follows a reclamation program and a long-range reclamation plan. As locations are identified for reclamation, WIPP personnel reclaim these areas by using the best acceptable reclamation practices. Seed mixes 
used reflect those species indigenous to the area with priority given to those plant species which are conducive to soil stabilization, wildlife, and livestock needs.

In 1999, reclamation efforts on the Site Preliminary Design and Validation (SPDV) salt pile were initiated. This action followed an evaluation of alternatives proposed in a 1996 site characterization report (Daniel B. Stephens \& Associates 1996). The preferred alternative was to regrade the pile, cap it with a geosynthetic clay liner to exclude moisture, add topsoil, and revegetate. This alternative was selected because it would result in a stable pile with low maintenance costs, would cause minimal site disturbance and fugitive dust emissions, and would minimize hazards associated with excavation and regrading. In addition, it had fewer disadvantages related to environmental damage, safety, and cost than the other alternatives. Activities in 1999 consisted primarily of recontouring the pile in preparation for subsequent capping and seeding.

Also in 1999, approximately 0.81 ha (2 ac) of the $\mathrm{H}-19 \mathrm{~m}$ hydro pad were disked and seeded with a seed mix consisting primarily of four-winged salt bush (Atriplex conescens).

\subsubsection{Oil and Gas Surveillance}

The oil and gas industry is well established in southeastern New Mexico. Nearly all phases of oil and gas activities have occurred in the vicinity of WIPP, including seismic exploration, exploratory drilling, field development (comprised of production and injection wells), and other activities associated with hydrocarbon extraction.

The Los Medaños region, where WIPP is located, is part of the Delaware Basin. Although the Delaware Basin accounts for approximately 32 percent of lands in Eddy County, only 17 percent of the oil and gas wells are located within its boundaries. During 1995, oil and gas reserves in the immediate vicinity of the WIPP Land Withdrawal Area were evaluated by the New Mexico Bureau of Mines and Mineral Resources.
Results from this evaluation were compiled in a report, Evaluation of Mineral Resources at the Waste Isolation Pilot Plant Site, March 31, 1996.

One aspect of the WIPP land withdrawal, unique to most DOE facilities, was the intent to maintain a multiple land use concept in the management of the property. However, an exception to a global multiple use strategy was required to reduce likelihood of inadvertent intrusion on the repository and to safeguard the surface infrastructure. Accordingly, all drilling and mining on the WIPP site has been prohibited. Oil and gas activities within $1.6 \mathrm{~km}(1 \mathrm{mi})$ of the WIPP boundary are monitored twice monthly to identify new activities associated with oil and gas exploration and production, including:

- drilling,

- survey staking,

- geophysical exploration,

- pipeline construction,

- work-overs,

- changes in well status, and

- anomalous occurrences (e.g., leaks, spills, accidents, etc.).

During 1999, WIPP surveillance teams conducted 224 oil and gas surveillances.

One exception to the prohibition of mining and drilling on the WIPP site involves two mineral leases. Under a provision contained in the Land Withdrawal Act (Public Law 102-579), these two mineral leases, consisting of 129 ha (320 ac) each, were not appropriated in the proceedings. Both tracts, located in T.22 S., R. 31 E., Section 31, prohibit drilling within the first $1,830 \mathrm{~m}(6,000 \mathrm{ft})$ of the surface. In accordance with the WIPP Land Withdrawal Act, existing rights under these leases will not be affected unless the Administrator of EPA determines, after consultation with the Secretary of Energy, that the area in question should be purchased.

This determination was made because of the presence of an existing gas well that had been drilled directionally from the adjacent Section 6 of Township 23 South, Range 31 East. During deliberations, it was determined the DOE would condemn the upper $1,830 \mathrm{~m}(6,000 \mathrm{ft})$ of $\mathrm{Sec}$ - 
tion 31. This action would require operators interested in accessing minerals under the section to stage drilling operations outside the WIPP boundary and directionally drill under Section 31 . The condemnation of the upper $1,830 \mathrm{~m}(6,000 \mathrm{ft})$ would provide an adequate protective zone for DOE operations while still allowing the legal owner of the minerals to access the reserves. Section 4(b)(5) of the Land Withdrawal Act describes this action as follows:

\section{(5) Mining:}

(A) In general. Except as provided in subparagraph (B), no surface or subsurface mining, or oil or gas production, including slant drilling from outside the boundaries of the Withdrawal, shall be permitted at any time (including after decommissioning) on lands on or under the Withdrawal.
(B) Exception. Existing rights under Federal Oil and Gas Leases No. NMNM 02953 and No. NMNM 02953 shall not be affected unless the Administrator determines, after consultation with the Secretary and the Secretary of the Interior, that the acquisition of such leases by the Secretary is required to comply with the final disposal regulations.

To date, no new wells have been directionally drilled under Section 31 .

\subsubsection{Aerial Photography}

Aerial photographs of the WIPP site are taken annually to record impacts of WIPP activities on the local ecology. The extent of habitat displacement, caused by the construction of roads, parking lots, buildings, and salt storage piles is documented in the aerial photographs. 


\section{Chapter 3 \\ Compliance Summary}

WIPP is required to comply with all applicable federal and state laws and DOE orders. Documentation of requisite federal and state permits, notifications, and applications for approval is maintained by the WID Environment, Safety, and Health Department. Regulatory requirements are incorporated in facility plans and implementing procedures. The Standards/Requirements Identification Document establishes the environmental, safety, and health requirements that apply to WID and documents the status of WID's compliance with those requirements.

\subsection{Compliance Overview}

In 1999, WIPP maintained compliance with applicable federal and state environmental regulations. Section 3.2 contains a listing of environmental statutes/regulations applicable to WIPP. Section 3.3 describes significant accomplishments and ongoing compliance activities relative to the regulations most pertinent to WIPP's development and eventual opening of the facility. A detailed breakdown of WIPP's compliance with all environmental regulations is available in the WIPP Biennial Environmental Compliance Report (DOE/WIPP 98-2171).

\subsection{Compliance Status}

A summary of WIPP's compliance with major environmental regulations is presented in Table 3.3. Applicable DOE Orders are found in Table 3.4, and a list of WIPP permits appears in Table 3.5 (see end of Chapter 3 ).

\subsubsection{Comprehensive Environmental Re- sponse, Compensation, and Liability Act}

The Comprehensive Environmental Response, Compensation, and Liability Act (CERCLA) establishes a comprehensive federal strategy for responding to, and establishing liability for, releases of hazardous substances from a facility to the environment. Hazardous substance cleanup procedures are specified in the National Oil and Hazardous Substances Pollution Contingency Plan (40 CFR § 300). No release sites have been identified at WIPP that would require cleanup under the provisions of CERCLA. Any spills of hazardous substances that exceed a reportable quantity must be reported to the National Response Center under the provisions of section 103 of CERCLA and 40 CFR $\S 302$.

Superfund Amendments and Reauthorization Act of 1986

WIPP is required by Sections 311 and 312 of the Superfund Amendments and Reauthorization Act (SARA) Title III (also known as the Emergency Planning and Community Right-toKnow Act) to submit (1) a list of chemicals for which a material safety data sheet is required, and (2) an Emergency and Hazardous Chemical Inventory Form (Tier II Form) to the State Emergency Response Commission, the Local Emergency Planning Committee, and the fire department with jurisdiction over the facility. The list of chemicals provides external emergency responders with information they may need when responding to a hazardous chemical emergency at WIPP. The Tier II Form, due on March 1 of each year, provides information to the public about hazardous chemicals that a facility has on site above threshold planning quantities at any time during the year. WIPP submits the list of chemicals and the Tier II Form to each fire department with which the Carlsbad Area Office maintains a MOU. 
Accidental Releases of Reportable Quantities of Hazardous Substances

During 1999, no releases of hazardous substances exceeded the reportable quantity limits.

\subsubsection{Federal Acquisition, Recycling, and Pollution Prevention}

In July 1995, WIPP adopted a systematic and cost-effective affirmative procurement plan for the promotion and procurement of products containing recovered materials. Affirmative procurement is designed to "close a loop" in the waste minimization recycling process by supporting the market for materials collected through recycling and salvage operations.

Affirmative procurement programs are mandated by RCRA section 6002(I), which requires federal agencies and their procuring agencies to establish material preference programs targeted to purchase recycled materials. Executive Order 13101 and the EPA guidelines in 40 CFR $\S \S 248$ through 250 and 252 through 253 provide additional guidance for implementing affirmative procurement programs at federal facilities.

Affirmative procurement programs must include four elements: (1) a preference program, (2) a promotion program, (3) an estimation, certification, and verification procedure, and (4) procedures for annual review and monitoring procedures. The purchase and use of recycled products at WIPP will help foster markets for recovered materials and reduce the amount of solid waste requiring disposal.
WIPPs Affirmative Procurement Program Plan is WP 02-EC.07. In 1999, WID purchased 98 percent of the items required by EPA through this program.

\section{Pollution Prevention Programs}

Noteworthy pollution prevention (P2) activities during 1999 included the following items:

- Leaded Brine Reduction-Leaded brine was identified as a Resource Conservation and Recovery Act (RCRA) waste stream at WIPP in 1995. Natural waters present in mining operations pick up some salt from the shaft walls. The resulting brine leaches traces of lead from the galvanized chain link fence material used to cover the walls of the shaft. In 1999 WIPP implemented process changes that resulted in meeting the 50 percent reduction goal, and ISO 14001 targets and objectives, by December 1999.

- Pollution Prevention Opportunity Assessment-An assessment (PPOA 9902) was performed to address concerns of using an industrial cleaner (CRC Lectra Motive [Aerosol/Bulk]) containing a known carcinogenic component. Two products were identified which may likely replace the one presently in use; both are undergoing suitability and performance testing for specific applications.

- Recycling-WIPP continued its mandatory recycling program. Increases of 100 to 300 percent above 1998 levels were realized for most recycled materials (Table 3.1). 
Table 3.1 Materials recycled at WIPP in 1999.

\begin{tabular}{|c|c|c|}
\hline \multirow[b]{2}{*}{ Material } & \multicolumn{2}{|c|}{ Mass } \\
\hline & Metric Tons & Pounds \\
\hline Office and mixed paper & 125.72 & 277,1265 \\
\hline Aluminum cans & 0.25 & 551 \\
\hline Cardboard & 48.96 & 107,938 \\
\hline Pallets & 0.25 & 551 \\
\hline Oil & 5.12 & 11,288 \\
\hline Scrap metal & 12.66 & 5,864 \\
\hline Plastic & 0.77 & 170 \\
\hline Fire extinguishers & 0.003 & 7 \\
\hline Ethylene glycol & 1.34 & 2,954 \\
\hline Solvent & 12.66 & 27,910 \\
\hline
\end{tabular}

\subsubsection{Resource Conservation and Re- covery Act}

Resource Conservation and Recovery Act (42 United States Code [U.S.C.] § 3251 et seq.) was enacted in 1976. Implementing regulations were promulgated in May 1980. This body of regulations ensures that hazardous wastes are managed and disposed in a way that protects human health and the environment. The Hazardous and Solid Waste Amendments of 1984 prohibit land disposal of hazardous wastes unless treatment standards are met. The amendments also place increased emphasis on waste minimization activities and serve as a mechanism to enforce RCRA cleanup requirements.

The WIPP facility is subject to the permitting requirements under RCRA and the New Mexico Hazardous Waste Act. Title 40 CFR § 264 outlines the technical standards for treatment, storage, and disposal facilities. Title 40 CFR $\S 270$ outlines the requirements of the RCRA permitting program with respect to general format and content for applications and the administrative aspects of the permitting and modification processes.
Non-mixed, TRU radioactive waste shipments began on March 26, 1999. Shipments continued until November 22, 1999, when they were postponed in order to address requirements of the Waste Isolation Pilot Plant Hazardous Waste Facility Permit NM4890139088-TSDF. On October 27, 1999, WIPP received the final permit which became effective on November 26, 1999.

\section{Hazardous Waste Generator Compliance}

Nonradioactive hazardous waste is currently generated through normal facility operations, and is managed in Satellite Accumulation Areas and "less-than-90-day" storage areas. In addition, hazardous waste generated at WIPP is characterized, packaged, labeled, and manifested prior to shipment to an off-site treatment, storage, and disposal facility in accordance with the requirements codified in $40 \mathrm{CFR} \S 262$.

WIPP Solid Waste Management Units and Areas of Concerns

The New Mexico Environment Department (NMED) on October 27, 1999 issued the WIPP Hazardous Waste Facility Permit. Module VII of 
the permit contains the requirements for corrective action for the WIPP Solid Waste Management Units (SWMUs) and Areas of Concern (AOCs). The permit identified 15 SWMUs requiring a RCRA Facility Investigation (RFI), three SWMUs not requiring a RFI (the Hazardous Waste Management Units), and eight AOCs in the 4,146 ha $\left(16 \mathrm{mi}^{2}\right)$ WIPP Land Withdrawal Area.

\section{Solid Waste Management Units}

The 15 SWMUs included in the permit that require a RFI are listed below:

SWMU 001g (H-14/P-1 Mud Pits)

SWMU 001h (H-15/P-2 Mud Pits)

SWMU001j (P-3 Mud Pit)

SWMU 001k (P-4 Mud Pit)

SWMU 0011 (WIPP-12/P-5 Drilling

Mud Pits)

SWMU 001m (P-6 Mud Pit)

SWMU 001n (P-15 Mud Pit)

SWMU 001o (Badger Unit Drilling Mud Pits)

SWMU 001p (Cotton Baby Drilling Mud Pits)

SWMU 001q (DOE-1 Drilling Mud Pits)

SWMU 001s (ERDA 9 Mud Pit)

SWMU 001t (IMC 347 Mud Pit)

SWMU 001x (WIPP-13 Drilling Mud Pits)

SWMU 004a (Portacamp Storage Yard, West

Side)

SWMU 007b (SW Evaporation Pond)

\section{Areas of Concern}

Following are the eight AOCs included in the permit.

AOC 001r (D-123 Mud Pit)

AOC 001u (IMC-376 Mud Pit)

AOC 001v (IMC-456 Mud Pit)

AOC 001w (IMC-457 Mud Pit)

AOC 001ac (DSP-207 Mud Pit)

AOC 001ae (IMC-377 Mud Pit)

AOC 010b (Waste Handling Shaft Sump)

AOC 010c (Exhaust Shaft Sump)

Some of the SWMUs and AOCs were identified in the original RCRA Part B Permit Application for the facility (Revision 0, DOE/WIPP 91-005), and were included in a
RCRA Facility Assessment (RFA) performed by NMED (NMED/DOE/AIP 94/1 1994). The 15 SWMUs and eight AOCs identified in the permit are associated with: natural resource exploration activities prior to the development of the WIPP, early WIPP mineral assessment and geological studies to support the development of the facility, or facility construction.

The SWMU program at WIPP began in 1994 under EPA regulatory authority. NMED subsequently received regulatory authority from EPA. A Phase 1 RFI was completed at WIPP during 1996 as part of a Voluntary Release Assessment.

Samples were collected at some of the SWMUs as part of a RFA performed by NMED (NMED/DOE/AIP 94/1 1994). WIPP conducted two rounds of soil sampling at selected SWMUs in 1995 and 1996. In the summer of 1995, soil samples were collected for initial characterization by the toxicity characteristic leaching procedure (TCLP). A second round of sampling at the same SWMUs was conducted in the summer of 1996 and involved collecting soil samples for total constituent analyses. The total constituent analysis data were collected based on a request from NMED to support the TCLP data collected in the initial sampling round. NMED reviewed the sampling conducted by WIPP at the SWMUs and defined a list of SWMUs with constituents of concern and AOCs to be included in the permit. These SWMUs/AOCs and constituents of concern for the SWMUs were described in the Technical Support Document, Exclusion/Inclusion of Solid Waste Management Units and Areas of Concern, Permit Module VII Correction Action for Solid Waste Management Units (NMED 1999).

\section{Program Deliverables and Schedule}

Currently, WIPP is preparing a WIPP Sampling and Analysis Plan (SAP) for SWMUs and AOCs which fulfill requirements of Module VII, Section VII.M.2 and Table VII.1, requirement 4 of the permit.

The SAP addresses the current permit requirements for a RFI of SWMUs and AOCs. It 
uses the results of previous investigations performed at WIPP and expands the investigations as required by the permit. As an alternative to the RFI specified in Module VII of the permit, current NMED guidance identifies an Accelerated Corrective Action Approach (ACAA) that may be used for any SWMU or AOC (NMED 1998). This ACAA is used to replace the standard RFI Work Plan and Report sequence with a more flexible decision-making approach. The ACAA process allows a facility to exit the schedule of compliance contained in the facility's Hazardous and Solid Waste Amendments permit module and proceed on an accelerated time line. The ACAA process can be entered either before or after a RFI Work Plan. According to NMED's guidance, a facility can prepare a RFI Work Plan or ACAA for any SWMU or AOC (NMED 1998).

This SAP has two primary objectives: to define the extent of concentrations of hazardous constituents that exceed background metal concentrations in soil at specific SWMUs, and to perform a release assessment at specific AOCs to determine if hazardous constituents are present above background concentrations. The scope of this investigation is limited to the SWMUs and AOCs identified in the permit.

\subsubsection{National Environmental Policy Act}

The National Environmental Policy Act (NEPA) requires the federal government to use all practicable means to consider potential environmental impacts of proposed projects as part of the decision-making process. NEPA dictates the public shall be allowed to review and comment on proposed projects that have the potential to significantly affect the environment. NEPA also directs the federal government to use all practicable means to improve and coordinate federal plans, functions, programs, and resources relating to human health and the environment.
NEPA procedural objectives and public involvement requirements are detailed in the Council on Environmental Quality regulations implementing NEPA in 40 CFR $\S \S 1500-1508$. DOE codified its requirements for implementing the council's regulations in 10 CFR $\S 1021$. Further procedural NEPA compliance guidance is provided in DOE Order 451.1A. Title $10 \mathrm{CFR} \S 1021.331$ requires that, following completion of each Environmental Impact Statement (EIS) and its associated Record of Decision (ROD), DOE shall prepare a mitigation action plan that addresses mitigation commitments expressed in the ROD.

Further, DOE Order 451.1A requires DOE facilities to track and annually report progress in implementing a commitment for environmental impact mitigation that is essential to render the impacts of a proposed action not significant or that is made in a ROD. The 1998 Annual Mitigation Report for the Waste Isolation Pilot Plant (NEPA ID\# WIP:99:001) was issued June 28, 1999.

A commitment was made by DOE in the Supplemental Environmental Impact Statement (SEIS-I, DOE-EIS-0026-FS) ROD to prepare a second SEIS (SEIS-II) prior to beginning disposal operations at WIPP.

New hydrologic and geologic information was used in the development of the WIPP performance assessment and the evaluation of the facility's ability to isolate waste. In September 1997, DOE published the SEIS-II (DOE/EIS-0026-S-2), taking into account all of the relevant changes since publication of the SEIS-I that might result in potential environmental impacts from WIPP disposal and closures operations. DOE issued the ROD for the SEIS-II on January 16, 1998. 
Table 3.2 WIPP's key RCRA ${ }^{1}$ permit deliverables and due dates.

Due Date

Deliverable(s)
December 8, 1999

February 24, 2000

May 24, 2000
A notice to inform individuals on the WIPP mailing list maintained by the Secretary of the New Mexico Environmental Department that the U.S. Department of Energy has established three repositories for information associated with corrective action activities at WIPP. Completed.

Facility Work Plan. Annual reviews and updates to the Facility Work Plan will be completed as necessary.

RCRA Facility Investigation Work Plan or Accelerated Corrective Action Approach.

${ }^{1}$ Resource Conservation and Recovery Act

\subsubsection{Clean Air Act}

The Clean Air Act (42 U.S.C. § 7401 et seq.) provides for the preservation, protection, and enhancement of air quality, particularly at locations of special interest such as areas of natural, recreational, scenic, or historic value.

Under section 109 of the Clean Air Act, the EPA established the National Ambient Air Quality Standards for six "criteria" pollutants: sulfur dioxide, total suspended particulates, carbon monoxide, ozone, nitrogen oxides, and lead. These standards establish primary and secondary criteria for ambient air quality that the EPA considers necessary to protect public health and welfare.

The initial WIPP hazardous air pollutant (HAP) emission inventory was developed as a baseline document to calculate maximum potential hourly and annual emissions of both hazardous and criteria pollutants. A HAPs inventory is conducted biennially and compared to the baseline data to identify trends and potential emissions problems. The biennial inventory scheduled for calendar year 1998 was postponed because conditions at the site were unchanged from the previous inventory. The next inventory will be conducted in 2000. Emission estimates are used to determine if WIPP is required to obtain an air permit as specified in the following regulations.

- Clean Air Act, § 112, National Emissions
Standards for Hazardous Air Pollutants (NESHAP)

- Clean Air Act, Part C Prevention of Significant Deterioration-Criteria Pollutants

- New Mexico Administrative Code Title 20, Chapter 2, Air Quality

Based on the current HAPs inventory, WIPP operations do not exceed the 10-ton-per-year emission limit for any individual HAP or the 25-ton-per-year limit for any combination of HAPs emissions established in Subpart A of NESHAP.

Title $40 \S$ CFR 61, Subpart A, Section 61.09(a)(1), requires the WIPP facility to notify the EPA of its anticipated date of initial start-up (i.e., receipt of waste) not more than 60 days and not less than 30 days before actual start-up date. This notification was made on February 23,1999, with the actual startup date being March 26, 1999. In addition, the EPA required notification of the actual date of initial start-up be made within 15 days of actual start-up. The 15-day notice of actual start-up was submitted March 26, 1999.

Based on emission estimates generated in the HAPs inventory, the WIPP site is not required to obtain federal Clean Air Act permits. WIPP, in consultation with the NMED Air Quality Bureau, working in concert with data provided in the first HAPs inventory, was required to obtain a New Mexico Air Quality Control Regulation 702, Operating Permit (recodified in 1997 as Title 20, 
Chapter 2, Part 72, Construction Permits) for two primary backup diesel generators at the site. The only emission points where the WIPP site exceeds state threshold criteria are the backup diesel generators. WIPP completed all necessary requirements for emissions monitoring and sampling required by New Mexico Air Quality Permit 310-M-2. During 1999, the backup diesel generators were operated for approximately 31 of the 480 hours allowed by the permit. There were no malfunctions or abnormal conditions of operation that would cause a violation of the permit.

WIPP's normal operations do not involve or entail any planned or expected releases of airborne radioactive materials to the workplace or the environment. Waste containers accepted for disposal at WIPP are required to meet the 10 CFR $\S 835$ external contamination limits. To ensure compliance, the containers are surveyed both prior to release from the generator sites and as the Transuranic Package Transporter Model (TRUPACT-II) containers are opened at WIPP. Since radioactive material remains in the waste containers unless an accident occurs, there will be no emissions of radionuclides to the ambient air from DOE facilities during normal WIPP waste handling, and the public will not be subjected to radioactivity from the WIPP facility. Since no radioactivity above background was released from the WIPP facility during 1999, it may be concluded that WIPP was operated in compliance with the release standards of 40 CFR $\S 191$, Subpart A, and 40 CFR $\S 61$, Subpart H.

The 1995 Safety Analysis Report (DOE/WIPP 95-2065) established the adequacy of the WIPP safety bases regarding plant response to conditions considered to be "extremely unlikely." External doses to workers from the handling of contact-handled waste containers were estimated to be well within DOE's "as low as reasonably achievable" goals and well below regulatory limits. Similarly, consequences to the public and workers as a result of the release of volatile organic compounds (VOC) during disposal phase normal operations were shown to be many orders of magnitude below health-based limits.

\subsubsection{Clean Water Act}

Section 402 of the Clean Water Act (33 U.S.C. $\S \S 1251-1376)$ establishes provisions for the issuance of permits for discharges into waters of the United States. Regulations promulgated to define this permitting process are contained in 40 CFR $§ 122$, subpart A, Section (b)(1), and state that "...National Pollutant Discharge Elimination System(NPDES) program requires permits for the discharge of 'pollutants' from any 'point source' into waters of the United States." WIPP has no pollutant discharges from point sources and is currently exempted from obtaining a standard NPDES permit.

In August 1997, WIPP submitted to the EPA a Notice of Intent (NOI) for Storm Water Discharges Associated with Industrial Activity under a NPDES Multi-Sector General Permit. On December 2, 1997, WIPP received a request for additional information necessary to process the NOI. The requested information was submitted in January 1998 and permit NMR00A021 was issued February 23, 1998. This permit replaces the NPDES Storm Water General Permit that was terminated when the national permit program expired on September 9, 1997.

As a condition of the multi-sector general permit, a pollution prevention plan has been developed and implemented. The plan describes how the Best Management Practices and other requirements of the NPDES storm water regulations are being implemented at WIPP.

No sampling is required to demonstrate compliance with the WIPP Storm Water Permit unless a release occurs. Operational permit compliance activities are limited to quarterly inspections of retention basins, spill containment devices, reclamation sites, and site housekeeping practices.

The NPDES sewage sludge regulations promulgated in $40 \mathrm{CFR} \S 122.21$ require all facilities that generate or dispose of sewage sludge to submit an information package describing sewage sludge management and disposal practices. This information is reviewed 
by the EPA to determine if a NPDES permit will be required for the disposal of sewage sludge at a facility.

On February 14, 1994, DOE submitted an information package to the EPA Water Management Division and requested a written determination of whether a NPDES permit would be required for sewage sludge generated at WIPP. On March 31, 1994, the EPA Region VI Permits Issuance Section notified DOE that they had received the information package. The agency determined that the information package was complete and, at a future date, would notify DOE if a full and complete sewage sludge permit application would be required. To date this notification has not been made, indicating an application is not yet required.

On January 16, 1992, NMED issued the Sewage System Discharge Plan (DP-831) for the WIPP sewage facility. In addition to sewage effluent, DP-831 allows for the disposal of a maximum of $5,680 \mathrm{~L}(1,500 \mathrm{gal})$ per day of nonhazardous brines from pumping of observation wells at the site. Observation well brine waters are collected in portable tanks and transported to the north sewage system evaporation basin. Characterization samples were collected to appropriately disposition brines. On August 28, 1995, WID submitted a request to NMED requesting a minor amendment to DP-831, increasing the amount of nonhazardous brine for disposal to $7,570 \mathrm{~L}$ (2,000 gal) per day. On October 4, 1995, NMED approved the amendment to DP-831.

In December 1996, an application for renewal of DP-831 was submitted to NMED. The application requested the renewal of the existing permit conditions and the addition of the H-19 evaporation pond. This pond was constructed by Sandia National Laboratories for use during the Culebra Transport Test Program. The discharge plan renewal and modification was approved by NMED on July 3, 1997. The permit approves the discharge of up to $30,300 \mathrm{~L}$ (8,000 gal) per day to the H-19 evaporation pond. DOE submits quarterly discharge monitoring reports to NMED to demonstrate compliance with the inspection, monitoring, and reporting requirements identified in the plan.

Water quality analysis as specified by DP-831 was modified with the issuance of the July 3, 1997, permit. The permit requires quarterly sampling and analysis of the sewage system influent for nitrate, total Kjeldahl nitrogen, total dissolved solids (TDS), ${ }^{238} \mathrm{Pu},{ }^{239+240} \mathrm{Pu},{ }^{241} \mathrm{Am}$, ${ }^{234} \mathrm{U},{ }^{235} \mathrm{U},{ }^{238} \mathrm{U}$, and ${ }^{90} \mathrm{Sr}$.

\subsubsection{Safe Drinking Water Act}

The Safe Drinking Water Act (SDWA) (42 U.S.C. $§ 300 f$, et seq.) of 1974 provides the regulatory strategy for protecting public water supply systems and underground sources of drinking water. NMED notified WIPP in a September 9, 1992, letter that the WIPP public water supply was categorized as a nontransient, noncommunity system for reporting and testing requirements.

New Mexico water supply regulations mandate that when a public water supply system supplements other systems, that water system is treated as a single system for compliance sampling purposes. The Carlsbad municipal water supply system is contracted to provide raw water to WIPP from city-owned wells $50 \mathrm{~km}(31 \mathrm{mi})$ north of the site. Because of this contractual agreement, the city of Carlsbad completes the source, or point-of-entry, samples for the various chemical constituents at each well field source.

In a letter dated August 28, 1996, NMED set the sampling frequency at ten samples every three years. The required samples were collected in July 1999 and the results were submitted to NMED. All samples were below action levels as specified by New Mexico monitoring requirements for lead and copper in tap water.

Bacterial samples were collected and reported monthly throughout 1999. All bacteriological/ analytical results were below the SDWA regulatory limits. 


\subsubsection{National Historic Preservation Act}

The National Historic Preservation Act (NHPA) (16 U.S.C. $\$ 470$ et seq.) was enacted to protect the nation's cultural resources and establish the National Register of Historic Places. Federal agencies are required to coordinate NEPA compliance with the responsibilities of the NHPA to ensure that historic and cultural properties are given proper consideration in the preparation of environmental assessments (EAs) and EISs. Agency obligations under the NHPA, however, are independent from NEPA and must be complied with even when no EA or EIS is required (i.e., for proposed projects not classified as major federal actions with significant environmental impacts, DOE must still consider impacts to historic properties and sites). Where both NEPA and the NHPA are applicable, draft EISs must integrate NHPA considerations along with other environmental impact analyses and studies (see 40 CFR $§ 1502.25$ ).

No new archaeological sites were discovered during 1999, nor were any WIPP-related activities initiated that required archaeological investigation.

\subsubsection{Hazardous Materials Transportation Act}

The Hazardous Materials Transportation Act (49 App. U.S.C. $\S 1801$ et seq.; 49 CFR $\S \S 106-179)$ is one of the major transportation-related statutes that affects DOE at WIPP. It provides for safe transportation of hazardous materials, including radioactive materials. In the second modification to the Agreement for Consultation and Cooperation, DOE agreed to comply with all applicable U.S. Department of Transportation (DOT) regulations and corresponding Nuclear Regulatory Commission (NRC) regulations. DOE orders ensure compliance. DOE orders establish packaging and transportation safety criteria and require that DOE Field Elements conduct their operations in accordance with all applicable international, federal, state, local, and tribal laws, rules, and regulations governing materials transportation. These DOE orders also require the development of a transportation plan and use of DOE TRANSCOM (transportation tracking and communications) system to monitor shipments. Additional requirements are included for shipment inspections, notifications, dates, and special instructions.

The following federal regulations are applicable to WIPP.

- Title $10 \mathrm{CFR} \S 71, \mathrm{NRC}$ requirements for packaging, preparing, and transporting licensed material

- Title 49 CFR $\S \S 171-178$, hazardous/ radioactive materials regulations

- $\quad$ Title 49 CFR $\S \S 173$ and 178, packaging specifications

- Title 49 CFR $\S 174$, Subparts A through $\mathrm{D}$ and $\mathrm{K}$, shipment of radioactive material by rail regulations

- Title 49 CFR $§ 177$, routing and training requirements for highway shipments of nuclear material

The WID Waste Operations Section implements applicable DOT and EPA regulations and DOE orders for the transport of hazardous waste and hazardous materials from WIPP. Shipping sites implement applicable DOT and EPA regulations and DOE orders for the transport of TRU waste to WIPP.

\subsubsection{Packaging and Transporting Ra- dioactive Materials}

Regulations for transportation of radioactive materials, under the authority of the DOT, are found in 49 CFR $\S \S 171$ through 178 . If the quantity of radioactive material exceeds certain limits, as determined by 49 CFR $\S 173.433$, a Type B shipping container (packaging) must be used. The specific requirements for the shipment of radioactive materials and requirements applicable to the Type B packages to be used to transport waste to the WIPP facility are detailed in 49 CFR 172-173 (the certificate of compliance for the package) and 40 CFR 262. Regulations for Type B packaging, under the authority of the NRC, are found in 10 CFR $\S 71$, Packaging and Transportation of Radioactive Materials. The 
WIPP Land Withdrawal Act requires that TRU waste containers shipped to WIPP shall be transported using packages which have had the design certified by the NRC and which have been determined by the NRC to satisfy its QA requirements.

Additional transportation requirements for the mixed waste shipments (i.e., TRU mixed wastes) are detailed in 40 CFR $\S 262$. The appendix to $\S 262$ provides an example of a uniform hazardous waste manifest and instructions to waste generators and shippers of hazardous wastes.

Contact-handled TRU waste will be shipped in the TRUPACT-II and the HalfPACT. The HalfPACT is a shorter version of the TRUPACT-II; it was designed to transport heavier contact-handled TRU waste containers. The NRC certified the TRUPACT-II container on August 30, 1989. Since 1989, expansion of the TRUPACT-II payload envelope has been accomplished through applications to the NRC for revisions of the TRUPACT-II Safety Analysis Report for Packaging (SARP) and the Certificate of Compliance ( $\mathrm{C}$ of $\mathrm{C}$ ), when applicable. A HalfPACT certification test unit was subjected to hypothetical accident conditions in accordance with the requirements described in 10 CFR $\S 71$, Subpart F. The test results are included in a HalfPACT SARP submitted to the NRC for approval in August 1998. The current revision of the TRUPACT-II C of C, No. 11, expires June 30, 2004.

\subsection{Other Significant Accomplish- ments and Ongoing Compliance Ac- tivities}

\subsubsection{Environmental Compliance Assess- ment Program}

The Environmental Compliance Assessment Program plays a major role in the overall program for environmental protection activities at WIPP. The program was developed to determine if impactive or potentially impactive facility activities protect human health and the environment and if these activities are in compliance with applicable federal, state, and local requirements; with permit conditions and requirements; and with best management practices.

During 1999, six environmental compliance assessments were conducted. Forty-six improvements were identified and implemented as a result of these assessments. The assessed areas included: SWMUs-RCRA Permit Requirements, Environmental Compliance and Support Permits, Universal Waste Requirements, RCRA Equipment Inspection Requirements, Hazardous Waste Generator Requirements, and NESHAP Regulations.

\subsubsection{ISO 14000 - Standards for Environ- mental Management}

ISO 14001 is the specific section of the ISO 14000 standard devoted to Environment Management Systems (EMS). Integration of WIPP's ISO 14001 program with other Westinghouse government-owned, contractoroperated (GOCO) programs has been initiated. Westinghouse corporate officials and GOCO ISO 14001 coordinators meet regularly to discuss activities to more effectively implement the ISO standard at sites throughout the DOE complex. Information sharing has already occurred, with benefits to all Westinghouse GOCO programs. The WID continues to support the ISO 14001 lessons learned programs and shares EMS implementation documentation with both the DOE complex and the private sector.

The WID Environmental Management System (EMS) received third-party registration on August 5, 1997. Two third-party registration surveillance audits were conducted in 1999 . One minor nonconformance was identified during the March audit and the Environmental Policy was revised to include in the EMS voluntary programs such as VPP and ISMS. No findings or observations were identified during the second surveillance conducted in August.

The EMS Implementation Document (WP 02-EC.0) was developed to define the roles of WID departments and subcontractors to implement the EMS and update the WID 
Environmental Management Policy. WP 02-EC.0 applies to all WID operations and designated WID subcontractors at the WIPP site.

The WID Environmental Aspects and Impacts table in WP 02-EC.0 identifies activities at WIPP that have the potential to have a significant impact on the environment. The Environmental Objectives and Targets table identifies environmental objectives and targets designed to mitigate potential environmental impacts and identifies the dates and organization responsible for implementing each of the significant objectives. The goals for this activity are to ensure a system of continuous environmental improvements to more clearly define each organization's roles and responsibilities for implementing the EMS, and to promote pollution prevention at WIPP. Additionally, EMS training has been provided to the entire WIPP workforce and EMS training modules have now been integrated into sitewide training programs.

Several actions have been taken to more effectively implement the ISO 14001 Standards at the site. WID formed an ISO 14001 Integration Team that includes members from a majority of WID and subcontractor organizations. Each member is tasked with providing their department's environmental objectives and targets leading to overall improvement under WIPP's EMS.

Articles on ISO 14001 requirements are published periodically in the Westinghouse employee newsletter, TRU News. The Environmental Compliance and Support Section of the WID Environment, Safety, and Health Department is responsible for coordinating the annual sitewide review of the EMS Implementation Document, the Environmental Policy, and the Aspects and Impacts and Objectives and Targets tables to ensure that the EMS remains effective.

\subsubsection{Pollution Prevention Committee}

The Pollution Prevention (P2) Committee was formed in 1993 with a representative from each department. The committee prepared a waste minimization charter, which outlines the committee's responsibilities.

The P2 Committee celebrates Earth Day to promote awareness of waste minimization and other environmental issues. Rewards are given to those who participate in this campaign. Activities for the 1999 Earth Day celebration included implementation of the "Oscar" Mini Bin Program, in which traditional $49 \mathrm{~L}$ (13 gal) under-the-desk trash cans were replaced by $1.9 \mathrm{~L}$ (2 qt) "Oscar" Mini Bins. This program encourages employees to recycle, sort, and properly dispose of office trash.

During October 1999, Energy Month was celebrated with a display of solar powered equipment. The P2 Committee baked cookies in a large solar oven. This demonstrated the significant advances in solar technologies as an alternative source of electricity.

\subsubsection{Environmental Training}

Environmental training was provided to personnel associated with environmental operations at WIPP. Training courses included technical topics (e.g., RCRA sampling), EMS, basic environmental safety and health training, and general sitewide training such as the required General Employee Training module. These courses were conducted both on-site by WIPP personnel and off-site by various contractors. 


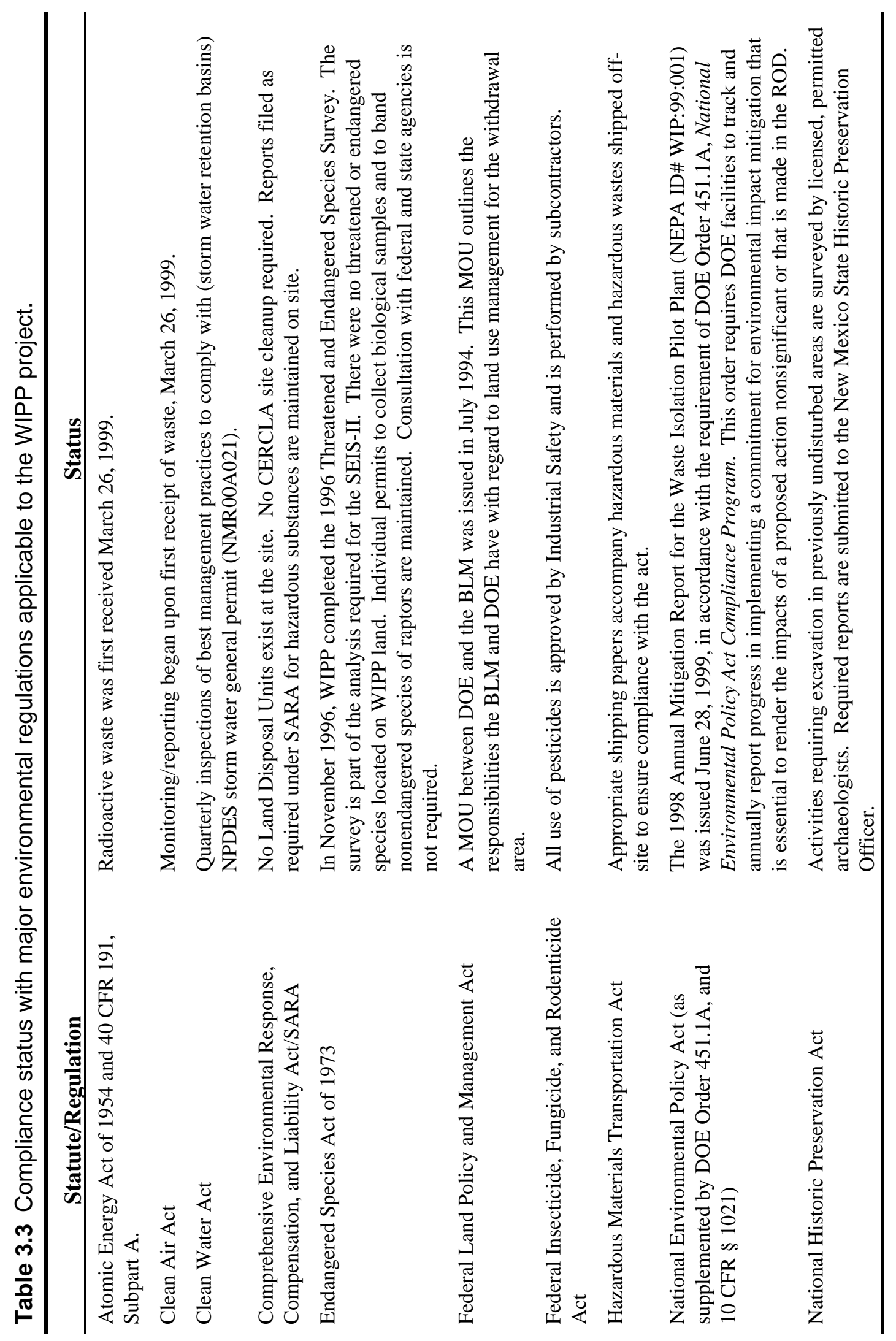




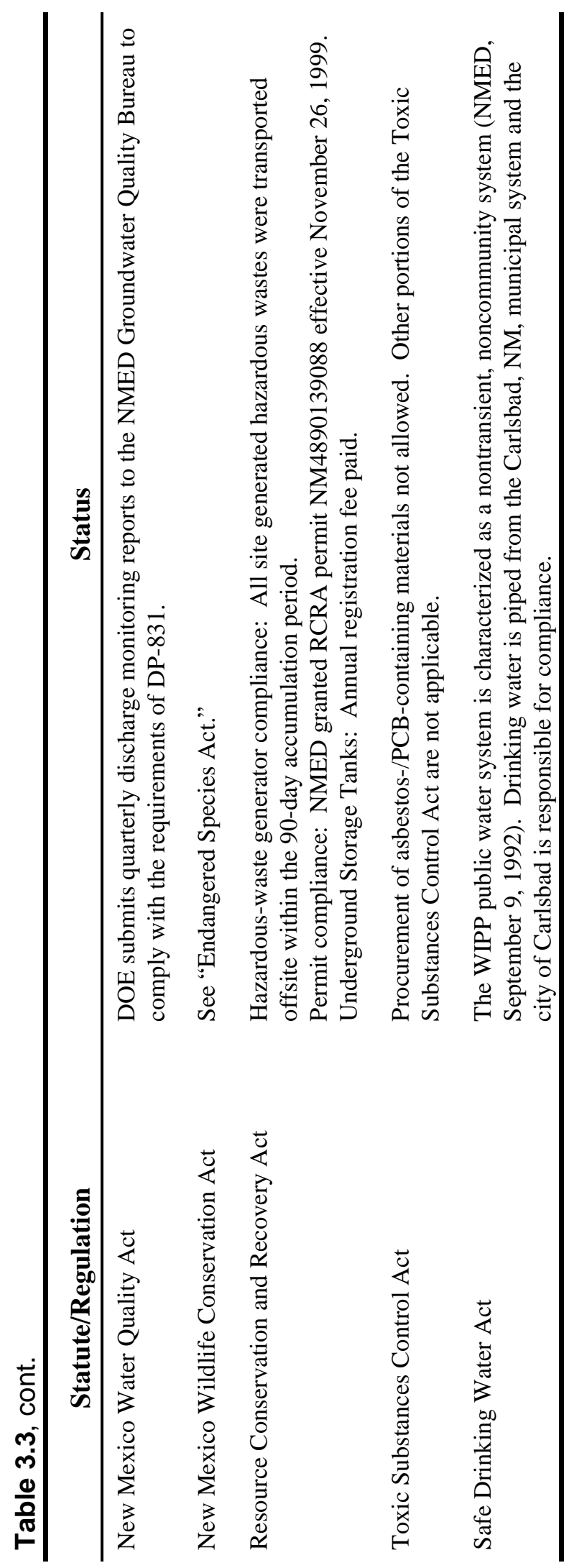




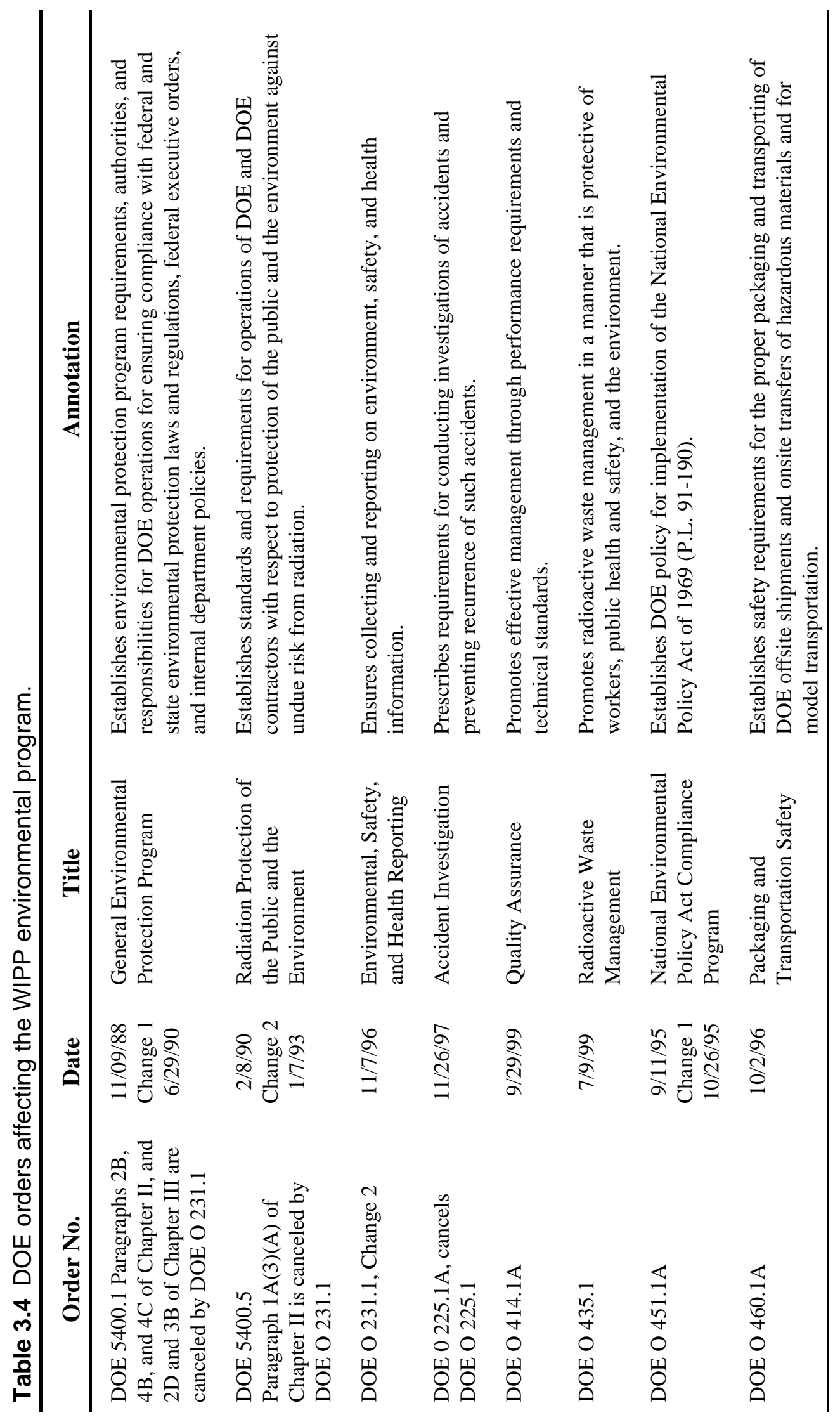




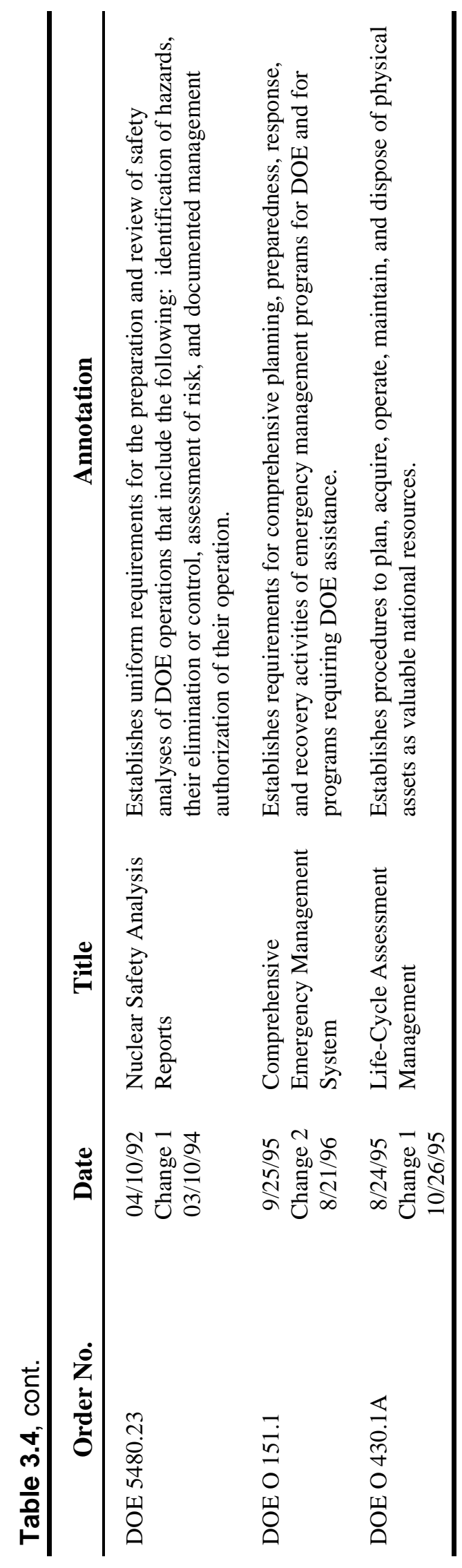




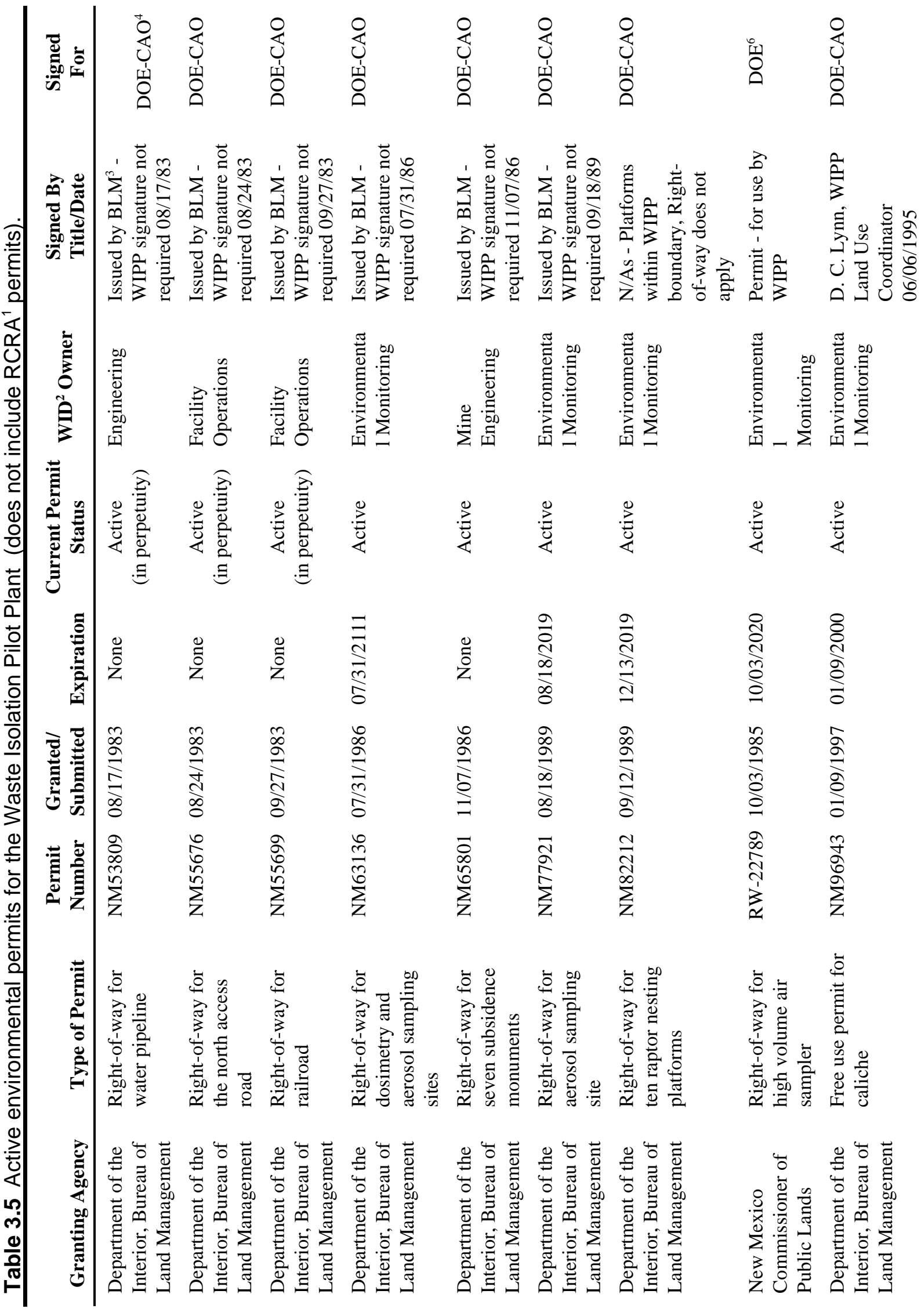




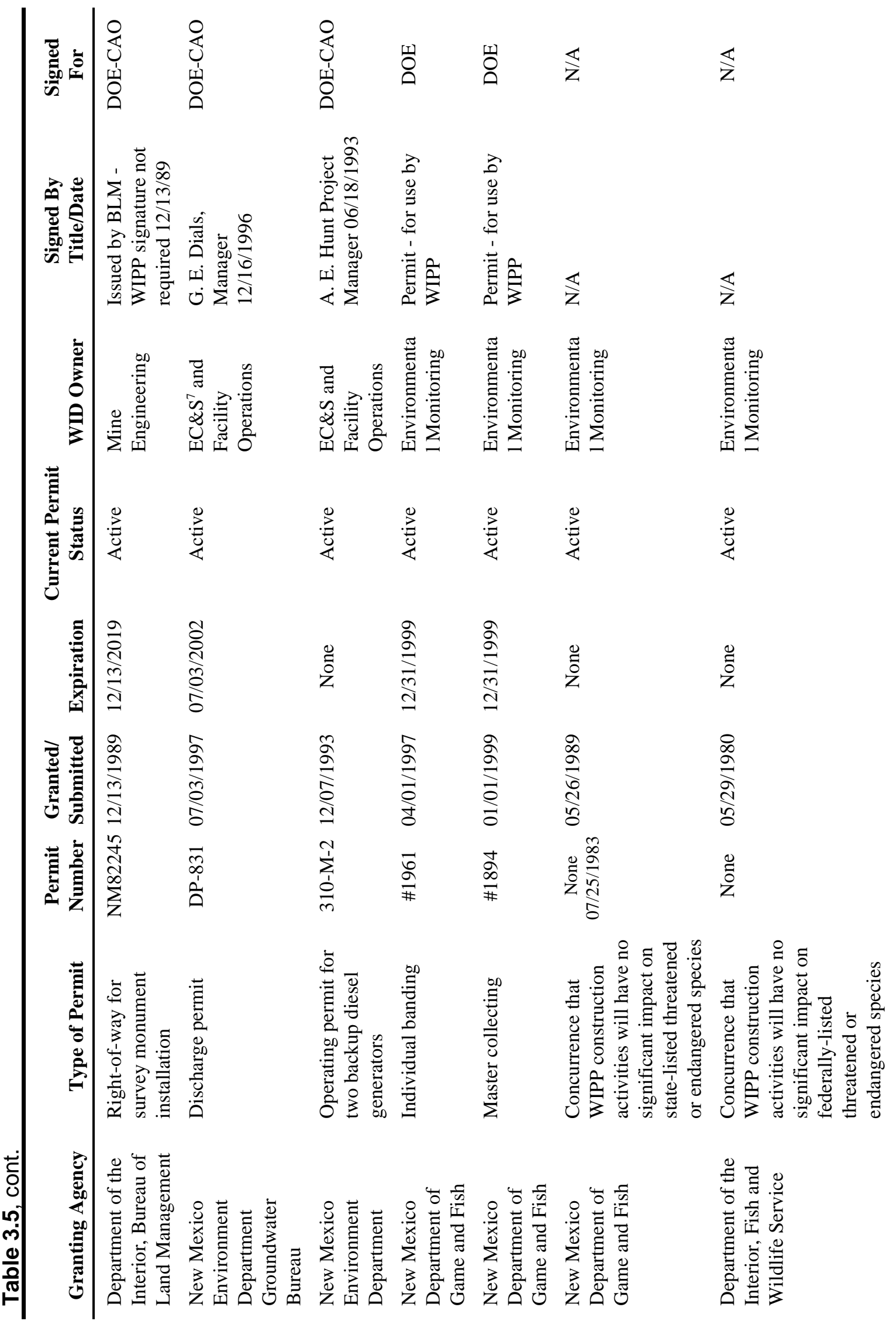




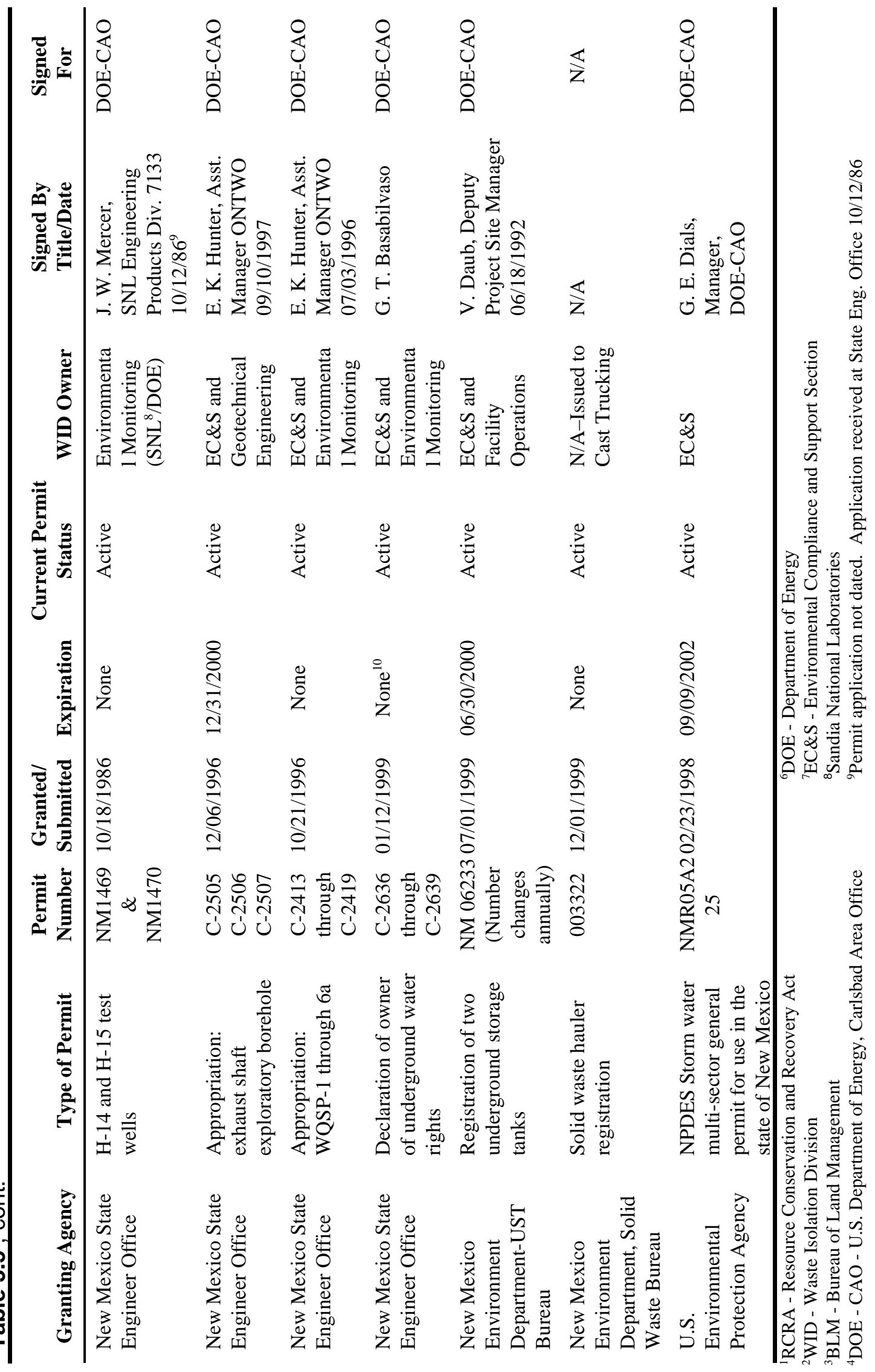




\section{Chapter 4 Environmental Radiological Program Information}

Radionuclides present in the environment, whether naturally-occurring, from above-ground nuclear weapons tests, or from releases from nuclear facilities, contribute to radiation doses to humans. Therefore, environmental monitoring around nuclear facilities is imperative to characterize radiation conditions, detect releases, and determine their effects, should they occur. Because of this, DOE requires an environmental monitoring program around nuclear facilities (DOE Order 5400.1). The WIPP Environmental Monitoring Program monitors air, surface and ground water, soils, and biota to characterize the radiation environment and to detect potential releases from WIPP activities. This chapter summarizes the results of monitoring in 1999.

Throughout this chapter, radionuclides were considered "detected" in a sample if the measured concentration or activity exceeded the minimum detectable concentration (MDC) or activity (MDA). The MDC was determined by the analytical laboratory based on the natural background radiation, the analytical technique, and inherent characteristics of the analytical equipment. The MDC represents the minimum concentration of a radionuclide detectable in a given sample using the given equipment and techniques.

Total propagated uncertainty (TPU) is an estimate of the uncertainty in the measurement due to all sources, including counting error, measurement error, chemical recovery error, detector efficiency, and any other sources of uncertainty. Additional measurements of the same sample have a 95 percent probability of falling within 2xTPU of the original measurement. Thus, in this chapter, 2xTPU is reported for all data. The TPU for a single measurement is equivalent to the standard deviation (SD) of the mean of several measurements. Where the mean is reported, this chapter also includes 2 x SD. In every case, the standard deviation was calculated using the sum of squares of the individual TPUs.

Comparisons of radionuclide concentrations were made between years and locations using the statistical procedure, Analysis of Variance (ANOVA). When this, or another statistical test, was used, the value of $p$, the probability of obtaining the value of the test statistic by chance alone, was reported. In many cases, scientists have accepted a value of $p<0.05$ as indicative of a difference between samples. However, interpretation of p requires some judgement on the part of the reader; individual readers may choose to defend higher or lower values of $p$ as their cutoff value.

\subsection{Effluent Monitoring}

If radionuclides are released into the environment from WIPP, they would first be detected in airborne effluents. Thus, WIPP monitors airborne effluents from the facility at three locations, effluent monitoring Stations A, B, and C. Station A samples the unfiltered underground exhaust air. Station B samples the underground exhaust air after HEPA filtration and, sometimes, non-filtered air during maintenance. Station $C$ samples the air in the Waste Handling Building after HEPA filtration. Each is a fixed air sampler, collecting particulates from the effluent air stream on a Versapore filter.

During 1999, 154 samples were collected from Station A for a total air volume sampled of $8,305 \mathrm{~m}^{3}\left(293,300 \mathrm{ft}^{3}\right)$. Because only a small fraction of the air released through Station A is sampled, the activity on the filter is normalized to the total air flow through Station A using an EPA approved methodology. Forty-five samples were collected from Station B for a total air volume sampled of $26,132 \mathrm{~m}^{3}\left(922,830 \mathrm{ft}^{3}\right)$, and 42 samples were collected from Station $\mathrm{C}$ for a total 
air volume sampled of 4,069 $\mathrm{m}^{3}\left(143,700 \mathrm{ft}^{3}\right)$. Samples were composited each quarter and analyzed radiochemically for ${ }^{241} \mathrm{Am},{ }^{238} \mathrm{Pu}$, and ${ }^{239+240} \mathrm{Pu}$, the components of the contact handled waste at WIPP expected to produce 98 percent of the potential dose to humans. Although ${ }^{241} \mathrm{Am}$ was detected ( $>$ MDC) in composites from at least one station in each of the last three quarters, no values were over the decision level activity (DLA) (Table 4.1). The DLA was calculated based upon analysis of a batch of filters which were not exposed to the effluent stream (blanks) using the following formula.

$$
D L A=\frac{1.645 *(T B B C)^{1 / 2}+2.71}{2.22 * I * D * E * V * T * R * A}
$$

Where :

$$
\begin{aligned}
& \text { TBBC = Total batch blank counts } \\
& 2.22=\text { disintegrations per minute/pCi } \\
& \mathrm{I}=\text { ingrowth correction factor } \\
& \mathrm{D}=\text { decay correction factor } \\
& \mathrm{E}=\text { detector efficiency } \\
& \mathrm{V}=\text { sample volume or weight }
\end{aligned}
$$

$\mathrm{T}=$ sample count time

$\mathrm{R}=$ chemical recovery

$\mathrm{A}=$ emission abundance.

DLA represents background activity. Therefore no sample had activity greater than background levels. In addition, the 1998 composite filter averages for ${ }^{241} \mathrm{Am}$ from Stations A, B, and C were compared with the 1999 composite filter averages for ${ }^{241} \mathrm{Am}$. These results showed an average activity of $1.3 \times 10^{-4} \mathrm{~Bq}\left(3.5 \times 10^{-3} \mathrm{pCi}\right)$ in 1998 and $1.2 \times 10^{-4} \mathrm{~Bq}\left(3.3 \times 10^{-3} \mathrm{pCi}\right)$ in 1999 . The MDA averages were $3.4 \times 10^{-4} \mathrm{~Bq}\left(9.1 \times 10^{-3} \mathrm{pCi}\right)$ in 1998 and $3.4 \times 10^{-4} \mathrm{~Bq}\left(9.3 \times 10^{-3} \mathrm{pCi}\right)$ in 1999 . These values indicate there is no change in the 1999 release results when compared to 1998 and contamination survey results of emplaced waste packages indicate no release of activity. Results from Stations A, B, and C were used as input for the dose assessment presented in Chapter 7.

Additional sampling was routinely performed in the underground using fixed air samplers and

\begin{tabular}{|c|c|c|c|c|c|c|c|c|c|}
\hline \multirow[b]{2}{*}{ Nuclide } & \multicolumn{3}{|c|}{ Station A } & \multicolumn{3}{|c|}{ Station B } & \multicolumn{3}{|c|}{ Station C } \\
\hline & Activity & MDA $^{1}$ & DLA $^{2}$ & Activity & MDA & DLA & Activity & MDA & DLA \\
\hline \multicolumn{10}{|c|}{$1^{\text {st }}$ Quarter } \\
\hline $241 \mathrm{Am}$ & $0.00 \times 10^{0}$ & $4.14 \times 10^{-4}$ & $3.37 \times 10^{-4}$ & $1.78 \times 10^{-4}$ & $6.40 \times 10^{-4}$ & $3.56 \times 10^{-4}$ & $0.00 \times 10^{0}$ & $4.74 \times 10^{-4}$ & $3.85 \times 10^{-4}$ \\
\hline${ }^{8} \mathrm{Pu}$ & $0.00 \times 10^{0}$ & $2.32 \times 10^{-4}$ & $2.32 \times 10^{-4}$ & $-5.88 \times 10^{-5}$ & $4.29 \times 10^{-4}$ & $1.58 \times 10^{-4}$ & $-6.40 \times 10^{-5}$ & $4.66 \times 10^{-4}$ & $1.72 \times 10^{-4}$ \\
\hline${ }^{239 / 240} \mathrm{Pu}$ & $8.58 \times 10^{-5}$ & $2.32 \times 10^{-4}$ & $3.74 \times 10^{-4}$ & $5.85 \times 10^{-5}$ & $1.58 \times 10^{-4}$ & $2.54 \times 10^{-4}$ & $-6.33 \times 10^{-5}$ & $4.66 \times 10^{-4}$ & $2.76 \times 10^{-4}$ \\
\hline \multicolumn{10}{|c|}{$2^{\text {nd }}$ Quarter } \\
\hline${ }^{41} \mathrm{Am}$ & $2.41 \times 10^{-4}$ & $1.63 \times 10^{-4}$ & $1.66 \times 10^{-4}$ & $1.79 \times 10^{-4}$ & $1.71 \times 10^{-4}$ & $3.57 \times 10^{-4}$ & $1.19 \times 10^{-4}$ & $1.61 \times 10^{-4}$ & $3.56 \times 10^{-4}$ \\
\hline${ }^{8} \mathrm{Pu}$ & $0.00 \times 10^{0}$ & $1.66 \times 10^{-4}$ & $9.99 \times 10^{-4}$ & $0.00 \times 10^{0}$ & $5.22 \times 10^{-4}$ & $1.91 \times 10^{-4}$ & $-6.55 \times 10^{-5}$ & $7.03 \times 10^{-4}$ & $1.76 \times 10^{-4}$ \\
\hline${ }^{239 / 240} \mathrm{Pu}$ & $6.11 \times 10^{-5}$ & $1.66 \times 10^{-4}$ & $2.66 \times 10^{-4}$ & $0.00 \times 10^{0}$ & $1.91 \times 10^{-4}$ & $3.07 \times 10^{-4}$ & $0.00 \times 10^{0}$ & $1.76 \times 10^{-4}$ & $2.83 \times 10^{-4}$ \\
\hline \multicolumn{10}{|c|}{$3^{\text {rd }}$ Quarter } \\
\hline${ }^{41} \mathrm{Am}$ & $6.36 \times 10^{-5}$ & $1.72 \times 10^{-4}$ & $3.81 \times 10^{-4}$ & $-1.26 \times 10^{-4}$ & $5.85 \times 10^{-4}$ & $3.77 \times 10^{-4}$ & $1.67 \times 10^{-4}$ & $1.50 \times 10^{-4}$ & $3.33 \times 10^{-4}$ \\
\hline${ }^{238} \mathrm{Pu}$ & $0.00 \times 10^{0}$ & $1.76 \times 10^{-4}$ & $1.76 \times 10^{-4}$ & $0.00 \times 10^{0}$ & $4.29 \times 10^{-4}$ & $1.58 \times 10^{-4}$ & $0.00 \times 10^{0}$ & $1.81 \times 10^{-4}$ & $1.81 \times 10^{-4}$ \\
\hline${ }^{239 / 240} \mathrm{Pu}$ & $0.00 \times 10^{0}$ & $4.77 \times 10^{-4}$ & $2.83 \times 10^{-4}$ & $-5.85 \times 10^{-5}$ & $4.29 \times 10^{-4}$ & $2.55 \times 10^{-4}$ & $0.00 \times 10^{0}$ & $1.81 \times 10^{-4}$ & $2.90 \times 10^{-4}$ \\
\hline \multicolumn{10}{|c|}{$4^{\text {th }}$ Quarter } \\
\hline${ }^{241} \mathrm{Am}$ & $3.03 \times 10^{-4}$ & $4.48 \times 10^{-4}$ & $3.64 \times 10^{-4}$ & $3.34 \times 10^{-4}$ & $1.81 \times 10^{-4}$ & $4.00 \times 10^{-4}$ & $0.00 \times 10^{0}$ & $5.81 \times 10^{-4}$ & $3.74 \times 10^{-4}$ \\
\hline${ }^{238} \mathrm{Pu}$ & $6.11 \times 10^{-5}$ & $1.65 \times 10^{-4}$ & $1.65 \times 10^{-4}$ & $6.29 \times 10^{-5}$ & $1.71 \times 10^{-4}$ & $1.71 \times 10^{-4}$ & $-1.90 \times 10^{-4}$ & $6.81 \times 10^{-4}$ & $1.71 \times 10^{-4}$ \\
\hline${ }^{239 / 240} \mathrm{Pu}$ & $6.07 \times 10^{-5}$ & $4.48 \times 10^{-4}$ & $2.65 \times 10^{-4}$ & $6.29 \times 10^{-5}$ & $1.71 \times 10^{-4}$ & $2.74 \times 10^{-4}$ & $0.00 \times 10^{0}$ & $1.71 \times 10^{-4}$ & $2.75 \times 10^{-4}$ \\
\hline
\end{tabular}
continuous air monitors. Evaluation of the samples from both indicate there were no detectable releases above background activity from the WIPP facility.

Table 4.1 Activity $(\mathrm{Bq})$ of quarterly composite air samples from effluent monitoring Stations $\mathrm{A}$, $\mathrm{B}$, and $\mathrm{C}$.

${ }^{1}$ Minimum detectable activity

${ }^{2}$ Decision level activity 


\subsection{Airborne Gross Alpha/Beta}

Gross alpha and beta measurements in airborne particulates are used as a screening technique to provide timely information on levels of radioactivity in the environment around the WIPP site. Airborne particulate samples were collected from seven different locations around WIPP: Southeast Control (SEC), Carlsbad (CBD), J.C. Mills Ranch (MLR), Smith Ranch (SMR), WIPP East (WEE), WIPP South (WSS), and WIPP Far Field (WFF) (Figure 4.1). Each week at each station, approximately $600 \mathrm{~m}^{3}\left(21,200 \mathrm{ft}^{3}\right)$ of air was filtered through a $4.7-\mathrm{cm}(1.85-\mathrm{in})$ diameter glass microfiber filter using a low-volume continuous air sampler. The samples were collected at a height of 1.5-2 m (5-6.5 ft) to closely match the height at which air is inhaled by humans. Filters were counted for gross alpha and beta only after being stored for five to seven days in the laboratory to make sure the short-lived radon progeny had decayed.
Blank fiberglass filters were also counted for gross alpha and beta activities so that background corrections (activities present in the blank filters) could be made in the gross alpha and beta measurements of the air samples. Blanks were counted weekly along with the samples. Counts obtained for blank filters were then subtracted from the counts observed for the samples to obtain the net gross alpha and beta counts for the sample. The net gross alpha and beta activities per cubic meter of air were then determined by dividing the net total activity of gross alpha and beta found in each weekly sample by the amount of air pulled through each sample. The results are given in Appendix C. The mass and volume of air collected each week are reported in Appendix E.

Weekly gross alpha activity concentrations measured in 1999 varied throughout the year at each location (Figure 4.2). The sampling stations tracked one another throughout the year, implying they were responding to the same environmental conditions. 


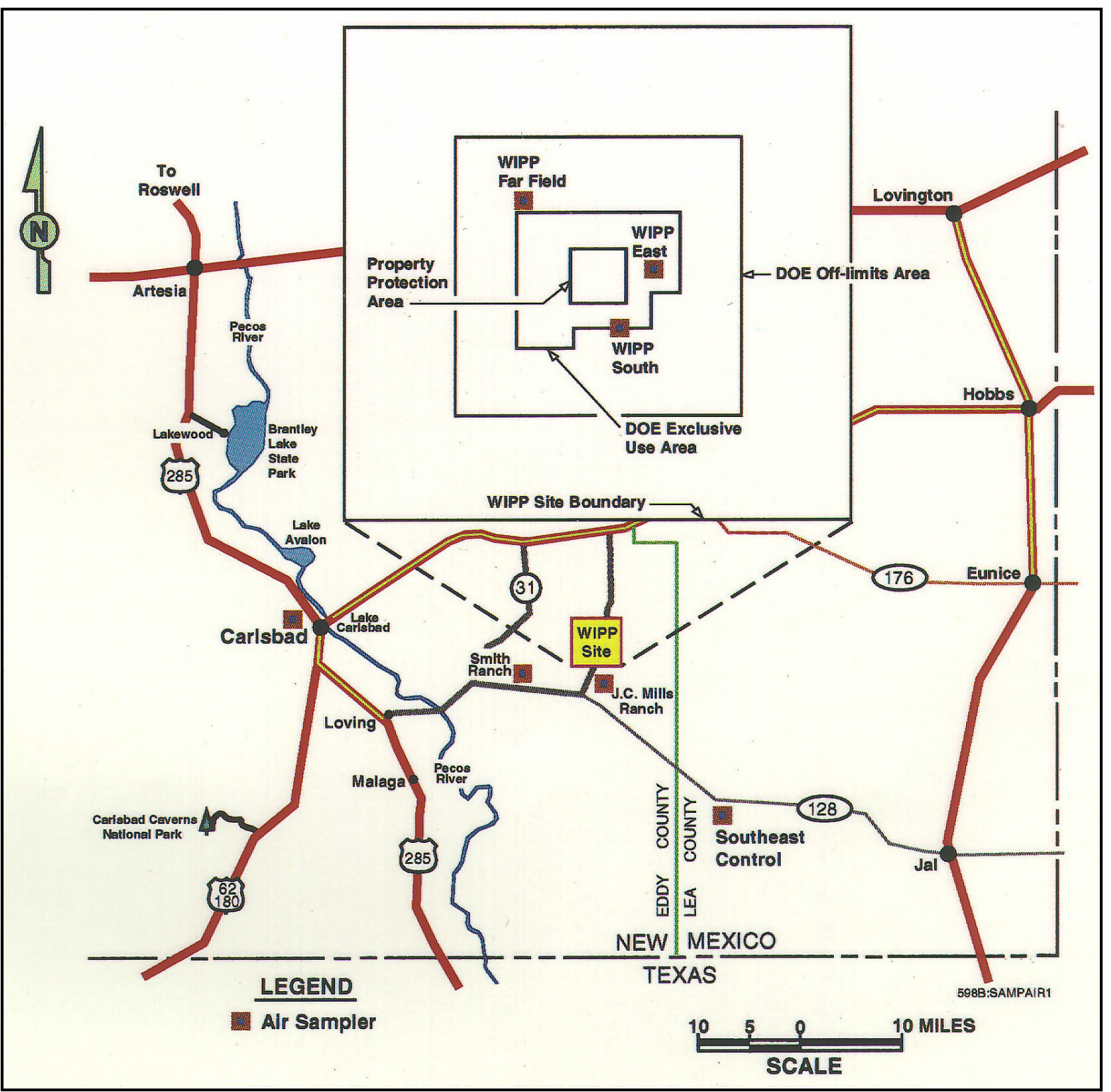

Figure 4.1 Air Sampling Locations on and near the WIPP Facility 


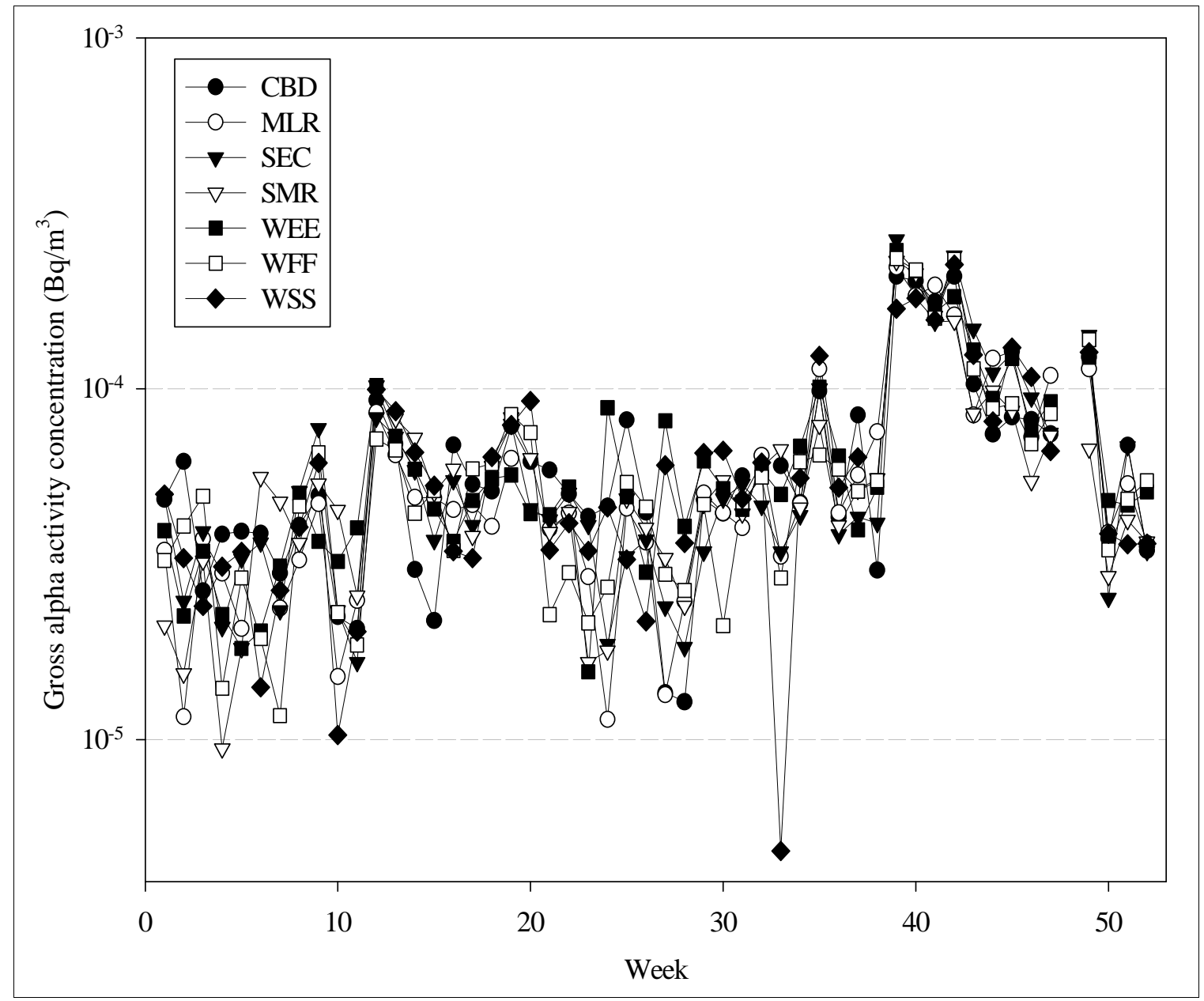

Figure 4.2 Gross Alpha Activity Concentration Measured in Air Particulates Each Week in 1999. See Text for Sampling Station Locations.

Measured concentrations ranged from a minimum of $-3.78 \times 10^{-6} \pm 1.88 \times 10^{-5} \mathrm{~Bq} / \mathrm{m}^{3}$ $\left(-1.02 \times 10^{-4} \pm 5.08 \times 10^{-4} \mathrm{pCi} / \mathrm{m}^{3}\right)$ to a maximum of $2.35 \times 10^{-4} \pm 4.82 \times 10^{-5} \mathrm{~Bq} / \mathrm{m}^{3} \quad\left(6.35 \times 10^{-3} \pm\right.$ $1.30 \times 10^{-3} \mathrm{pCi} / \mathrm{m}^{3}$ ) (Table 4.2). However, the annual mean concentrations of gross alpha activities found at all locations were similar, ranging from $6.09 \times 10^{-5} \pm 8.83 \times 10^{-5}$ to $6.31 \times 10^{-5} \pm$ $8.76 \times 10^{-5} \mathrm{~Bq} / \mathrm{m}^{3}\left(1.65 \times 10^{-3} \pm 2.39 \times 10^{-3}\right.$ to $\left.1.71 \times 10^{-3} \pm 2.37 \times 10^{-3} \mathrm{pCi} / \mathrm{m}^{3}\right)$. Analysis of Variance indicated no statistically significant difference between sampling stations $(\mathrm{p}=0.637)$.

The annual mean gross alpha activity concentrations found at each location in 1998 and 1999 were compared (Table 4.2) with a t-test to determine whether gross alpha in air particulates had increased since waste has been stored at WIPP. There was no significant difference between gross alpha activity concentration measured in 1998 and 1999 ( $\mathrm{p}=0.78)$.

In 1999, the weekly gross beta concentrations varied throughout the year at each station (Figure 4.3). Stations tended to vary together, showing a strong annual pattern.

Concentrations ranged over almost an order of magnitude, from a minimum of $4.89 \times 10^{-4} \pm$ $7.57 \times 10^{-5} \mathrm{~Bq} / \mathrm{m}^{3}\left(1.32 \times 10^{-2} \pm 2.05 \times 10^{-3} \mathrm{pCi} / \mathrm{m}^{3}\right)$ to a maximum of $1.79 \times 10^{-3} \pm 1.21 \times 10^{-4} \mathrm{~Bq} / \mathrm{m}^{3}$ $\left(4.84 \times 10^{-2} \pm 3.27 \times 10^{-3} \mathrm{pCi} / \mathrm{m}^{3}\right)$ (Table 4.3). However, the annual mean concentrations of gross 
beta activities found at all locations were similar, ranging from $8.82 \times 10^{-4} \pm 1.41 \times 10^{-5}$ to $9.45 \times 10^{-4} \pm$ $1.42 \times 10^{-5} \mathrm{~Bq} / \mathrm{m}^{3}\left(2.38 \times 10^{-2} \pm 3.81 \times 10^{-4}\right.$ to $\left.2.55 \times 10^{-2} \pm 3.84 \times 10^{-4} \mathrm{pCi} / \mathrm{m}^{3}\right)$. There was no significant difference between sampling stations (ANOVA, $\mathrm{p}<0.352$ ).

Table 4.2 Annual minimum, maximum, and mean gross alpha activity concentrations $\left(\mathrm{Bq} / \mathrm{m}^{3}\right)$ found in air particulate samples collected weekly at various locations.

\begin{tabular}{lcccccc}
\hline Location & Minimum & 2 $\times$ TPU & Maximum & 2 $\times$ TPU & Mean & 2 $\times$ SD $^{\mathbf{2}}$ \\
\hline & \multicolumn{5}{c}{$\mathbf{1 9 9 8}$} \\
CBD & $-5.40 \times 10^{-6}$ & $4.00 \times 10^{-5}$ & $1.40 \times 10^{-4}$ & $4.20 \times 10^{-5}$ & $4.90 \times 10^{-5}$ & $3.20 \times 10^{-5}$ \\
MLR & $-2.20 \times 10^{-5}$ & $3.70 \times 10^{-5}$ & $1.30 \times 10^{-4}$ & $4.00 \times 10^{-5}$ & $5.00 \times 10^{-5}$ & $3.10 \times 10^{-5}$ \\
SEC & $-1.00 \times 10^{-5}$ & $3.70 \times 10^{-5}$ & $1.70 \times 10^{-4}$ & $6.20 \times 10^{-5}$ & $5.50 \times 10^{-5}$ & $3.40 \times 10^{-5}$ \\
SMR & $-2.20 \times 10^{-5}$ & $3.70 \times 10^{-5}$ & $1.20 \times 10^{-4}$ & $4.00 \times 10^{-5}$ & $4.60 \times 10^{-5}$ & $3.00 \times 10^{-5}$ \\
WEE & $-1.20 \times 10^{-5}$ & $4.10 \times 10^{-5}$ & $1.40 \times 10^{-4}$ & $5.80 \times 10^{-5}$ & $5.40 \times 10^{-5}$ & $3.20 \times 10^{-5}$ \\
WFF & $-3.30 \times 10^{-6}$ & $4.30 \times 10^{-5}$ & $2.00 \times 10^{-4}$ & $6.10 \times 10^{-5}$ & $5.30 \times 10^{-5}$ & $3.50 \times 10^{-5}$ \\
WSS & $-9.80 \times 10^{-6}$ & $4.00 \times 10^{-5}$ & $1.30 \times 10^{-4}$ & $6.40 \times 10^{-5}$ & $5.00 \times 10^{-5}$ & $3.00 \times 10^{-5}$ \\
\cline { 2 - 7 } & \multicolumn{5}{c}{$\mathbf{1 9 9 9}$} \\
CBD & $1.28 \times 10^{-5}$ & $2.15 \times 10^{-5}$ & $2.09 \times 10^{-4}$ & $4.61 \times 10^{-5}$ & $6.57 \times 10^{-5}$ & $9.02 \times 10^{-5}$ \\
MLR & $-3.78 \times 10^{-6}$ & $1.88 \times 10^{-5}$ & $2.22 \times 10^{-4}$ & $4.68 \times 10^{-5}$ & $6.11 \times 10^{-5}$ & $9.04 \times 10^{-5}$ \\
SEC & $1.66 \times 10^{-5}$ & $2.53 \times 10^{-5}$ & $2.66 \times 10^{-4}$ & $5.14 \times 10^{-5}$ & $6.33 \times 10^{-5}$ & $5.77 \times 10^{-5}$ \\
SMR & $9.42 \times 10^{-6}$ & $1.75 \times 10^{-5}$ & $2.31 \times 10^{-4}$ & $4.78 \times 10^{-5}$ & $6.09 \times 10^{-5}$ & $8.83 \times 10^{-5}$ \\
WEE & $1.56 \times 10^{-5}$ & $2.11 \times 10^{-5}$ & $2.48 \times 10^{-4}$ & $4.98 \times 10^{-5}$ & $6.78 \times 10^{-5}$ & $9.08 \times 10^{-5}$ \\
WFF & $1.17 \times 10^{-5}$ & $1.94 \times 10^{-5}$ & $2.35 \times 10^{-4}$ & $4.82 \times 10^{-5}$ & $6.31 \times 10^{-5}$ & $8.76 \times 10^{-5}$ \\
WSS & $4.81 \times 10^{-6}$ & $2.18 \times 10^{-5}$ & $2.26 \times 10^{-4}$ & $4.87 \times 10^{-5}$ & $6.57 \times 10^{-5}$ & $9.00 \times 10^{-5}$ \\
\hline
\end{tabular}

${ }^{1}$ Total propagated uncertainty

${ }^{2}$ Standard deviation of the mean

Table 4.3 Annual minimum, maximum, and mean gross beta activity concentrations $\left(\mathrm{Bq} / \mathrm{m}^{3}\right)$ found in air particulate samples collected weekly at various locations.

\begin{tabular}{|c|c|c|c|c|c|c|}
\hline Location & Minimum & $2 \times$ TPU $^{1}$ & Maximum & $2 \times \mathrm{TPU}$ & Mean & $2 \times \mathrm{SD}^{2}$ \\
\hline & \multicolumn{6}{|c|}{1998} \\
\hline CBD & $3.30 \times 10^{-4}$ & $8.60 \times 10^{-5}$ & $1.30 \times 10^{-3}$ & $1.10 \times 10^{-4}$ & $7.40 \times 10^{-4}$ & $2.60 \times 10^{-4}$ \\
\hline MLR & $6.60 \times 10^{-5}$ & $8.20 \times 10^{-5}$ & $1.30 \times 10^{-3}$ & $1.10 \times 10^{-4}$ & $7.00 \times 10^{-4}$ & $3.00 \times 10^{-4}$ \\
\hline SEC & $-2.10 \times 10^{-5}$ & $6.00 \times 10^{-5}$ & $1.50 \times 10^{-3}$ & $1.20 \times 10^{-4}$ & $7.70 \times 10^{-4}$ & $3.10 \times 10^{-4}$ \\
\hline SMR & $1.70 \times 10^{-4}$ & $1.10 \times 10^{-4}$ & $1.40 \times 10^{-3}$ & $1.10 \times 10^{-4}$ & $7.30 \times 10^{-4}$ & $2.90 \times 10^{-4}$ \\
\hline WEE & $6.30 \times 10^{-5}$ & $1.00 \times 10^{-4}$ & $1.60 \times 10^{-3}$ & $1.40 \times 10^{-4}$ & $7.20 \times 10^{-4}$ & $3.10 \times 10^{-4}$ \\
\hline WFF & $2.90 \times 10^{-4}$ & $9.80 \times 10^{-5}$ & $1.40 \times 10^{-3}$ & $1.10 \times 10^{-4}$ & $7.70 \times 10^{-4}$ & $2.90 \times 10^{-4}$ \\
\hline \multirow[t]{2}{*}{ WSS } & $2.30 \times 10^{-4}$ & $9.20 \times 10^{-5}$ & $1.50 \times 10^{-3}$ & $1.10 \times 10^{-4}$ & $6.80 \times 10^{-4}$ & $3.00 \times 10^{-4}$ \\
\hline & \multicolumn{6}{|c|}{1999} \\
\hline CBD & $5.60 \times 10^{-4}$ & $7.74 \times 10^{-5}$ & $1.66 \times 10^{-3}$ & $2.28 \times 10^{-4}$ & $9.50 \times 10^{-4}$ & $1.47 \times 10^{-5}$ \\
\hline MLR & $4.89 \times 10^{-4}$ & $7.57 \times 10^{-5}$ & $1.60 \times 10^{-3}$ & $1.07 \times 10^{-4}$ & $8.86 \times 10^{-4}$ & $1.42 \times 10^{-5}$ \\
\hline SEC & $5.95 \times 10^{-4}$ & $7.89 \times 10^{-5}$ & $1.78 \times 10^{-3}$ & $1.08 \times 10^{-4}$ & $9.67 \times 10^{-4}$ & $1.39 \times 10^{-5}$ \\
\hline SMR & $5.95 \times 10^{-4}$ & $7.92 \times 10^{-5}$ & $1.56 \times 10^{-3}$ & $1.07 \times 10^{-4}$ & $8.85 \times 10^{-4}$ & $1.42 \times 10^{-5}$ \\
\hline WEE & $5.66 \times 10^{-4}$ & $7.84 \times 10^{-5}$ & $1.57 \times 10^{-3}$ & $1.07 \times 10^{-4}$ & $9.23 \times 10^{-4}$ & $1.43 \times 10^{-5}$ \\
\hline WFF & $5.48 \times 10^{-4}$ & $7.65 \times 10^{-5}$ & $1.79 \times 10^{-3}$ & $1.21 \times 10^{-4}$ & $9.45 \times 10^{-4}$ & $1.42 \times 10^{-5}$ \\
\hline WSS & $5.60 \times 10^{-4}$ & $7.69 \times 10^{-5}$ & $1.64 \times 10^{-3}$ & $1.19 \times 10^{-4}$ & $8.82 \times 10^{-4}$ & $1.41 \times 10^{-5}$ \\
\hline
\end{tabular}

${ }^{1}$ Total propagated uncertainty

${ }^{2}$ Standard deviation of the mean 


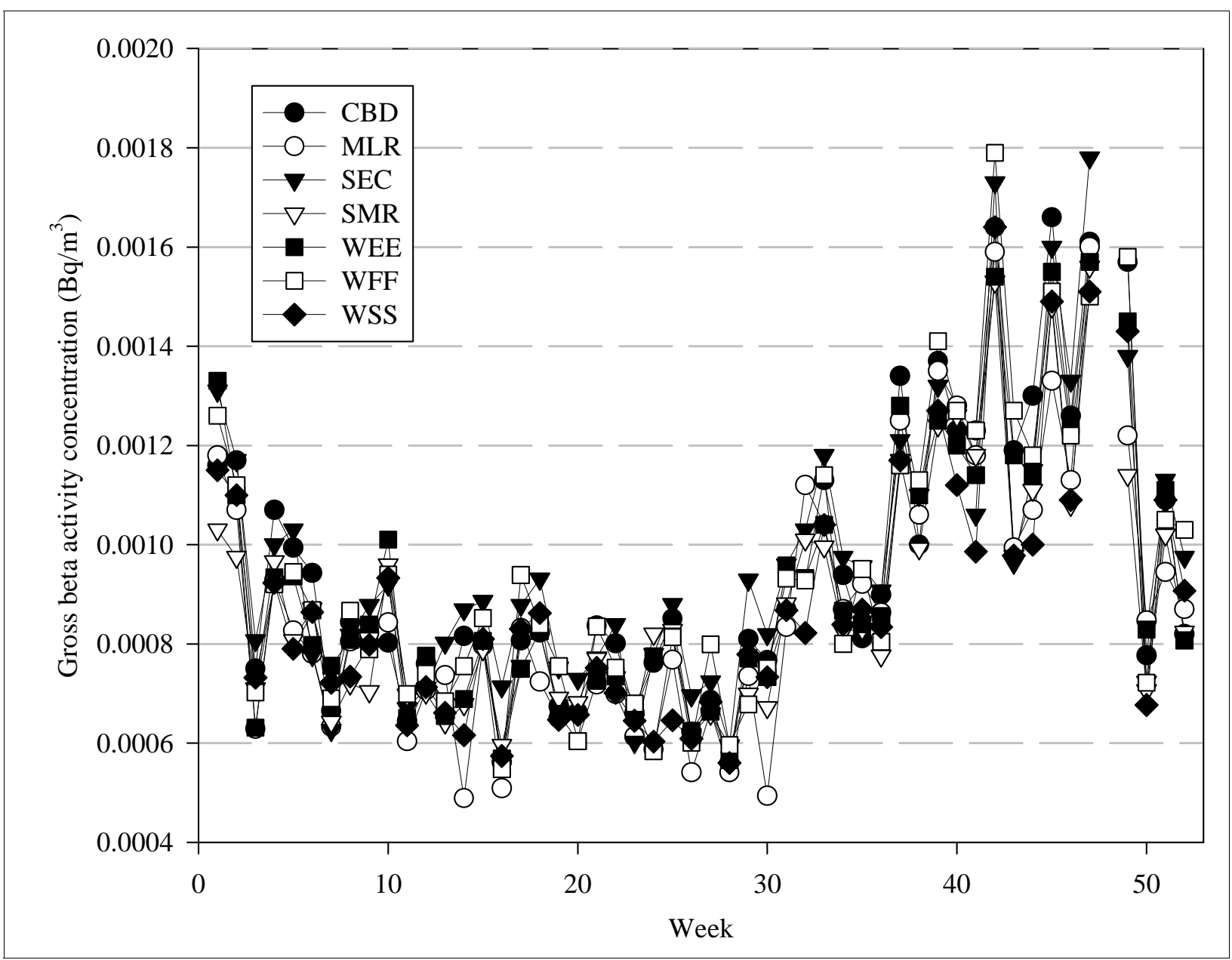

Figure 4.3 Gross Beta Activity Concentration Measured in Air Particulates Each Week in 1999. See Text for Sampling Station Locations.

One duplicate sample was collected every quarter by rotating the portable sampler from one location to another every quarter: WFF in the first quarter, WEE in the second quarter, WSS in the third quarter, and MLR in the fourth quarter. The samples were collected by both samplers in identical conditions at all four locations. Duplicate samples were collected and analyzed for the quality control of (1) air sampling technique, (2) determination of gross alpha and beta activities, and (3) analysis of the individual radionuclides in airborne particulate. Relative Error Ratios (RER; see Appendix D) were less than one in 96 percent of the weekly gross alpha and beta measurements. A RER less then one indicates good agreement between duplicates. A t-test for each quarter confirmed that the means were not different between duplicates $(p>0.2$ in every case). The duplicate data are provided in Appendix C.

\subsection{Airborne Particulate}

The major pathways for the intake of radioactive materials into the human body are from the inhalation of dust particles and the ingestion of food and drinking water. The uptake of insoluble materials (classified as class $\mathrm{Y}$ compounds in earlier metabolic models or "S" type materials in recent models) through ingestion is very poor; therefore, inhalation becomes the major pathway for the intake of such radioactive materials. Plutonium, the major constituent of the TRU wastes to be disposed at the WIPP site, is 
mostly in insoluble form (class $\mathrm{Y}$ or S); therefore, the inhalation pathway would contribute most of the radiation doses. Accordingly, plutonium and other radionuclides of interest were determined in air particulate samples around the WIPP site.

Isotopes of plutonium and americium were measured because they are the most significant alpha-emitting radionuclides among the constituents of TRU wastes received at the WIPP site. Uranium isotopes were measured because they are prominent alpha-emitting radionuclides in the natural environment.

Strontium-90 and ${ }^{137} \mathrm{Cs}$ are potentially important beta and gamma-emitting constituents of the TRU waste disposed at WIPP. Therefore, they have been the subject of background studies at WIPP prior to 1999 and continue to be monitored. Cobalt-60 and other gamma-emitters, though not major constituents of the TRU waste, were also monitored. Potassium-40, a natural gamma-emitting radionuclide which is ubiquitous in the earth's crust, was also monitored because of its possible enhancement in southeastern New Mexico due to potash mining.

\subsubsection{Sample Preparation}

Weekly air particulate samples were collected as described in Section 4.2 and composited for each quarter. The composites were transferred into a Pyrex beaker, spiked with appropriate tracers, and heated in a Muffle oven at $250^{\circ} \mathrm{C}$ $\left(482^{\circ} \mathrm{F}\right)$ for two hours, followed by two hours at $375^{\circ} \mathrm{C}\left(707^{\circ} \mathrm{F}\right)$ and six hours at $525^{\circ} \mathrm{C}\left(977^{\circ} \mathrm{F}\right)$. The ash was cooled, transferred quantitatively into a Teflon beaker by rinsing with concentrated nitric acid, and heated with concentrated hydrofluoric acid. The residue was heated with a mixture of nitric and hydrofluoric acids until completely dissolved. Hydrofluoric acid was removed quantitatively by evaporating to dryness. Approximately $25 \mathrm{ml}(0.845 \mathrm{oz})$ of concentrated nitric acid and one gram $(0.0353 \mathrm{oz})$ of boric acid were added, heated, and finally evaporated to dryness. The residue was dissolved in $8 \mathrm{M}$ (molar) nitric acid for gamma spectrometry and determinations of ${ }^{90} \mathrm{Sr}$ and alpha-emitting radionuclides.

\subsubsection{Determination of Individual Radio- nuclides}

Potassium-40, ${ }^{60} \mathrm{Co},{ }^{137} \mathrm{Cs}$, and other gammaemitting radionuclides were determined by gamma spectrometry. Strontium-90 and alpha-emitting radionuclides were determined by sequential separation and counting. Determination of actinides involved co-precipitation, ion exchange separation, and alpha spectrometry.

\subsubsection{Results and Discussions}

The minimum and the maximum concentrations of naturally occurring isotopes of uranium $\left({ }^{233+234} \mathrm{U},{ }^{235} \mathrm{U}\right.$, and $\left.{ }^{238} \mathrm{U}\right)$ found among the four quarters of the composited air particulate samples are given in Tables 4.4, 4.5, and 4.6, respectively. Uranium-233+234 was detected in 64 percent of the samples, and in at least one sample from every location. The concentrations of ${ }^{233+234} \mathrm{U}$ ranged from $-1.04 \times 10^{-6} \pm 1.48 \times 10^{-6}$ $\mathrm{Bq} / \mathrm{m}^{3}\left(-2.81 \times 10^{-5} \pm 4.00 \times 10^{-5} \mathrm{pCi} / \mathrm{m}^{3}\right)$ at $\mathrm{SEC}$ to $1.62 \times 10^{-5} \pm 2.37 \times 10^{-6} \mathrm{~Bq} / \mathrm{m}^{3}\left(4.37 \times 10^{-4} \pm\right.$ $6.41 \times 10^{-5} \mathrm{pCi} / \mathrm{m}^{3}$ ) at WFF (Table 4.4). Results are not significantly different between locations or quarters (ANOVA, $\mathrm{p}>0.05$ ).

The concentration of ${ }^{235} \mathrm{U}$ in the natural environment is very low compared to the concentrations of ${ }^{233+234} \mathrm{U}$ and ${ }^{238} \mathrm{U}$ (1 $\mu \mathrm{g}$ [microgram] of natural uranium contains 12.4 $\mathrm{mBq}[0.33 \mathrm{pCi}]$ of ${ }^{238} \mathrm{U}, 0.37 \mathrm{mBq}[0.01 \mathrm{pCi}]$ of ${ }^{235} \mathrm{U}$, and $12.4 \mathrm{mBq}[0.33 \mathrm{pCi}]$ of $\left.{ }^{233+234} \mathrm{U}\right)$; therefore, the amount of ${ }^{235} \mathrm{U}$ in air particulate samples is expected to be very low. The concentration of ${ }^{235} \mathrm{U}$ found in every sample in 1999 was lower than the MDC (Table 4.5).

Uranium-238 was detected in 27 of the 28 composite air filters. Concentrations ranged from $1.22 \times 10^{-6} \pm 1.04 \times 10^{-6} \mathrm{~Bq} / \mathrm{m}^{3}\left(3.30 \times 10^{-5} \pm\right.$ $\left.2.81 \times 10^{-5} \mathrm{pCi} / \mathrm{m}^{3}\right)$ at WFF to $6.81 \times 10^{-6} \pm 1.55 \times 10^{-6}$ $\mathrm{Bq} / \mathrm{m}^{3}\left(1.84 \times 10^{-4} \pm 4.19 \times 10^{-5} \mathrm{pCi} / \mathrm{m}^{3}\right)$ at $\mathrm{WFF}$ (Table 4.6). Although there were not significant differences in concentration between sampling locations, there were significant quarterly differences (ANOVA, $\mathrm{p}=0.047$ ), with the second quarter having the highest concentration. 
Table 4.4 Uranium-233+234 concentration $\left(\mathrm{Bq} / \mathrm{m}^{3}\right)$ in air particulates.

\begin{tabular}{lccccccc}
\hline Location & Minimum & $\mathbf{2}^{\mathbf{x}} \mathbf{T P U}^{1}$ & Maximum & $\mathbf{2 \times}$ TPU & Mean & $\mathbf{2 \times \text { SD} ^ { 2 }}$ & MDC $^{\mathbf{3}}$ \\
\hline CBD & $1.15 \times 10^{-6}$ & $2.07 \times 10^{-6}$ & $3.44 \times 10^{-6}$ & $1.48 \times 10^{-6}$ & $2.39 \times 10^{-6}$ & $8.66 \times 10^{-7}$ & $2.58 \times 10^{-6}$ \\
MLR & $1.55 \times 10^{-6}$ & $1.04 \times 10^{-6}$ & $3.29 \times 10^{-6}$ & $1.33 \times 10^{-6}$ & $2.65 \times 10^{-6}$ & $6.62 \times 10^{-7}$ & $1.74 \times 10^{-6}$ \\
SEC & $-1.04 \times 10^{-6}$ & $1.48 \times 10^{-6}$ & $3.15 \times 10^{-6}$ & $1.70 \times 10^{-6}$ & $1.50 \times 10^{-6}$ & $7.69 \times 10^{-7}$ & $2.64 \times 10^{-6}$ \\
SMR & $1.81 \times 10^{-6}$ & $1.55 \times 10^{-6}$ & $3.85 \times 10^{-6}$ & $1.55 \times 10^{-6}$ & $3.01 \times 10^{-6}$ & $7.96 \times 10^{-7}$ & $2.14 \times 10^{-6}$ \\
WEE & $2.22 \times 10^{-7}$ & $1.48 \times 10^{-6}$ & $3.96 \times 10^{-6}$ & $1.41 \times 10^{-6}$ & $2.09 \times 10^{-6}$ & $6.44 \times 10^{-7}$ & $2.04 \times 10^{-6}$ \\
WFF & $-1.11 \times 10^{-7}$ & $1.33 \times 10^{-6}$ & $1.62 \times 10^{-5}$ & $2.37 \times 10^{-6}$ & $5.49 \times 10^{-6}$ & $8.16 \times 10^{-7}$ & $1.81 \times 10^{-6}$ \\
WSS & $8.88 \times 10^{-7}$ & $1.63 \times 10^{-6}$ & $6.29 \times 10^{-6}$ & $1.63 \times 10^{-6}$ & $3.01 \times 10^{-6}$ & $6.97 \times 10^{-7}$ & $1.90 \times 10^{-6}$ \\
\hline
\end{tabular}

${ }^{1}$ Total propagated uncertainty

${ }^{2}$ Standard deviation of the mean

${ }^{3}$ Mean minimum detectable concentration among all samples from the indicated location

Table 4.5 Uranium-235 concentration $\left(\mathrm{Bq} / \mathrm{m}^{3}\right)$ in air particulates.

\begin{tabular}{lccccccc}
\hline Location & Minimum & $\mathbf{2} \times$ TPU $^{1}$ & Maximum & $\mathbf{2} \times \mathbf{T P U}$ & Mean & 2 $\times$ SD $^{2}$ & MDC $^{3}$ \\
\hline CBD & $2.22 \times 10^{-7}$ & $4.44 \times 10^{-7}$ & $2.96 \times 10^{-7}$ & $5.92 \times 10^{-7}$ & $2.47 \times 10^{-7}$ & $2.66 \times 10^{-7}$ & $1.16 \times 10^{-6}$ \\
MLR & $-1.11 \times 10^{-7}$ & $2.22 \times 10^{-7}$ & $3.70 \times 10^{-7}$ & $4.44 \times 10^{-7}$ & $8.63 \times 10^{-8}$ & $1.65 \times 10^{-7}$ & $9.07 \times 10^{-7}$ \\
SEC & $-1.85 \times 10^{-7}$ & $3.70 \times 10^{-7}$ & $1.11 \times 10^{-7}$ & $5.92 \times 10^{-7}$ & $-3.70 \times 10^{-8}$ & $3.49 \times 10^{-7}$ & $1.30 \times 10^{-6}$ \\
SMR & $-6.29 \times 10^{-7}$ & $7.40 \times 10^{-7}$ & $8.51 \times 10^{-7}$ & $8.14 \times 10^{-7}$ & $1.76 \times 10^{-23}$ & $3.80 \times 10^{-7}$ & $1.52 \times 10^{-6}$ \\
WEE & $1.11 \times 10^{-7}$ & $5.92 \times 10^{-7}$ & $3.33 \times 10^{-7}$ & $3.70 \times 10^{-7}$ & $2.22 \times 10^{-7}$ & $3.49 \times 10^{-7}$ & $1.02 \times 10^{-6}$ \\
WFF & $1.48 \times 10^{-7}$ & $3.70 \times 10^{-7}$ & $3.33 \times 10^{-7}$ & $3.70 \times 10^{-7}$ & $2.41 \times 10^{-7}$ & $1.76 \times 10^{-7}$ & $6.94 \times 10^{-7}$ \\
WSS & $1.11 \times 10^{-7}$ & $3.70 \times 10^{-7}$ & $5.92 \times 10^{-7}$ & $5.18 \times 10^{-7}$ & $3.61 \times 10^{-7}$ & $2.24 \times 10^{-7}$ & $8.51 \times 10^{-7}$ \\
\hline
\end{tabular}

${ }^{1}$ Total propagated uncertainty

${ }^{2}$ Standard deviation of the mean

${ }^{3}$ Mean minimum detectable concentration among all samples from the indicated location

Table 4.6 Uranium-238 concentration $(\mathrm{Bq} / \mathrm{m} 3)$ in air particulates.

\begin{tabular}{lccccccc}
\hline Location & Minimum & $\mathbf{2} \times$ TPU $^{1}$ & Maximum & $\mathbf{2 \times}$ TPU & Mean & 2 x SD & MDC $^{\mathbf{2}}$ \\
\hline CBD & $2.18 \times 10^{-6}$ & $1.26 \times 10^{-6}$ & $3.33 \times 10^{-6}$ & $1.55 \times 10^{-6}$ & $2.83 \times 10^{-6}$ & $6.61 \times 10^{-7}$ & $1.40 \times 10^{-6}$ \\
MLR & $2.15 \times 10^{-6}$ & $1.04 \times 10^{-6}$ & $3.00 \times 10^{-6}$ & $1.26 \times 10^{-6}$ & $2.52 \times 10^{-6}$ & $5.95 \times 10^{-7}$ & $1.40 \times 10^{-6}$ \\
SEC & $1.48 \times 10^{-6}$ & $9.62 \times 10^{-7}$ & $3.55 \times 10^{-6}$ & $1.41 \times 10^{-6}$ & $2.49 \times 10^{-6}$ & $6.21 \times 10^{-7}$ & $1.48 \times 10^{-6}$ \\
SMR & $3.11 \times 10^{-6}$ & $1.33 \times 10^{-6}$ & $4.22 \times 10^{-6}$ & $1.63 \times 10^{-6}$ & $3.58 \times 10^{-6}$ & $7.61 \times 10^{-7}$ & $1.51 \times 10^{-6}$ \\
WEE & $1.78 \times 10^{-6}$ & $1.04 \times 10^{-6}$ & $2.92 \times 10^{-6}$ & $9.62 \times 10^{-7}$ & $2.35 \times 10^{-6}$ & $5.12 \times 10^{-7}$ & $1.14 \times 10^{-6}$ \\
WFF & $1.22 \times 10^{-6}$ & $1.04 \times 10^{-6}$ & $6.81 \times 10^{-6}$ & $1.55 \times 10^{-6}$ & $3.05 \times 10^{-6}$ & $5.89 \times 10^{-7}$ & $1.31 \times 10^{-6}$ \\
WSS & $2.18 \times 10^{-6}$ & $1.04 \times 10^{-6}$ & $4.07 \times 10^{-6}$ & $1.48 \times 10^{-6}$ & $2.93 \times 10^{-6}$ & $5.99 \times 10^{-7}$ & $1.11 \times 10^{-6}$ \\
\hline
\end{tabular}

${ }^{1}$ Total propagated uncertainty

${ }^{2}$ Standard deviation of the mean

${ }^{3}$ Mean minimum detectable concentration among all samples from the indicated location

Plutonium-238 was detected in quarterly composited air filters from the fourth quarter at SEC $\left(9.25 \times 10^{-7} \pm 6.66 \times 10^{-7} \mathrm{~Bq} / \mathrm{m}^{3} ; \mathrm{MDC}=\right.$ $6.66 \times 10^{-7} \mathrm{~Bq} / \mathrm{m}^{3}\left[2.50 \times 10^{-5} \pm 1.80 \times 10^{-5} \mathrm{pCi} / \mathrm{m}^{3}\right.$; $\left.\left.\mathrm{MDC}=1.80 \times 10^{-5} \mathrm{pCi} / \mathrm{m}^{3}\right]\right)$ and the third quarter at WFF $\left(1.48 \times 10^{-7} \pm 4.44 \times 10^{-7} \mathrm{~Bq} / \mathrm{m}^{3} ; \mathrm{MDC}=\right.$ $9.62 \times 10^{-8} \mathrm{~Bq} / \mathrm{m}^{3}\left[4.00 \times 10^{-6} \pm 1.20 \times 10^{-5} \mathrm{pCi} / \mathrm{m}^{3}\right.$; $\left.\mathrm{MDC}=2.60 \times 10^{-6} \mathrm{pCi} / \mathrm{m}^{3}\right]$ ). In the WFF sample, however, the TPU was much larger than both the reported sample MDC and the reported concentration, indicating the true MDC may be larger than that calculated for this sample. Detection is questionable for this result. The concentration of ${ }^{238} \mathrm{Pu}$ was below the MDC in each of the 26 other quarterly composites and the annual mean (Table 4.7) for every sampling location, including those closest to WIPP. Thus, the SEC detection by itself does not indicate plutonium contamination of the environment.

Plutonium-239+240 was greater than the MDC in quarterly composited air filters from the fourth quarter at WSS $\left(1.85 \times 10^{-7} \pm 1.85 \times 10^{-7}\right.$ $\mathrm{Bq} / \mathrm{m}^{3} ; \mathrm{MDC}=1.48 \times 10^{-7} \mathrm{~Bq} / \mathrm{m}^{3}\left[5.00 \times 10^{-6} \pm\right.$ $\left.\left.5.00 \times 10^{-6} \mathrm{pCi} / \mathrm{m}^{3} ; \mathrm{MDC}=4.00 \times 10^{-6} \mathrm{pCi} / \mathrm{m}^{3}\right]\right)$. However, the TPU was equal to the measurement 
and larger than the MDC, calling into question the true value of the MDC. The concentration of ${ }^{239+240} \mathrm{Pu}$ was below the MDC in each of the 27 other quarterly composites and the annual mean (Table 4.8) for every sampling location. Thus, the WSS detection by itself does not indicate plutonium contamination of the environment.
Concentrations of ${ }^{241} \mathrm{Am}$ (Table ${ }^{4.9}$ ), ${ }^{40} \mathrm{~K}$ (Table 4.10), ${ }^{60} \mathrm{Co}$ (Table 4.11), ${ }^{90} \mathrm{Sr}$ (Table 4.12) and, ${ }^{137} \mathrm{Cs}$ (Table 4.13) in each quarterly composite, and in the annual means, were below their MDCs at all seven locations.

Table 4.7 Plutonium-238 concentration $\left(\mathrm{Bq} / \mathrm{m}^{3}\right)$ in air particulates.

\begin{tabular}{|c|c|c|c|c|c|c|c|}
\hline Location & Minimum & $2 \times$ TPU $^{1}$ & Maximum & $2 \times$ TPU & Mean & $2 \times \mathrm{SD}^{2}$ & $\mathrm{MDC}^{3}$ \\
\hline CBD & $-5.18 \times 10^{-7}$ & $1.11 \times 10^{-6}$ & $4.07 \times 10^{-7}$ & $6.29 \times 10^{-7}$ & $-1.20 \times 10^{-7}$ & $3.54 \times 10^{-7}$ & $1.32 \times 10^{-6}$ \\
\hline MLR & $-4.07 \times 10^{-7}$ & $4.44 \times 10^{-7}$ & $2.22 \times 10^{-7}$ & $4.44 \times 10^{-7}$ & $-4.93 \times 10^{-8}$ & $2.11 \times 10^{-7}$ & $7.31 \times 10^{-7}$ \\
\hline SEC & $-8.51 \times 10^{-7}$ & $1.70 \times 10^{-6}$ & $9.25 \times 10^{-7}$ & $6.66 \times 10^{-7}$ & $-1.60 \times 10^{-7}$ & $6.48 \times 10^{-7}$ & $1.71 \times 10^{-6}$ \\
\hline SMR & $-1.48 \times 10^{-7}$ & $4.44 \times 10^{-7}$ & $5.18 \times 10^{-7}$ & $1.26 \times 10^{-6}$ & $8.32 \times 10^{-8}$ & $3.51 \times 10^{-7}$ & $1.25 \times 10^{-6}$ \\
\hline WEE & $-5.18 \times 10^{-7}$ & $6.66 \times 10^{-7}$ & $1.48 \times 10^{-7}$ & $2.96 \times 10^{-7}$ & $-1.48 \times 10^{-7}$ & $2.62 \times 10^{-7}$ & $1.17 \times 10^{-6}$ \\
\hline $\mathrm{WFF}^{4}$ & $-5.18 \times 10^{-7}$ & $5.18 \times 10^{-7}$ & $3.70 \times 10^{-7}$ & $1.04 \times 10^{-6}$ & $5.55 \times 10^{-8}$ & $3.36 \times 10^{-7}$ & $1.12 \times 10^{-6}$ \\
\hline WSS & $-7.03 \times 10^{-7}$ & $5.92 \times 10^{-7}$ & $-3.70 \times 10^{-8}$ & $2.96 \times 10^{-7}$ & $-3.70 \times 10^{-7}$ & $3.31 \times 10^{-7}$ & $1.22 \times 10^{-6}$ \\
\hline \multicolumn{5}{|c|}{$\begin{array}{l}\text { Annual sample average } \\
\text { ration guide (DCG) class W }\end{array}$} & $\begin{array}{l}-8.88 \times 10^{-8} \\
1.11 \times 10^{-3}\end{array}$ & $1.70 \times 10^{-6}$ & $1.22 \times 10^{-6}$ \\
\hline
\end{tabular}

${ }^{1}$ Total propagated uncertainty

${ }^{2}$ Standard deviation of the mean

${ }^{3}$ Mean minimum detectable concentration among all samples from the indicated location

${ }^{4}$ Only the $3^{\text {rd }}$ quarter had a detectable concentration $\left(1.48 \times 10^{-7} \pm 4.44 \times 10^{-7} \mathrm{~Bq} / \mathrm{m}^{3}, \mathrm{MDC}=9.62 \times 10^{-8} \mathrm{~Bq} / \mathrm{m}^{3}\right)$

Table 4.8 Plutonium-239+240 concentration $\left(\mathrm{Bq} / \mathrm{m}^{3}\right)$ in air particulates.

\begin{tabular}{|c|c|c|c|c|c|c|c|}
\hline Location & Minimum & $2 \times \mathrm{TPU}^{1}$ & Maximum & $2 \times \mathrm{TPU}$ & Mean & $2 \times \mathrm{SD}^{2}$ & $\mathrm{MDC}^{3}$ \\
\hline$\overline{\mathrm{CBD}}$ & $-5.92 \times 10^{-7}$ & $5.55 \times 10^{-7}$ & $1.48 \times 10^{-7}$ & $2.11 \times 10^{-7}$ & $-1.94 \times 10^{-7}$ & $2.39 \times 10^{-7}$ & $9.62 \times 10^{-7}$ \\
\hline MLR & $-2.22 \times 10^{-7}$ & $5.55 \times 10^{-7}$ & $2.59 \times 10^{-7}$ & $2.89 \times 10^{-7}$ & $-4.93 \times 10^{-8}$ & $2.42 \times 10^{-7}$ & $8.97 \times 10^{-7}$ \\
\hline SEC & $-5.18 \times 10^{-7}$ & $7.77 \times 10^{-7}$ & $7.40 \times 10^{-8}$ & $3.29 \times 10^{-7}$ & $-1.57 \times 10^{-7}$ & $2.39 \times 10^{-7}$ & $1.15 \times 10^{-6}$ \\
\hline SMR & $-7.77 \times 10^{-7}$ & $8.88 \times 10^{-7}$ & $1.11 \times 10^{-7}$ & $5.92 \times 10^{-7}$ & $-3.82 \times 10^{-7}$ & $3.85 \times 10^{-7}$ & $1.46 \times 10^{-6}$ \\
\hline WEE & $-5.92 \times 10^{-7}$ & $6.29 \times 10^{-7}$ & $1.85 \times 10^{-7}$ & $4.44 \times 10^{-7}$ & $-1.39 \times 10^{-7}$ & $2.53 \times 10^{-7}$ & $1.14 \times 10^{-6}$ \\
\hline WFF & $-7.03 \times 10^{-7}$ & $6.29 \times 10^{-7}$ & $7.40 \times 10^{-8}$ & $3.33 \times 10^{-7}$ & $-2.50 \times 10^{-7}$ & $2.57 \times 10^{-7}$ & $1.10 \times 10^{-6}$ \\
\hline WSS & $-5.92 \times 10^{-7}$ & $7.03 \times 10^{-7}$ & $1.85 \times 10^{-7}$ & $1.85 \times 10^{-7}$ & $-1.20 \times 10^{-7}$ & $2.18 \times 10^{-7}$ & $9.71 \times 10^{-7}$ \\
\hline \multicolumn{5}{|c|}{ Annual sample average } & $-1.78 \times 10^{-7}$ & $1.25 \times 10^{-6}$ & $1.10 \times 10^{-6}$ \\
\hline \multicolumn{5}{|c|}{ Inhaled air derived concentration guide (DCG) class W } & $7.40 \times 10^{-3}$ & & \\
\hline
\end{tabular}

${ }^{1}$ Total propagated uncertainty

${ }^{2}$ Standard deviation of the mean

${ }^{3}$ Mean minimum detectable concentration among all samples from the indicated location

Table 4.9 Americium-241 concentration $\left(\mathrm{Bq} / \mathrm{m}^{3}\right)$ in air particulates.

\begin{tabular}{|c|c|c|c|c|c|c|c|}
\hline Location & Minimum & $2 \times$ TPU $^{1}$ & Maximum & $2 \times$ TPU & Mean & $2 \times \mathrm{SD}^{2}$ & MDC $^{3}$ \\
\hline $\mathrm{CBD}$ & $2.96 \times 10^{-7}$ & $5.18 \times 10^{-7}$ & $7.03 \times 10^{-7}$ & $5.92 \times 10^{-7}$ & $5.55 \times 10^{-7}$ & $6.03 \times 10^{-7}$ & $1.81 \times 10^{-6}$ \\
\hline MLR & $-4.44 \times 10^{-7}$ & $9.62 \times 10^{-7}$ & $5.99 \times 10^{-7}$ & $8.14 \times 10^{-7}$ & $1.04 \times 10^{-7}$ & $3.56 \times 10^{-7}$ & $1.79 \times 10^{-6}$ \\
\hline SEC & $-5.55 \times 10^{-7}$ & $6.66 \times 10^{-7}$ & $3.17 \times 10^{-7}$ & $4.44 \times 10^{-7}$ & $5.18 \times 10^{-9}$ & $2.91 \times 10^{-7}$ & $1.42 \times 10^{-6}$ \\
\hline SMR & $-7.40 \times 10^{-7}$ & $2.66 \times 10^{-6}$ & $0.00 \times 10^{0}$ & $1.48 \times 10^{-21}$ & $-3.35 \times 10^{-7}$ & $7.18 \times 10^{-7}$ & $3.10 \times 10^{-6}$ \\
\hline WEE & $-6.85 \times 10^{-7}$ & $6.66 \times 10^{-7}$ & $9.62 \times 10^{-7}$ & $1.33 \times 10^{-6}$ & $2.36 \times 10^{-7}$ & $4.48 \times 10^{-7}$ & $1.84 \times 10^{-6}$ \\
\hline WFF & $7.40 \times 10^{-8}$ & $2.96 \times 10^{-7}$ & $8.88 \times 10^{-7}$ & $1.18 \times 10^{-6}$ & $4.12 \times 10^{-7}$ & $3.42 \times 10^{-7}$ & $1.41 \times 10^{-6}$ \\
\hline WSS & $-2.96 \times 10^{-7}$ & $1.11 \times 10^{-6}$ & $9.44 \times 10^{-7}$ & $2.22 \times 10^{-6}$ & $2.82 \times 10^{-7}$ & $6.49 \times 10^{-7}$ & $2.52 \times 10^{-6}$ \\
\hline \multicolumn{5}{|c|}{$\begin{array}{l}\text { Annual sample average } \\
\text { ration guide (DCG) class W }\end{array}$} & $\begin{array}{l}1.69 \times 10^{-7} \\
7.40 \times 10^{-3}\end{array}$ & $2.42 \times 10^{-6}$ & $1.98 \times 10^{-6}$ \\
\hline
\end{tabular}

${ }^{1}$ Total propagated uncertainty

${ }^{2}$ Standard deviation of the mean

${ }^{3}$ Mean minimum detectable concentration among all samples from the indicated location 
Table 4.10 Potassium-40 concentration $\left(\mathrm{Bg} / \mathrm{m}^{3}\right)$ in air particulates.

\begin{tabular}{lccccccc}
\hline Location & Minimum & $\mathbf{2} \times \mathbf{T P U}^{\mathbf{1}}$ & Maximum & $\mathbf{2 \times} \mathbf{\text { TPU}}$ & Mean & $\mathbf{2} \times \mathbf{S D}^{\mathbf{2}}$ & $\mathbf{M D C}^{\mathbf{3}}$ \\
\hline CBD & $\mathrm{NR}^{4}$ & $\mathrm{NR}$ & $\mathrm{NR}$ & $\mathrm{NR}$ & $\mathrm{NR}$ & $\mathrm{NR}$ & $\mathrm{NR}$ \\
MLR & $\mathrm{NR}$ & $\mathrm{NR}$ & $\mathrm{NR}$ & $\mathrm{NR}$ & $\mathrm{NR}$ & $\mathrm{NR}$ & $\mathrm{NR}$ \\
SEC & $\mathrm{NR}$ & $\mathrm{NR}$ & $\mathrm{NR}$ & $\mathrm{NR}$ & $\mathrm{NR}$ & $\mathrm{NR}$ & $\mathrm{NR}$ \\
SMR & $\mathrm{NR}$ & $\mathrm{NR}$ & $\mathrm{NR}$ & $\mathrm{NR}$ & $\mathrm{NR}$ & $\mathrm{NR}$ & $3.00 \times 10^{-4}$ \\
WEE & $2.48 \times 10^{-5}$ & $2.29 \times 10^{-4}$ & $2.48 \times 10^{-5}$ & $2.29 \times 10^{-4}$ & $2.48 \times 10^{-5}$ & $2.29 \times 10^{-4}$ & $3.92 \times 10^{-4}$ \\
WFF & $1.22 \times 10^{-4}$ & $1.89 \times 10^{-4}$ & $2.43 \times 10^{-4}$ & $2.29 \times 10^{-4}$ & $1.83 \times 10^{-4}$ & $1.49 \times 10^{-4}$ & $3.02 \times 10^{-4}$ \\
WSS & $6.07 \times 10^{-6}$ & $2.00 \times 10^{-4}$ & $5.40 \times 10^{-5}$ & $1.85 \times 10^{-4}$ & $3.00 \times 10^{-5}$ & $1.36 \times 10^{-4}$ & $3.33 \times 10^{-4}$ \\
\hline
\end{tabular}

${ }^{1}$ Total propagated uncertainty

${ }^{2}$ Standard deviation of the mean

${ }^{3}$ Mean minimum detectable concentration among all samples from the indicated location

${ }^{4}$ No data reported

Table 4.11 Cobalt-60 concentration $\left(\mathrm{Bg} / \mathrm{m}^{3}\right)$ in air particulates.

\begin{tabular}{lccccccc}
\hline Location & Minimum & $\mathbf{2} \times \mathbf{T P U}^{\mathbf{1}}$ & Maximum & $\mathbf{2} \times \mathbf{T P U}$ & Mean & $\mathbf{2} \times \mathbf{S D}^{\mathbf{2}}$ & $\mathbf{M D C}^{\mathbf{3}}$ \\
\hline CBD & $\mathrm{NR}^{4}$ & $\mathrm{NR}$ & $\mathrm{NR}$ & $\mathrm{NR}$ & $\mathrm{NR}$ & $\mathrm{NR}$ & $\mathrm{NR}$ \\
MLR & $\mathrm{NR}$ & $\mathrm{NR}$ & $\mathrm{NR}$ & $\mathrm{NR}$ & $\mathrm{NR}$ & $\mathrm{NR}$ & $\mathrm{NR}$ \\
SEC & $\mathrm{NR}$ & $\mathrm{NR}$ & $\mathrm{NR}$ & $\mathrm{NR}$ & $\mathrm{NR}$ & $\mathrm{NR}$ & $\mathrm{NR}$ \\
SMR & $\mathrm{NR}$ & $\mathrm{NR}$ & $\mathrm{NR}$ & $\mathrm{NR}$ & $\mathrm{NR}$ & $\mathrm{NR}$ & $3.48 \times 10^{-5}$ \\
WEE & $\mathrm{NR}$ & $\mathrm{NR}$ & $\mathrm{NR}$ & $\mathrm{NR}$ & $\mathrm{NR}$ & $\mathrm{NR}$ & $3.11 \times 10^{-5}$ \\
WFF & $-3.89 \times 10^{-6}$ & $1.78 \times 10^{-5}$ & $-3.89 \times 10^{-6}$ & $1.78 \times 10^{-5}$ & $-3.89 \times 10^{-6}$ & $1.78 \times 10^{-5}$ & $3.15 \times 10^{-5}$ \\
WSS & $-3.16 \times 10^{-6}$ & $2.04 \times 10^{-5}$ & $-3.16 \times 10^{-6}$ & $2.04 \times 10^{-5}$ & $-3.16 \times 10^{-6}$ & $2.04 \times 10^{-5}$ & $3.57 \times 10^{-5}$ \\
\hline
\end{tabular}

${ }^{1}$ Total propagated uncertainty

${ }^{2}$ Standard deviation of the mean

${ }^{3}$ Mean minimum detectable concentration among all samples from the indicated location

${ }^{4}$ No data reported

Table 4.12 Strontium-90 concentration $\left(\mathrm{Bq} / \mathrm{m}^{3}\right)$ in air particulates.

\begin{tabular}{lccccccc}
\hline Location & Minimum & $\mathbf{2} \times$ TPU $^{1}$ & Maximum & $\mathbf{2} \times \mathbf{T P U}$ & Mean & $\mathbf{2 \times \text { SD } ^ { 2 }}$ & MDC $^{\mathbf{3}}$ \\
\hline CBD & $\mathrm{NR}^{4}$ & $\mathrm{NR}$ & $\mathrm{NR}$ & $\mathrm{NR}$ & $\mathrm{NR}$ & $\mathrm{NR}$ & $\mathrm{NR}$ \\
MLR & $\mathrm{NR}$ & $\mathrm{NR}$ & $\mathrm{NR}$ & $\mathrm{NR}$ & $\mathrm{NR}$ & $\mathrm{NR}$ & $\mathrm{NR}$ \\
SEC & $\mathrm{NR}$ & $\mathrm{NR}$ & $\mathrm{NR}$ & $\mathrm{NR}$ & $\mathrm{NR}$ & $\mathrm{NR}$ & $\mathrm{NR}$ \\
SMR & $-2.05 \times 10^{-5}$ & $2.15 \times 10^{-5}$ & $6.14 \times 10^{-6}$ & $1.96 \times 10^{-5}$ & $-7.20 \times 10^{-6}$ & $1.45 \times 10^{-5}$ & $3.70 \times 10^{-5}$ \\
WEE & $-1.18 \times 10^{-5}$ & $2.52 \times 10^{-5}$ & $1.11 \times 10^{-5}$ & $2.11 \times 10^{-5}$ & $-3.15 \times 10^{-7}$ & $1.64 \times 10^{-5}$ & $3.98 \times 10^{-5}$ \\
WFF & $-2.10 \times 10^{-5}$ & $2.29 \times 10^{-5}$ & $4.37 \times 10^{-7}$ & $2.07 \times 10^{-5}$ & $-1.03 \times 10^{-5}$ & $1.55 \times 10^{-5}$ & $3.87 \times 10^{-5}$ \\
WSS & $-1.76 \times 10^{-5}$ & $2.26 \times 10^{-5}$ & $8.21 \times 10^{-6}$ & $2.18 \times 10^{-5}$ & $-4.70 \times 10^{-6}$ & $1.57 \times 10^{-5}$ & $3.89 \times 10^{-5}$ \\
\hline
\end{tabular}

${ }^{1}$ Total propagated uncertainty

${ }^{2}$ Standard deviation of the mean

${ }^{3}$ Mean minimum detectable concentration among all samples from the indicated location

${ }^{4}$ No data reported

Table 4.13 Cesium-137 concentration $\left(\mathrm{Bq} / \mathrm{m}^{3}\right)$ in air particulates.

\begin{tabular}{lccccccc}
\hline Location & Minimum & $\mathbf{2} \times$ TPU $^{1}$ & Maximum & $\mathbf{2} \times \mathbf{T P U}$ & Mean & $\mathbf{2} \times$ SD $^{\mathbf{2}}$ & MDC $^{\mathbf{3}}$ \\
\hline CBD & $\mathrm{NR}^{4}$ & $\mathrm{NR}$ & $\mathrm{NR}$ & $\mathrm{NR}$ & $\mathrm{NR}$ & $\mathrm{NR}$ & $\mathrm{NR}$ \\
MLR & $\mathrm{NR}$ & $\mathrm{NR}$ & $\mathrm{NR}$ & $\mathrm{NR}$ & $\mathrm{NR}$ & $\mathrm{NR}$ & $\mathrm{NR}$ \\
SEC & $\mathrm{NR}$ & $\mathrm{NR}$ & $\mathrm{NR}$ & $\mathrm{NR}$ & $\mathrm{NR}$ & $\mathrm{NR}$ & $\mathrm{NR}$ \\
SMR & $\mathrm{NR}$ & $\mathrm{NR}$ & $\mathrm{NR}$ & $\mathrm{NR}$ & $\mathrm{NR}$ & $\mathrm{NR}$ & $2.72 \times 10^{-5}$ \\
WE & $\mathrm{NR}$ & $\mathrm{NR}$ & $\mathrm{NR}$ & $\mathrm{NR}$ & $\mathrm{NR}$ & $\mathrm{NR}$ & $3.07 \times 10^{-5}$ \\
WFF & $8.88 \times 10^{-6}$ & $1.81 \times 10^{-5}$ & $8.88 \times 10^{-6}$ & $1.81 \times 10^{-5}$ & $8.88 \times 10^{-6}$ & $1.81 \times 10^{-5}$ & $3.07 \times 10^{-5}$ \\
WSS & $-6.29 \times 10^{-6}$ & $1.96 \times 10^{-5}$ & $-6.29 \times 10^{-6}$ & $1.96 \times 10^{-5}$ & $-6.29 \times 10^{-6}$ & $1.96 \times 10^{-5}$ & $3.09 \times 10^{-5}$ \\
\hline
\end{tabular}

${ }^{1}$ Total propagated uncertainty

${ }^{2}$ Standard deviation of the mean

${ }^{3}$ Mean minimum detectable concentration among all samples from the indicated location

${ }^{4}$ No data reported 
Duplicate air particulate samples were collected by rotating the portable sampler from one location to another every quarter: WFF in the first quarter, WEE in the second quarter, WSS in the third quarter and MLR in the fourth quarter. The samples were collected by both samplers in identical conditions at all four locations. The duplicate samples were analyzed to check the reproducibility of the data. The results are given in Table 4.14.
The original and duplicate results for ${ }^{233+234} \mathrm{U}$, ${ }^{238} \mathrm{U},{ }^{238} \mathrm{Pu}$, and ${ }^{239+240} \mathrm{Pu}$ were compared using the RER. One duplicate result was obtained for ${ }^{90} \mathrm{Sr}$. The results for all other radionuclides were excluded because of insufficient data for a meaningful test. Relative Error Ratios were less than one for all results except ${ }^{233+234} \mathrm{U}$ at MLR and ${ }^{238} \mathrm{Pu}$ at WEE. This suggests overall good agreement between duplicates.

Table 4.14 Concentration of radionuclides $\left(\mathrm{Bq} / \mathrm{m}^{3}\right)$ in duplicate air particulate samples.

\begin{tabular}{|c|c|c|c|c|c|c|}
\hline Location & Concentration & $2 \times \mathrm{TPU}^{1}$ & MDC $^{2}$ & Concentration & $2 \times$ TPU & MDC \\
\hline & & ${ }^{233+234} \mathbf{U}$ & & & ${ }^{238} \mathrm{U}$ & \\
\hline MLR & $3.29 \times 10^{-6}$ & $1.33 \times 10^{-6}$ & $1.18 \times 10^{-6}$ & $2.37 \times 10^{-6}$ & $1.11 \times 10^{-6}$ & $1.18 \times 10^{-6}$ \\
\hline MLR Duplicate & $1.18 \times 10^{-6}$ & $9.62 \times 10^{-7}$ & $1.63 \times 10^{-6}$ & $2.33 \times 10^{-6}$ & $8.88 \times 10^{-7}$ & $7.77 \times 10^{-7}$ \\
\hline WEE & $3.07 \times 10^{-6}$ & $1.11 \times 10^{-6}$ & $1.22 \times 10^{-6}$ & $2.92 \times 10^{-6}$ & $9.62 \times 10^{-7}$ & $7.77 \times 10^{-7}$ \\
\hline WEE Duplicate & $1.74 \times 10^{-6}$ & $1.33 \times 10^{-6}$ & $2.33 \times 10^{-6}$ & $3.52 \times 10^{-6}$ & $1.41 \times 10^{-6}$ & $1.26 \times 10^{-6}$ \\
\hline WFF & $3.03 \times 10^{-6}$ & $1.48 \times 10^{-6}$ & $2.11 \times 10^{-6}$ & $2.26 \times 10^{-6}$ & $1.18 \times 10^{-6}$ & $1.52 \times 10^{-6}$ \\
\hline WFF Duplicate & $5.14 \times 10^{-6}$ & $1.63 \times 10^{-6}$ & $1.37 \times 10^{-6}$ & $2.41 \times 10^{-6}$ & $1.18 \times 10^{-6}$ & $1.37 \times 10^{-6}$ \\
\hline WSS & $2.52 \times 10^{-6}$ & $1.18 \times 10^{-6}$ & $1.41 \times 10^{-6}$ & $2.18 \times 10^{-6}$ & $1.04 \times 10^{-6}$ & $1.26 \times 10^{-6}$ \\
\hline \multirow[t]{2}{*}{ WSS Duplicate } & $1.18 \times 10^{-6}$ & $9.62 \times 10^{-7}$ & $1.63 \times 10^{-6}$ & $2.33 \times 10^{-6}$ & $8.88 \times 10^{-7}$ & $7.77 \times 10^{-7}$ \\
\hline & & ${ }^{238} \mathrm{Pu}$ & & & ${ }^{239+240} \mathbf{P u}$ & \\
\hline MLR & $3.70 \times 10^{-8}$ & $7.40 \times 10^{-8}$ & $1.48 \times 10^{-7}$ & $2.59 \times 10^{-7}$ & $2.89 \times 10^{-7}$ & $4.44 \times 10^{-7}$ \\
\hline MLR Duplicate & $1.11 \times 10^{-7}$ & $2.22 \times 10^{-7}$ & $2.59 \times 10^{-7}$ & $0.00 \times 10^{0}$ & $1.48 \times 10^{-21}$ & $8.88 \times 10^{-7}$ \\
\hline WEE & $-5.18 \times 10^{-7}$ & $6.66 \times 10^{-7}$ & $1.52 \times 10^{-6}$ & $-3.33 \times 10^{-7}$ & $5.18 \times 10^{-7}$ & $1.26 \times 10^{-6}$ \\
\hline WEE Duplicate & $-1.03 \times 10^{-4}$ & $6.66 \times 10^{-5}$ & $9.25 \times 10^{-5}$ & $-7.18 \times 10^{-6}$ & $1.52 \times 10^{-5}$ & $2.52 \times 10^{-5}$ \\
\hline WFF & $3.70 \times 10^{-7}$ & $1.04 \times 10^{-6}$ & $2.07 \times 10^{-6}$ & $-3.70 \times 10^{-7}$ & $7.40 \times 10^{-7}$ & $2.07 \times 10^{-6}$ \\
\hline WFF Duplicate & $-4.44 \times 10^{-7}$ & $1.55 \times 10^{-6}$ & $3.22 \times 10^{-6}$ & $-4.44 \times 10^{-7}$ & $8.88 \times 10^{-7}$ & $2.29 \times 10^{-6}$ \\
\hline WSS & $\mathrm{NR}^{3}$ & NR & $6.66 \times 10^{-7}$ & $7.40 \times 10^{-8}$ & $2.55 \times 10^{-7}$ & $6.66 \times 10^{-7}$ \\
\hline \multirow[t]{2}{*}{ WSS Duplicate } & $1.11 \times 10^{-7}$ & $2.22 \times 10^{-7}$ & $2.59 \times 10^{-7}$ & $0.00 \times 10^{0}$ & $1.48 \times 10^{-21}$ & $8.88 \times 10^{-7}$ \\
\hline & & ${ }^{40} \mathrm{~K}$ & & & ${ }^{90} \mathrm{Sr}$ & \\
\hline MLR & NR & NR & NR & NR & NR & NR \\
\hline MLR Duplicate & NR & NR & $2.85 \times 10^{-4}$ & $8.58 \times 10^{-7}$ & $1.92 \times 10^{-5}$ & $3.40 \times 10^{-5}$ \\
\hline WEE & NR & NR & NR & NR & NR & NR \\
\hline WEE Duplicate & NR & NR & NR & NR & NR & NR \\
\hline WFF & NR & NR & NR & NR & NR & NR \\
\hline WFF Duplicate & NR & NR & NR & NR & NR & NR \\
\hline WSS & $5.40 \times 10^{-5}$ & $1.85 \times 10^{-4}$ & $2.59 \times 10^{-4}$ & $8.21 \times 10^{-6}$ & $2.18 \times 10^{-5}$ & $3.70 \times 10^{-5}$ \\
\hline WSS Duplicate & NR & NR & $2.85 \times 10^{-4}$ & $8.58 \times 10^{-7}$ & $1.92 \times 10^{-5}$ & $3.40 \times 10^{-5}$ \\
\hline
\end{tabular}


Table 4.15 Quarterly average radionuclide concentrations $\left(\mathrm{Bq} / \mathrm{m}^{3}\right)$ measured in air particulate samples by the EEG ${ }^{1} 1999$.

\begin{tabular}{|c|c|c|c|c|}
\hline & & & & \\
\hline & 1 & 2 & 3 & 4 \\
\hline & & & & \\
\hline Concentration & $3.17 \times 10^{-8}$ & $1.76 \times 10^{-8}$ & $2.49 \times 10^{-11}$ & $3.94 \times 10^{-9}$ \\
\hline $2 \times \mathrm{TPU}^{1}$ & $4.12 \times 10^{-8}$ & $5.07 \times 10^{-8}$ & $3.82 \times 10^{-8}$ & $3.78 \times 10^{-8}$ \\
\hline & & & & \\
\hline Concentration & $2.40 \times 10^{-9}$ & $1.10 \times 10^{-9}$ & $-4.44 \times 10^{-9}$ & $-4.93 \times 10^{-9}$ \\
\hline $2 \times \mathrm{TPU}$ & $3.59 \times 10^{-8}$ & $4.37 \times 10^{-8}$ & $3.53 \times 10^{-8}$ & $4.47 \times 10^{-8}$ \\
\hline & & & & \\
\hline Concentration & $1.33 \times 10^{-8}$ & $1.57 \times 10^{-8}$ & $4.22 \times 10^{-9}$ & $1.79 \times 10^{-9}$ \\
\hline $2 \times \mathrm{TPU}$ & $1.47 \times 10^{-8}$ & $1.89 \times 10^{-8}$ & $1.28 \times 10^{-8}$ & $1.63 \times 10^{-8}$ \\
\hline & & & & \\
\hline Concentration & $-6.90 \times 10^{-9}$ & $7.22 \times 10^{-7}$ & $3.44 \times 10^{-8}$ & $\mathrm{NR}^{3}$ \\
\hline $2 \times \mathrm{TPU}$ & $2.49 \times 10^{-6}$ & $2.73 \times 10^{-6}$ & $2.70 \times 10^{-6}$ & NR \\
\hline & & & & \\
\hline Concentration & $1.86 \times 10^{-6}$ & $2.99 \times 10^{-7}$ & $5.31 \times 10^{-7}$ & $8.33 \times 10^{-7}$ \\
\hline $2 \times$ TPU & $9.15 \times 10^{-7}$ & $7.21 \times 10^{-7}$ & $6.31 \times 10^{-7}$ & $6.79 \times 10^{-7}$ \\
\hline
\end{tabular}

The results obtained for the concentrations of ${ }^{238} \mathrm{Pu},{ }^{239+240} \mathrm{Pu},{ }^{241} \mathrm{Am},{ }^{90} \mathrm{Sr}$, and ${ }^{137} \mathrm{Cs}$ in air particulates compared favorably with those measured by the Environmental Evaluation Group (EEG) (Table 4.15). The annual mean concentrations of these radionuclides were very low, and most samples collected by either WID or EEG did not contain detectable concentrations.

\subsection{Ground Water}

\subsubsection{Sample Collection}

Ground water samples were collected from seven different wells around the WIPP site as shown in Figure 6.1. Approximately three bore volumes (approximately 3,800 L [1,000 gal]) of water were pumped out of these wells before collecting approximately $38 \mathrm{~L}$ (10 gal) of water samples. The water samples were collected from depths ranging from $180-270 \mathrm{~m}(600-900 \mathrm{ft})$ from six wells (WQSP-1 to WQSP-6), and from a depth of $69 \mathrm{~m}(225 \mathrm{ft})$ from WQSP-6A. Samples were collected twice in 1999. Approximately 8 L (2 gal) of water were sent to the contract laboratory for the determination of radionuclides of interest.
The rest of the samples were used to analyze for nonradiological parameters or were put in storage. The samples were acidified to $\mathrm{pH} \leq 2$ by adding concentrated nitric acid drop by drop.

\subsubsection{Determination of Individual Radio- nuclides}

The acidified water samples were used for the determination of gamma-emitting radionuclides, such as ${ }^{40} \mathrm{~K},{ }^{60} \mathrm{Co}$, and ${ }^{137} \mathrm{Cs}$, by gammaspectrometry. An aliquot of approximately 500 $\mathrm{ml}(17 \mathrm{oz})$ was used for the determination of ${ }^{90} \mathrm{Sr}$. Another aliquot was used for the sequential determinations of uranium, plutonium, and americium by alpha spectrometry, which involved the co-precipitation of actinides with iron carrier, ion exchange chromatographic separation of individual radionuclides, source preparation by electrodeposition or micro-precipitating, and alpha spectrometry.

\subsubsection{Results and Discussions}

Isotopes of naturally-occurring uranium were detected in every well in 1999 (Table 4.16). The 
mean concentrations of ${ }^{233+234} \mathrm{U}$ ranged from $2.26 \times 10^{-1} \pm 1.09 \times 10^{-2} \mathrm{~Bq} / \mathrm{L}\left(6.11 \times 10^{0} \pm 2.95 \times 10^{-1}\right.$ $\mathrm{pCi} / \mathrm{L})$ in WQSP-6A to $1.44 \times 10^{0} \pm 8.14 \times 10^{-2} \mathrm{~Bq} / \mathrm{L}$ $\left(3.89 \times 10^{1} \pm 2.20 \times 10^{0} \mathrm{pCi} / \mathrm{L}\right)$ in WQSP-2. Uranium-235 ranged from $2.02 \times 10^{-3} \pm 1.23 \times 10^{-3}$ $\mathrm{Bq} / \mathrm{L}\left(5.46 \times 10^{-2} \pm 3.32 \times 10^{-2} \mathrm{pCi} / \mathrm{L}\right)$ in WQSP-3 to $9.62 \times 10^{-3} \pm 2.81 \times 10^{-3} \mathrm{~Bq} / \mathrm{L}\left(2.60 \times 10^{-1} \pm 7.59 \times 10^{-2}\right.$ $\mathrm{pCi} / \mathrm{L}$ ) in WQSP-1. The mean concentration of ${ }^{238} \mathrm{U}$ ranged from $4.07 \times 10^{-2} \pm 4.98 \times 10^{-3} \mathrm{~Bq} / \mathrm{L}$ $\left(1.10 \times 10^{0} \pm 1.35 \times 10^{-1} \mathrm{pCi} / \mathrm{L}\right)$ in WQSP-3 to $2.41 \times 10^{-1} \pm 1.81 \times 10^{-2} \mathrm{~Bq} / \mathrm{L}\left(6.51 \times 10^{0} \pm 4.89 \times 10^{-1}\right.$ $\mathrm{pCi} / \mathrm{L})$ in WQSP-1. The concentrations of ${ }^{233+234} \mathrm{U}$ and ${ }^{238} \mathrm{U}$ were significantly different between wells (ANOVA, $\mathrm{p}<0.001$ ), but no pattern related to WIPP activities could be determined. Uranium235 did not differ between wells $(\mathrm{p}=0.468)$

The results for the concentrations of uranium isotopes in water samples collected from these wells in 1999 were compared with the results from water samples collected in 1998 (Table 4.16). There was no significant difference in the concentration of any uranium isotope between ground-water samples collected in 1998 and those collected in 1999 (ANOVA, p>0.05).

Plutonium-238, ${ }^{239+240} \mathrm{Pu}$, and ${ }^{241} \mathrm{Am}$ were also analyzed in these ground-water samples (Table 4.17). Plutonium-238 was detected in only one sample, which was collected from well WQSP-1 $\left(4.07 \times 10^{-3} \pm 2.04 \times 10^{-3} \mathrm{~Bq} / \mathrm{L} ; \mathrm{MDC}=2.30 \times 10^{-3}\right.$ $\mathrm{Bq} / \mathrm{L}\left[1.10 \times 10^{-1} \pm 5.50 \times 10^{-2} \mathrm{pCi} / \mathrm{L} ; \mathrm{MDC}=\right.$ $\left.\left.6.20 \times 10^{-2} \mathrm{pCi} / \mathrm{L}\right]\right)$. There was no evidence of analytical problems for this sample. However, the annual mean from WQSP-1 as well as all other individual sample results and means were below the detection limit for ${ }^{238} \mathrm{Pu}$. Analysis of variance did not show differences in ${ }^{238} \mathrm{Pu}$ between wells in 1999 ( $p=0.887)$, or between 1998 and 1999 for all wells $\left(\mathrm{p}=0.133\right.$ ). Both ${ }^{239+240} \mathrm{Pu}$ and ${ }^{241} \mathrm{Am}$ were nondetectable in all samples.

Ground-water results from wells WQSP-1, WQSP-3, and WQSP-4 in the years, 1997, 1998, and 1999 exhibit a trend for activity above the MDC for ${ }^{238} \mathrm{Pu}$ and ${ }^{241} \mathrm{Am}$ (Table 4.18). These apparently high concentrations may be explained by TENORM.

TENORM stands for technologically enhanced naturally occurring radioactive materials - certain radionuclides that are naturally present in rocks, soils, and minerals and that human industrial activities have concentrated or exposed to the accessible environment. TENORM is generated by certain industrial activities, such as mining, fertilizer productions, and oil and gas production. Oil and gas production can generate large volumes of water with dissolved minerals with certain radionuclides. These minerals can form a crust or scale in pipes and oil field equipment. In certain cases, these wastes can emit radionuclides into the water, air, and soil. Concentrations of the radionuclide ${ }^{226} \mathrm{Ra}$, a decay product of uranium and thorium with a half-life of 1,600 years, is commonly found in TENORM materials and wastes (www.epa.gov/rpdweb00/tenorm/about.htm). 
Table 4.16 Uranium concentration $(\mathrm{Bg} / \mathrm{L})$ in ground water.

\begin{tabular}{|c|c|c|c|c|c|c|c|c|c|}
\hline \multirow[b]{2}{*}{ Location } & \multicolumn{3}{|c|}{${ }^{233+234} \mathbf{U}$} & \multicolumn{3}{|c|}{${ }^{235} \mathbf{U}$} & \multicolumn{3}{|c|}{${ }^{238} \mathbf{U}$} \\
\hline & Mean & $2 \times \mathrm{SD}^{1}$ & MDC $^{2}$ & Mean & $2 \times \mathrm{SD}$ & MDC & Mean & $2 \times \mathrm{SD}$ & MDC \\
\hline & \multicolumn{9}{|c|}{1998} \\
\hline WQSP-1 & $1.48 \times 10^{-2}$ & $2.27 \times 10^{-1}$ & $2.45 \times 10^{-3}$ & $7.95 \times 10^{-3}$ & $8.81 \times 10^{-4}$ & $1.78 \times 10^{-3}$ & $1.99 \times 10^{-1}$ & $3.78 \times 10^{-2}$ & $1.54 \times 10^{-3}$ \\
\hline WQSP-2 & $1.20 \times 10^{0}$ & $1.85 \times 10^{-1}$ & $1.71 \times 10^{-2}$ & $5.36 \times 10^{-3}$ & $3.94 \times 10^{-3}$ & $1.48 \times 10^{-2}$ & $1.97 \times 10^{-1}$ & $4.14 \times 10^{-2}$ & $1.58 \times 10^{-2}$ \\
\hline WQSP-3 & $2.60 \times 10^{-1}$ & $2.26 \times 10^{-2}$ & $4.35 \times 10^{-3}$ & $2.94 \times 10^{-3}$ & $1.08 \times 10^{-3}$ & $1.54 \times 10^{-3}$ & $5.30 \times 10^{-2}$ & $2.17 \times 10^{-2}$ & $1.65 \times 10^{-3}$ \\
\hline WQSP-4 & $3.64 \times 10^{-1}$ & $3.96 \times 10^{-2}$ & $1.14 \times 10^{-2}$ & $4.28 \times 10^{-2}$ & $6.87 \times 10^{-2}$ & $7.71 \times 10^{-3}$ & $7.28 \times 10^{-2}$ & $1.30 \times 10^{-2}$ & $8.34 \times 10^{-3}$ \\
\hline WQSP-5 & $5.92 \times 10^{-1}$ & $3.70 \times 10^{-2}$ & $2.74 \times 10^{-3}$ & $3.58 \times 10^{-3}$ & $1.20 \times 10^{-3}$ & $1.01 \times 10^{-3}$ & $9.00 \times 10^{-2}$ & $7.70 \times 10^{-3}$ & $1.01 \times 10^{-3}$ \\
\hline WQSP-6 & $4.93 \times 10^{-1}$ & $2.14 \times 10^{-2}$ & $4.08 \times 10^{-3}$ & $4.07 \times 10^{-3}$ & $3.70 \times 10^{-4}$ & $2.31 \times 10^{-3}$ & $7.40 \times 10^{-2}$ & $3.70 \times 10^{-3}$ & $2.79 \times 10^{-3}$ \\
\hline \multirow[t]{2}{*}{ WQSP-6A } & & $4.27 \times 10^{-3}$ & $4.85 \times 10^{-3}$ & $1.38 \times 10^{-2}$ & $1.05 \times 10^{-2}$ & $1.30 \times 10^{-3}$ & $1.30 \times 10^{-1}$ & $9.79 \times 10^{-3}$ & $1.91 \times 10^{-3}$ \\
\hline & \multicolumn{9}{|c|}{1999} \\
\hline WQSP-1 & $1.44 \times 10^{0}$ & $8.14 \times 10^{-2}$ & $4.07 \times 10^{-3}$ & $9.62 \times 10^{-3}$ & $2.81 \times 10^{-3}$ & $1.96 \times 10^{-3}$ & $2.41 \times 10^{-1}$ & $1.81 \times 10^{-2}$ & $2.29 \times 10^{-3}$ \\
\hline WQSP-2 & $1.17 \times 10^{0}$ & $6.67 \times 10^{-2}$ & $4.11 \times 10^{-3}$ & $7.03 \times 10^{-3}$ & $1.82 \times 10^{-3}$ & $2.31 \times 10^{-3}$ & $1.81 \times 10^{-1}$ & $1.26 \times 10^{-2}$ & $2.11 \times 10^{-3}$ \\
\hline WQSP-3 & $2.79 \times 10^{-1}$ & $1.95 \times 10^{-2}$ & $4.46 \times 10^{-3}$ & $2.02 \times 10^{-3}$ & $1.23 \times 10^{-3}$ & $2.59 \times 10^{-3}$ & $4.07 \times 10^{-2}$ & $4.98 \times 10^{-3}$ & $2.44 \times 10^{-3}$ \\
\hline WQSP-4 & $5.18 \times 10^{-1}$ & $3.75 \times 10^{-2}$ & $8.51 \times 10^{-3}$ & $4.81 \times 10^{-3}$ & $2.15 \times 10^{-3}$ & $3.89 \times 10^{-3}$ & $9.44 \times 10^{-2}$ & $1.00 \times 10^{-2}$ & $4.44 \times 10^{-3}$ \\
\hline WQSP-5 & $5.92 \times 10^{-1}$ & $3.70 \times 10^{-2}$ & $5.18 \times 10^{-3}$ & $5.37 \times 10^{-3}$ & $1.77 \times 10^{-3}$ & $2.37 \times 10^{-3}$ & $8.51 \times 10^{-2}$ & $7.89 \times 10^{-3}$ & $2.98 \times 10^{-3}$ \\
\hline WQSP-6 & $5.55 \times 10^{-1}$ & $2.41 \times 10^{-2}$ & $1.31 \times 10^{-2}$ & $5.00 \times 10^{-3}$ & $1.39 \times 10^{-3}$ & $2.07 \times 10^{-3}$ & $7.40 \times 10^{-2}$ & $5.70 \times 10^{-3}$ & $1.85 \times 10^{-3}$ \\
\hline WQSP-6A & $2.26 \times 10^{-1}$ & $1.09 \times 10^{-2}$ & $3.05 \times 10^{-3}$ & $4.90 \times 10^{-3}$ & $1.44 \times 10^{-3}$ & $2.33 \times 10^{-3}$ & $1.22 \times 10^{-1}$ & $7.18 \times 10^{-3}$ & $2.63 \times 10^{-3}$ \\
\hline
\end{tabular}

${ }^{1}$ Standard deviation of the mean

${ }^{2}$ Mean minimum detectable concentration among all samples from the indicated location

Table 4.17 Plutonium and americium concentrations $(\mathrm{Bq} / \mathrm{L})$ in ground water.

\begin{tabular}{|c|c|c|c|c|c|c|c|c|c|}
\hline \multirow[b]{2}{*}{ Location } & \multicolumn{3}{|c|}{${ }^{241} \mathrm{Am}$} & \multicolumn{3}{|c|}{${ }^{238} \mathrm{Pu}$} & \multicolumn{3}{|c|}{${ }^{239+240} \mathrm{Pu}$} \\
\hline & Mean & $2 \times \mathrm{SD}^{1}$ & & Mean & $2 \times \mathrm{SD}$ & & Mean & $2 \times \mathrm{SD}$ & MDC \\
\hline & \multicolumn{9}{|c|}{1998} \\
\hline WQSP-1 & & $5.52 \times 10^{-4}$ & & & $1.25 \times 10^{-3}$ & & & $1.57 \times 10^{-4}$ & \\
\hline WQSP-2 & $1.31 \times 10^{-3}$ & $9.05 \times 10^{-4}$ & $2.81 \times 10^{-3}$ & $5.18 \times 10^{-4}$ & $3.97 \times 10^{-4}$ & $2.03 \times 10^{-3}$ & $-9.25 \times 10^{-5}$ & $3.48 \times 10^{-4}$ & $1.59 \times 10^{-3}$ \\
\hline WQSP-3 & $2.92 \times 10^{-3}$ & $1.62 \times 10^{-3}$ & $2.01 \times 10^{-3}$ & $2.50 \times 10^{-3}$ & $2.87 \times 10^{-4}$ & $2.53 \times 10^{-3}$ & $3.21 \times 10^{-4}$ & $1.40 \times 10^{-4}$ & $2.15 \times 10^{-3}$ \\
\hline WQSP-4 & $9.62 \times 10^{-4}$ & $1.22 \times 10^{-3}$ & $2.87 \times 10^{-3}$ & $2.02 \times 10^{-3}$ & $1.69 \times 10^{-3}$ & $1.43 \times 10^{-3}$ & & $7.43 \times 10^{-4}$ & $1.74 \times 10^{-3}$ \\
\hline WQSP & $3.49 \times 10^{-3}$ & $6.60 \times 10^{-3}$ & $1.41 \times 10^{-2}$ & $4.56 \times 10^{-4}$ & $6.96 \times 10^{-4}$ & $1.63 \times 10^{-3}$ & $3.70 \times 10^{-5}$ & $2.06 \times 10^{-4}$ & $1.27 \times 10^{-3}$ \\
\hline WQSP-6 & $-3.82 \times 10^{-4}$ & $6.32 \times 10^{-3}$ & $1.48 \times 10^{-2}$ & $-6.66 \times 10^{-4}$ & $1.03 \times 10^{-3}$ & $1.53 \times 10^{-3}$ & $2.22 \times 10^{-4}$ & $6.22 \times 10^{-4}$ & $1.57 \times 10^{-3}$ \\
\hline \multirow[t]{2}{*}{ WQSP-6A } & $.70 \times 10^{-3}$ & $4.65 \times 10^{-3}$ & $1.40 \times 10^{-2}$ & $1.73 \times 10^{-4}$ & $1.54 \times 10^{-4}$ & $2.49 \times 10^{-3}$ & $1.36 \times 10^{-4}$ & $2.35 \times 10^{-4}$ & $1.30 \times 10^{-3}$ \\
\hline & \multicolumn{9}{|c|}{1999} \\
\hline WQS & $-9.62 \times 10^{-4}$ & $1.26 \times 10^{-3}$ & $3.89 \times 10^{-3}$ & $1.46 \times 10^{-3}$ & $.14 \times 10^{-3}$ & $2.39 \times 10^{-3}$ & $-3.52 \times 10^{-4}$ & $7.06 \times 10^{-4}$ & $2.16 \times 10^{-3}$ \\
\hline WQSP & & $2.14 \times 10^{-3}$ & $4.74 \times 10^{-3}$ & $-7.22 \times 10^{-4}$ & $8.13 \times 10^{-4}$ & $2.42 \times 10^{-3}$ & $-1.70 \times 10^{-3}$ & $1.25 \times 10^{-3}$ & $4.29 \times 10^{-3}$ \\
\hline WQSP-3 & $5.00 \times 10^{-4}$ & $9.11 \times 10^{-4}$ & $2.37 \times 10^{-3}$ & $-2.22 \times 10^{-4}$ & $6.70 \times 10^{-4}$ & $2.02 \times 10^{-3}$ & $-1.11 \times 10^{-4}$ & $4.73 \times 10^{-4}$ & $1.44 \times 10^{-3}$ \\
\hline WQSP-4 & $8.14 \times 10^{-4}$ & $1.15 \times 10^{-3}$ & $3.24 \times 10^{-3}$ & $6.66 \times 10^{-4}$ & $1.33 \times 10^{-3}$ & $3.46 \times 10^{-3}$ & $3.33 \times 10^{-4}$ & $6.95 \times 10^{-4}$ & $1.79 \times 10^{-3}$ \\
\hline WQSP-5 & & $2.88 \times 10^{-3}$ & $6.29 \times 10^{-3}$ & $6.48 \times 10^{-4}$ & $2.09 \times 10^{-3}$ & $4.64 \times 10^{-3}$ & $1.67 \times 10^{-4}$ & $6.84 \times 10^{-4}$ & $2.44 \times 10^{-3}$ \\
\hline WQSP-6 & $4.81 \times 10^{-4}$ & $1.01 \times 10^{-3}$ & $2.52 \times 10^{-3}$ & $-2.22 \times 10^{-4}$ & $3.56 \times 10^{-4}$ & $1.70 \times 10^{-3}$ & $5.37 \times 10^{-4}$ & $7.75 \times 10^{-4}$ & $2.02 \times 10^{-3}$ \\
\hline WQSP-6A & $0.00 \times 10^{0}$ & $6.37 \times 10^{-4}$ & $2.02 \times 10^{-3}$ & $-5.00 \times 10^{-4}$ & $6.16 \times 10^{-4}$ & $2.00 \times 10^{-3}$ & $2.22 \times 10^{-4}$ & $6.30 \times 10^{-4}$ & $1.67 \times 10^{-3}$ \\
\hline
\end{tabular}

${ }^{1}$ Standard deviation of the mean

${ }^{2}$ Mean minimum detectable concentration among all samples from the indicated location

${ }^{3} \mathrm{Pu}-238$ was detected in a single sample from this well $\left(4.07 \times 10^{-3} \pm 2.04 \times 10^{-3} \mathrm{~Bq} / \mathrm{L} ; \mathrm{MDC}=2.30 \times 10^{-3} \mathrm{~Bq} / \mathrm{L}\right)$ 
Table 4.18 Reported concentrations $(\mathrm{Bq} / \mathrm{L})$ of ${ }^{238} \mathrm{Pu}$ and ${ }^{241} \mathrm{Am}$ in ground-water samples from 1997-1999.

\begin{tabular}{|c|c|c|c|c|}
\hline Well & Sample Date & Concentration & $2 \times$ TPU $^{1}$ & $\mathrm{MDC}^{2}$ \\
\hline \multicolumn{5}{|c|}{${ }^{238} \mathrm{Pu}$} \\
\hline WQSP-1 & April 1997 & $4.92 \times 10^{-3}$ & $2.15 \times 10^{-3}$ & $2.70 \times 10^{-3}$ \\
\hline WQSP-1 & March 1998 & $2.96 \times 10^{-3}$ & $1.48 \times 10^{-3}$ & $1.37 \times 10^{-3}$ \\
\hline WQSP-1 & March 1999 & $4.07 \times 10^{-3}$ & $2.04 \times 10^{-3}$ & $2.30 \times 10^{-3}$ \\
\hline WQSP-3 & May 1998 & $2.74 \times 10^{-3}$ & $2.07 \times 10^{-3}$ & $2.70 \times 10^{-3}$ \\
\hline WQSP-3 & September 1998 & $2.18 \times 10^{-3}$ & $1.26 \times 10^{-3}$ & $1.44 \times 10^{-3}$ \\
\hline WQSP-4 & May 1998 & $2.48 \times 10^{-3}$ & $1.29 \times 10^{-3}$ & $1.07 \times 10^{-3}$ \\
\hline \multicolumn{5}{|c|}{${ }^{241} \mathrm{Am}$} \\
\hline WQSP-3 & May 1998 & $4.40 \times 10^{-3}$ & $2.55 \times 10^{-3}$ & $2.92 \times 10^{-3}$ \\
\hline WQSP-4 & June 1997 & $1.59 \times 10^{-3}$ & $9.62 \times 10^{-4}$ & $1.04 \times 10^{-3}$ \\
\hline WQSP-4 & Mav 1998 & $2.33 \times 10^{-3}$ & $1.33 \times 10^{-3}$ & $1.59 \times 10^{-3}$ \\
\hline
\end{tabular}

${ }^{\mathrm{T}}$ Total propagated uncertainty

${ }^{2}$ Minimum detectable concentration

In 1995, wells WQSP-1 through WQSP-6A were sampled and analyzed for ${ }^{226} \mathrm{Ra}$ and the results were published in the 1995 Annual Site Environmental Report. The results indicated that WQSP-4 had the highest activity of ${ }^{226} \mathrm{Ra}(9.1 \pm$ $0.07 \mathrm{~Bq} / \mathrm{L})$, WQSP-3 the second highest $(7.8 \pm$ $0.06 \mathrm{~Bq} / \mathrm{L})$, and WQSP-1 the third highest $(6.0 \pm$ $0.06 \mathrm{~Bq} / \mathrm{L})$. One decay product of ${ }^{226} \mathrm{Ra},{ }^{222} \mathrm{Rn}$, emits alpha particles with an energy of 5.489 $\mathrm{MeV}$. Americium-241 alpha energy is at 5.486 $\mathrm{MeV}$ and ${ }^{238} \mathrm{Pu}$ alpha energy is detected at 5.499 $\mathrm{MeV}$. (Only the most abundant energies are listed here). Because these energies are close, the region of interest in the alpha spectrum from the samples mentioned in Table 4.18 likely contained counts originating from ${ }^{222} \mathrm{Rn}$ that were identified as ${ }^{238} \mathrm{Pu}$ or ${ }^{241} \mathrm{Am}$. Additional ${ }^{226} \mathrm{Ra}$ progeny were also likely present. The solubility of the components can vary causing the ${ }^{222} \mathrm{Rn}$ activity and associated ${ }^{226} \mathrm{Ra}$ progeny to appear in some analyses, but not all. This phenomenon may explain the trend of seemingly high concentrations of ${ }^{238} \mathrm{Pu}$ and ${ }^{241} \mathrm{Am}$ observed in some ground-water samples over time.

WIPP will take the following actions to investigate this naturally occurring phenomena.

- $\quad$ The data validator will be required to identify the ${ }^{226} \mathrm{Ra}$ progeny on the alpha spectrum and note them properly. If only plutonium or americium contamination is present, the ${ }^{226} \mathrm{Ra}$ progeny (located at higher energy regions) will not be present.

- WIPP will request the laboratory to analyze for ${ }^{226} \mathrm{Ra}$ to confirm the 1995 published results. This analysis will begin with sampling round 11 due to begin in September 2000 and end in November 2000. Based on that information, WIPP will request the laboratory to perform an extra clean-up on the samples to eliminate the contribution of ${ }^{226} \mathrm{Ra}$ and progeny to the alpha spectrum.

The results of the measurements of ${ }^{40} \mathrm{~K},{ }^{60} \mathrm{Co}$, ${ }^{90} \mathrm{Sr}$, and ${ }^{137} \mathrm{Cs}$ were only reported by the laboratory for the autumn sampling (Table 4.19). Strontium-90 was detectable in well WQSP-2, albeit with a large TPU, and ${ }^{40} \mathrm{~K}$ was detected in wells WQSP-4 and WQSP-5. All other concentrations for all four radionuclides were below the MDC.

EEG also measured ground water for ${ }^{238} \mathrm{Pu}$, ${ }^{239+240} \mathrm{Pu},{ }^{90} \mathrm{Sr}$, and ${ }^{137} \mathrm{Cs}$ (Table 4.20). There was no statistically significant difference between the mean concentrations of ${ }^{238} \mathrm{Pu}$ (paired t-test, $\mathrm{p}=0.86)$ or ${ }^{239+240} \mathrm{Pu}(\mathrm{p}=0.11)$ measured by WID and EEG. No other radionuclides were detected by EEG in any sample. 
Table 4.19 Gamma-emitters and ${ }^{90} \mathrm{Sr}$ in ground water (Bq/L).

\begin{tabular}{|c|c|c|c|c|c|c|}
\hline Location & Concentration & $2 \times$ TPU $^{1}$ & MDC $^{2}$ & Concentration & $2 \times \mathrm{TPU}$ & MDC \\
\hline & \multicolumn{3}{|c|}{${ }^{40} \mathbf{K}$} & \multicolumn{3}{|c|}{${ }^{60} \mathrm{Co}$} \\
\hline WQSP-1 & $\mathrm{NR}^{3}$ & NR & $1.37 \times 10^{1}$ & NR & NR & $5.92 \times 10^{-1}$ \\
\hline WQSP-2 & NR & NR & $1.37 \times 10^{1}$ & NR & NR & $5.92 \times 10^{-1}$ \\
\hline WQSP-3 & NR & NR & $1.67 \times 10^{1}$ & NR & NR & $5.92 \times 10^{-1}$ \\
\hline WQSP-4 & $2.96 \times 10^{1}$ & $4.44 \times 10^{0}$ & $3.00 \times 10^{0}$ & NR & NR & $2.70 \times 10^{-1}$ \\
\hline WQSP-5 & $8.51 \times 10^{0}$ & $4.44 \times 10^{0}$ & $5.92 \times 10^{0}$ & NR & NR & $2.41 \times 10^{-1}$ \\
\hline WQSP-6 & $3.26 \times 10^{0}$ & $1.26 \times 10^{1}$ & $1.85 \times 10^{1}$ & NR & NR & $4.44 \times 10^{-1}$ \\
\hline \multirow[t]{2}{*}{ WQSP-6A } & $4.81 \times 10^{0}$ & $1.18 \times 10^{1}$ & $1.63 \times 10^{1}$ & NR & NR & $4.44 \times 10^{-1}$ \\
\hline & \multicolumn{3}{|c|}{${ }^{90} \mathrm{Sr}$} & \multicolumn{3}{|c|}{${ }^{137} \mathrm{Cs}$} \\
\hline WQSP-1 & $9.99 \times 10^{-3}$ & $3.44 \times 10^{-2}$ & $5.55 \times 10^{-2}$ & NR & NR & $6.29 \times 10^{-1}$ \\
\hline WQSP-2 & $2.44 \times 10^{-1}$ & $1.22 \times 10^{-1}$ & $1.63 \times 10^{-1}$ & NR & NR & $6.29 \times 10^{-1}$ \\
\hline WQSP-3 & $5.18 \times 10^{-2}$ & $5.18 \times 10^{-2}$ & $7.77 \times 10^{-2}$ & NR & NR & $6.29 \times 10^{-1}$ \\
\hline WQSP-4 & $2.44 \times 10^{-2}$ & $3.00 \times 10^{-2}$ & $4.81 \times 10^{-2}$ & NR & NR & $2.04 \times 10^{-1}$ \\
\hline WQSP-5 & $5.18 \times 10^{-2}$ & $4.07 \times 10^{-2}$ & $6.29 \times 10^{-2}$ & NR & NR & $1.92 \times 10^{-1}$ \\
\hline WQSP-6 & $-7.40 \times 10^{-5}$ & $3.37 \times 10^{-2}$ & $5.18 \times 10^{-2}$ & $3.18 \times 10^{-1}$ & $5.92 \times 10^{-1}$ & $9.25 \times 10^{-1}$ \\
\hline WQSP-6A & $-3.70 \times 10^{-3}$ & $2.66 \times 10^{-2}$ & $4.07 \times 10^{-2}$ & $1.59 \times 10^{-1}$ & $5.55 \times 10^{-1}$ & $8.88 \times 10^{-1}$ \\
\hline
\end{tabular}

${ }^{\mathrm{I}}$ Total propagated uncertainty. Only the autumn sampling data were reported for these radionuclides.

${ }^{2}$ Minimum detectable concentration

${ }^{3}$ No data reported.

Table 4.20 Radionuclide concentrations $(\mathrm{Bq} / \mathrm{L})$ measured by $E E G^{1}$ in ground water.

\begin{tabular}{|c|c|c|c|c|c|c|c|c|}
\hline \multirow[b]{2}{*}{ Well } & \multicolumn{2}{|c|}{${ }^{238} \mathbf{P u}$} & \multicolumn{2}{|c|}{${ }^{239+240} \mathrm{Pu}$} & \multicolumn{2}{|l|}{${ }^{90} \mathrm{Sr}$} & \multicolumn{2}{|l|}{${ }^{137} \mathrm{Cs}$} \\
\hline & Concentration & $2 \times \mathrm{TPU}^{1}$ & Concentration & $2 \times$ TPU & Concentration & $2 \times$ TPU & Concentration & $2 \times \mathrm{TPU}$ \\
\hline WQSP-1 & $\mathrm{NR}^{2}$ & NR & $1.09 \times 10^{-4}$ & $8.14 \times 10^{-4}$ & $3.51 \times 10^{-2}$ & $3.62 \times 10^{-2}$ & $-1.18 \times 10^{-1}$ & $1.56 \times 10^{-1}$ \\
\hline WQSP-2 & NR & NR & $-1.48 \times 10^{-4}$ & $7.52 \times 10^{-4}$ & $1.20 \times 10^{-2}$ & $4.52 \times 10^{-2}$ & $-5.25 \times 10^{-2}$ & $1.52 \times 10^{-1}$ \\
\hline WQSP-3 & $-1.47 \times 10^{-4}$ & $1.34 \times 10^{-3}$ & $9.59 \times 10^{-4}$ & $1.48 \times 10^{-3}$ & $2.02 \times 10^{-2}$ & $3.26 \times 10^{-2}$ & $-5.86 \times 10^{-2}$ & $1.60 \times 10^{-1}$ \\
\hline WQSP-4 & $-2.45 \times 10^{-4}$ & $8.82 \times 10^{-4}$ & $9.09 \times 10^{-4}$ & $8.50 \times 10^{-4}$ & $6.60 \times 10^{-3}$ & $3.01 \times 10^{-2}$ & $1.13 \times 10^{-2}$ & $1.63 \times 10^{-1}$ \\
\hline WQSP-5 & NR & NR & $-6.70 \times 10^{-5}$ & $7.44 \times 10^{-4}$ & $2.40 \times 10^{-3}$ & $3.75 \times 10^{-2}$ & $1.11 \times 10^{-2}$ & $1.54 \times 10^{-1}$ \\
\hline WQSP-6 & $1.25 \times 10^{-3}$ & $1.05 \times 10^{-3}$ & $3.03 \times 10^{-4}$ & $8.01 \times 10^{-4}$ & $-1.05 \times 10^{-4}$ & $4.67 \times 10^{-2}$ & $1.18 \times 10^{-2}$ & $1.49 \times 10^{-1}$ \\
\hline WQSP-6A & $-2.45 \times 10^{-4}$ & $8.82 \times 10^{-4}$ & $3.17 \times 10^{-4}$ & $8.50 \times 10^{-4}$ & $-1.38 \times 10^{-2}$ & $1.04 \times 10^{-1}$ & $-5.02 \times 10^{-2}$ & $1.56 \times 10^{-1}$ \\
\hline
\end{tabular}

\subsection{Surface Water}

\subsubsection{Sample Collection}

Twelve different locations around the WIPP site, as shown in Figure 4.4, were identified for collecting the surface water samples (see Appendix B for location codes). Samples were collected once in 1999 . If the surface water collection location was dry, sediment was collected. These results are described in Section 4.6. Sampling sites BHT and LST were not sampled in 1999 because they were dry.

Water from the sampling location was used to rinse $3.78-\mathrm{L}$ (1-gal) polyethylene containers several times. Approximately $3.78 \mathrm{~L}$ (1-gal) of water was collected from each of locations. The samples were acidified immediately after collection with concentrated nitric acid to $\mathrm{pH} \leq 2$. Later, the samples were shipped to the contract laboratory for analysis. Chain of custody was maintained throughout the process.

\subsubsection{Determination of Individual Radio- nuclides}

Gamma-spectrometry was used for the determination of ${ }^{40} \mathrm{~K},{ }^{60} \mathrm{Co}$, and ${ }^{137} \mathrm{Cs}$. Strontium-90, a beta-emitting radionuclide, was determined by separating it from the sample and beta counting. Uranium, plutonium, and americium were determined by alpha spectrometry. These alpha-emitting radionuclides 


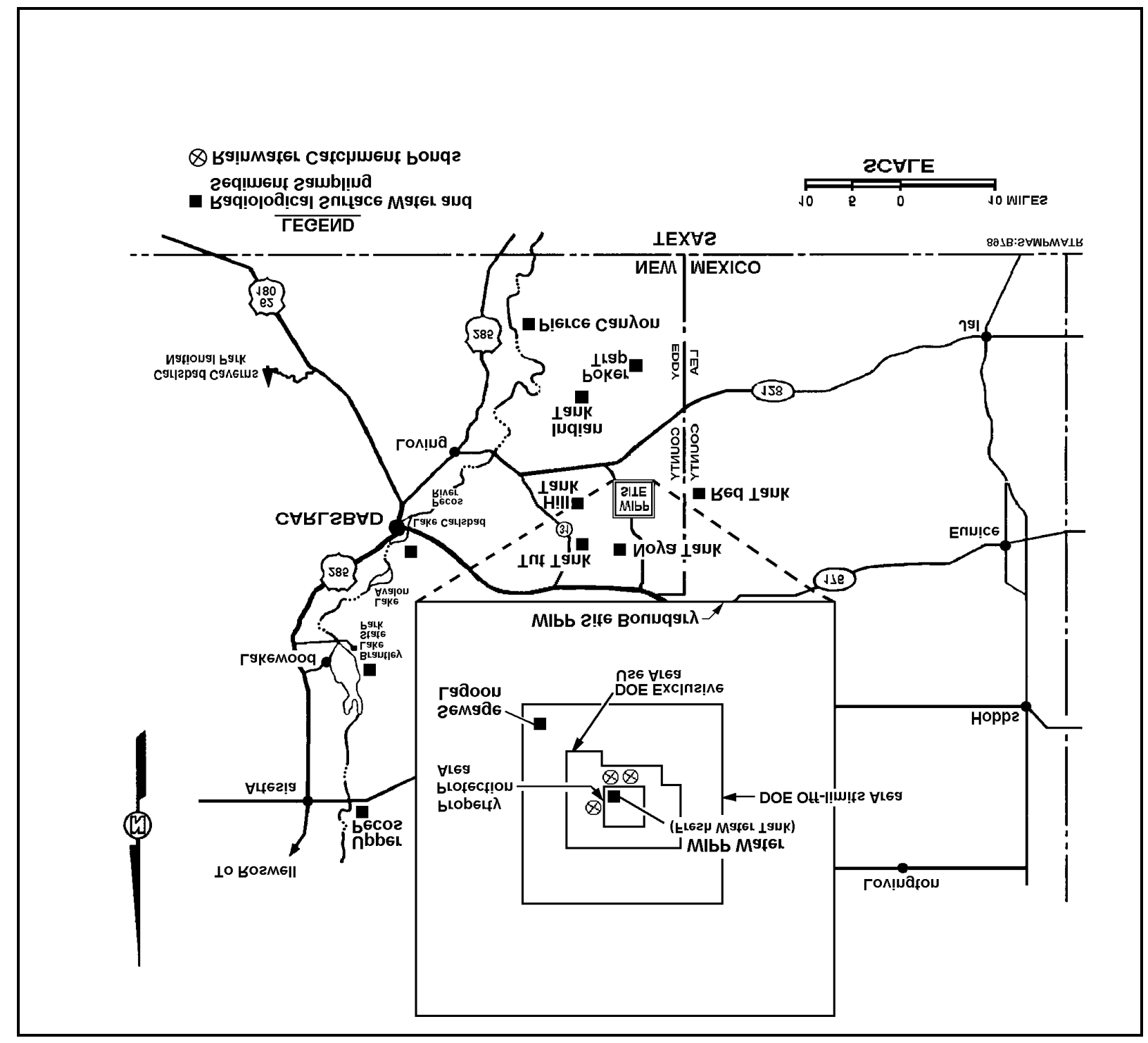

Figure 4.4 Surface Water Sampling Locations in 1999

were separated from the bulk of water samples by co-precipitation with iron carrier. Ion-exchange chromatography was used for the separation of individual radionuclides. Finally, the samples were counted by alpha spectrometry.

\subsubsection{Results and Discussions}

Uranium-238 was detected in surface water at every sampling location (Table 4.21). It was lowest at SWL $\left(2.63 \times 10^{-3} \pm 1.44 \times 10^{-3} \mathrm{~Bq} / \mathrm{L}\right.$ $\left.\left[7.11 \times 10^{-2} \pm 3.89 \times 10^{-2} \mathrm{pCi} / \mathrm{L}\right]\right)$ and highest at $\mathrm{PCN}$ $\left(8.51 \times 10^{-2} \pm 1.11 \times 10^{-2} \mathrm{~Bq} / \mathrm{L}\left[2.30 \times 10^{0} \pm 3.00 \times 10^{-1}\right.\right.$ $\mathrm{pCi} / \mathrm{L}])$. Uranium-235 was detected in 42 percent of the sampling locations. Concentrations ranged from $-6.66 \times 10^{-4} \pm 1.30 \times 10^{-3} \mathrm{~Bq} / \mathrm{L}\left(-1.80 \times 10^{-2} \pm\right.$ $\left.3.51 \times 10^{-2} \mathrm{pCi} / \mathrm{L}\right)$ at TUT to $3.03 \times 10^{-3} \pm 1.52 \times 10^{-3}$ $\mathrm{Bq} / \mathrm{L}\left(8.19 \times 10^{-2} \pm 4.11 \times 10^{-2} \mathrm{pCi} / \mathrm{L}\right)$ at $\mathrm{PCN}$. Concentrations of ${ }^{233+234} \mathrm{U}$ ranged from $-6.66 \times 10^{-4}$ $\pm 4.07 \times 10^{-3} \mathrm{~Bq} / \mathrm{L}\left(-1.8 \times 10^{-2} \pm 1.10 \times 10^{-1} \mathrm{pCi} / \mathrm{L}\right)$ at TUT to $1.59 \times 10^{-1} \pm 1.81 \times 10^{-2} \mathrm{~Bq} / \mathrm{L}\left(4.30 \times 10^{0} \pm\right.$ $\left.4.89 \times 10^{-1} \mathrm{pCi} / \mathrm{L}\right)$ at $\mathrm{PCN}$. It was detected in 83 percent of the samples.

Analysis of variance was used to test for differences in uranium concentration between sampling locations. Differences were detected for each uranium isotope $\left({ }^{233+234} \mathrm{U},{ }^{235} \mathrm{U} \mathrm{p}=0.001 ;{ }^{238} \mathrm{U}\right.$ 
$\mathrm{p}<0.001)$. Large spatial variations in uranium concentration in surface water are expected because of the different characteristics of the water bodies and the underlying sediments. For example, the PCN site drains a large surface area and leaches uranium from the sediments. The TUT tank is mostly rainwater and has little contact with sediments.

In 1998, significant differences in uranium concentrations were observed between sampling locations along the Pecos River. These were explained as resulting from different concentrations of suspended sediments due to different water speeds. No significant differences were observed in 1999 (ANOVA, ${ }^{233+234} \mathrm{U}$ $\mathrm{p}=0.193,{ }^{235} \mathrm{U} \mathrm{p}=0.472,{ }^{238} \mathrm{U} \mathrm{p}=0.150$ ). This may be due to natural variability in uranium concentrations and several years' data may be required to establish any trend.

Results for uranium concentrations in 1999 samples were compared with the uranium concentrations in 1998 samples (Table 4.21). There was no significant difference in the concentration of any uranium isotope between 1998 and 1999 (ANOVA, ${ }^{233+234} \mathrm{U} \mathrm{p}=0.0 .375,{ }^{235} \mathrm{U}$ $\left.\mathrm{p}=0.440,{ }^{238} \mathrm{U} \mathrm{p}=0.372\right)$.

Plutonium-238, ${ }^{239+240} \mathrm{Pu}$, and ${ }^{241} \mathrm{Am}$ were also measured in these water samples (Table 4.22).
For all these radionuclides, measured concentrations were below the MDC. In 1998, location IDN had detectable concentrations of ${ }^{238} \mathrm{Pu}$ and ${ }^{241} \mathrm{Am}$ in surface waters.

While ${ }^{40} \mathrm{~K},{ }^{60} \mathrm{Co},{ }^{90} \mathrm{Sr}$, and ${ }^{137} \mathrm{Cs}$ are ubiquitous in soils and might reasonably be expected in surface water samples due to leaching from sediments, none of them were detected in surface waters in 1999 (Table 4.23).

Duplicate samples were collected from one location (RED) to check the reproducibility of the sampling and the measurement techniques. Because the concentrations of all the radionuclides except uranium were nondetectable in the water samples, only the results for the uranium isotopes were compared between original and duplicate samples (Table 4.24). The RER values for uranium isotopes in these samples were all less than one, indicating no difference between duplicate samples.

EEG also measured the concentrations of ${ }^{238} \mathrm{Pu},{ }^{239+240} \mathrm{Pu},{ }^{241} \mathrm{Am},{ }^{137} \mathrm{Cs}$, and ${ }^{90} \mathrm{Sr}$ in surface water samples collected from around the WIPP site (Table 4.25). Similar to the WID results, none of the target radionuclides were detected by EEG. 


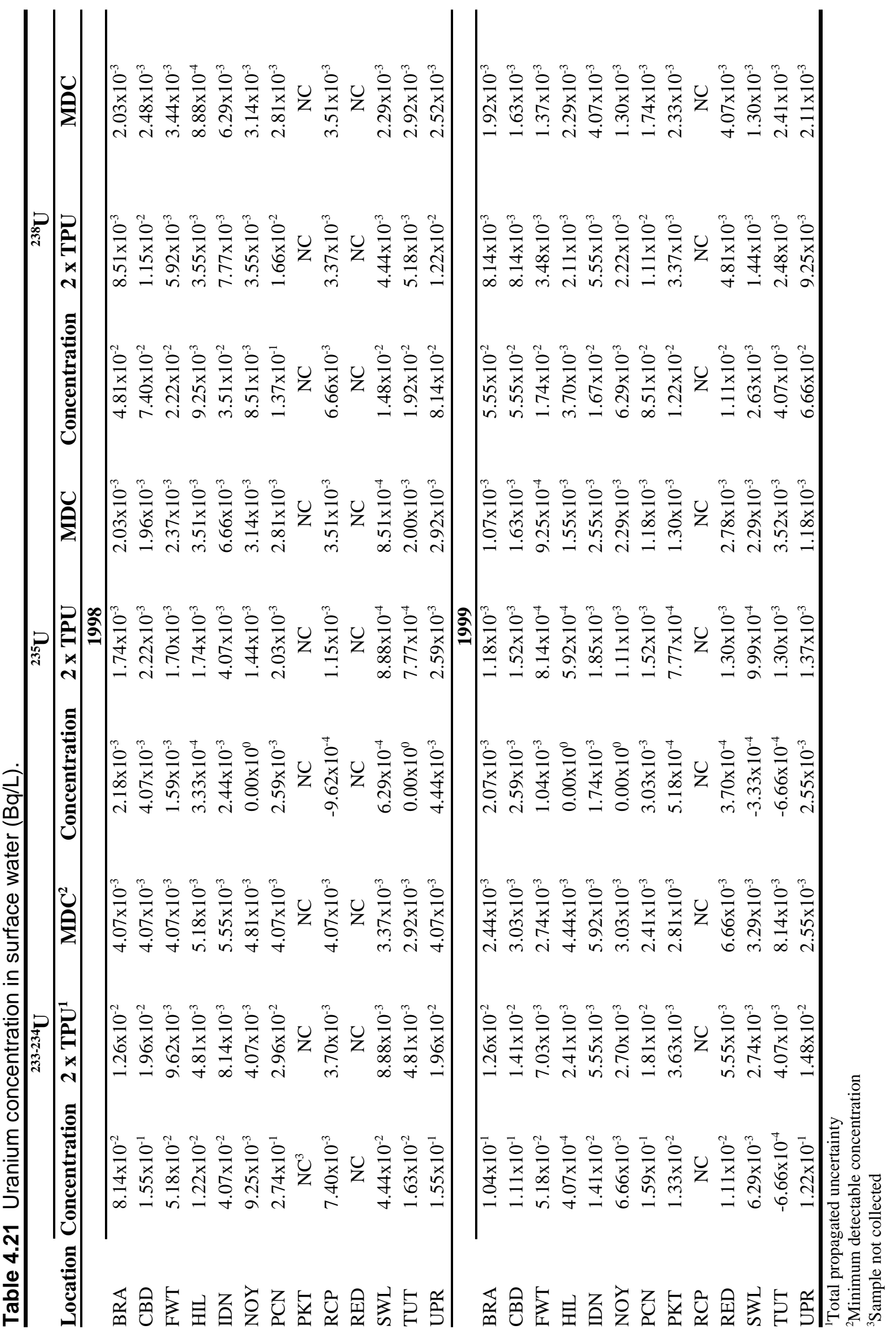




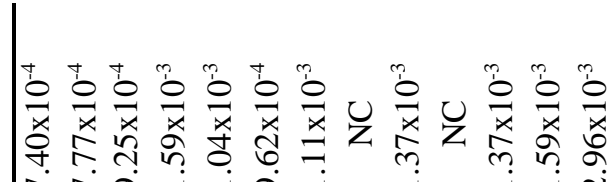

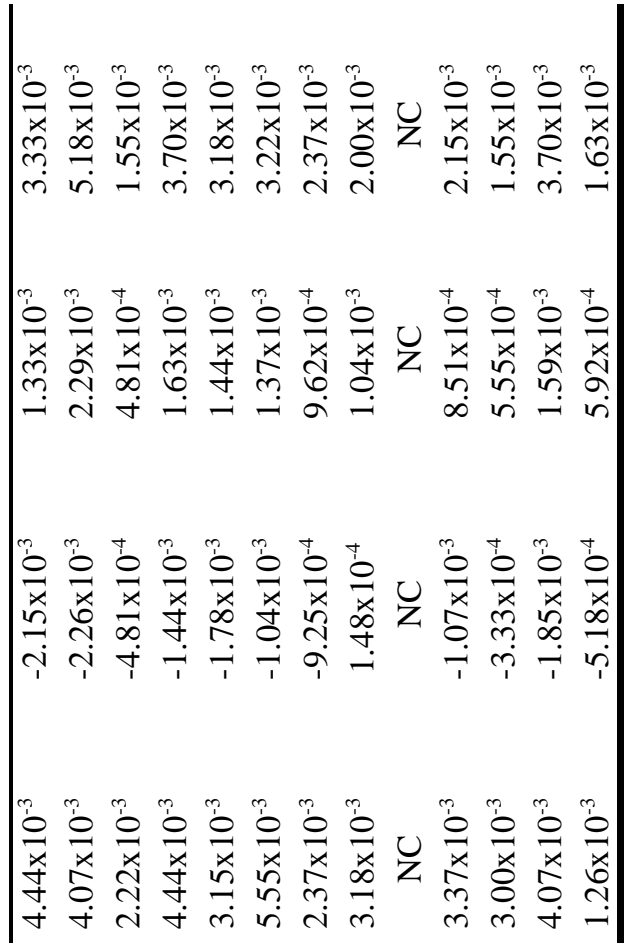

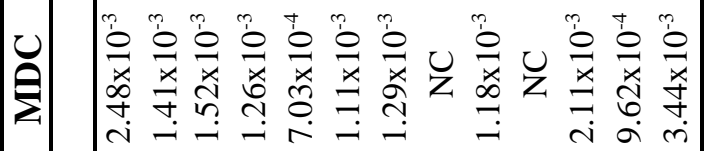

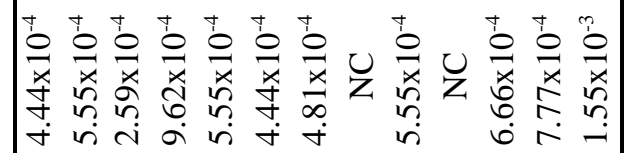

(n)

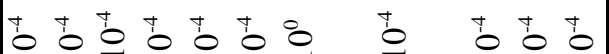

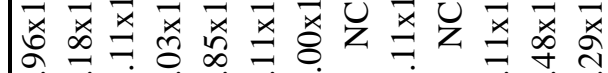

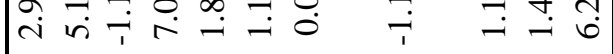

Q

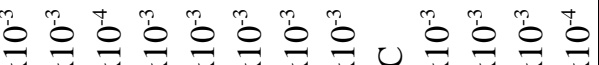

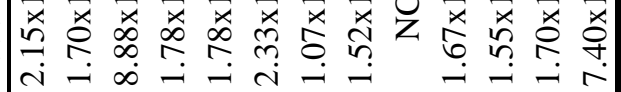

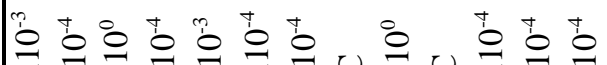

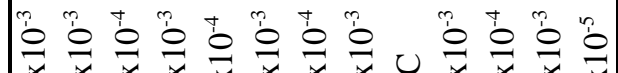

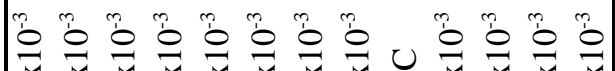

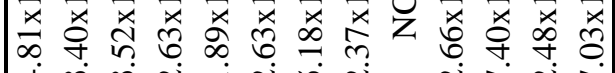

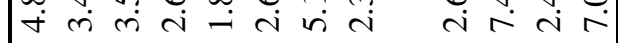

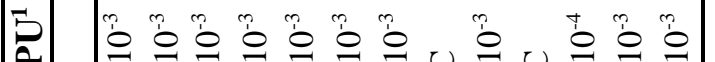

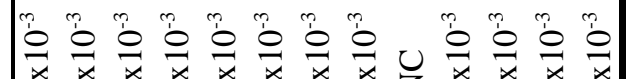

t) i c

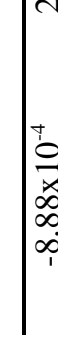


Table 4.23 Surface water concentration $(\mathrm{Bq} / \mathrm{L})$ of gamma emitters.

\begin{tabular}{|c|c|c|c|c|c|c|}
\hline Location & Concentration & $2 \times$ TPU $^{1}$ & $\mathrm{MDC}^{2}$ & Concentration & $2 \times \mathrm{TPU}$ & MDC \\
\hline & \multicolumn{3}{|c|}{${ }^{40} K$} & \multicolumn{3}{|c|}{${ }^{60} \mathrm{Co}$} \\
\hline BRA & $\mathrm{NR}^{3}$ & NR & $3.70 \times 10^{0}$ & NR & NR & $2.37 \times 10^{-1}$ \\
\hline CBD & NR & NR & $3.70 \times 10^{0}$ & NR & NR & $2.26 \times 10^{-1}$ \\
\hline FWT & NR & NR & $3.70 \times 10^{0}$ & NR & NR & $2.29 \times 10^{-1}$ \\
\hline HIL & NR & NR & $3.52 \times 10^{0}$ & NR & NR & $2.37 \times 10^{-1}$ \\
\hline IDN & NR & NR & $4.07 \times 10^{0}$ & NR & NR & $2.52 \times 10^{-1}$ \\
\hline NOY & NR & NR & $3.70 \times 10^{0}$ & NR & NR & $2.41 \times 10^{-1}$ \\
\hline $\mathrm{PCN}$ & NR & NR & $4.07 \times 10^{0}$ & NR & NR & $2.63 \times 10^{-1}$ \\
\hline PKT & NR & NR & $3.70 \times 10^{0}$ & NR & NR & $2.48 \times 10^{-1}$ \\
\hline RED & $6.29 \times 10^{-1}$ & $4.81 \times 10^{0}$ & $7.77 \times 10^{0}$ & NR & NR & $2.41 \times 10^{-1}$ \\
\hline SWL & $1.15 \times 10^{0}$ & $4.07 \times 10^{0}$ & $5.92 \times 10^{0}$ & NR & NR & $2.41 \times 10^{-1}$ \\
\hline TUT & $1.63 \times 10^{0}$ & $4.07 \times 10^{0}$ & $6.29 \times 10^{0}$ & NR & NR & $2.22 \times 10^{-1}$ \\
\hline \multirow[t]{2}{*}{ UPR } & NR & NR & $3.70 \times 10^{0}$ & NR & NR & $2.44 \times 10^{-1}$ \\
\hline & \multicolumn{3}{|c|}{${ }^{90} \mathrm{Sr}$} & \multicolumn{3}{|c|}{${ }^{137} \mathrm{Cs}$} \\
\hline BRA & $1.26 \times 10^{-1}$ & $1.55 \times 10^{-1}$ & $2.33 \times 10^{-1}$ & $1.15 \times 10^{-1}$ & $1.74 \times 10^{-1}$ & $2.66 \times 10^{-1}$ \\
\hline CBD & $1.07 \times 10^{-1}$ & $1.26 \times 10^{-1}$ & $1.96 \times 10^{-1}$ & NR & NR & $1.89 \times 10^{-1}$ \\
\hline FWT & $2.78 \times 10^{-2}$ & $3.70 \times 10^{-2}$ & $5.92 \times 10^{-2}$ & NR & NR & $1.96 \times 10^{-1}$ \\
\hline HIL & $3.48 \times 10^{-2}$ & $3.07 \times 10^{-2}$ & $4.44 \times 10^{-2}$ & NR & NR & $1.85 \times 10^{-1}$ \\
\hline IDN & $3.59 \times 10^{-2}$ & $2.89 \times 10^{-2}$ & $4.44 \times 10^{-2}$ & NR & NR & $1.96 \times 10^{-1}$ \\
\hline NOY & $4.07 \times 10^{-2}$ & $2.92 \times 10^{-2}$ & $4.44 \times 10^{-2}$ & NR & NR & $1.96 \times 10^{-1}$ \\
\hline $\mathrm{PCN}$ & $1.41 \times 10^{-2}$ & $7.40 \times 10^{-2}$ & $1.18 \times 10^{-1}$ & $2.18 \times 10^{-1}$ & $2.22 \times 10^{-1}$ & $3.29 \times 10^{-1}$ \\
\hline PKT & $3.33 \times 10^{-2}$ & $2.81 \times 10^{-2}$ & $4.44 \times 10^{-2}$ & $1.26 \times 10^{-1}$ & $1.59 \times 10^{-1}$ & $2.41 \times 10^{-1}$ \\
\hline RED & $2.66 \times 10^{-2}$ & $2.63 \times 10^{-2}$ & $4.07 \times 10^{-2}$ & NR & NR & $2.00 \times 10^{-1}$ \\
\hline SWL & $1.29 \times 10^{-2}$ & $2.92 \times 10^{-2}$ & $4.81 \times 10^{-2}$ & NR & NR & $1.81 \times 10^{-1}$ \\
\hline TUT & $1.29 \times 10^{-2}$ & $2.48 \times 10^{-2}$ & $4.07 \times 10^{-2}$ & NR & NR & $1.92 \times 10^{-1}$ \\
\hline UPR & $4.81 \times 10^{-2}$ & $8.51 \times 10^{-2}$ & $1.30 \times 10^{-1}$ & NR & NR & $2.00 \times 10^{-1}$ \\
\hline
\end{tabular}

${ }^{1}$ Total propagated uncertainty

${ }^{2}$ Minimum detectable concentration

${ }^{3}$ Not reported

Table 4.24 Results of duplicate surface water sample analyses. Units are Bq/L.

\begin{tabular}{lccc}
\hline Location & Concentration & $\mathbf{2} \mathbf{x}$ TPU & MDC $^{\mathbf{2}}$ \\
\cline { 2 - 4 } RED (Original) & & ${ }^{\mathbf{2 3 3 + 2 3 4} \mathbf{U}}$ & $6.66 \mathrm{E}-03$ \\
RED (Duplicate) & $1.11 \mathrm{E}-02$ & $5.55 \mathrm{E}-03$ & $4.07 \mathrm{E}-03$ \\
\hline & $8.88 \mathrm{E}-03$ & $3.37 \mathrm{E}-03$ & $2.78 \mathrm{E}-03$ \\
RED (Original) & $3.70 \mathrm{E}-04$ & $1.30 \mathrm{E}-03$ & $1.70 \mathrm{E}-03$ \\
\hline RED (Duplicate) & $6.29 \mathrm{E}-04$ & $9.99 \mathrm{E}-04$ & $4.07 \mathrm{E}-03$ \\
& & ${ }^{\mathbf{2 3 8}} \mathbf{U}$ & $4.44 \mathrm{E}-04$ \\
\hline
\end{tabular}

${ }^{1}$ Total propagated uncertainty

${ }^{2}$ Minimum detectable concentration 
Table 4.25 Concentration $(\mathrm{Bq} / \mathrm{L})$ of radionuclides measured by $E E \mathrm{G}^{1}$ in surface water.

\begin{tabular}{|c|c|c|c|c|c|c|}
\hline Location & Concentration & $2 \times \mathrm{TPU}^{1}$ & Concentration & $2 \times$ TPU & Concentration & $2 \times$ TPU \\
\hline & \multicolumn{2}{|c|}{${ }^{241} \mathrm{Am}$} & \multicolumn{2}{|c|}{${ }^{239+240} \mathrm{Pu}$} & \multicolumn{2}{|l|}{${ }^{238} \mathrm{Pu}$} \\
\hline CBD & $-2.52 \times 10^{-4}$ & $1.24 \times 10^{-3}$ & $7.00 \times 10^{-5}$ & $7.71 \times 10^{-4}$ & $-1.16 \times 10^{-4}$ & $8.51 \times 10^{-4}$ \\
\hline HIL & $-7.30 \times 10^{-4}$ & $1.22 \times 10^{-3}$ & $-1.93 \times 10^{-4}$ & $7.55 \times 10^{-4}$ & $-1.11 \times 10^{-4}$ & $8.81 \times 10^{-4}$ \\
\hline IDN & $4.59 \times 10^{-4}$ & $1.30 \times 10^{-3}$ & $1.29 \times 10^{-4}$ & $8.29 \times 10^{-4}$ & $-4.84 \times 10^{-4}$ & $8.54 \times 10^{-4}$ \\
\hline $\mathrm{LAG}^{3}$ & $1.67 \times 10^{-3}$ & $3.68 \times 10^{-3}$ & $2.31 \times 10^{-4}$ & $1.63 \times 10^{-3}$ & $-7.93 \times 10^{-5}$ & $2.10 \times 10^{-3}$ \\
\hline NOY & $-8.82 \times 10^{-4}$ & $1.09 \times 10^{-3}$ & $-1.05 \times 10^{-4}$ & $7.46 \times 10^{-4}$ & $-1.09 \times 10^{-4}$ & $8.59 \times 10^{-4}$ \\
\hline PCN & $6.04 \times 10^{-6}$ & $1.21 \times 10^{-3}$ & $-1.87 \times 10^{-4}$ & $7.51 \times 10^{-4}$ & $1.87 \times 10^{-5}$ & $9.06 \times 10^{-4}$ \\
\hline RED & $2.79 \times 10^{-4}$ & $1.30 \times 10^{-3}$ & $1.55 \times 10^{-4}$ & $8.15 \times 10^{-4}$ & $-3.83 \times 10^{-5}$ & $9.06 \times 10^{-4}$ \\
\hline \multirow[t]{2}{*}{ SWL } & $-3.99 \times 10^{-4}$ & $1.15 \times 10^{-3}$ & $1.65 \times 10^{-4}$ & $7.95 \times 10^{-4}$ & $-2.42 \times 10^{-4}$ & $8.40 \times 10^{-4}$ \\
\hline & \multicolumn{2}{|l|}{${ }^{137} \mathrm{Cs}$} & \multicolumn{2}{|l|}{${ }^{90} \mathrm{Sr}$} & & \\
\hline CBD & $8.53 \times 10^{-3}$ & $1.48 \times 10^{-1}$ & $-3.00 \times 10^{-3}$ & $2.95 \times 10^{-2}$ & & \\
\hline HIL & $1.42 \times 10^{-2}$ & $1.51 \times 10^{-1}$ & $-8.90 \times 10^{-3}$ & $2.63 \times 10^{-2}$ & & \\
\hline IDN & $-7.65 \times 10^{-2}$ & $1.50 \times 10^{-1}$ & $1.36 \times 10^{-2}$ & $8.29 \times 10^{-2}$ & & \\
\hline LAG & $3.22 \times 10^{-2}$ & $1.86 \times 10^{-1}$ & $3.69 \times 10^{-2}$ & $1.02 \times 10^{-1}$ & & \\
\hline NOY & $-3.28 \times 10^{-2}$ & $1.49 \times 10^{-1}$ & $-3.90 \times 10^{-3}$ & $2.52 \times 10^{-2}$ & & \\
\hline PCN & $-6.73 \times 10^{-2}$ & $1.50 \times 10^{-1}$ & $-6.90 \times 10^{-3}$ & $2.63 \times 10^{-2}$ & & \\
\hline RED & $3.72 \times 10^{-2}$ & $1.48 \times 10^{-1}$ & $-4.20 \times 10^{-3}$ & $2.60 \times 10^{-2}$ & & \\
\hline SWL & $3.43 \times 10^{-3}$ & $1.50 \times 10^{-1}$ & $-6.30 \times 10^{-3}$ & $2.50 \times 10^{-2}$ & & \\
\hline
\end{tabular}

${ }^{1}$ Environmental Evaluation Group

${ }^{2}$ Total propagated uncertainty

${ }^{2}$ Laguna Grande

\subsection{Soil Samples}

\subsubsection{Sampling}

Soil samples were collected from near the low-volume air samplers at six different locations around the WIPP site; MLR, SEC, SMR, WEE, WFF, and WSS (Figure 4.5; Appendix B). Samples were collected from each location in three incremental profiles: surface soil (SS, 0-2 $\mathrm{cm}$ [0-0.8 in]), intermediate soil (SI, 2-5 cm [0.8-2 in]), and deep soil (SD, 5-10 $\mathrm{cm}$ [2-4 in ]). Measurements of radionuclides in depth profiles provide information about their vertical movements in the soil systems.

\subsubsection{Sample Preparation}

Soil samples were dried at $110^{\circ} \mathrm{C}\left(230^{\circ} \mathrm{F}\right)$ for several hours and homogenized by grinding to small particle sizes. One gram $(0.04 \mathrm{oz})$ of soil was dissolved by heating it with a mixture of nitric, hydrochloric, and hydrofluoric acids. Finally, it was heated with nitric and boric acids, and the residue was dissolved in hydrochloric acid for the determination of individual radionuclides.

\subsubsection{Determination of Individual Radio- nuclides}

Gamma-emitting radionuclides $\left({ }^{40} \mathrm{~K},{ }^{60} \mathrm{Co}\right.$, and ${ }^{137} \mathrm{Cs}$ ) were determined by counting an aliquot of well-homogenized ground soil samples by gamma-spectrometry. Strontium-90 was determined from an aliquot of the sample solution by separating it from other stable and radioactive elements using radiochemical techniques and beta counting. Another aliquot of the sample solution was used for the sequential determinations of alpha-emitting radionuclides, such as ${ }^{233+234} \mathrm{U}$, ${ }^{235} \mathrm{U}$, and ${ }^{238} \mathrm{U} ;{ }^{238} \mathrm{Pu}$ and ${ }^{239+240} \mathrm{Pu}$; and ${ }^{241} \mathrm{Am}$. These radionuclides were separated from the bulk of the inorganic materials present in the soil samples and from one another by radiochemical separations including co-precipitation and ion-exchange chromatography. Finally, they were micro-precipitated, filtered onto micro-filters, and counted alpha spectrometrically. 


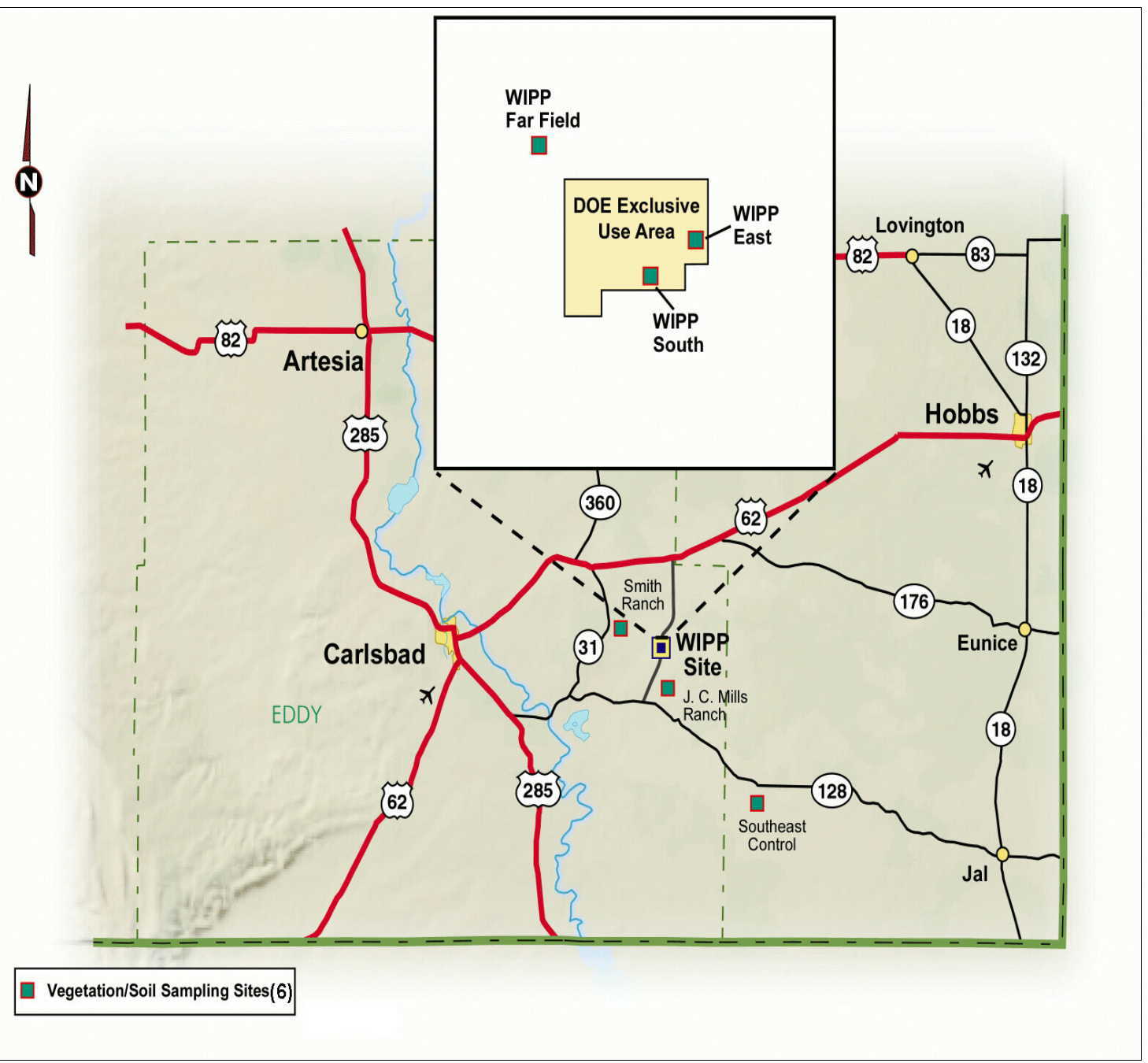

Figure 4.5 Soil and Vegetation Sampling Locations

\subsubsection{Results and Discussions}

Uranium-233+234 was detected in every soil sample in 1999 and ${ }^{238} \mathrm{U}$ was detected in all but one. Uranium-235 was detected in three of the 18 samples. Concentrations of ${ }^{233+234} U$ in surface soils (SS) ranged from a minimum of $3.40 \times 10^{-3} \pm$ $1.63 \times 10^{-3} \mathrm{~Bq} / \mathrm{g}\left(9.19 \times 10^{-2} \pm 4.41 \times 10^{-2} \mathrm{pCi} / \mathrm{g}\right)$ at WFF to a maximum of $1.55 \times 10^{-2} \pm 2.29 \times 10^{-3} \mathrm{~Bq} / \mathrm{g}$ $\left(4.19 \times 10^{-1} \pm 6.19 \times 10^{-2} \mathrm{pCi} / \mathrm{g}\right)$ at MLR (Table 4.26). Concentrations of ${ }^{238} \mathrm{U}$ in the same $\mathrm{SS}$ samples ranged from $4.07 \times 10^{-4} \pm 4.44 \times 10^{-4} \mathrm{~Bq} / \mathrm{g}$ $\left(1.10 \times 10^{-2} \pm 1.20 \times 10^{-2} \mathrm{pCi} / \mathrm{g}\right)$ at SMR to $1.55 \times 10^{-2}$ $\pm 2.22 \times 10^{-3} \mathrm{~Bq} / \mathrm{g}\left(4.19 \times 10^{-1} \pm 6.00 \times 10^{-2} \mathrm{pCi} / \mathrm{g}\right)$ at MLR. The concentration of ${ }^{235} \mathrm{U}$ in surface soils ranged from $0.00 \times 10^{0} \pm 1.48 \times 10^{-21} \mathrm{~Bq} / \mathrm{g}\left(0.00 \times 10^{0}\right.$ $\left.\pm 4.00 \times 10^{-20} \mathrm{pCi} / \mathrm{g}\right)$ at WFF to $4.44 \times 10^{-3} \pm$
$1.18 \times 10^{-3} \mathrm{~Bq} / \mathrm{g}\left(1.20 \times 10^{-1} \pm 3.19 \times 10^{-2} \mathrm{pCi} / \mathrm{g}\right)$ at MLR. Because of the very low activity of ${ }^{235} \mathrm{U}$ in soil, most of the results were non-detects and associated with large analytical uncertainties.

The results for uranium in SI soil samples are also given in Table 4.26. The concentration of ${ }^{233+234} \mathrm{U}$ ranged from $4.81 \times 10^{-3} \pm 1.55 \times 10^{-3} \mathrm{~Bq} / \mathrm{g}$ $\left(1.30 \times 10^{-1} \pm 4.19 \times 10^{-2} \mathrm{pCi} / \mathrm{g}\right)$ at both WFF and SEC to $1.41 \times 10^{-2} \pm 2.22 \times 10^{-3} \mathrm{~Bq} / \mathrm{g}\left(3.81 \times 10^{-1} \pm\right.$ $6.00 \times 10^{-2} \mathrm{pCi} / \mathrm{g}$ ) at MLR. Uranium-238 in SI was lowest at SEC $\left(3.70 \times 10^{-3} \pm 1.11 \times 10^{-3} \mathrm{~Bq} / \mathrm{g}\right.$ $\left.\left[1.00 \times 10^{-1} \pm 3.00 \times 10^{-2} \mathrm{pCi} / \mathrm{g}\right]\right)$ and highest at MLR $\left(1.37 \times 10^{-2} \pm 2.22 \times 10^{-3} \mathrm{~Bq} / \mathrm{g}\left[3.70 \times 10^{-1} \pm 6.00 \times 10^{-2}\right.\right.$ $\mathrm{pCi} / \mathrm{g}])$. As in surface soils, ${ }^{235} \mathrm{U}$ in intermediate soils was detectible in only one sample. Concentrations ranged from $-4.07 \times 10^{-4} \pm$ 
$6.66 \times 10^{-4} \mathrm{~Bq} / \mathrm{g}\left(-1.10 \times 10^{-2} \pm 1.80 \times 10^{-2} \mathrm{pCi} / \mathrm{g}\right)$ at WFF to $7.03 \times 10^{-4} \pm 4.44 \times 10^{-4} \mathrm{~Bq} / \mathrm{g}\left(1.90 \times 10^{-2} \pm\right.$ $1.20 \times 10^{-2} \mathrm{pCi} / \mathrm{g}$ ) at MLR.

Concentrations of ${ }^{233+234} \mathrm{U},{ }^{235} \mathrm{U}$, and ${ }^{238} \mathrm{U}$ were also measured in deep soils (SD) (Table 4.26). Concentrations of ${ }^{233+234} \mathrm{U}$ varied from $4.44 \times 10^{-3} \pm$ $1.41 \times 10^{-3} \mathrm{~Bq} / \mathrm{g}\left(1.20 \times 10^{-1} \pm 3.81 \times 10^{-2} \mathrm{pCi} / \mathrm{g}\right)$ at WFF to $1.37 \times 10^{-2} \pm 2.15 \times 10^{-3} \mathrm{~Bq} / \mathrm{g}\left(3.70 \times 10^{-1} \pm\right.$ $\left.5.81 \times 10^{-2} \mathrm{pCi} / \mathrm{g}\right)$ at MLR. The lowest concentration of ${ }^{238} \mathrm{U}$ in SD was found at WFF $\left(4.81 \times 10^{-3} \pm 1.18 \times 10^{-3} \mathrm{~Bq} / \mathrm{g}\left[1.30 \times 10^{-1} \pm 3.19 \times 10^{-2}\right.\right.$ $\mathrm{pCi} / \mathrm{g}]$ ) and the highest concentration was found at $\operatorname{MLR}\left(1.41 \times 10^{-2} \pm 2.00 \times 10^{-3} \mathrm{~Bq} / \mathrm{g}\left[3.81 \times 10^{-1} \pm\right.\right.$ $\left.\left.5.41 \times 10^{-2} \mathrm{pCi} / \mathrm{g}\right]\right)$. Uranium-235 was at detectable concentrations in only one sample of deep soil. Measured concentration ranged from $-3.70 \times 10^{-5} \pm$ $4.44 \times 10^{-4} \mathrm{~Bq} / \mathrm{g}\left(-1.00 \times 10^{-3} \pm 1.20 \times 10^{-2} \mathrm{pCi} / \mathrm{g}\right)$ at MLR to $3.33 \times 10^{-4} \pm 4.44 \times 10^{-4} \mathrm{~Bq} / \mathrm{g}\left(9.00 \times 10^{-3} \pm\right.$ $1.20 \times 10^{-2} \mathrm{pCi} / \mathrm{g}$ ) at SEC.

Uranium-233+234 varied significantly between sampling locations (ANOVA, $\mathrm{p}<0.001$ ). The J.C. Mills Ranch (MLR) consistently had the highest concentrations while either WFF or SEC had the lowest. Although the difference for the other uranium isotopes was not statistically significant, the same pattern was evident (Table 4.26). However, all measured concentrations fell within the range of natural concentrations of uranium found in soils throughout the world $\left({ }^{233+234} \mathrm{U}, 1.01 \times 10^{-2}\right.$ to $4.85 \times 10^{-2} \mathrm{~Bq} / \mathrm{g}\left[2.73 \times 10^{-1}\right.$ to $\left.1.31 \times 10^{0} \mathrm{pCi} / \mathrm{g}\right]$; Pais and Jones 1997$)$. There was no statistically significant difference in the concentration of any uranium isotope with depth (ANOVA, p>0.05). Both ${ }^{233+234} U$ and ${ }^{238} U$ varied significantly between 1998 and 1999 (ANOVA, $\mathrm{p}<0.001$ ). For both isotopes, the mean of the 1998 samples was higher than the mean of the 1999 samples. All these results suggest a pattern of natural variability consistent with the existence of natural uranium, without amendment from artificial sources.

Plutonium-238, ${ }^{239+240} \mathrm{Pu}$, and ${ }^{241} \mathrm{Am}$ were also measured in these soil samples (Table 4.27). Neither ${ }^{241} \mathrm{Am}$ nor ${ }^{238} \mathrm{Pu}$ was detected in any sample. Plutonium-239+240 was detected in one sample, from intermediate depth soils at WFF. Although there were no apparent analytical problems with this result, its presence in a subsurface soil sample means it is not likely the result of releases from WIPP. It may be an anomalous result.

Potassium-40 was, as expected, detected in every sample (Table 4.28). This naturallyoccurring gamma-emitting radionuclide is ubiquitous in soils. Concentrations in SS ranged from $1.74 \times 10^{-1} \pm 4.07 \times 10^{-2} \mathrm{~Bq} / \mathrm{g}\left(4.70 \times 10^{0} \pm\right.$ $1.10 \times 10^{0} \mathrm{pCi} / \mathrm{g}$ ) at WSS to $4.44 \times 10^{-1} \pm 8.14 \times 10^{-2}$ $\mathrm{Bq} / \mathrm{g}\left(1.20 \times 10^{1} \pm 2.20 \times 10^{1} \mathrm{pCi} / \mathrm{g}\right)$ at MLR. In SI soils, concentrations of ${ }^{40} \mathrm{~K}$ varied from $1.78 \times 10^{-1}$ $\pm 4.44 \times 10^{-2} \mathrm{~Bq} / \mathrm{g}\left(4.80 \times 10^{0} \pm 1.20 \times 10^{0} \mathrm{pCi} / \mathrm{g}\right)$ at SEC to $5.18 \times 10^{-1} \pm 9.99 \times 10^{-2} \mathrm{~Bq} / \mathrm{g}\left(1.40 \times 10^{1} \pm\right.$ $\left.2.70 \times 10^{0} \mathrm{pCi} / \mathrm{g}\right)$ at MLR. Potassium-40 concentrations in deep soils (SD) were lowest at WFF $\left(1.59 \times 10^{-1} \pm 4.81 \times 10^{-2} \mathrm{~Bq} / \mathrm{g}\left(4.30 \times 10^{0} \pm\right.\right.$ $\left.1.30 \times 10^{0} \mathrm{pCi} / \mathrm{g}\right)$ and highest at MLR $\left(4.07 \times 10^{-1} \pm\right.$ $8.51 \times 10^{-2} \mathrm{~Bq} / \mathrm{g}\left(1.1 \times 10^{1} \pm 2.3 \times 10^{0} \mathrm{pCi} / \mathrm{g}\right)$. 


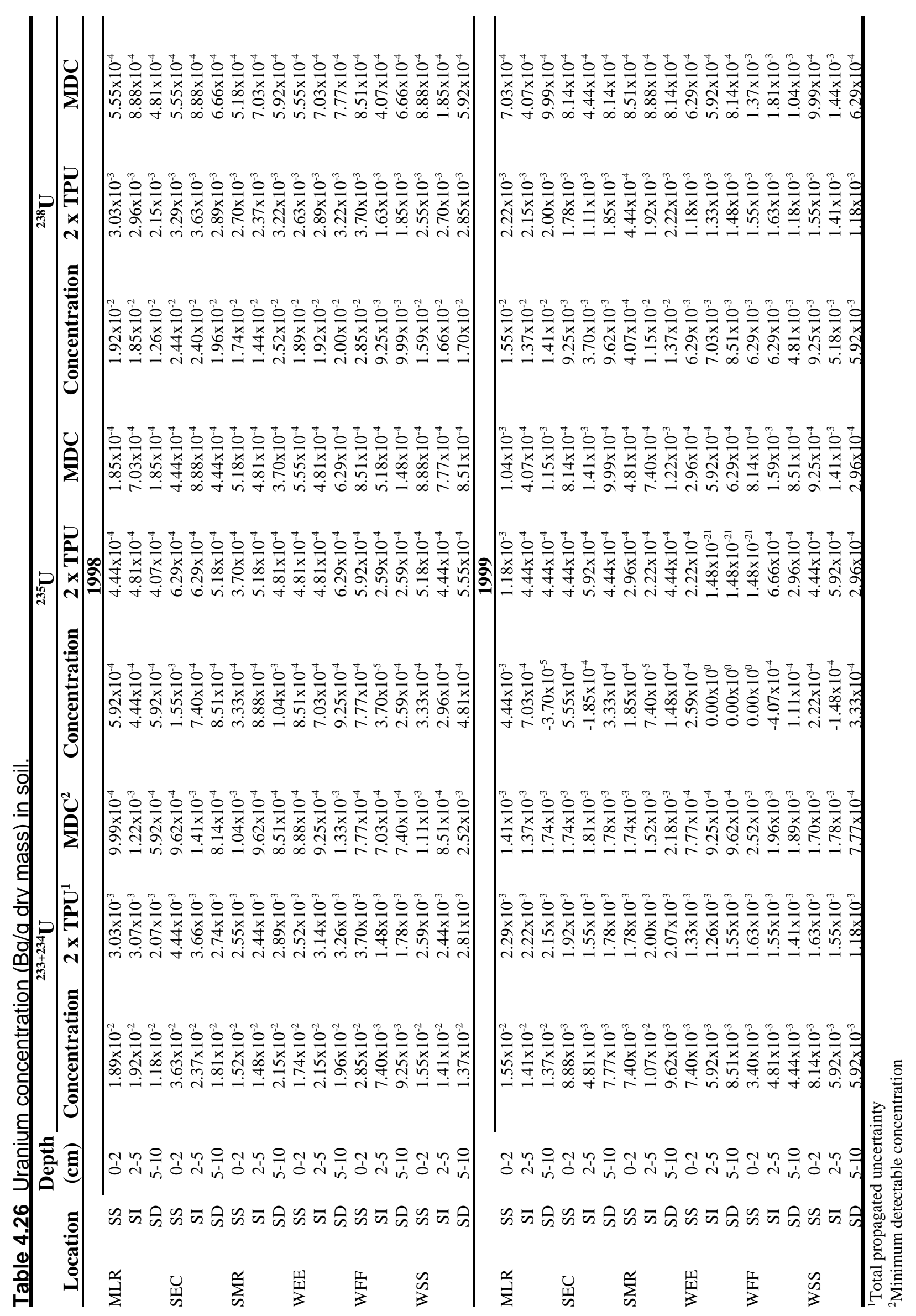




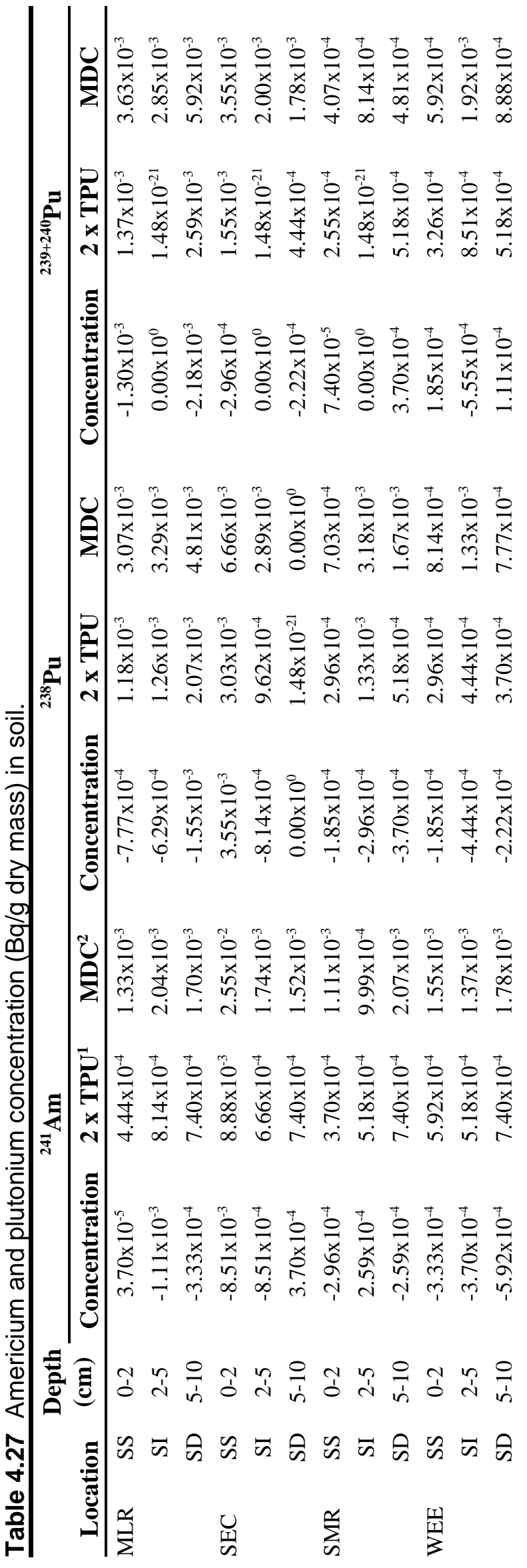


Table 4.28 Concentration $(\mathrm{Bq} / \mathrm{g})$ of beta and gamma emitters in soil.

\begin{tabular}{|c|c|c|c|c|c|c|c|c|}
\hline \multicolumn{2}{|c|}{ Location } & $\begin{array}{c}\text { Depth } \\
\text { (cm) }\end{array}$ & Concentration & $2 \times$ TPU $^{1}$ & MDC $^{2}$ & Concentration & $2 \times$ TPU & MDC \\
\hline & & & & ${ }^{40} K$ & & & ${ }^{60} \mathrm{Co}$ & \\
\hline \multirow[t]{3}{*}{ MLR } & SS & $0-2$ & $4.44 \times 10^{-1}$ & $8.14 \times 10^{-2}$ & $2.89 \times 10^{-2}$ & $\overline{\mathrm{NR}^{3}}$ & NR & $3.66 \times 10^{-3}$ \\
\hline & SI & $2-5$ & $5.18 \times 10^{-1}$ & $9.99 \times 10^{-2}$ & $3.66 \times 10^{-2}$ & NR & NR & $5.18 \times 10^{-3}$ \\
\hline & SD & $5-10$ & $4.07 \times 10^{-1}$ & $8.51 \times 10^{-2}$ & $2.96 \times 10^{-2}$ & NR & NR & $5.55 \times 10^{-3}$ \\
\hline \multirow[t]{3}{*}{ SEC } & SS & $0-2$ & $1.81 \times 10^{-1}$ & $4.44 \times 10^{-2}$ & $2.11 \times 10^{-2}$ & NR & NR & $3.22 \times 10^{-3}$ \\
\hline & SI & $2-5$ & $1.78 \times 10^{-1}$ & $4.44 \times 10^{-2}$ & $2.41 \times 10^{-2}$ & NR & NR & $3.15 \times 10^{-3}$ \\
\hline & SD & $5-10$ & $2.37 \times 10^{-1}$ & $5.18 \times 10^{-2}$ & $2.37 \times 10^{-2}$ & NR & NR & $3.40 \times 10^{-3}$ \\
\hline \multirow[t]{3}{*}{ SMR } & SS & $0-2$ & $3.55 \times 10^{-1}$ & $7.03 \times 10^{-2}$ & $3.55 \times 10^{-2}$ & NR & NR & $4.07 \times 10^{-3}$ \\
\hline & SI & $2-5$ & $4.44 \times 10^{-1}$ & $8.14 \times 10^{-2}$ & $2.70 \times 10^{-2}$ & NR & NR & $4.44 \times 10^{-3}$ \\
\hline & SD & $5-10$ & $3.70 \times 10^{-1}$ & $7.40 \times 10^{-2}$ & $3.03 \times 10^{-2}$ & NR & NR & $4.44 \times 10^{-3}$ \\
\hline \multirow[t]{3}{*}{ WEE } & SS & $0-2$ & $1.81 \times 10^{-1}$ & $4.44 \times 10^{-2}$ & $3.15 \times 10^{-2}$ & NR & NR & $4.07 \times 10^{-3}$ \\
\hline & SI & $2-5$ & $1.96 \times 10^{-1}$ & $4.44 \times 10^{-2}$ & $2.18 \times 10^{-2}$ & NR & NR & $2.85 \times 10^{-3}$ \\
\hline & SD & $5-10$ & $2.33 \times 10^{-1}$ & $5.18 \times 10^{-2}$ & $2.92 \times 10^{-2}$ & NR & NR & $3.29 \times 10^{-3}$ \\
\hline \multirow[t]{3}{*}{ WFF } & SS & $0-2$ & $2.11 \times 10^{-1}$ & $4.81 \times 10^{-2}$ & $1.63 \times 10^{-2}$ & NR & NR & $3.70 \times 10^{-3}$ \\
\hline & SI & $2-5$ & $1.78 \times 10^{-1}$ & $4.44 \times 10^{-2}$ & $2.78 \times 10^{-2}$ & NR & NR & $3.18 \times 10^{-3}$ \\
\hline & SD & $5-10$ & $1.59 \times 10^{-1}$ & $4.81 \times 10^{-2}$ & $2.96 \times 10^{-2}$ & NR & NR & $3.29 \times 10^{-3}$ \\
\hline \multirow[t]{4}{*}{ WSS } & SS & $0-2$ & $1.74 \times 10^{-1}$ & $4.07 \times 10^{-2}$ & $2.22 \times 10^{-2}$ & NR & NR & $4.07 \times 10^{-3}$ \\
\hline & SI & $2-5$ & $2.22 \times 10^{-1}$ & $4.81 \times 10^{-2}$ & $2.33 \times 10^{-2}$ & NR & NR & $3.70 \times 10^{-3}$ \\
\hline & SD & $5-10$ & $2.00 \times 10^{-1}$ & $4.81 \times 10^{-2}$ & $3.33 \times 10^{-2}$ & NR & NR & $4.07 \times 10^{-3}$ \\
\hline & & & & ${ }^{90} \mathrm{Sr}$ & & & ${ }^{137} \mathrm{Cs}$ & \\
\hline \multirow[t]{3}{*}{ MLR } & SS & $0-2$ & $9.99 \times 10^{-3}$ & $1.52 \times 10^{-2}$ & $2.52 \times 10^{-2}$ & $1.18 \times 10^{-2}$ & $4.44 \times 10^{-3}$ & $3.40 \times 10^{-3}$ \\
\hline & SI & $2-5$ & $1.04 \times 10^{-2}$ & $1.48 \times 10^{-2}$ & $2.48 \times 10^{-2}$ & $1.15 \times 10^{-2}$ & $5.18 \times 10^{-3}$ & $4.44 \times 10^{-3}$ \\
\hline & SD & $5-10$ & $2.89 \times 10^{-3}$ & $1.26 \times 10^{-2}$ & $2.18 \times 10^{-2}$ & $6.66 \times 10^{-3}$ & $3.59 \times 10^{-3}$ & $3.70 \times 10^{-3}$ \\
\hline \multirow[t]{3}{*}{ SEC } & SS & $0-2$ & $1.41 \times 10^{-2}$ & $1.44 \times 10^{-2}$ & $2.37 \times 10^{-2}$ & $4.81 \times 10^{-3}$ & $2.66 \times 10^{-3}$ & $2.74 \times 10^{-3}$ \\
\hline & SI & $2-5$ & $1.29 \times 10^{-2}$ & $1.41 \times 10^{-2}$ & $2.26 \times 10^{-2}$ & $3.59 \times 10^{-3}$ & $2.74 \times 10^{-3}$ & $2.70 \times 10^{-3}$ \\
\hline & SD & $5-10$ & $1.07 \times 10^{-2}$ & $1.29 \times 10^{-2}$ & $2.15 \times 10^{-2}$ & $3.59 \times 10^{-3}$ & $2.59 \times 10^{-3}$ & $2.96 \times 10^{-3}$ \\
\hline \multirow[t]{3}{*}{ SMR } & SS & $0-2$ & $7.03 \times 10^{-3}$ & $1.37 \times 10^{-2}$ & $2.33 \times 10^{-2}$ & NR & NR & $3.70 \times 10^{-3}$ \\
\hline & SI & $2-5$ & $-4.81 \times 10^{-3}$ & $1.07 \times 10^{-2}$ & $2.00 \times 10^{-2}$ & NR & NR & $3.66 \times 10^{-3}$ \\
\hline & SD & $5-10$ & $9.25 \times 10^{-3}$ & $1.04 \times 10^{-2}$ & $2.33 \times 10^{-2}$ & NR & NR & $3.40 \times 10^{-3}$ \\
\hline \multirow[t]{3}{*}{ WEE } & SS & $0-2$ & $7.77 \times 10^{-3}$ & $1.52 \times 10^{-2}$ & $2.41 \times 10^{-2}$ & $7.03 \times 10^{-4}$ & $2.96 \times 10^{-3}$ & $3.18 \times 10^{-3}$ \\
\hline & SI & $2-5$ & $1.74 \times 10^{-2}$ & $1.85 \times 10^{-2}$ & $2.85 \times 10^{-2}$ & $4.81 \times 10^{-3}$ & $2.37 \times 10^{-3}$ & $2.66 \times 10^{-3}$ \\
\hline & SD & $5-10$ & $1.41 \times 10^{-2}$ & $1.11 \times 10^{-2}$ & $1.67 \times 10^{-2}$ & $3.70 \times 10^{-3}$ & $3.15 \times 10^{-3}$ & $3.07 \times 10^{-3}$ \\
\hline \multirow[t]{3}{*}{ WFF } & SS & $0-2$ & $1.33 \times 10^{-2}$ & $1.15 \times 10^{-2}$ & $1.67 \times 10^{-2}$ & $1.96 \times 10^{-3}$ & $2.44 \times 10^{-3}$ & $2.74 \times 10^{-3}$ \\
\hline & SI & $2-5$ & $1.26 \times 10^{-2}$ & $1.22 \times 10^{-2}$ & $1.89 \times 10^{-2}$ & NR & NR & $3.70 \times 10^{-3}$ \\
\hline & SD & $5-10$ & $6.66 \times 10^{-3}$ & $1.18 \times 10^{-2}$ & $1.89 \times 10^{-2}$ & $3.52 \times 10^{-3}$ & $2.78 \times 10^{-3}$ & $2.66 \times 10^{-3}$ \\
\hline \multirow[t]{3}{*}{ WSS } & SS & $0-2$ & $7.40 \times 10^{-3}$ & $1.11 \times 10^{-2}$ & $1.78 \times 10^{-2}$ & NR & NR & $4.07 \times 10^{-3}$ \\
\hline & SI & $2-5$ & $7.77 \times 10^{-3}$ & $1.11 \times 10^{-2}$ & $1.74 \times 10^{-2}$ & NR & NR & $4.44 \times 10^{-3}$ \\
\hline & SD & $5-10$ & $7.03 \times 10^{-3}$ & $1.26 \times 10^{-2}$ & $2.00 \times 10^{-2}$ & $5.18 \times 10^{-3}$ & $3.18 \times 10^{-3}$ & $2.81 \times 10^{-3}$ \\
\hline
\end{tabular}


The concentration of ${ }^{40} \mathrm{~K}$ was not significantly different between depths or between 1998 and 1999. However, it was significantly different between sampling locations. Like the uranium isotopes, ${ }^{40} \mathrm{~K}$ was highest at MLR (Table 4.28). The lowest concentrations occurred at three different sampling sites. Although the highest concentrations of ${ }^{40} \mathrm{~K}$ were observed at the same location as the highest concentration of uranium, the range of concentrations observed is consistent with the average natural potassium-40 concentration in soils around the world $\left(4.00 \times 10^{-1}\right.$ $\mathrm{Bq} / \mathrm{g}\left[1.08 \times 10^{1} \mathrm{pCi} / \mathrm{g}\right]$; NCRP 1994).

Cesium-137 was detected in 10 of the 18 soil samples (Table 4.28). In surface soils, concentrations ranged from $7.03 \times 10^{-4} \pm 2.96 \times 10^{-3}$ $\mathrm{Bq} / \mathrm{g}\left(1.90 \times 10^{-2} \pm 8.00 \times 10^{-2} \mathrm{pCi} / \mathrm{g}\right)$ at WEE to $1.18 \times 10^{-2} \pm 4.44 \times 10^{-3} \mathrm{~Bq} / \mathrm{g}\left(3.19 \times 10^{-1} \pm 1.20 \times 10^{-1}\right.$ $\mathrm{pCi} / \mathrm{g}$ ) at MLR. The concentration in intermediate depth soils ranged from $3.59 \times 10^{-3} \pm 2.74 \times 10^{-3}$ $\mathrm{Bq} / \mathrm{g}\left(9.70 \times 10^{-2} \pm 7.41 \times 10^{-2} \mathrm{pCi} / \mathrm{g}\right)$ at $\mathrm{SEC}$ to $1.15 \times 10^{-2} \pm 5.18 \times 10^{-3} \mathrm{~Bq} / \mathrm{g}\left(3.11 \times 10^{-1} \pm 1.40 \times 10^{-1}\right.$ $\mathrm{pCi} / \mathrm{g})$ at MLR. In deep soils, the lowest concentrations of ${ }^{137} \mathrm{Cs}$ were found at WFF $\left(3.52 \times 10^{-3} \pm 2.78 \times 10^{-3} \mathrm{~Bq} / \mathrm{g}\left[9.51 \times 10^{-2} \pm 7.51 \times 10^{-2}\right.\right.$ $\mathrm{pCi} / \mathrm{g}]$ ) and the highest concentrations were found at MLR $\left(6.66 \times 10^{-3} \pm 3.59 \times 10^{-3} \mathrm{~Bq} / \mathrm{g}\left[1.8 \times 10^{-1} \pm\right.\right.$ $\left.\left.9.70 \times 10^{-2} \mathrm{pCi} / \mathrm{g}\right]\right)$. There was no significant difference in ${ }^{137} \mathrm{Cs}$ concentration between locations (ANOVA, $\mathrm{p}=0.054$ ), or soil depths $(p=0.722)$. Although differences between soil sampling locations were not significant, the highest concentrations were again found at MLR.

Although ${ }^{137} \mathrm{Cs}$ is a fission product, and a potential component of the waste stored at WIPP, it is ubiquitous in soils because of global fallout from atmospheric nuclear weapons testing. In 1998 , prior to WIPP accepting any waste, the average concentration of ${ }^{137} \mathrm{Cs}$ in soils around WIPP was $4.3 \times 10^{-3} \mathrm{~Bq} / \mathrm{g}\left(1.16 \times 10^{-1} \mathrm{pCi} / \mathrm{g}\right)$. There was no statistically significant difference between concentrations measured in 1998 and those measured in 1999 (ANOVA, $\mathrm{p}=0.560$ ).

Neither ${ }^{60} \mathrm{Co}$ nor ${ }^{90} \mathrm{Sr}$ was detected in any soil sample in 1999 (Table 4.28). However, in addition to the expected natural gamma-emitting radionuclides, two anthropogenic radionuclides, ${ }^{58} \mathrm{Co}$ and ${ }^{65} \mathrm{Zn}$, were detected. Cobalt-58 was detected in intermediate depth soils at SMR with a concentration of $6.29 \times 10^{-2} \pm 3.22 \times 10^{-2} \mathrm{~Bq} / \mathrm{g}$; $\mathrm{MDC}=2.37 \times 10^{-2} \mathrm{~Bq} / \mathrm{g}\left(1.70 \times 10^{0} \pm 8.7 \times 10^{-1}\right.$ $\left.\mathrm{pCi} / \mathrm{g} ; \mathrm{MDC}=6.41 \times 10^{-1} \mathrm{pCi} / \mathrm{g}\right)$. Zinc- 65 was detected in deep soils at WSS with a concentration of $5.92 \times 10^{-3} \pm 4.81 \times 10^{-3} \mathrm{~Bq} / \mathrm{g}$; $\mathrm{MDC}=1.18 \times 10^{-3} \mathrm{~Bq} / \mathrm{g}\left(1.60 \times 10^{-1} \pm 1.30 \times 10^{-1}\right.$ $\left.\mathrm{pCi} / \mathrm{g} ; \quad \mathrm{MDC}=3.19 \times 10^{-2} \mathrm{pCi} / \mathrm{g}\right)$. Although examination of the laboratory records does not reveal any laboratory error, it is very likely they were anomalous results. These detections are unusual because both radionuclides have a short half life ( ${ }^{65} \mathrm{Zn}, 245$ days; ${ }^{58} \mathrm{Co}, 71.3$ days), and both were detected in subsurface soils. Shortlived radionuclides detected on the surface could be explained as accidental releases; short-lived radionuclides at depth cannot easily be explained. This interpretation is supported by the large analytical uncertainties on both of these measurements.

Soil samples collected from one location (SEC) were divided into two parts and analyzed separately (Table 4.29). Uranium-233+234, ${ }^{238} \mathrm{U}$, ${ }^{40} \mathrm{~K}$, and ${ }^{137} \mathrm{Cs}$ were compared between the duplicates. Other radionuclides of interest had insufficient detections to allow a reasonable comparison. The RER was less than one for all radionuclides in all samples except for both uranium isotopes in the intermediate depth soil. This indicates generally good agreement between duplicates. 
Table 4.29 Duplicate measurements of soil concentration (Bq/g).

\begin{tabular}{|c|c|c|c|c|c|c|c|c|}
\hline Location & & $\begin{array}{r}\text { Depth } \\
\text { (cm) }\end{array}$ & Concentration & $2 \times$ TPU $^{1}$ & MDC $^{2}$ & Concentration & $2 \times$ TPU & MDC \\
\hline & & & & ${ }^{40} \mathrm{~K}$ & & & ${ }^{137} \mathrm{Cs}$ & \\
\hline \multirow[t]{3}{*}{ SEC (Original) } & SS & $0-2$ & $1.81 \times 10^{-1}$ & $4.44 \times 10^{-2}$ & $2.11 \times 10^{-2}$ & $4.81 \times 10^{-3}$ & $2.66 \times 10^{-3}$ & $2.74 \times 10^{-3}$ \\
\hline & SI & $2-5$ & $1.78 \times 10^{-1}$ & $4.44 \times 10^{-2}$ & $2.41 \times 10^{-2}$ & $3.59 \times 10^{-3}$ & $2.74 \times 10^{-3}$ & $2.70 \times 10^{-3}$ \\
\hline & SD & $5-10$ & $2.37 \times 10^{-1}$ & $5.18 \times 10^{-2}$ & $2.37 \times 10^{-2}$ & $3.59 \times 10^{-3}$ & $2.59 \times 10^{-3}$ & $2.96 \times 10^{-3}$ \\
\hline \multirow[t]{4}{*}{ SEC (Duplicate) } & SS & $0-2$ & $1.74 \times 10^{-1}$ & $4.44 \times 10^{-2}$ & $2.63 \times 10^{-2}$ & $3.70 \times 10^{-3}$ & $2.48 \times 10^{-3}$ & $2.89 \times 10^{-3}$ \\
\hline & SI & $2-5$ & $1.92 \times 10^{-1}$ & $4.44 \times 10^{-2}$ & $2.59 \times 10^{-2}$ & $4.44 \times 10^{-3}$ & $2.81 \times 10^{-3}$ & $2.66 \times 10^{-3}$ \\
\hline & SD & $5-10$ & $2.29 \times 10^{-1}$ & $5.18 \times 10^{-2}$ & $2.92 \times 10^{-2}$ & $\mathrm{NR}^{3}$ & NR & $4.44 \times 10^{-3}$ \\
\hline & & & & $\frac{233+234}{U}$ & & & $\overline{{ }^{238} \mathbf{U}}$ & \\
\hline \multirow[t]{3}{*}{ SEC (Original) } & SS & $0-2$ & $8.88 \times 10^{-3}$ & $1.92 \times 10^{-3}$ & $1.74 \times 10^{-3}$ & $9.25 \times 10^{-3}$ & $1.78 \times 10^{-3}$ & $8.14 \times 10^{-4}$ \\
\hline & SI & $2-5$ & $4.81 \times 10^{-3}$ & $1.55 \times 10^{-3}$ & $1.81 \times 10^{-3}$ & $3.70 \times 10^{-3}$ & $1.11 \times 10^{-3}$ & $4.44 \times 10^{-4}$ \\
\hline & SD & $5-10$ & $7.77 \times 10^{-3}$ & $1.78 \times 10^{-3}$ & $1.78 \times 10^{-3}$ & $9.62 \times 10^{-3}$ & $1.85 \times 10^{-3}$ & $8.14 \times 10^{-4}$ \\
\hline \multirow[t]{3}{*}{ SEC (Duplicate) } & SS & $0-2$ & $8.14 \times 10^{-3}$ & $1.85 \times 10^{-3}$ & $1.59 \times 10^{-3}$ & $9.62 \times 10^{-3}$ & $1.85 \times 10^{-3}$ & $8.14 \times 10^{-4}$ \\
\hline & SI & $2-5$ & $7.40 \times 10^{-3}$ & $1.78 \times 10^{-3}$ & $1.63 \times 10^{-3}$ & $7.03 \times 10^{-3}$ & $1.55 \times 10^{-3}$ & $9.99 \times 10^{-4}$ \\
\hline & SD & $5-10$ & $8.88 \times 10^{-3}$ & $1.78 \times 10^{-3}$ & $8.14 \times 10^{-4}$ & $9.99 \times 10^{-3}$ & $1.85 \times 10^{-3}$ & $4.44 \times 10^{-4}$ \\
\hline
\end{tabular}

${ }^{1}$ Total propagated uncertainty

${ }^{2}$ Mean minimum detectable concentration among all samples from the indicated location

\subsection{Sediments}

\subsubsection{Sample Collection}

Sediment samples were collected from 12 locations around the WIPP site, mostly from the same water bodies from which the surface water samples were collected (Figure 4.6, see Appendix $\mathrm{B}$ for location codes). The samples were collected in polyethylene bags from the top $15 \mathrm{~cm}$ (6 in) of the sediments of the water bodies, brought to the laboratory, dried, and shipped to a commercial laboratory for the determination of individual radionuclides.

\subsubsection{Sample Preparation}

Sediment samples were dried at $110^{\circ} \mathrm{C}\left(230^{\circ}\right.$ F) for several hours and homogenized by grinding to smaller particle sizes. A $1-\mathrm{g}(0.04-\mathrm{oz})$ aliquot was dissolved by heating it with a mixture of nitric, hydrochloric, and hydrofluoric acids. The residue was heated with nitric and boric acids to remove hydrofluoric acid quantitatively. Finally, the residue was dissolved in hydrochloric acid for the determination of individual radionuclides.

\subsubsection{Determination of Individual Radio- nuclides}

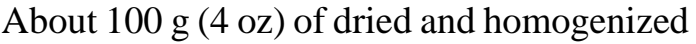
sediment samples were counted by gamma-spectrometry for the determinations of ${ }^{40} \mathrm{~K}$, ${ }^{60} \mathrm{Co}$, and ${ }^{137} \mathrm{Cs}$. Strontium-90 was determined from an aliquot of dissolved sediment samples by chemical separation and beta counting. Uranium, plutonium, and americium were determined by alpha spectrometry after chemical separations and micro-precipitating and filtering onto micro filter papers.

\subsubsection{Results and Discussions}

Uranium-233+234 and ${ }^{238} \mathrm{U}$ were detected in every sediment sample in 1999 (Table 4.30). Uranium-235 was detected in 42 percent of the samples. The concentration of ${ }^{233+234} \mathrm{U}$ ranged from $7.40 \times 10^{-3} \pm 1.78 \times 10^{-3} \mathrm{~Bq} / \mathrm{g}\left(2.00 \times 10^{-1} \pm\right.$ $4.81 \times 10^{-2} \mathrm{pCi} / \mathrm{g}$ ) at NOY to $6.29 \times 10^{-2} \pm 5.92 \times 10^{-3}$ $\mathrm{Bq} / \mathrm{g}\left(1.70 \times 10^{0} \pm 1.6 \times 10^{-1} \mathrm{pCi} / \mathrm{g}\right)$ at $\mathrm{PCN}$. The concentration of ${ }^{238} \mathrm{U}$ ranged from $9.62 \times 10^{-3} \pm$ $1.74 \times 10^{-3} \mathrm{~Bq} / \mathrm{g}\left(0.00 \times 10^{0} \pm 4.00 \times 10^{-20} \mathrm{pCi} / \mathrm{g}\right)$ at NOY to $5.18 \times 10^{-2} \pm 5.55 \times 10^{-3} \mathrm{~Bq} / \mathrm{g}\left(6.11 \times 10^{-2} \pm\right.$ 


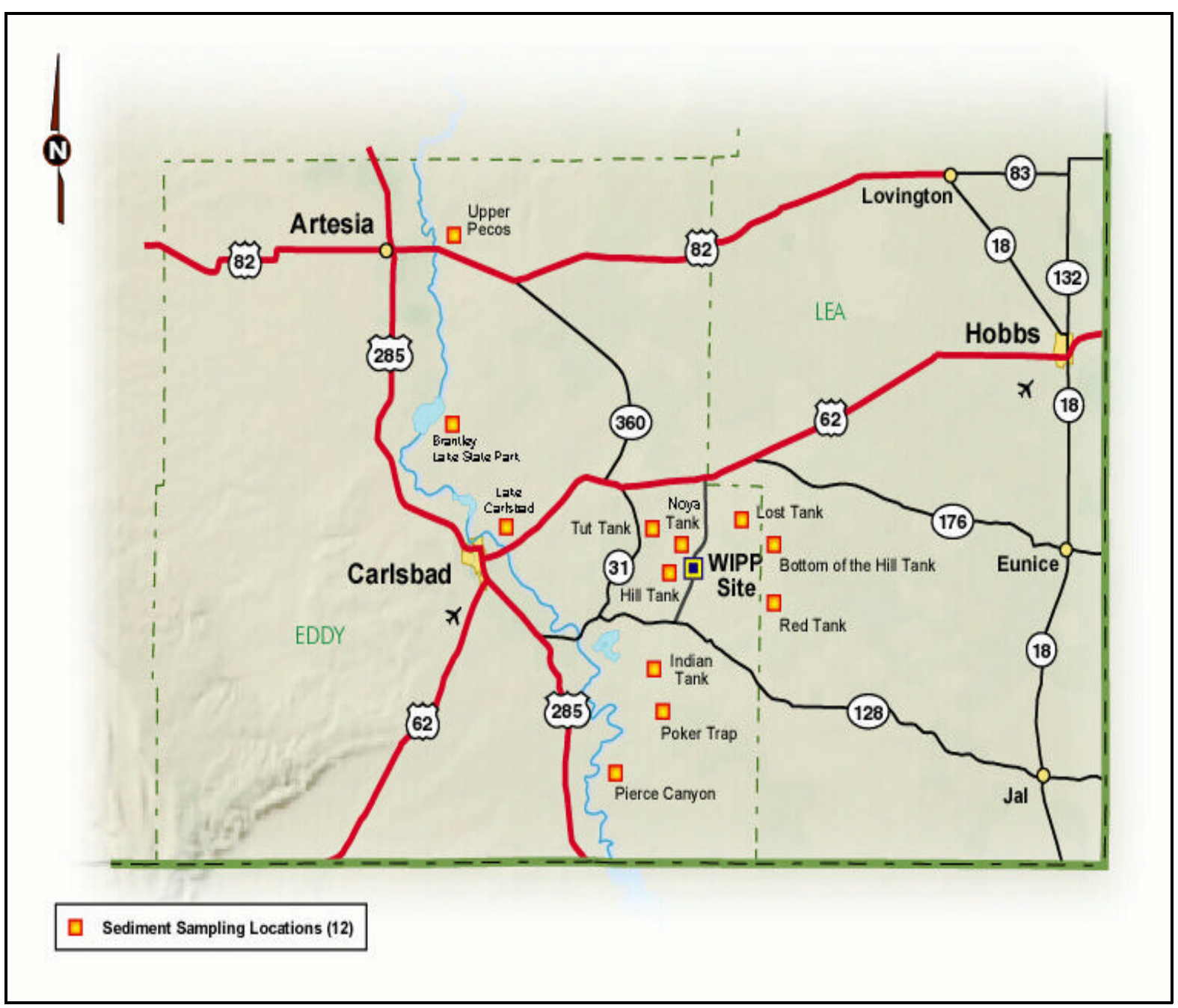

Figure 4.6. Sediment Sampling Sites

$\left.2.60 \times 10^{-2} \mathrm{pCi} / \mathrm{g}\right)$ at $\mathrm{PCN}$. The concentration of ${ }^{235} \mathrm{U}$ was lowest at IDN $\left(0.00 \times 10^{0} \pm 1.48 \times 10^{-21}\right.$ $\left.\mathrm{Bq} / \mathrm{g}\left[0.00 \times 10^{0} \pm 4.00 \times 10^{-20} \mathrm{pCi} / \mathrm{g}\right]\right)$ and highest at PCN $\left(2.26 \times 10^{-3} \pm 9.62 \times 10^{-4} \mathrm{~Bq} / \mathrm{g}\left[6.11 \times 10^{-2} \pm\right.\right.$ $\left.\left.2.60 \times 10^{-2} \mathrm{pCi} / \mathrm{g}\right]\right)$. As expected, the ${ }^{235} \mathrm{U}$ concentration was much lower than the concentrations of ${ }^{233+234} \mathrm{U}$ and ${ }^{238} \mathrm{U}$. None of the uranium isotopes varied significantly between sampling locations (ANOVA, ${ }^{233+234} \mathrm{U} p=0.126$, ${ }^{235} \mathrm{U} \mathrm{p}=0.301,{ }^{238} \mathrm{U} \mathrm{p}=0.434$ ) or between 1998 and 1999 (ANOVA, ${ }^{233+234} \mathrm{U} \mathrm{p}=0.527,{ }^{235} \mathrm{U} \mathrm{p}=0.460$, $\left.{ }^{238} \mathrm{U} \mathrm{p}=0.338\right)$.

Neither ${ }^{238} \mathrm{Pu}$ nor ${ }^{239+240} \mathrm{Pu}$ were detected in any sediment sample in 1999 (Table 4.31). Americium-241 was detected in seven of the 12 sediment samples. It ranged from a minimum of $-9.99 \times 10^{-4} \pm 7.40 \times 10^{-4} \mathrm{~Bq} / \mathrm{g}\left(-2.70 \times 10^{-2} \pm\right.$ $\left.2.00 \times 10^{-2} \mathrm{pCi} / \mathrm{g}\right)$ at UPR to a maximum of $2.15 \times 10^{-3} \pm 6.66 \times 10^{-4} \mathrm{~Bq} / \mathrm{g}\left(5.81 \times 10^{-2} \pm 1.80 \times 10^{-2}\right.$ $\mathrm{pCi} / \mathrm{g}$ ) at PKT. The concentration of ${ }^{241} \mathrm{Am}$ in sediments was not significantly different between sampling locations (ANOVA, $\mathrm{p}=0.139$ ) or between 1998 and 1999 ( $\mathrm{p}=0.960)$.

Strontium-90 was detected in one sediment sample, that from HIL (Table 4.32). Cesium-137 was detected in 42 percent of the sediment samples, ranging from $2.11 \times 10^{-3} \pm 1.63 \times 10^{-3} \mathrm{~Bq} / \mathrm{g}$ $\left(5.70 \times 10^{-2} \pm 4.41 \times 10^{-2} \mathrm{pCi} / \mathrm{g}\right)$ at NOY to $1.92 \times 10^{-2}$ $\pm 4.44 \times 10^{-3} \mathrm{~Bq} / \mathrm{g}\left(5.19 \times 10^{-1} \pm 1.20 \times 10^{-1} \mathrm{pCi} / \mathrm{g}\right)$ at PKT. Cobalt-60 was not detected in any sediment 
sample. None of these radionuclides had sufficient detections to justify statistical comparisons between locations or years.

Potassium-40 was detected, as expected, in all sediment samples (Table 4.32). Its lowest concentration was found at RED $\left(2.96 \times 10^{-1} \pm\right.$ $\left.6.66 \times 10^{-2} \mathrm{~Bq} / \mathrm{g}\left[8.00 \times 10^{0} \pm 1.80 \times 10^{0} \mathrm{pCi} / \mathrm{g}\right]\right)$ and its highest concentration was found at HIL $\left(8.88 \times 10^{-1} \pm 1.33 \times 10^{-1} \mathrm{~Bq} / \mathrm{g}\left[2.40 \times 10^{1} \pm 3.59 \times 10^{0}\right.\right.$ $\mathrm{pCi} / \mathrm{g}])$. Potassium-40 did not vary significantly between 1998 and 1999 (ANOVA, p=0.824) but it did vary significantly between locations ( $\mathrm{p}=0.036)$. The concentrations measured in 1999 were similar to the average concentration of ${ }^{40} \mathrm{~K}$ found in soils throughout the United States (4.00x $10^{-1} \mathrm{~Bq} / \mathrm{g}$ [1.08x10 $\left.\mathrm{pCi} / \mathrm{g}\right]$; NCRP 1994).

Duplicate analyses were performed for all the radionuclides in a sediment sample from RED. The sample was dried, homogenized, and divided into two parts for the duplicate analyses. Both parts were analyzed separately; the results are given in Table 4.33. The RER was less then one, indicating acceptable correspondence between the original and the duplicate samples, for all radionuclides except ${ }^{238} \mathrm{U}$. 


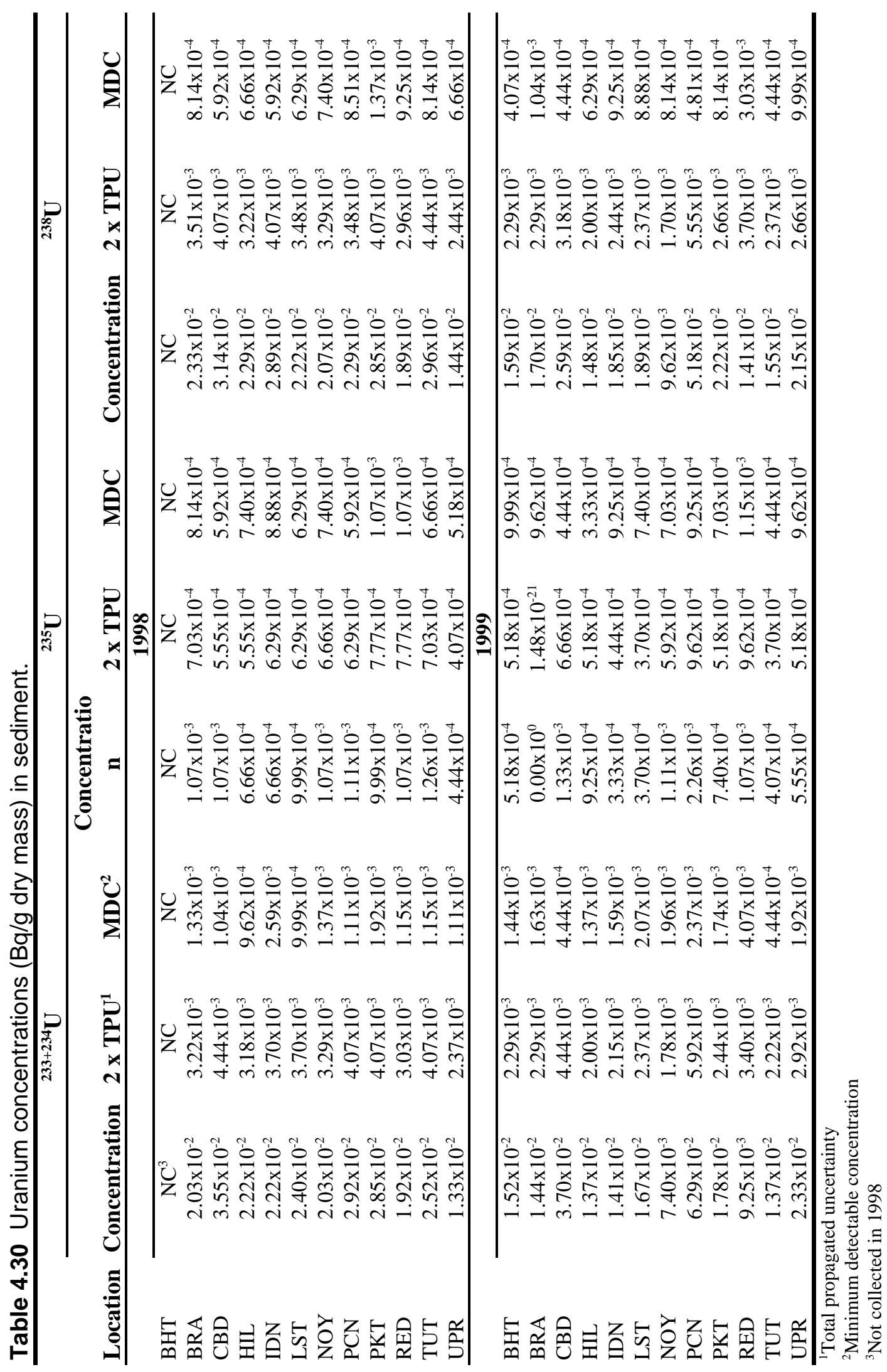



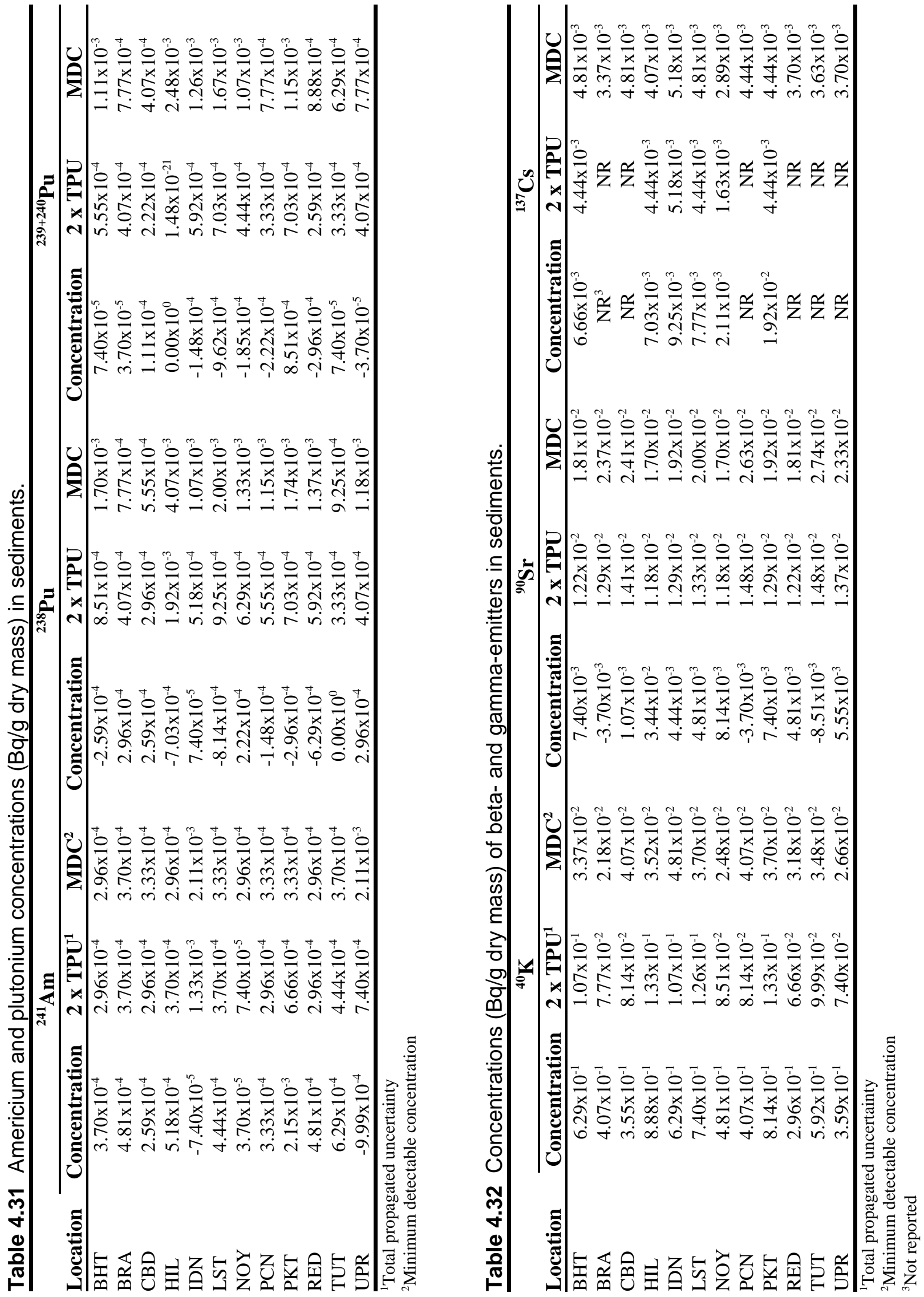


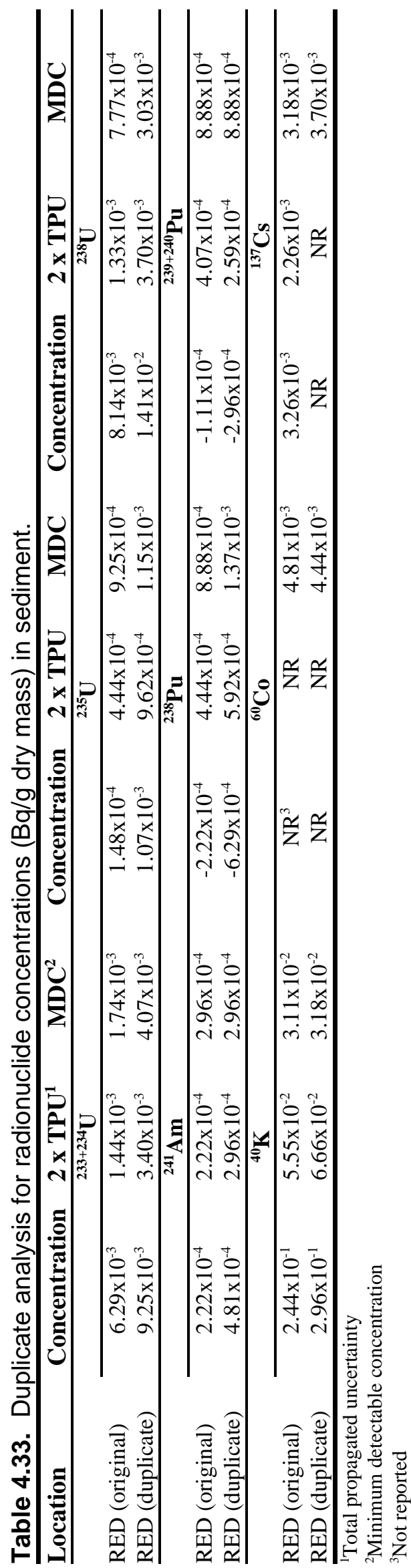




\subsection{Biota}

\subsubsection{Sample Collection}

The concentration of radionuclides in plants is an important factor in estimating the intake of individual radionuclides by humans through ingestion. Therefore, rangeland vegetation samples were collected from the same six locations from where the soil samples were collected (Figure 4.5). The vegetation samples were chopped into $2.5-5-\mathrm{cm}$ (1-2-in)-pieces, mixed together well, air dried at room temperature, and sent to the contract laboratory for analysis. Also collected were muscle tissues from three road-killed deer and a composite of several quail, both species commonly consumed by humans. Fish is also consumed in large amounts; therefore, fish samples from PCN, PEC, and BRA (three different locations on the Pecos River) were collected. The muscle tissues from the deer and quail, and whole fish were sent to the contract laboratory for analysis.

\subsubsection{Sample Preparation}

Weighed aliquots were taken from the bulk of the chopped vegetation samples and animal tissue samples from each location. The aliquots were transferred into separate containers and dried at $100^{\circ} \mathrm{C}\left(212^{\circ} \mathrm{F}\right) . \quad$ Gamma spectrometric determinations of ${ }^{40} \mathrm{~K},{ }^{60} \mathrm{Co}$, and ${ }^{137} \mathrm{Cs}$ were performed directly from these aliquots. The samples were then dry-ashed, followed by wet-ashing and dissolution in 8M nitric acid. Aliquots from the dissolved samples were taken for the determinations of ${ }^{90} \mathrm{Sr},{ }^{233+234} \mathrm{U},{ }^{235} \mathrm{U},{ }^{238} \mathrm{U}$, ${ }^{238} \mathrm{Pu},{ }^{239+240} \mathrm{Pu}$, and ${ }^{241} \mathrm{Am}$.

\subsubsection{Results and Discussions}

\section{Vegetation}

Uranium-233+234 was detected in five of the six vegetation samples and ${ }^{238} \mathrm{U}$ was detected in all vegetation samples; ${ }^{235} \mathrm{U}$ was not detected in any vegetation sample (Table 4.34). Concentrations of ${ }^{233+234} \mathrm{U}$ ranged from $7.96 \times 10^{-6} \pm 2.07 \times 10^{-6} \mathrm{~Bq} / \mathrm{g}$ $\left(2.15 \times 10^{-4} \pm 5.59 \times 10^{-5} \mathrm{pCi} / \mathrm{g}\right)$ at WFF to $2.13 \times 10^{-5}$ $\pm 1.70 \times 10^{-5} \mathrm{~Bq} / \mathrm{g}\left(5.76 \times 10^{-4} \pm 4.59 \times 10^{-4} \mathrm{pCi} / \mathrm{g}\right)$ at
SEC. Uranium-238 varied between $7.55 \times 10^{-6} \pm$ $2.33 \times 10^{-6} \mathrm{~Bq} / \mathrm{g}\left(2.04 \times 10^{-4} \pm 6.30 \times 10^{-5} \mathrm{pCi} / \mathrm{g}\right)$ at WFF to $4.26 \times 10^{-5} \pm 1.41 \times 10^{-5} \mathrm{~Bq} / \mathrm{g}\left(1.15 \times 10^{-3} \pm\right.$ $3.81 \times 10^{-4} \mathrm{pCi} / \mathrm{g}$ ) at SMR. The concentration of ${ }^{233+234} \mathrm{U}$ and ${ }^{238} \mathrm{U}$ did not vary significantly between locations (ANOVA, ${ }^{233+234} \mathrm{U} \mathrm{p}=0.955$, ${ }^{238} \mathrm{U} \mathrm{p}=0.927$ ), but it did vary significantly between 1998 and 1999 (ANOVA, ${ }^{233+234} \mathrm{U}$ $\left.\mathrm{p}<0.001,{ }^{238} \mathrm{U} \quad \mathrm{p}=0.001\right)$, with the average concentration for 1998 being higher than that for 1999. This is consistent with what was observed for soil. Concentrations of ${ }^{241} \mathrm{Am},{ }^{238} \mathrm{Pu}$, and ${ }^{239+240} \mathrm{Pu}$ were equal to or less than the minimum detectable concentrations in every vegetation sample (Table 4.35).

Potassium-40 was detected in five of the six vegetation samples and ${ }^{90} \mathrm{Sr}$ was detected in each of them (Table 4.36). No other radionuclides of interest were detected in any sample. Potassium40 ranged from $4.48 \times 10^{-4} \pm 6.29 \times 10^{-3} \mathrm{~Bq} / \mathrm{g}$ $\left(1.21 \times 10^{-2} \pm 1.70 \times 10^{-1} \mathrm{pCi} / \mathrm{g}\right)$ at WEE to $6.07 \times 10^{0}$ $\pm 8.51 \times 10^{-1} \mathrm{~Bq} / \mathrm{g}\left(1.64 \times 10^{2} \pm 2.30 \times 10^{1} \mathrm{pCi} / \mathrm{g}\right)$ at SMR. The lowest concentration of ${ }^{90} \mathrm{Sr}$ in vegetation was found at MLR $\left(2.35 \times 10^{-3} \pm\right.$ $\left.1.04 \times 10^{-3} \mathrm{~Bq} / \mathrm{g}\left[6.35 \times 10^{-2} \pm 2.81 \times 10^{-2} \mathrm{pCi} / \mathrm{g}\right]\right)$ and the highest was found at WFF $\left(7.62 \times 10^{-3} \pm\right.$ $\left.1.33 \times 10^{-3} \mathrm{~Bq} / \mathrm{g}\left[2.06 \times 10^{-1} \pm 3.59 \times 10^{-2} \mathrm{pCi} / \mathrm{g}\right]\right)$. Neither ${ }^{40} \mathrm{~K}$ nor ${ }^{90} \mathrm{Sr}$ varied significantly between locations (ANOVA, ${ }^{40} \mathrm{~K} p=0.932,{ }^{90} \mathrm{Sr} \mathrm{p}=0.183$ ). Strontium-90 did not vary between 1998 and 1999 $(p=0.652)$. However, the concentration of ${ }^{40} \mathrm{~K}$ in vegetation was significantly different between 1998 and 1999 (ANOVA, $p=0.001$ ) with the 1999 mean being higher than the 1998 mean. Like uranium, the primary source for potassium in plant tissues is the soil, so this difference from the ${ }^{40} \mathrm{~K}$ results for soil is difficult to explain. However, uptake of radionuclides and contamination by resuspension are highly species dependent (and sometimes different between plants of the same species collected adjacent to one another). The difference may be related to a difference in the species mix sampled between years.

A duplicate analysis of the vegetation sample from SEC was performed for all the radionuclides of interest (Table 4.37). Concentrations of ${ }^{233+234} \mathrm{U},{ }^{238} \mathrm{U},{ }^{40} \mathrm{~K}$, and ${ }^{90} \mathrm{Sr}$ were detectable in the 
duplicate sample. The RER for ${ }^{90} \mathrm{Sr}$ was less than one but, for each of the other radionuclides, the RER was greater than 1 , indicating that laboratory results were not reproducible.

\section{Animals}

Of the radionuclides of interest, only ${ }^{40} \mathrm{~K}$ was detected in deer tissue (Tables 4.38-4.40). Its mean concentration was $1.41 \times 10^{-1} \pm 4.62 \times 10^{-2}$ $\mathrm{Bq} / \mathrm{g}\left(3.81 \times 10^{0} \pm 1.25 \times 10^{0} \mathrm{pCi} / \mathrm{g}\right)$, similar to that found in other mammals throughout the world. No radionuclides were detected in the composite quail sample.

Uranium-233+234 was detected in every fish sample and ${ }^{238} \mathrm{U}$ was detected in two of the three fish samples (Table 4.38). The concentration of ${ }^{233+234} \mathrm{U}$ in fish ranged from $7.14 \times 10^{-5} \pm 2.78 \times 10^{-5}$ $\mathrm{Bq} / \mathrm{g}\left(1.93 \times 10^{-3} \pm 7.51 \times 10^{-4} \mathrm{pCi} / \mathrm{g}\right)$ at $\mathrm{BRA}$ to $1.06 \times 10^{-4} \pm 3.22 \times 10^{-5} \mathrm{~Bq} / \mathrm{g}\left(2.86 \times 10^{-3} \pm 8.70 \times 10^{-4}\right.$ $\mathrm{pCi} / \mathrm{g}$ ) at PCN. Uranium-238 in fish was also lowest at BRA $\left(1.19 \times 10^{-5} \pm 2.00 \times 10^{-5} \mathrm{~Bq} / \mathrm{g}\right.$ $\left.\left[3.22 \times 10^{-4} \pm 5.41 \times 10^{-4} \mathrm{pCi} / \mathrm{g}\right]\right)$ and highest at $\mathrm{PCN}$ $\left(1.62 \times 10^{-4} \pm 2.22 \times 10^{-5} \mathrm{~Bq} / \mathrm{g}\left[4.38 \times 10^{-3} \pm 6.00 \times 10^{-4}\right.\right.$ $\mathrm{pCi} / \mathrm{g}])$.

Americium-241, ${ }^{238} \mathrm{Pu}$, and ${ }^{239+240} \mathrm{Pu}$ were not detected in fish (Table 4.39). Strontium-90 was detected in two of the three fish samples and ${ }^{40} \mathrm{~K}$ was detected in all fish (Table 4.40). The concentration of ${ }^{90} \mathrm{Sr}$ in fish ranged from $2.55 \times 10^{-4}$ $\pm 2.59 \times 10^{-4} \mathrm{~Bq} / \mathrm{g}\left(6.89 \times 10^{-3} \pm 7.00 \times 10^{-3} \mathrm{pCi} / \mathrm{g}\right)$ at BRA to $7.40 \times 10^{-4} \pm 3.70 \times 10^{-4} \mathrm{~Bq} / \mathrm{g}\left(2.00 \times 10^{-2} \pm\right.$
$1.00 \times 10^{-2} \mathrm{pCi} / \mathrm{g}$ ) at PCN. As for all other radionuclides, ${ }^{40} \mathrm{~K}$ in fish was lowest at BRA $\left(3.41 \times 10^{-1} \pm 7.77 \times 10^{-2} \mathrm{~Bq} / \mathrm{g}\left[9.21 \times 10^{0} \pm 2.10 \times 10^{0}\right.\right.$ $\mathrm{pCi} / \mathrm{g}])$ and highest at $\mathrm{PCN}\left(3.74 \times 10^{-1} \pm 8.14 \times 10^{-2}\right.$ $\left.\mathrm{Bq} / \mathrm{g}\left[1.21 \times 10^{1} \pm 2.20 \times 10^{0} \mathrm{pCi} / \mathrm{g}\right]\right)$.

There was no statistically significant difference between concentrations of any radionuclide in fish at any location (ANOVA, $\mathrm{p}>0.568$ ). However, there was a significant difference between 1998 and 1999 for ${ }^{233+234} U$ $(\mathrm{p}=0.011)$ and ${ }^{40} \mathrm{~K}(\mathrm{p}<0.001)$. Uranium-233+234 was higher in 1998 while ${ }^{40} \mathrm{~K}$ was higher in 1999. This is attributed to natural variability because both radionuclides are naturally-occurring and are not major components of the waste stored at WIPP.

\subsection{Summary and Conclusion}

The Environmental Monitoring Program collected samples of air particulates, soil, sediment, ground water, surface water, and biota and analyzed them for radionuclides considered to be indicators of potential contamination from the WIPP facility, as well as other radionuclides of potential interest. Radionuclide concentrations observed were highly variable in space and time and between media. In no case, could environmental contamination be attributed to WIPP releases. 


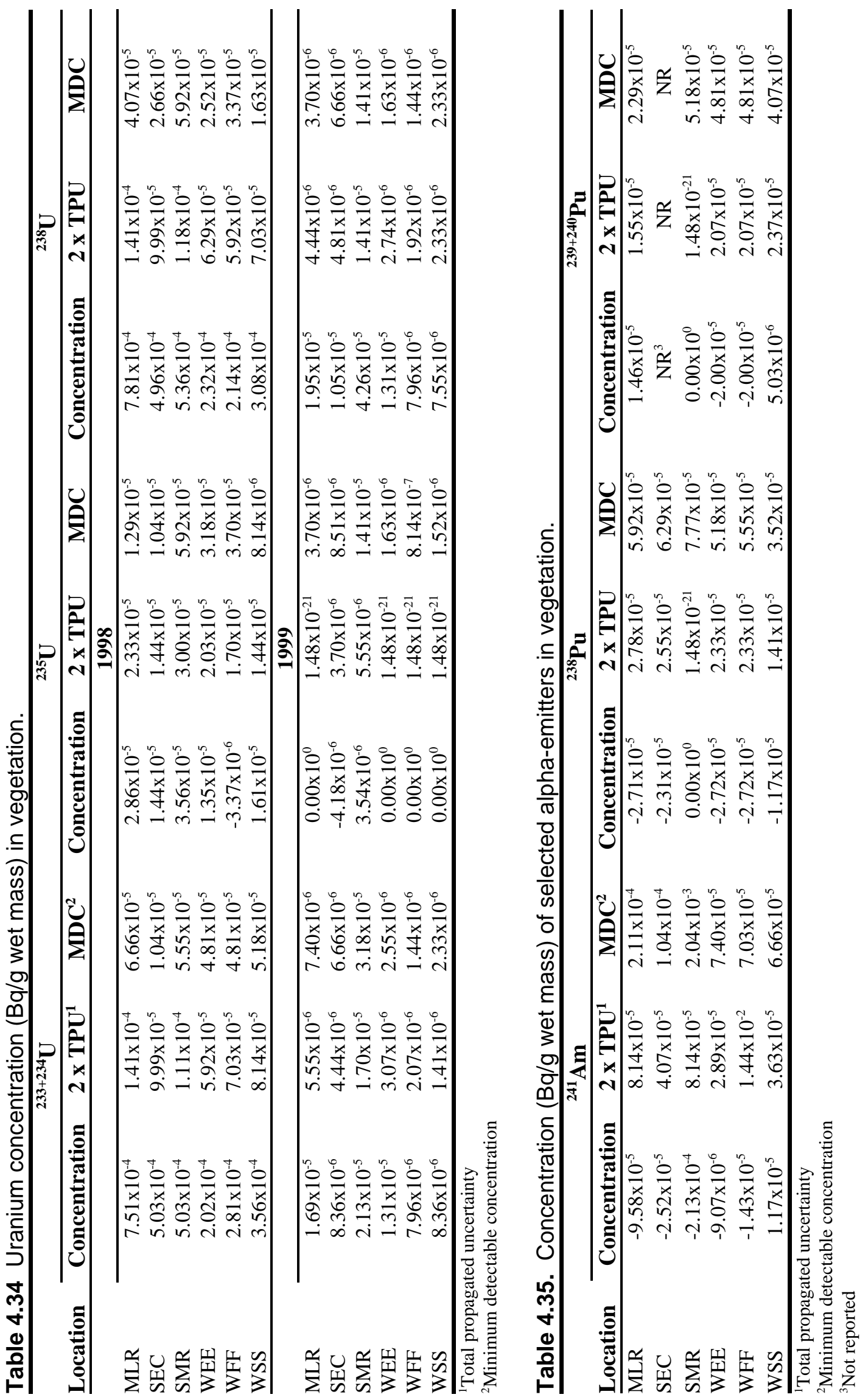


Table 4.36 Concentration (Bq/g wet mass) of beta and gamma-emitters in vegetation.

\begin{tabular}{|c|c|c|c|c|c|c|}
\hline Location & Concentration & $2 \times \mathrm{TPU}^{1}$ & $\mathrm{MDC}^{2}$ & Concentration & $2 \times$ TPU & MDC \\
\hline & \multicolumn{6}{|c|}{1998} \\
\hline & \multicolumn{3}{|c|}{${ }^{40} \mathbf{K}$} & \multicolumn{3}{|c|}{${ }^{60} \mathrm{Co}$} \\
\hline MLR & $2.46 \times 10^{-1}$ & $5.92 \times 10^{-2}$ & $3.70 \times 10^{-2}$ & $-4.62 \times 10^{-3}$ & $2.89 \times 10^{-3}$ & $2.22 \times 10^{-3}$ \\
\hline SEC & $1.30 \times 10^{-1}$ & $1.18 \times 10^{-1}$ & $1.33 \times 10^{-1}$ & $-9.06 \times 10^{-3}$ & $7.03 \times 10^{-3}$ & $6.29 \times 10^{-3}$ \\
\hline SMR & $4.70 \times 10^{-1}$ & $6.66 \times 10^{-2}$ & $1.89 \times 10^{-2}$ & $5.62 \times 10^{-3}$ & $2.07 \times 10^{-3}$ & $2.48 \times 10^{-3}$ \\
\hline WEE & $2.46 \times 10^{-1}$ & $9.62 \times 10^{-2}$ & $8.51 \times 10^{-2}$ & $3.67 \times 10^{-3}$ & $4.07 \times 10^{-3}$ & $3.70 \times 10^{-3}$ \\
\hline WFF & $1.69 \times 10^{-1}$ & $9.25 \times 10^{-2}$ & $9.62 \times 10^{-2}$ & $-5.66 \times 10^{-3}$ & $4.44 \times 10^{-3}$ & $3.55 \times 10^{-3}$ \\
\hline \multirow[t]{2}{*}{ WSS } & $2.11 \times 10^{-1}$ & $4.07 \times 10^{-2}$ & $1.78 \times 10^{-2}$ & $-5.18 \times 10^{-4}$ & $2.11 \times 10^{-3}$ & $2.11 \times 10^{-3}$ \\
\hline & \multicolumn{3}{|c|}{${ }^{90} \mathrm{Sr}$} & \multicolumn{3}{|c|}{${ }^{137} \mathrm{Cs}$} \\
\hline MLR & $-3.30 \times 10^{-3}$ & $3.33 \times 10^{-3}$ & $5.92 \times 10^{-3}$ & $5.33 \times 10^{-4}$ & $2.48 \times 10^{-3}$ & $4.07 \times 10^{-3}$ \\
\hline SEC & $4.51 \times 10^{-3}$ & $4.81 \times 10^{-3}$ & $8.14 \times 10^{-3}$ & $2.38 \times 10^{-3}$ & $6.29 \times 10^{-3}$ & $5.92 \times 10^{-3}$ \\
\hline SMR & $-4.07 \times 10^{-3}$ & $3.44 \times 10^{-3}$ & $6.29 \times 10^{-3}$ & $1.32 \times 10^{-3}$ & $2.15 \times 10^{-3}$ & $1.96 \times 10^{-3}$ \\
\hline WEE & $2.06 \times 10^{-2}$ & $1.15 \times 10^{-2}$ & $1.74 \times 10^{-2}$ & $-4.33 \times 10^{-3}$ & $5.18 \times 10^{-3}$ & $4.44 \times 10^{-3}$ \\
\hline WFF & $1.71 \times 10^{-2}$ & $1.04 \times 10^{-2}$ & $1.63 \times 10^{-2}$ & $2.86 \times 10^{-3}$ & $4.07 \times 10^{-3}$ & $4.07 \times 10^{-3}$ \\
\hline \multirow[t]{3}{*}{ WSS } & $3.68 \times 10^{-3}$ & $3.37 \times 10^{-3}$ & $5.18 \times 10^{-3}$ & $-6.10 \times 10^{-4}$ & $1.78 \times 10^{-3}$ & $1.52 \times 10^{-3}$ \\
\hline & \multicolumn{6}{|c|}{1999} \\
\hline & \multicolumn{3}{|c|}{${ }^{40} \mathrm{~K}$} & \multicolumn{3}{|c|}{${ }^{60} \mathrm{Co}$} \\
\hline MLR & $4.77 \times 10^{0}$ & $7.03 \times 10^{-1}$ & $1.11 \times 10^{-1}$ & $1.12 \times 10^{-2}$ & $1.30 \times 10^{-2}$ & $2.52 \times 10^{-2}$ \\
\hline SEC & $5.48 \times 10^{0}$ & $8.51 \times 10^{-1}$ & $1.15 \times 10^{-1}$ & $1.49 \times 10^{-2}$ & $1.37 \times 10^{-2}$ & $2.78 \times 10^{-2}$ \\
\hline SMR & $6.07 \times 10^{0}$ & $8.51 \times 10^{-1}$ & $1.37 \times 10^{-1}$ & $1.54 \times 10^{-2}$ & $1.37 \times 10^{-2}$ & $2.63 \times 10^{-2}$ \\
\hline WEE & $4.48 \times 10^{-4}$ & $6.29 \times 10^{-3}$ & $6.66 \times 10^{-2}$ & $-4.66 \times 10^{-3}$ & $9.99 \times 10^{-3}$ & $1.70 \times 10^{-2}$ \\
\hline WFF & $4.51 \times 10^{0}$ & $7.03 \times 10^{-1}$ & $1.44 \times 10^{-1}$ & $1.10 \times 10^{-3}$ & $1.26 \times 10^{-2}$ & $2.37 \times 10^{-2}$ \\
\hline \multirow[t]{2}{*}{ WSS } & $5.00 \times 10^{0}$ & $7.40 \times 10^{-1}$ & $9.25 \times 10^{-2}$ & $-2.30 \times 10^{-3}$ & $1.07 \times 10^{-2}$ & $1.92 \times 10^{-2}$ \\
\hline & \multicolumn{3}{|c|}{${ }^{90} \mathrm{Sr}$} & \multicolumn{3}{|c|}{${ }^{137} \mathrm{Cs}$} \\
\hline MLR & $2.35 \times 10^{-3}$ & $1.04 \times 10^{-3}$ & $1.48 \times 10^{-3}$ & $7.44 \times 10^{-3}$ & $9.25 \times 10^{-3}$ & $1.81 \times 10^{-2}$ \\
\hline SEC & $4.48 \times 10^{-3}$ & $1.55 \times 10^{-3}$ & $2.04 \times 10^{-3}$ & $9.51 \times 10^{-3}$ & $7.77 \times 10^{-3}$ & $1.67 \times 10^{-2}$ \\
\hline SMR & $2.64 \times 10^{-3}$ & $1.55 \times 10^{-3}$ & $2.29 \times 10^{-3}$ & $7.62 \times 10^{-3}$ & $9.25 \times 10^{-3}$ & $1.63 \times 10^{-2}$ \\
\hline WEE & $5.44 \times 10^{-3}$ & $1.37 \times 10^{-3}$ & $1.48 \times 10^{-3}$ & $2.72 \times 10^{-3}$ & $5.92 \times 10^{-3}$ & $1.11 \times 10^{-2}$ \\
\hline WFF & $7.62 \times 10^{-3}$ & $1.33 \times 10^{-3}$ & $9.99 \times 10^{-4}$ & $-2.92 \times 10^{-3}$ & $9.99 \times 10^{-3}$ & $1.78 \times 10^{-2}$ \\
\hline WSS & $4.07 \times 10^{-3}$ & $1.41 \times 10^{-3}$ & $1.81 \times 10^{-3}$ & $-1.22 \times 10^{-4}$ & $6.66 \times 10^{-3}$ & $1.22 \times 10^{-2}$ \\
\hline
\end{tabular}

${ }^{1}$ Total propagated uncertainty

${ }^{2}$ Minimum detectable concentration 


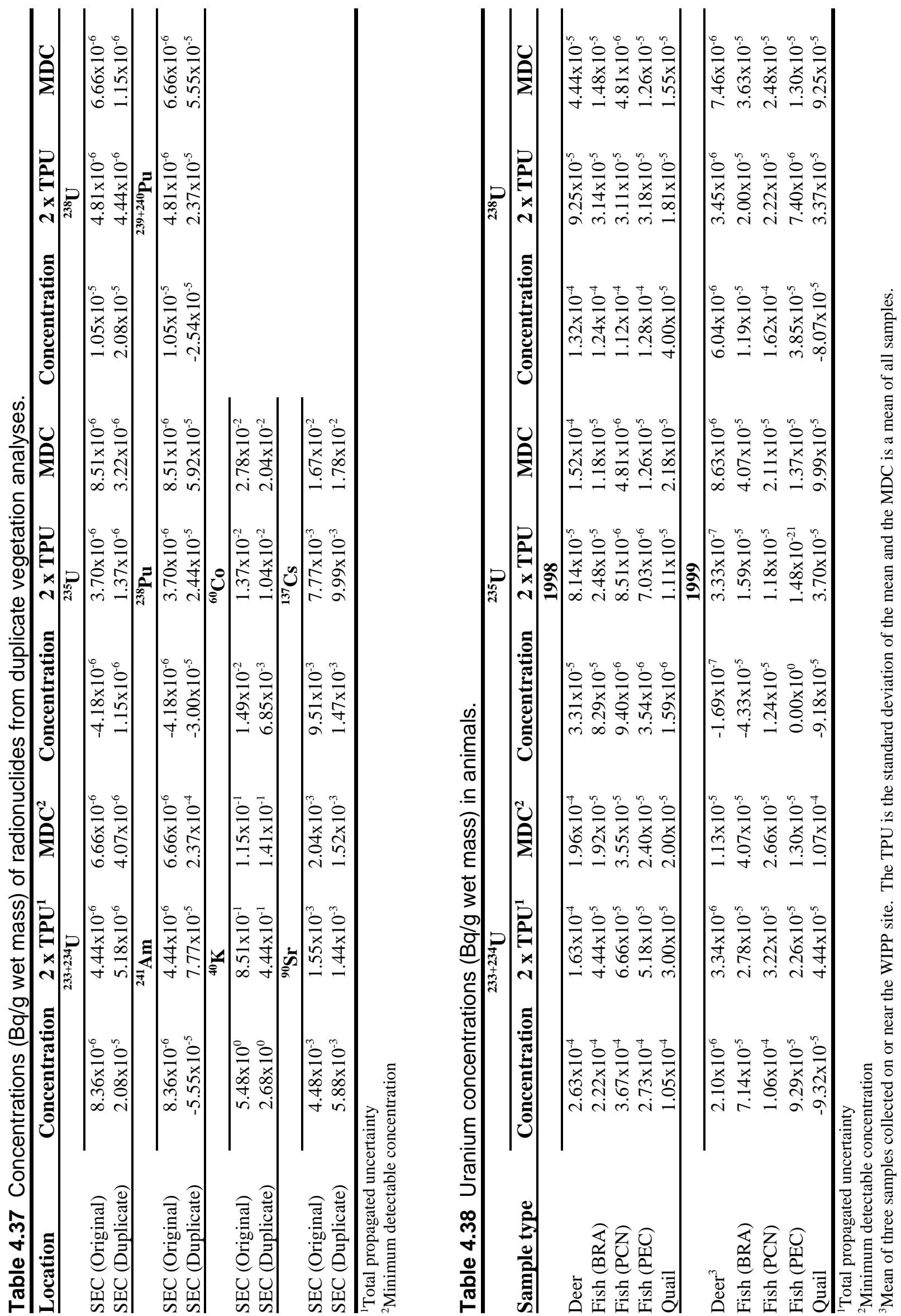




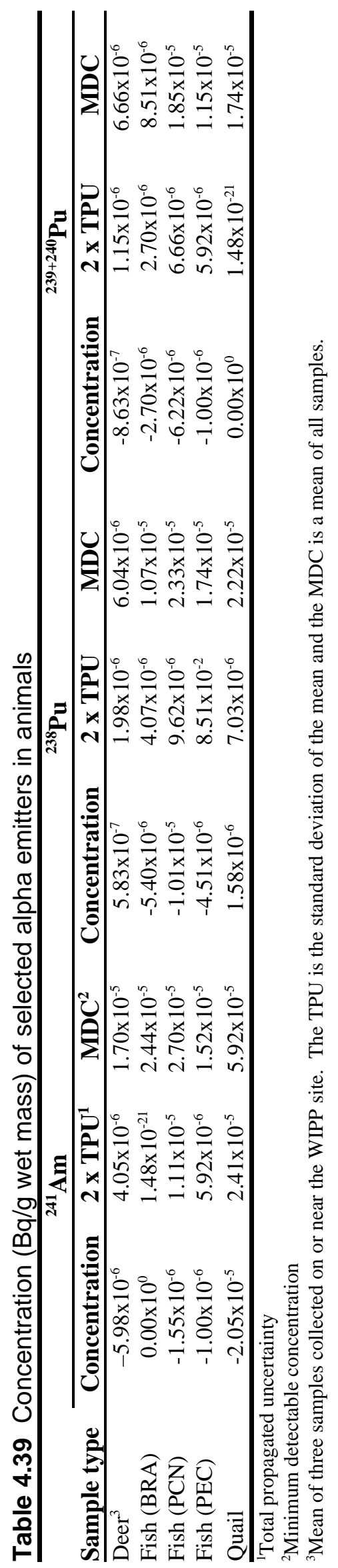


Table 4.40 Concentrations (Bq/g wet mass) of selected beta- and gamma-emitters in animals.

\begin{tabular}{|c|c|c|c|c|c|c|}
\hline Sample type & Concentration & $2 \times \mathrm{TPU}^{1}$ & MDC $^{2}$ & Concentration & $2 \times \mathrm{TPU}$ & MDC \\
\hline & \multicolumn{3}{|c|}{${ }^{40} K$} & \multicolumn{3}{|c|}{${ }^{60} \mathrm{Co}$} \\
\hline Deer $^{3}$ & $1.41 \times 10^{-1}$ & $4.62 \times 10^{-2}$ & $1.02 \times 10^{-1}$ & $\mathrm{NR}^{4}$ & NR & $4.44 \times 10^{-3}$ \\
\hline Fish (BRA) & $3.41 \times 10^{-1}$ & $7.77 \times 10^{-2}$ & $2.66 \times 10^{-2}$ & $-2.44 \times 10^{-3}$ & $3.11 \times 10^{-3}$ & $4.07 \times 10^{-3}$ \\
\hline Fish (PCN) & $3.46 \times 10^{-1}$ & $8.88 \times 10^{-2}$ & $4.81 \times 10^{-2}$ & $9.62 \times 10^{-4}$ & $3.70 \times 10^{-3}$ & $6.29 \times 10^{-3}$ \\
\hline Fish (PEC) & $3.74 \times 10^{-1}$ & $8.14 \times 10^{-2}$ & $2.96 \times 10^{-2}$ & $9.25 \times 10^{-4}$ & $2.29 \times 10^{-3}$ & $4.81 \times 10^{-3}$ \\
\hline \multirow[t]{2}{*}{ Quail } & $1.38 \times 10^{-1}$ & $2.63 \times 10^{-2}$ & $2.33 \times 10^{-2}$ & NR & NR & $1.67 \times 10^{-3}$ \\
\hline & \multicolumn{3}{|c|}{${ }^{90} \mathrm{Sr}$} & \multicolumn{3}{|c|}{${ }^{137} \mathrm{Cs}$} \\
\hline Deer & $-2.16 \times 10^{-4}$ & $1.11 \times 10^{-4}$ & $3.49 \times 10^{-4}$ & NR & NR & $4.44 \times 10^{-3}$ \\
\hline Fish (BRA) & $2.55 \times 10^{-4}$ & $2.59 \times 10^{-4}$ & $4.07 \times 10^{-4}$ & $1.48 \times 10^{-4}$ & $1.67 \times 10^{-3}$ & $3.33 \times 10^{-3}$ \\
\hline Fish $(\mathrm{PCN})$ & $7.40 \times 10^{-4}$ & $3.70 \times 10^{-4}$ & $5.55 \times 10^{-4}$ & $4.44 \times 10^{-4}$ & $2.74 \times 10^{-3}$ & $5.18 \times 10^{-3}$ \\
\hline Fish (PEC) & $4.59 \times 10^{-4}$ & $2.18 \times 10^{-4}$ & $3.15 \times 10^{-4}$ & $1.74 \times 10^{-3}$ & $1.96 \times 10^{-3}$ & $4.07 \times 10^{-3}$ \\
\hline Quail & $7.03 \times 10^{-4}$ & $6.66 \times 10^{-4}$ & $1.07 \times 10^{-3}$ & NR & NR & $1.41 \times 10^{-3}$ \\
\hline
\end{tabular}

${ }^{1}$ Total propagated uncertainty

${ }^{2}$ Minimum detectable concentration

${ }^{3}$ Mean of three samples collected on or near the WIPP site. The TPU is the standard deviation of the mean and the MDC is a mean of all samples.

${ }^{4}$ Not reported 


\section{Chapter 5 \\ Environmental Nonradiological Program Information}

This chapter discusses nonradiological environmental surveillance data collected between January 1 and December 31, 1999. Nonradiological programs at WIPP include the following subprograms: land management, including reclamation and restoration of disturbed lands; oil and gas surveillance; wildlife population monitoring (all discussed in Chapter 2, "Environmental Program Information"); and meteorological monitoring. In addition to the nonradiological environmental surveillance programs, VOCs were monitored to comply with the provisions of WIPP's hazardous waste permit, and liquid effluent monitoring was conducted in accordance with WIPP's Sewage System Discharge Plan (DP-831). The results of the environmental monitoring activities and discussions are presented in Chapters 4, 5, and 6 of this report.

\subsection{Principal Functions of Nonradio- logical Sampling}

The principal functions of the nonradiological environmental surveillance program are to:

- assess the impacts of WIPP construction and operations activities on the surrounding ecosystem;

- monitor ecological conditions in the Los Medaños region;

- investigate unusual or unexpected elements in the ecological databases;

- provide environmental data which are important to the mission of the WIPP project, but which have not or will not be acquired by other programs; and

- comply with applicable commitments identified with existing agreements (e.g., BLM/DOE MOU, Interagency Agreements, Agreements in Principle, etc.).

\subsection{WIPP Raptor Program}

WIPP, and the region surrounding it, is widely recognized for its concentration and diversity of raptors. The area is home to several raptor species of special concern, including Harris' hawks, Swainson's hawks, burrowing owls, and barn owls, as well as other species.

DOE, the BLM, and other government agencies are aware of the value and importance of protecting and monitoring raptor populations. To assist in this effort at WIPP, the BLM and DOE established the WRP in the early 1990s to monitor and protect raptors on the WIPP site, and to educate site workers and the public about these birds. The WRP is administrated by the WIPP Environmental Monitoring Program with input from the BLM and others. Scientific consultation, research direction, and field operations are conducted by scientists from Sonora Environmental Consultants, Inc., a private firm specializing in ecological research, wildlife inventory and monitoring, and environmental education programs (Dawson et al. 2000).

Raptor research at WIPP began in 1981 when DOE initiated a study of the social behavior of Harris' hawks conducted by the University of New Mexico. Research results revealed the extent of the overall raptor population, and provided new information about raptor species in the area. In the late 1980s, the BLM designated the Los Medaños Raptor Area, which included the WIPP site, as a National Key Raptor Area. This designation served as a catalyst for the development of the WRP.

Simultaneously, DOE reorganized its program to encompass expanded objectives. A significant addition to the program was the incorporation of an environmental education outreach effort. The primary objectives of the education program were 
to heighten public awareness of raptors in southeastern New Mexico and encourage environmentally responsible behavior regarding raptors and other wildlife. A large part of the educational outreach program is providing raptor education for local school children. Presentations using live animals are made to school children throughout New Mexico as well as to other organized groups.

The WRP presently serves four significant functions:

- Wildlife Monitoring The WRP provides DOE, BLM, and other agencies with current information about the status of raptor populations in and around WIPP.

- Scientific Research WRP staff conduct research on topics that contribute to the understanding of raptors in the desert southwest.

- Community Outreach The program offers a community service by providing educational programs to schools and organized groups.

- Interagency Cooperation The WRP is funded by DOE, but works closely with several other federal and state agencies.

In 1999, research continued on long-term studies of productivity and population demographics of the raptor community in and around WIPP. One study specifically targeted the behavior ecology of the Harris' hawk, while another investigated breeding activity and nesting behavior of Swainson's hawks. Great horned owls, burrowing owls, and Chihuahuan ravens were also examined as part of the program. Data were collected on resident raptors within an area of approximately $2,253 \mathrm{~km}^{2}\left(870 \mathrm{mi}^{2}\right)$ in the vicinity of WIPP, with WIPP as the center of the area.

Precipitation in the WIPP vicinity was lower than average in 1999, continuing an eight-year trend of lower-than-average precipitation levels. Raptor productivity in deserts is directly influenced by precipitation levels, which is the most likely cause of ongoing low productivity of raptors in the WIPP area. Therefore, low population levels of raptors may be a result of natural climatic fluctuations.

"Nest tenure," or the long-term presence in a nest area, was low in 1999 compared to previous years for Harris' hawks. The percentage of known nesting territories that were occupied declined in 1999. Nesting densities also declined in 1999. In 1999, 12 instances of fall nesting by Harris' hawks were found, which was a dramatic increase over the average of three fall nesting attempts in past years. Data collected in this and past years support the idea that birds that are not caring for offspring from an earlier brood tend to nest in fall.

An ongoing study of the vegetation and physical features of nest sites continued in 1999. A series of measurements, such as tree crown height, height of nest, and distance to humanmade features (e.g., roads) were made at active nest sites within one month after the young fledged. The measurements will be used to create nesting habitat profiles to examine the effects on productivity of human-made habitat features.

A pilot study was initiated in 1999 to evaluate methods for observing Swainson's hawks at the nest. Researchers observed nesting behavior from fully-enclosed, elevated blinds located within 10 $\mathrm{m}(33 \mathrm{ft})$ of active nests.

Dead raptors were regularly encountered by researchers who were conducting nest surveys and driving through the study area. All carcasses, loose feathers, or bones found were investigated in detail. When a dead bird was found, the cause of death could usually be determined through visual examination; however, in cases that could not be confidently determined in the field, the carcasses were taken to local veterinarians to be examined and x-rayed for bullets or lead fragments. Between 1996 and 1999, 105 dead raptors were found during WRP research. While many of these birds died due to natural causes, such as predation, others died as a result of human actions. Human-related causes of death included electrocution by utility lines, gunshots, collisions with automobiles, drowning in livestock watering tanks, and drowning in oil pits (a by-product of 
the local oil industry). For more information on the WIPP Raptor Program, see WIPP Raptor Program 1999 Annual Report (Dawson et al. 2000).

\subsection{Meteorology}

The primary WIPP meteorological station is located $600 \mathrm{~m}(1,970 \mathrm{ft})$ northeast of the Waste Handling Building. The main function of the station is to provide data for atmospheric dispersion modeling. The station measures and records wind speed, wind direction, and temperature at elevations of 2,10 , and $50 \mathrm{~m}(6.5$, 33 , and $165 \mathrm{ft}$ ). The station records ground-level measurements of barometric pressure, relative humidity, precipitation, and solar radiation.

In addition to the primary meteorological station, the WIPP Far Field Station is located $1,000 \mathrm{~m}(3,300 \mathrm{ft})$ northwest of the Waste Handling Building. At the WIPP Far Field Station, a secondary meteorological station measures and records temperature and atmospheric pressure at ground level and wind speed and wind direction at $10 \mathrm{~m}$ (33 ft).

\subsubsection{Climatic Data}

The annual precipitation at the WIPP site for 1999 was $200 \mathrm{~mm}$ (7.8 in), which was $41 \mathrm{~mm}$ (1.6 in) greater than the previous year's rainfall. The annual precipitation for 1999 was 25 percent greater than that recorded for 1998, but this was the second consecutive year of below-average rainfall in the area. Figure 5.1 displays the monthly precipitation at WIPP.

The mean annual temperature for the WIPP area in 1999 was $18^{\circ} \mathrm{C}\left(64^{\circ} \mathrm{F}\right)$. The mean monthly temperatures for the WIPP area ranged from $6^{\circ} \mathrm{C}$ $\left(43^{\circ} \mathrm{F}\right)$ during December to $28^{\circ} \mathrm{C}\left(83^{\circ} \mathrm{F}\right)$ in August. Generally, maximum temperatures occurred from June through September, while minimum temperatures occurred in January, February, and December, as illustrated in Figures 5.2, 5.3, and 5.4 and Tables 5.1, 5.2, and 5.3. The lowest recorded temperature was $-10^{\circ} \mathrm{C}\left(14^{\circ} \mathrm{F}\right)$ on December 15. The maximum recorded temperature was $41.6^{\circ} \mathrm{C}\left(107^{\circ} \mathrm{F}\right)$ on July 1 .

\subsubsection{Wind Direction and Wind Speed}

Winds in the WIPP area in 1999 blew predominantly from the southeast $\left(135^{\circ}\right)$. Seasonal weather systems move through this area, briefly altering the predominant southeasterly winds and sometimes resulting in violent convectional storms. Wind speed measured at the 10 -m (33-ft) level were calm (less than 0.5 meters per second $[\mathrm{m} / \mathrm{s}])(1.1$ miles per hour $[\mathrm{mph}])$ about 0.5 percent of the time. At the $10-\mathrm{m}$ level, winds of 3.7 through $6.3 \mathrm{~m} / \mathrm{s}$ ( 8.3 to $14.1 \mathrm{mph}$ ) were the most prevalent over 1999 , occurring 37.4 percent of the time. Figures 5.5, 5.6, and 5.7 and Tables $5.4,5.5$, and 5.6 display the annual wind data at WIPP for 1999.

\subsection{Volatile Organic Compound Mon- itoring}

Volatile organic compound monitoring was implemented on April 21, 1997, in accordance with WP12-VC.01, Confirmatory Volatile Organic Compound Monitoring Program. The program is designed to measure VOC concentrations attributable to hazardous waste disposal units (panels) which are either open and in the process of being filled or which are full and have been closed. Nine target compounds, which contribute approximately 99 percent of the calculated human health risks from RCRA constituents, were chosen for monitoring. These target compounds are 1,1-dichloroethylene, methylene chloride, chloroform, 1,1,1trichloroethane, carbon tetrachloride, 1,2-dichloroethane, toluene, chlorobenzene, and 1,1,2,2-tetrachloroethane.

Sampling for target compounds is done at two air monitoring stations. The stations are identified as VOC-A, located downstream from hazardous waste disposal unit Panel 1 in Drift E300, and VOC-B, located upstream from Panel 1. In 1999, VOC-B was located in Drift S1950. As waste is placed in new panels, VOC-B will be relocated to ensure that it samples circulated mine air before it passes the waste panels. The location of VOC-A will not change. 


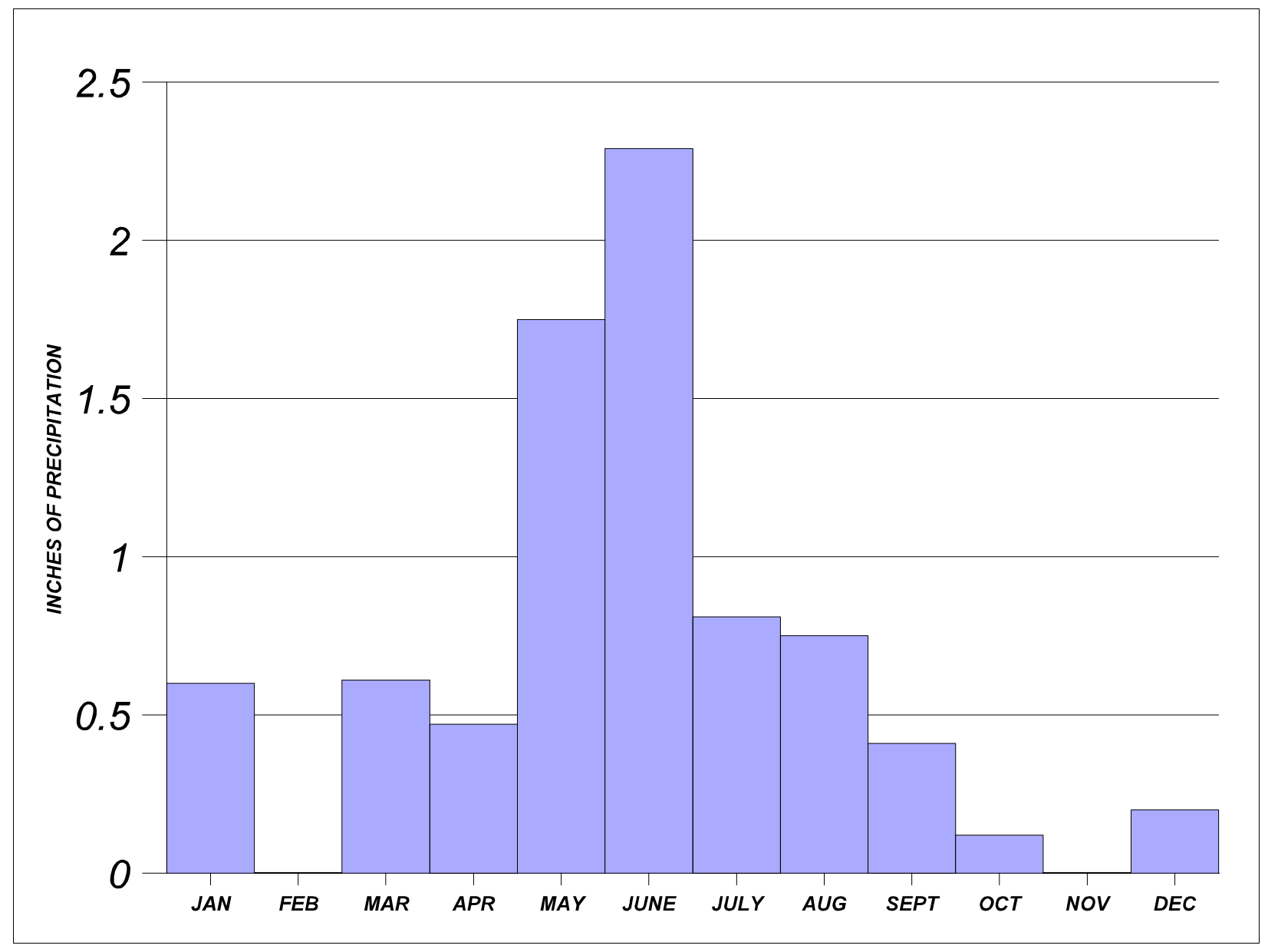

Figure 5.1 1999 Precipitation at WIPP 


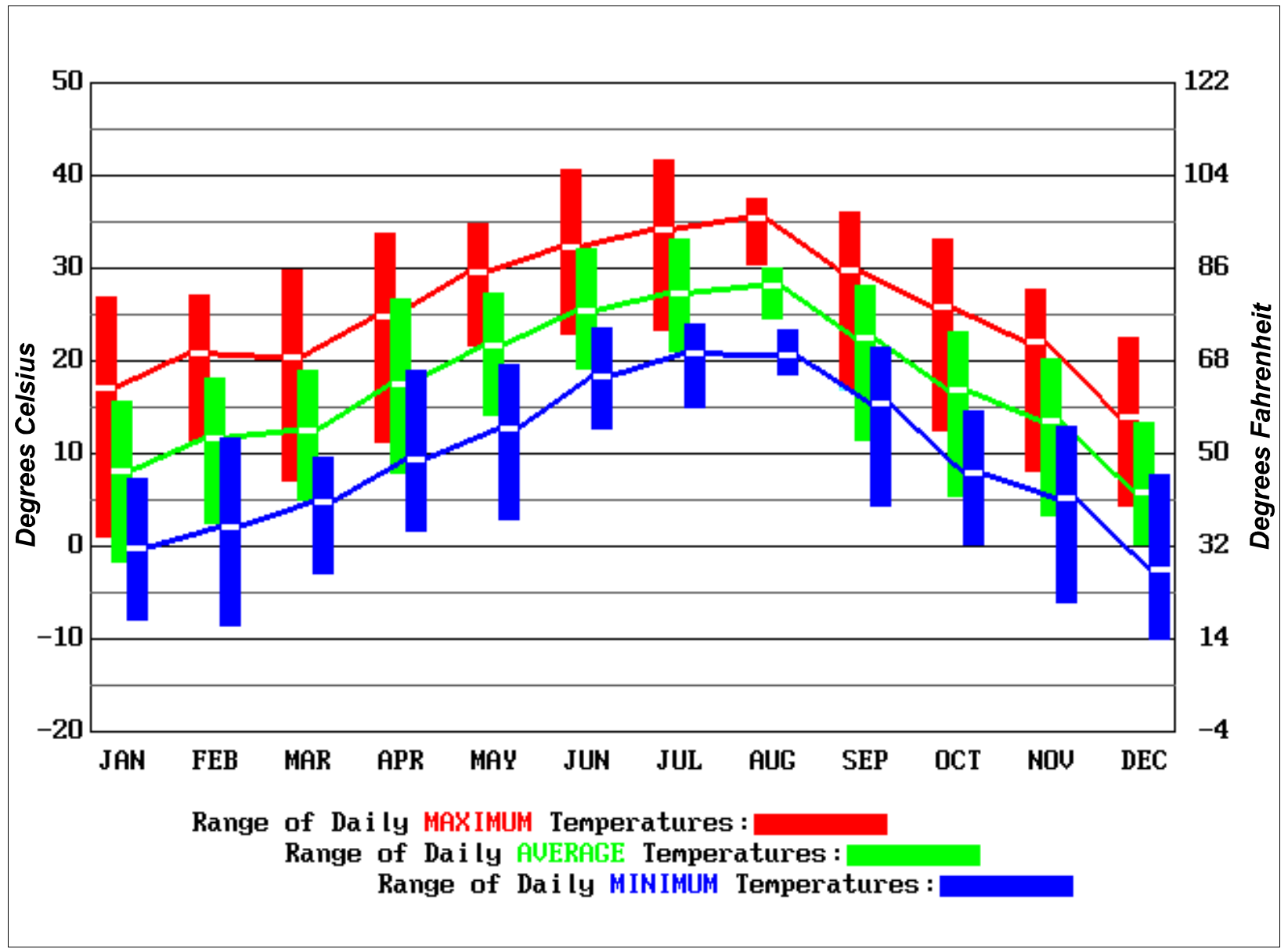

Figure 5.2 1999 WIPP Site Temperature at 2-Meter Height

Table 5.1 A summary of 1999 temperature observations at 2-meter height.

\begin{tabular}{|c|c|c|c|c|c|c|c|c|c|}
\hline Month & $\begin{array}{c}\text { Max of } \\
\text { Daily } \\
\text { Highs } \\
\left({ }^{\circ} \mathrm{C}\right) \\
\end{array}$ & $\begin{array}{c}\text { Avg of } \\
\text { Daily } \\
\text { Highs } \\
\left({ }^{\circ} \mathrm{C}\right) \\
\end{array}$ & $\begin{array}{c}\text { Min of } \\
\text { Daily } \\
\text { Highs } \\
\left({ }^{\circ} \mathrm{C}\right) \\
\end{array}$ & $\begin{array}{c}\text { Max } \\
\text { of Daily } \\
\text { Averages } \\
\left({ }^{\circ} \mathrm{C}\right) \\
\end{array}$ & $\begin{array}{c}\text { Avg of } \\
\text { Daily } \\
\text { Averages } \\
\left({ }^{\circ} \mathrm{C}\right) \\
\end{array}$ & $\begin{array}{c}\text { Min of } \\
\text { Daily } \\
\text { Averages } \\
\left({ }^{\circ} \mathrm{C}\right) \\
\end{array}$ & $\begin{array}{c}\text { Max of } \\
\text { Daily } \\
\text { Lows } \\
\left({ }^{\circ} \mathrm{C}\right) \\
\end{array}$ & $\begin{array}{c}\text { Avg of } \\
\text { Daily } \\
\text { Lows } \\
\left({ }^{\circ} \mathrm{C}\right) \\
\end{array}$ & $\begin{array}{c}\text { Min of } \\
\text { Daily } \\
\text { Lows } \\
\left({ }^{\circ} \mathrm{C}\right) \\
\end{array}$ \\
\hline Jan & 27.0 & 17.0 & 1.1 & 15.5 & 8.2 & -1.6 & 7.3 & -0.1 & -8.0 \\
\hline Feb & 27.2 & 20.8 & 11.4 & 18.1 & 11.7 & 2.4 & 11.6 & 2.2 & -8.6 \\
\hline Mar & 29.9 & 20.5 & 7.0 & 19.0 & 12.5 & 5.0 & 9.6 & 4.9 & -2.9 \\
\hline Apr & 33.8 & 24.8 & 11.2 & 26.6 & 17.4 & 7.9 & 19.0 & 9.4 & 1.7 \\
\hline May & 34.7 & 29.6 & 21.7 & 27.2 & 21.6 & 14.1 & 19.5 & 12.6 & 2.8 \\
\hline Jun & 40.6 & 32.3 & 23.0 & 32.1 & 25.4 & 19.2 & 23.4 & 18.3 & 12.6 \\
\hline Jul & 41.6 & 34.1 & 23.3 & 33.0 & 27.3 & 21.1 & 24.0 & 20.8 & 15.0 \\
\hline Aug & 37.5 & 35.3 & 30.5 & 30.1 & 28.1 & 24.6 & 23.3 & 20.7 & 18.5 \\
\hline Sep & 36.0 & 29.8 & 16.9 & 28.2 & 22.4 & 11.6 & 21.4 & 15.5 & 4.3 \\
\hline Oct & 33.0 & 25.8 & 12.5 & 23.2 & 16.9 & 5.4 & 14.6 & 8.0 & 0.2 \\
\hline Nov & 27.7 & 22.1 & 8.2 & 20.2 & 13.6 & 3.4 & 12.9 & 5.2 & -6.0 \\
\hline Dec & 22.4 & 14.0 & 4.5 & 13.4 & 5.9 & 0.3 & 7.8 & -2.5 & -10.1 \\
\hline Annual & 41.6 & 25.5 & 1.1 & 33.0 & 17.6 & -1.6 & 24.0 & 9.6 & -10.1 \\
\hline
\end{tabular}




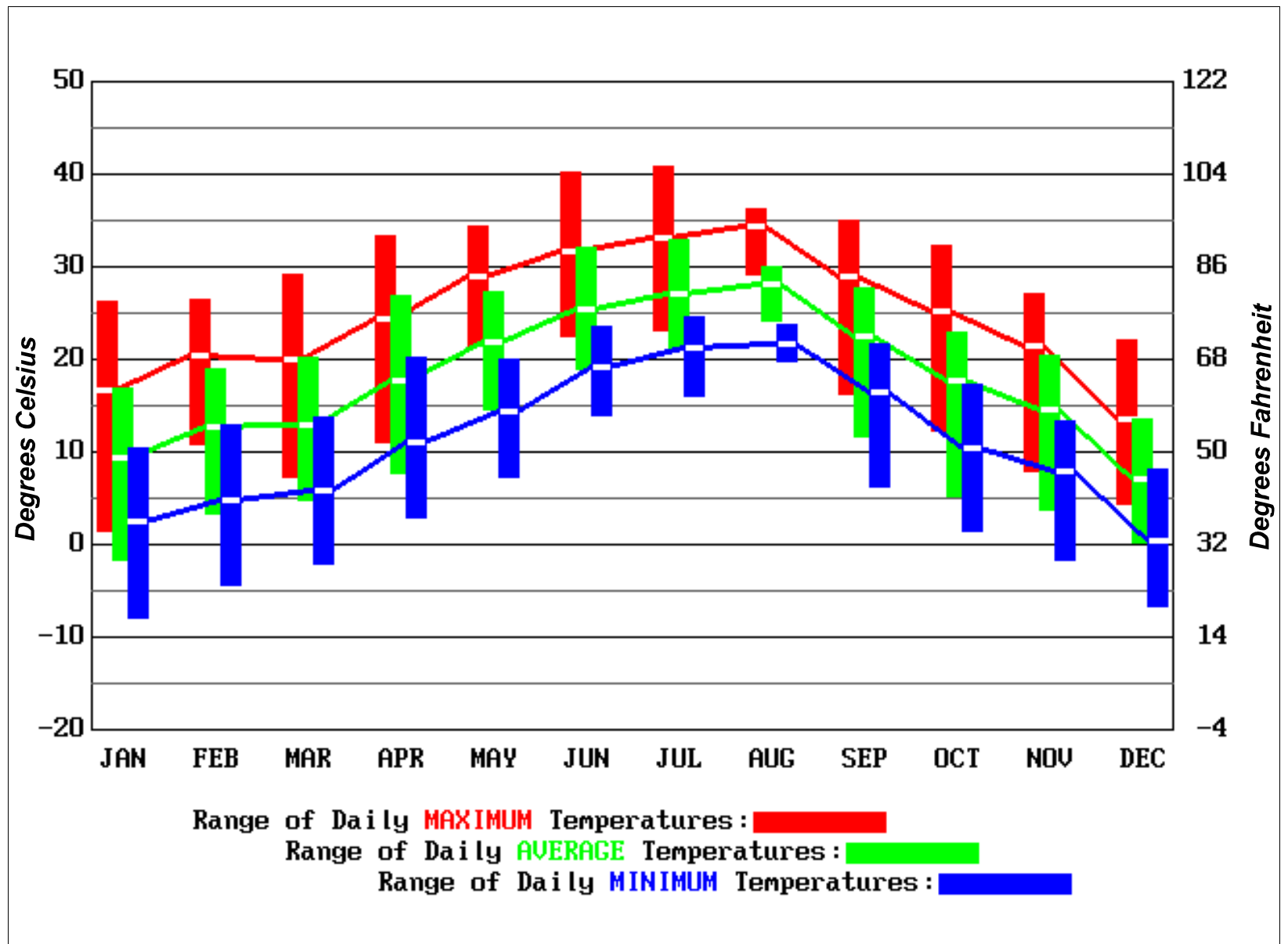

Figure 5.3 1999 WIPP Site Temperature at 10-Meter Height

Table 5.2 A summary of 1999 temperature observations at 10-meter height.

\begin{tabular}{|c|c|c|c|c|c|c|c|c|c|}
\hline Month & $\begin{array}{c}\text { Max of } \\
\text { Daily } \\
\text { Highs } \\
\left({ }^{\circ} \mathbf{C}\right) \\
\end{array}$ & $\begin{array}{c}\text { Avg of } \\
\text { Daily } \\
\text { Highs } \\
\left({ }^{\circ} \mathrm{C}\right) \\
\end{array}$ & $\begin{array}{c}\text { Min of } \\
\text { Daily } \\
\text { Highs } \\
\left({ }^{\circ} \mathrm{C}\right) \\
\end{array}$ & $\begin{array}{c}\text { Max of } \\
\text { Daily } \\
\text { Averages } \\
\left({ }^{\circ} \mathrm{C}\right) \\
\end{array}$ & $\begin{array}{c}\text { Avg of } \\
\text { Daily } \\
\text { Averages } \\
\left({ }^{\circ} \mathrm{C}\right) \\
\end{array}$ & $\begin{array}{c}\text { Min of } \\
\text { Daily } \\
\text { Averages } \\
\left({ }^{\circ} \mathrm{C}\right) \\
\end{array}$ & $\begin{array}{c}\text { Max of } \\
\text { Daily } \\
\text { Lows } \\
\left({ }^{\circ} \mathrm{C}\right) \\
\end{array}$ & $\begin{array}{l}\text { Avg of } \\
\text { Daily } \\
\text { Lows } \\
\left({ }^{\circ} \mathrm{C}\right) \\
\end{array}$ & $\begin{array}{c}\text { Min of } \\
\text { Daily } \\
\text { Lows } \\
\left({ }^{\circ} \mathrm{C}\right) \\
\end{array}$ \\
\hline Jan & 26.2 & 16.6 & 1.5 & 16.9 & 9.5 & -1.8 & 10.3 & 2.6 & -7.9 \\
\hline $\mathrm{Feb}$ & 26.4 & 20.3 & 10.8 & 18.9 & 12.6 & 3.4 & 12.9 & 4.8 & -4.5 \\
\hline Mar & 29.1 & 20.0 & 7.3 & 20.2 & 13.0 & 4.7 & 13.8 & 5.9 & -2.1 \\
\hline Apr & 33.3 & 24.3 & 10.9 & 27.0 & 17.8 & 7.8 & 20.2 & 11.0 & 2.9 \\
\hline May & 34.4 & 29.0 & 21.5 & 27.4 & 21.9 & 14.6 & 20.1 & 14.3 & 7.3 \\
\hline Jun & 40.1 & 31.7 & 22.6 & 32.1 & 25.4 & 19.0 & 23.6 & 19.1 & 14.1 \\
\hline Jul & 40.9 & 33.1 & 23.2 & 32.9 & 27.0 & 21.1 & 24.6 & 21.2 & 16.0 \\
\hline Aug & 36.3 & 34.3 & 29.2 & 30.1 & 28.1 & 24.2 & 23.7 & 21.6 & 19.8 \\
\hline Sep & 35.1 & 29.0 & 16.3 & 27.8 & 22.5 & 11.7 & 21.6 & 16.5 & 6.7 \\
\hline Oct & 32.3 & 25.1 & 12.2 & 22.9 & 17.6 & 5.3 & 17.3 & 10.4 & 1.5 \\
\hline Nov & 27.1 & 21.5 & 7.9 & 20.5 & 14.6 & 3.7 & 13.3 & 7.9 & -1.8 \\
\hline Dec & 22.1 & 13.5 & 4.4 & 13.6 & 7.1 & 0.1 & 8.1 & 0.4 & -6.7 \\
\hline Annual & 40.9 & 24.9 & 1.5 & 32.9 & 18.1 & -1.8 & 24.6 & 11.3 & -7.9 \\
\hline
\end{tabular}




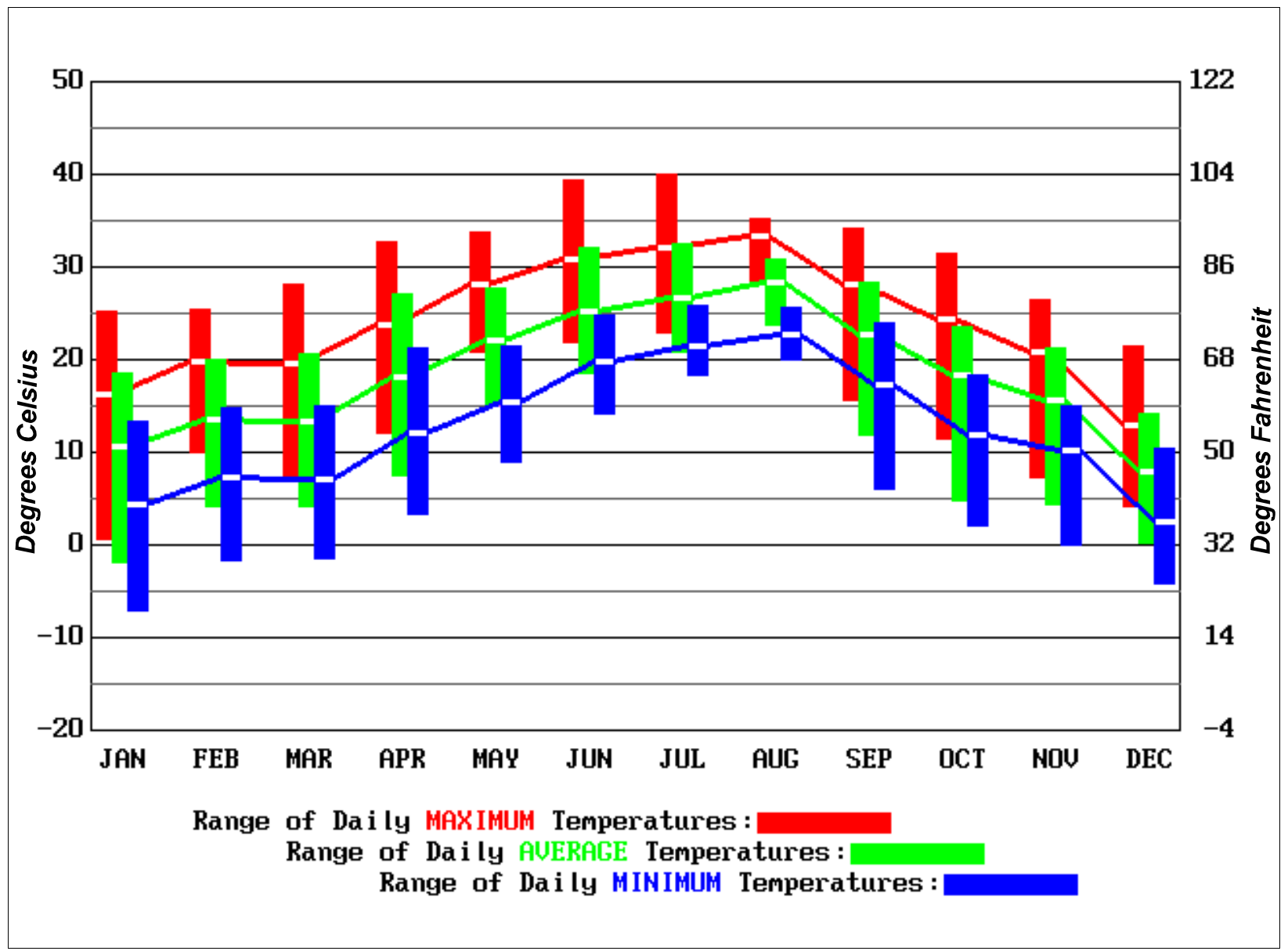

Figure 5.4 1999 WIPP Site Temperature at 50-Meter Height

Table 5.3 A summary of 1999 temperature observations at 50-meter height.

\begin{tabular}{|c|c|c|c|c|c|c|c|c|c|}
\hline Month & $\begin{array}{c}\text { Max of } \\
\text { Daily } \\
\text { Highs } \\
\left({ }^{\circ} \mathrm{C}\right) \\
\end{array}$ & $\begin{array}{c}\text { Avg of } \\
\text { Daily } \\
\text { Highs } \\
\left({ }^{\circ} \mathrm{C}\right) \\
\end{array}$ & $\begin{array}{c}\text { Min of } \\
\text { Daily } \\
\text { Highs } \\
\left({ }^{\circ} \mathrm{C}\right) \\
\end{array}$ & $\begin{array}{c}\text { Max of } \\
\text { Daily } \\
\text { Averages } \\
\left({ }^{\circ} \mathrm{C}\right) \\
\end{array}$ & $\begin{array}{c}\text { Avg of } \\
\text { Daily } \\
\text { Averages } \\
\left({ }^{\circ} \mathrm{C}\right) \\
\end{array}$ & $\begin{array}{c}\text { Min of } \\
\text { Daily } \\
\text { Averages } \\
\left({ }^{\circ} \mathrm{C}\right) \\
\end{array}$ & $\begin{array}{c}\text { Max of } \\
\text { Daily } \\
\text { Lows } \\
\left({ }^{\circ} \mathrm{C}\right) \\
\end{array}$ & $\begin{array}{c}\text { Avg of } \\
\text { Daily } \\
\text { Lows } \\
\left({ }^{\circ} \mathrm{C}\right) \\
\end{array}$ & $\begin{array}{l}\text { Min of } \\
\text { Daily } \\
\text { Lows } \\
\left({ }^{\circ} \mathrm{C}\right) \\
\end{array}$ \\
\hline Jan & 25.2 & 16.2 & 0.7 & 18.5 & 10.5 & -2.0 & 13.3 & 4.5 & -7.1 \\
\hline $\mathrm{Feb}$ & 25.4 & 19.8 & 10.1 & 20.1 & 13.5 & 4.1 & 14.8 & 7.2 & -1.7 \\
\hline Mar & 28.1 & 19.6 & 7.1 & 20.7 & 13.4 & 4.2 & 15.0 & 7.1 & -1.4 \\
\hline Apr & 32.7 & 23.7 & 12.1 & 27.1 & 18.1 & 7.5 & 21.2 & 12.1 & 3.3 \\
\hline May & 33.7 & 28.1 & 20.1 & 27.7 & 22.0 & 15.1 & 21.4 & 15.5 & 8.9 \\
\hline Jun & 39.4 & 30.9 & 21.8 & 32.1 & 25.3 & 18.5 & 24.8 & 19.8 & 14.2 \\
\hline Jul & 40.1 & 32.1 & 22.8 & 32.5 & 26.8 & 20.8 & 25.9 & 21.5 & 18.2 \\
\hline Aug & 35.2 & 33.3 & 28.2 & 30.7 & 28.3 & 23.7 & 25.7 & 22.8 & 20.1 \\
\hline Sep & 34.2 & 28.2 & 15.7 & 28.3 & 22.6 & 11.8 & 24.0 & 17.4 & 5.9 \\
\hline Oct & 31.5 & 24.4 & 11.5 & 23.6 & 18.4 & 4.8 & 18.4 & 11.9 & 2.1 \\
\hline Nov & 26.4 & 20.9 & 7.4 & 21.3 & 15.6 & 4.3 & 15.0 & 10.2 & 0.0 \\
\hline Dec & 21.5 & 13.0 & 4.2 & 14.2 & 7.9 & 0.2 & 10.5 & 2.6 & -4.1 \\
\hline Annual & 40.1 & 24.2 & 0.7 & 32.5 & 18.5 & -2.0 & 25.9 & 12.7 & -7.1 \\
\hline
\end{tabular}




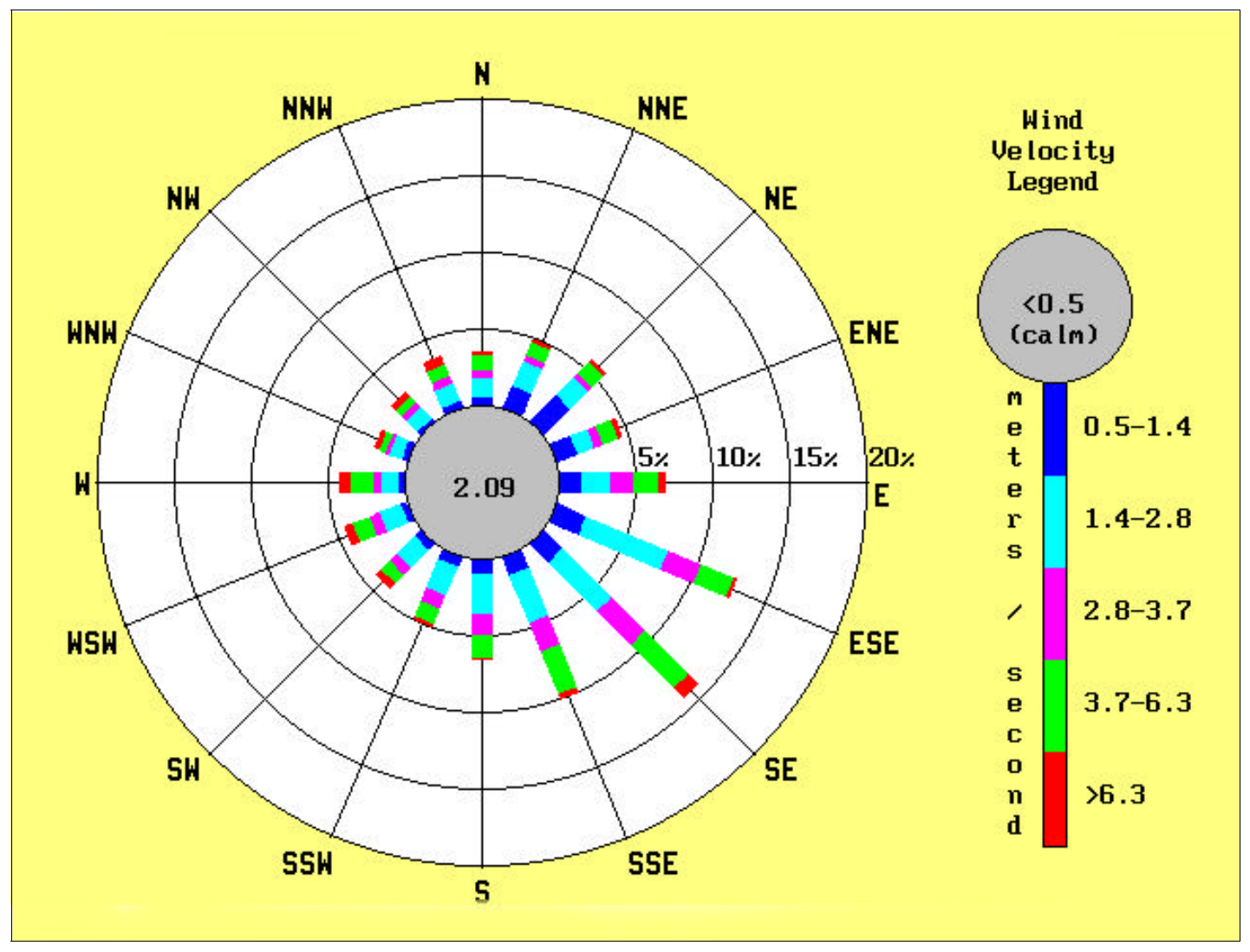

Figure 5.5 1999 WIPP Site Wind Rose at 2-Meter Height

Table 5.41999 wind frequencies at 2-meter height, stratified by direction and speed (percent).

\begin{tabular}{|c|c|c|c|c|c|c|c|}
\hline \multicolumn{8}{|c|}{ Wind Speed Range, meters/second } \\
\hline Direction & $\leq 0.5$ & $\underline{0.5-1.4}$ & 1.4-2.8 & 2.8-3.7 & $3.7-6.3$ & $\geq 6.3$ & Totals \\
\hline $\mathrm{N}$ & $0.13^{1}$ & 0.55 & 1.34 & 0.53 & 1.04 & 0.17 & 3.76 \\
\hline NNE & 0.23 & 1.55 & 1.81 & 0.58 & 0.99 & 0.15 & 5.30 \\
\hline NE & 0.26 & 2.44 & 1.71 & 0.47 & 1.03 & 0.17 & 6.08 \\
\hline ENE & 0.29 & 1.42 & 1.16 & 0.67 & 1.08 & 0.37 & 4.99 \\
\hline E & 0.25 & 1.39 & 1.93 & 1.55 & 1.68 & 0.49 & 7.29 \\
\hline ESE & 0.22 & 2.08 & 5.83 & 2.42 & 2.30 & 0.21 & 13.05 \\
\hline SE & 0.16 & 1.65 & 4.62 & 3.19 & 4.09 & 0.83 & 14.54 \\
\hline SSE & 0.09 & 1.30 & 3.40 & 2.06 & 3.10 & 0.34 & 10.28 \\
\hline S & 0.08 & 0.94 & 2.63 & 1.48 & 1.61 & 0.10 & 6.83 \\
\hline SSW & 0.06 & 0.63 & 2.09 & 1.12 & 1.02 & 0.19 & 5.11 \\
\hline SW & 0.06 & 0.52 & 1.63 & 0.74 & 0.95 & 0.45 & 4.35 \\
\hline WSW & 0.05 & 0.50 & 1.53 & 0.78 & 1.18 & 0.54 & 4.57 \\
\hline W & 0.02 & 0.46 & 1.19 & 0.51 & 1.53 & 0.68 & 4.40 \\
\hline WNW & 0.05 & 0.41 & 0.91 & 0.34 & 0.51 & 0.29 & 2.51 \\
\hline NW & 0.06 & 0.34 & 1.12 & 0.48 & 0.66 & 0.31 & 2.97 \\
\hline NNW & 0.08 & 0.43 & 1.34 & 0.59 & 0.92 & 0.60 & 3.96 \\
\hline Totals & 2.09 & 16.60 & 34.23 & 17.51 & 23.69 & 5.88 & 100.00 \\
\hline
\end{tabular}




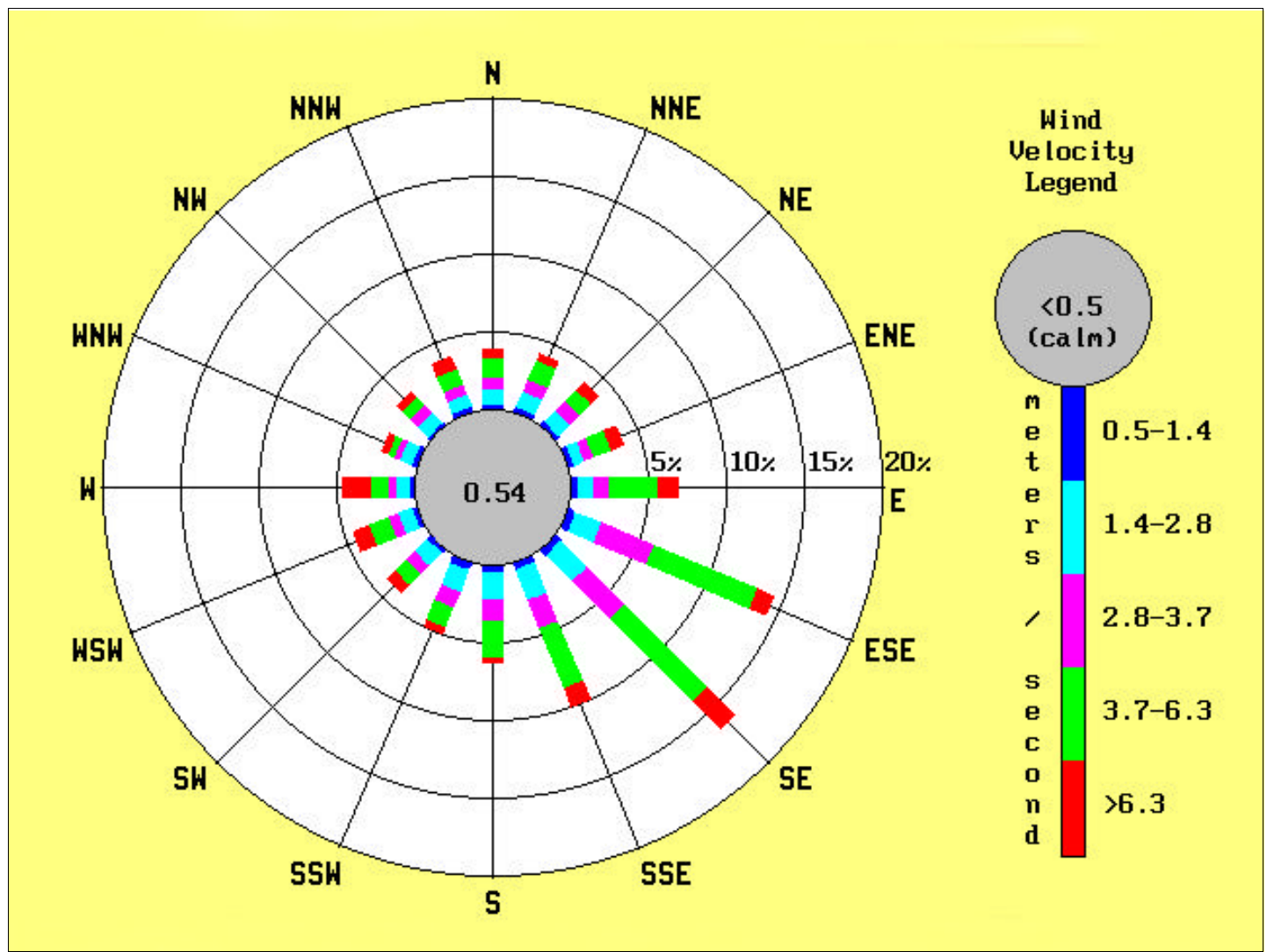

Figure 5.6 1999 WIPP Site Wind Rose at 10-Meter Height

Table 5.5 1999 wind frequencies at 10-meter height, stratified by direction and speed (percent).

\begin{tabular}{lccccccc}
\hline & \multicolumn{7}{c}{ Wind Speed Range, meters/second } \\
Direction & $\mathbf{0 . 5}$ & $\mathbf{0 . 5 - 1 . 4}$ & $\mathbf{1 . 4 - 2 . 8}$ & $\mathbf{2 . 8 - 3 . 7}$ & $\mathbf{3 . 7 - 6 . 3}$ & $\mathbf{> 6 . 3}$ & Totals \\
\hline & & & & & & & \\
N & $0.04^{1}$ & 0.32 & 1.03 & 0.77 & 1.33 & 0.61 & 4.09 \\
NNE & 0.04 & 0.35 & 1.23 & 0.91 & 1.43 & 0.48 & 4.44 \\
NE & 0.04 & 0.31 & 1.03 & 0.92 & 1.07 & 0.73 & 4.08 \\
ENE & 0.02 & 0.26 & 0.86 & 0.69 & 1.37 & 0.87 & 4.07 \\
E & 0.05 & 0.45 & 1.04 & 1.12 & 3.24 & 1.34 & 7.24 \\
ESE & 0.03 & 0.47 & 1.90 & 3.68 & 7.28 & 1.05 & 14.40 \\
SE & 0.03 & 0.44 & 2.40 & 3.46 & 7.52 & 2.74 & 16.58 \\
SSE & 0.03 & 0.48 & 2.13 & 2.06 & 4.19 & 1.29 & 10.17 \\
S & 0.05 & 0.45 & 1.82 & 1.43 & 2.40 & 0.33 & 6.48 \\
SSW & 0.03 & 0.41 & 1.62 & 1.19 & 1.47 & 0.40 & 5.10 \\
SW & 0.03 & 0.35 & 1.14 & 0.83 & 1.07 & 0.71 & 4.13 \\
WSW & 0.01 & 0.31 & 1.12 & 0.70 & 1.41 & 1.10 & 4.65 \\
W & 0.03 & 0.34 & 0.91 & 0.54 & 1.15 & 1.76 & 4.73 \\
WNW & 0.04 & 0.34 & 0.93 & 0.48 & 0.57 & 0.39 & 2.74 \\
NW & 0.05 & 0.24 & 1.01 & 0.65 & 0.80 & 0.38 & 3.12 \\
NNW & 0.04 & 0.28 & 0.88 & 0.76 & 1.18 & 0.86 & 3.98 \\
Totals: & & & & & & & \\
\hline
\end{tabular}

1 Percentage of time in which wind blew from this direction at this speed 


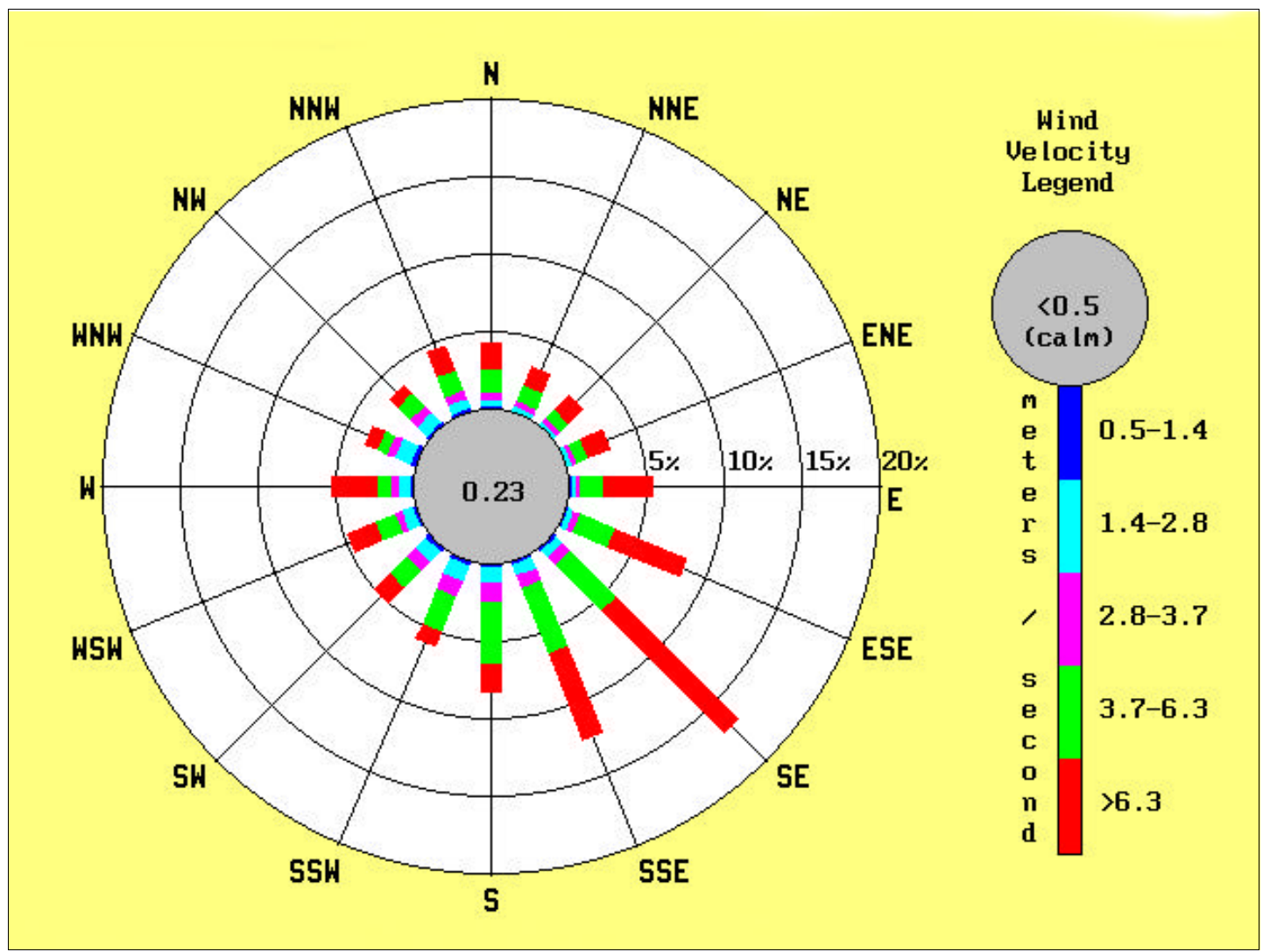

Figure 5.7 1999 WIPP Site Wind Rose at 50-Meter Height

Table 5.6 1999 wind frequencies at 50-meter height, stratified by direction and speed (percent).

\begin{tabular}{|c|c|c|c|c|c|c|c|}
\hline \multicolumn{8}{|c|}{ Wind Speed Range, meters/second } \\
\hline Direction & $<0.5$ & $0.5-1.4$ & $1.4-2.8$ & 2.8-3.7 & $3.7-6.3$ & $>6.3$ & Totals \\
\hline $\mathrm{N}$ & $0.01^{1}$ & 0.15 & 0.49 & 0.61 & 1.56 & 1.64 & 4.46 \\
\hline NNE & 0.02 & 0.08 & 0.38 & 0.35 & 1.13 & 1.27 & 3.23 \\
\hline $\mathrm{NE}$ & 0.03 & 0.10 & 0.26 & 0.29 & 0.85 & 1.38 & 2.91 \\
\hline ENE & 0.01 & 0.10 & 0.30 & 0.30 & 0.92 & 1.58 & 3.22 \\
\hline E & 0.01 & 0.15 & 0.36 & 0.32 & 1.51 & 3.23 & 5.57 \\
\hline ESE & 0.02 & 0.12 & 0.49 & 0.52 & 2.45 & 5.11 & 8.72 \\
\hline SE & 0.01 & 0.13 & 0.65 & 0.74 & 4.36 & 11.15 & 17.04 \\
\hline SSE & 0.01 & 0.18 & 0.85 & 0.96 & 4.63 & 5.92 & 12.55 \\
\hline $\mathrm{S}$ & 0.02 & 0.21 & 1.05 & 1.25 & 4.01 & 1.81 & 8.35 \\
\hline SSW & 0.01 & 0.19 & 1.22 & 1.20 & 2.42 & 1.02 & 6.06 \\
\hline SW & 0.01 & 0.28 & 0.97 & 0.77 & 1.65 & 1.39 & 5.06 \\
\hline WSW & 0.01 & 0.21 & 0.87 & 0.60 & 1.49 & 1.93 & 5.11 \\
\hline W & 0.01 & 0.25 & 0.83 & 0.51 & 0.89 & 2.94 & 5.42 \\
\hline WNW & 0.02 & 0.32 & 1.14 & 0.60 & 0.86 & 0.77 & 3.71 \\
\hline NW & 0.02 & 0.21 & 0.93 & 0.74 & 1.17 & 0.87 & 3.93 \\
\hline NNW & 0.01 & 0.17 & 0.69 & 0.70 & 1.45 & 1.66 & 4.68 \\
\hline Totals & 0.23 & 2.83 & 11.47 & 10.47 & 31.35 & 43.65 & 100.00 \\
\hline
\end{tabular}

${ }^{1}$ Percentage of time in which wind blew from this direction at this speed 
Target compounds found in VOC-B represent circulated air found in the mine before the air passes through the panels containing waste. The VOC concentrations measured at this location are the sum of background concentrations entering the mine through the air intake shaft plus additional concentrations contributed by facility operations upstream of the waste panels. Concentrations measured at VOC-A will be equal to those found at VOC-B plus any contributions from the waste panels. Differences measured between the two stations will then represent any VOC contributions from the waste panels. Any concentration differences between the two stations must be less than the concentrations of concern listed in Attachment $\mathrm{N}$ of the Hazardous Waste Facility Permit (Table 5.7). Sample pair differences are calculated by subtracting the concentration of a compound of interest observed at VOC-B from that measured at VOC-A for the given sampling period (Table 5.8). Negative values indicate ambient air concentrations of a compound (VOC-B) were greater than concentrations in the air passing through the panel (VOC-A). Negative values could be caused by emissions from normal mining activities near VOC-B which quickly dispersed in the mine ventilation flow and were not detected at VOC-A. The annual averages shown in Table 5.8 were calculated by averaging all sample pair differences from January 1, 1999 to December 31, 1999. Samples in which a compound of interest was non-detectable (less than the 0.5 parts per billion by volume [ppbv] minimum detection limit [MDL]) were assigned a value of zero for the purposes of computing this average.

During 1999, only three of the nine target compounds (chlorobenzene, methylene chloride, and toluene) were measured above the $0.5 \mathrm{ppbv}$ method detection limit. For each of the three detected target compounds, the annual average was less than 0.06 percent of the respective concentration of concern listed in Table 5.7.

Positive sample pair differences for methylene chloride were found in 12 of 88 sample pairs. The 1999 annual average sample pair difference for methylene chloride was -0.97 ppbv, with a minimum difference value of $-117.3 \mathrm{ppbv}$ and a maximum value of 32.03 ppbv. The low minimum value was caused by a single VOC B sample concentration of $120 \mathrm{ppbv}$. This value appears to be an outlier. This measurement was evaluated to see if it was within 20 per cent of its nearest neighbor. It was found to be significantly larger than 20 percent greater than any other value. If this outlier were deleted, the 1999 annual average for methylene chloride would be similar to the 1998 annual average. Methylene chloride, a common laboratory contaminant, can also be found in paint remover, aerosol propellant, degreasing and metal cleaning agents, and adhesives.

Positive sample pair differences for toluene were found in 29 of the 88 sample pairs. The overall 1999 average for toluene sample pair differences was $0.11 \mathrm{ppbv}$, with a minimum difference value of -9.08 and a maximum difference value of $5.9 \mathrm{ppbv}$, just over its $5.0 \mathrm{ppbv}$ reporting limit and slightly lower than the 1998 calculated values. Possible sources of toluene 
contamination could be products of incomplete combustion of diesel fuel, cleaning solvents, or paint.

A positive sample pair difference for chlorobenzene was found in one of 88 sample pairs in 1999. The overall 1999 average for chlorobenzene sample differences was $0.02 \mathrm{ppbv}$, with a minimum difference of -3.5 and a maximum difference value of $6.0 \mathrm{ppbv}$. Chlorobenzene was not detected in 1998 sampling. Chlorobenzene can be found as a tar and grease remover in cleaning and degreasing operations and is used in the manufacture of insecticides.

The routine laboratory reporting limit was 5.0 ppbv for 1,1,1-trichloroethane, 1,1dichloroethylene, methylene chloride, and toluene and 2.0 (ppbv) for 1,1,2,2-tetrachloroethane, 1,2dichloroethane, carbon tetrachloride, chlorobenzene, and chloroform. For dilution factors greater than one, the $5.0 \mathrm{ppbv}$ and 2.0 ppbv values are multiplied by the dilution factor to calculate the laboratory reporting limits for the diluted sample.

The minimum detection limit (MDL) is defined as the minimum concentration of a substance that can be measured and reported with a 99 percent confidence to be greater than zero. Values were estimated for constituents detected at concentrations less than the laboratory reporting limits but above the 0.5 ppbv MDL.

Volatile organic compound sampling reported in this section was performed using guidance included in Compendium Method TO-14A, Determination of Volatile Organic Compounds (Volatile organic compounds) in Ambient Air Using Specially Prepared Canisters with Subsequent Analysis By Gas Chromatography (EPA 1997). The samples were analyzed using gas chromatography/mass spectrometry under an established QA/QC program. Laboratory analytical procedures were developed based on the concepts contained in both TO-14A and the draft EPA Contract Laboratory Program Volatile Organics Analysis of Ambient Air in Canisters (EPA 1994).

Table 5.8 Volatile organic compound sample pair differences measured at WIPP in 1999.

\begin{tabular}{lcccc}
\hline Compound & $\begin{array}{c}\text { Nos. of } \\
\text { Sample Pairs } \\
\text { (A and B) }\end{array}$ & $\begin{array}{c}\text { 1999 Annual } \\
\text { Average of } \\
\text { Sample Pair } \\
\text { Differences } \\
\left(\mathbf{p p b v}^{\mathbf{1}}\right)\end{array}$ & $\begin{array}{c}\text { Minimum of } \\
\text { Sample Pair } \\
\text { Differences } \\
\left(\mathbf{p p b v}^{\mathbf{1}}\right)\end{array}$ & $\begin{array}{c}\text { Maximum of } \\
\text { Sample Pair } \\
\text { Differences } \\
\left(\mathbf{p p b v}^{\mathbf{1}}\right)\end{array}$ \\
\hline 1,1,1-Trichloroethane & 88 & 0 & 0 & 0 \\
1,1,2,2-Tetrachloroethane & 88 & 0 & 0 & 0 \\
1,1-Dichloroethylene & 88 & 0 & 0 & 0 \\
1,2-Dichloroethane & 88 & 0 & 0 & 0 \\
Carbon Tetrachloride & 88 & 0 & -3.5 & 0 \\
Chlorobenzene & 88 & 0.02 & 0 & 6 \\
Chloroform & 88 & 0 & -117.3 & 0 \\
Methylene Chloride & 88 & -0.97 & -9.08 & 32.03 \\
Toluene & 88 & 0.10 & & 5.9 \\
\hline
\end{tabular}

${ }^{1}$ Parts per billion by volume

\subsection{Seismic Activity}

WIPP is located about 60 miles east of the western margin of the Permian Basin. The geologic structure and tectonic pattern of the
Permian Basin are chiefly the result of large-scale subsidence and uplift during the Paleozoic era. The broad basin is divided into a series of subbasins which passed through their last stage of significant subsidence during the Late Permian 
age. The Delaware sub-basin occupies the southwestern portion of the Permian Basin and hosts the WIPP site. It is bordered by the Roosevelt Uplift to the north, the Marathon Thrust Belt to the south, the Central (Permian) Basin Platform to the east, and the Sierra Diablo Platform and Guadalupe and Sacramento Mountains to the west. The Delaware Basin contains a thick sequence of evaporite layers.

All major tectonic elements of the Delaware Basin were essentially formed before deposition of the Permian evaporites, and the region has been relatively stable since then. Deep-seated faults are rare, except along the western and eastern basin margins, and there is no evidence of young, deep-seated faults inside the basin.

Researchers suspect that some low-magnitude earthquakes may result from secondary oil recovery (water flooding). Their foci are about as deep as the bottom of relatively shallow wells, most of which are concentrated on the Central Basin Platform.

Significant recent seismic events near WIPP on January 2, 1992, and April 14, 1995, had magnitudes of 5.0 and 5.3 respectively. The January 2, 1992, Rattlesnake Canyon earthquake had an epicenter $60 \mathrm{~km}$ (36 mi) east-southeast of the WIPP site, while an April 14, 1995, event's epicenter was located about $240 \mathrm{~km}$ (144 mi) southwest of WIPP, near Alpine, Texas. Neither earthquake had any effect on WIPP structures, as documented by post-event inspections by WIPP staff and the New Mexico Environment Department. The magnitudes of both events were within the parameters used to develop the seismic risk assessment of the WIPP structures.
Seismic information for the WIPP region before 1962 was derived from chronicles of the effects of those tremors on people, structures, and surface features. Seismicity in New Mexico reported prior to 1962 was mostly limited to the corridor between Albuquerque and Socorro, part of a structure known as the Rio Grande Rift. Since 1962, most seismic information has been based on instrumental data recorded at various seismograph stations. Currently, seismicity within $300 \mathrm{~km}$ (186 mi) of the WIPP site is being monitored by the New Mexico Institute of Mining and Technology (NMIMT), in Socorro, New Mexico, using data from a seven-station network approximately centered on the site (Figure 5.8). Station signals are transmitted to the NMIMT Seismological Observatory in Socorro. When appropriate, readings from the WIPP network stations are combined with readings from an additional NMIMT network in the central Rio Grande Rift. Occasionally, data are also exchanged with the University of Texas at El Paso and Texas Tech University in Lubbock, both of which operate stations in west Texas.

The mean operational efficiency of the WIPP seismic monitoring stations during 1999 was approximately 95.6 percent. From January 1 through December 31, 1999, locations for 120 seismic events were recorded within $300 \mathrm{~km}$ (186 mi) of WIPP. These data included origin times, epicenter coordinates, and magnitudes. The strongest recorded event (magnitude 4.0) was located approximately $80 \mathrm{~km}(50 \mathrm{mi})$ westnorthwest of the site. This event was part of a swarm which appeared to be centered within the Cass Ranch gas field. The possibility therefore exists that the swarm events were induced by hydrocarbon extraction activities. These events had no effect on WIPP structures. 


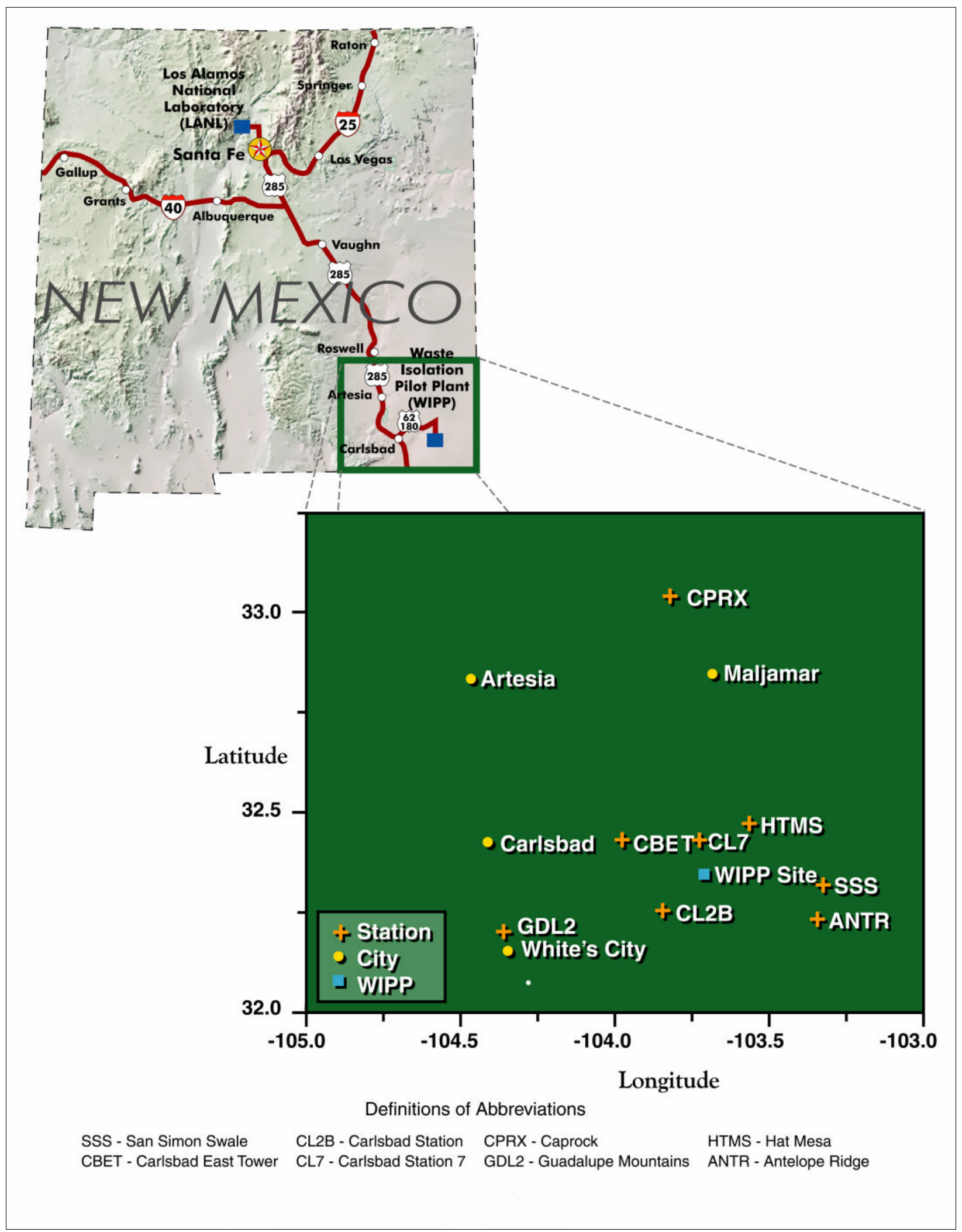

Figure 5.8 WIPP Seismograph Station Locations 


\subsection{Liquid Effluent Monitoring}

The WIPP sewage lagoon system is a zero-discharge facility consisting of two primary settling lagoons, two polishing lagoons, a chlorination system, and three evaporation basins. The entire facility is lined with 30-mil synthetic liners and is designed to dispose of domestic sewage as well as site-generated brine waters from observation well pumping and underground dewatering activities at the site.

The WIPP sewage facility is operated under Sewage System Discharge Permit No. 831 (DP831 ), issued by the state of New Mexico in accordance with the Clean Water Act, and is managed in accordance with EPA sewage sludge regulations (40 CFR $\S 503$ ), New Mexico Solid
Waste Management Regulations (Part 700), New Mexico Water Quality Control Regulations (3-100), and applicable WIPP controlled procedures. These requirements provide guidance for disposal of domestic sewage, site-generated brine waters, and non-hazardous waste waters.

DP-831 allows for the disposal of 7,570 L $(2,000 \mathrm{gal})$ per day of nonhazardous brines. DOE submits quarterly discharge monitoring reports to NMED to demonstrate compliance with the inspection, monitoring, and reporting requirements identified in the plan. No effluent limits were established in DP-831. The NMED Groundwater Protection and Remediation Bureau established a list of analytes to be sampled on a quarterly basis as indicators of sewage system performance. 


\section{Chapter 6 Ground-water Monitoring}

Current ground-water monitoring activities at WIPP are outlined in the Groundwater Surveillance Program Plan (WID WP 02-1, Revision 5). The plan is a QA document that contains program plans for each of the activities performed by ground-water monitoring personnel. In addition, WIPP has detailed procedures for performing specific activities, such as pumping system installations, field parameter analyses and documentation, and QA records management. Ground-water monitoring activities are also defined in the EMP.

The objectives of the Ground-water Monitoring Program are to:

- determine the physical and chemical characteristics of ground water;

- maintain surveillance of ground-water levels surrounding the WIPP facility, both before and throughout the operational lifetime of the facility;

- document and identify effects, if any, of WIPP operations on ground-water parameters; and

- fulfill the requirements of the RCRA Part B Permit Application and DOE Order 5400.1.

The data obtained by the WIPP Ground-water Monitoring Program (formerly designated the WIPP Groundwater Quality Surveillance Program [WQSP]) supported two major programs at WIPP: (1) the RCRA Detection Monitoring Program supporting the RCRA Part B Permit Application in compliance with $40 \mathrm{CFR} \S 264$ and 20 New Mexico Administrative Code (NMAC) 4.1, and (2) performance assessment supporting the Compliance Certification Application (DOE/CAO 96-2184) in compliance with 40 CFR $\S 191$ and 40 CFR $\S 194$. Each of these programs requires a unique set of analyses and data. Particular sample needs are defined by each program.
Background data were collected from 1995 through 1997 and reported in the Waste Isolation Pilot Plant RCRA Background Groundwater Quality Baseline Report (DOE/WIPP 98-2285). These background data will be compared to water quality data collected throughout the operational life of the facility.

Ground-water monitoring activities during 1999 included ground-water quality sampling and ground-water level surveillance. Ground-water quality data were gathered from six wells completed in the Culebra member of the Rustler Formation (wells WQSP-1 through WQSP-6) and one well completed in the Dewey Lake Formation (well WQSP-6A; Figure 6.1). Ground-water surface elevation data were gathered from 70 well bores, five of which were equipped with production-inflated packers to allow ground-water level surveillance of more than one producing zone through the same well bore (Figure 6.2).

\subsection{Ground-water Quality Sampling}

The RCRA Permit Module V requires groundwater quality sampling twice a year, from March through May (Round 8 for 1999) and, again, from September through November (Round 9 for 1999). Sampling for ground-water quality was performed at seven well sites during 1999 (Figure 6.1). The wells were serially sampled as soon as possible after the pump was turned on to better observe early chemical reactions to pumping. Field analysis for Eh (Intensity Factor: an indicator of oxidation or reduction of chemical species), specific gravity, specific conductance, acidity or alkalinity, chloride, divalent cations, and total iron were performed on a periodic basis during the serial sampling. 


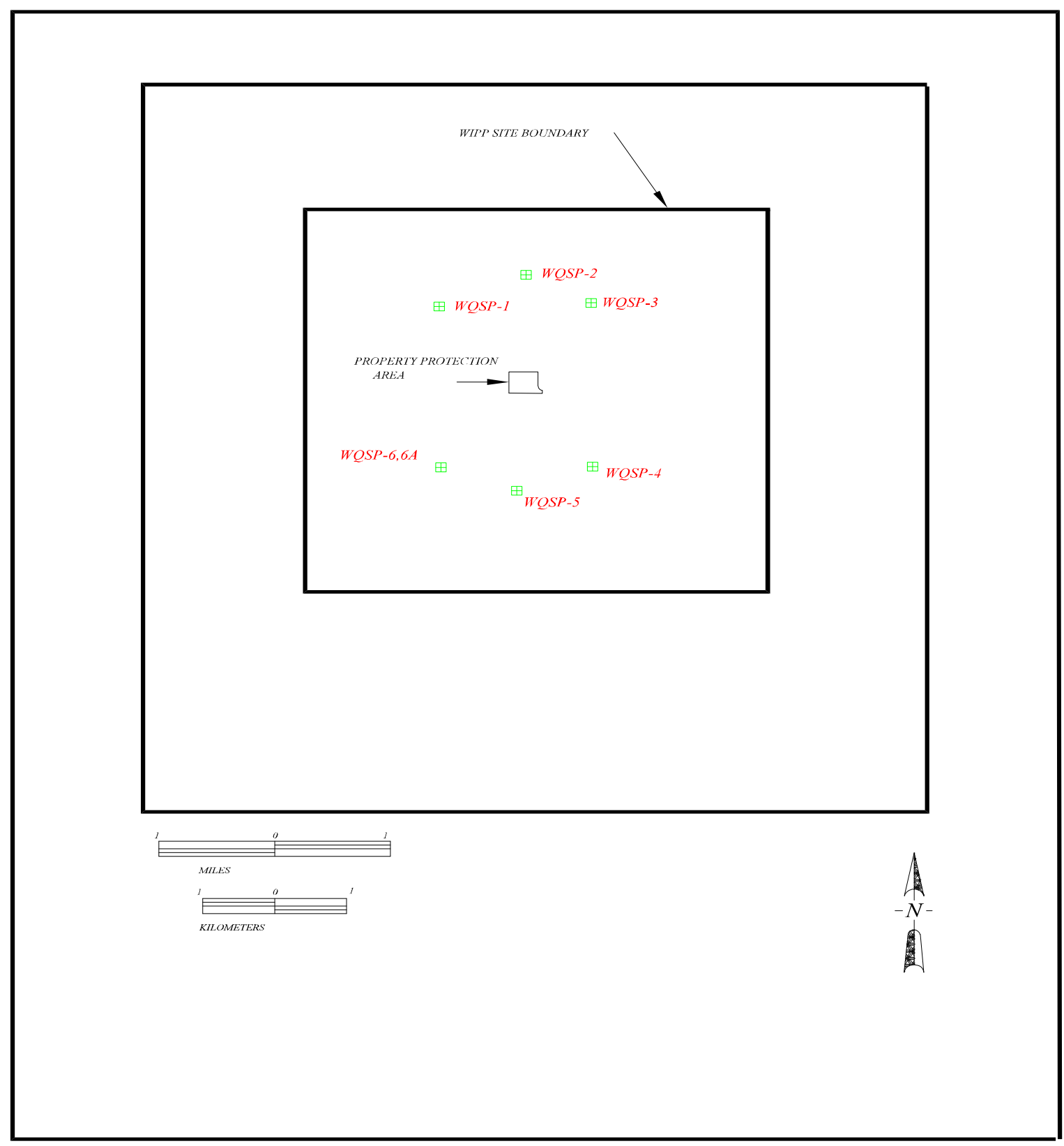

Figure 6.1 Water Quality Sampling Program Sample Wells 


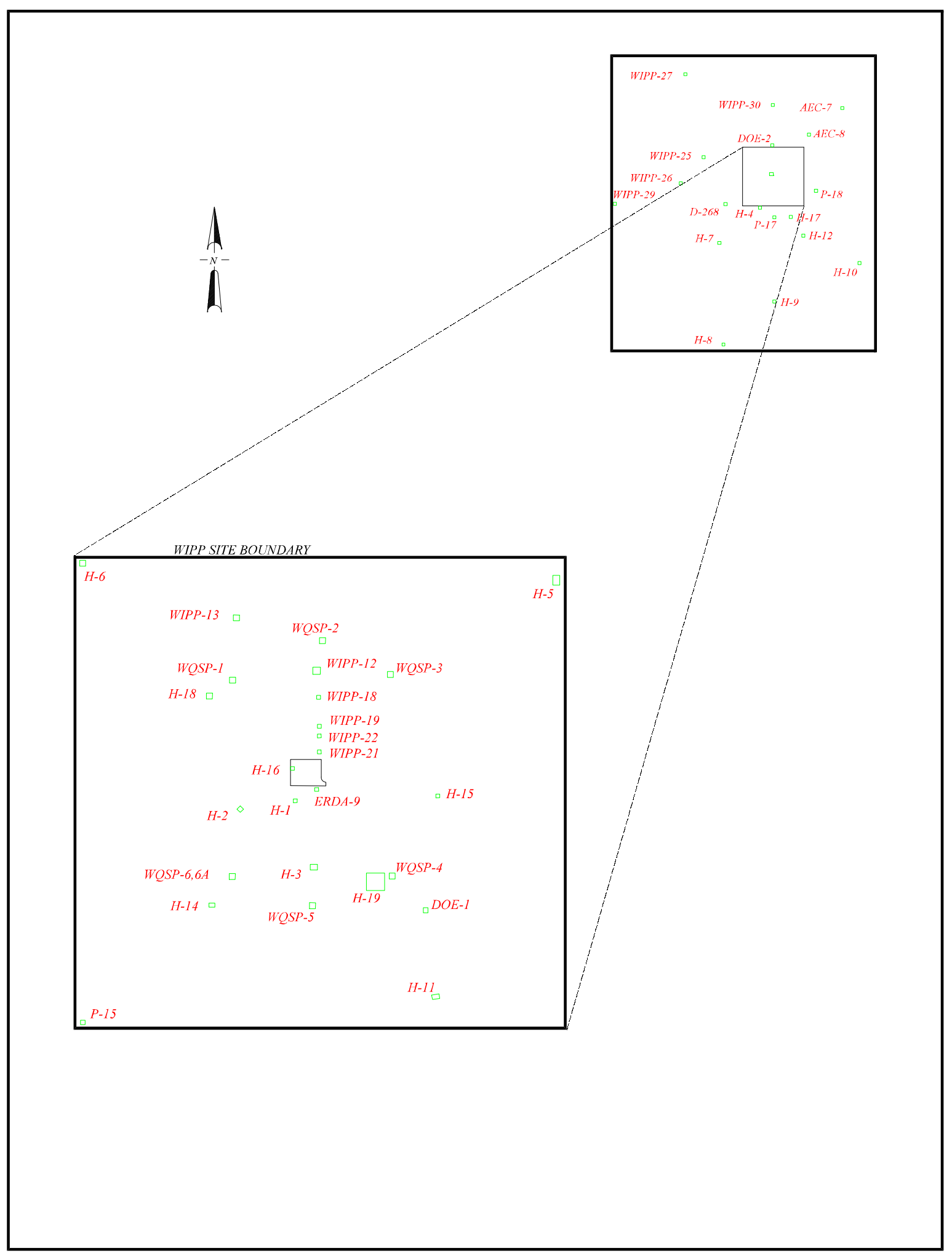

Figure 6.2 Ground-water Level Surveillance Wells 
During 1999, ground-water surveillance activities removed approximately $37,340 \mathrm{~L}(9,864$ gal) of water from the Culebra member of the Rustler Formation and 24,380 L (6,441 gal) from the Dewey Lake Formation. The quality of the Culebra water sampled near WIPP is naturally poor and not suitable for human consumption or for agricultural purposes. TDS concentrations measured in the Culebra ranged from less than 10,000 to $280,000 \mathrm{mg} / \mathrm{L}$. The ground water of the Culebra is considered to be Class III water by EPA guidelines.

Water quality measurements performed in the Dewey Lake Formation indicate the waters are considerably better quality than the Culebra water. TDS values were below $10,000 \mathrm{mg} / \mathrm{L}$. The water is suitable for livestock consumption, and classified as Class II water according to EPA guidance. Saturation of the Dewey Lake Formation in the area of WIPP is discontinuous. No hydrologic connection has been established that would indicate WIPP activities would have a potential impact on the Dewey Lake Formation.

The New Mexico Environmental Department (NMED) Hazardous Waste Permit, Attachment L, Section L-4a states "detection monitoring will start when the Permittees emplace waste . ..." Because wastes were expected to be shipped to WIPP much sooner than the year 2000, it was expected that baselines would be established using only four samples from each well, per Hazardous Waste Permit, Module V, Section V.F.2. Because no hazardous wastes were received at WIPP before or during 1999, the results of the ground-water quality sampling for 1999 (rounds eight and nine), and all previous sampling rounds, will be used to calculate the baseline for the parameters and constituents listed in Table 6.1, per the NMED Hazardous Waste Permit Module V, Table V.D. Baseline calculations will also include data from the first sampling round of 2000 (round 10), the final sampling session before the first shipment of waste was received at WIPP. By including sampling rounds six through ten as part of the baseline data, the baseline population will more than double and consequently allow for more meaningful and robust statistical analyses. In addition, using a larger sample size to calculate baseline metrics will better address the issue of variability in results reported by different laboratories conducting the same analyses (see below).

Because of the highly variable transmissivity and density values within the Culebra, baseline ground-water quality was defined for each individual well. These values were calculated prior to the decision to include sampling rounds six through ten in baseline calculations, and are based only on earlier sampling rounds. These values will be re-computed when all baseline sampling is completed in 2000. Tables 6.2 through 6.8 summarize the results of analyses for each parameter or constituent for the two sampling sessions in 1999 (rounds eight and nine).

In these tables, either the $95^{\text {th }}$ upper tolerance limit value (UTLV) or the $95^{\text {th }}$ percentile value is presented for baseline data with concentrations that were well above the method detection limit prior to 1999. Both values represent the value beneath which 95 percent of the values in a population are expected to occur. UTLVs were calculated for data which exhibited a normal or a lognormal distribution. The $95^{\text {th }}$ percentile was determined for data which were considered nonparametric; having neither a normal nor a lognormal distribution. Due to the large number of non-detectable concentrations of organic compounds, the limits for organic compounds were considered non-parametric and based on the method detection limit reported by the laboratory. These values will be re-computed when all baseline sampling is completed in 2000, and will be used in subsequent sampling rounds to evaluate for contamination of the ground-water wells. 
Table 6.1 Analytical parameters for which ground water was analyzed.

\begin{tabular}{|c|c|c|c|c|c|}
\hline CAS No. ${ }^{1}$ & Parameter & $\begin{array}{c}\text { EPA } \\
\text { Method } \\
\text { Number }\end{array}$ & CAS No. & Parameter & $\begin{array}{c}\text { EPA } \\
\text { Method } \\
\text { Number }\end{array}$ \\
\hline $71-55-6$ & 1,1,1-Trichloroethane & $8260 \mathrm{~B}$ & $7727-37-9$ & Nitrate (as N) & 300.0 \\
\hline $79-34-5$ & $1,1,2,2$-Tetrachloroethane & $8260 \mathrm{~B}$ & & Orthophosphate (as P) & 365.2 \\
\hline $79-00-5$ & 1,1,2-Trichloroethane & $8260 \mathrm{~B}$ & & $\mathrm{pH}$ & 150.1 \\
\hline $75-34-3$ & 1,1-Dichloroethane & $8260 \mathrm{~B}$ & & Specific conductance & 120.1 \\
\hline $75-35-4$ & 1,1-Dichloroethylene & 8260B & & Sulfate & 300.0 \\
\hline $107-06-2$ & 1,2-Dichloroethane & 8260B & & Total dissolved solids & 160.1 \\
\hline $56-23-5$ & Carbon tetrachloride & $8260 \mathrm{~B}$ & & Total organic carbon & 415.1 \\
\hline $108-90-7$ & Chlorobenzene & $8260 B$ & & Total organic halogen & $9020 \mathrm{~B}$ \\
\hline 67-66-3 & Chloroform & 8260B & & Total phenols & 420.1 \\
\hline $540-59-0$ & cis-1,2-Dichloroethylene & 8260B & & Total suspended solids & 160.2 \\
\hline $78-93-3$ & Methyl ethyl ketone & 8260B & & Gross alpha & 900 \\
\hline $75-09-2$ & Methylene chloride & $8260 \mathrm{~B}$ & & Gross beta & 900 \\
\hline $127-18-4$ & Tetrachloroethylene & $8260 \mathrm{~B}$ & $7440-36-0$ & Antimony & $6010 \mathrm{~B}$ \\
\hline $108-88-3$ & Toluene & 8260B & $7440-38-2$ & Arsenic & $6010 \mathrm{~B}$ \\
\hline 79-01-6 & Trichloroethylene & $8260 \mathrm{~B}$ & $7440-39-3$ & Barium & 6010B \\
\hline $75-69-4$ & Trichlorofluoromethane & 8260B & $7440-41-7$ & Beryllium & 6010B \\
\hline 75-01-4 & Vinyl chloride & 8260B & $7440-42-8$ & Boron & 6010B \\
\hline $1330-20-7$ & Xylene & $8260 \mathrm{~B}$ & $7440-43-9$ & Cadmium & $6010 \mathrm{~B}$ \\
\hline $95-50-1$ & 1,2-Dichlorobenzene & $8270 \mathrm{C}$ & $7440-70-2$ & Calcium & $6010 \mathrm{~B}$ \\
\hline $106-46-7$ & 1,4-Dichlorobenzene & $8270 \mathrm{C}$ & $7440-47-3$ & Chromium & 6010B \\
\hline $51-28-5$ & 2,4-Dinitrophenol & $8270 \mathrm{C}$ & $7440-48-4$ & Cobalt & $6010 \mathrm{~B}$ \\
\hline $121-14-2$ & 2,4-Dinitrotoluene & $8270 \mathrm{C}$ & $7440-50-8$ & Copper & $6010 \mathrm{~B}$ \\
\hline $95-48-7$ & 2-Methylphenol & $8270 \mathrm{C}$ & $7439-89-6$ & Iron & 6010B \\
\hline 108-39-4/ & 3-Methylphenol/ & & $7439-92-1$ & Lead & 6010B \\
\hline $106-44-5$ & 4-Methylphenol & $8270 \mathrm{C}$ & $7439-93-2$ & Lithium & $6010 \mathrm{~B}$ \\
\hline $118-74-1$ & Hexachlorobenzene & $8270 \mathrm{C}$ & $7439-95-4$ & Magnesium & $6010 \mathrm{~B}$ \\
\hline $67-72-1$ & Hexachloroethane & $8270 \mathrm{C}$ & $7439-97-6$ & Mercury & $7470 \mathrm{~A}$ \\
\hline $98-95-3$ & Nitrobenzene & $8270 \mathrm{C}$ & $7440-02-0$ & Nickel & 6010B \\
\hline $87-86-5$ & Pentachlorophenol & $8270 \mathrm{C}$ & 7440-09-7 & Potassium & 6010B \\
\hline $110-86-1$ & Pyridine & $8270 \mathrm{C}$ & $7782-49-2$ & Selenium & 6010B \\
\hline \multirow[t]{2}{*}{ 78-83-1 } & Isobutanol & 8015B & $7631-86-9$ & Silica & 6010B \\
\hline & Alkalinity & 310.1 & $7440-22-4$ & Silver & 6010B \\
\hline $7726-95-6$ & Bromide & 300.0 & $7440-23-5$ & Sodium & 6010B \\
\hline \multirow[t]{4}{*}{$7782-50-5$} & Chloride & 300.0 & $7440-28-0$ & Thallium & 6010B \\
\hline & Density $^{2}$ & & $7440-31-5$ & Tin & 6010B \\
\hline & Fluoride & 300.0 & $7440-62-2$ & Vanadium & $6010 \mathrm{~B}$ \\
\hline & Iodide & 345.1 & $7440-66-6$ & Zinc & $6010 \mathrm{~B}$ \\
\hline
\end{tabular}

${ }^{1}$ Chemical Abstract Service Registry Number

${ }^{2}$ Analysis method was ASTM (American Society for Testing and Materials) D854-92 
As stated above, TDS, measured as filterable residue, of the Culebra Member in the WIPP area ranged from less than 10,000 to over 280,000 $\mathrm{mg} / \mathrm{L}$. High TDS samples require dilution prior to analysis. The dilution factors varied between sampling rounds and wells. The variable dilution factors resulted in method detection limits for organics and other constituents that were inconsistent and inconclusive: some concentrations reported as "nondetect" exceeded the maximum permissible contamination levels. For gross alpha and beta analyses the total aliquot size was much smaller than the normal aliquot for clean water, and ranged from $1 \mathrm{ml}(0.033 \mathrm{oz})$ to $15 \mathrm{ml}(0.507 \mathrm{oz})$. Consequently, the reported detection limits were very high. Three different contract laboratories used recommended EPA methods to perform the ground-water chemistry analyses. Due to the variability in dilution factors and sensitivity of instruments, the concentrations and method detection limits from different laboratories were also different.

The analytical results for detectable constituents are plotted as Time Trend Plots compared to the baseline established prior to 1999 (Figures 6.5 through 6.123). Because data from ground-water quality sampling rounds eight and nine are to be included in calculations to establish baseline conditions, summary accounts of comparisons for individual wells and analytes were not developed for 1999.

\subsection{Ground-water Level Surveillance}

Ground-water surface elevations in the vicinity of WIPP may be influenced by site activities, such as pumping tests for site characterization, water quality sampling, or shaft sealing. Other influences on ground-water surface elevations may be caused by natural ground-water level fluctuations and industrial influences from agriculture, mining, and resource exploration.

In October 1988, WIPP was tasked with conducting a Ground-water Level Surveillance Program. Seventy well bores were used to perform surveillance of eight water-bearing zones in the WIPP area (Figure 6.2). The two zones of primary interest were the Culebra and Magenta members of the Rustler Formation (see Figure 1.1). Sixty measurements were taken in the Culebra and nine in the Magenta. Three measurements each were taken in the Dewey Lake and Santa Rosa Formations. Two measurements were taken in the Rustler/Salado contact. One measurement each was taken in Bell Canyon, Forty-niner, and an unnamed lower member. In 1999, ground-water level measurements were taken monthly in at least one accessible well bore at each well site for each available formation. Redundant well bores at each well site were measured on a quarterly basis.

Four well bores (H-01 Culebra/Magenta, H-03d Dewey Lake/Forty-niner, H-16 Dewey Lake/unnamed lower member, and WIPP-25 Culebra/Magenta) were completed at multiple depths. By using packers, these bores may be monitored in more than one formation.

Ground-water elevation measurements in the Culebra member indicated the generalized directional flow of ground water was north to south in the vicinity of WIPP (Figure 6.3a). Modeling of flow patterns produced similar results (Figure 6.3b). Regional ground-water levels taken in Culebra observation wells with four or more data points for the year showed increasing trends in water levels in 49 wells and decreasing trends in nine wells.

Total fluctuations of more than $0.6 \mathrm{~m}(2 \mathrm{ft})$ in ground-water levels occurred in six wells completed to the Culebra. Three wells with fluctuations of more than $0.6 \mathrm{~m}(2 \mathrm{ft})$ (WQSP-2, WQSP-3, and WQSP-6) may have been influenced by ground-water sampling activities. Two wells ( $\mathrm{H}-1$ and Cabin Baby) experienced water-level fluctuations due to maintenance activities. Water level in P-18 continued a rising trend, of unknown cause, dating back to its completion in 1977.

Ground-water level data were transmitted on a monthly basis to the NMED, EEG, Sandia National Laboratories, CTAC, and technical subcontractors as requested by the CAO. A copy of the data was placed in the operating record for inspection by authorized agencies. 
Ground-water modeling efforts for 1999, using a one percent porosity value, developed a particle-based flow simulation estimating the minimum travel time as 880 years from the center of WIPP to the boundary (Figure 6.4).
The interpretation of ground-water data collected in 1999 are similar to previous years. To date there is no indication WIPP operations have had a measurable and significant impact on either the level or the quality of ground water underlying WIPP. 


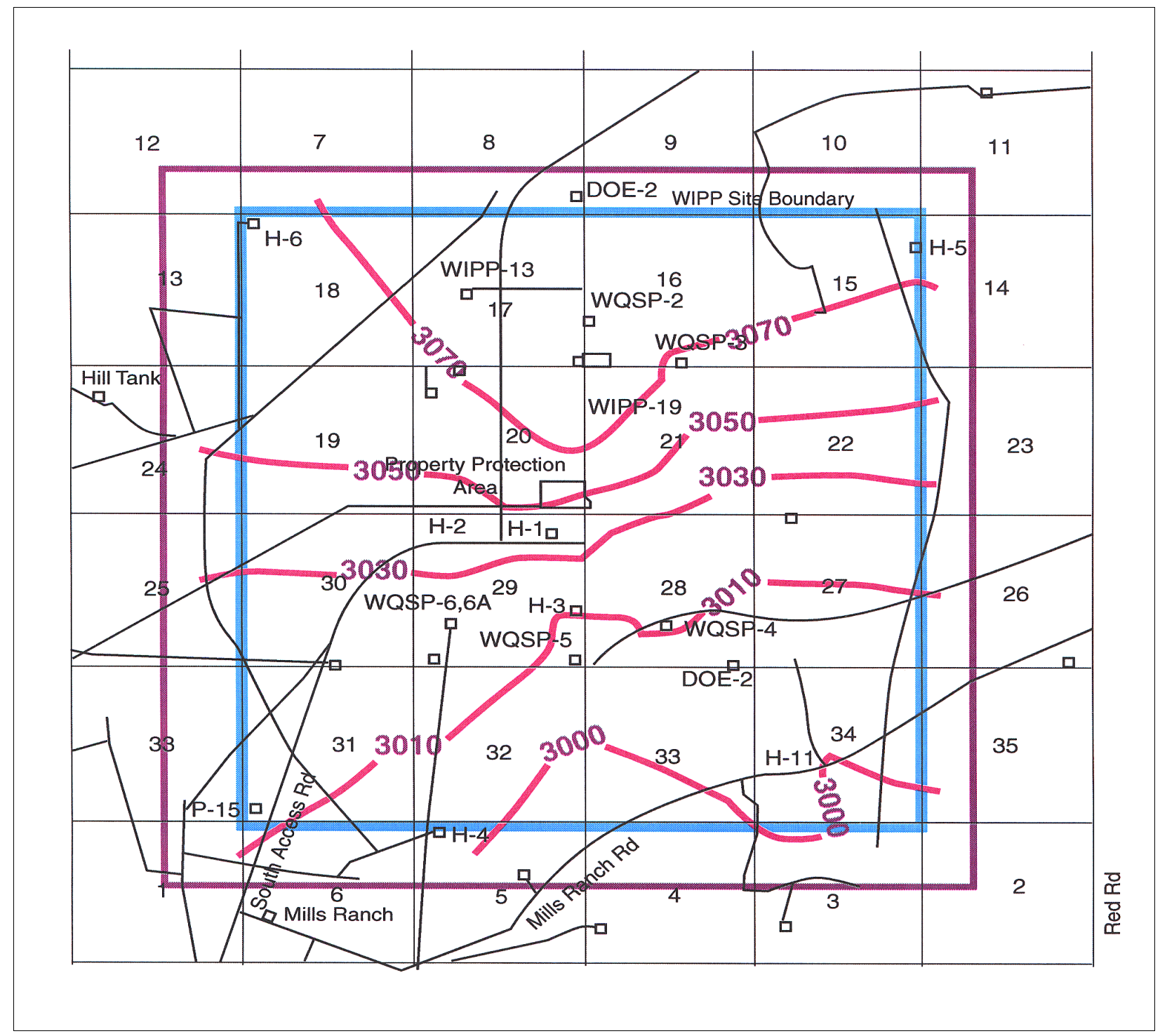

Figure 6.3a Measured Ground-water Potentiometric Surface (feet) in the Culebra Member of the Rustler Formation 


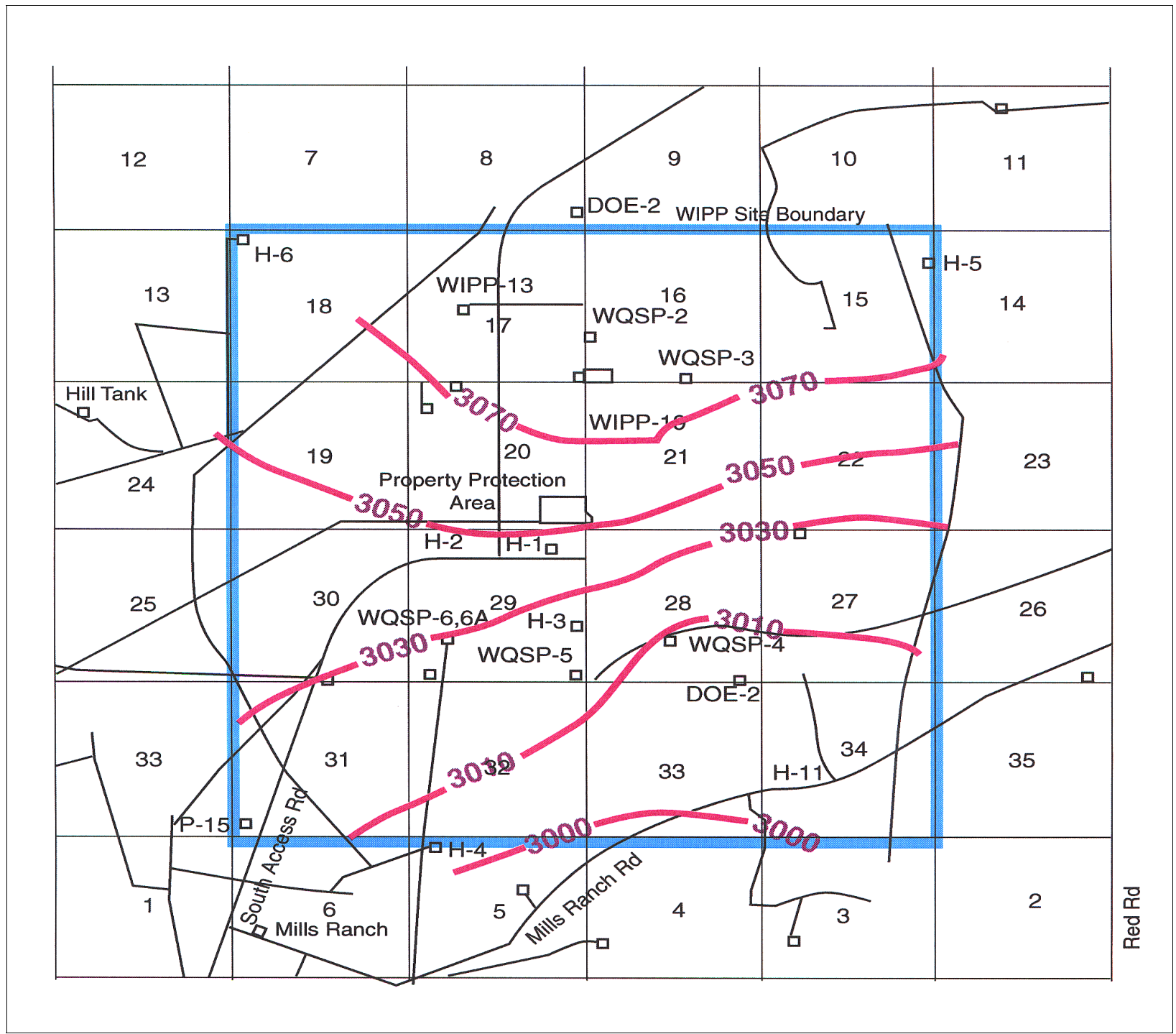

Figure 6.3b Modeled Ground-water Potentiometric Surface (feet) in the Culebra Member of the Rustler Formation 


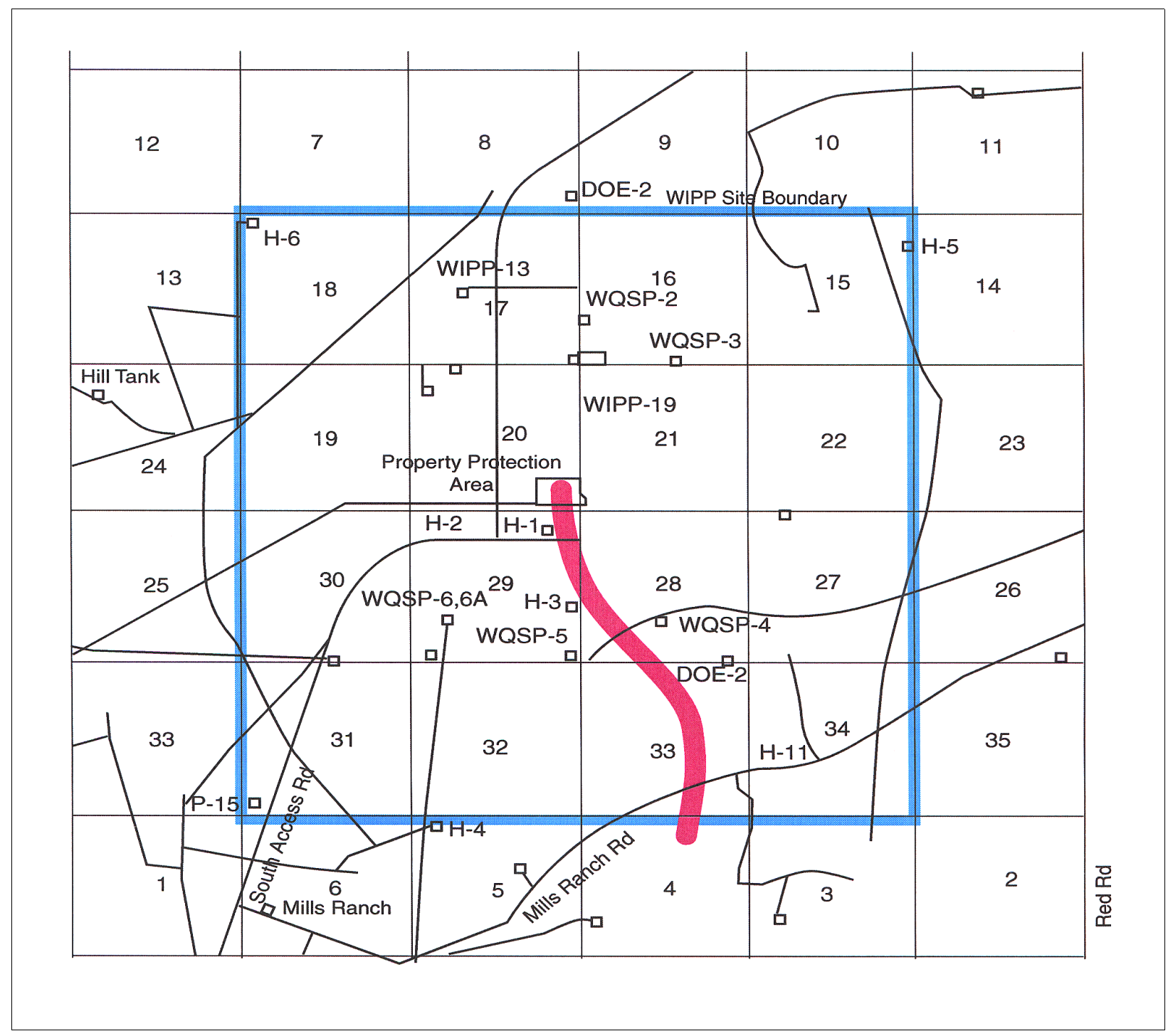

Figure 6.4 Modeled particle movement in ground-water flow in the Culebra Member of the Rustler Formation 
Table 6.2 Analytical results for ground water sampled from well WQSP-1.

Concentration

$\underline{\text { Round } 8} \quad \underline{\text { Round } 9}$

$\underline{\text { Reporting Limit }}$

Parameter Sample Dup. Sample Dup. Units Round 8 Round 9 95 $^{\text {th }}$

\begin{tabular}{|c|c|c|c|c|c|c|c|c|}
\hline 1,1,1-Trichloroethane & $<1$ & $<1$ & $<2$ & $<2$ & $\mu \mathrm{g} / \mathrm{L}$ & 1 & 2 & $<\mathrm{RL}^{2}$ \\
\hline 1,1,2,2-Tetrachloroethane & $<1$ & $<1$ & $<2$ & $<2$ & $\mu \mathrm{g} / \mathrm{L}$ & 1 & 2 & $<\mathrm{RL}$ \\
\hline 1,1,2-Trichloroethane & $<1$ & $<1$ & $<2$ & $<2$ & $\mu \mathrm{g} / \mathrm{L}$ & 1 & 2 & $<\mathrm{RL}$ \\
\hline 1,1-Dichloroethane & $\mathrm{NR}^{3}$ & NR & $<2$ & $<2$ & $\mu \mathrm{g} / \mathrm{L}$ & NR & 2 & $<\mathrm{RL}$ \\
\hline 1,1-Dichloroethylene & $<1$ & $<1$ & $<2$ & $<2$ & $\mu \mathrm{g} / \mathrm{L}$ & 1 & 2 & $<\mathrm{RL}$ \\
\hline 1,2-Dichloroethane & $<1$ & $<1$ & $<2$ & $<2$ & $\mu \mathrm{g} / \mathrm{L}$ & 1 & 2 & $<R L$ \\
\hline Carbon tetrachloride & $<1$ & $<1$ & $<2$ & $<2$ & $\mu \mathrm{g} / \mathrm{L}$ & 1 & 2 & $<R L$ \\
\hline Chlorobenzene & $<1$ & $<1$ & $<2$ & $<2$ & $\mu \mathrm{g} / \mathrm{L}$ & 1 & 2 & $<\mathrm{RL}$ \\
\hline Chloroform & $<1$ & $<1$ & $<2$ & $<2$ & $\mu \mathrm{g} / \mathrm{L}$ & 1 & 2 & $<\mathrm{RL}$ \\
\hline cis-1,2-Dichloroethylene & $<1$ & $<1$ & $<2$ & $<2$ & $\mu \mathrm{g} / \mathrm{L}$ & $<1$ & 2 & $<R L$ \\
\hline Methyl ethyl ketone & $<50$ & $<50$ & $<10$ & $<10$ & $\mu \mathrm{g} / \mathrm{L}$ & 50 & 10 & $<\mathrm{RL}$ \\
\hline Methylene chloride & $<5$ & $<5$ & $<5$ & $<5$ & $\mu \mathrm{g} / \mathrm{L}$ & 5 & 5 & $<R L$ \\
\hline Tetrachloroethylene & $<1$ & $<1$ & $<2$ & $<2$ & $\mu \mathrm{g} / \mathrm{L}$ & 1 & 2 & $<\mathrm{RL}$ \\
\hline Toluene & $<1$ & $<1$ & $<2$ & $<2$ & $\mu \mathrm{g} / \mathrm{L}$ & 1 & 2 & $<\mathrm{RL}$ \\
\hline Trichloroethylene & $<1$ & $<1$ & $<2$ & $<2$ & $\mu \mathrm{g} / \mathrm{L}$ & 1 & 2 & $<\mathrm{RL}$ \\
\hline Trichlorofluoromethane & $<1$ & $<1$ & $<2$ & $<2$ & $\mu \mathrm{g} / \mathrm{L}$ & 1 & 2 & $<\mathrm{RL}$ \\
\hline Vinyl chloride & $<1$ & $<1$ & $<2$ & $<2$ & $\mu \mathrm{g} / \mathrm{L}$ & 1 & 2 & $<\mathrm{RL}$ \\
\hline Xylene & $<1$ & $<1$ & $<2$ & $<2$ & $\mu \mathrm{g} / \mathrm{L}$ & 1 & 2 & $<\mathrm{RL}$ \\
\hline 1,2-Dichlorobenzene & $<1$ & $<1$ & $<1$ & $<1$ & $\mu \mathrm{g} / \mathrm{L}$ & 1 & 1 & $<\mathrm{RL}$ \\
\hline 1,4-Dichlorobenzene & $<1$ & $<1$ & $<1$ & $<1$ & $\mu \mathrm{g} / \mathrm{L}$ & 1 & 1 & $<\mathrm{RL}$ \\
\hline 2,4-Dinitrophenol & $<1$ & $<1$ & $<1$ & $<1$ & $\mu \mathrm{g} / \mathrm{L}$ & 1 & 1 & $<\mathrm{RL}$ \\
\hline 2,4-Dinitrotoluene & $<1$ & $<1$ & $<1$ & $<1$ & $\mu \mathrm{g} / \mathrm{L}$ & 1 & 1 & $<\mathrm{RL}$ \\
\hline 2-Methylphenol & $<1$ & $<1$ & $<1$ & $<1$ & $\mu \mathrm{g} / \mathrm{L}$ & 1 & 1 & $<\mathrm{RL}$ \\
\hline $\begin{array}{l}\text { 3-Methylphenol/ } \\
\text { 4-Methylphenol }\end{array}$ & $<1$ & $<1$ & $<1$ & $<1$ & $\mu \mathrm{g} / \mathrm{L}$ & 1 & 1 & $<R L$ \\
\hline Hexachlorobenzene & $<1$ & $<1$ & $<1$ & $<1$ & $\mu \mathrm{g} / \mathrm{L}$ & 1 & 1 & $<R L$ \\
\hline Hexachloroethane & $<1$ & $<1$ & $<1$ & $<1$ & $\mu \mathrm{g} / \mathrm{L}$ & 1 & 1 & $<\mathrm{RL}$ \\
\hline Nitrobenzene & $<1$ & $<1$ & $<1$ & $<1$ & $\mu \mathrm{g} / \mathrm{L}$ & 1 & 1 & $<\mathrm{RL}$ \\
\hline Pentachlorophenol & $<1$ & $<1$ & $<1$ & $<1$ & $\mu \mathrm{g} / \mathrm{L}$ & 1 & 1 & $<R L$ \\
\hline Pyridine & $<1$ & $<1$ & $<1$ & $<1$ & $\mu \mathrm{g} / \mathrm{L}$ & 1 & 1 & $<\mathrm{RL}$ \\
\hline
\end{tabular}


Table 6.2, cont.

Concentration

$\underline{\text { Round } 8}$

Round 9

\begin{tabular}{|c|c|c|c|c|c|c|c|c|}
\hline Parameter & Sample & Dup. & Sample & Dup. & Units & Round 8 & Round 9 & $\begin{array}{c}9^{\text {th }} \\
\text { UTLV }^{1}\end{array}$ \\
\hline Isobutanol & $<500$ & $<500$ & $<500$ & $<500$ & $\mu \mathrm{g} / \mathrm{L}$ & 500 & 500 & $<\mathrm{RL}$ \\
\hline Alkalinity & 55 & 50 & 46 & 46 & $\mathrm{mg} / \mathrm{L}$ & 4.0 & 4.0 & 55.7 \\
\hline Bromide & 42 & 42 & 42 & 41 & $\mathrm{mg} / \mathrm{L}$ & 0.2 & 0.2 & 51.8 \\
\hline Chloride & 33,000 & 33,000 & 40,000 & 40,000 & $\mathrm{mg} / \mathrm{L}$ & 0.5 & 0.5 & 39,105 \\
\hline Density & 1.046 & 1.044 & 1.045 & 1.049 & $\mathrm{~g} / \mathrm{ml}$ & $\mathrm{N} / \mathrm{A}^{4}$ & N/A & 1.072 \\
\hline Fluoride & 1.2 & 1.2 & 1.2 & 1.3 & $\mathrm{mg} / \mathrm{L}$ & 0.1 & 0.1 & 4.36 \\
\hline Iodide & $<2.0$ & $<2.0$ & $<2.0$ & $<2.0$ & $\mathrm{mg} / \mathrm{L}$ & 2.0 & 2.0 & 2.0 \\
\hline Nitrate (as N) & $<10$ & $<10$ & $<10$ & $<10$ & $\mathrm{mg} / \mathrm{L}$ & 0.2 & 0.2 & 0.2 \\
\hline Orthophosphate (as P) & $<0.10$ & $<0.10$ & $<0.010$ & 0.011 & $\mathrm{mg} / \mathrm{L}$ & 0.10 & 0.01 & 0.02 \\
\hline $\mathrm{pH}$ & 7.2 & 7.2 & 7.2 & 7.2 & $\mathrm{SU}^{5}$ & N/A & N/A & $6.89-7.65$ \\
\hline Specific conductance & 98,000 & 98,000 & 99,000 & 96,000 & $\mu \mathrm{mhos} / \mathrm{cm}$ & N/A & N/A & 90,030 \\
\hline Sulfate & 4,600 & 4,900 & 5,000 & 4,700 & $\mathrm{mg} / \mathrm{L}$ & 0.5 & 0.5 & 6,477 \\
\hline Total dissolved solids & 64,000 & 64,000 & 59,000 & 61,000 & $\mathrm{mg} / \mathrm{L}$ & 10 & 10 & 77,600 \\
\hline Total organic carbon & $<5.0$ & $<5.0$ & $<1.0$ & $<1.0$ & $\mathrm{mg} / \mathrm{L}$ & 5.0 & 1.0 & 2.37 \\
\hline Total organic halogen & 4.0 & 2.7 & 9.1 & 8.6 & $\mathrm{mg} / \mathrm{L}$ & N/A & N/A & 0.045 \\
\hline Total phenols & $<0.07$ & $<0.07$ & $<0.07$ & $<0.07$ & $\mathrm{mg} / \mathrm{L}$ & 0.07 & 0.07 & $<\mathrm{RL}$ \\
\hline Total suspended solids & $<1.0$ & $<1.0$ & $<1.0$ & $<1.0$ & $\mathrm{mg} / \mathrm{L}$ & 1.0 & 1.0 & 33.5 \\
\hline Gross alpha & $150 \pm 320$ & NR & $290 \pm 390$ & NR & $\mathrm{pCi} / \mathrm{L}$ & 570 & 610 & 600 \\
\hline Gross beta & $470 \pm 270$ & NR & $310 \pm 390$ & $\mathrm{NR}$ & $\mathrm{pCi} / \mathrm{L}$ & 400 & 650 & 470 \\
\hline Antimony & $<0.10$ & $<0.10$ & 0.07 & $<0.05$ & $\mathrm{mg} / \mathrm{L}$ & 0.10 & 0.05 & 0.05 \\
\hline Arsenic & $<0.10$ & $<0.10$ & $<0.05$ & $<0.05$ & $\mathrm{mg} / \mathrm{L}$ & 0.10 & 0.05 & 0.05 \\
\hline Barium & $<0.10$ & $<0.10$ & $<0.10$ & $<0.10$ & $\mathrm{mg} / \mathrm{L}$ & 0.10 & 0.10 & 0.026 \\
\hline Beryllium & $<0.01$ & $<0.01$ & $<0.02$ & $<0.02$ & $\mathrm{mg} / \mathrm{L}$ & 0.01 & 0.02 & 0.02 \\
\hline Boron & 13 & 0.21 & NR & NR & $\mathrm{mg} / \mathrm{L}$ & 0.10 & NR & 15.3 \\
\hline Cadmium & $<0.01$ & $<0.01$ & $<0.02$ & $<0.02$ & $\mathrm{mg} / \mathrm{L}$ & 0.01 & 0.02 & 0.01 \\
\hline Calcium & 1,770 & $<0.50$ & 1,710 & 1,726 & $\mathrm{mg} / \mathrm{L}$ & 0.50 & 0.50 & 1,740 \\
\hline Chromium & $<0.05$ & $<0.05$ & $<0.02$ & $<0.02$ & $\mathrm{mg} / \mathrm{L}$ & 0.05 & 0.02 & 0.1 \\
\hline Cobalt & $<0.05$ & $<0.05$ & NR & NR & $\mathrm{mg} / \mathrm{L}$ & 0.05 & NR & 0.05 \\
\hline Copper & $<0.10$ & $<0.10$ & NR & NR & $\mathrm{mg} / \mathrm{L}$ & 0.10 & NR & 0.25 \\
\hline Iron & $<0.10$ & $<0.10$ & $<0.10$ & $<0.10$ & $\mathrm{mg} / \mathrm{L}$ & 0.10 & 0.10 & 1.32 \\
\hline Lead & $<0.05$ & $<0.05$ & $<0.02$ & $<0.02$ & $\mathrm{mg} / \mathrm{L}$ & 0.05 & 0.02 & 0.05 \\
\hline Lithium & 0.33 & $<0.01$ & NR & NR & $\mathrm{mg} / \mathrm{L}$ & 0.01 & NR & 0.46 \\
\hline
\end{tabular}


Table 6.2, cont.

\section{Concentration}

\section{Round $8 \quad$ Round 9}

\section{$\underline{\text { Reporting Limit }}$}

\begin{tabular}{|c|c|c|c|c|c|c|c|c|}
\hline Parameter & Sample & Dup. & Sample & Dup. & Units & Round 8 & Round 9 & $\begin{array}{c}95^{\text {th }} \\
\text { UTLV }^{1}\end{array}$ \\
\hline Magnesium & 993 & $<0.5$ & 1,100 & 1,120 & $\mathrm{mg} / \mathrm{L}$ & 0.50 & 0.50 & 1,310 \\
\hline Mercury & $<0.0002$ & $<0.0002$ & $<0.0002$ & $<0.0002$ & $\mathrm{mg} / \mathrm{L}$ & 0.0002 & 0.0002 & 0.002 \\
\hline Nickel & $<0.10$ & $<0.10$ & 0.49 & 0.37 & $\mathrm{mg} / \mathrm{L}$ & 0.10 & 0.05 & 0.1 \\
\hline Potassium & 661 & $<1.0$ & 700 & 728 & $\mathrm{mg} / \mathrm{L}$ & 1.0 & 0.50 & 525 \\
\hline Selenium & $<0.05$ & $<0.05$ & 0.07 & $<0.05$ & $\mathrm{mg} / \mathrm{L}$ & 0.05 & 0.05 & 0.05 \\
\hline Silica & 5.3 & 0.8 & NR & $\mathrm{NR}$ & $\mathrm{mg} / \mathrm{L}$ & 0.10 & NR & 12 \\
\hline Silver & $<0.05$ & $<0.05$ & $<0.05$ & $<0.05$ & $\mathrm{mg} / \mathrm{L}$ & 0.05 & 0.05 & 0.05 \\
\hline Sodium & 19,700 & $<1.0$ & $\mathrm{NR}$ & $\mathrm{NR}$ & $\mathrm{mg} / \mathrm{L}$ & 1.0 & NR & 21,550 \\
\hline Thallium & $<0.10$ & $<0.10$ & $<0.02$ & $<0.02$ & $\mathrm{mg} / \mathrm{L}$ & 0.10 & 0.02 & 0.05 \\
\hline Tin & $<0.10$ & $<0.10$ & NR & NR & $\mathrm{mg} / \mathrm{L}$ & 0.10 & NR & 0.1 \\
\hline Vanadium & $<0.01$ & $<0.01$ & NR & NR & $\mathrm{mg} / \mathrm{L}$ & 0.01 & NR & 0.1 \\
\hline Zinc & $<0.10$ & $<0.10$ & NR & NR & $\mathrm{mg} / \mathrm{L}$ & 0.10 & NR & 0.2 \\
\hline
\end{tabular}

${ }^{1} 95^{\text {th }}$ Upper Tolerance Limit Value, equivalent to $95 \%$ Confidence Limit

${ }^{2}$ Reporting Limit

${ }^{3}$ Not reported by laboratory

${ }^{4}$ Not Applicable

${ }^{5}$ Standard Unit 
Table 6.3 Analytical results for ground water sampled from well WQSP-2.

\section{Concentration}

$\underline{\text { Round } 8} \quad \underline{\text { Round } 9}$

\begin{tabular}{|c|c|c|c|c|c|c|c|c|}
\hline Parameter & Sample & Dup. & Sample & Dup. & Units & Round 8 & Round 9 & $\begin{array}{c}95^{\text {th }} \\
\mathbf{U T L V}^{1}\end{array}$ \\
\hline 1,1,1-Trichloroethane & $<1$ & $<1$ & $<2$ & $<2$ & $\mu \mathrm{g} / \mathrm{L}$ & 1 & 2 & $<\mathrm{RL}^{2}$ \\
\hline 1,1,2,2-Tetrachloroethane & $<1$ & $<1$ & $\mathrm{NR}^{3}$ & NR & NR & 1 & NR & $<\mathrm{RL}$ \\
\hline 1,1,2-Trichloroethane & $<1$ & $<1$ & $<2$ & $<2$ & $\mu \mathrm{g} / \mathrm{L}$ & 1 & 2 & $<\mathrm{RL}$ \\
\hline 1,1-Dichloroethane & NR & NR & $<2$ & $<2$ & $\mu \mathrm{g} / \mathrm{L}$ & NR & 2 & $<\mathrm{RL}$ \\
\hline 1,1-Dichloroethylene & $<1$ & $<1$ & $<2$ & $<2$ & $\mu \mathrm{g} / \mathrm{L}$ & 1 & 2 & $<\mathrm{RL}$ \\
\hline 1,2-Dichloroethane & 1.4 & 1.2 & $<2$ & $<2$ & $\mu \mathrm{g} / \mathrm{L}$ & 1 & 2 & $<\mathrm{RL}$ \\
\hline Carbon tetrachloride & $<1$ & $<1$ & $<2$ & $<2$ & $\mu \mathrm{g} / \mathrm{L}$ & 1 & 2 & $<R L$ \\
\hline Chlorobenzene & $<1$ & $<1$ & $<2$ & $<2$ & $\mu \mathrm{g} / \mathrm{L}$ & 1 & 2 & $<\mathrm{RL}$ \\
\hline Chloroform & $<1$ & $<1$ & $<2$ & $<2$ & $\mu \mathrm{g} / \mathrm{L}$ & 1 & 2 & $<\mathrm{RL}$ \\
\hline cis-1,2-Dichloroethylene & NR & NR & $<2$ & $<2$ & $\mu \mathrm{g} / \mathrm{L}$ & NR & 2 & $<\mathrm{RL}$ \\
\hline Methyl ethyl ketone & $<50$ & $<50$ & $<10$ & $<10$ & $\mu \mathrm{g} / \mathrm{L}$ & 50 & 10 & $<\mathrm{RL}$ \\
\hline Methylene chloride & $<5$ & $<5$ & $<5$ & $<5$ & $\mu \mathrm{g} / \mathrm{L}$ & 5 & 5 & $<\mathrm{RL}$ \\
\hline Tetrachloroethylene & $<1$ & $<1$ & $<2$ & $<2$ & $\mu \mathrm{g} / \mathrm{L}$ & 1 & 2 & $<\mathrm{RL}$ \\
\hline Toluene & $<1$ & $<1$ & $<2$ & $<2$ & $\mu \mathrm{g} / \mathrm{L}$ & 1 & 2 & $<\mathrm{RL}$ \\
\hline Trichloroethylene & $<1$ & $<1$ & $<2$ & $<2$ & $\mu \mathrm{g} / \mathrm{L}$ & 1 & 2 & $<\mathrm{RL}$ \\
\hline Trichlorofluoromethane & $<1$ & $<1$ & $<2$ & $<2$ & $\mu \mathrm{g} / \mathrm{L}$ & 1 & 2 & $<\mathrm{RL}$ \\
\hline Vinyl chloride & $<1$ & $<1$ & $<2$ & $<2$ & $\mu \mathrm{g} / \mathrm{L}$ & 1 & 2 & $<\mathrm{RL}$ \\
\hline Xylene & $<1$ & $<1$ & $<2$ & $<2$ & $\mu \mathrm{g} / \mathrm{L}$ & 1 & 2 & $<R L$ \\
\hline 1,2-Dichlorobenzene & $<1$ & $<1$ & $<5$ & $<5$ & $\mu \mathrm{g} / \mathrm{L}$ & 1 & 5 & $<\mathrm{RL}$ \\
\hline 1,4-Dichlorobenzene & $<1$ & $<1$ & $<5$ & $<5$ & $\mu \mathrm{g} / \mathrm{L}$ & 1 & 5 & $<\mathrm{RL}$ \\
\hline 2,4-Dinitrophenol & $<1$ & $<1$ & $<5$ & $<5$ & $\mu \mathrm{g} / \mathrm{L}$ & 1 & 5 & $<\mathrm{RL}$ \\
\hline 2,4-Dinitrotoluene & $<1$ & $<1$ & $<5$ & $<5$ & $\mu \mathrm{g} / \mathrm{L}$ & 1 & 5 & $<\mathrm{RL}$ \\
\hline 2-Methylphenol & $<1$ & $<1$ & $<5$ & $<5$ & $\mu \mathrm{g} / \mathrm{L}$ & 1 & 5 & $<\mathrm{RL}$ \\
\hline $\begin{array}{l}\text { 3-Methylphenol/ } \\
\text { 4-Methylphenol }\end{array}$ & $<1$ & $<1$ & $<5$ & $<5$ & $\mu \mathrm{g} / \mathrm{L}$ & 1 & 5 & $<\mathrm{RL}$ \\
\hline Hexachlorobenzene & $<1$ & $<1$ & $<5$ & $<5$ & $\mu \mathrm{g} / \mathrm{L}$ & 1 & 5 & $<R L$ \\
\hline Hexachloroethane & $<1$ & $<1$ & $<5$ & $<5$ & $\mu \mathrm{g} / \mathrm{L}$ & 1 & 5 & $<R L$ \\
\hline Nitrobenzene & $<1$ & $<1$ & $<5$ & $<5$ & $\mu \mathrm{g} / \mathrm{L}$ & 1 & 5 & $<\mathrm{RL}$ \\
\hline Pentachlorophenol & $<1$ & $<1$ & $<5$ & $<5$ & $\mu \mathrm{g} / \mathrm{L}$ & 1 & 5 & $<\mathrm{RL}$ \\
\hline Pyridine & $<1$ & $<1$ & $<5$ & $<5$ & $\mu \mathrm{g} / \mathrm{L}$ & 1 & 5 & $<\mathrm{RL}$ \\
\hline Isobutanol & 9,400 & $<500$ & $<500$ & $<500$ & $\mu \mathrm{g} / \mathrm{L}$ & 500 & 500 & $<\mathrm{RL}$ \\
\hline Alkalinity & 47 & 49 & NR & NR & $\mathrm{mg} / \mathrm{L}$ & $\mathrm{NA}^{4}$ & NR & 52.5 \\
\hline
\end{tabular}


Table 6.3, cont.

\section{Concentration}

$\underline{\text { Round } 8} \quad \underline{\text { Round } 9}$

Reporting Limit

\begin{tabular}{|c|c|c|c|c|c|c|c|c|}
\hline Parameter & Sample & Dup. & Sample & Dup. & Units & Round 8 & Round 9 & $\begin{array}{c}{95^{\text {th }}} \\
\text { UTLV }^{1}\end{array}$ \\
\hline Bromide & 32 & 32 & NR & NR & $\mathrm{mg} / \mathrm{L}$ & 0.2 & NR & 61.3 \\
\hline Chloride & 34,000 & 34,000 & 36,000 & 36,000 & $\mathrm{mg} / \mathrm{L}$ & 0.5 & 0.5 & 42,167 \\
\hline Density & 1.043 & 1.045 & 1.055 & 1.043 & $\mathrm{~g} / \mathrm{ml}$ & $N / A^{5}$ & N/A & 1.06 \\
\hline Fluoride & 1.2 & 1.2 & NR & NR & $\mathrm{mg} / \mathrm{L}$ & 0.1 & NR & 20 \\
\hline Iodide & $<2.0$ & $<2.0$ & NR & NR & $\mathrm{mg} / \mathrm{L}$ & 2.0 & NR & 2.0 \\
\hline Nitrate (as N) & $<2.0$ & $<2.0$ & NR & NR & $\mathrm{mg} / \mathrm{L}$ & 2.0 & NR & 0.270 \\
\hline Orthophosphate (as P) & $<0.01$ & $<0.01$ & NR & NR & $\mathrm{mg} / \mathrm{L}$ & 0.01 & NR & 0.03 \\
\hline $\mathrm{pH}$ & 7.3 & 7.3 & 7.3 & 7.2 & $\mathrm{SU}^{6}$ & N/A & N/A & $6.91-7.66$ \\
\hline Specific conductance & 110,000 & 110,000 & 97,428 & 100,004 & $\mu \mathrm{mhos} / \mathrm{cm}$ & N/A & N/A & 85,420 \\
\hline Sulfate & 5,000 & 4,600 & NR & NR & $\mathrm{mg} / \mathrm{L}$ & 0.5 & NR & 6,829 \\
\hline Total dissolved solids & 63,000 & 38,000 & 48,000 & 54,000 & $\mathrm{mg} / \mathrm{L}$ & 10 & 10 & 74,660 \\
\hline Total organic carbon & $<1.0$ & $<1.0$ & $<1.0$ & $<1.0$ & $\mathrm{mg} / \mathrm{L}$ & 1.0 & 1.0 & 8.15 \\
\hline Total organic halogen & 12 & 2.7 & 0.90 & 1.4 & $\mathrm{mg} / \mathrm{L}$ & N/A & N/A & 63.8 \\
\hline Total phenols & $<0.07$ & $<0.07$ & NR & NR & $\mathrm{mg} / \mathrm{L}$ & 0.07 & NR & $<\mathrm{RL}$ \\
\hline Total suspended solids & $<1.0$ & $<1.0$ & $<1.0$ & $<1.0$ & $\mathrm{mg} / \mathrm{L}$ & 1.0 & 1.0 & 44.0 \\
\hline Gross alpha & $150 \pm 300$ & NR & $260 \pm 320$ & NR & $\mathrm{pCi} / \mathrm{L}$ & 530 & 500 & 430 \\
\hline Gross beta & $270 \pm 260$ & NR & $250 \pm 350$ & NR & $\mathrm{pCi} / \mathrm{L}$ & 430 & 590 & 310 \\
\hline Antimony & $<0.005$ & $<0.01$ & $<0.05$ & $<0.05$ & $\mathrm{mg} / \mathrm{L}$ & 0.01 & 0.05 & 0.05 \\
\hline Arsenic & $<0.05$ & $<0.05$ & $<0.05$ & $<0.05$ & $\mathrm{mg} / \mathrm{L}$ & 0.05 & 0.05 & 0.05 \\
\hline Barium & $<0.10$ & $<0.10$ & $<0.10$ & $<0.10$ & $\mathrm{mg} / \mathrm{L}$ & 0.10 & 0.10 & 0.026 \\
\hline Beryllium & $<0.001$ & $<0.001$ & $<0.02$ & $<0.02$ & $\mathrm{mg} / \mathrm{L}$ & 0.001 & 0.02 & 0.02 \\
\hline Boron & 18 & 17 & NR & NR & $\mathrm{mg} / \mathrm{L}$ & 0.50 & NR & 18.7 \\
\hline Cadmium & $<0.005$ & $<0.005$ & $<0.02$ & $<0.02$ & $\mathrm{mg} / \mathrm{L}$ & 0.005 & 0.02 & 0.01 \\
\hline Calcium & 1,510 & 1,470 & 1,509 & 1,428 & $\mathrm{mg} / \mathrm{L}$ & 0.50 & 0.50 & 1,640 \\
\hline Chromium & $<0.05$ & $<0.05$ & $<0.02$ & $<0.02$ & $\mathrm{mg} / \mathrm{L}$ & 0.05 & 0.02 & 0.1 \\
\hline Cobalt & $<0.05$ & $<0.05$ & NR & NR & $\mathrm{mg} / \mathrm{L}$ & 0.05 & NR & 0.05 \\
\hline Copper & $<0.10$ & $<0.10$ & NR & NR & $\mathrm{mg} / \mathrm{L}$ & 0.10 & NR & 0.25 \\
\hline Iron & $<0.10$ & $<0.10$ & $<0.10$ & $<0.10$ & $\mathrm{mg} / \mathrm{L}$ & 0.10 & 0.10 & 1.00 \\
\hline Lead & $<0.005$ & $<0.005$ & $<0.02$ & $<0.02$ & $\mathrm{mg} / \mathrm{L}$ & 0.005 & 0.02 & 0.05 \\
\hline Lithium & 0.34 & 0.33 & NR & NR & $\mathrm{mg} / \mathrm{L}$ & 0.01 & NR & 0.46 \\
\hline Magnesium & 1,010 & 986 & 1,010 & 931 & $\mathrm{mg} / \mathrm{L}$ & 0.50 & 0.50 & 1,173 \\
\hline
\end{tabular}


Table 6.3, cont.

\section{Concentration}

$\underline{\text { Round } 8} \underline{\text { Round } 9}$

$\underline{\text { Reporting Limit }}$

\begin{tabular}{lcccccccc}
\multicolumn{1}{c}{ Parameter } & Sample & Dup. & Sample & Dup. & Units & Round 8 & Round 9 & $\begin{array}{c}\mathbf{9 5}^{\text {th }} \\
\text { UTLV }^{\mathbf{1}}\end{array}$ \\
\hline Mercury & $<0.0010$ & $<0.0010$ & $<0.0002$ & $<0.0002$ & $\mathrm{mg} / \mathrm{L}$ & 0.0010 & 0.0002 & 0.002 \\
Nickel & $<0.10$ & $<0.10$ & 0.41 & 0.48 & $\mathrm{mg} / \mathrm{L}$ & 0.10 & 0.05 & 0.050 \\
Potassium & 581 & 570 & 625 & 606 & $\mathrm{mg} / \mathrm{L}$ & 0.50 & 0.50 & 529 \\
Selenium & $<0.01$ & $<0.05$ & $<0.05$ & 0.06 & $\mathrm{mg} / \mathrm{L}$ & 0.01 & 0.05 & 0.05 \\
Silica & 8.0 & 8.0 & $\mathrm{NR}$ & $\mathrm{NR}$ & $\mathrm{mg} / \mathrm{L}$ & 1.0 & $\mathrm{NR}$ & 12.2 \\
Silver & $<0.05$ & $<0.05$ & $<0.05$ & $<0.05$ & $\mathrm{mg} / \mathrm{L}$ & 0.05 & 0.05 & 0.05 \\
Sodium & 19,100 & 19,400 & $\mathrm{NR}$ & $\mathrm{NR}$ & $\mathrm{mg} / \mathrm{L}$ & 1.0 & $\mathrm{NR}$ & 21,042 \\
Thallium & $<0.001$ & $<0.001$ & $<0.05$ & $<0.05$ & $\mathrm{mg} / \mathrm{L}$ & 0.001 & 0.05 & 0.05 \\
Tin & $<0.10$ & $<0.10$ & $\mathrm{NR}$ & $\mathrm{NR}$ & $\mathrm{mg} / \mathrm{L}$ & 0.10 & $\mathrm{NR}$ & 0.1 \\
Vanadium & $<0.10$ & $<0.10$ & $\mathrm{NR}$ & $\mathrm{NR}$ & $\mathrm{mg} / \mathrm{L}$ & 0.10 & $\mathrm{NR}$ & 0.1 \\
Zinc & $<0.10$ & $<0.10$ & $\mathrm{NR}$ & $\mathrm{NR}$ & $\mathrm{mg} / \mathrm{L}$ & 0.10 & $\mathrm{NR}$ & 0.2 \\
\hline
\end{tabular}

${ }^{1} 95^{\text {th }}$ Upper Tolerance Limit Value, equivalent to $95 \%$ Confidence Limit

${ }^{2}$ Reporting Limit

${ }^{3}$ Not reported by laboratory

${ }^{4}$ Not Available

${ }^{5}$ Not Applicable

${ }^{6}$ Standard Unit 
Table 6.4 Analytical results for ground water sampled from well WQSP-3.

\begin{tabular}{|c|c|c|c|c|c|c|c|c|}
\hline \multirow[b]{3}{*}{ Parameter } & \multicolumn{7}{|c|}{ Concentration } & \multirow[b]{3}{*}{$\begin{array}{c}\mathbf{9 5}^{\text {th }} \\
\text { UTLV }^{1}\end{array}$} \\
\hline & \multicolumn{2}{|c|}{$\underline{\text { Round } 8}$} & \multicolumn{2}{|c|}{$\underline{\text { Round } 9}$} & \multicolumn{3}{|c|}{ Reporting Limit } & \\
\hline & Sample & Dup. & Sample & Dup. & Units & Round 8 & Round 9 & \\
\hline 1,1,1-Trichloroethane & $<1$ & $<1$ & $<2$ & $<2$ & $\mu \mathrm{g} / \mathrm{L}$ & 1 & 2 & $<\mathrm{RL}^{2}$ \\
\hline $1,1,2,2$-Tetrachloroethane & $<1$ & $<1$ & $<2$ & $<2$ & $\mu \mathrm{g} / \mathrm{L}$ & 1 & 2 & $<\mathrm{RL}$ \\
\hline 1,1,2-Trichloroethane & $<1$ & $<1$ & $<2$ & $<2$ & $\mu \mathrm{g} / \mathrm{L}$ & 1 & 2 & $<R L$ \\
\hline 1,1-Dichloroethane & $\mathrm{NR}^{3}$ & NR & $<2$ & $<2$ & $\mu \mathrm{g} / \mathrm{L}$ & NR & 2 & $<\mathrm{RL}$ \\
\hline 1,1-Dichloroethylene & $<1$ & $<1$ & $<2$ & $<2$ & $\mu \mathrm{g} / \mathrm{L}$ & 1 & 2 & $<\mathrm{RL}$ \\
\hline 1,2-Dichloroethane & $<1$ & $<1$ & $<2$ & $<2$ & $\mu \mathrm{g} / \mathrm{L}$ & 1 & 2 & $<R L$ \\
\hline Carbon tetrachloride & $<1$ & $<1$ & $<2$ & $<2$ & $\mu \mathrm{g} / \mathrm{L}$ & 1 & 2 & $<R L$ \\
\hline Chlorobenzene & $<1$ & $<1$ & $<2$ & $<2$ & $\mu \mathrm{g} / \mathrm{L}$ & 1 & 2 & $<R L$ \\
\hline Chloroform & $<1$ & $<1$ & $<2$ & $<2$ & $\mu \mathrm{g} / \mathrm{L}$ & 1 & 2 & $<\mathrm{RL}$ \\
\hline cis-1,2-Dichloroethylene & NR & NR & $<2$ & $<2$ & $\mu \mathrm{g} / \mathrm{L}$ & NR & 2 & $<\mathrm{RL}$ \\
\hline Methyl ethyl ketone & $<50$ & $<50$ & $<10$ & $<10$ & $\mu \mathrm{g} / \mathrm{L}$ & 50 & 10 & $<R L$ \\
\hline Methylene chloride & $<5$ & $<5$ & $<5$ & $<5$ & $\mu \mathrm{g} / \mathrm{L}$ & 5 & 5 & $<\mathrm{RL}$ \\
\hline Tetrachloroethylene & $<1$ & $<1$ & $<2$ & $<2$ & $\mu \mathrm{g} / \mathrm{L}$ & 1 & 2 & $<\mathrm{RL}$ \\
\hline Toluene & $<1$ & $<1$ & $<2$ & $<2$ & $\mu \mathrm{g} / \mathrm{L}$ & 1 & 2 & $<R L$ \\
\hline Trichloroethylene & $<1$ & $<1$ & $<2$ & $<2$ & $\mu \mathrm{g} / \mathrm{L}$ & 1 & 2 & $<\mathrm{RL}$ \\
\hline Trichlorofluoromethane & $<1$ & $<1$ & $<2$ & $<2$ & $\mu \mathrm{g} / \mathrm{L}$ & 1 & 2 & $<\mathrm{RL}$ \\
\hline Vinyl chloride & $<1$ & $<1$ & $<2$ & $<2$ & $\mu \mathrm{g} / \mathrm{L}$ & 1 & 2 & $<\mathrm{RL}$ \\
\hline Xylene & $<1$ & $<1$ & $<2$ & $<2$ & $\mu \mathrm{g} / \mathrm{L}$ & 1 & 2 & $<\mathrm{RL}$ \\
\hline 1,2-Dichlorobenzene & $<1$ & $<1$ & $<1$ & $<1$ & $\mu \mathrm{g} / \mathrm{L}$ & 1 & 1 & $<R L$ \\
\hline 1,4-Dichlorobenzene & $<1$ & $<1$ & $<1$ & $<1$ & $\mu \mathrm{g} / \mathrm{L}$ & 1 & 1 & $<\mathrm{RL}$ \\
\hline 2,4-Dinitrophenol & $<1$ & $<1$ & $<1$ & $<1$ & $\mu \mathrm{g} / \mathrm{L}$ & 1 & 1 & $<\mathrm{RL}$ \\
\hline 2,4-Dinitrotoluene & $<1$ & $<1$ & $<1$ & $<1$ & $\mu \mathrm{g} / \mathrm{L}$ & 1 & 1 & $<\mathrm{RL}$ \\
\hline 2-Methylphenol & $<1$ & $<1$ & $<1$ & $<1$ & $\mu \mathrm{g} / \mathrm{L}$ & 1 & 1 & $<R L$ \\
\hline $\begin{array}{l}\text { 3-Methylphenol/ } \\
\text { 4-Methylphenol }\end{array}$ & $<1$ & $<1$ & $<1$ & $<1$ & $\mu \mathrm{g} / \mathrm{L}$ & 1 & 1 & $<\mathrm{RL}$ \\
\hline Hexachlorobenzene & $<1$ & $<1$ & $<1$ & $<1$ & $\mu \mathrm{g} / \mathrm{L}$ & 1 & 1 & $<\mathrm{RL}$ \\
\hline Hexachloroethane & $<1$ & $<1$ & $<1$ & $<1$ & $\mu \mathrm{g} / \mathrm{L}$ & 1 & 1 & $<\mathrm{RL}$ \\
\hline Nitrobenzene & $<1$ & $<1$ & $<1$ & $<1$ & $\mu \mathrm{g} / \mathrm{L}$ & 1 & 1 & $<R L$ \\
\hline Pentachlorophenol & $<1$ & $<1$ & $<1$ & $<1$ & $\mu \mathrm{g} / \mathrm{L}$ & 1 & 1 & $<\mathrm{RL}$ \\
\hline Pyridine & $<1$ & $<1$ & $<1$ & $<1$ & $\mu \mathrm{g} / \mathrm{L}$ & 1 & 1 & $<\mathrm{RL}$ \\
\hline Isobutanol & $<500$ & $<500$ & $<500$ & $<500$ & $\mu \mathrm{g} / \mathrm{L}$ & 500 & 500 & $<R L$ \\
\hline Alkalinity & 31 & 33 & 36 & 37 & $\mathrm{mg} / \mathrm{L}$ & $\mathrm{NA}^{4}$ & N/A & 44.0 \\
\hline
\end{tabular}


Table 6.4, cont.

\begin{tabular}{|c|c|c|c|c|c|c|c|c|}
\hline \multirow[b]{3}{*}{ Parameter } & \multicolumn{7}{|c|}{ Concentration } & \multirow[b]{3}{*}{$\begin{array}{c}\mathbf{9 5}^{\text {th }} \\
\text { UTLV }^{1}\end{array}$} \\
\hline & \multicolumn{2}{|c|}{$\underline{\text { Round } 8}$} & \multicolumn{2}{|c|}{$\underline{\text { Round } 9}$} & \multicolumn{3}{|c|}{ Reporting Limit } & \\
\hline & Sample & Dup. & Sample & Dup. & Units & Round 8 & Round 9 & \\
\hline Bromide & $<200$ & $<200$ & 76 & 73 & $\mathrm{mg} / \mathrm{L}$ & 0.2 & & 166.2 \\
\hline Chloride & 120,000 & 130,000 & 140,000 & 140,000 & $\mathrm{mg} / \mathrm{L}$ & 0.5 & 0.5 & 156,600 \\
\hline Density & 1.144 & 1.138 & 1.145 & 1.139 & $\mathrm{~g} / \mathrm{ml}$ & $\mathrm{N} / \mathrm{A}^{5}$ & N/A & 1.16 \\
\hline Fluoride & $<2.0$ & $<2.0$ & 0.52 & 0.51 & $\mathrm{mg} / \mathrm{L}$ & 0.10 & 0.10 & 10 \\
\hline Iodide & $<2.0$ & $<2.0$ & $<2.0$ & $<2.0$ & $\mathrm{mg} / \mathrm{L}$ & 2.0 & 2.0 & 2.22 \\
\hline Nitrate (as N) & $<10$ & $<10$ & $<10$ & $<10$ & $\mathrm{mg} / \mathrm{L}$ & 0.2 & 0.2 & 0.820 \\
\hline Orthophosphate (as P) & 0.012 & 0.014 & 0.014 & $<0.01$ & $\mathrm{mg} / \mathrm{L}$ & 0.01 & 0.01 & 0.02 \\
\hline $\mathrm{pH}$ & 6.9 & 6.9 & 6.9 & 6.9 & $\mathrm{SU}^{6}$ & N/A & N/A & $6.7-7.1$ \\
\hline Specific conductance & 400,000 & 400,000 & 420,000 & 420,000 & $\mu \mathrm{mhos} / \mathrm{cm}$ & N/A & N/A & 206,500 \\
\hline Sulfate & 7,300 & 7,300 & 7,500 & 7,400 & $\mathrm{mg} / \mathrm{L}$ & 0.5 & 0.5 & 8,415 \\
\hline Total dissolved solids & 220,000 & 200,000 & 220,000 & 220,000 & $\mathrm{mg} / \mathrm{L}$ & 10 & 10 & 230,400 \\
\hline Total organic carbon & $<1.0$ & $<1.0$ & $<1.0$ & $<1.0$ & $\mathrm{mg} / \mathrm{L}$ & 1.0 & 1.0 & 2.49 \\
\hline Total organic halogen & 4.5 & 9.7 & 1.2 & 1.2 & $\mathrm{mg} / \mathrm{L}$ & NA & N/A & 56.400 \\
\hline Total phenols & $<0.07$ & $<0.07$ & $<0.07$ & $<0.07$ & $\mathrm{mg} / \mathrm{L}$ & 0.07 & 0.07 & $<\mathrm{RL}$ \\
\hline Total suspended solids & $<1.0$ & $<1.0$ & $<1.0$ & $<1.0$ & $\mathrm{mg} / \mathrm{L}$ & 1.0 & 1.0 & 113.0 \\
\hline Gross alpha & $26 \pm 1,000$ & NR & $\begin{array}{r}1,900 \pm \\
1,600\end{array}$ & NR & $\mathrm{pCi} / \mathrm{L}$ & 2,000 & 2,050 & 1,900 \\
\hline Gross beta & $820 \pm 810$ & NR & $\begin{array}{c}770 \\
\pm 1,500\end{array}$ & NR & $\mathrm{pCi} / \mathrm{L}$ & 1,300 & 2,500 & 1,100 \\
\hline Antimony & $<1.0$ & $<1.0$ & $<0.05$ & $<0.05$ & $\mathrm{mg} / \mathrm{L}$ & 1.0 & 0.05 & 0.13 \\
\hline Arsenic & $<0.05$ & $<0.05$ & $<0.05$ & $<0.05$ & $\mathrm{mg} / \mathrm{L}$ & 0.05 & 0.05 & 0.13 \\
\hline Barium & $<1.0$ & $<1.0$ & $<0.10$ & $<0.10$ & $\mathrm{mg} / \mathrm{L}$ & 1.0 & 0.10 & 0.16 \\
\hline Beryllium & $<0.01$ & $<0.01$ & $<0.02$ & $<0.02$ & $\mathrm{mg} / \mathrm{L}$ & 0.01 & 0.02 & 0.08 \\
\hline Boron & 48 & 53 & 39.2 & 39.0 & $\mathrm{mg} / \mathrm{L}$ & 0.50 & 0.50 & 58.52 \\
\hline Cadmium & $<0.05$ & $<0.05$ & $<0.02$ & $<0.02$ & $\mathrm{mg} / \mathrm{L}$ & 0.05 & 0.02 & 0.025 \\
\hline Calcium & 1,400 & 1,530 & 1,500 & 1,500 & $\mathrm{mg} / \mathrm{L}$ & 1.00 & 1.00 & 1,680 \\
\hline Chromium & $<0.05$ & $<0.05$ & $<0.05$ & $<0.05$ & $\mathrm{mg} / \mathrm{L}$ & 0.05 & 0.05 & 0.25 \\
\hline Cobalt & $<0.50$ & $<0.50$ & $<0.10$ & $<0.10$ & $\mathrm{mg} / \mathrm{L}$ & 0.50 & 0.10 & 0.13 \\
\hline Copper & $<0.50$ & $<0.50$ & $<0.10$ & $<0.10$ & $\mathrm{mg} / \mathrm{L}$ & 0.50 & 0.10 & 0.13 \\
\hline Iron & $<0.30$ & $<0.30$ & $<0.10$ & $<0.10$ & $\mathrm{mg} / \mathrm{L}$ & 0.30 & 0.10 & 4.0 \\
\hline Lead & $<0.05$ & $<0.05$ & $<0.02$ & $<0.02$ & $\mathrm{mg} / \mathrm{L}$ & 0.05 & 0.02 & 0.13 \\
\hline Lithium & 1.6 & 0.01 & 2.77 & 2.83 & $\mathrm{mg} / \mathrm{L}$ & 0.01 & 0.01 & 0.917 \\
\hline
\end{tabular}


Table 6.4, cont.

\section{Concentration}

\section{Round 8}

Round 9

$\underline{\text { Reporting Limit }}$

\begin{tabular}{lcccccccc}
\multicolumn{1}{c}{ Parameter } & Sample & Dup. & Sample & Dup. & Units & Round 8 & Round 9 & $\begin{array}{c}\mathbf{9 5}^{\text {th }} \\
\text { UTLV }^{\mathbf{1}}\end{array}$ \\
\hline Magnesium & 2,070 & 2,290 & 2,290 & 2,310 & $\mathrm{mg} / \mathrm{L}$ & 1.00 & 0.50 & 2,363 \\
Mercury & $<0.0002$ & $<0.0002$ & $<0.0002$ & $<0.0002$ & $\mathrm{mg} / \mathrm{L}$ & 0.0002 & 0.0002 & 0.002 \\
Nickel & $<0.10$ & $<0.10$ & $<0.10$ & $<0.10$ & $\mathrm{mg} / \mathrm{L}$ & 0.10 & 0.10 & 0.25 \\
Potassium & 2,140 & 2,440 & 2,870 & 2,800 & $\mathrm{mg} / \mathrm{L}$ & 1.0 & 0.50 & 1,914 \\
Selenium & $<0.05$ & $<0.05$ & 0.129 & 0.141 & $\mathrm{mg} / \mathrm{L}$ & 0.05 & 0.05 & 0.13 \\
Silica & 5.0 & 5.5 & 2.10 & 2.04 & $\mathrm{mg} / \mathrm{L}$ & 5.0 & 2.0 & 5.09 \\
Silver & $<0.05$ & $<0.05$ & $<0.05$ & $<0.05$ & $\mathrm{mg} / \mathrm{L}$ & 0.05 & 0.05 & 0.13 \\
Sodium & 146,800 & 134,000 & 66,600 & 68,300 & $\mathrm{mg} / \mathrm{L}$ & 1.0 & 1.0 & 83,230 \\
Thallium & $<0.10$ & $<0.10$ & $<0.10$ & $<0.10$ & $\mathrm{mg} / \mathrm{L}$ & 0.10 & 0.10 & 0.13 \\
Tin & $<0.10$ & $<0.10$ & $<0.10$ & $<0.10$ & $\mathrm{mg} / \mathrm{L}$ & 0.10 & 0.10 & 0.25 \\
Vanadium & $<0.10$ & $<0.10$ & $<0.10$ & $<0.10$ & $\mathrm{mg} / \mathrm{L}$ & 0.10 & 0.10 & 0.25 \\
Zinc & $<5.0$ & $<5.0$ & 0.15 & 0.11 & $\mathrm{mg} / \mathrm{L}$ & 5.0 & 0.10 & 0.5 \\
\hline
\end{tabular}

${ }^{1} 95^{\text {th }}$ Upper Tolerance Limit Value, equivalent to $95 \%$ Confidence Limit

${ }^{2}$ Reporting Limit

${ }^{3}$ Not reported by laboratory

${ }^{4}$ Not Available

${ }^{5}$ Not Applicable

${ }^{6}$ Standard Unit 
Table 6.5 Analytical results for ground water sampled from well WQSP-4.

\section{Concentration}

Round 8

Round 9

$\underline{\text { Reporting Limit }}$

\begin{tabular}{|c|c|c|c|c|c|c|c|c|}
\hline Parameter & Sample & Dup. & Sample & Dup. & Units & Round 8 & Round 9 & $\begin{array}{c}9^{\text {th }} \\
\text { UTLV }^{1}\end{array}$ \\
\hline 1,1,1-Trichloroethane & $<1$ & $<1$ & $<2$ & $<2$ & $\mu \mathrm{g} / \mathrm{L}$ & 1 & 2 & $<\mathrm{RL}^{2}$ \\
\hline 1,1,2,2-Tetrachloroethane & $<1$ & $<1$ & $<2$ & $<2$ & $\mu \mathrm{g} / \mathrm{L}$ & 1 & 2 & $<\mathrm{RL}$ \\
\hline 1,1,2-Trichloroethane & $<1$ & $<1$ & $<2$ & $<2$ & $\mu \mathrm{g} / \mathrm{L}$ & 1 & 2 & $<\mathrm{RL}$ \\
\hline 1,1-Dichloroethane & $\mathrm{NR}^{3}$ & NR & $<2$ & $<2$ & $\mu \mathrm{g} / \mathrm{L}$ & NR & 2 & $<\mathrm{RL}$ \\
\hline 1,1-Dichloroethylene & $<1$ & $<1$ & $<2$ & $<2$ & $\mu \mathrm{g} / \mathrm{L}$ & 1 & 2 & $<\mathrm{RL}$ \\
\hline 1,2-Dichloroethane & $<1$ & $<1$ & $<2$ & $<2$ & $\mu \mathrm{g} / \mathrm{L}$ & 1 & 2 & $<\mathrm{RL}$ \\
\hline Carbon tetrachloride & $<1$ & $<1$ & $<2$ & $<2$ & $\mu \mathrm{g} / \mathrm{L}$ & 1 & 2 & $<\mathrm{RL}$ \\
\hline Chlorobenzene & $<1$ & $<1$ & $<2$ & $<2$ & $\mu \mathrm{g} / \mathrm{L}$ & 1 & 2 & $<\mathrm{RL}$ \\
\hline Chloroform & $<1$ & $<1$ & $<2$ & $<2$ & $\mu \mathrm{g} / \mathrm{L}$ & 1 & 2 & $<\mathrm{RL}$ \\
\hline cis-1,2-Dichloroethylene & NR & NR & $<2$ & $<2$ & $\mu \mathrm{g} / \mathrm{L}$ & NR & 2 & $<\mathrm{RL}$ \\
\hline Methyl ethyl ketone & $<50$ & $<50$ & $<20$ & $<20$ & $\mu \mathrm{g} / \mathrm{L}$ & 50 & 20 & $<\mathrm{RL}$ \\
\hline Methylene chloride & $<5$ & $<5$ & $<5$ & $<5$ & $\mu \mathrm{g} / \mathrm{L}$ & 5 & 5 & $<\mathrm{RL}$ \\
\hline Tetrachloroethylene & $<1$ & $<1$ & $<2$ & $<2$ & $\mu \mathrm{g} / \mathrm{L}$ & 1 & 2 & $<\mathrm{RL}$ \\
\hline Toluene & $<1$ & $<1$ & $<2$ & $<2$ & $\mu \mathrm{g} / \mathrm{L}$ & 1 & 2 & $<\mathrm{RL}$ \\
\hline Trichloroethylene & $<1$ & $<1$ & NR & NR & $\mu \mathrm{g} / \mathrm{L}$ & 1 & NR & $<\mathrm{RL}$ \\
\hline Trichlorofluoromethane & $<1$ & $<1$ & $<2$ & $<2$ & $\mu \mathrm{g} / \mathrm{L}$ & 1 & 2 & $<\mathrm{RL}$ \\
\hline Vinyl chloride & $<1$ & $<1$ & $<2$ & $<2$ & $\mu \mathrm{g} / \mathrm{L}$ & 1 & 2 & $<\mathrm{RL}$ \\
\hline Xylene & $<1$ & $<1$ & $<2$ & $<2$ & $\mu \mathrm{g} / \mathrm{L}$ & 1 & 2 & $<\mathrm{RL}$ \\
\hline 1,2-Dichlorobenzene & $<1$ & $<1$ & $<1$ & $<1$ & $\mu \mathrm{g} / \mathrm{L}$ & 1 & 1 & $<\mathrm{RL}$ \\
\hline 1,4-Dichlorobenzene & $<1$ & $<1$ & $<1$ & $<1$ & $\mu \mathrm{g} / \mathrm{L}$ & 1 & 1 & $<\mathrm{RL}$ \\
\hline 2,4-Dinitrophenol & $<1$ & $<1$ & $<1$ & $<1$ & $\mu \mathrm{g} / \mathrm{L}$ & 1 & 1 & $<\mathrm{RL}$ \\
\hline 2,4-Dinitrotoluene & $<1$ & $<1$ & $<1$ & $<1$ & $\mu \mathrm{g} / \mathrm{L}$ & 1 & 1 & $<\mathrm{RL}$ \\
\hline 2-Methylphenol & $<1$ & $<1$ & $<1$ & $<1$ & $\mu \mathrm{g} / \mathrm{L}$ & 1 & 1 & $<\mathrm{RL}$ \\
\hline $\begin{array}{l}\text { 3-Methylphenol/ } \\
\text { 4-Methylphenol }\end{array}$ & $<1$ & $<1$ & $<1$ & $<1$ & $\mu \mathrm{g} / \mathrm{L}$ & 1 & 1 & $<\mathrm{RL}$ \\
\hline Hexachlorobenzene & $<1$ & $<1$ & $<1$ & $<1$ & $\mu \mathrm{g} / \mathrm{L}$ & 1 & 1 & $<\mathrm{RL}$ \\
\hline Hexachloroethane & $<1$ & $<1$ & $<1$ & $<1$ & $\mu \mathrm{g} / \mathrm{L}$ & 1 & 1 & $<\mathrm{RL}$ \\
\hline Nitrobenzene & $<1$ & $<1$ & $<1$ & $<1$ & $\mu \mathrm{g} / \mathrm{L}$ & 1 & 1 & $<\mathrm{RL}$ \\
\hline Pentachlorophenol & $<1$ & $<1$ & $<1$ & $<1$ & $\mu \mathrm{g} / \mathrm{L}$ & 1 & 1 & $<\mathrm{RL}$ \\
\hline Pyridine & $<1$ & $<1$ & $<1$ & $<1$ & $\mu \mathrm{g} / \mathrm{L}$ & 1 & 1 & $<\mathrm{RL}$ \\
\hline Isobutanol & $<500$ & $<500$ & $<500$ & $<500$ & $\mu \mathrm{g} / \mathrm{L}$ & 500 & 500 & $<\mathrm{RL}$ \\
\hline Alkalinity & 39 & 39 & 38 & 36 & $\mathrm{mg} / \mathrm{L}$ & $\mathrm{NA}^{4}$ & NA & 42.0 \\
\hline
\end{tabular}


Table 6.5, cont.

\section{Concentration}

$\underline{\text { Round } 8} \quad \underline{\text { Round } 9}$

$\underline{\text { Reporting Limit }}$

\begin{tabular}{|c|c|c|c|c|c|c|c|c|}
\hline Parameter & Sample & Dup. & Sample & Dup. & Units & Round 8 & Round 9 & $\begin{array}{c}9^{\text {th }} \\
\text { UTLV }^{1}\end{array}$ \\
\hline Bromide & $<200$ & $<200$ & 52 & 52 & $\mathrm{mg} / \mathrm{L}$ & 0.2 & 0.2 & 58.6 \\
\hline Chloride & 57,000 & 57,000 & 57,000 & 55,000 & $\mathrm{mg} / \mathrm{L}$ & 0.5 & 0.5 & 63,900 \\
\hline Density & 1.075 & 1.072 & 1.068 & 1.072 & $\mathrm{~g} / \mathrm{ml}$ & $\mathrm{N} / \mathrm{A}^{5}$ & N/A & 1.09 \\
\hline Fluoride & 1.1 & 1.1 & 1.1 & 1.1 & $\mathrm{mg} / \mathrm{L}$ & 0.1 & 0.1 & 2.76 \\
\hline Iodide & $<2.0$ & $<2.0$ & $<2.0$ & $<2.0$ & $\mathrm{mg} / \mathrm{L}$ & 2.0 & 2.0 & 2.0 \\
\hline Nitrate (as N) & $<10$ & $<10$ & $<10$ & $<10$ & $\mathrm{mg} / \mathrm{L}$ & 0.2 & 0.2 & 0.1 \\
\hline Orthophosphate (as P) & 0.02 & 0.02 & 0.024 & 0.022 & $\mathrm{mg} / \mathrm{L}$ & 0.01 & 0.01 & 0.02 \\
\hline $\mathrm{pH}$ & 7.2 & 7.2 & 7.0 & 7.1 & $\mathrm{SU}^{6}$ & N/A & N/A & $7.13-7.61$ \\
\hline Specific conductance & 320,000 & 310,000 & 190,000 & 220,000 & $\mu \mathrm{mhos} / \mathrm{cm}$ & N/A & N/A & 127,000 \\
\hline Sulfate & 6,800 & 6,600 & 6,500 & 6,200 & $\mathrm{mg} / \mathrm{L}$ & 0.5 & 0.5 & 8,300 \\
\hline Total dissolved solids & 100,000 & 100,000 & 110,000 & 100,000 & $\mathrm{mg} / \mathrm{L}$ & 10 & 10 & 125,000 \\
\hline Total organic carbon & $<1.0$ & $<1.0$ & $<3.0$ & $<3.0$ & $\mathrm{mg} / \mathrm{L}$ & 1.0 & 3.0 & 3.8 \\
\hline Total organic halogen & 7.9 & 17 & 0.71 & 0.80 & $\mathrm{mg} / \mathrm{L}$ & N/A & N/A & 0.275 \\
\hline Total phenols & 0.272 & 0.230 & $<0.07$ & $<0.07$ & $\mathrm{mg} / \mathrm{L}$ & 0.07 & 0.07 & $<\mathrm{RL}$ \\
\hline Total suspended solids & $<1.0$ & $<1.0$ & $<1.0$ & $<1.0$ & $\mathrm{mg} / \mathrm{L}$ & 1.0 & 1.0 & 59.0 \\
\hline Gross alpha & $590 \pm 680$ & NR & $630 \pm 540$ & NR & $\mathrm{pCi} / \mathrm{L}$ & 1,100 & 710 & 790 \\
\hline Gross beta & $510 \pm 440$ & NR & $100 \pm 380$ & NR & $\mathrm{pCi} / \mathrm{L}$ & 690 & 650 & 660 \\
\hline Antimony & 0.15 & 0.8 & $<0.05$ & $<0.05$ & $\mathrm{mg} / \mathrm{L}$ & 0.05 & 0.05 & 0.05 \\
\hline Arsenic & $<0.50$ & $<0.50$ & $<0.05$ & $<0.05$ & $\mathrm{mg} / \mathrm{L}$ & 0.05 & 0.05 & 0.05 \\
\hline Barium & $<1.0$ & $<1.0$ & $<0.10$ & $<0.10$ & $\mathrm{mg} / \mathrm{L}$ & 1.0 & 0.10 & 0.16 \\
\hline Beryllium & $<0.01$ & $<0.01$ & $<0.05$ & $<0.05$ & $\mathrm{mg} / \mathrm{L}$ & 0.01 & 0.05 & 0.08 \\
\hline Boron & 28 & 26 & 26.2 & 25.9 & $\mathrm{mg} / \mathrm{L}$ & 0.75 & 0.50 & 33.7 \\
\hline Cadmium & $<0.05$ & $<0.05$ & $<0.02$ & $<0.02$ & $\mathrm{mg} / \mathrm{L}$ & 0.05 & 0.02 & 0.13 \\
\hline Calcium & 1,480 & 1,670 & 1,640 & 1,824 & $\mathrm{mg} / \mathrm{L}$ & 1.0 & 0.05 & 1,790 \\
\hline Chromium & $<0.50$ & $<0.50$ & $<0.05$ & $<0.05$ & $\mathrm{mg} / \mathrm{L}$ & 0.50 & 0.05 & 0.1 \\
\hline Cobalt & $<0.50$ & $<0.50$ & $<0.05$ & $<0.05$ & $\mathrm{mg} / \mathrm{L}$ & 0.50 & 0.05 & 0.05 \\
\hline Copper & $<1.0$ & $<1.0$ & $<0.10$ & $<0.10$ & $\mathrm{mg} / \mathrm{L}$ & 1.0 & 0.10 & 0.05 \\
\hline Iron & $<0.30$ & $<0.30$ & $<0.30$ & $<0.30$ & $\mathrm{mg} / \mathrm{L}$ & 0.30 & 0.30 & 2.49 \\
\hline Lead & $<0.05$ & $<0.05$ & $<0.02$ & $<0.02$ & $\mathrm{mg} / \mathrm{L}$ & 0.05 & 0.02 & 0.525 \\
\hline Lithium & 0.34 & 0.36 & 0.79 & 0.88 & $\mathrm{mg} / \mathrm{L}$ & 0.01 & 0.01 & 0.623 \\
\hline Magnesium & 1,040 & 1,180 & 1,249 & 1,397 & $\mathrm{mg} / \mathrm{L}$ & 1.0 & 0.50 & 1,370 \\
\hline
\end{tabular}


Table 6.5, cont.

Concentration

$\underline{\text { Round } 8}$ Round 9

$\underline{\text { Reporting Limit }}$

\begin{tabular}{lcccccccc}
\multicolumn{1}{c}{ Parameter } & Sample & Dup. & Sample & Dup. & Units & Round 8 & Round 9 & $\begin{array}{c}\mathbf{9 5}^{\text {th }} \\
\text { UTLV }^{\mathbf{1}}\end{array}$ \\
\hline Mercury & $<0.0002$ & $<0.0002$ & $<0.0002$ & $<0.0002$ & $\mathrm{mg} / \mathrm{L}$ & 0.0002 & 0.0002 & 0.002 \\
Nickel & $<0.10$ & $<0.10$ & $<0.02$ & $<0.02$ & $\mathrm{mg} / \mathrm{L}$ & 0.10 & 0.02 & 0.1 \\
Potassium & 935 & 1060 & 980 & 1,049 & $\mathrm{mg} / \mathrm{L}$ & 1.0 & 0.50 & 841 \\
Selenium & $<0.10$ & $<0.10$ & 0.106 & 0.122 & $\mathrm{mg} / \mathrm{L}$ & 0.10 & 0.05 & 0.05 \\
Silica & 2.1 & 2.0 & 3.3 & 3.2 & $\mathrm{mg} / \mathrm{L}$ & 0.10 & 0.10 & 6.92 \\
Silver & $<0.50$ & $<0.50$ & $<0.05$ & $<0.05$ & $\mathrm{mg} / \mathrm{L}$ & 0.50 & 0.05 & 0.05 \\
Sodium & 32,900 & 32,500 & 30,310 & 33,250 & $\mathrm{mg} / \mathrm{L}$ & 1.0 & 0.5 & 37,600 \\
Thallium & $<0.10$ & $<0.10$ & $<0.05$ & $<0.05$ & $\mathrm{mg} / \mathrm{L}$ & 0.10 & 0.05 & 0.05 \\
Tin & $<0.10$ & $<0.10$ & $<0.10$ & $<0.10$ & $\mathrm{mg} / \mathrm{L}$ & 0.10 & 0.10 & 0.1 \\
Vanadium & $<0.10$ & $<0.10$ & $<0.10$ & $<0.10$ & $\mathrm{mg} / \mathrm{L}$ & 0.10 & 0.10 & 0.1 \\
Zinc & $<5.0$ & $<5.0$ & $<0.10$ & $<0.10$ & $\mathrm{mg} / \mathrm{L}$ & 5.0 & 0.10 & 0.2 \\
\hline
\end{tabular}

${ }_{1}^{1} 95^{\text {th }}$ Upper Tolerance Limit Value, equivalent to $95 \%$ Confidence Limit

${ }^{2}$ Reporting Limit

${ }^{3}$ Not reported by laboratory

${ }^{4}$ Not Available

${ }^{5}$ Not Applicable

${ }^{6}$ Standard Unit 
Table 6.6 Analytical results for ground water sampled from well WQSP-5.

\section{Concentration}

$\underline{\text { Round } 8} \underline{\text { Round } 9}$

\begin{tabular}{|c|c|c|c|c|c|c|c|c|}
\hline Parameter & Sample & Dup. & Sample & Dup. & Units & Round 8 & Round 9 & $\begin{array}{c}\mathbf{9 5}^{\text {th }} \\
\text { UTLV }^{1}\end{array}$ \\
\hline 1,1,1-Trichloroethane & $<1$ & $<1$ & $<2$ & $<2$ & $\mu \mathrm{g} / \mathrm{L}$ & 1 & 2 & $<\mathrm{RL}^{2}$ \\
\hline 1,1,2,2-Tetrachloroethane & $<1$ & $<1$ & $<2$ & $<2$ & $\mu \mathrm{g} / \mathrm{L}$ & 1 & 2 & $<\mathrm{RL}$ \\
\hline 1,1,2-Trichloroethane & $<1$ & $<1$ & $<2$ & $<2$ & $\mu \mathrm{g} / \mathrm{L}$ & 1 & 2 & $<\mathrm{RL}$ \\
\hline 1,1-Dichloroethane & $\mathrm{NR}^{3}$ & NR & $<2$ & $<2$ & $\mu \mathrm{g} / \mathrm{L}$ & NR & 2 & $<\mathrm{RL}$ \\
\hline 1,1-Dichloroethylene & $<1$ & $<1$ & $<2$ & $<2$ & $\mu \mathrm{g} / \mathrm{L}$ & 1 & 2 & $<\mathrm{RL}$ \\
\hline 1,2-Dichloroethane & $<1$ & $<1$ & $<2$ & $<2$ & $\mu \mathrm{g} / \mathrm{L}$ & 1 & 2 & $<\mathrm{RL}$ \\
\hline Carbon tetrachloride & $<1$ & $<1$ & $<2$ & $<2$ & $\mu \mathrm{g} / \mathrm{L}$ & 1 & 2 & $<\mathrm{RL}$ \\
\hline Chlorobenzene & $<1$ & $<1$ & $<2$ & $<2$ & $\mu \mathrm{g} / \mathrm{L}$ & 1 & 2 & $<\mathrm{RL}$ \\
\hline Chloroform & $<1$ & $<1$ & $<2$ & $<2$ & $\mu \mathrm{g} / \mathrm{L}$ & 1 & 2 & $<\mathrm{RL}$ \\
\hline cis-1,2-Dichloroethylene & $<1$ & $<1$ & $<2$ & $<2$ & $\mu \mathrm{g} / \mathrm{L}$ & 1 & 2 & $<\mathrm{RL}$ \\
\hline Methyl ethyl ketone & $<50$ & $<50$ & $<20$ & $<20$ & $\mu \mathrm{g} / \mathrm{L}$ & 50 & 20 & $<\mathrm{RL}$ \\
\hline Methylene chloride & $<5$ & $<5$ & $<5$ & $<5$ & $\mu \mathrm{g} / \mathrm{L}$ & 5 & 5 & $<\mathrm{RL}$ \\
\hline Tetrachloroethylene & $<1$ & $<1$ & $<2$ & $<2$ & $\mu \mathrm{g} / \mathrm{L}$ & 1 & 2 & $<\mathrm{RL}$ \\
\hline Toluene & $<1$ & $<1$ & $<2$ & $<2$ & $\mu \mathrm{g} / \mathrm{L}$ & 1 & 2 & $<\mathrm{RL}$ \\
\hline Trichloroethylene & $<1$ & $<1$ & $<2$ & $<2$ & $\mu \mathrm{g} / \mathrm{L}$ & 1 & 2 & $<\mathrm{RL}$ \\
\hline Trichlorofluoromethane & $<1$ & $<1$ & $<2$ & $<2$ & $\mu \mathrm{g} / \mathrm{L}$ & 1 & 2 & $<\mathrm{RL}$ \\
\hline Vinyl chloride & $<1$ & $<1$ & $<2$ & $<2$ & $\mu \mathrm{g} / \mathrm{L}$ & 1 & 2 & $<\mathrm{RL}$ \\
\hline Xylene & $<1$ & $<1$ & $<2$ & $<2$ & $\mu \mathrm{g} / \mathrm{L}$ & 1 & 2 & $<\mathrm{RL}$ \\
\hline 1,2-Dichlorobenzene & $<1$ & $<1$ & $<5$ & $<5$ & $\mu \mathrm{g} / \mathrm{L}$ & 1 & 5 & $<\mathrm{RL}$ \\
\hline 1,4-Dichlorobenzene & $<1$ & $<1$ & $<5$ & $<5$ & $\mu \mathrm{g} / \mathrm{L}$ & 1 & 5 & $<\mathrm{RL}$ \\
\hline 2,4-Dinitrophenol & $<1$ & $<1$ & $<5$ & $<5$ & $\mu \mathrm{g} / \mathrm{L}$ & 1 & 5 & $<\mathrm{RL}$ \\
\hline 2,4-Dinitrotoluene & $<1$ & $<1$ & $<5$ & $<5$ & $\mu \mathrm{g} / \mathrm{L}$ & 1 & 5 & $<\mathrm{RL}$ \\
\hline 2-Methylphenol & $<1$ & $<1$ & $<5$ & $<5$ & $\mu \mathrm{g} / \mathrm{L}$ & 1 & 5 & $<\mathrm{RL}$ \\
\hline $\begin{array}{l}\text { 3-Methylphenol/ } \\
\text { 4-Methylphenol }\end{array}$ & $<1$ & $<1$ & $<5$ & $<5$ & $\mu \mathrm{g} / \mathrm{L}$ & 1 & 5 & $<\mathrm{RL}$ \\
\hline Hexachlorobenzene & $<1$ & $<1$ & $<5$ & $<5$ & $\mu \mathrm{g} / \mathrm{L}$ & 1 & 5 & $<\mathrm{RL}$ \\
\hline Hexachloroethane & $<1$ & $<1$ & $<5$ & $<5$ & $\mu \mathrm{g} / \mathrm{L}$ & 1 & 5 & $<\mathrm{RL}$ \\
\hline Nitrobenzene & $<1$ & $<1$ & $<5$ & $<5$ & $\mu \mathrm{g} / \mathrm{L}$ & 1 & 5 & $<\mathrm{RL}$ \\
\hline Pentachlorophenol & $<1$ & $<1$ & $<5$ & 5 & $\mu \mathrm{g} / \mathrm{L}$ & 1 & 5 & $<\mathrm{RL}$ \\
\hline Pyridine & $<1$ & $<1$ & $<5$ & $<5$ & $\mu \mathrm{g} / \mathrm{L}$ & 1 & 5 & $<\mathrm{RL}$ \\
\hline Isobutanol & $<500$ & $<500$ & $<500$ & $<500$ & $\mu \mathrm{g} / \mathrm{L}$ & 500 & 500 & $<\mathrm{RL}$ \\
\hline Alkalinity & 50 & 46 & 44 & 46 & $\mathrm{mg} / \mathrm{L}$ & 1.0 & $\mathrm{NA}^{4}$ & 52.0 \\
\hline
\end{tabular}


Table 6.6, cont.

\section{Concentration}

$\underline{\text { Round } 8}$

Round 9

$\underline{\text { Reporting Limit }}$

\begin{tabular}{|c|c|c|c|c|c|c|c|c|}
\hline Parameter & Sample & Dup. & Sample & Dup. & Units & Round 8 & Round 9 & $\begin{array}{c}\mathbf{9 5}^{\text {th }} \\
\text { UTLV }^{1}\end{array}$ \\
\hline Bromide & $<100$ & $<100$ & 23 & 25 & $\mathrm{mg} / \mathrm{L}$ & 0.2 & 0.2 & 69.2 \\
\hline Chloride & 15,000 & 16,000 & 15,000 & 15,000 & $\mathrm{mg} / \mathrm{L}$ & 0.5 & 0.5 & 17,035 \\
\hline Density & 1.018 & 1.012 & 1.02 & 1.02 & $\mathrm{~g} / \mathrm{ml}$ & $\mathrm{N} / \mathrm{A}^{5}$ & N/A & 1.04 \\
\hline Fluoride & 1.9 & 1.9 & 2.9 & 2.9 & $\mathrm{mg} / \mathrm{L}$ & 0.1 & 0.1 & 3.08 \\
\hline Iodide & $<2.0$ & $<2.0$ & $<2.0$ & $<2.0$ & $\mathrm{mg} / \mathrm{L}$ & 2.0 & 2.0 & 2.0 \\
\hline Nitrate (as N) & $<10$ & $<10$ & $<10$ & $<10$ & $\mathrm{mg} / \mathrm{L}$ & 0.2 & 0.2 & 0.310 \\
\hline Orthophosphate (as P) & 0.034 & 0.023 & 0.037 & 0.037 & $\mathrm{mg} / \mathrm{L}$ & 0.01 & 0.01 & 0.02 \\
\hline $\mathrm{pH}$ & 7.6 & 7.7 & 7.5 & 7.6 & $\mathrm{SU}^{6}$ & N/A & N/A & $7.51-7.8$ \\
\hline Specific conductance & 66,000 & 65,000 & 51,000 & 54,000 & $\mu \mathrm{mhos} / \mathrm{cm}$ & N/A & N/A & 47,900 \\
\hline Sulfate & 4,900 & 5,200 & 4,300 & 4,300 & $\mathrm{mg} / \mathrm{L}$ & 0.5 & 0.5 & 6,560 \\
\hline Total dissolved solids & 31,000 & 33,000 & 36,000 & 34,000 & $\mathrm{mg} / \mathrm{L}$ & 10 & 10 & 44,100 \\
\hline Total organic carbon & $<1.0$ & $<1.0$ & $<2.0$ & $<2.0$ & $\mathrm{mg} / \mathrm{L}$ & 1.0 & 2.0 & 3.13 \\
\hline Total organic halogen & 0.870 & 0.850 & 0.290 & 0.390 & $\mathrm{mg} / \mathrm{L}$ & N/A & N/A & 0.094 \\
\hline Total phenols & $<0.07$ & $<0.07$ & $<0.07$ & $<0.07$ & $\mathrm{mg} / \mathrm{L}$ & 0.07 & 0.07 & $<\mathrm{RL}$ \\
\hline Total suspended solids & $<1.0$ & $<1.0$ & $<1.0$ & $<1.0$ & $\mathrm{mg} / \mathrm{L}$ & 1.0 & 1.0 & 10.0 \\
\hline Gross alpha & $260 \pm 220$ & NR & $100 \pm 150$ & NR & $\mathrm{pCi} / \mathrm{L}$ & 280 & 240 & 330 \\
\hline Gross beta & $120 \pm 140$ & NR & $230 \pm 140$ & NR & $\mathrm{pCi} / \mathrm{L}$ & 240 & 210 & 230 \\
\hline Antimony & $<0.05$ & $<0.05$ & 0.07 & $<0.05$ & $\mathrm{mg} / \mathrm{L}$ & 0.05 & 0.05 & 0.05 \\
\hline Arsenic & $<0.50$ & $<0.50$ & $<0.05$ & $<0.05$ & $\mathrm{mg} / \mathrm{L}$ & 0.50 & 0.05 & 0.05 \\
\hline Barium & $<1.0$ & $<1.0$ & $<0.10$ & $<0.10$ & $\mathrm{mg} / \mathrm{L}$ & 1.0 & 0.10 & 0.04 \\
\hline Beryllium & $<0.01$ & $<0.01$ & $<0.02$ & $<0.02$ & $\mathrm{mg} / \mathrm{L}$ & 0.01 & 0.02 & 0.02 \\
\hline Boron & 32 & 31 & 2.67 & 2.68 & $\mathrm{mg} / \mathrm{L}$ & 0.75 & 0.01 & 33 \\
\hline Cadmium & $<0.05$ & $<0.05$ & $<0.01$ & $<0.01$ & $\mathrm{mg} / \mathrm{L}$ & 0.05 & 0.01 & 0.01 \\
\hline Calcium & 1,090 & 1,220 & 1,071 & 1,126 & $\mathrm{mg} / \mathrm{L}$ & 1.0 & 0.05 & 1,070 \\
\hline Chromium & $<0.50$ & $<0.50$ & $<0.05$ & $<0.05$ & $\mathrm{mg} / \mathrm{L}$ & 0.50 & 0.05 & 0.1 \\
\hline Cobalt & $<0.50$ & $<0.50$ & $<0.10$ & $<0.10$ & $\mathrm{mg} / \mathrm{L}$ & 0.50 & 0.10 & 0.1 \\
\hline Copper & $<1.0$ & $<1.0$ & 0.34 & $<0.10$ & $\mathrm{mg} / \mathrm{L}$ & 1.0 & 0.10 & 0.5 \\
\hline Iron & $<0.30$ & $<0.30$ & 1.1 & $<0.10$ & $\mathrm{mg} / \mathrm{L}$ & 0.30 & 0.10 & 1.0 \\
\hline Lead & $<0.05$ & $<0.05$ & $<0.02$ & $<0.02$ & $\mathrm{mg} / \mathrm{L}$ & 0.05 & 0.02 & 0.05 \\
\hline Lithium & 0.53 & 0.50 & 0.36 & 0.36 & $\mathrm{mg} / \mathrm{L}$ & 0.01 & 0.01 & 0.407 \\
\hline Magnesium & 474 & 547 & 484 & 515 & $\mathrm{mg} / \mathrm{L}$ & 1.0 & 0.50 & 470 \\
\hline Mercury & $<0.0002$ & $<0.0002$ & $<0.0002$ & $<0.0002$ & $\mathrm{mg} / \mathrm{L}$ & 0.0002 & 0.0002 & 0.002 \\
\hline
\end{tabular}


Table 6.6, cont.

\begin{tabular}{|c|c|c|c|c|c|c|c|c|}
\hline \multirow[b]{3}{*}{ Parameter } & \multicolumn{7}{|c|}{ Concentration } & \multirow[b]{3}{*}{$\begin{array}{l}\mathbf{9 5}^{\text {th }} \\
\text { UTLV }^{1}\end{array}$} \\
\hline & \multicolumn{2}{|c|}{$\underline{\text { Round } 8}$} & \multicolumn{2}{|c|}{$\underline{\text { Round } 9}$} & \multicolumn{3}{|c|}{$\underline{\text { Reporting Limit }}$} & \\
\hline & Sample & Dup. & Sample & Dup. & Units & Round 8 & Round 9 & \\
\hline Nickel & $<0.10$ & $<0.10$ & $<0.02$ & $<0.02$ & $\mathrm{mg} / \mathrm{L}$ & 0.10 & 0.02 & 0.050 \\
\hline Nickel & $<0.10$ & $<0.10$ & $<0.02$ & $<0.02$ & $\mathrm{mg} / \mathrm{L}$ & 0.10 & 0.02 & 0.050 \\
\hline Potassium & 527 & 582 & 385 & 416 & $\mathrm{mg} / \mathrm{L}$ & 1.0 & 0.50 & 298 \\
\hline Selenium & $<0.10$ & $<0.10$ & $<0.05$ & $<0.05$ & $\mathrm{mg} / \mathrm{L}$ & 0.10 & 0.05 & 0.05 \\
\hline Silica & 4.2 & 4.2 & 4.6 & 4.6 & $\mathrm{mg} / \mathrm{L}$ & 0.10 & 0.01 & 12.1 \\
\hline Silver & $<0.50$ & $<0.50$ & $<0.05$ & $<0.05$ & $\mathrm{mg} / \mathrm{L}$ & 0.50 & 0.05 & 0.05 \\
\hline Sodium & 9,675 & 9,545 & 8,380 & 8,739 & $\mathrm{mg} / \mathrm{L}$ & 1.0 & 0.50 & 9,580 \\
\hline Thallium & $<0.01$ & $<0.01$ & $<0.05$ & $<0.05$ & $\mathrm{mg} / \mathrm{L}$ & 0.01 & 0.05 & 0.05 \\
\hline Tin & $<0.10$ & $<0.10$ & $<0.10$ & $<0.10$ & $\mathrm{mg} / \mathrm{L}$ & 0.10 & 0.10 & 0.1 \\
\hline Vanadium & 2.0 & 2.7 & $<0.10$ & $<0.10$ & $\mathrm{mg} / \mathrm{L}$ & 0.50 & 0.10 & 0.1 \\
\hline Zinc & $<5.0$ & $<5.0$ & $<0.10$ & $<0.10$ & $\mathrm{mg} / \mathrm{L}$ & 5.0 & 0.10 & 0.2 \\
\hline
\end{tabular}

${ }_{1}^{1} 95^{\text {th }}$ Upper Tolerance Limit Value, equivalent to 95\% Confidence Limit

${ }^{2}$ Reporting Limit

${ }^{3}$ Not reported by laboratory

${ }^{4}$ Not Available

${ }^{5}$ Not Applicable

${ }^{6}$ Standard Unit 
Table 6.7 Analytical results for ground water sampled from well WQSP-6.

\section{Concentration}

Round 8

Round 9

$\underline{\text { Reporting Limit }}$

\begin{tabular}{|c|c|c|c|c|c|c|c|c|}
\hline Parameter & Sample & Dup. & Sample & Dup. & Units & Round 8 & Round 9 & $\begin{array}{c}\mathbf{9 5}^{\text {th }} \\
\mathbf{U T L V}^{1}\end{array}$ \\
\hline 1,1,1-Trichloroethane & $<1$ & $<1$ & $<2$ & $<2$ & $\mu \mathrm{g} / \mathrm{L}$ & 1 & 2 & $<\mathrm{RL}^{2}$ \\
\hline 1,1,2,2-Tetrachloroethane & $<1$ & $<1$ & $<2$ & $<2$ & $\mu \mathrm{g} / \mathrm{L}$ & 1 & 2 & $<\mathrm{RL}$ \\
\hline 1,1,2-Trichloroethane & $<1$ & $<1$ & $<2$ & $<2$ & $\mu \mathrm{g} / \mathrm{L}$ & 1 & 2 & $<\mathrm{RL}$ \\
\hline 1,1-Dichloroethane & $\mathrm{NR}^{3}$ & NR & NR & NR & $\mu \mathrm{g} / \mathrm{L}$ & NR & NR & $<\mathrm{RL}$ \\
\hline 1,1-Dichloroethylene & $<1$ & $<1$ & $<2$ & $<2$ & $\mu \mathrm{g} / \mathrm{L}$ & 1 & 2 & $<\mathrm{RL}$ \\
\hline 1,2-Dichloroethane & $<1$ & $<1$ & $<2$ & $<2$ & $\mu \mathrm{g} / \mathrm{L}$ & 1 & 2 & $<\mathrm{RL}$ \\
\hline Carbon tetrachloride & $<1$ & $<1$ & $<20$ & $<20$ & $\mu \mathrm{g} / \mathrm{L}$ & 1 & 20 & $<\mathrm{RL}$ \\
\hline Chlorobenzene & $<1$ & $<1$ & $<2$ & $<2$ & $\mu \mathrm{g} / \mathrm{L}$ & 1 & 2 & $<\mathrm{RL}$ \\
\hline Chloroform & $<1$ & $<1$ & $<2$ & $<2$ & $\mu \mathrm{g} / \mathrm{L}$ & 1 & 2 & $<\mathrm{RL}$ \\
\hline cis-1,2-Dichloroethylene & NR & NR & $<2$ & $<2$ & $\mu \mathrm{g} / \mathrm{L}$ & NR & 2 & $<\mathrm{RL}$ \\
\hline Methyl ethyl ketone & $<50$ & $<50$ & $<20$ & $<20$ & $\mu \mathrm{g} / \mathrm{L}$ & 50 & 20 & $<\mathrm{RL}$ \\
\hline Methylene chloride & $<5$ & $<5$ & $<5$ & $<5$ & $\mu \mathrm{g} / \mathrm{L}$ & 5 & 5 & $<\mathrm{RL}$ \\
\hline Tetrachloroethylene & $<1$ & $<1$ & $<2$ & $<2$ & $\mu \mathrm{g} / \mathrm{L}$ & 1 & 2 & $<\mathrm{RL}$ \\
\hline Xylene & $<1$ & $<1$ & $<2$ & $<2$ & $\mu \mathrm{g} / \mathrm{L}$ & 1 & 2 & $<\mathrm{RL}$ \\
\hline 1,2-Dichlorobenzene & $<1$ & $<1$ & $<5$ & $<5$ & $\mu \mathrm{g} / \mathrm{L}$ & 1 & 5 & $<\mathrm{RL}$ \\
\hline 1,4-Dichlorobenzene & $<1$ & $<1$ & $<5$ & $<5$ & $\mu \mathrm{g} / \mathrm{L}$ & 1 & 5 & $<\mathrm{RL}$ \\
\hline 2,4-Dinitrophenol & $<1$ & $<1$ & $<5$ & $<5$ & $\mu \mathrm{g} / \mathrm{L}$ & 1 & 5 & $<\mathrm{RL}$ \\
\hline 2,4-Dinitrotoluene & $<1$ & $<1$ & $<5$ & $<5$ & $\mu \mathrm{g} / \mathrm{L}$ & 1 & 5 & $<\mathrm{RL}$ \\
\hline 2-Methylphenol & $<1$ & $<1$ & $<5$ & $<5$ & $\mu \mathrm{g} / \mathrm{L}$ & 1 & 5 & $<\mathrm{RL}$ \\
\hline $\begin{array}{l}\text { 3-Methylphenol/ } \\
\text { 4-Methylphenol }\end{array}$ & $<1$ & $<1$ & $<5$ & $<5$ & $\mu \mathrm{g} / \mathrm{L}$ & 1 & 5 & $<\mathrm{RL}$ \\
\hline Hexachlorobenzene & $<1$ & $<1$ & $<5$ & $<5$ & $\mu \mathrm{g} / \mathrm{L}$ & 1 & 5 & $<\mathrm{RL}$ \\
\hline Hexachloroethane & $<1$ & $<1$ & $<5$ & $<5$ & $\mu \mathrm{g} / \mathrm{L}$ & 1 & 5 & $<\mathrm{RL}$ \\
\hline Nitrobenzene & $<1$ & $<1$ & $<5$ & $<5$ & $\mu \mathrm{g} / \mathrm{L}$ & 1 & 5 & $<\mathrm{RL}$ \\
\hline Pentachlorophenol & $<1$ & $<1$ & $<5$ & $<5$ & $\mu \mathrm{g} / \mathrm{L}$ & 1 & 5 & $<\mathrm{RL}$ \\
\hline Pyridine & $<1$ & $<1$ & $<5$ & $<5$ & $\mu \mathrm{g} / \mathrm{L}$ & 1 & 5 & $<\mathrm{RL}$ \\
\hline Isobutanol & $<500$ & $<500$ & $<500$ & $<500$ & $\mu \mathrm{g} / \mathrm{L}$ & 500 & 500 & $<\mathrm{RL}$ \\
\hline Alkalinity & 46 & 47 & 44 & 46 & $\mathrm{mg} / \mathrm{L}$ & 0.1 & $\mathrm{NA}^{4}$ & 58 \\
\hline Bromide & 6.4 & 6.2 & 13 & 12 & $\mathrm{mg} / \mathrm{L}$ & 0.2 & 0.2 & 14.4 \\
\hline Chloride & 5,900 & 6,000 & 6,000 & 5,700 & $\mathrm{mg} / \mathrm{L}$ & 0.5 & 0.5 & 6,200 \\
\hline Density & 1.014 & 1.005 & 1.014 & 1.013 & $\mathrm{~g} / \mathrm{ml}$ & $\mathrm{N} / \mathrm{A}^{5}$ & N/A & 1.02 \\
\hline
\end{tabular}


Table 6.7, cont.

Concentration

$\underline{\text { Round } 8} \underline{\text { Round } 9}$

Reporting Limit

\begin{tabular}{|c|c|c|c|c|c|c|c|c|}
\hline Parameter & Sample & Dup. & Sample & Dup. & Units & Round 8 & Round 9 & $\begin{array}{c}\mathbf{9 5}^{\text {th }} \\
\text { UTLV }^{1}\end{array}$ \\
\hline Fluoride & 2.4 & 2.4 & 2.0 & 1.96 & $\mathrm{mg} / \mathrm{L}$ & 0.1 & 0.1 & 2.91 \\
\hline Iodide & $<2.0$ & $<2.0$ & $<2.0$ & $<2.0$ & $\mathrm{mg} / \mathrm{L}$ & 2.0 & 2.0 & 1.59 \\
\hline Nitrate (as N) & 9.9 & $<5.0$ & $<10$ & $<10$ & $\mathrm{mg} / \mathrm{L}$ & 0.2 & 0.2 & 0.1 \\
\hline Orthophosphate (as P) & $<0.01$ & $<0.01$ & 0.02 & 0.02 & $\mathrm{mg} / \mathrm{L}$ & 0.01 & 0.01 & 0.02 \\
\hline $\mathrm{pH}$ & 7.7 & 7.7 & 7.7 & 7.7 & $\mathrm{SU}^{6}$ & N/A & N/A & $7.45-7.95$ \\
\hline Specific conductance & 22,000 & 21,000 & 21,000 & 20,000 & $\mu \mathrm{mhos} / \mathrm{cm}$ & N/A & N/A & 30,600 \\
\hline Sulfate & 4,400 & 4,200 & 5,000 & 4,800 & $\mathrm{mg} / \mathrm{L}$ & 0.5 & 0.5 & 6,030 \\
\hline Total dissolved solids & 15,000 & 15,000 & 13,000 & 12,000 & $\mathrm{mg} / \mathrm{L}$ & 10 & 10 & 21,600 \\
\hline Total organic carbon & $<1.0$ & 3.0 & 1.3 & 0.8 & $\mathrm{mg} / \mathrm{L}$ & 1.0 & N/A & 10.22 \\
\hline Total organic halogen & 0.20 & 0.16 & 0.17 & 0.17 & $\mathrm{mg} / \mathrm{L}$ & N/A & N/A & 0.065 \\
\hline Total phenols & $<0.07$ & $<0.07$ & $<0.07$ & $<0.07$ & $\mathrm{mg} / \mathrm{L}$ & 0.07 & 0.07 & $<\mathrm{RL}$ \\
\hline Total suspended solids & $<1.0$ & $<1.0$ & $<1.0$ & $<1.0$ & $\mathrm{mg} / \mathrm{L}$ & 1.0 & 1.0 & 15.00 \\
\hline Gross alpha & $93 \pm 130$ & NR & $220 \pm 130$ & NR & $\mathrm{pCi} / \mathrm{L}$ & 210 & 140 & 210 \\
\hline Gross beta & $41 \pm 71$ & NR & $92 \pm 68$ & NR & $\mathrm{pCi} / \mathrm{L}$ & 120 & 110 & 210 \\
\hline Antimony & 0.14 & 0.1 & $<0.05$ & $<0.05$ & $\mathrm{mg} / \mathrm{L}$ & 0.05 & 0.05 & 0.05 \\
\hline Arsenic & 0.09 & 0.09 & $<0.05$ & $<0.05$ & $\mathrm{mg} / \mathrm{L}$ & 0.05 & 0.05 & 0.05 \\
\hline Barium & $<1.0$ & $<1.0$ & $<0.10$ & $<0.10$ & $\mathrm{mg} / \mathrm{L}$ & 1.0 & 0.10 & 0.04 \\
\hline Beryllium & $<0.01$ & $<0.01$ & $<0.01$ & $<0.01$ & $\mathrm{mg} / \mathrm{L}$ & 0.01 & 0.01 & 0.02 \\
\hline Boron & 15 & 15 & 13.8 & 13.8 & $\mathrm{mg} / \mathrm{L}$ & 0.75 & 0.50 & 18.3 \\
\hline Cadmium & $<0.05$ & $<0.05$ & $<0.01$ & $<0.01$ & $\mathrm{mg} / \mathrm{L}$ & 0.05 & 0.01 & 0.01 \\
\hline Calcium & 675 & 728 & 677 & 690 & $\mathrm{mg} / \mathrm{L}$ & 1.0 & 1.0 & 818 \\
\hline Chromium & $<0.50$ & $<0.50$ & $<0.50$ & $<0.50$ & $\mathrm{mg} / \mathrm{L}$ & 0.50 & 0.05 & 0.1 \\
\hline Cobalt & $<0.50$ & $<0.50$ & $<0.05$ & $<0.05$ & $\mathrm{mg} / \mathrm{L}$ & 0.50 & 0.05 & 0.05 \\
\hline Copper & $<1.0$ & $<1.0$ & $<0.05$ & $<0.05$ & $\mathrm{mg} / \mathrm{L}$ & 1.0 & 0.05 & 0.05 \\
\hline Iron & $<1.0$ & $<1.0$ & $<1.0$ & $<1.0$ & $\mathrm{mg} / \mathrm{L}$ & 1.0 & 1.0 & 1.0 \\
\hline Lead & $<0.05$ & $<0.05$ & $<0.05$ & $<0.05$ & $\mathrm{mg} / \mathrm{L}$ & 0.05 & 0.05 & 0.05 \\
\hline Lithium & $<0.50$ & $<0.50$ & NR & NR & $\mathrm{mg} / \mathrm{L}$ & 0.50 & NR. & 0.370 \\
\hline Magnesium & 201 & 210 & 214 & 218 & $\mathrm{mg} / \mathrm{L}$ & 1.0 & 1.0 & 253 \\
\hline Mercury & $<0.0002$ & $<0.0002$ & $<0.0002$ & $<0.0002$ & $\mathrm{mg} / \mathrm{L}$ & 0.0002 & 0.0002 & 0.002 \\
\hline Nickel & $<0.50$ & $<0.50$ & $<0.50$ & $<0.50$ & $\mathrm{mg} / \mathrm{L}$ & 0.50 & 0.50 & 0.1 \\
\hline Potassium & 215 & 226 & 239 & 244 & $\mathrm{mg} / \mathrm{L}$ & 1.0 & 1.0 & 199 \\
\hline Selenium & $<0.10$ & $<0.10$ & $<0.10$ & $<0.10$ & $\mathrm{mg} / \mathrm{L}$ & 0.10 & 0.10 & 0.05 \\
\hline
\end{tabular}


Table 6.7, cont.

\section{Concentration}

$\underline{\text { Round } 8} \quad \underline{\text { Round } 9}$

$\underline{\text { Reporting Limit }}$

\begin{tabular}{lcccccccc}
\multicolumn{1}{c}{ Parameter } & Sample & Dup. & Sample & Dup. & Units & Round 8 & Round 9 & $\begin{array}{c}\mathbf{9 5}^{\text {th }} \\
\text { UTLV }^{\mathbf{1}}\end{array}$ \\
\hline Silica & 10 & 10 & 4.3 & 4.3 & $\mathrm{mg} / \mathrm{L}$ & 5.0 & 0.10 & 12.05 \\
Silver & $<0.05$ & $<0.05$ & $<0.05$ & $<0.05$ & $\mathrm{mg} / \mathrm{L}$ & 0.05 & 0.05 & 0.05 \\
Sodium & 4,460 & 4,090 & 4,350 & 4,470 & $\mathrm{mg} / \mathrm{L}$ & 1.0 & 1.0 & 6,070 \\
Thallium & $<0.01$ & $<0.01$ & $<0.05$ & $<0.05$ & $\mathrm{mg} / \mathrm{L}$ & 0.01 & 0.05 & 0.05 \\
Tin & $<0.01$ & $<0.01$ & $<0.01$ & $<0.01$ & $\mathrm{mg} / \mathrm{L}$ & 0.01 & 0.01 & 0.1 \\
Vanadium & $<0.01$ & $<0.01$ & $<0.05$ & $<0.05$ & $\mathrm{mg} / \mathrm{L}$ & 0.01 & 0.05 & 0.1 \\
Zinc & $<5.0$ & $<5.0$ & $<0.10$ & $<0.10$ & $\mathrm{mg} / \mathrm{L}$ & 5.0 & 0.10 & 0.2 \\
\hline 195 & 95 & & & & & & &
\end{tabular}

$95^{\text {th }}$ Upper Tolerance Limit Value, equivalent to $95 \%$ Confidence Limit

${ }^{2}$ Reporting Limit

${ }^{3}$ Not reported by laboratory

${ }^{4}$ Not Available

${ }^{5}$ Not Applicable

${ }^{6}$ Standard Unit 
Table 6.8 Analytical results for ground water sampled from well WQSP-6A.

\section{Concentration}

$\underline{\text { Round } 8} \underline{\text { Round } 9}$

$\underline{\text { Reporting Limit }}$

Parameter Sample Dup. Sample Dup. Units Round 8 Round 9 95 $^{\text {th }}$

\begin{tabular}{|c|c|c|c|c|c|c|c|c|}
\hline 1,1,1-Trichloroethane & $<1$ & $<1$ & $<2$ & $<2$ & $\mu \mathrm{g} / \mathrm{L}$ & 1 & 2 & $<\mathrm{RL}^{2}$ \\
\hline 1,1,2,2-Tetrachloroethane & $<1$ & $<1$ & $<2$ & $<2$ & $\mu \mathrm{g} / \mathrm{L}$ & 1 & 2 & $<\mathrm{RL}$ \\
\hline 1,1,2-Trichloroethane & $<1$ & $<1$ & $<2$ & $<2$ & $\mu \mathrm{g} / \mathrm{L}$ & 1 & 2 & $<\mathrm{RL}$ \\
\hline 1,1-Dichloroethane & $\mathrm{NR}^{3}$ & NR & NR & NR & $\mu \mathrm{g} / \mathrm{L}$ & NR & NR & $<\mathrm{RL}$ \\
\hline 1,1-Dichloroethylene & $<1$ & $<1$ & $<2$ & $<2$ & $\mu \mathrm{g} / \mathrm{L}$ & 1 & 2 & $<\mathrm{RL}$ \\
\hline 1,2-Dichloroethane & $<1$ & $<1$ & $<2$ & $<2$ & $\mu \mathrm{g} / \mathrm{L}$ & 1 & 2 & $<\mathrm{RL}$ \\
\hline Carbon tetrachloride & $<1$ & $<1$ & $<2$ & $<2$ & $\mu \mathrm{g} / \mathrm{L}$ & 1 & 2 & $<\mathrm{RL}$ \\
\hline Chlorobenzene & $<1$ & $<1$ & $<2$ & $<2$ & $\mu \mathrm{g} / \mathrm{L}$ & 1 & 2 & $<\mathrm{RL}$ \\
\hline Chloroform & $<1$ & $<1$ & $<2$ & $<2$ & $\mu \mathrm{g} / \mathrm{L}$ & 1 & 2 & $<\mathrm{RL}$ \\
\hline cis-1,2-Dichloroethylene & NR & NR & $<2$ & $<2$ & $\mu \mathrm{g} / \mathrm{L}$ & NR & 2 & $<\mathrm{RL}$ \\
\hline Methyl ethyl ketone & $<50$ & $<50$ & $<20$ & $<20$ & $\mu \mathrm{g} / \mathrm{L}$ & 50 & 20 & $<\mathrm{RL}$ \\
\hline Methylene chloride & $<5$ & $<5$ & $<5$ & $<5$ & $\mu \mathrm{g} / \mathrm{L}$ & 5 & 5 & $<\mathrm{RL}$ \\
\hline Tetrachloroethylene & $<1$ & $<1$ & $<2$ & $<2$ & $\mu \mathrm{g} / \mathrm{L}$ & 1 & 2 & $<\mathrm{RL}$ \\
\hline Toluene & $<1$ & $<1$ & $<2$ & $<2$ & $\mu \mathrm{g} / \mathrm{L}$ & 1 & 2 & $<\mathrm{RL}$ \\
\hline Trichloroethylene & $<1$ & $<1$ & $<2$ & $<2$ & $\mu \mathrm{g} / \mathrm{L}$ & 1 & 2 & $<\mathrm{RL}$ \\
\hline Trichlorofluoromethane & $<1$ & $<1$ & $<2$ & $<2$ & $\mu \mathrm{g} / \mathrm{L}$ & 1 & 2 & $<\mathrm{RL}$ \\
\hline Vinyl chloride & $<1$ & $<1$ & $<2$ & $<2$ & $\mu \mathrm{g} / \mathrm{L}$ & 1 & 2 & $<\mathrm{RL}$ \\
\hline Xylene & $<1$ & $<1$ & $<2$ & $<2$ & $\mu \mathrm{g} / \mathrm{L}$ & 1 & 2 & $<\mathrm{RL}$ \\
\hline 1,2-Dichlorobenzene & $<1$ & $<1$ & $<5$ & $<5$ & $\mu \mathrm{g} / \mathrm{L}$ & 1 & 5 & $<\mathrm{RL}$ \\
\hline 1,4-Dichlorobenzene & $<1$ & $<1$ & $<5$ & $<5$ & $\mu \mathrm{g} / \mathrm{L}$ & 1 & 5 & $<\mathrm{RL}$ \\
\hline 2,4-Dinitrophenol & $<1$ & $<1$ & $<5$ & $<5$ & $\mu \mathrm{g} / \mathrm{L}$ & 1 & 5 & $<\mathrm{RL}$ \\
\hline 2,4-Dinitrotoluene & $<1$ & $<1$ & $<5$ & $<5$ & $\mu \mathrm{g} / \mathrm{L}$ & 1 & 5 & $<\mathrm{RL}$ \\
\hline 2-Methylphenol & $<1$ & $<1$ & $<5$ & $<5$ & $\mu \mathrm{g} / \mathrm{L}$ & 1 & 5 & $<R L$ \\
\hline $\begin{array}{l}\text { 3-Methylphenol/ } \\
\text { 4-Methylphenol }\end{array}$ & $<1$ & $<1$ & $<5$ & $<5$ & $\mu \mathrm{g} / \mathrm{L}$ & 1 & 5 & $<\mathrm{RL}$ \\
\hline Hexachlorobenzene & $<1$ & $<1$ & $<5$ & $<5$ & $\mu \mathrm{g} / \mathrm{L}$ & 1 & 5 & $<\mathrm{RL}$ \\
\hline Hexachloroethane & $<1$ & $<1$ & $<5$ & $<5$ & $\mu \mathrm{g} / \mathrm{L}$ & 1 & 5 & $<\mathrm{RL}$ \\
\hline Nitrobenzene & $<1$ & $<1$ & $<5$ & $<5$ & $\mu \mathrm{g} / \mathrm{L}$ & 1 & 5 & $<R L$ \\
\hline Pentachlorophenol & $<1$ & $<1$ & $<5$ & $<5$ & $\mu \mathrm{g} / \mathrm{L}$ & 1 & 5 & $<\mathrm{RL}$ \\
\hline Pyridine & 1 & $<1$ & $<5$ & $<5$ & $\mu \mathrm{g} / \mathrm{L}$ & 1 & 5 & $<\mathrm{RL}$ \\
\hline Isobutanol & $<500$ & $<500$ & $<500$ & $<500$ & $\mu \mathrm{g} / \mathrm{L}$ & 500 & 500 & $<\mathrm{RL}$ \\
\hline Alkalinity & 102 & 106 & 100 & 102 & $\mathrm{mg} / \mathrm{L}$ & $\mathrm{NA}^{4}$ & NA & 117 \\
\hline
\end{tabular}


Table 6.8, cont.

\section{Concentration}

$\underline{\text { Round } 8}$

Round 9

$\underline{\text { Reporting Limit }}$

\begin{tabular}{|c|c|c|c|c|c|c|c|c|}
\hline Parameter & Sample & Dup. & Sample & Dup. & Units & Round 8 & Round 9 & $\begin{array}{c}9^{\text {th }} \\
\text { UTLV }^{1}\end{array}$ \\
\hline Bromide & 1.3 & 1.4 & $<2.0$ & $<2.0$ & $\mathrm{mg} / \mathrm{L}$ & 0.2 & 0.2 & 14.5 \\
\hline Chloride & 540 & 510 & 540 & 540 & $\mathrm{mg} / \mathrm{L}$ & 0.5 & 0.5 & 1,040 \\
\hline Density & 1.001 & 0.998 & 1.00 & 1.00 & $\mathrm{~g} / \mathrm{ml}$ & $\mathrm{N} / \mathrm{A}^{5}$ & N/A & 1.01 \\
\hline Fluoride & 2.2 & 2.2 & 2.4 & 2.3 & $\mathrm{mg} / \mathrm{L}$ & 0.1 & 0.1 & 1.50 \\
\hline Iodide & $<2.0$ & $<2.0$ & $<2.0$ & $<2.0$ & $\mathrm{mg} / \mathrm{L}$ & 2.0 & 2.0 & 2.0 \\
\hline Nitrate (as N) & 7 & 7.4 & 9.4 & 9.3 & $\mathrm{mg} / \mathrm{L}$ & 0.2 & 0.2 & 11.7 \\
\hline Orthophosphate (as P) & 0.025 & 0.057 & $<0.01$ & $<0.01$ & $\mathrm{mg} / \mathrm{L}$ & 0.01 & 0.01 & 0.02 \\
\hline $\mathrm{pH}$ & 7.2 & 7.3 & 7.2 & 7.3 & $\mathrm{SU}^{6}$ & N/A & N/A & $6.71-8.39$ \\
\hline Specific conductance & 5,000 & 5,000 & 4,400 & 4,300 & $\mu \mathrm{mhos} / \mathrm{cm}$ & N/A & N/A & 52,900 \\
\hline Sulfate & 1,900 & 1,900 & 1,900 & 2,000 & $\mathrm{mg} / \mathrm{L}$ & 0.5 & 0.5 & 2,990 \\
\hline Total dissolved solids & 3,800 & 3,900 & 3,800 & 4,000 & $\mathrm{mg} / \mathrm{L}$ & 10 & 10 & 4,500 \\
\hline Total organic carbon & $<1.0$ & 1.6 & 3.1 & 3.2 & $\mathrm{mg} / \mathrm{L}$ & 1.0 & N/A & 15.60 \\
\hline Total organic halogen & 0.100 & 0.130 & 0.076 & 0.034 & $\mathrm{mg} / \mathrm{L}$ & N/A & N/A & 0.181 \\
\hline Total phenols & $<0.07$ & $<0.07$ & $<0.07$ & $<0.07$ & $\mathrm{mg} / \mathrm{L}$ & 0.07 & 0.07 & $<\mathrm{RL}$ \\
\hline Total suspended solids & $<1.0$ & $<1.0$ & $<1.0$ & $<1.0$ & $\mathrm{mg} / \mathrm{L}$ & 1.0 & 1.0 & 91.00 \\
\hline Gross alpha & $56 \pm 33$ & NR & $-3.1 \pm 16$ & NR & $\mathrm{pCi} / \mathrm{L}$ & 36 & 35 & 56 \\
\hline Gross beta & $-21 \pm 24$ & NR & $0.88 \pm 16$ & NR & $\mathrm{pCi} / \mathrm{L}$ & 43 & 27 & 12 \\
\hline Antimony & 0.14 & 0.1 & 0.48 & $<0.05$ & $\mathrm{mg} / \mathrm{L}$ & 0.05 & 0.05 & 0.05 \\
\hline Arsenic & 0.08 & 0.07 & 0.187 & $<0.05$ & $\mathrm{mg} / \mathrm{L}$ & 0.05 & 0.05 & 0.05 \\
\hline Barium & $<1.0$ & $<1.0$ & $<0.10$ & 0.10 & $\mathrm{mg} / \mathrm{L}$ & 1.0 & 0.10 & 0.04 \\
\hline Beryllium & $<0.01$ & $<0.01$ & $<0.01$ & $<0.01$ & $\mathrm{mg} / \mathrm{L}$ & 0.01 & 0.01 & 0.01 \\
\hline Boron & $<0.75$ & $<0.75$ & 0.490 & 0.504 & $\mathrm{mg} / \mathrm{L}$ & 0.75 & 0.01 & 0.4 \\
\hline Cadmium & $<0.05$ & $<0.05$ & $<0.01$ & $<0.01$ & $\mathrm{mg} / \mathrm{L}$ & 0.05 & 0.01 & 0.01 \\
\hline Calcium & 654 & 637 & 613 & 606 & $\mathrm{mg} / \mathrm{L}$ & 1.0 & 0.5 & 681 \\
\hline Chromium & $<0.50$ & $<0.50$ & $<0.05$ & $<0.05$ & $\mathrm{mg} / \mathrm{L}$ & 0.50 & 0.05 & 0.1 \\
\hline Cobalt & $<0.50$ & $<0.50$ & $<0.05$ & $<0.05$ & $\mathrm{mg} / \mathrm{L}$ & 0.50 & 0.05 & 0.05 \\
\hline Copper & $<1.0$ & $<1.0$ & $<0.10$ & $<0.10$ & $\mathrm{mg} / \mathrm{L}$ & 1.0 & 0.10 & 0.05 \\
\hline Iron & $<1.0$ & $<1.0$ & 0.51 & 0.14 & $\mathrm{mg} / \mathrm{L}$ & 1.0 & 0.10 & 1.0 \\
\hline Lead & $<0.05$ & $<0.05$ & $<0.02$ & $<0.02$ & $\mathrm{mg} / \mathrm{L}$ & 0.05 & 0.02 & 0.05 \\
\hline Lithium & $<0.50$ & $<0.50$ & 0.14 & 0.14 & $\mathrm{mg} / \mathrm{L}$ & 0.50 & 0.01 & 0.100 \\
\hline Magnesium & 172 & 168 & 167 & 166 & $\mathrm{mg} / \mathrm{L}$ & 1.0 & 0.50 & 200 \\
\hline Mercury & $<0.0002$ & $<0.0002$ & $<0.0002$ & $<0.0002$ & $\mathrm{mg} / \mathrm{L}$ & 0.0002 & 0.0002 & 0.002 \\
\hline
\end{tabular}


Table 6.8, cont.

\begin{tabular}{|c|c|c|c|c|c|c|c|c|}
\hline \multirow[b]{3}{*}{ Parameter } & \multicolumn{7}{|c|}{ Concentration } & \multirow[b]{3}{*}{$\begin{array}{c}\mathbf{9 5}^{\text {th }} \\
\text { UTLV }^{1}\end{array}$} \\
\hline & \multicolumn{2}{|c|}{$\underline{\text { Round } 8}$} & \multicolumn{2}{|c|}{ Round 9} & \multicolumn{3}{|c|}{$\underline{\text { Reporting Limit }}$} & \\
\hline & Sample & Dup. & Sample & Dup. & Units & Round 8 & Round 9 & \\
\hline Nickel & $<0.50$ & $<0.50$ & 0.28 & 0.26 & $\mathrm{mg} / \mathrm{L}$ & 0.50 & 0.02 & 0.1 \\
\hline Potassium & 10 & 9.4 & $<10$ & $<10$ & $\mathrm{mg} / \mathrm{L}$ & 1.0 & 1.0 & 5.96 \\
\hline Selenium & $<0.10$ & $<0.10$ & $<0.05$ & $<0.05$ & $\mathrm{mg} / \mathrm{L}$ & 0.10 & 0.05 & 0.05 \\
\hline Silica & 7.4 & 7.9 & 10.3 & 10.2 & $\mathrm{mg} / \mathrm{L}$ & 5.0 & 0.01 & 28.10 \\
\hline Silver & $<0.50$ & $<0.50$ & 0.08 & $<0.05$ & $\mathrm{mg} / \mathrm{L}$ & 0.50 & 0.05 & 0.05 \\
\hline Sodium & 291 & 299 & 269 & 267 & $\mathrm{mg} / \mathrm{L}$ & 1.0 & 0.5 & 384 \\
\hline Thallium & $<0.01$ & $<0.01$ & 0.058 & $<0.05$ & $\mathrm{mg} / \mathrm{L}$ & 0.01 & 0.05 & 0.05 \\
\hline Tin & $<0.01$ & $<0.01$ & $<0.025$ & $<0.025$ & $\mathrm{mg} / \mathrm{L}$ & 0.01 & 0.025 & 0.1 \\
\hline Vanadium & $<0.01$ & $<0.01$ & $<0.10$ & $<0.10$ & $\mathrm{mg} / \mathrm{L}$ & 0.01 & 0.10 & 0.1 \\
\hline Zinc & $<5.0$ & $<5.0$ & $<0.10$ & $<0.10$ & $\mathrm{mg} / \mathrm{L}$ & 5.0 & 0.10 & 0.2 \\
\hline $\begin{array}{l}{ }^{1} 95^{\text {th }} \text { Upper Toleran } \\
{ }^{2} \text { Reporting Limit } \\
{ }^{3} \text { Not reported by lal } \\
{ }^{4} \text { Not Available } \\
{ }^{5} \text { Not Applicable } \\
{ }^{6} \text { Standard Unit }\end{array}$ & $\overline{\text { Talue, e }}$ & & & nce Lim & & & & \\
\hline
\end{tabular}




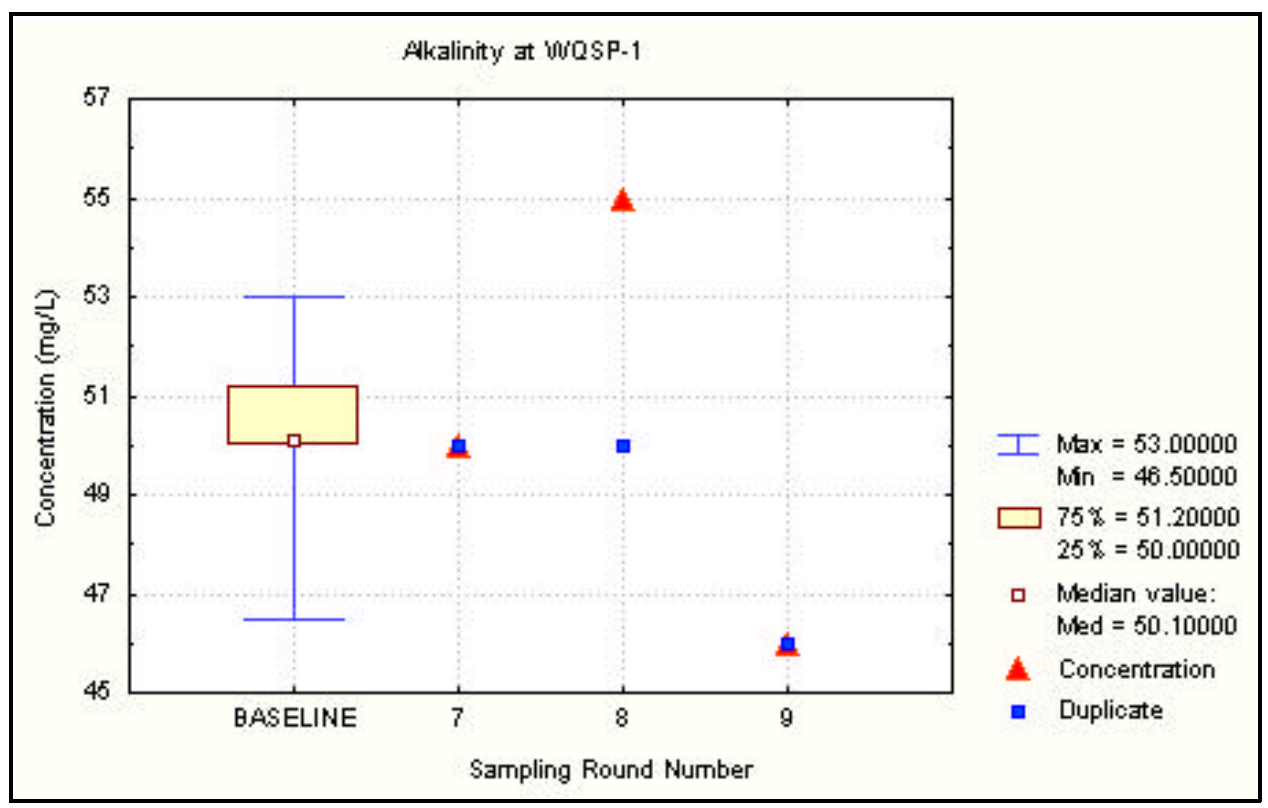

Figure 6.5 Time Trend Plot for Alkalinity at WQSP-1

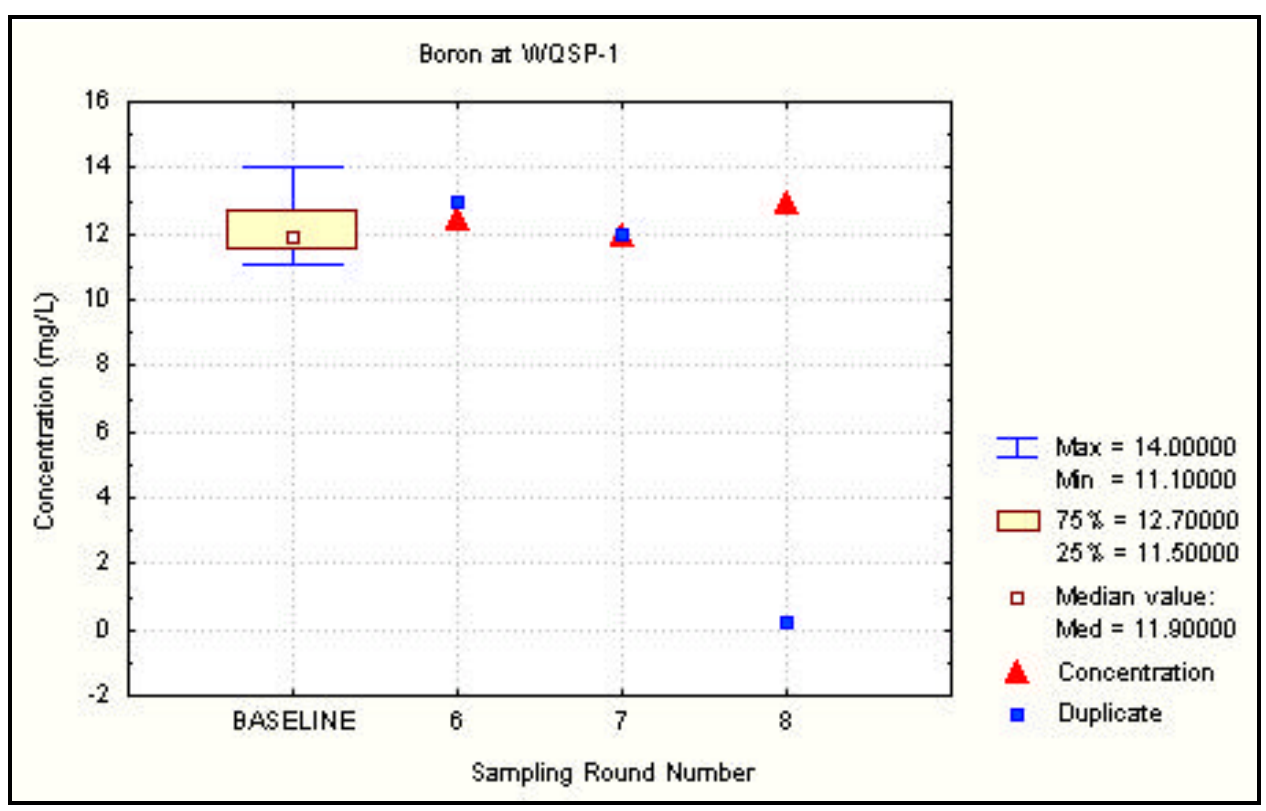

Figure 6.6 Time Trend Plot for Boron at WQSP-1 


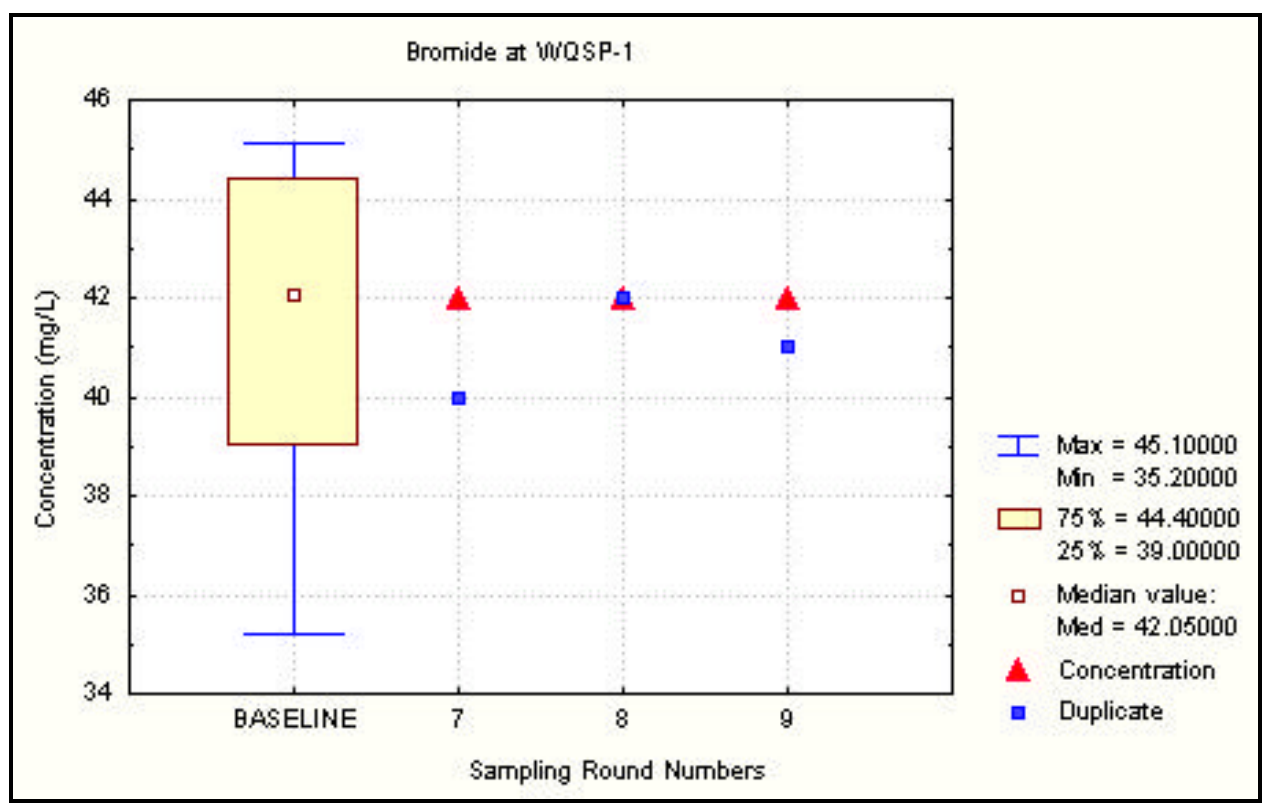

Figure 6.7 Time Trend Plot For Bromide at WQSP-1

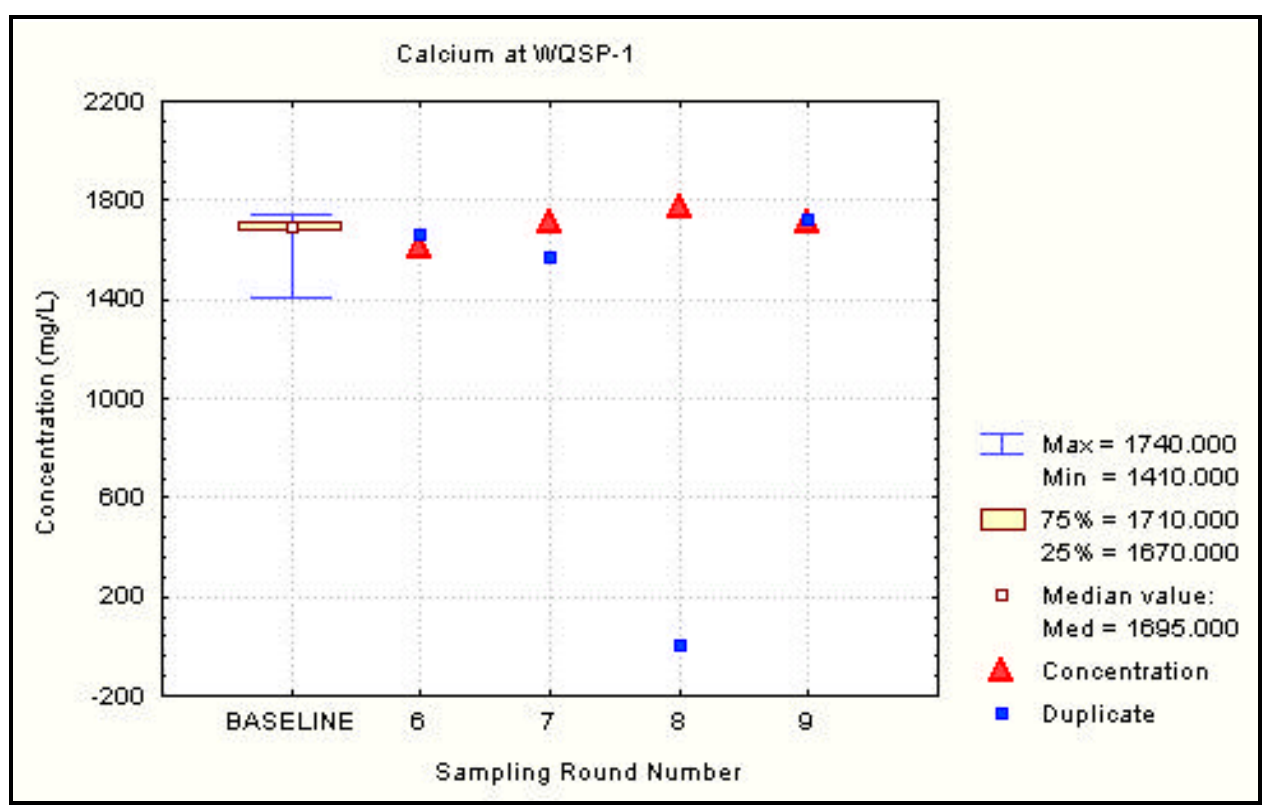

Figure 6.8 Time Trend Plot for Calcium at WQSP-1 


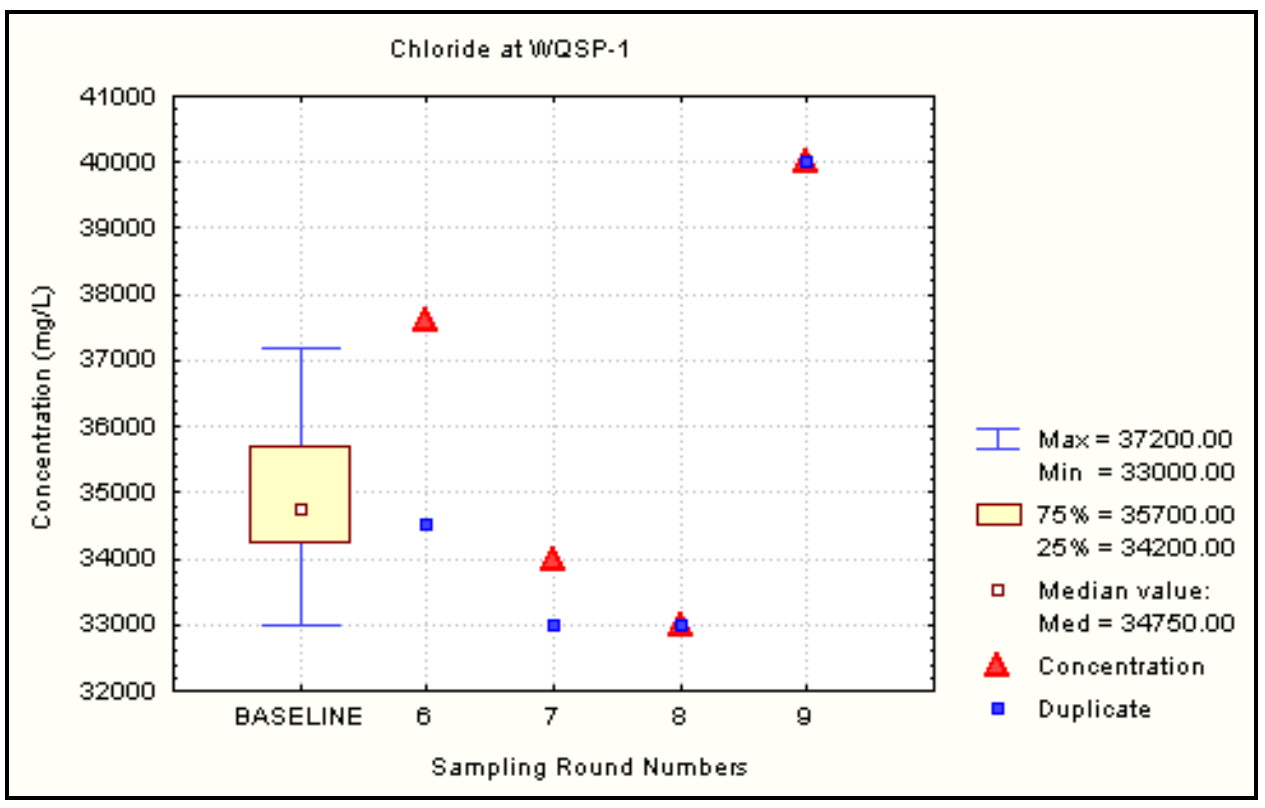

Figure 6.9 Time Trend Plot for Chloride at WQSP-1

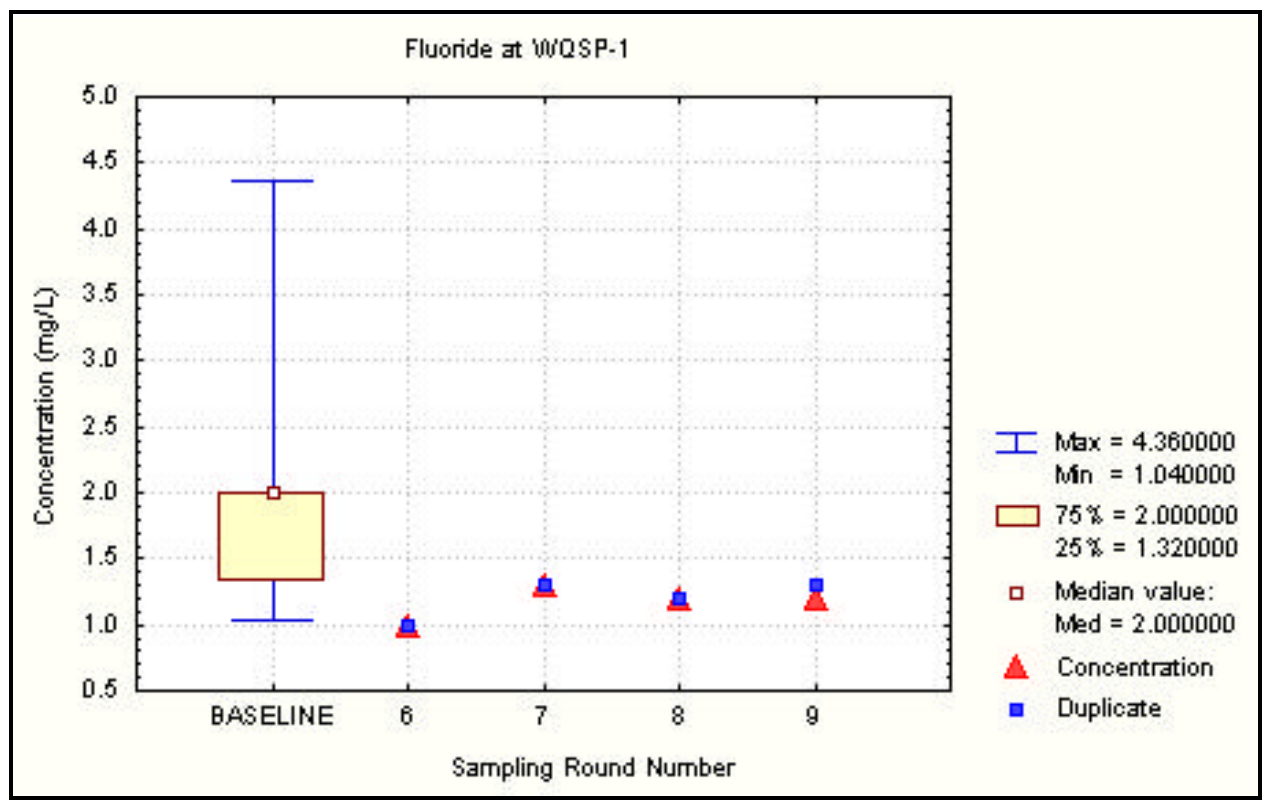

Figure 6.10 Time Trend Plot for Fluoride at WQSP-1 


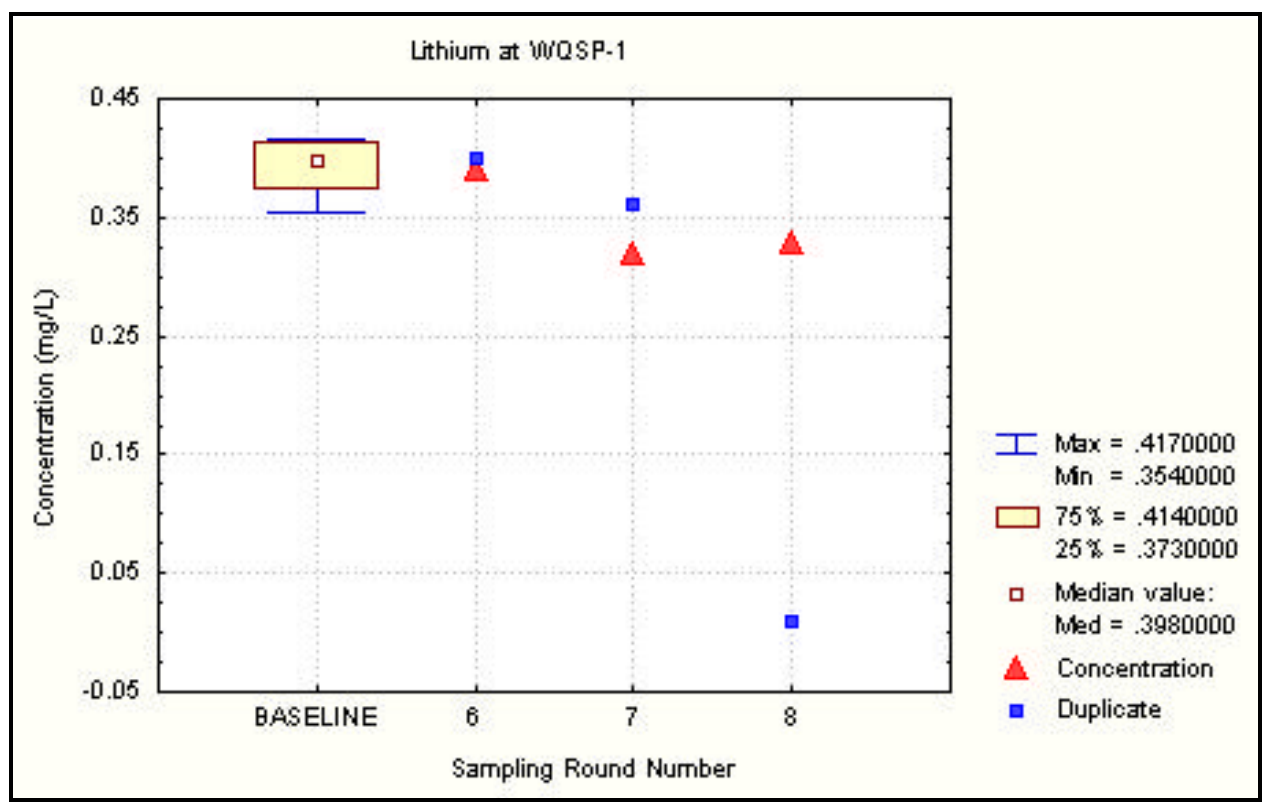

Figure 6.11 Time Trend Plot for Lithium at WQSP-1

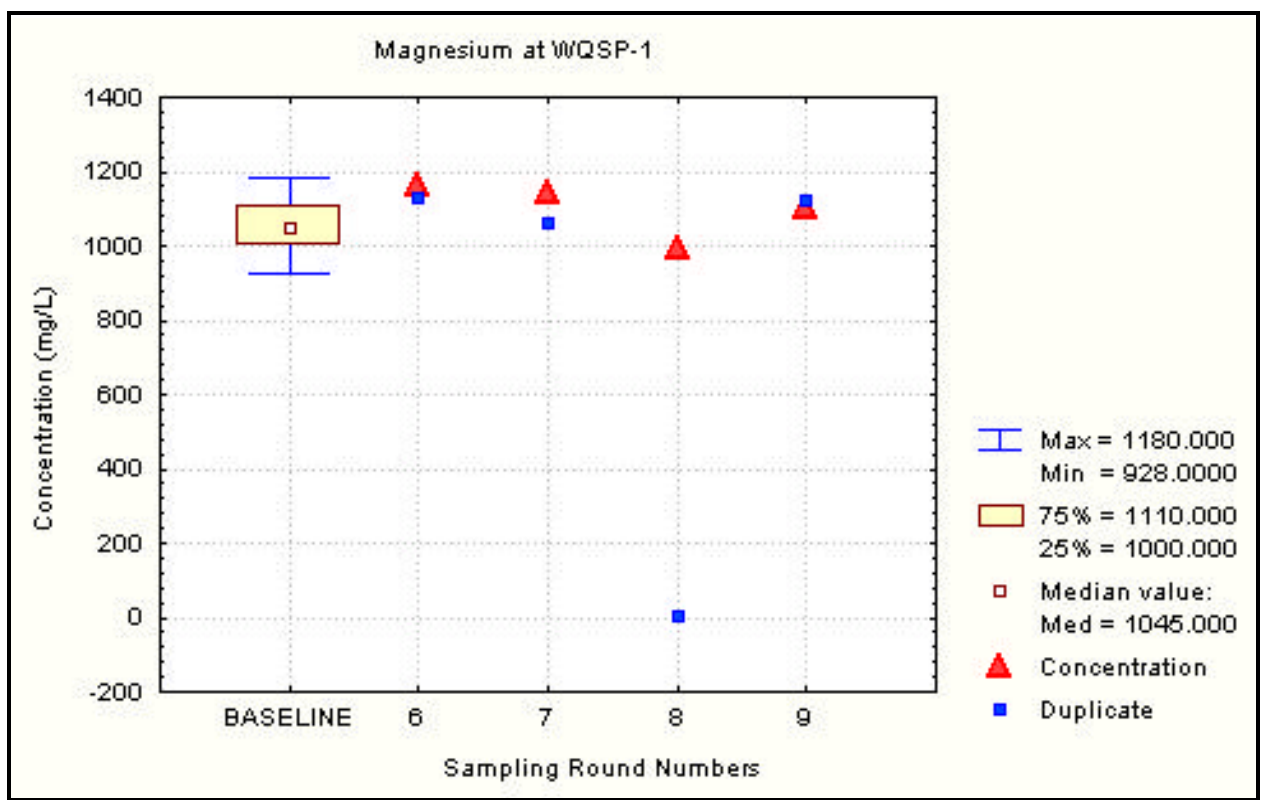

Figure 6.12 Time Trend Plot for Magnesium at WQSP-1 


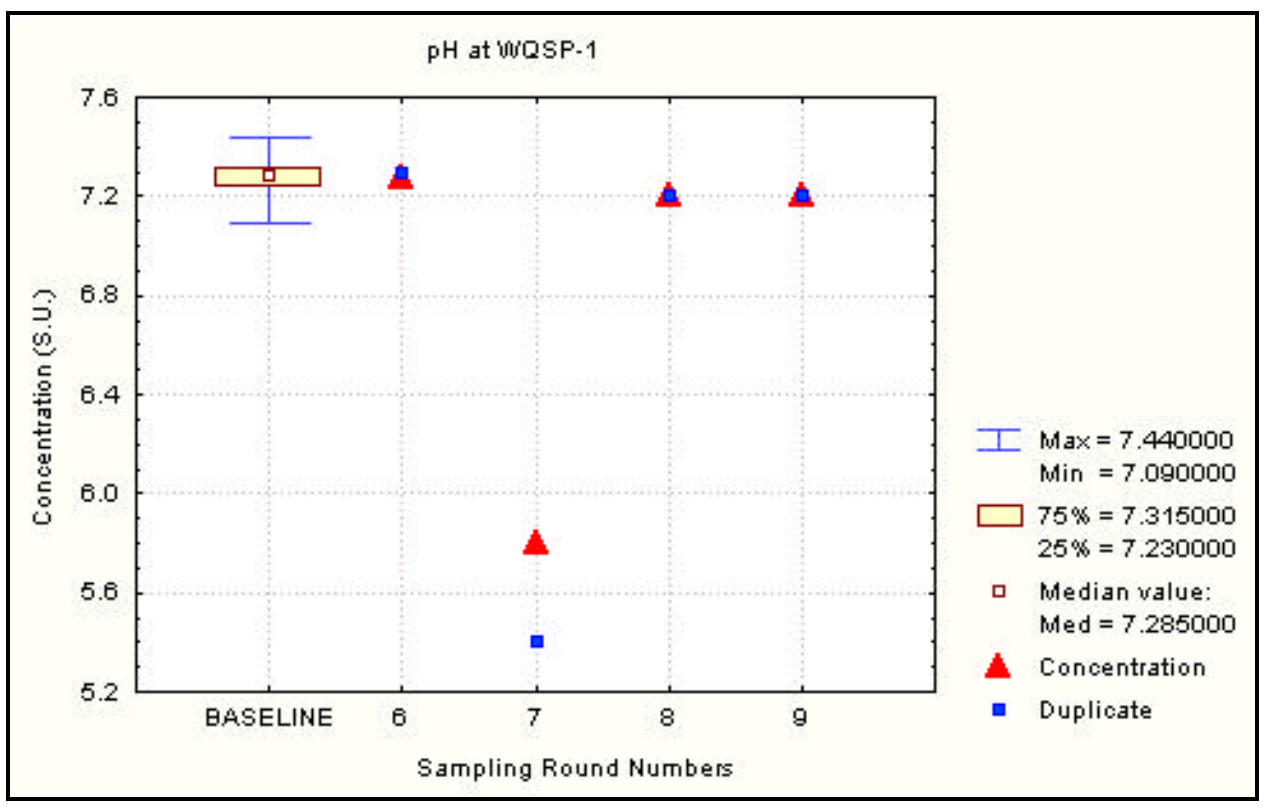

Figure 6.13 Time Trend Plot for $\mathrm{pH}$ at WQSP-1

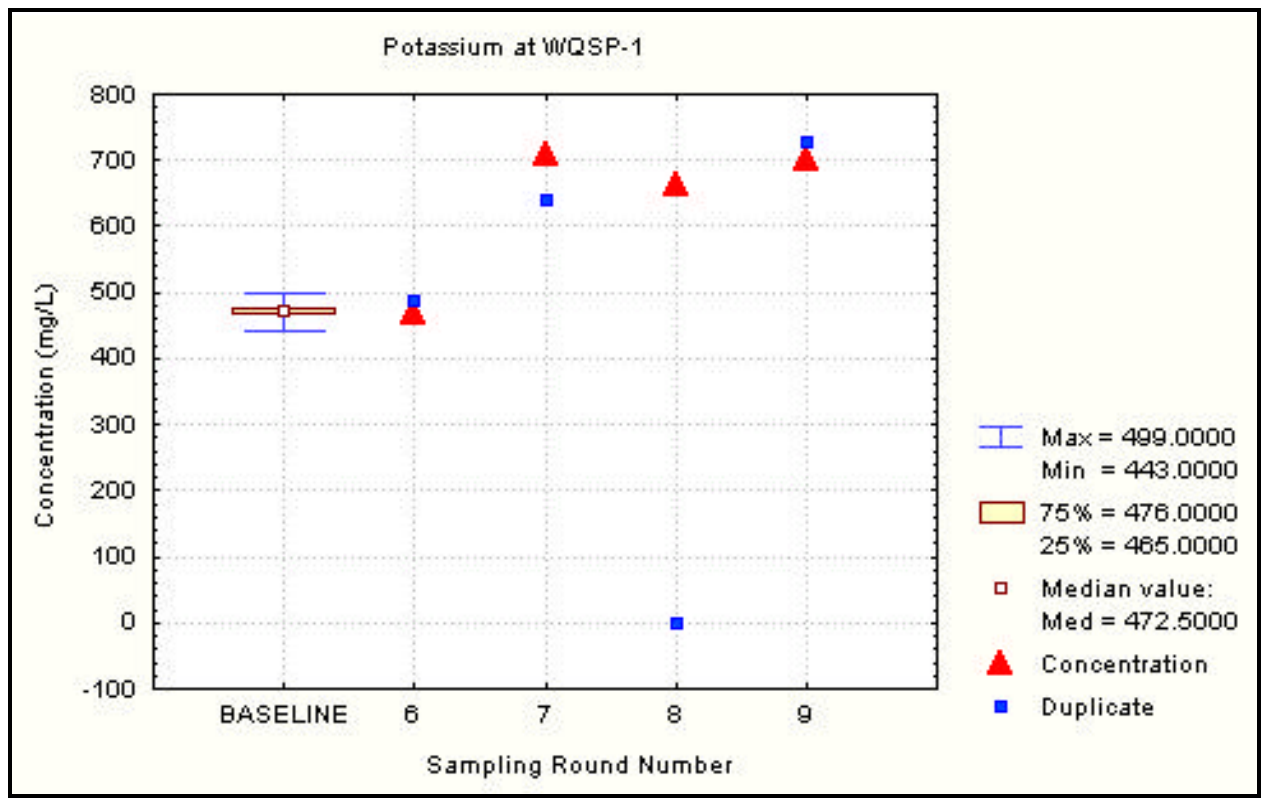

Figure 6.14 Time Trend Plot for Potassium at WQSP-1 


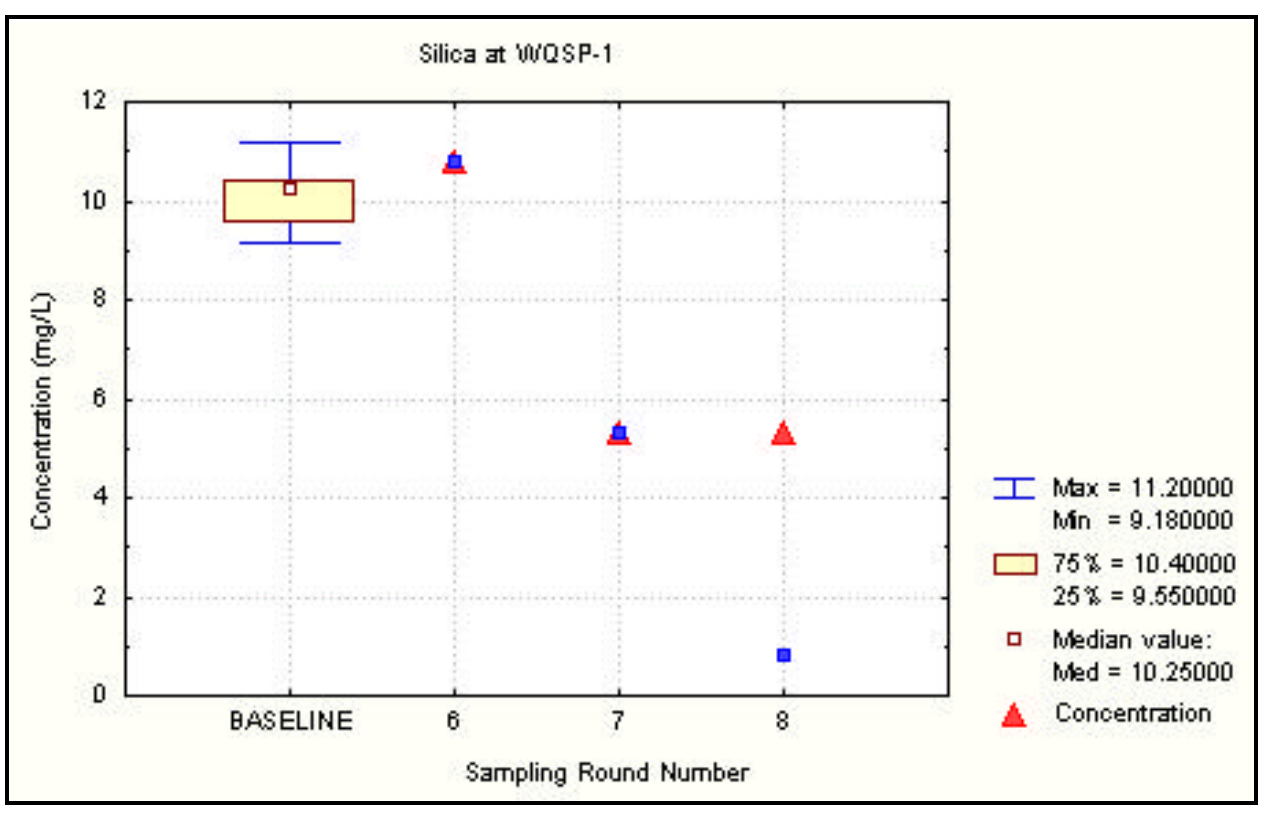

Figure 6.15 Time Trend Plot for Silica at WQSP-1

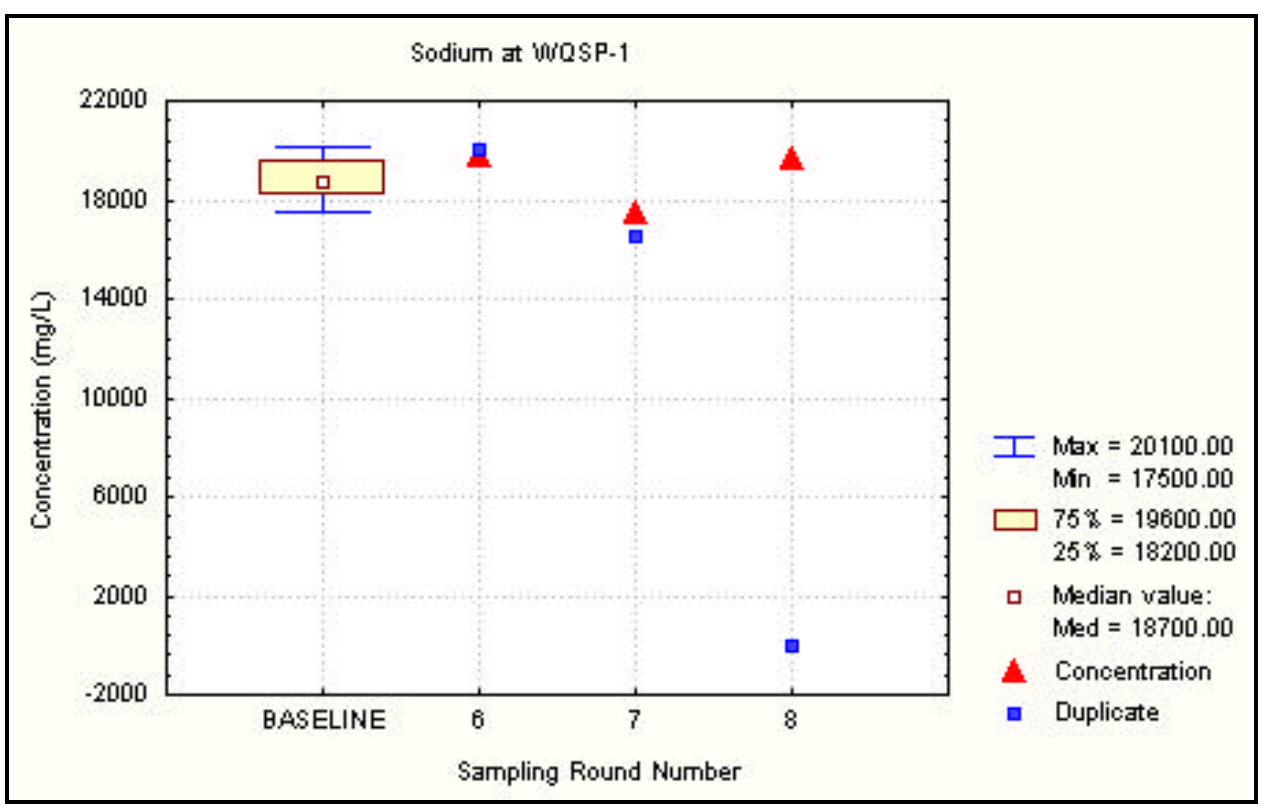

Figure 6.16 Time Trend Plot for Sodium at WQSP-1 


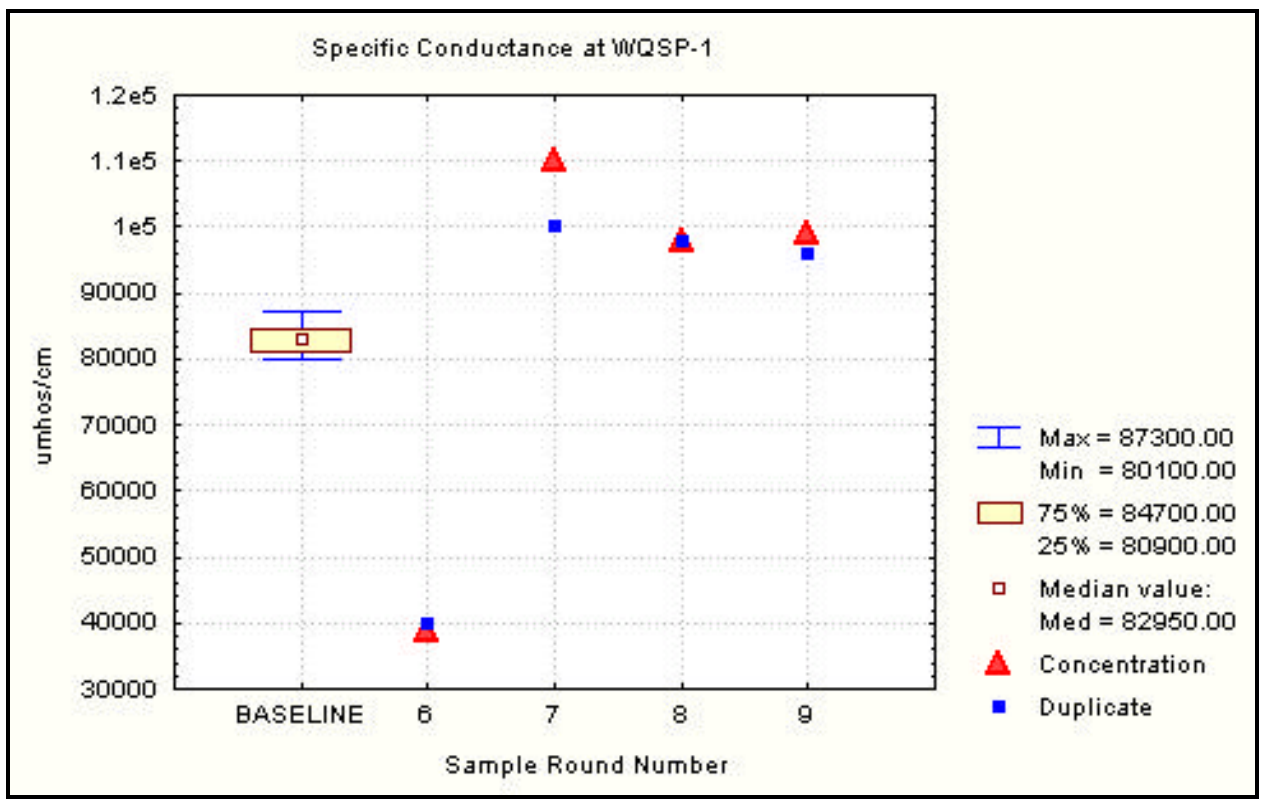

Figure 6.17 Time Trend Plot for Specific Conductance at WQSP-1

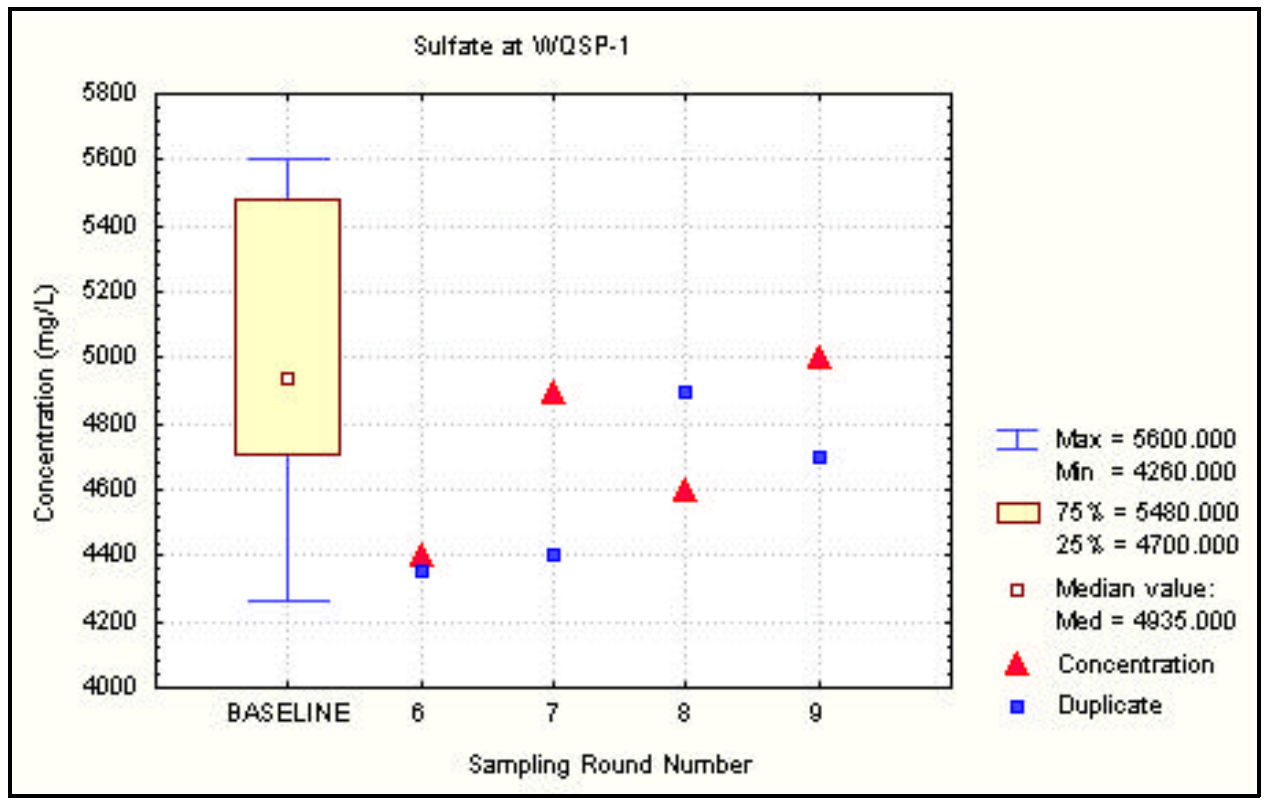

Figure 6.18 Time Trend Plot for Sulfate at WQSP-1 


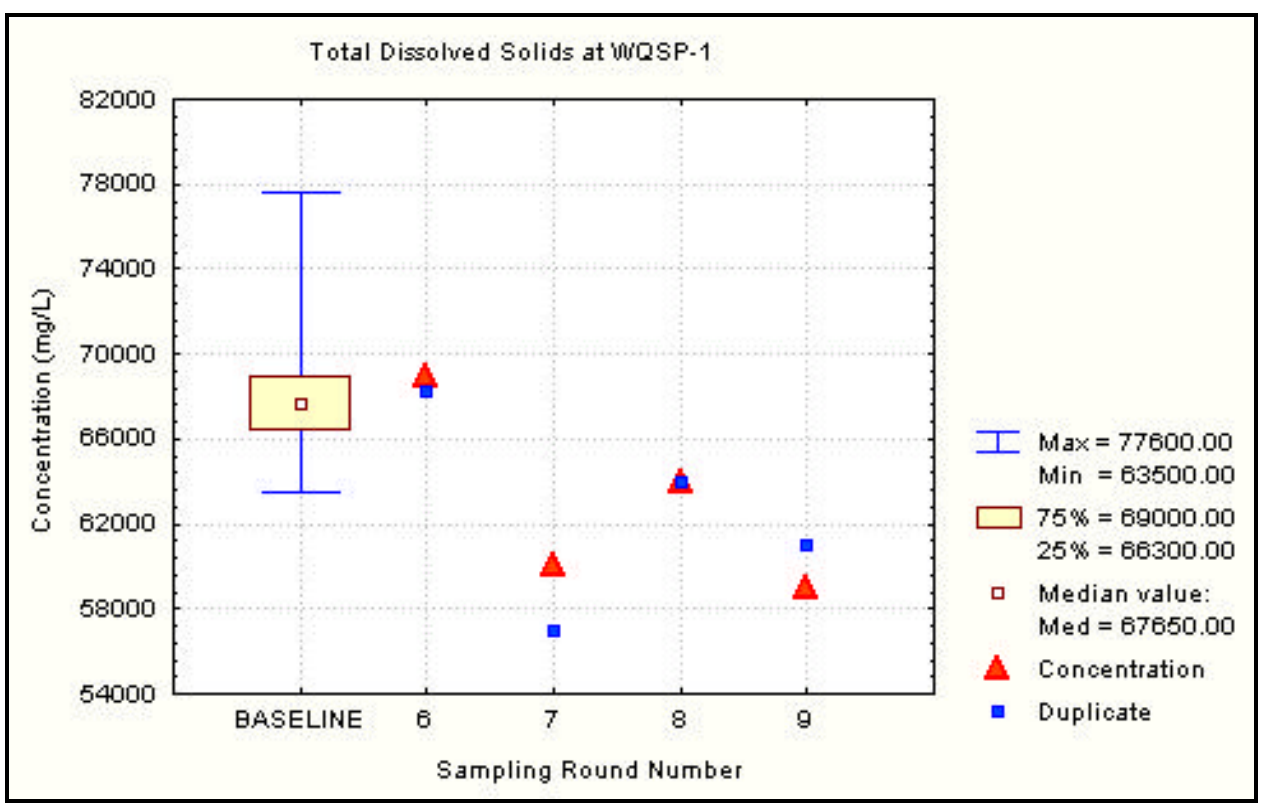

Figure 6.19 Time Trend Plot for Total Dissolved Solids at WQSP-1

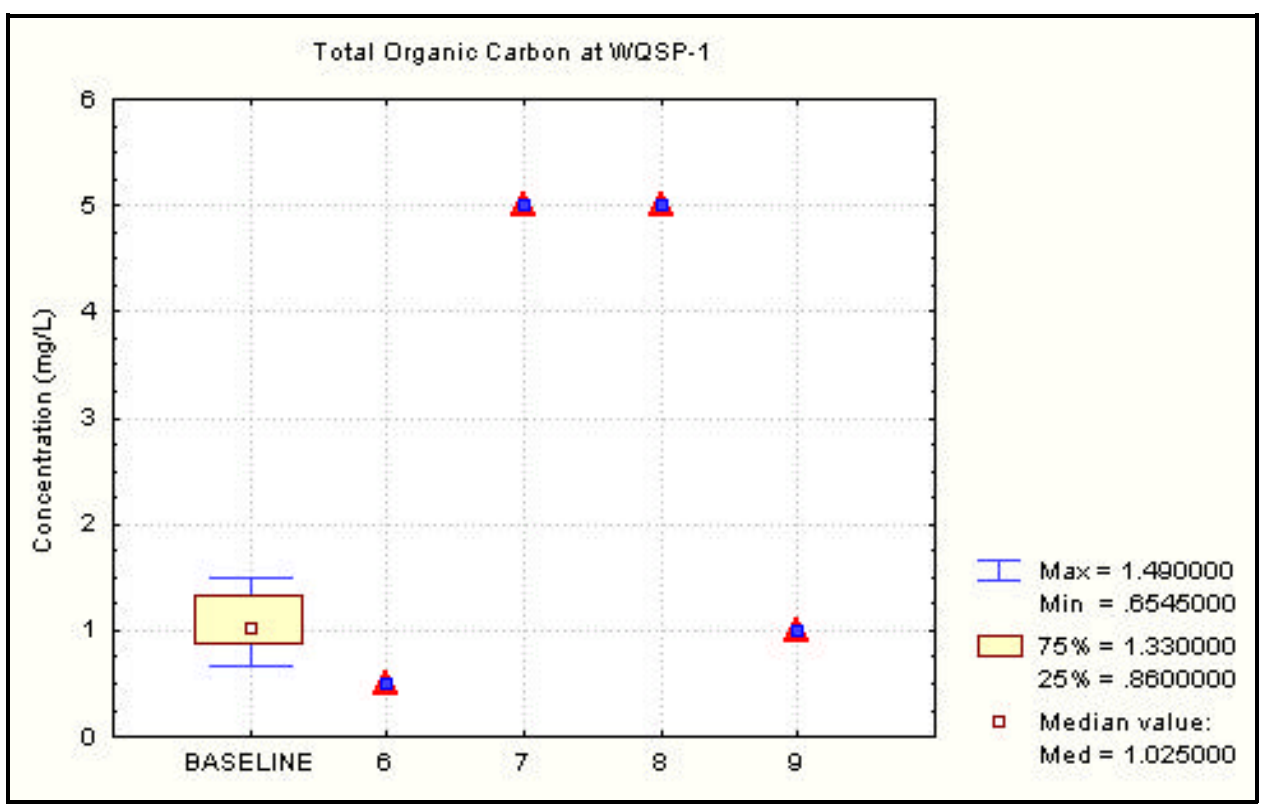

Figure 6.20 Time Trend Plot for Total Organic Carbon at WQSP-1 


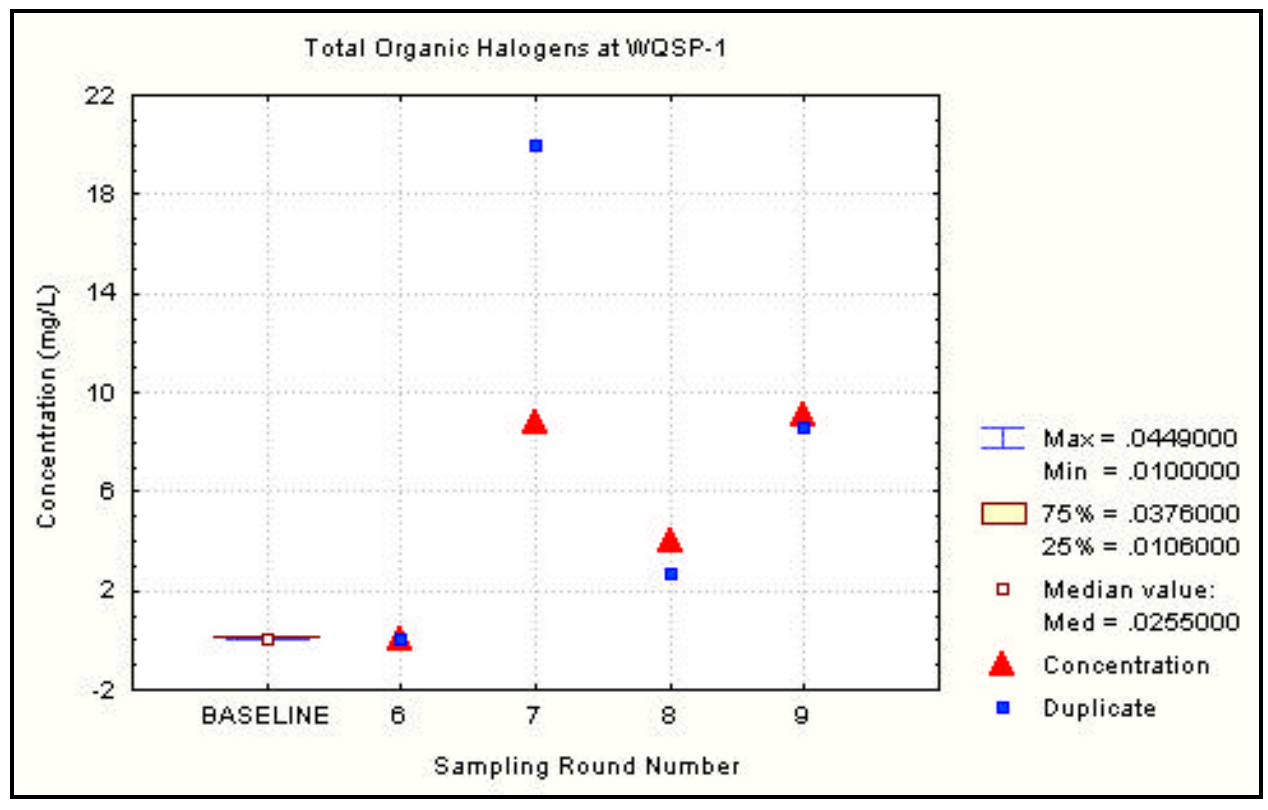

Figure 6.21 Time Trend Plot for Total Organic Halogens at WQSP-1

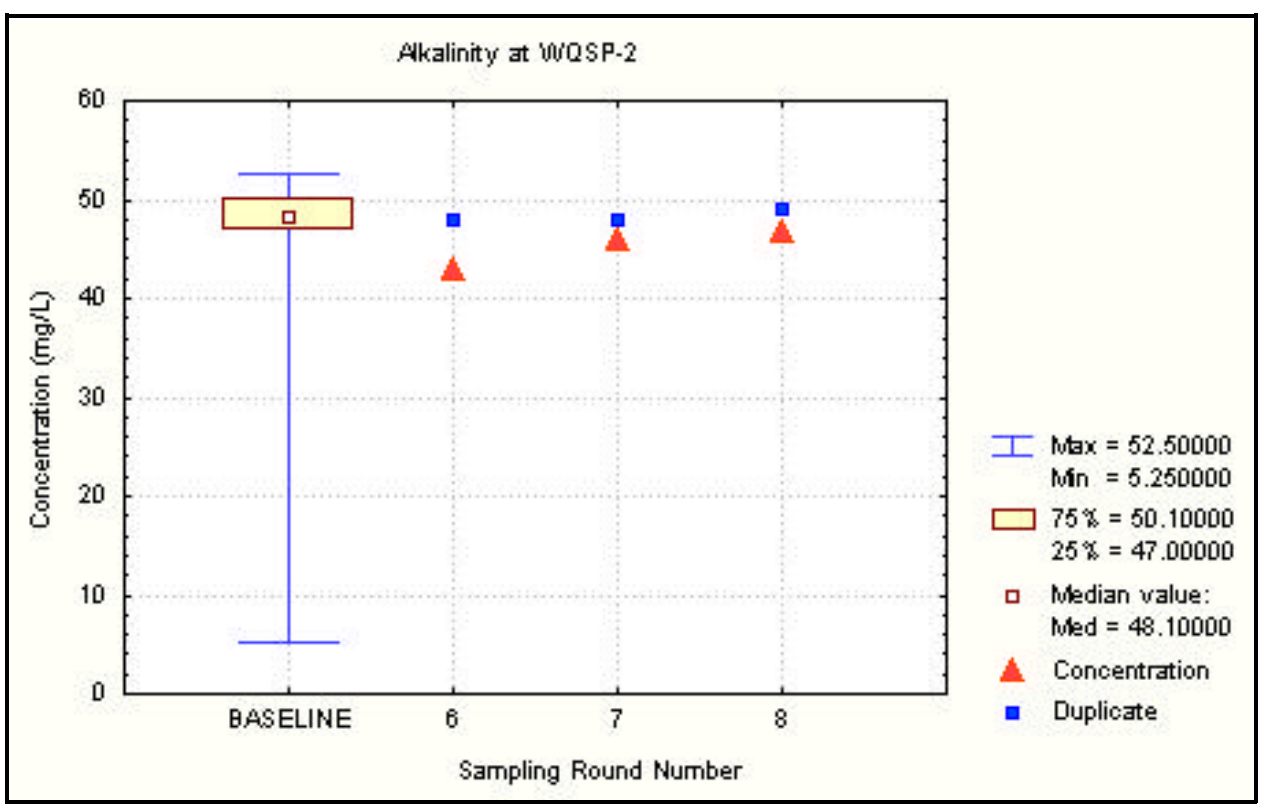

Figure 6.22 Time Trend Plot for Alkalinity at WQSP-2 


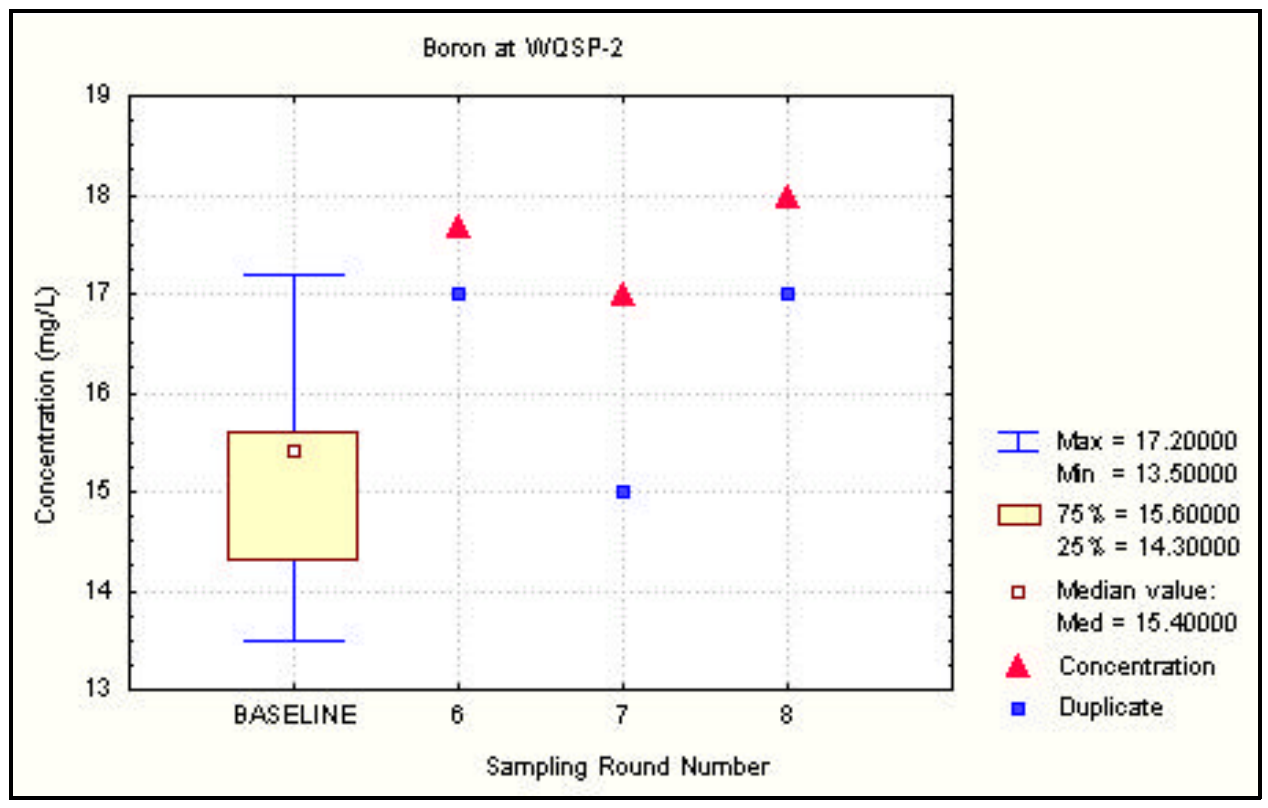

Figure 6.23 Time Trend Plot at WQSP-2

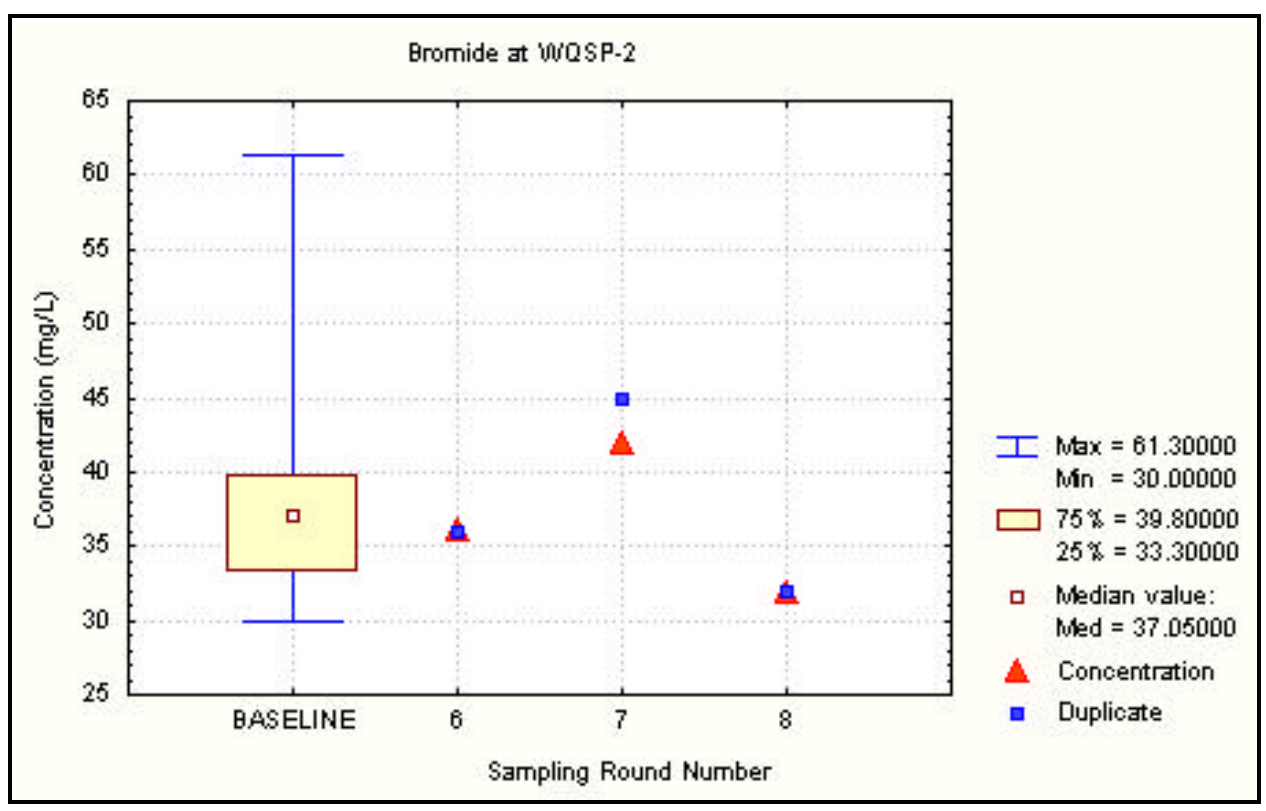

Figure 6.24 Time Trend Plot for Bromide at WQSP-2 


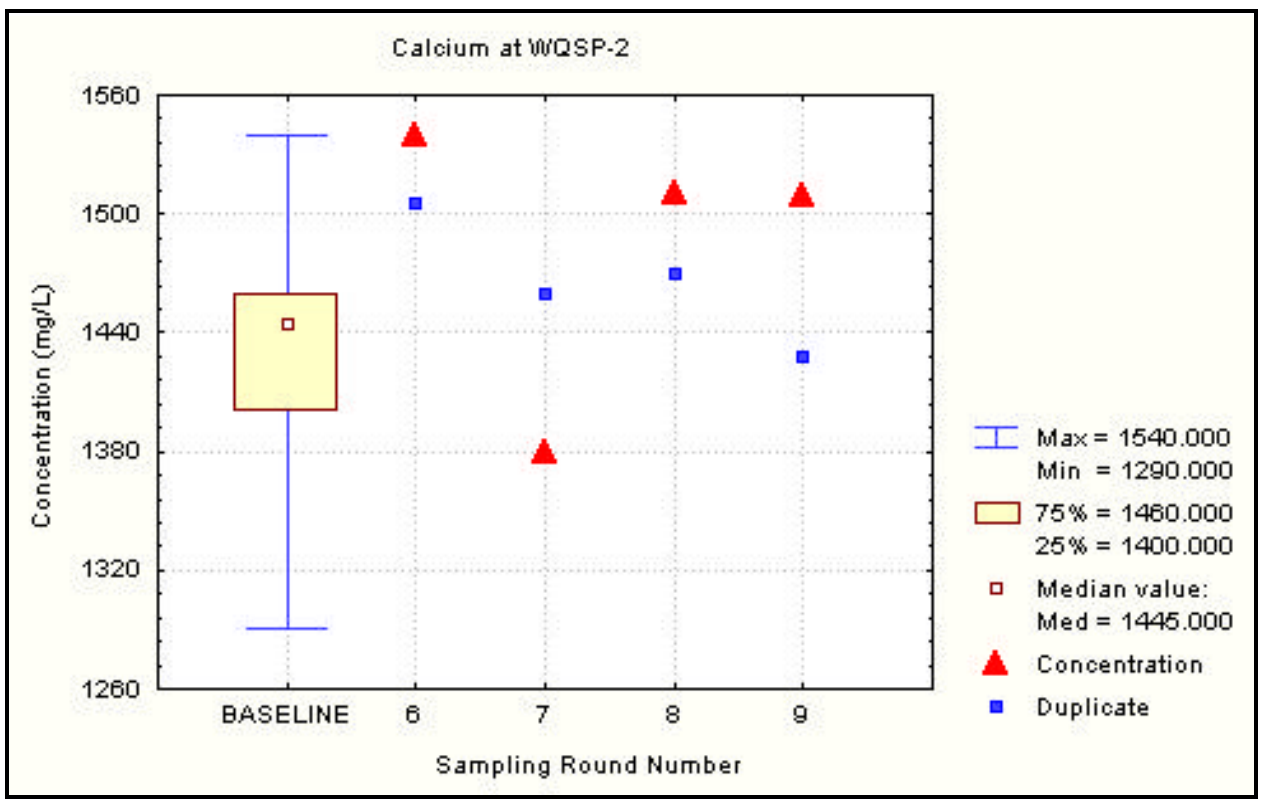

Figure 6.25 Time Trend Plot for Calcium at WQSP-2

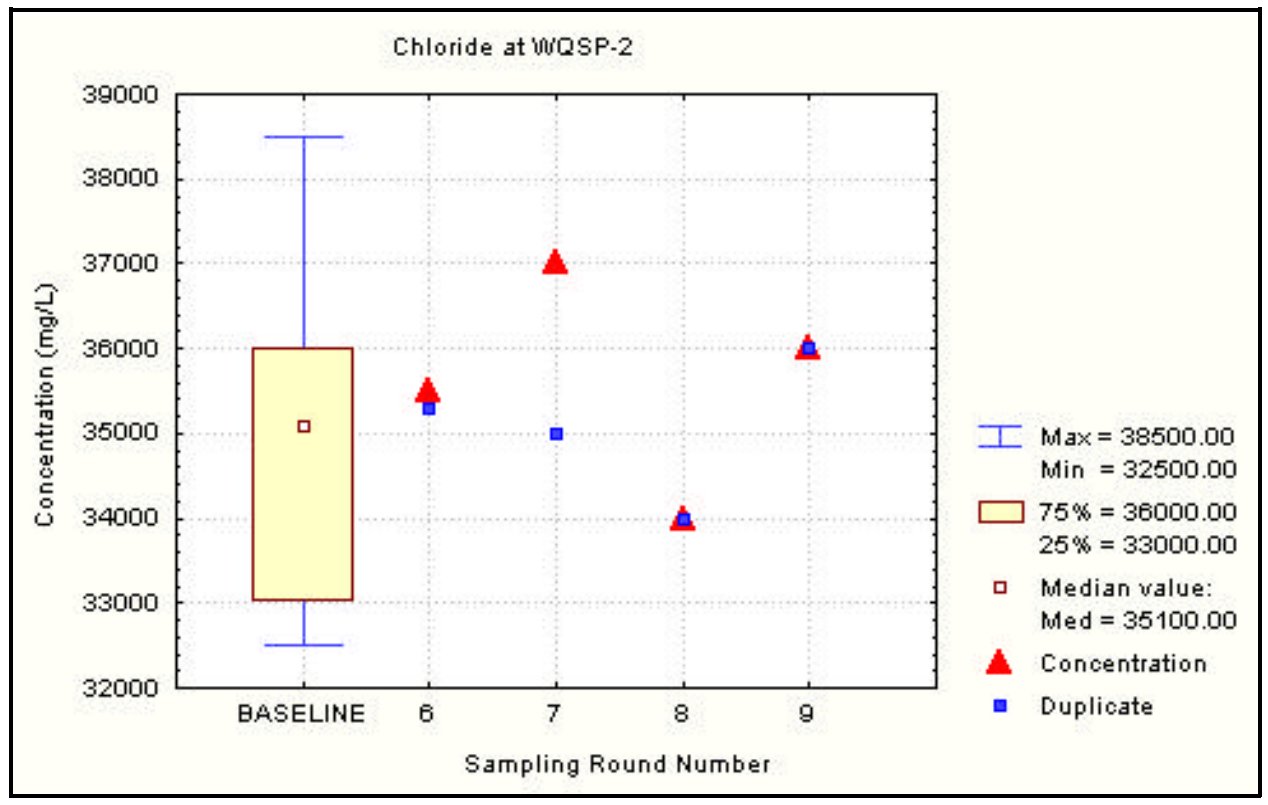

Figure 6.26 Time Trend Plot for Chloride at WQSP-2 


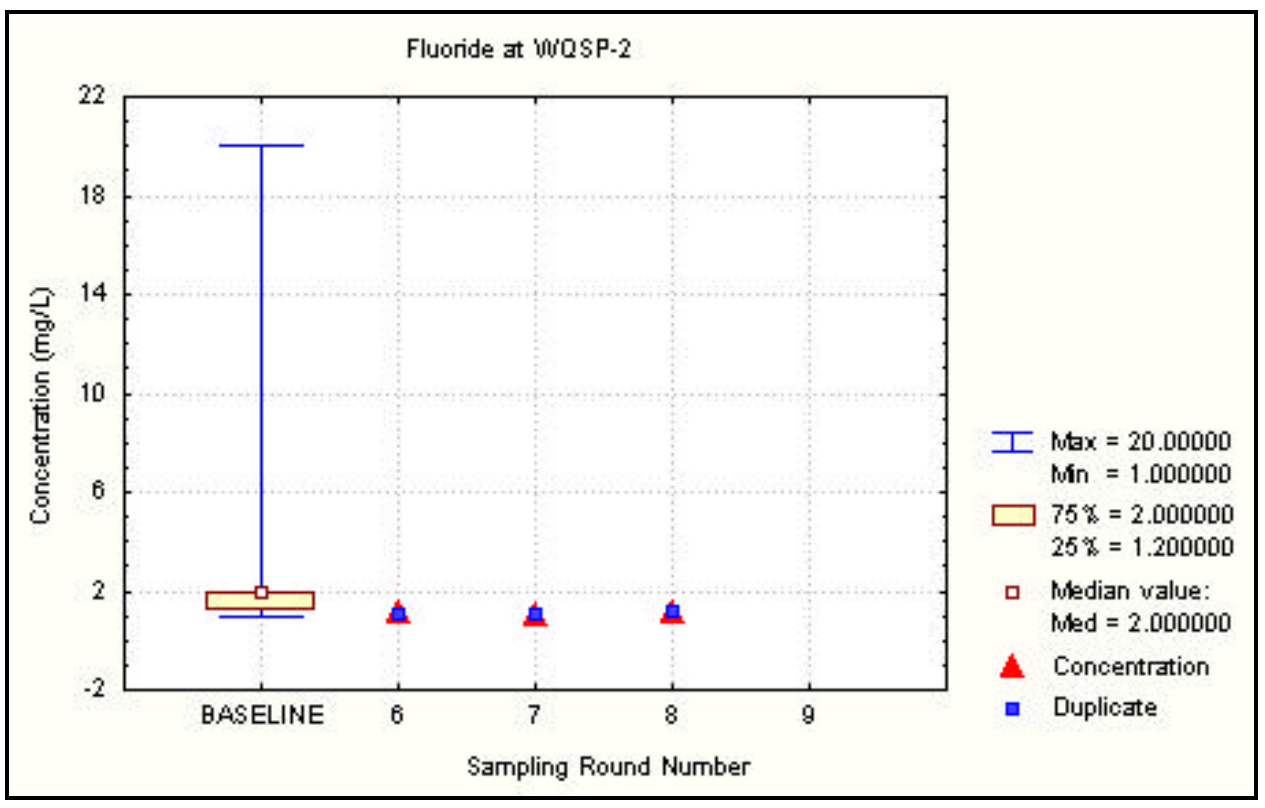

Figure 6.27 Time Trend Plot for Fluoride at WQSP-2

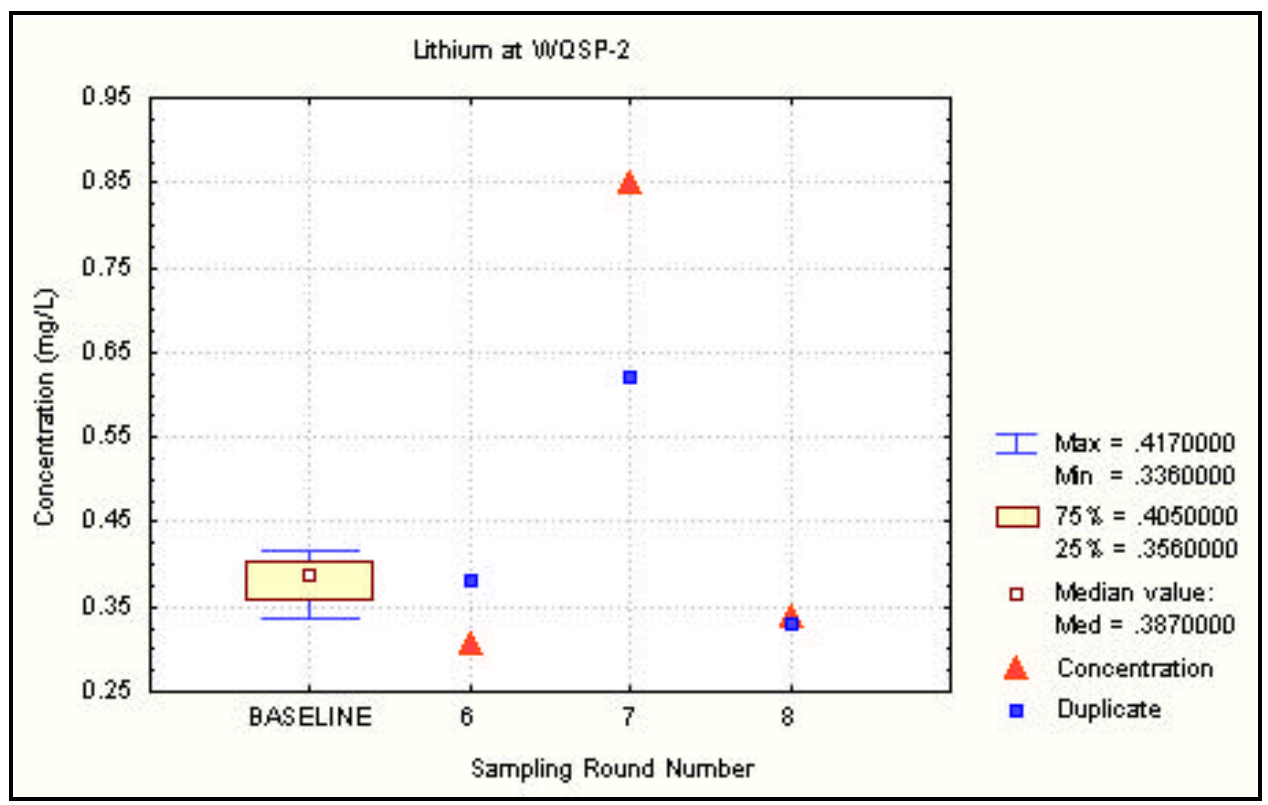

Figure 6.28 Time Trend Plot for Lithium at WQSP-2 


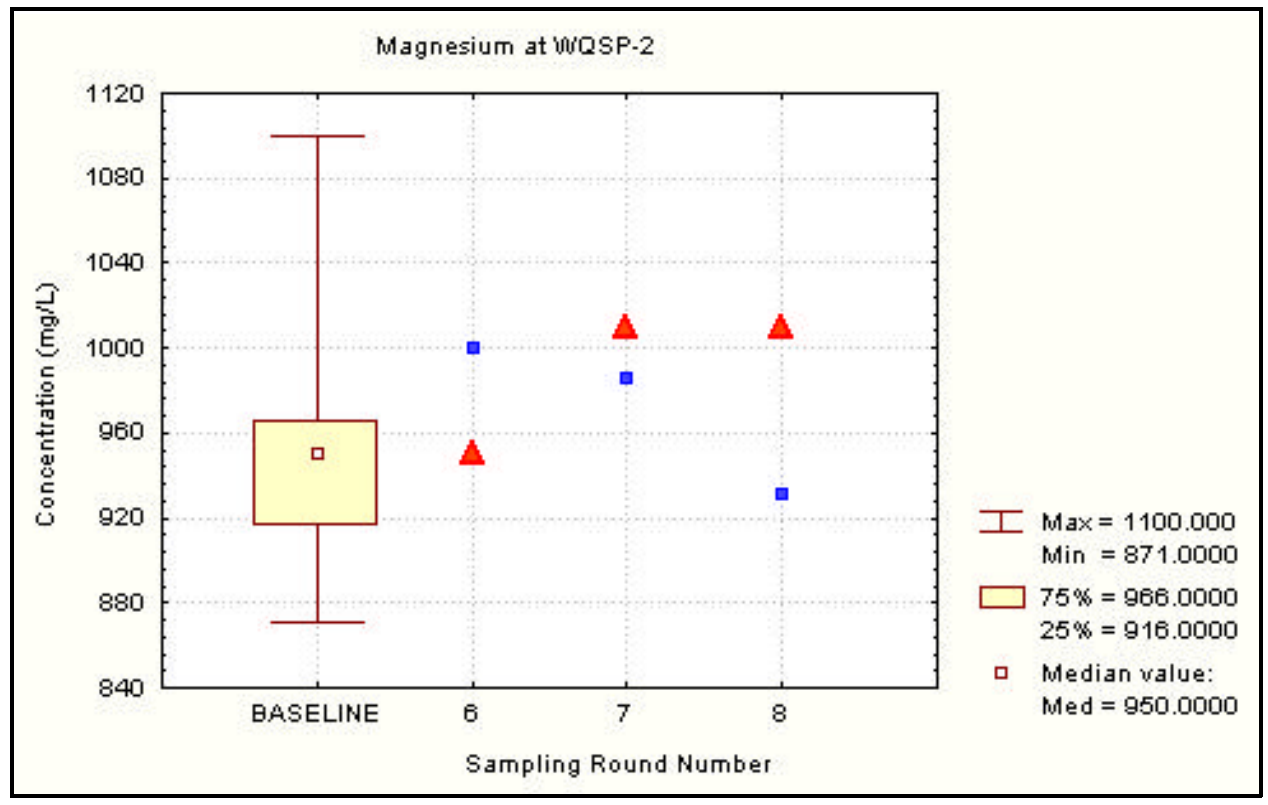

Figure 6.29 Time Trend Plot for Magnesium at WQSP-2

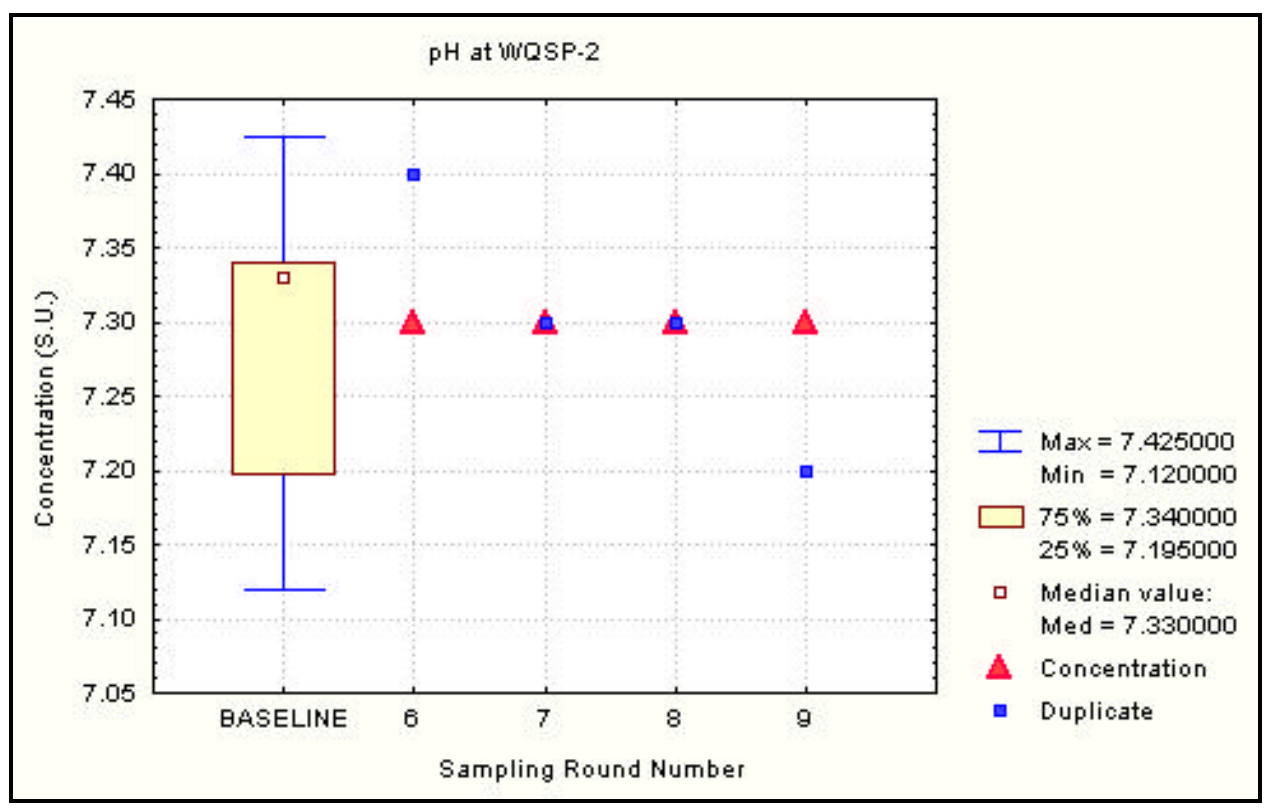

Figure 6.30 Time Trend Plot for $\mathrm{pH}$ at WQSP-2 


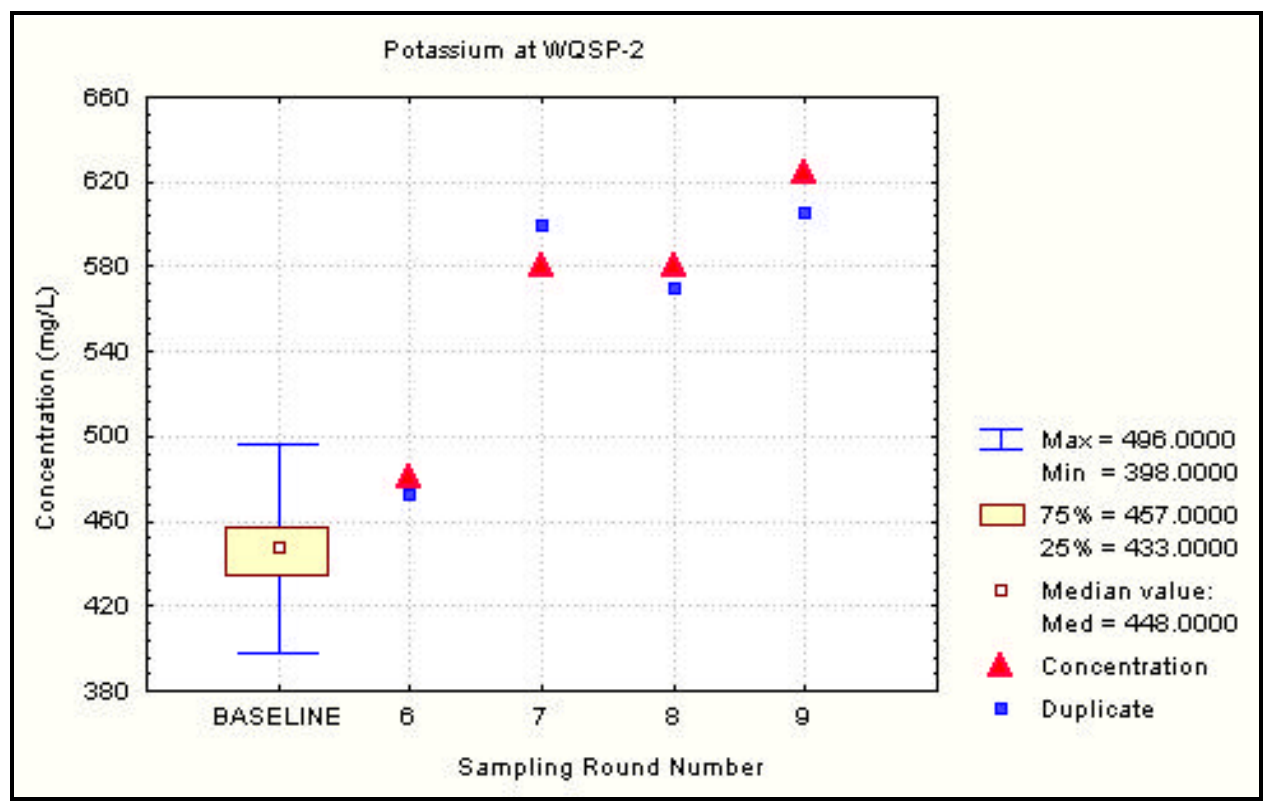

Figure 6.31 Time Trend Plot for Potassium at WQSP-2

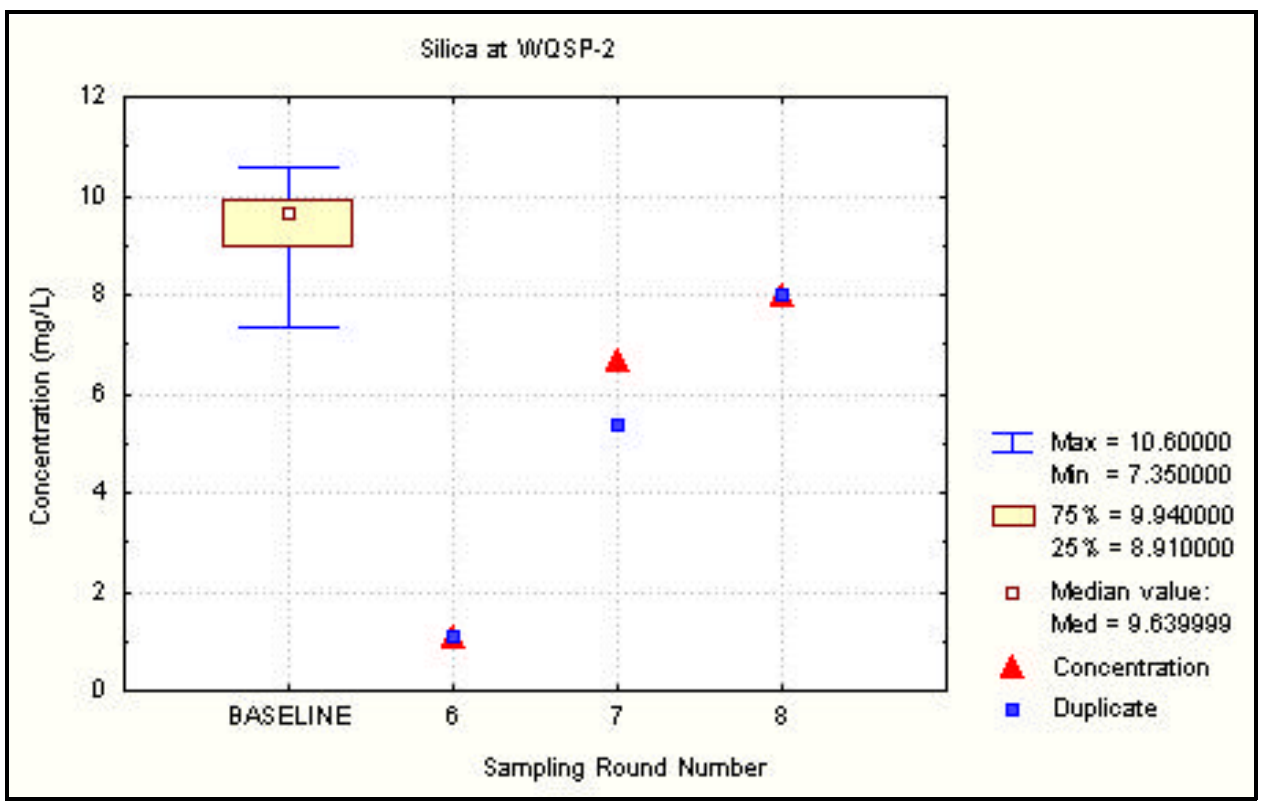

Figure 6.32 Time Trend Plot for Silica at WQSP-2 


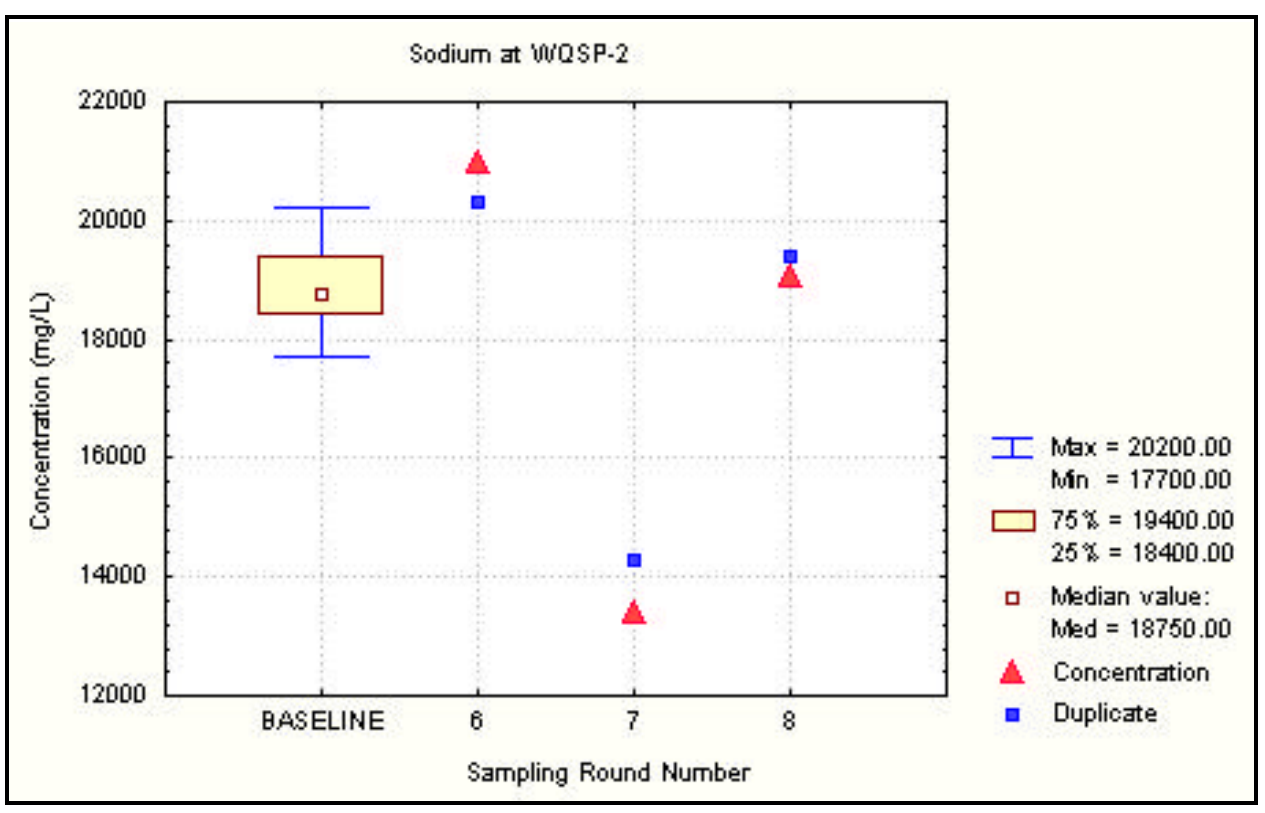

Figure 6.33 Time Trend Plot for Sodium at WQSP-2

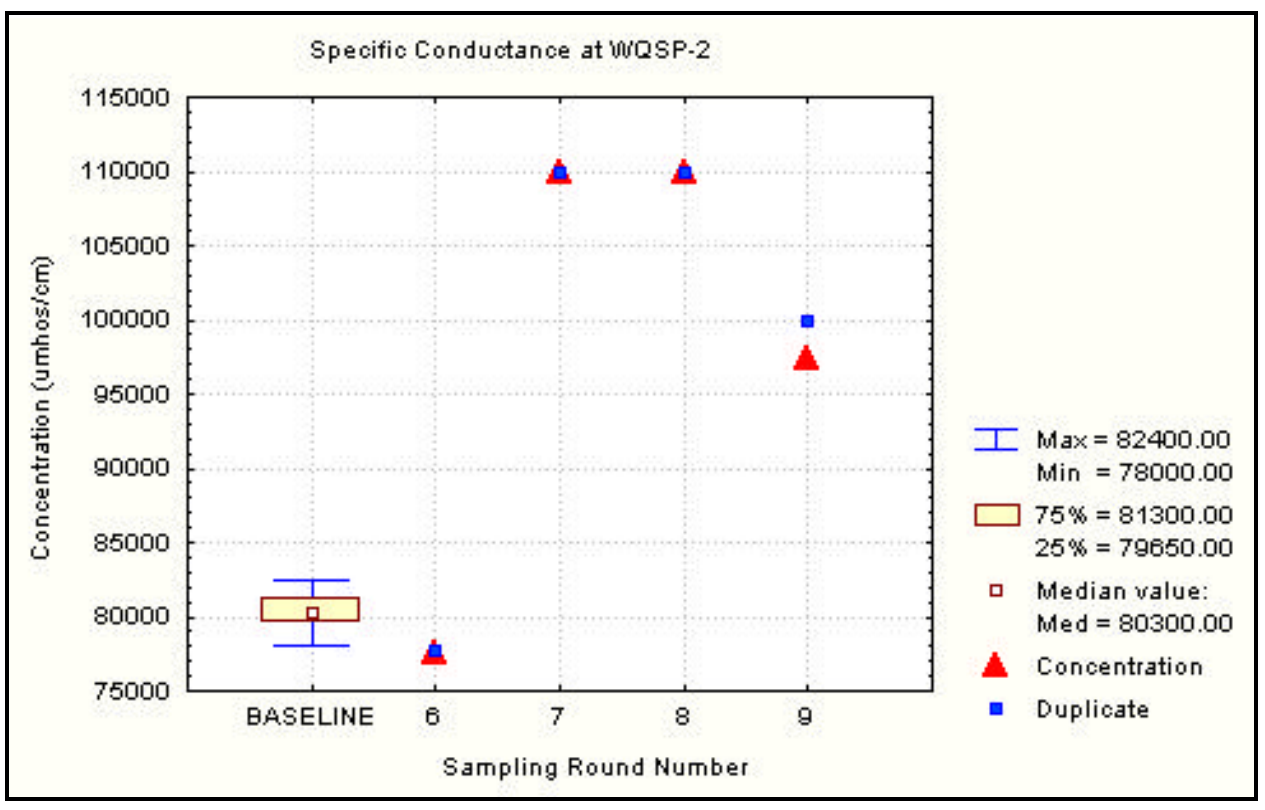

Figure 6.34 Time Trend Plot for Specific Conductance at WQSP-2 


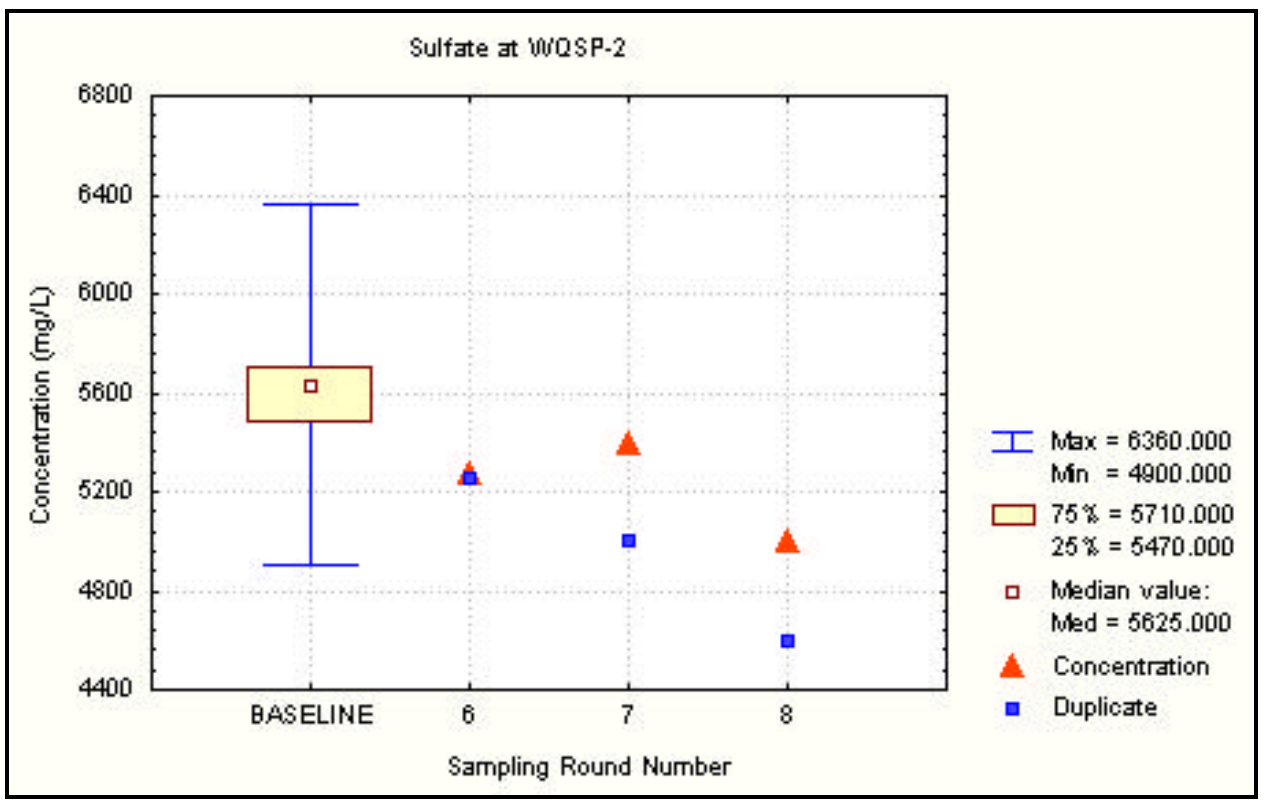

Figure 6.35 Time Trend Plot for Sulfate at WQSP-2

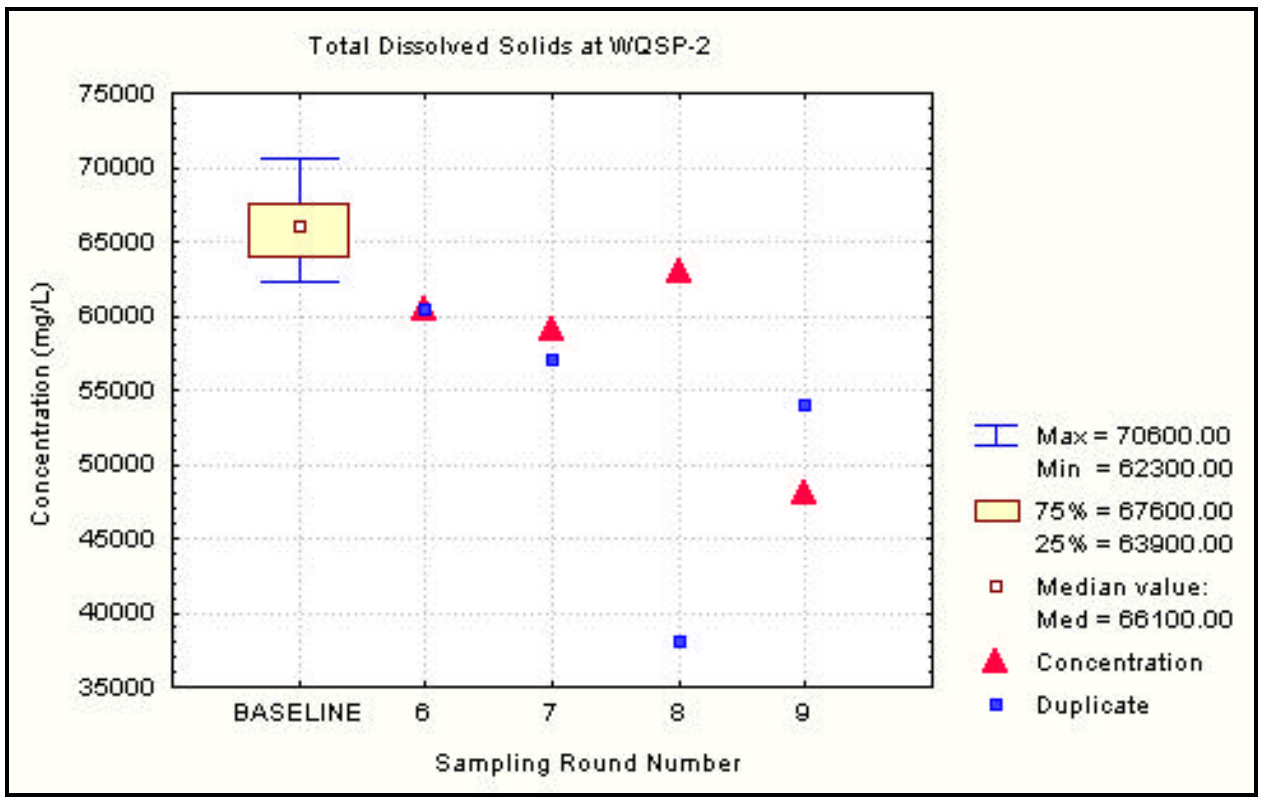

Figure 6.36 Time Trend Plot for Total Dissolved Solids at WQSP-2 


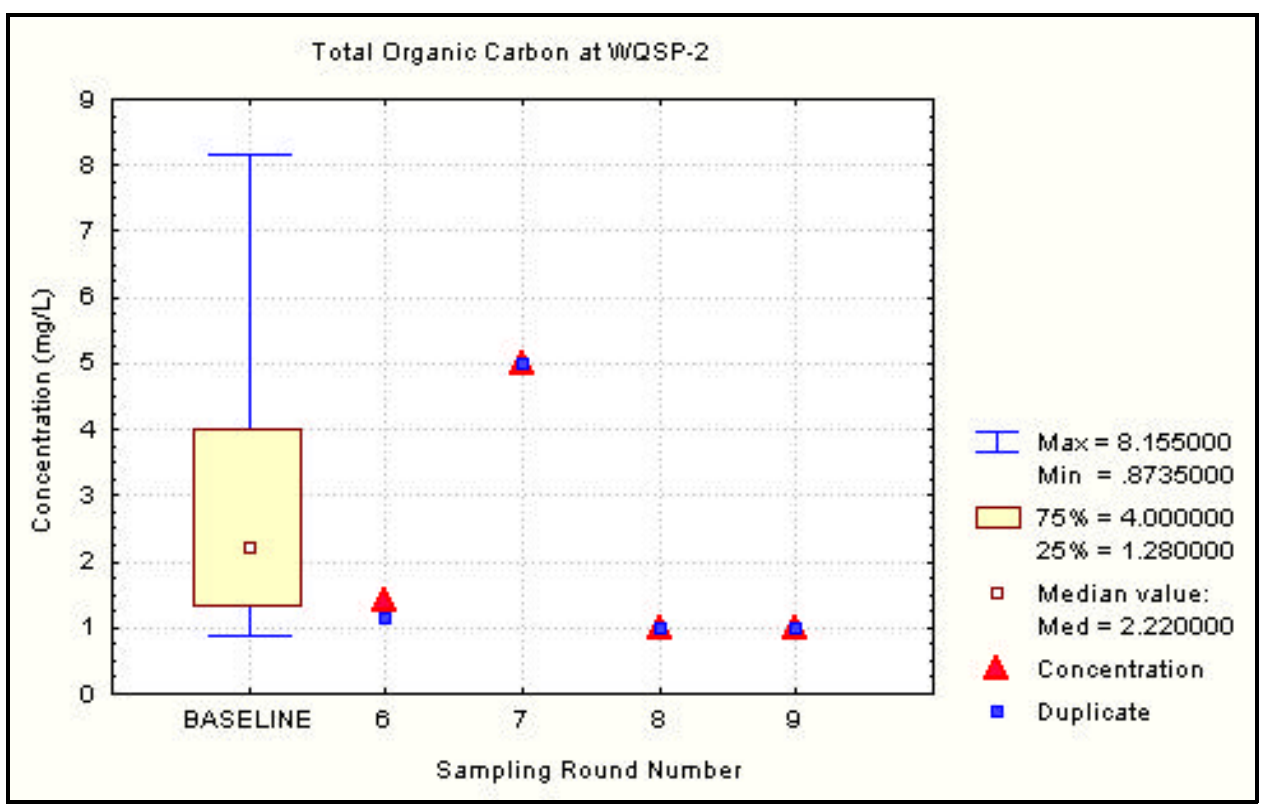

Figure 6.37 Time Trend Plot for Total Organic Carbon at WQSP-2

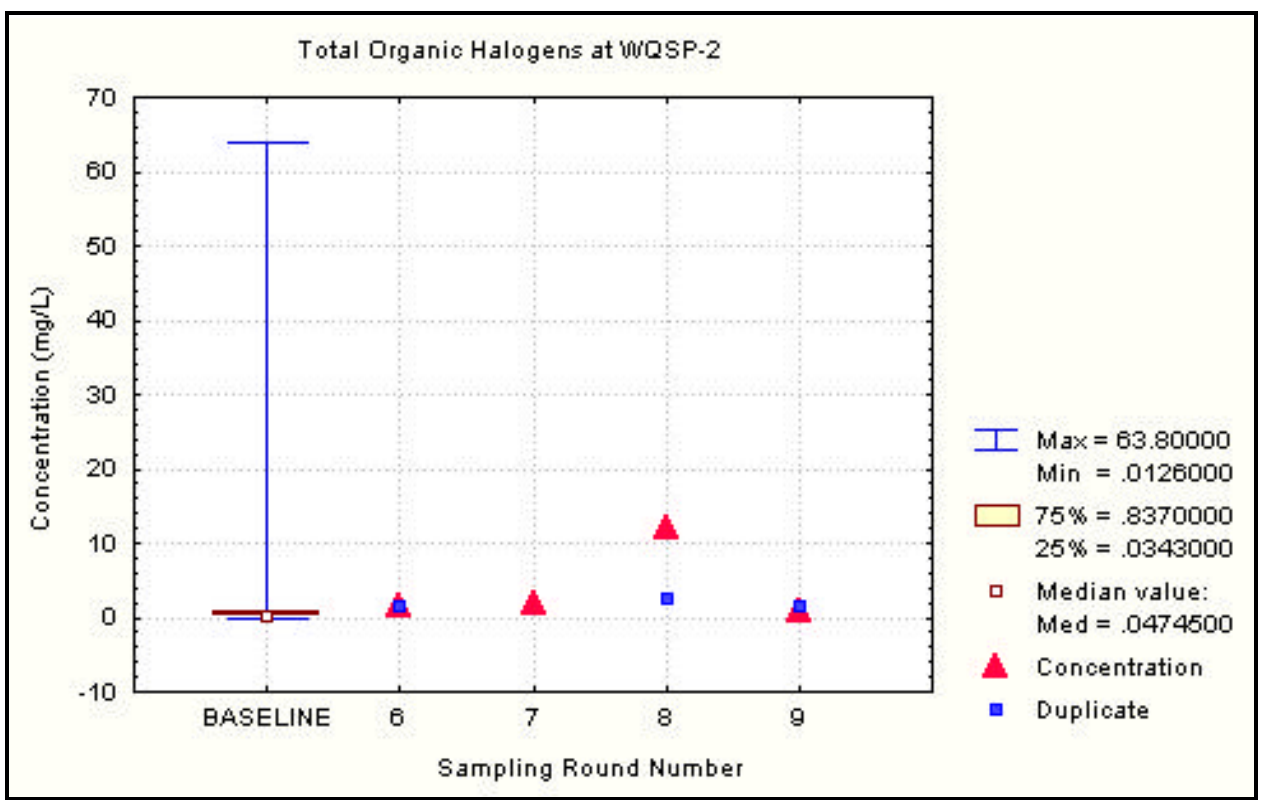

Figure 6.38 Time Trend Plot for Total Organic Halogens at WQSP-2 


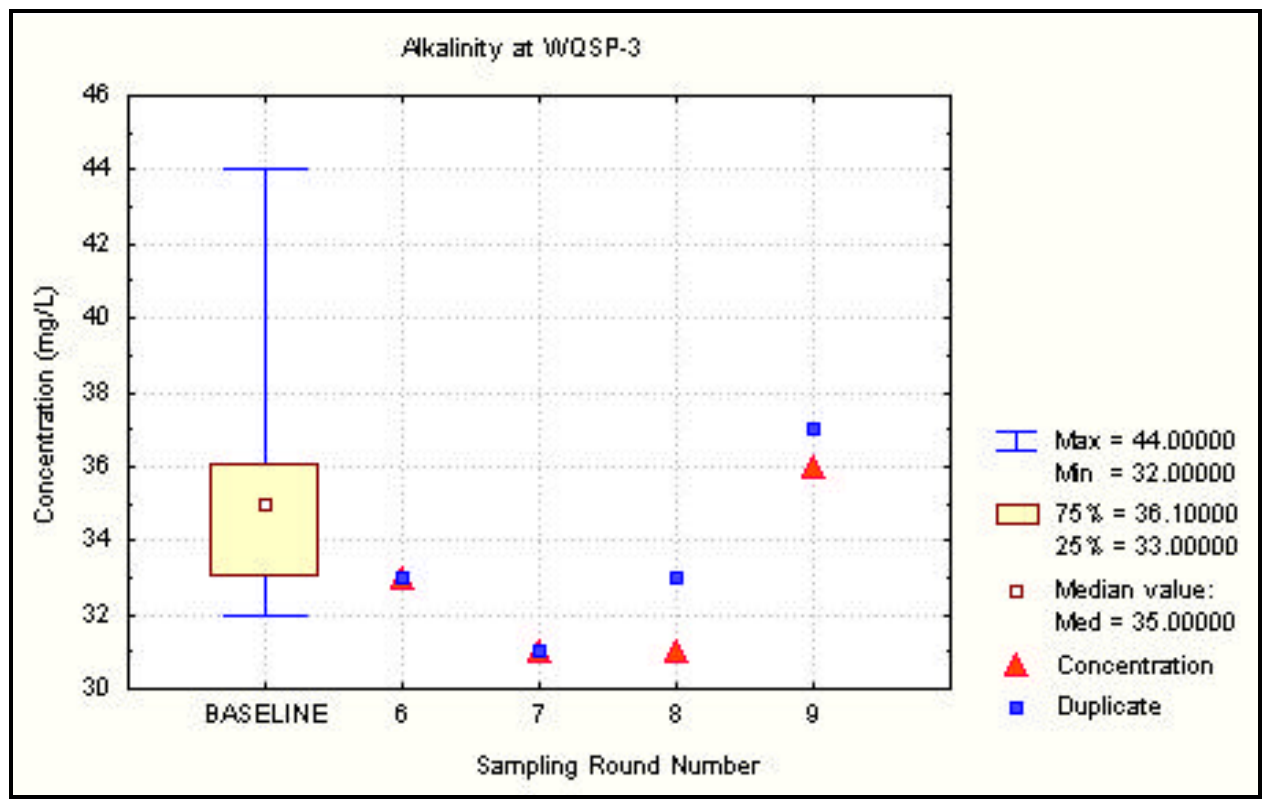

Figure 6.39 Time Trend Plot for Alkalinity at WQSP-3

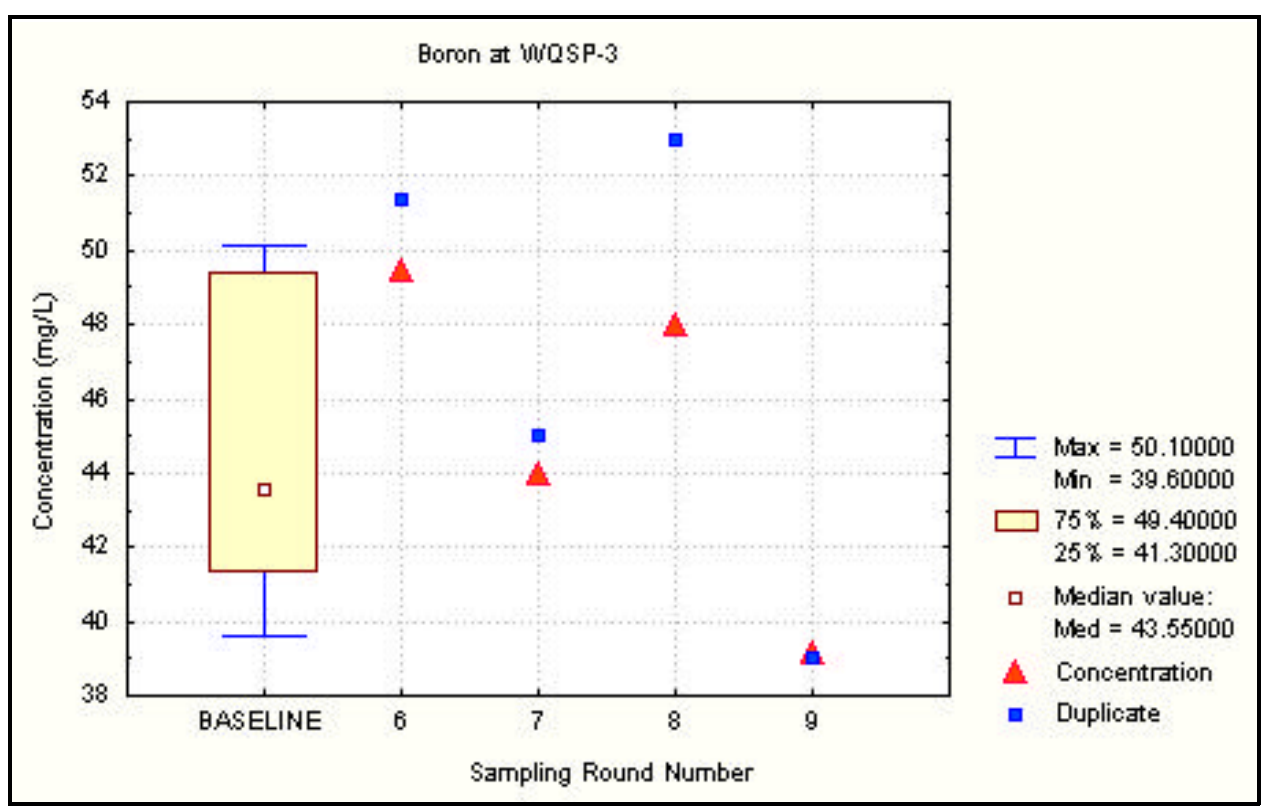

Figure 6.40 Time Trend Plot for Boron at WQSP-3 


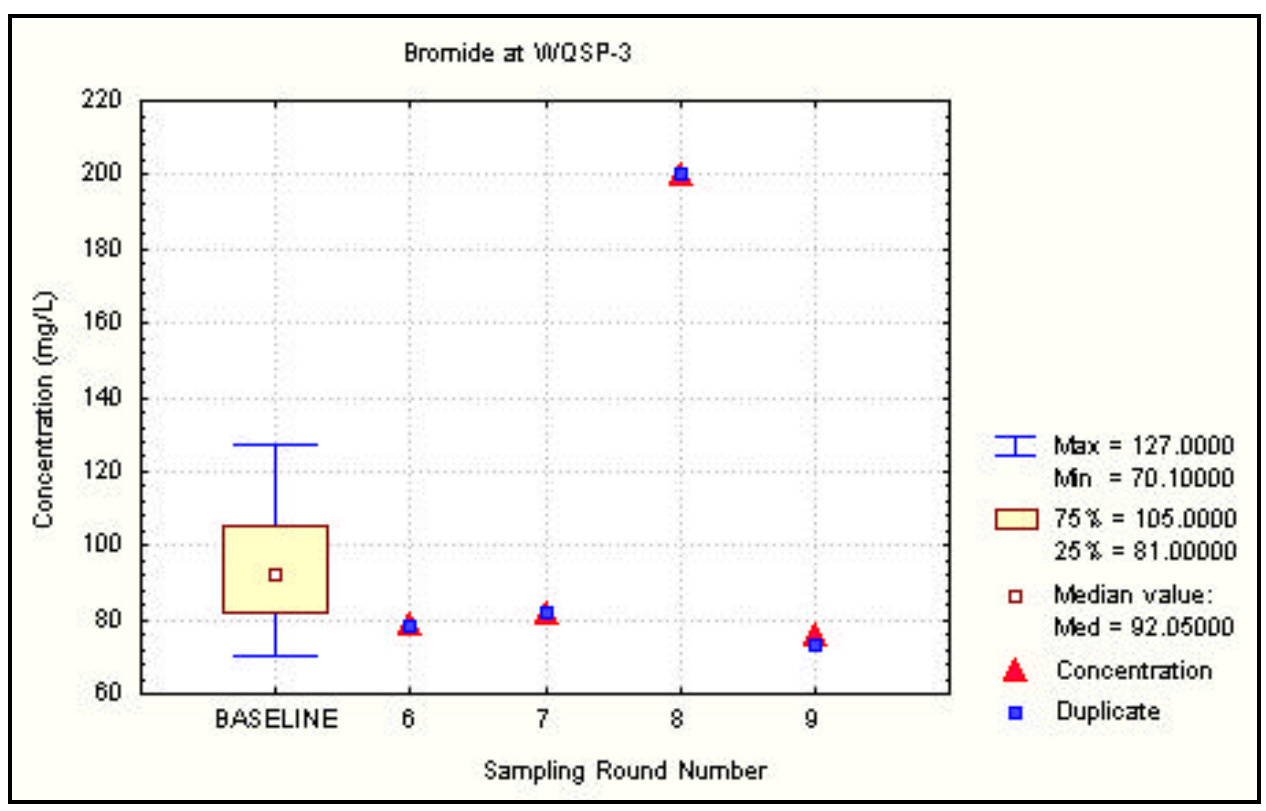

Figure 6.41 Time Trend Plot for Bromide at WQSP-3

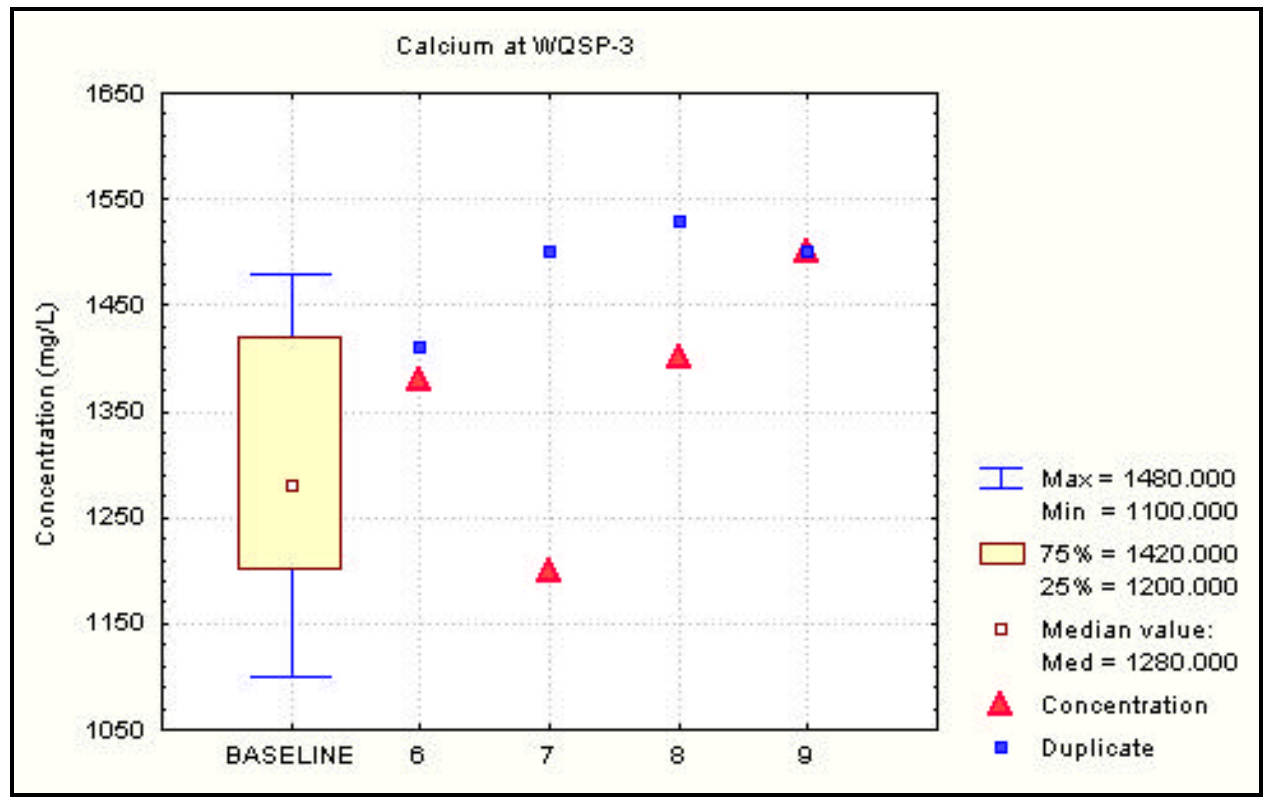

Figure 6.42 Time Trend Plot for Calcium at WQSP-3 


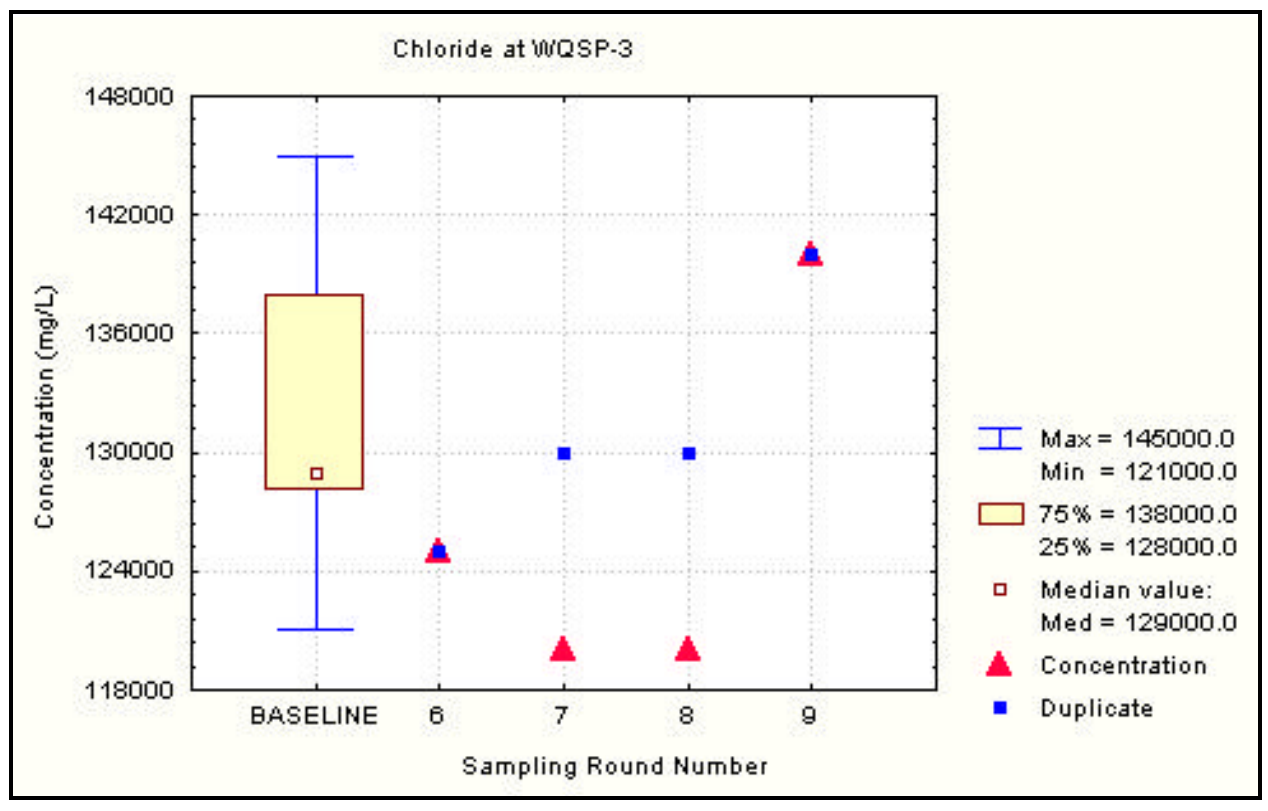

Figure 6.43 Time Trend Plot for Chloride at WQSP-3

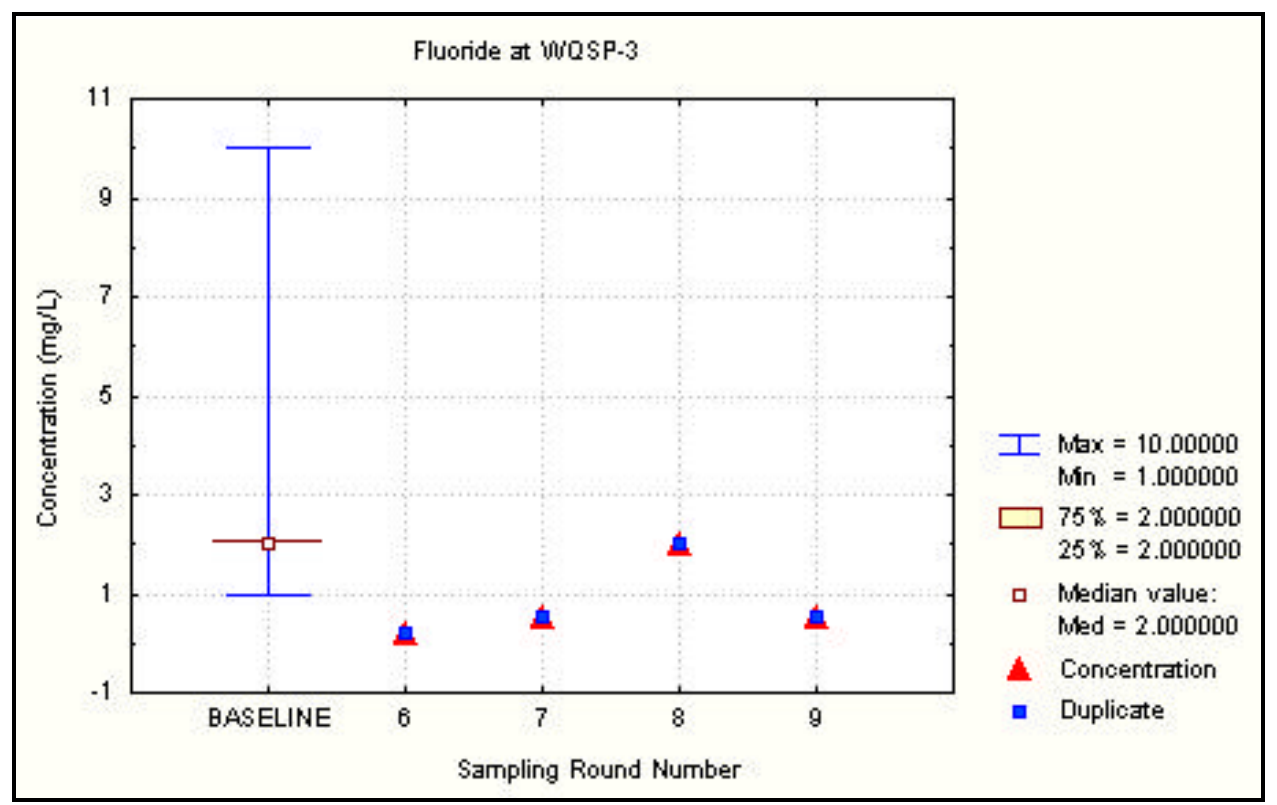

Figure 6.44 Time Trend Plot for Fluoride at WQSP-3 


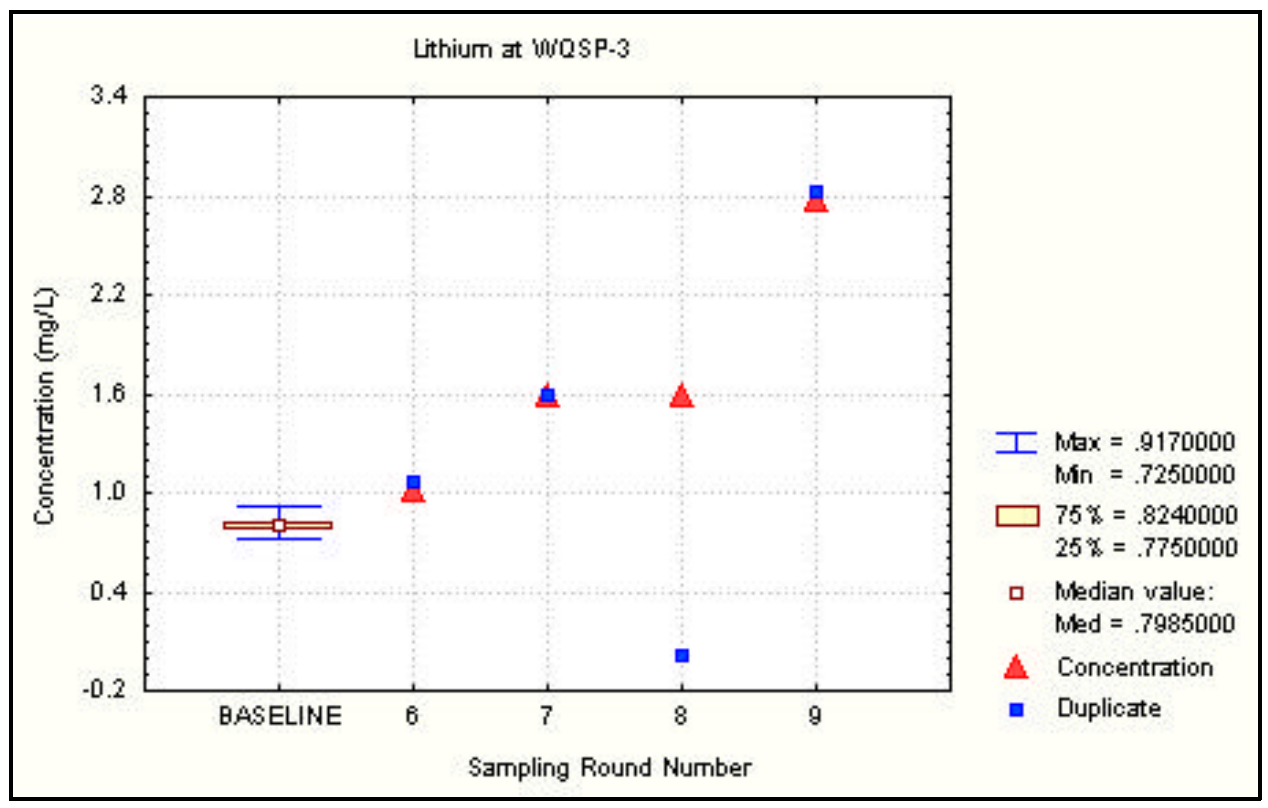

Figure 6.45 Time Trend Plot for Lithium at WQSP-3

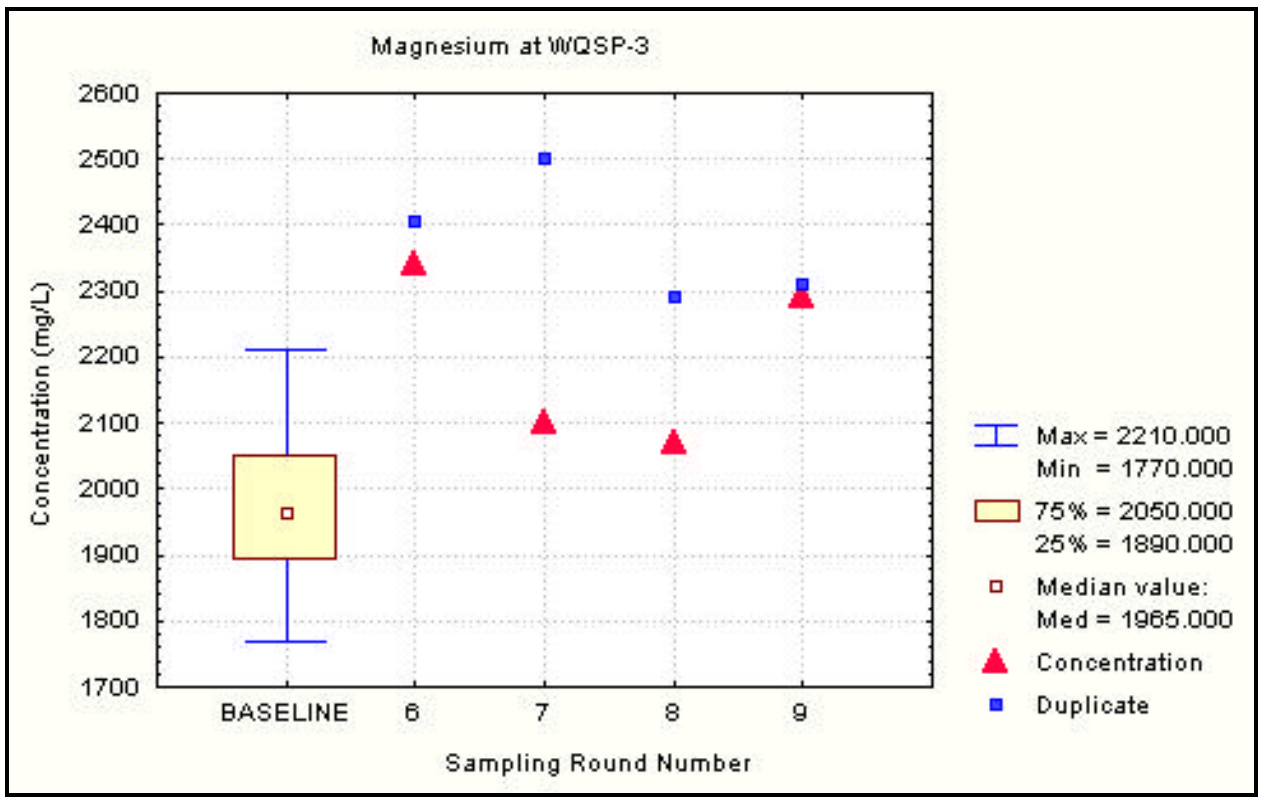

Figure 6.46 Time Trend Plot for Magnesium at WQSP-3 


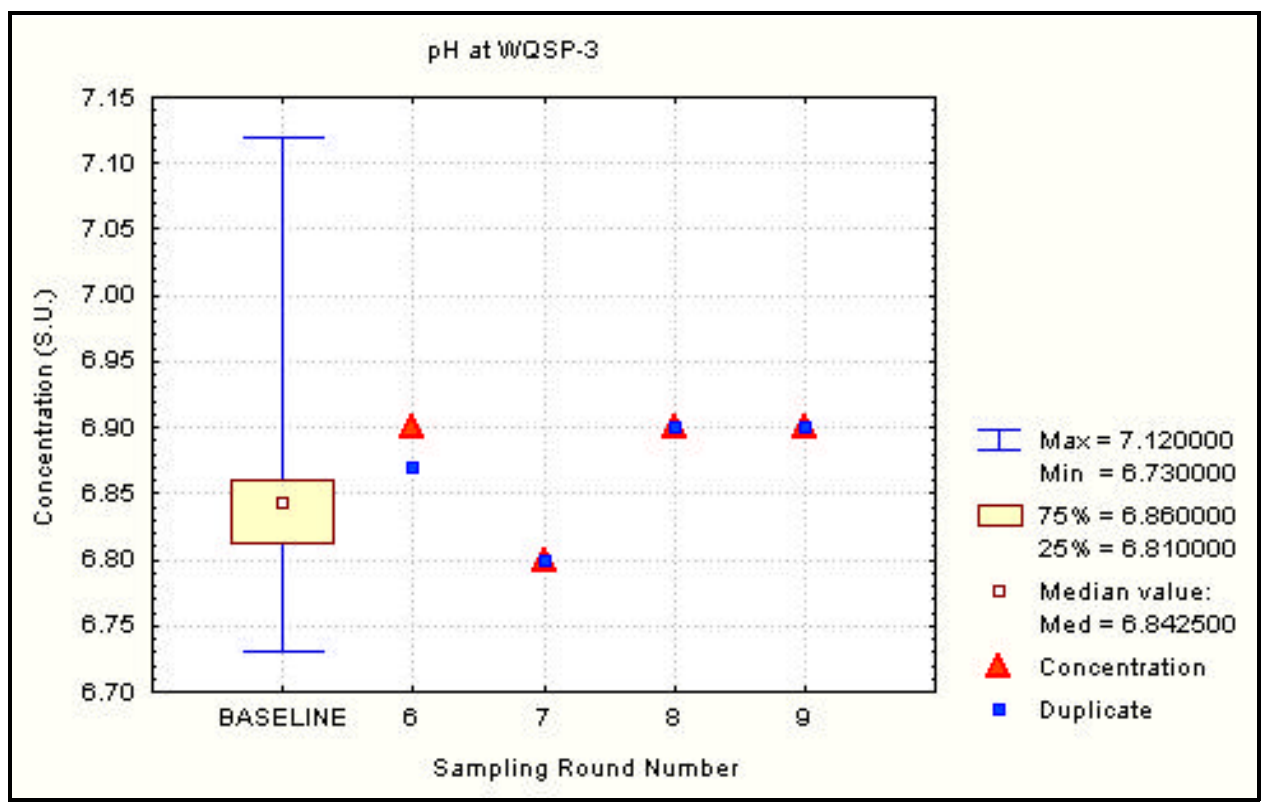

Figure 6.47 Time Trend Plot for $\mathrm{pH}$ at WQSP-3

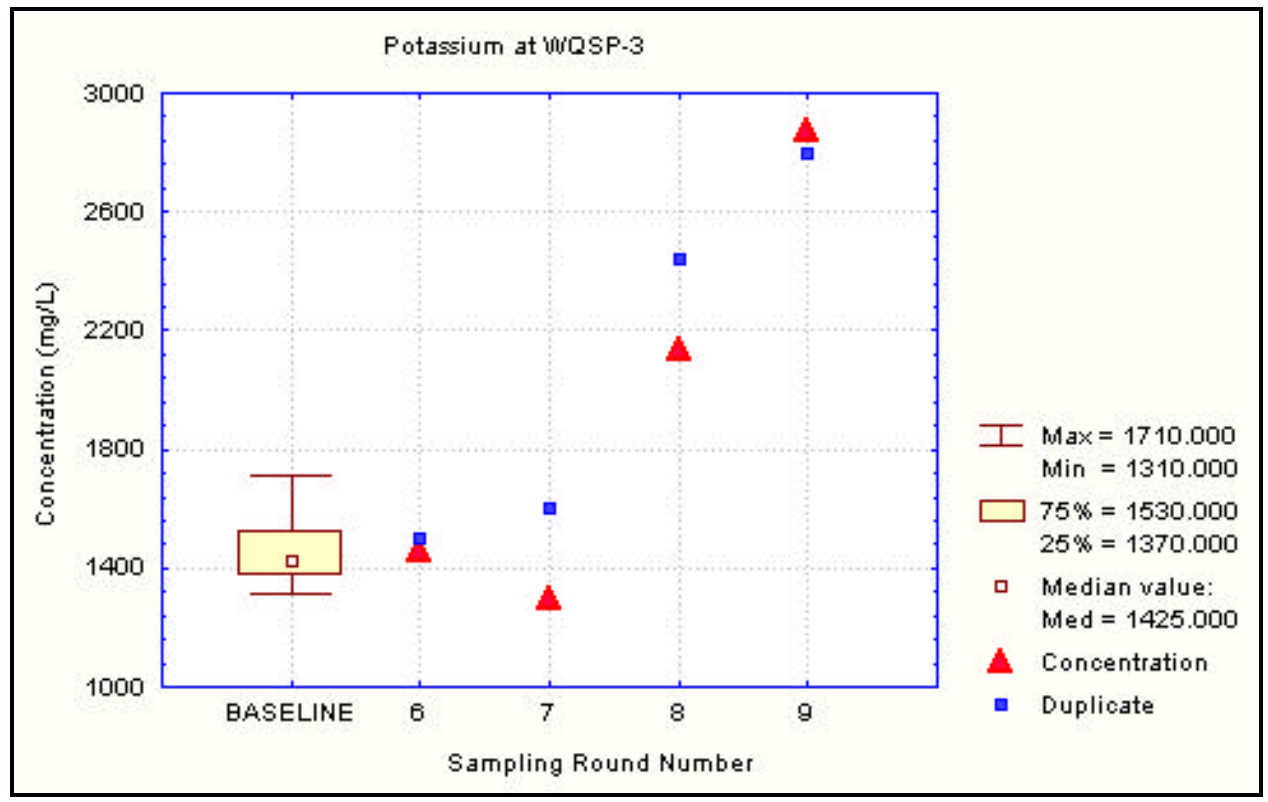

Figure 6.48 Time Trend Plot for Potassium at WQSP-3 


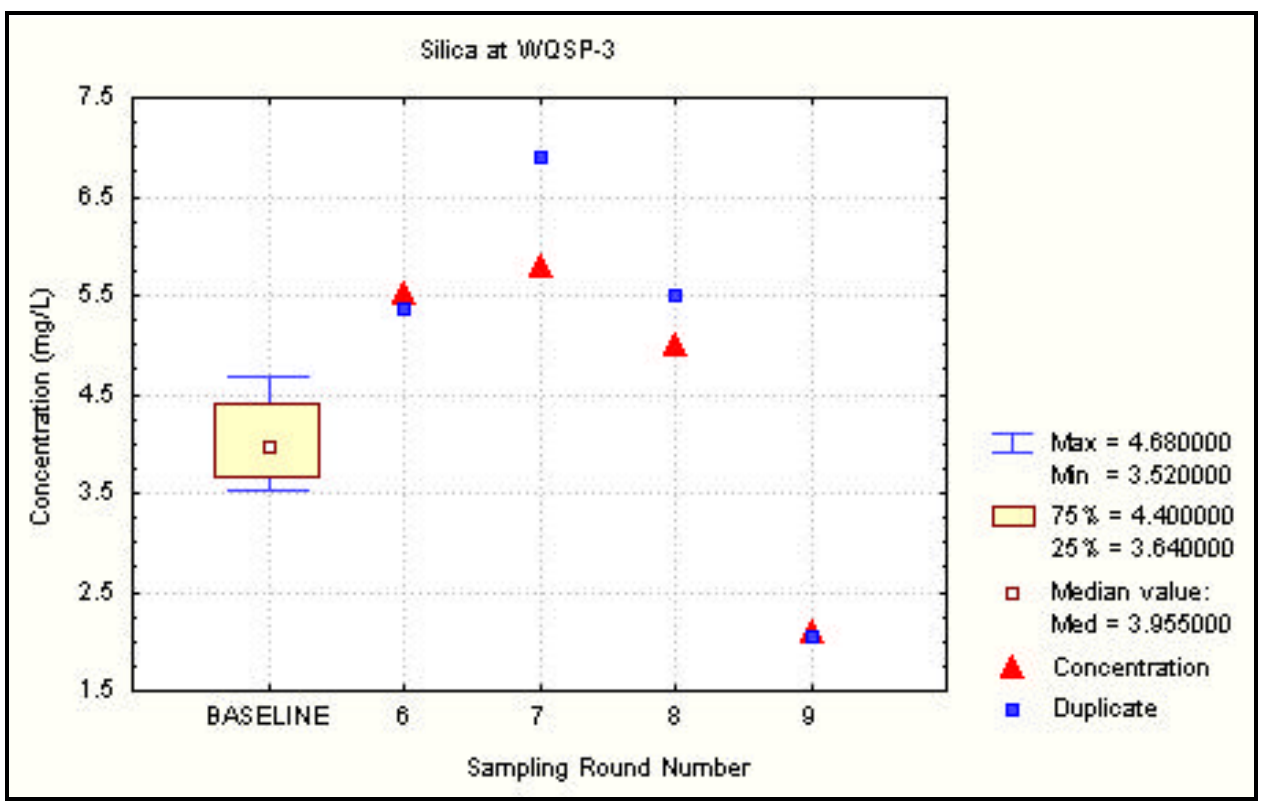

Figure 6.49 Time Trend Plot for Silica at WQSP-3

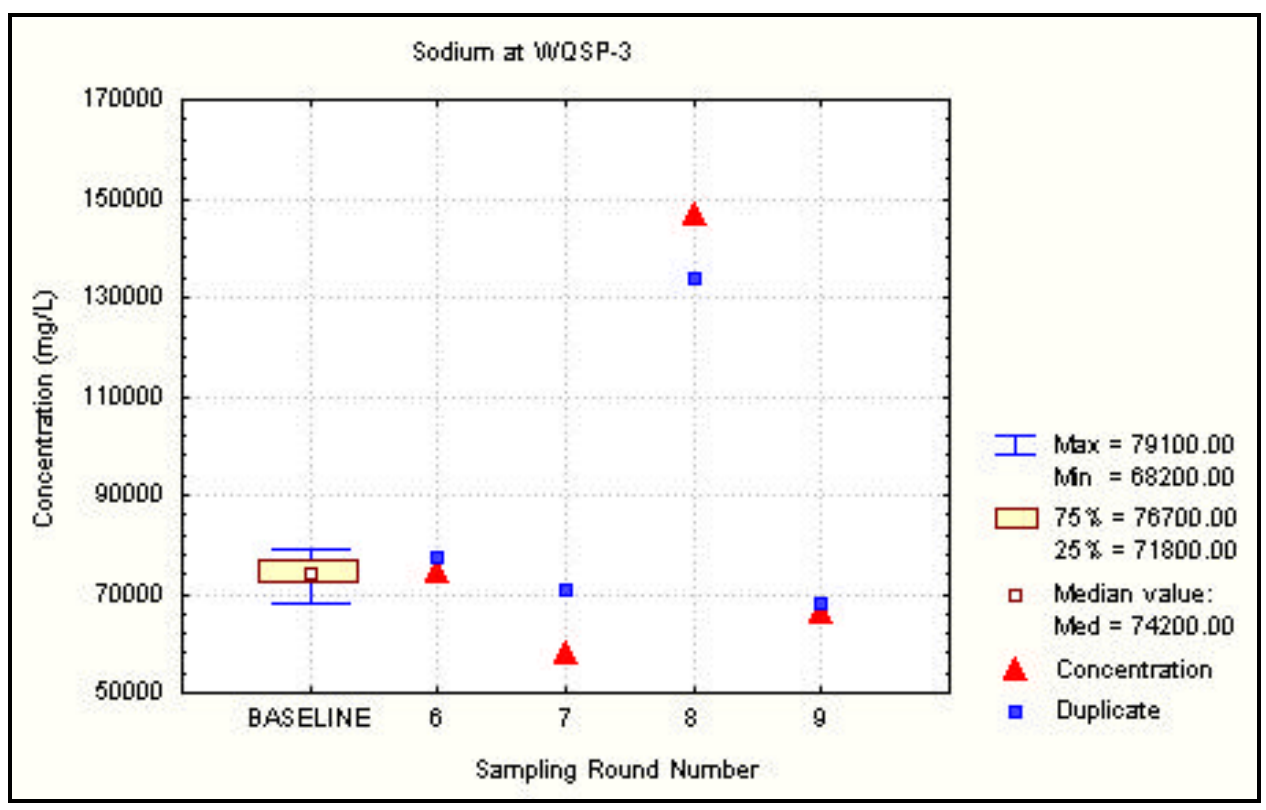

Figure 6.50 Time Trend Plot for Sodium at WQSP-3 


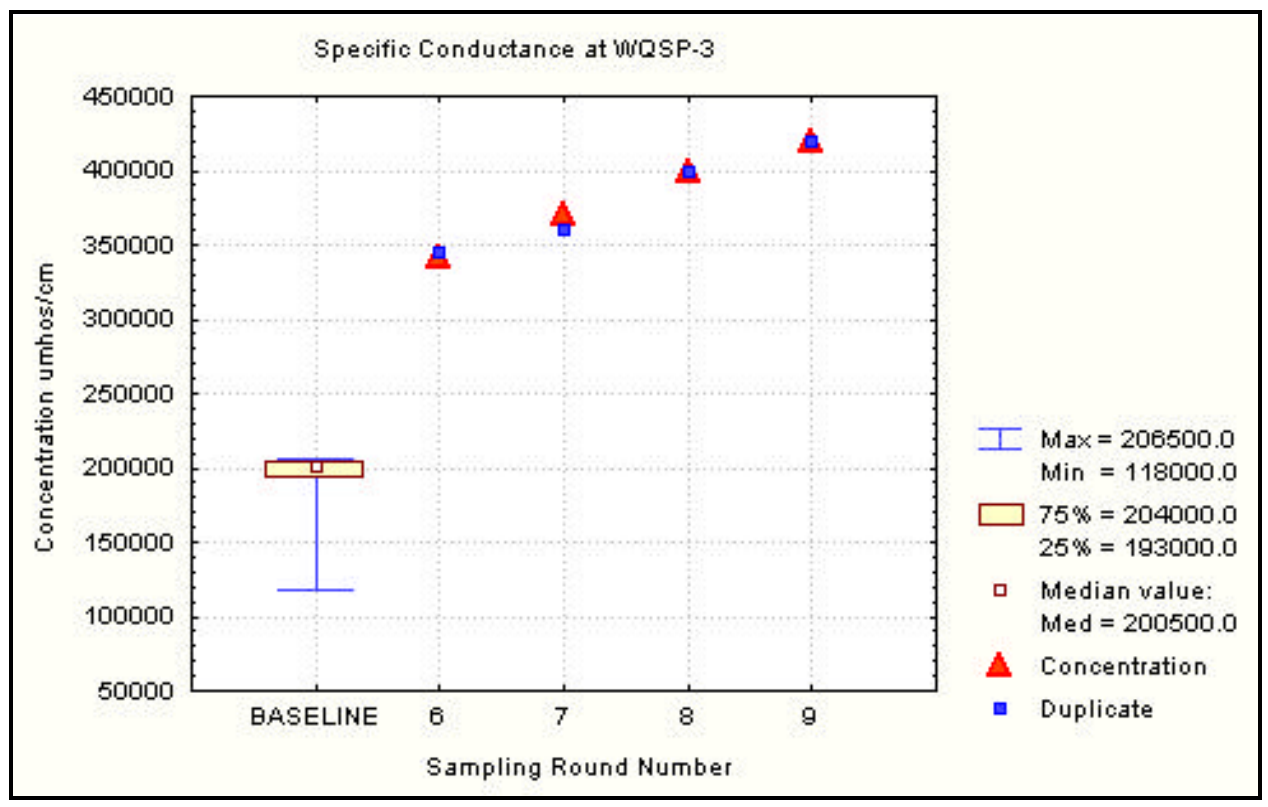

Figure 6.51 Time Trend Plot for Specific Conductance at WQSP-3

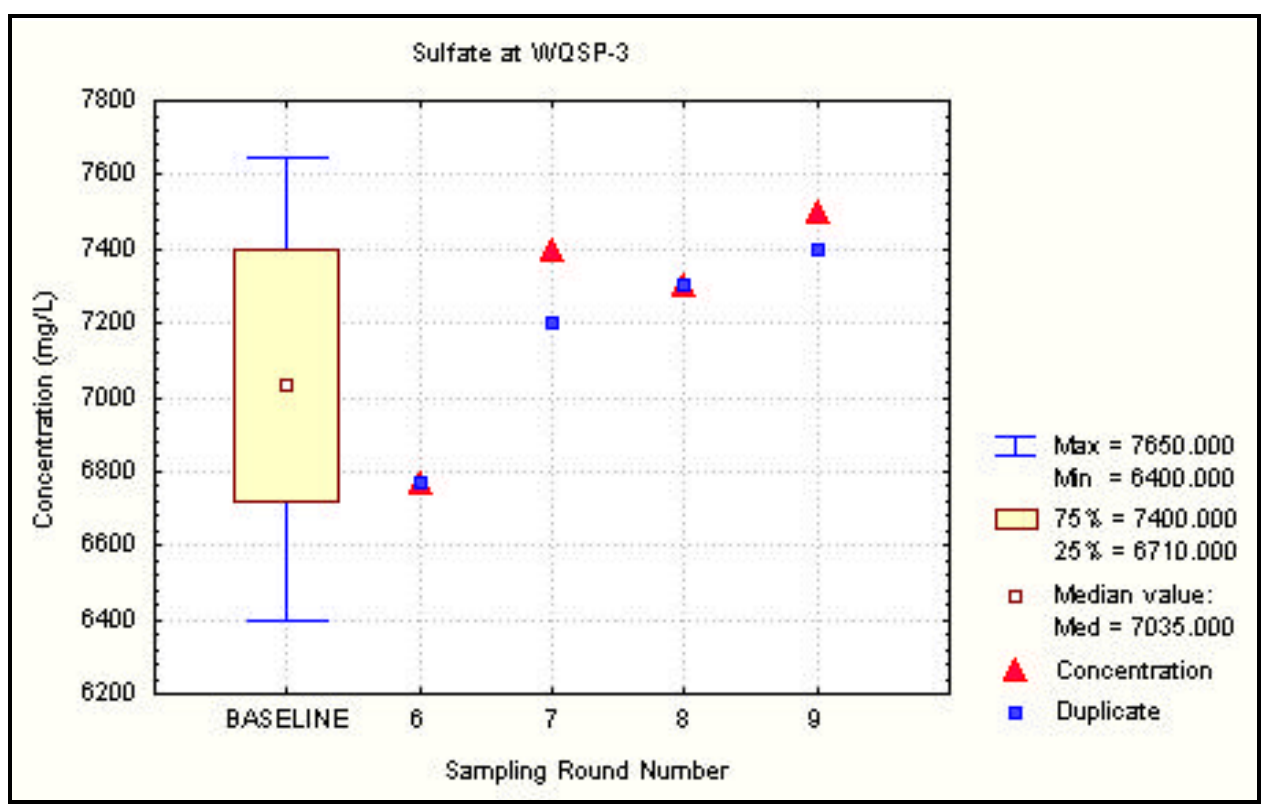

Figure 6.52 Time Trend Plot for Sulfate at WQSP-3 


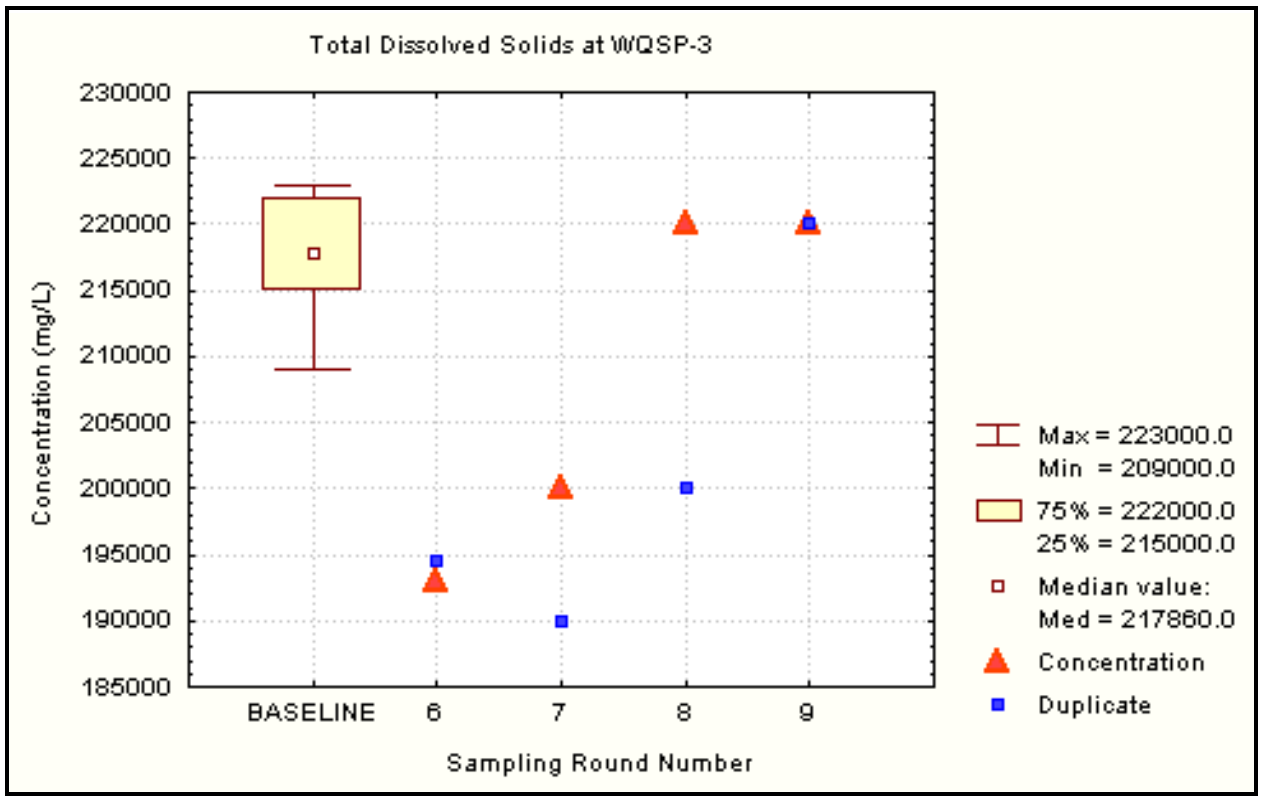

Figure 6.53 Time Trend Plot for Total Dissolved Solids at WQSP-3

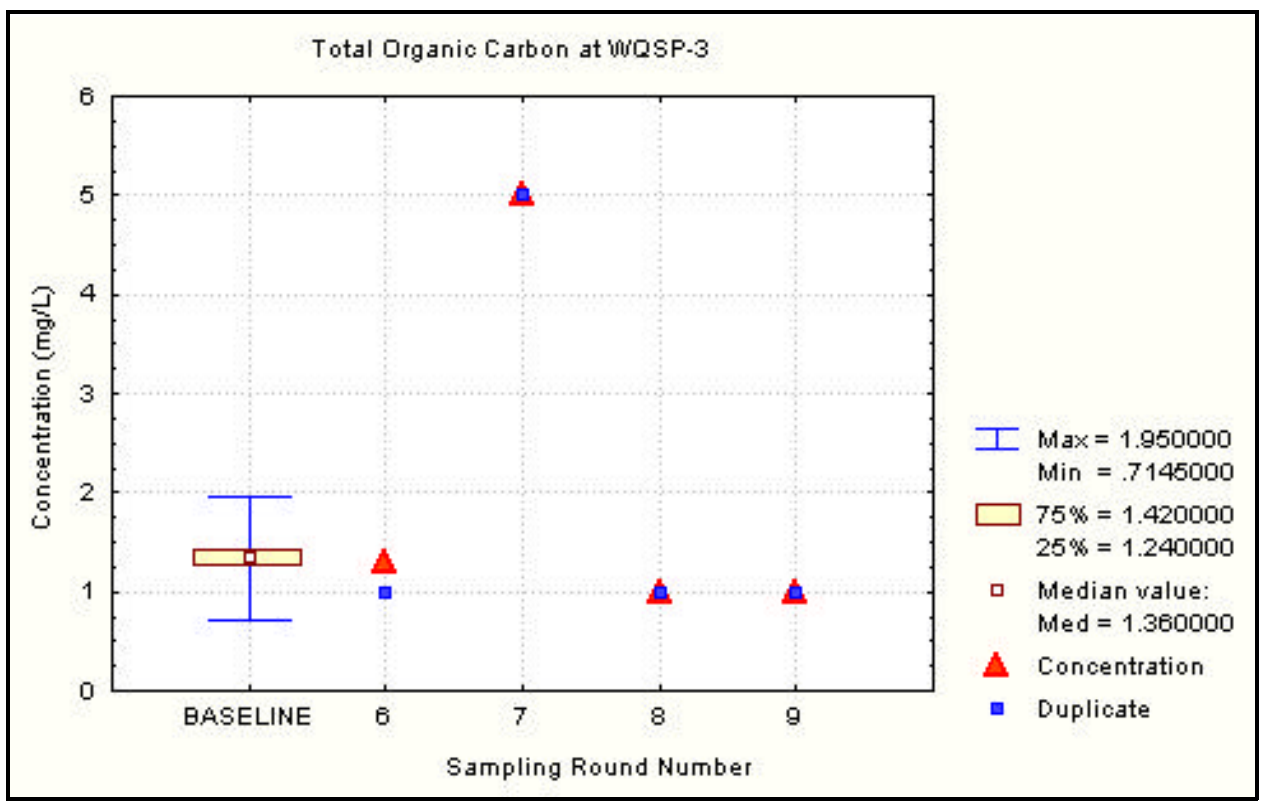

Figure 6.54 Time Trend Plot for Total Organic Carbon at WQSP-3 


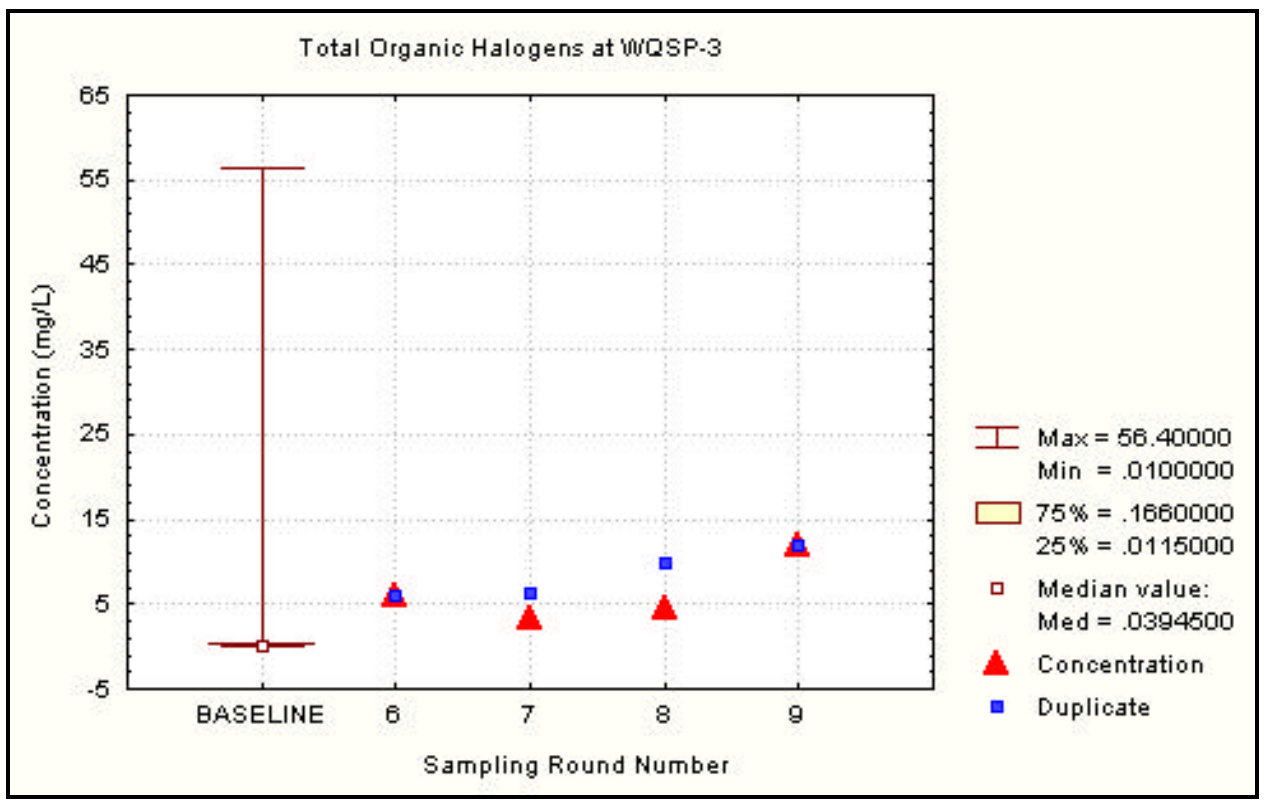

Figure 6.55 Time Trend Plot for Total Organic Halogens at WQSP-3

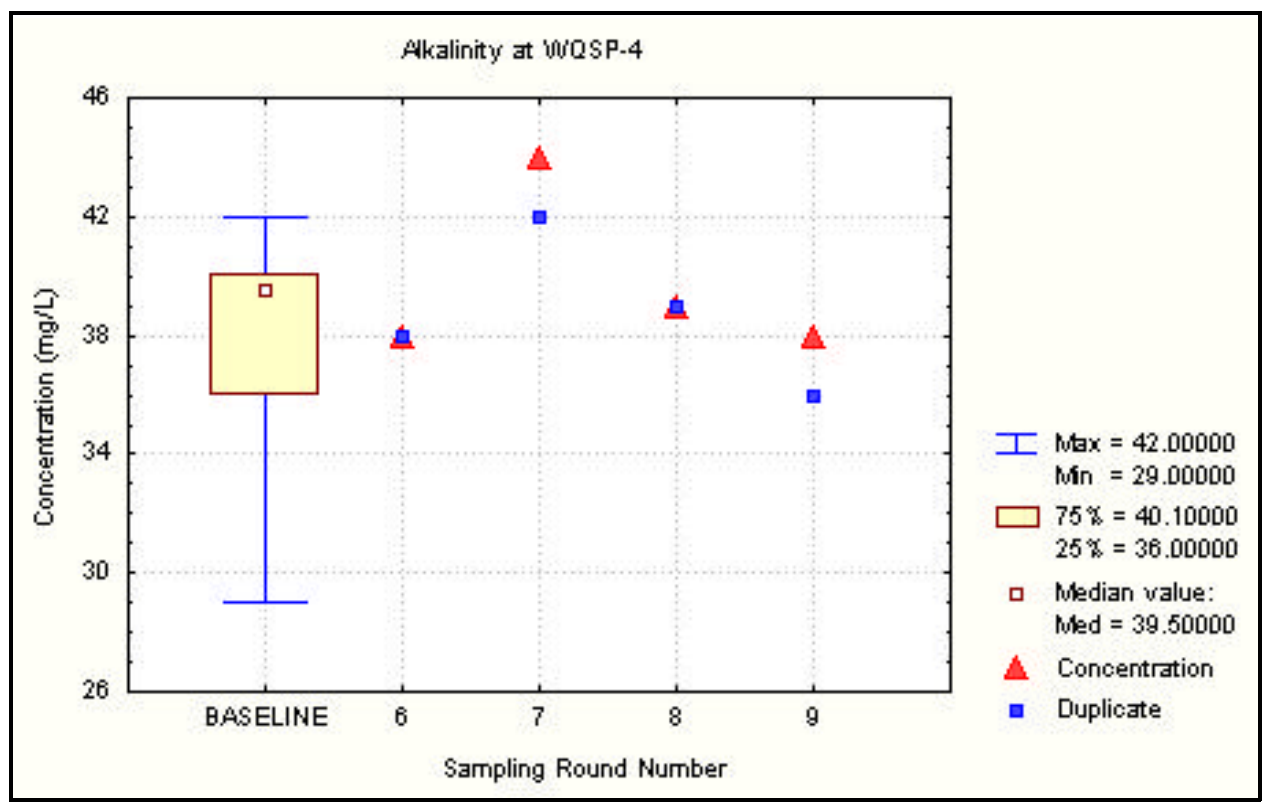

Figure 6.56 Time Trend Plot for Alkalinity at WQSP-4 


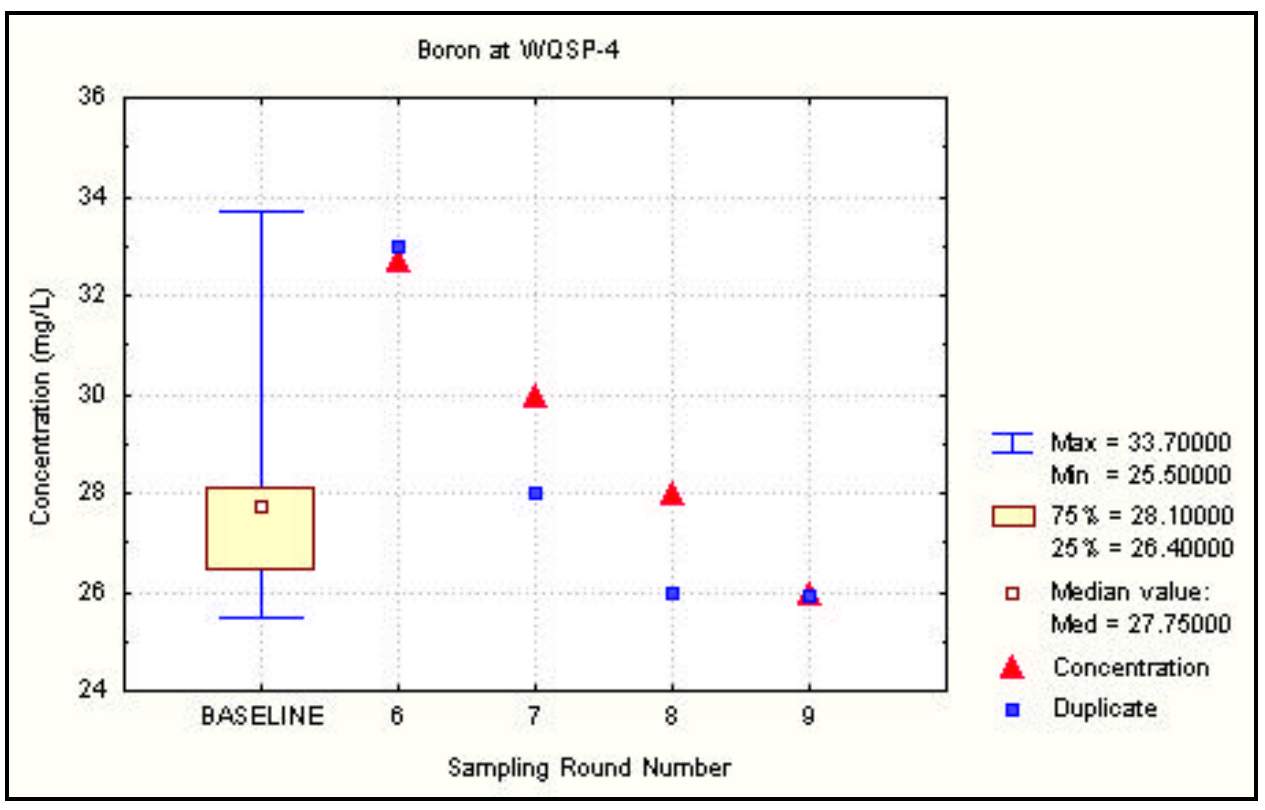

Figure 6.57 Time Trend Plot for Boron at WQSP-4

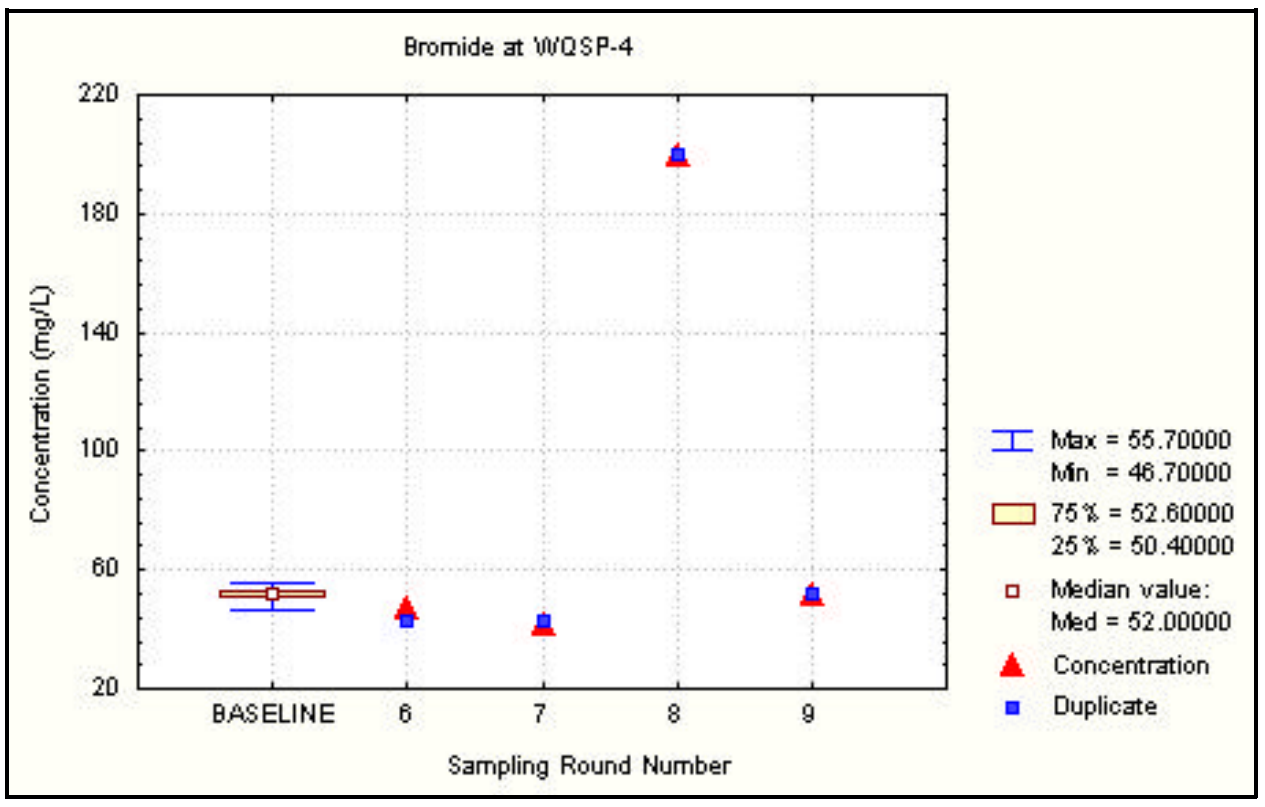

Figure 6.58 Time Trend Plot for Bromide at WQSP-4 


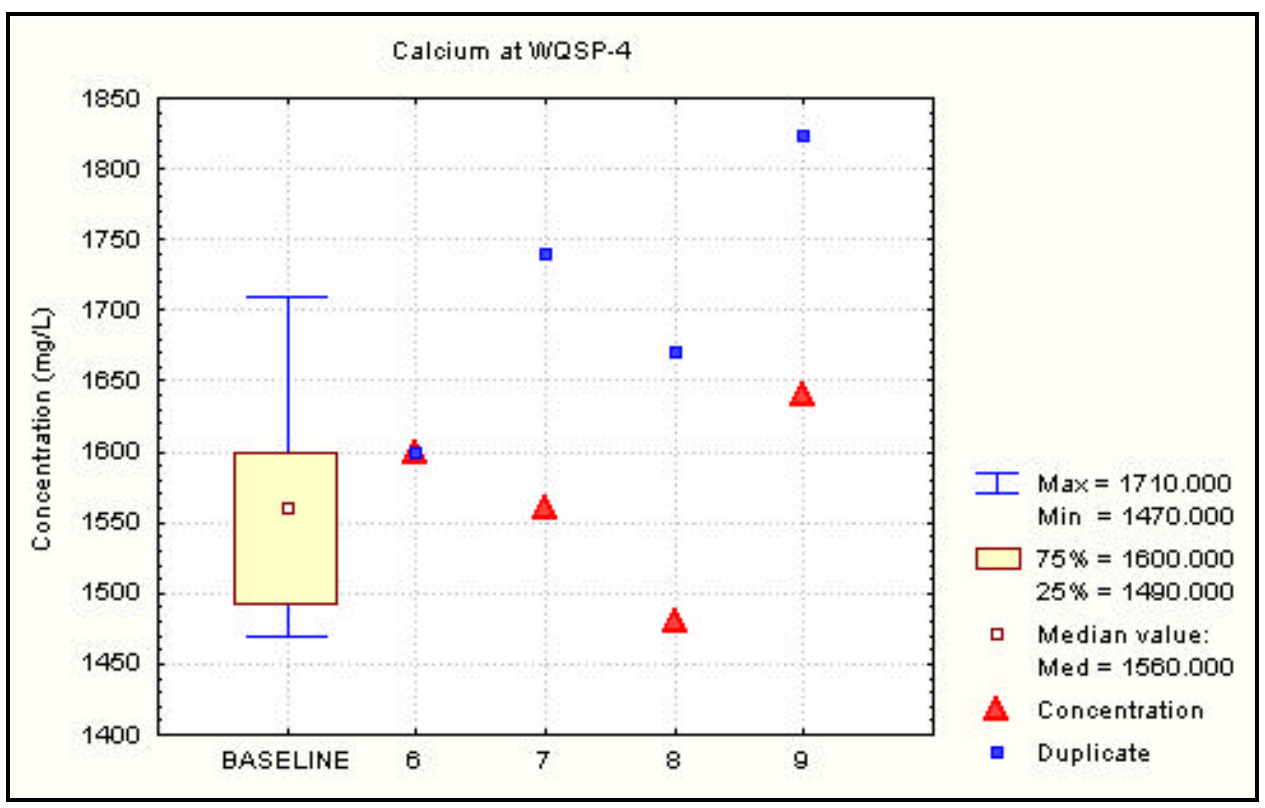

Figure 6.59 Time Trend Plot for Calcium at WQSP-4

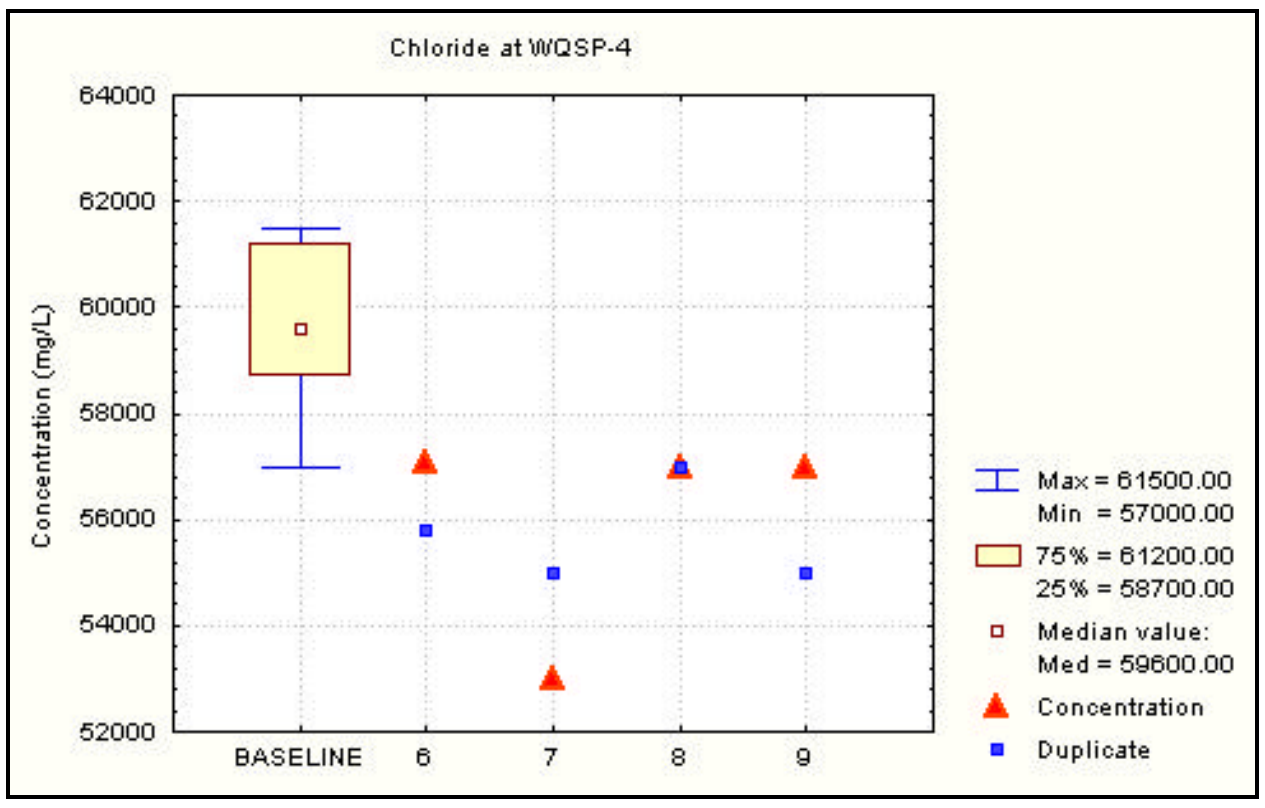

Figure 6.60 Time Trend Plot for Chloride at WQSP-4 


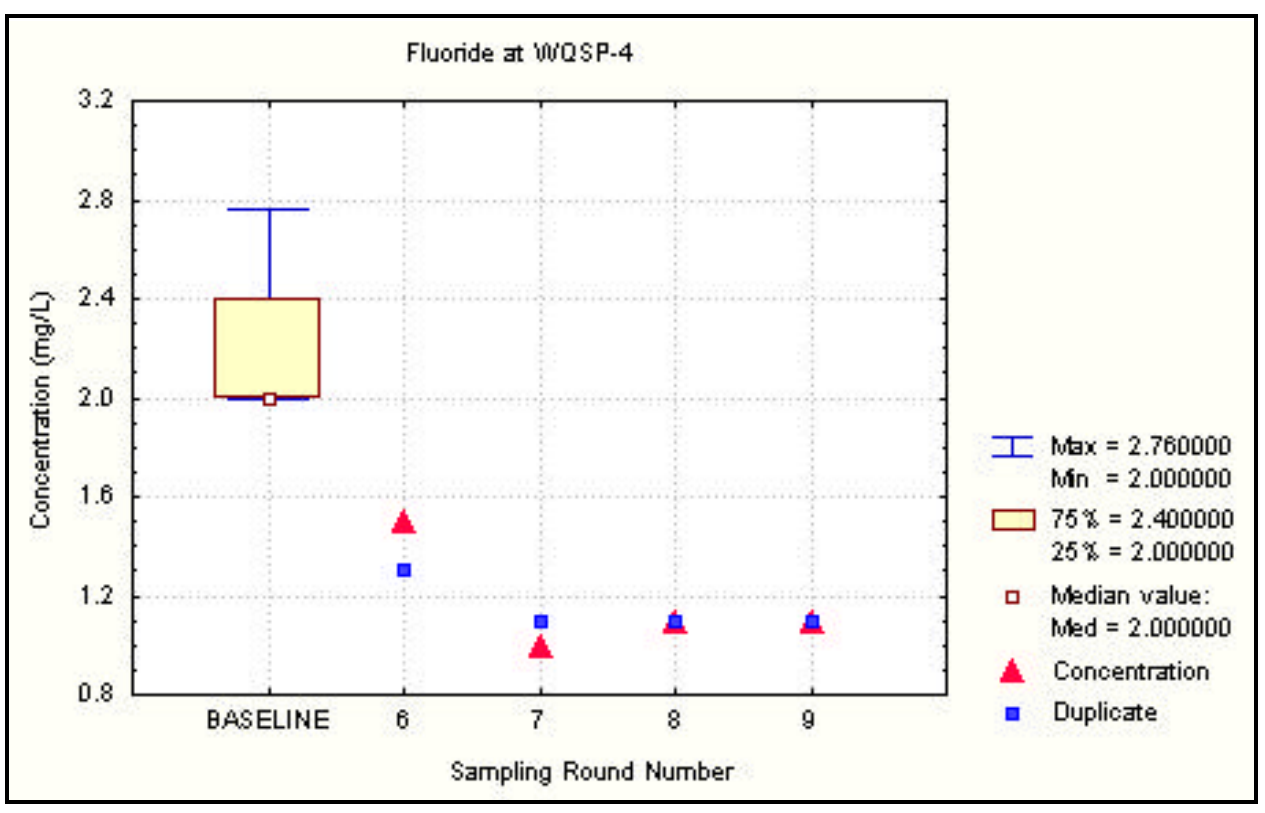

Figure 6.61 Time Trend Plot for Fluoride at WQSP-4

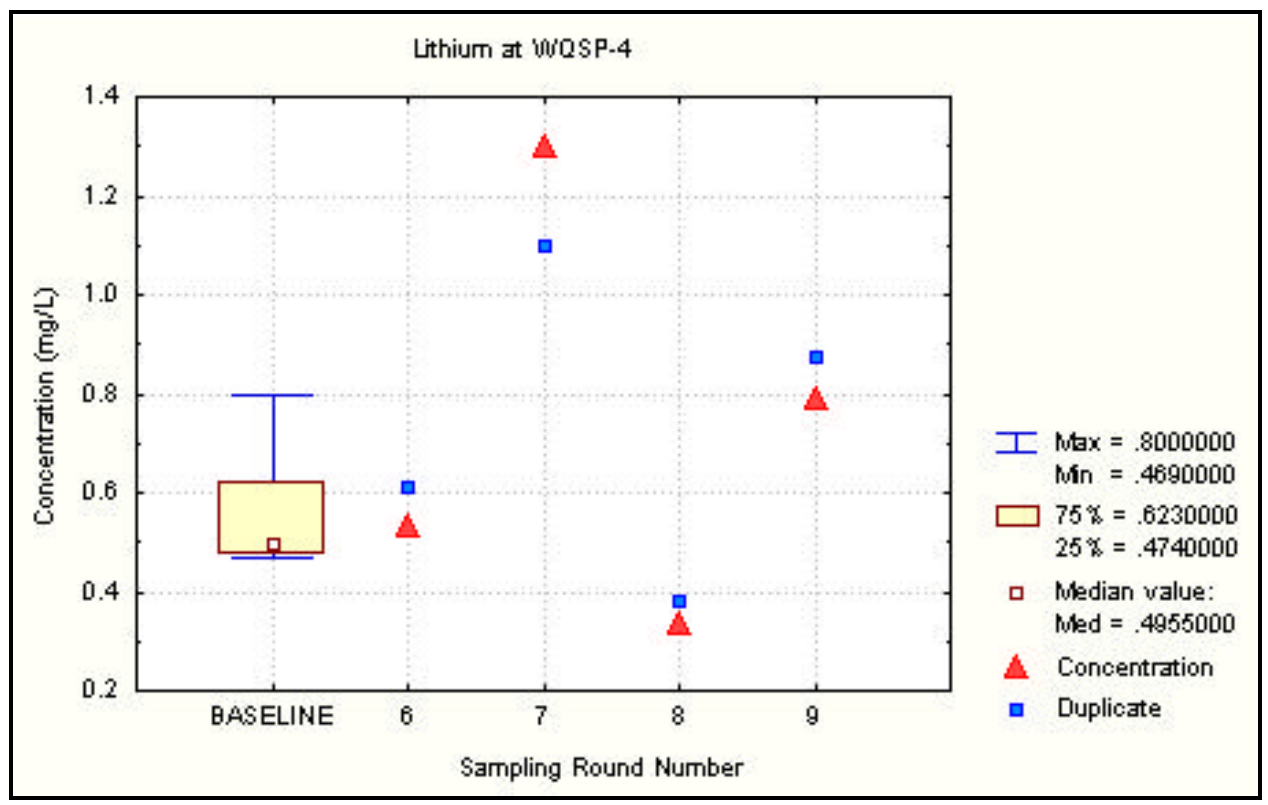

Figure 6.62 Time Trend Plot for Lithium at WQSP-4 


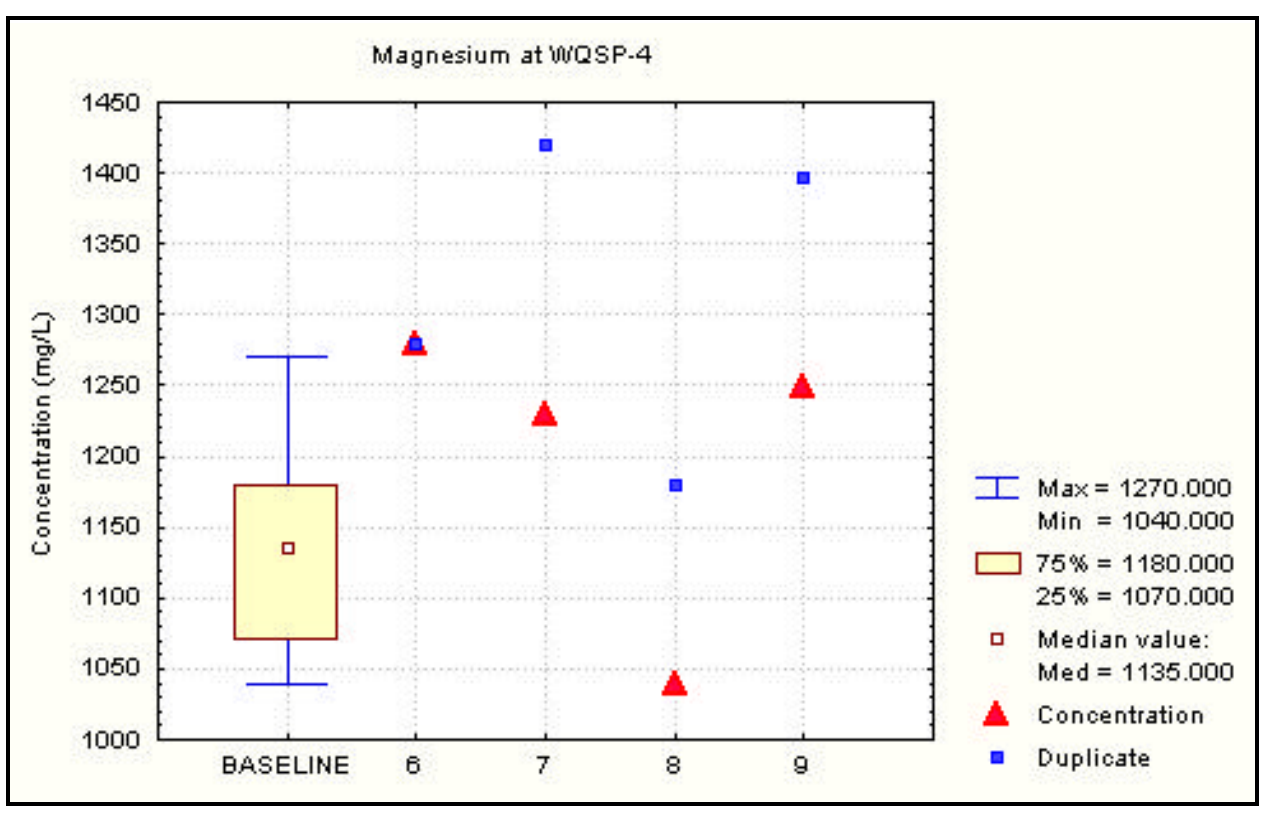

Figure 6.63 Time Trend Plot for Magnesium at WQSP-4

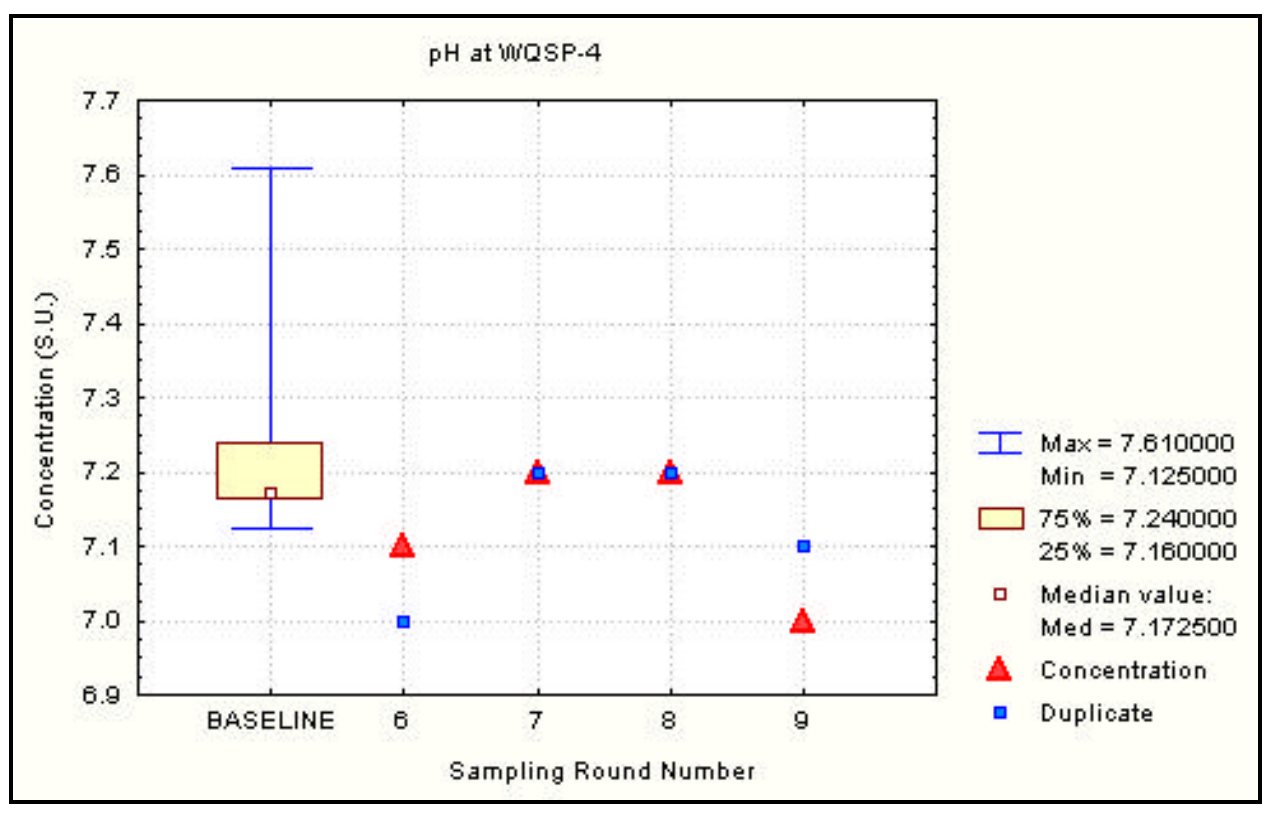

Figure 6.64 Time Trend Plot for $\mathrm{pH}$ at WQSP-4 


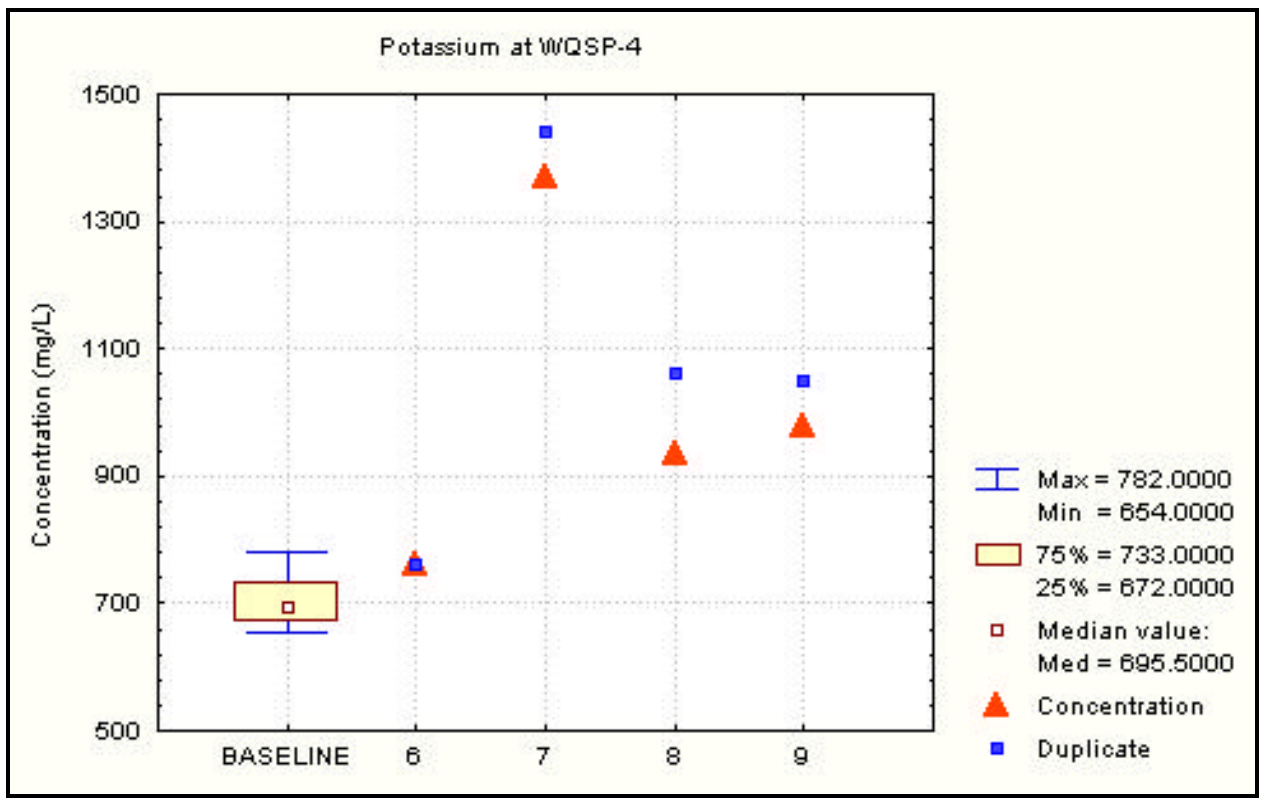

Figure 6.65 Time Trend Plot for Potassium at WQSP-4

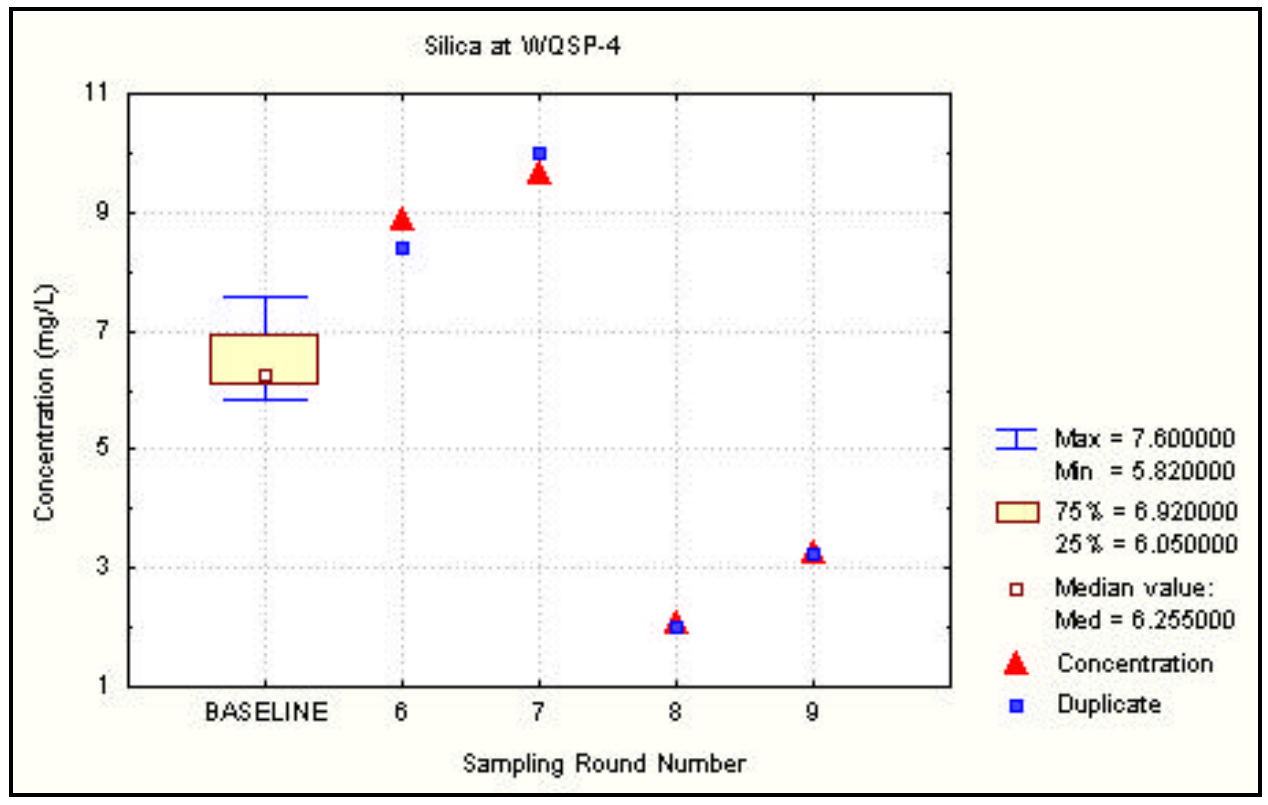

Figure 6.66 Time Trend Plot for Silica at WQSP-4 


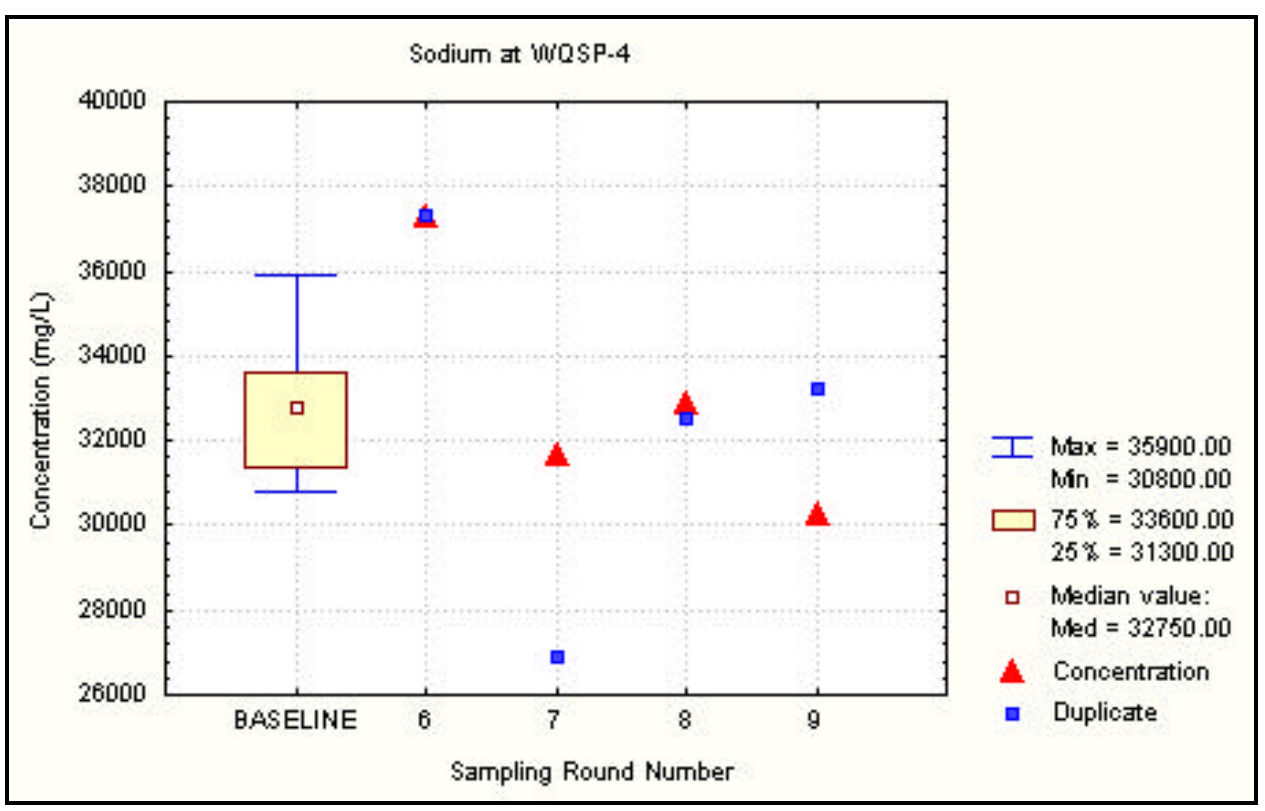

Figure 6.67 Time Trend Plot for Sodium at WQSP-4

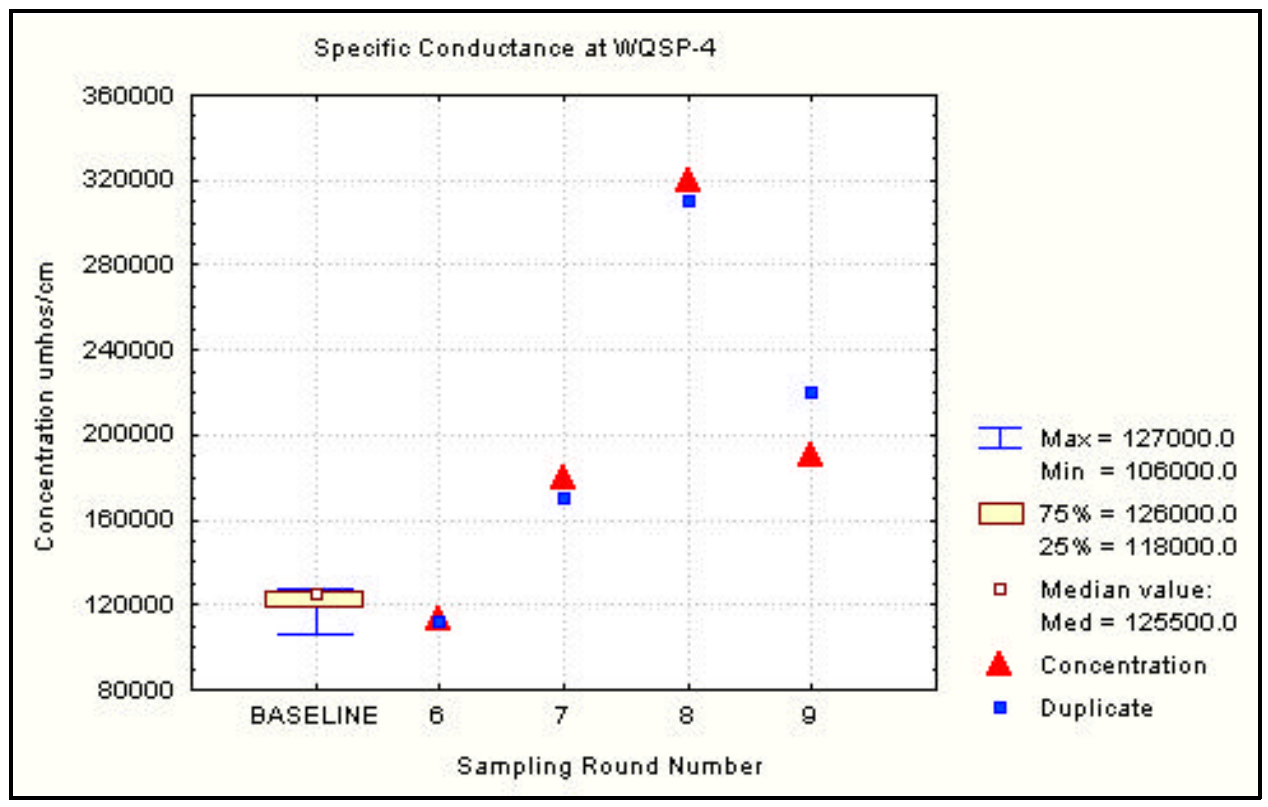

Figure 6.68 Time Trend Plot for Specific Conductance at WQSP-4 


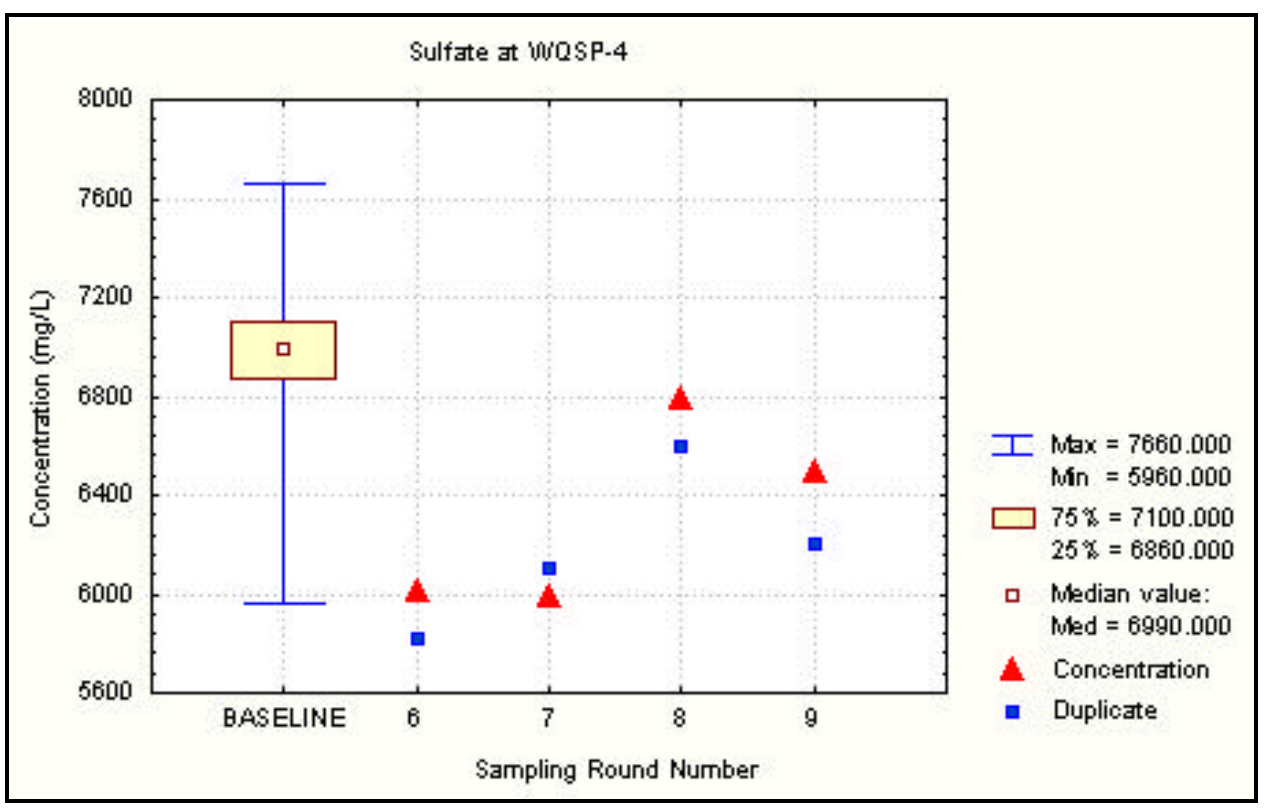

Figure 6.69 Time Trend Plot for Sulfate at WQSP-4

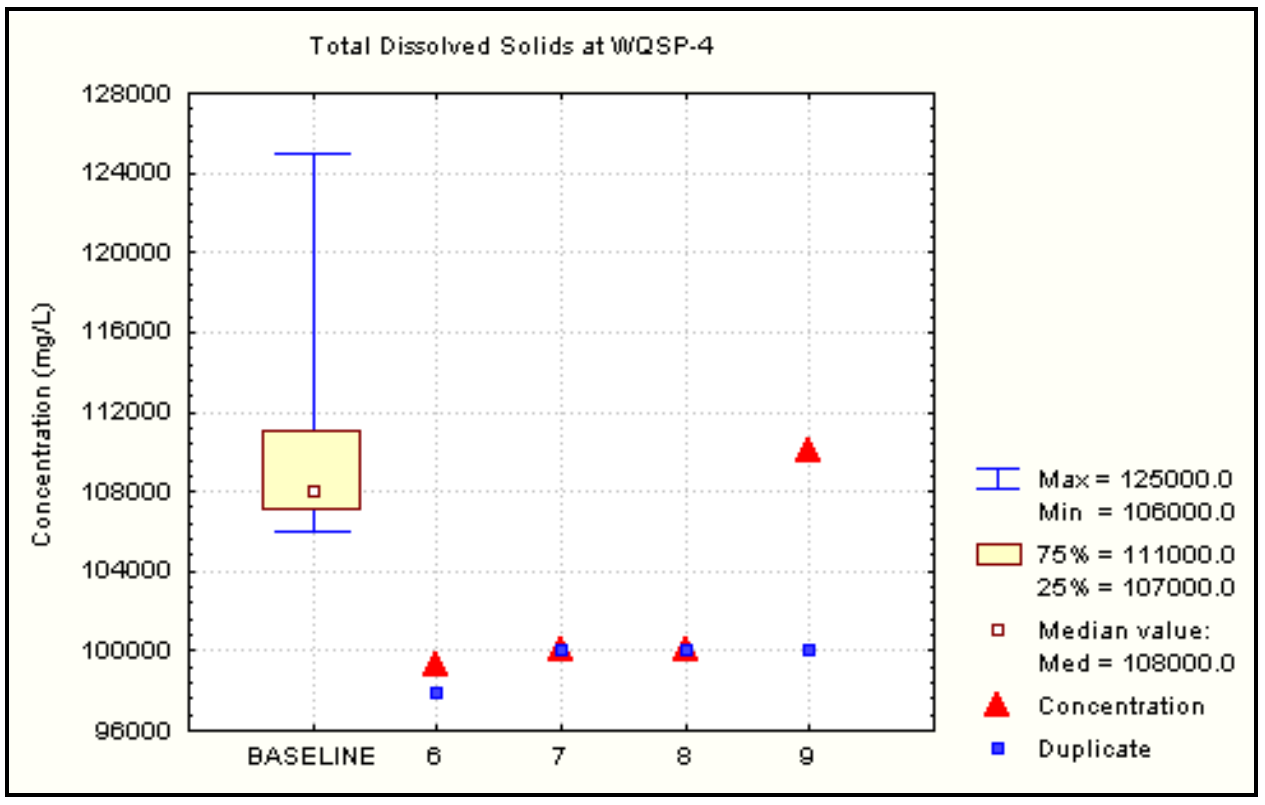

Figure 6.70 Time Trend Plot for Total Dissolved Solids at WQSP-4 


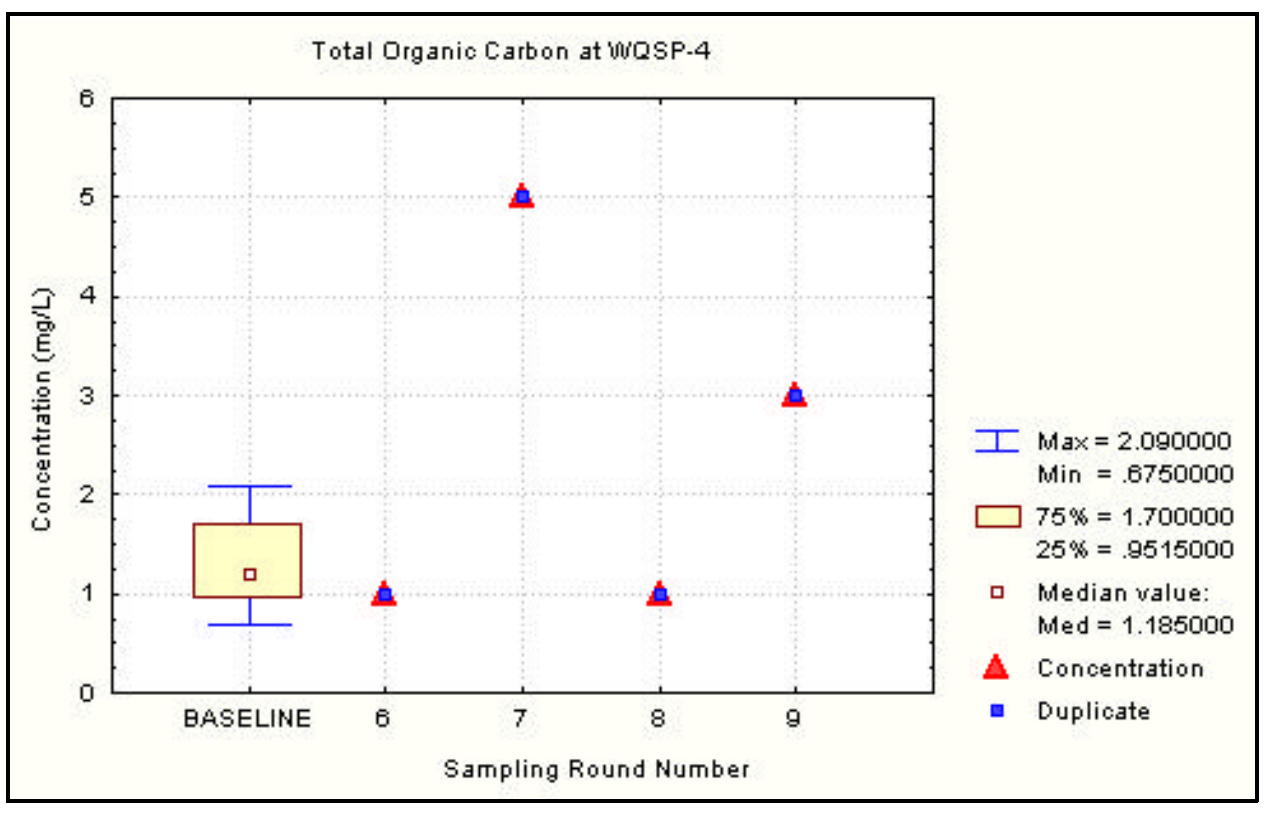

Figure 6.71 Time Trend Plot for Total Organic Carbon at WQSP-4

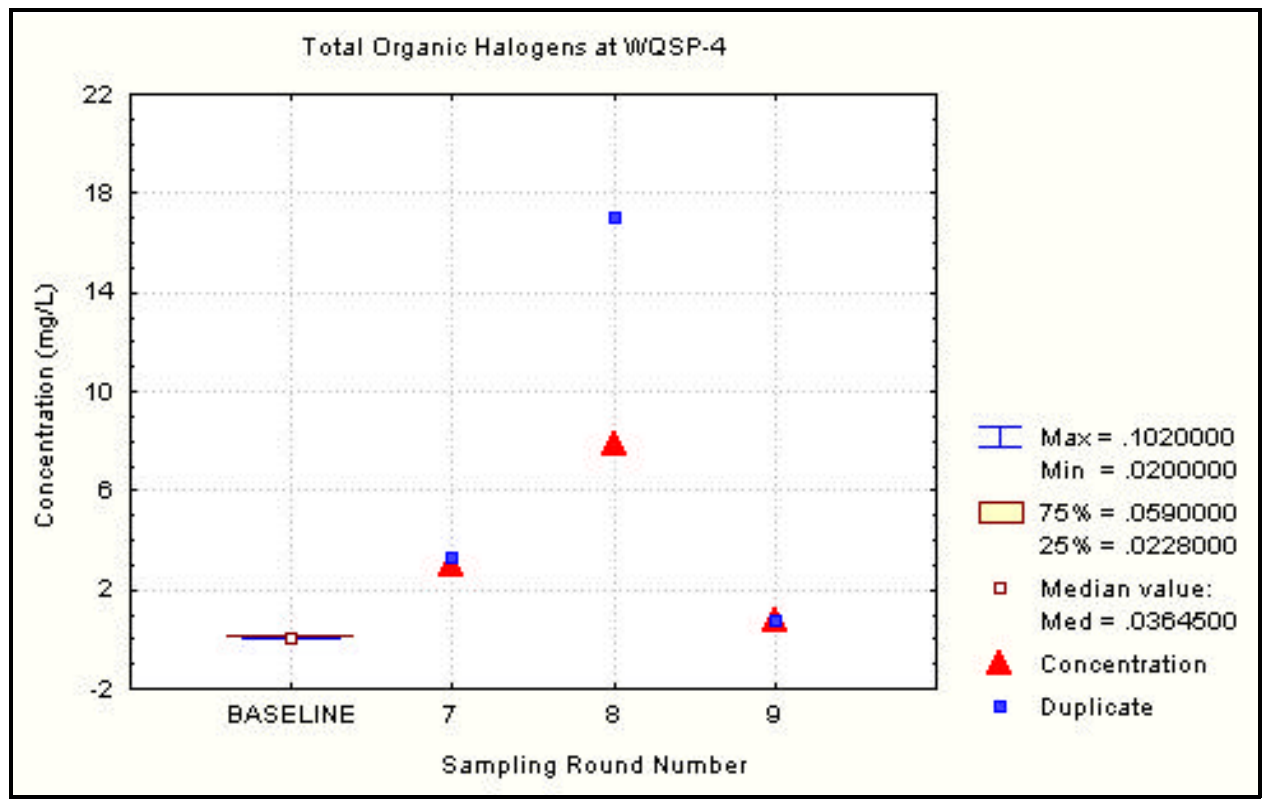

Figure 6.72 Time Trend Plot for Total Organic Halogens at WQSP-4 


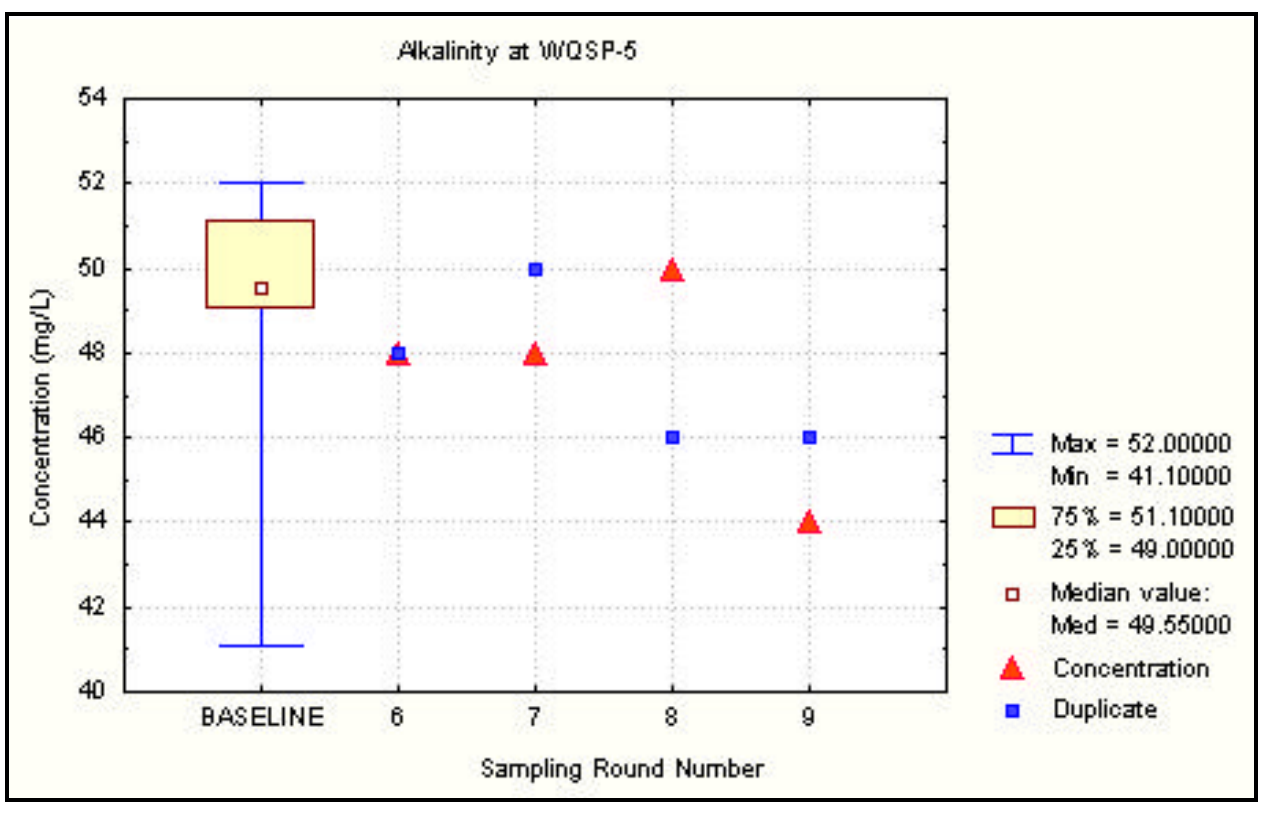

Figure 6.73 Time Trend Plot for Alkalinity at WQSP-5

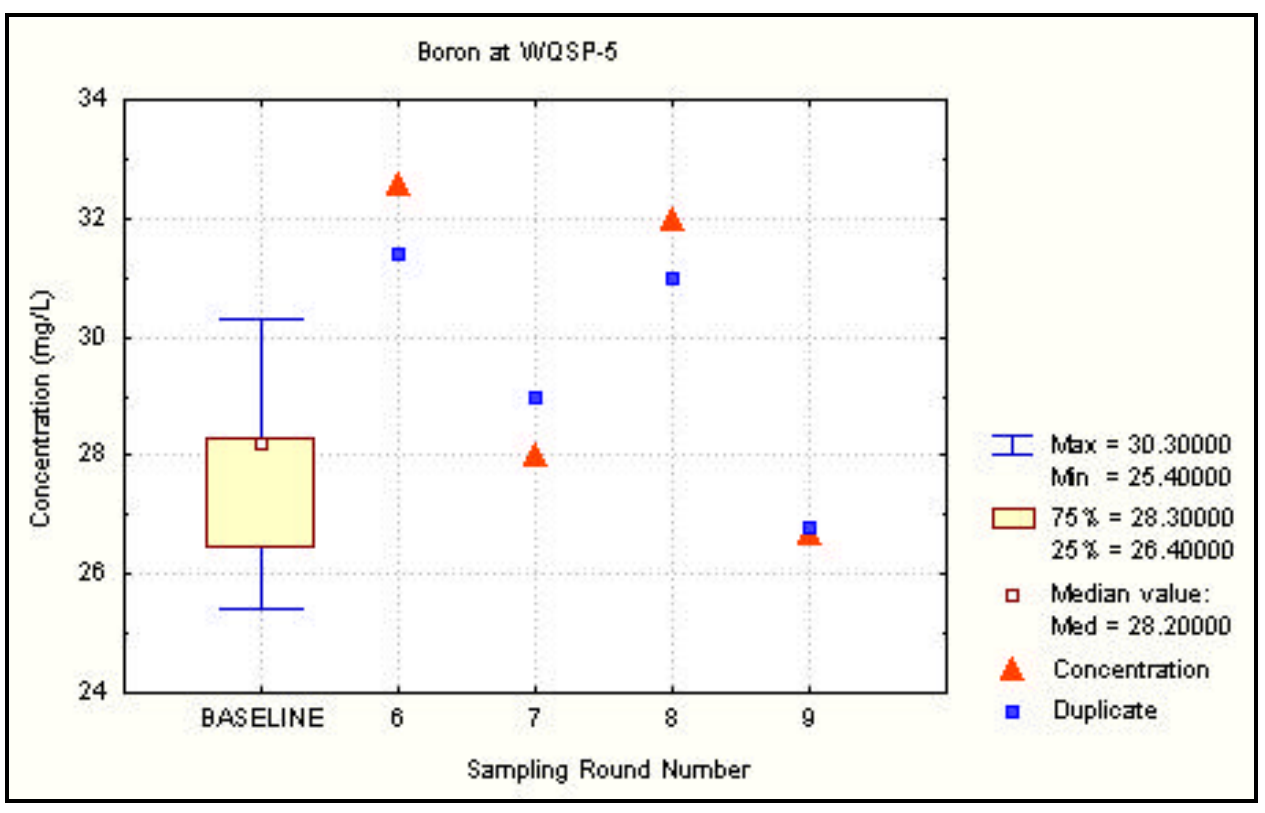

Figure 6.74 Time Trend Plot for Boron at WQSP-5 


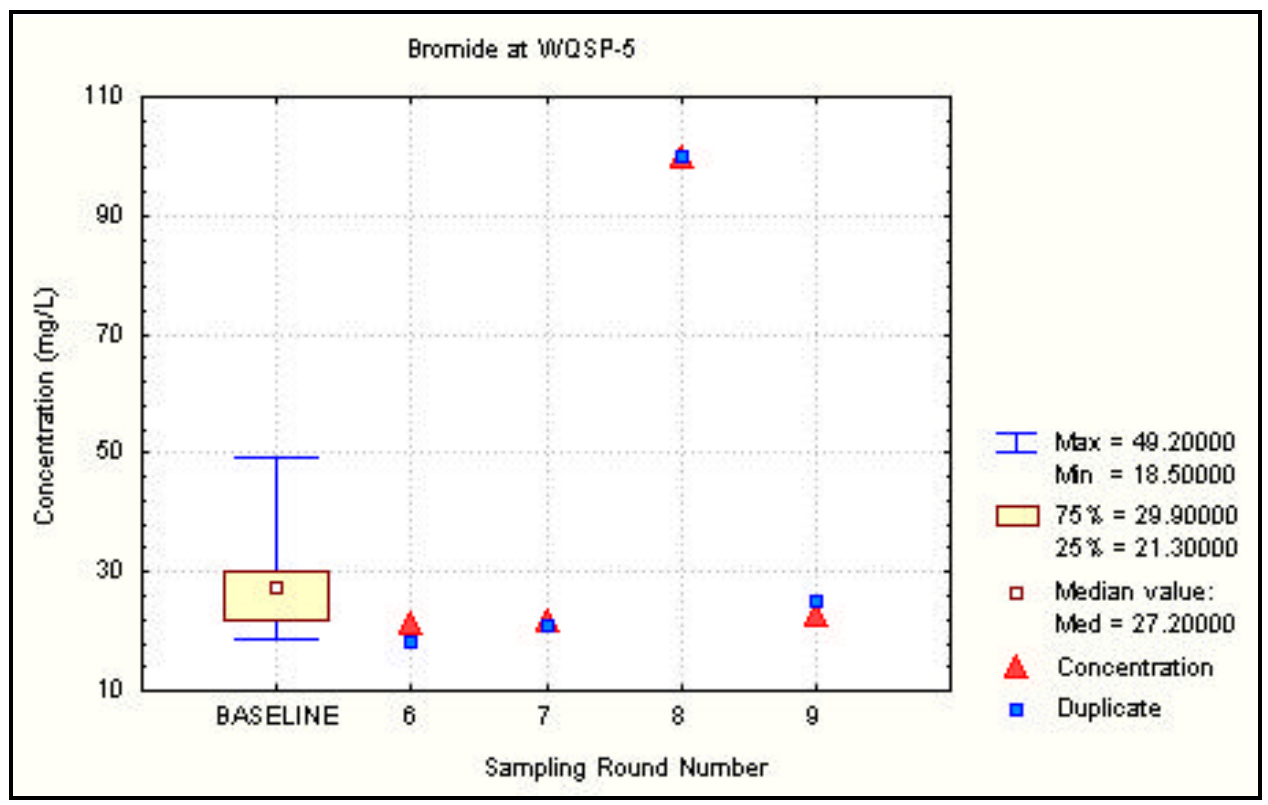

Figure 6.75 Time Trend Plot for Bromide at WQSP-5

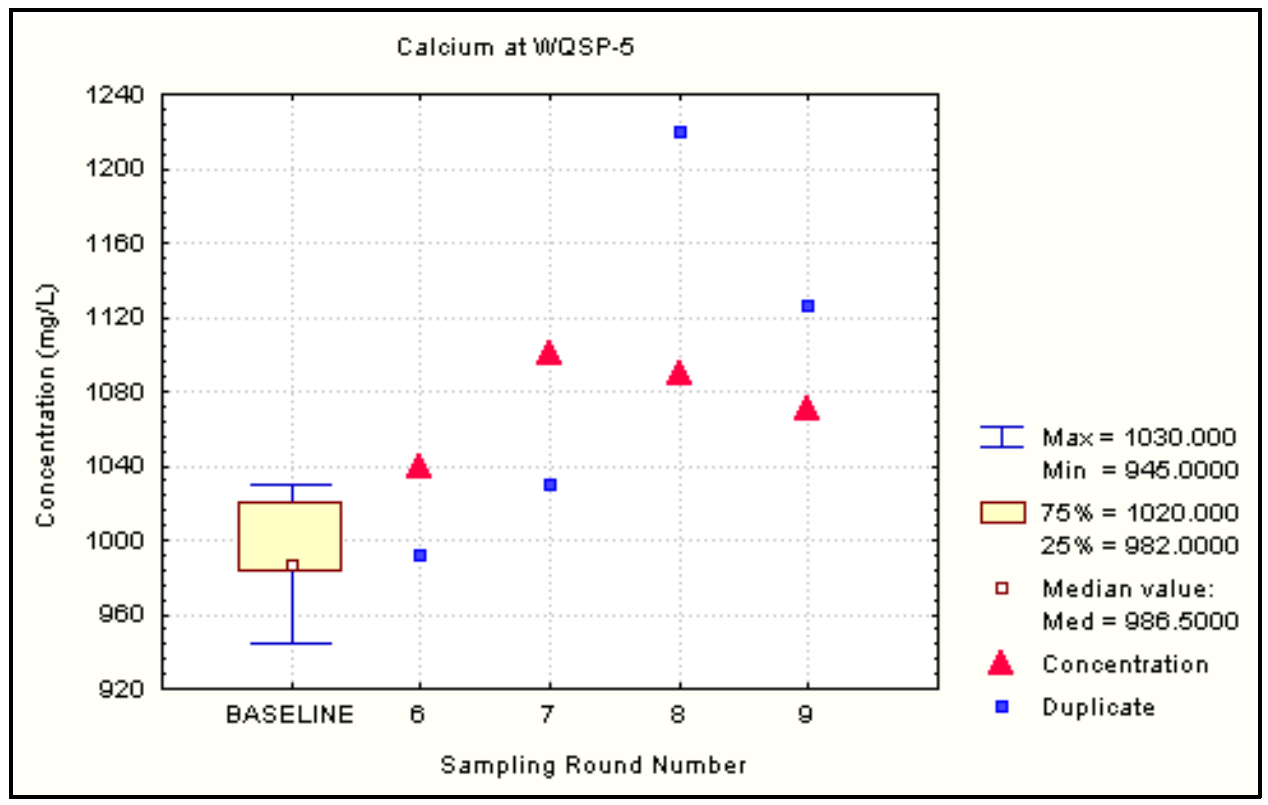

Figure 6.76 Time Trend Plot for Calcium at WQSP-5 


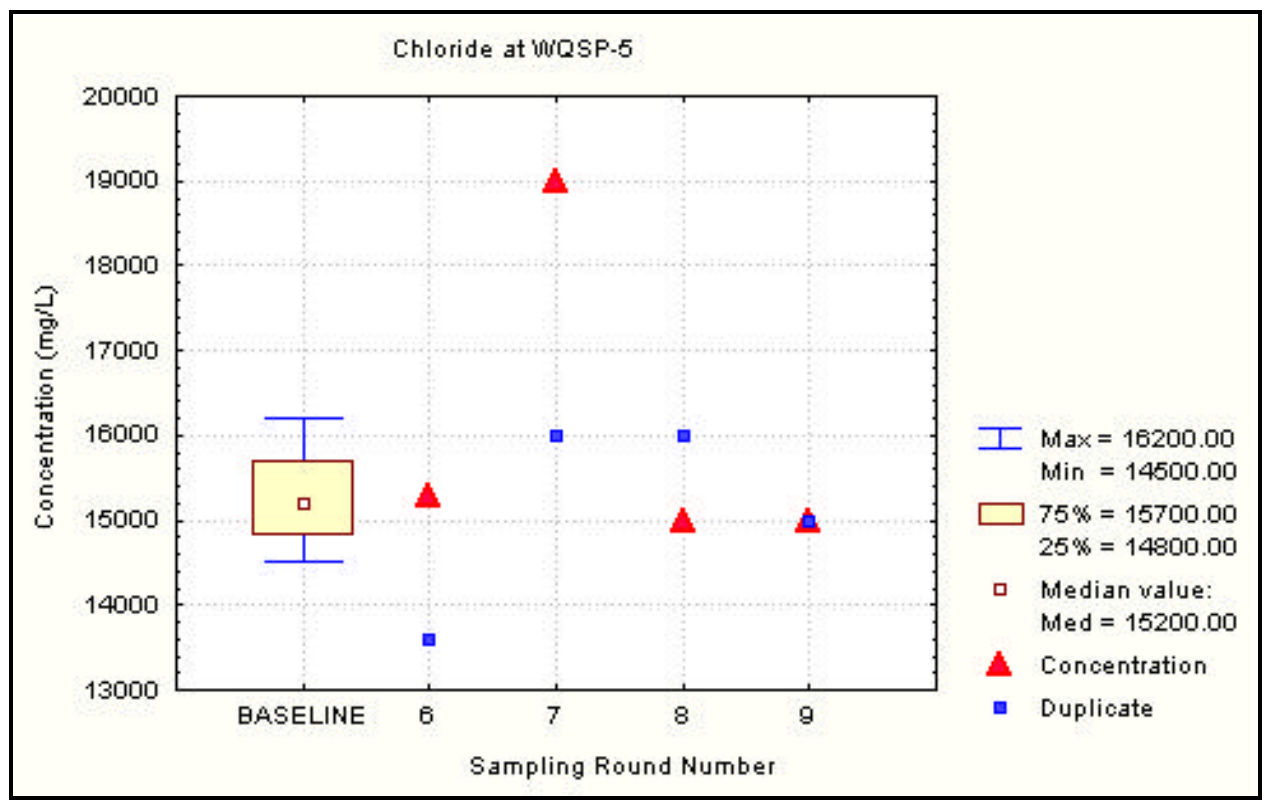

Figure 6.77 Time Trend Plot for Chloride at WQSP-5

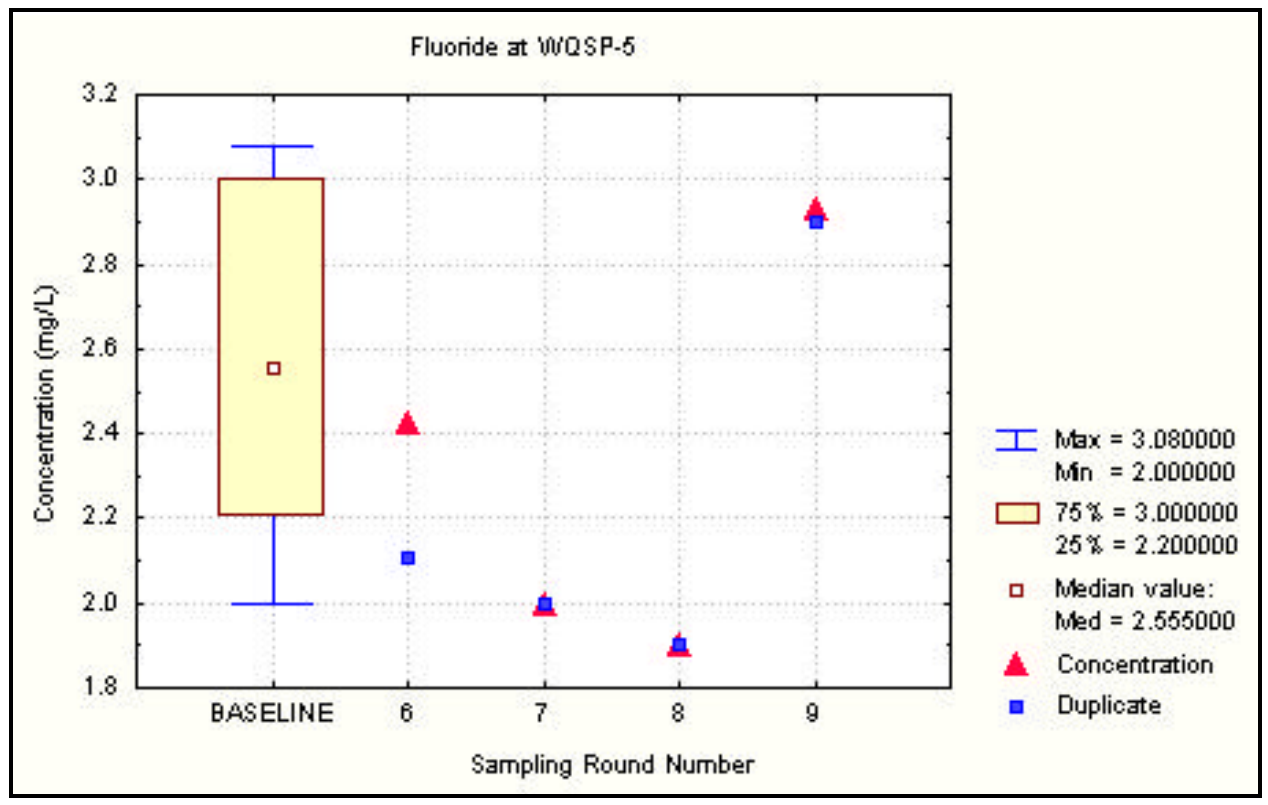

Figure 6.78 Time Trend Plot for Fluoride at WQSP-5 


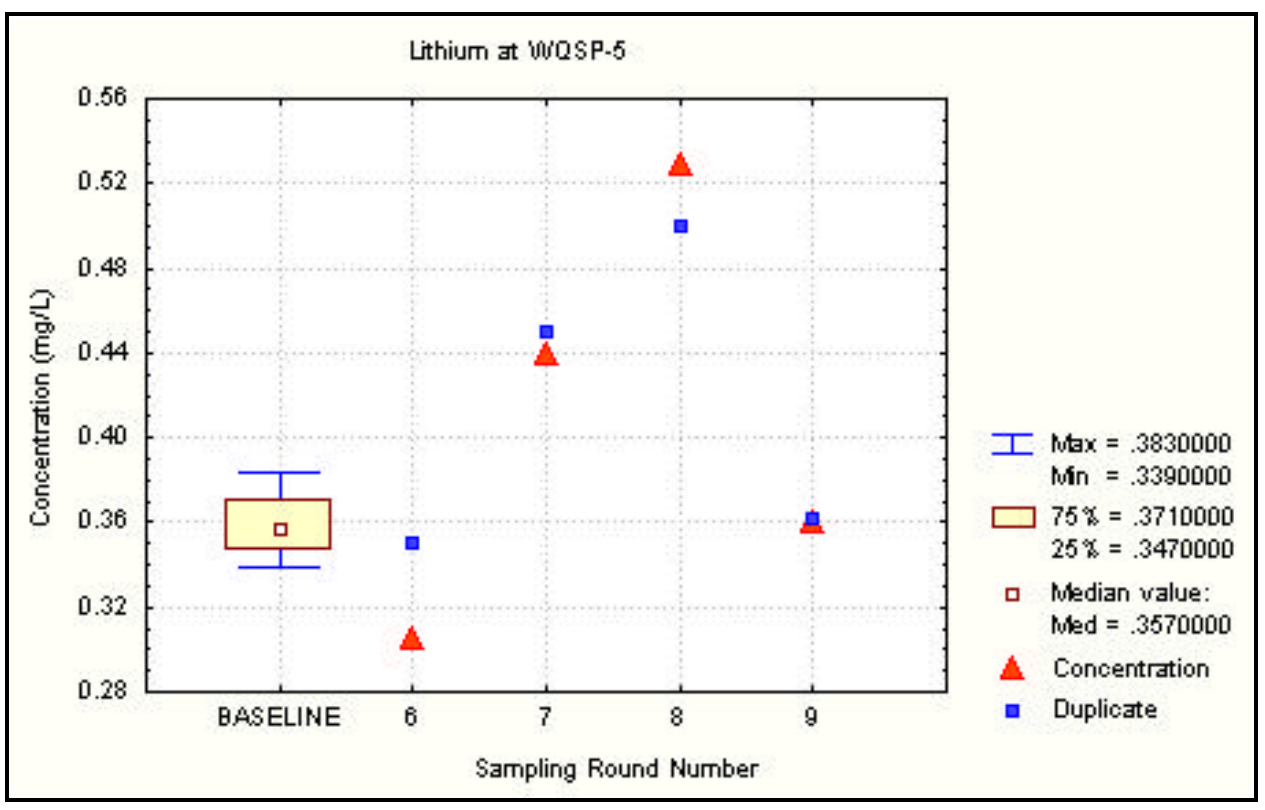

Figure 6.79 Time Trend Plot for Lithium at WQSP-5

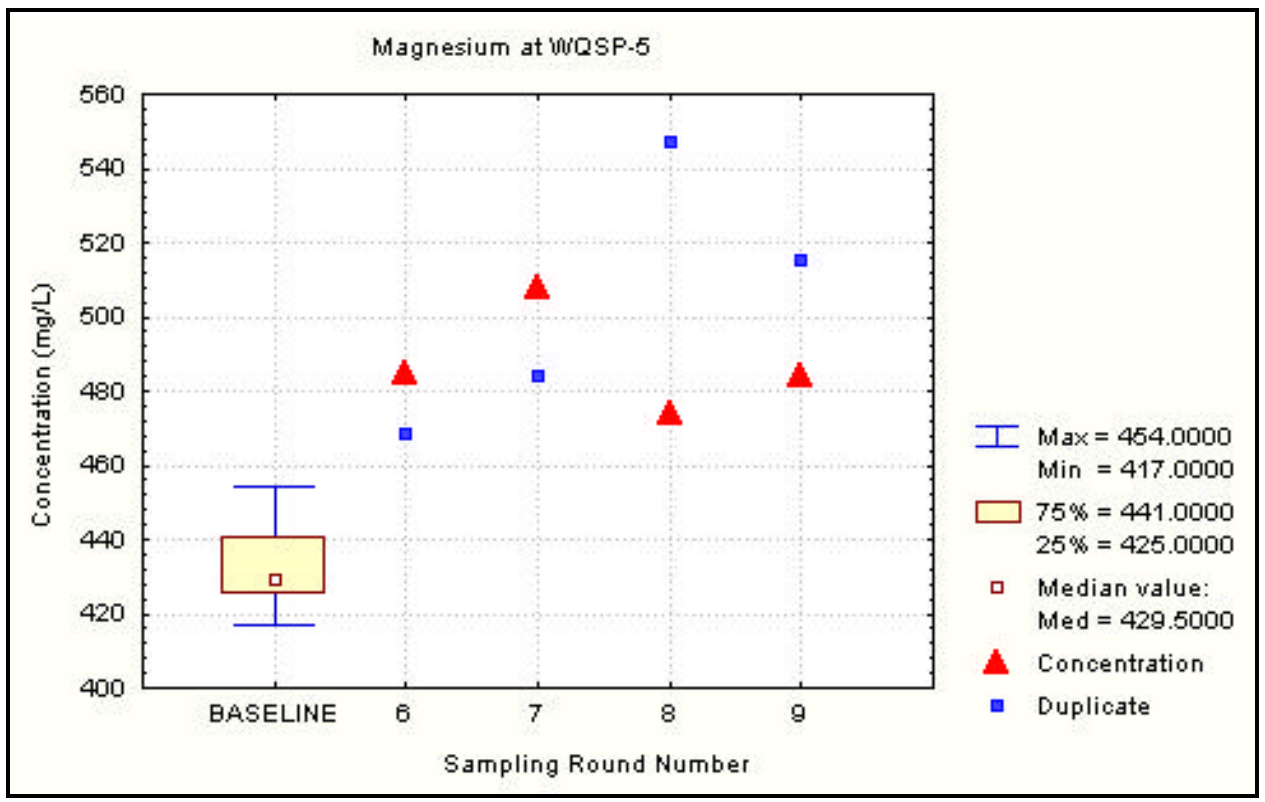

Figure 6.80 Time Trend Plot for Magnesium at WQSP-5 


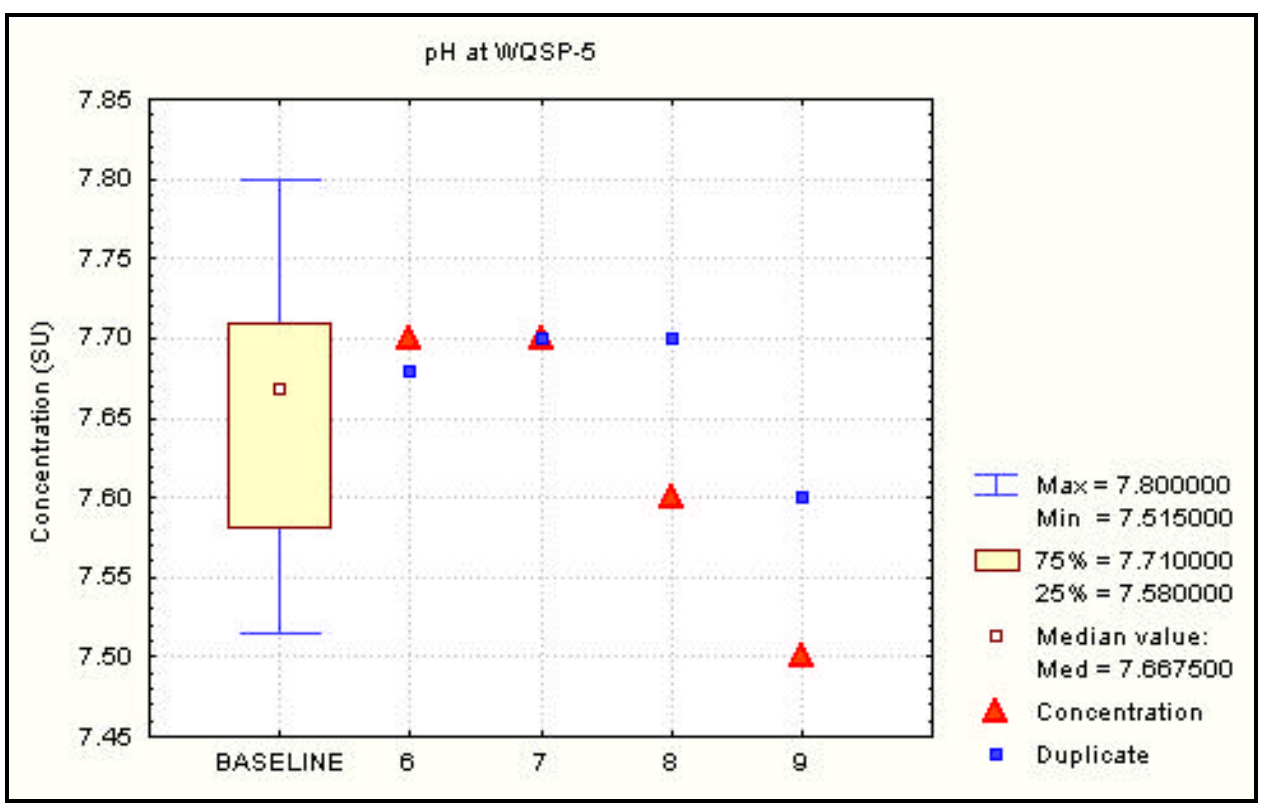

Figure 6.81 Time Trend Plot for $\mathrm{pH}$ at WQSP-5

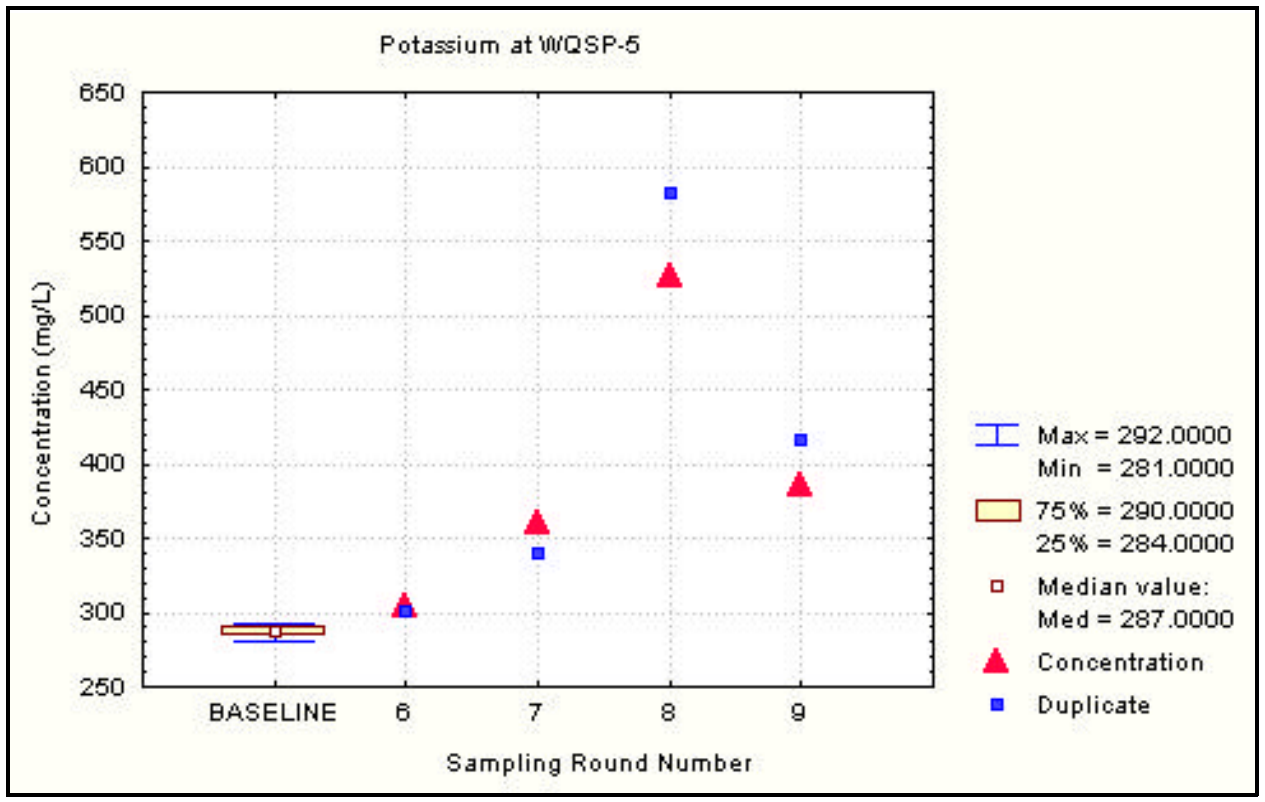

Figure 6.82 Time Trend Plot for Potassium at WQSP-5 


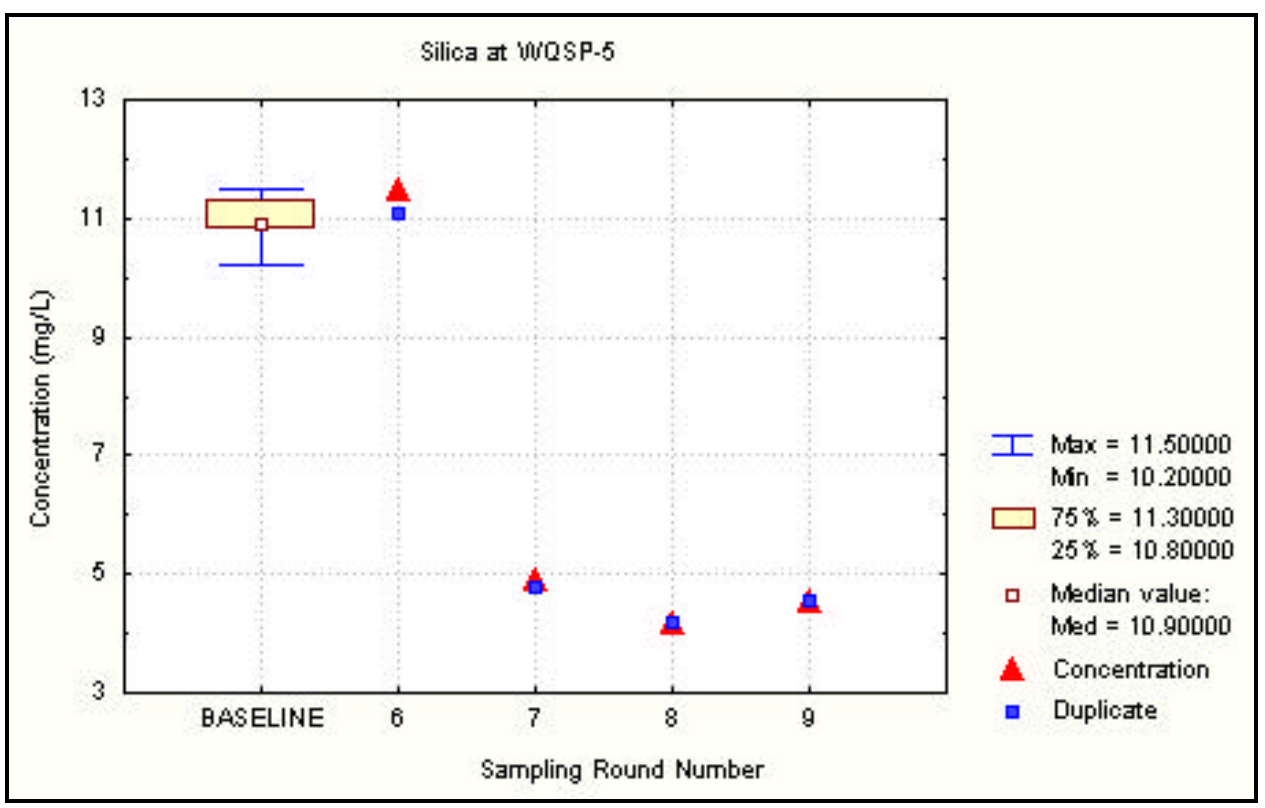

Figure 6.83 Time Trend Plot for Silica at WQSP-5

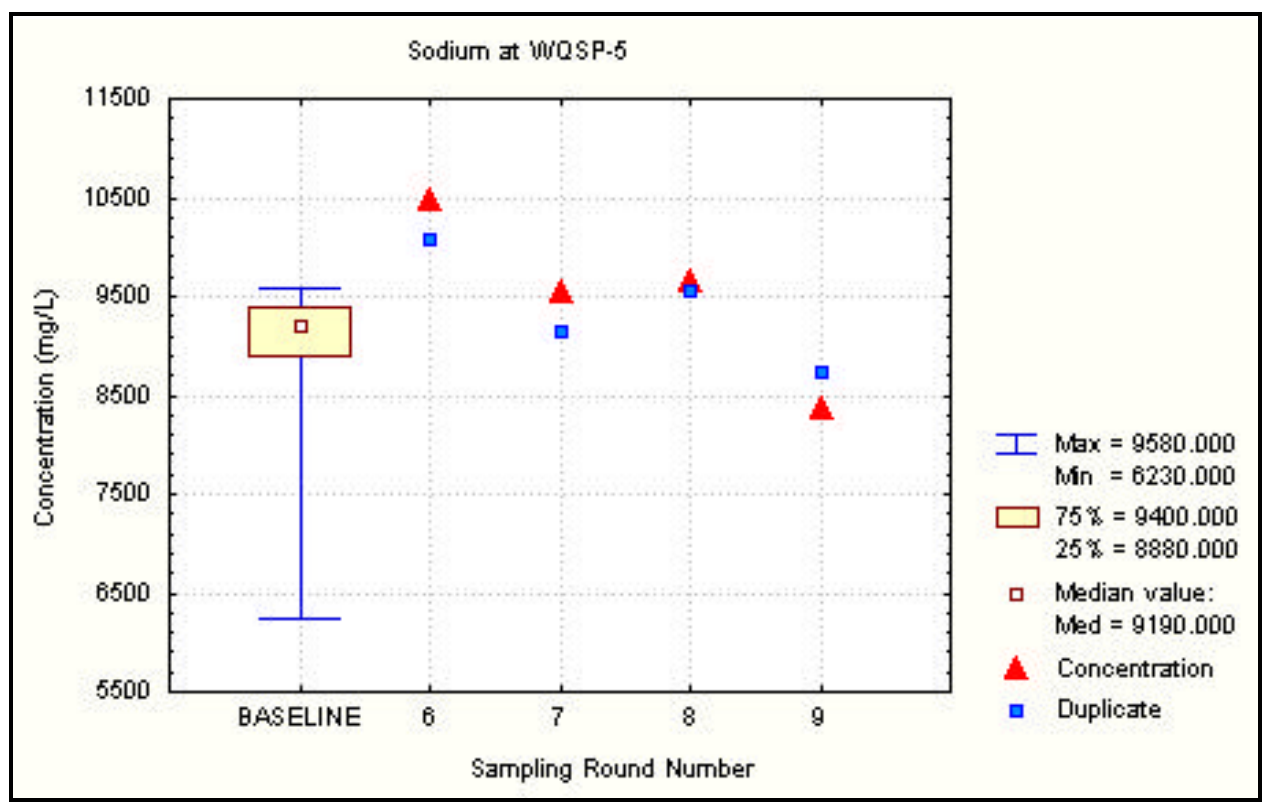

Figure 6.84 Time Trend Plot for Sodium at WQSP-5 


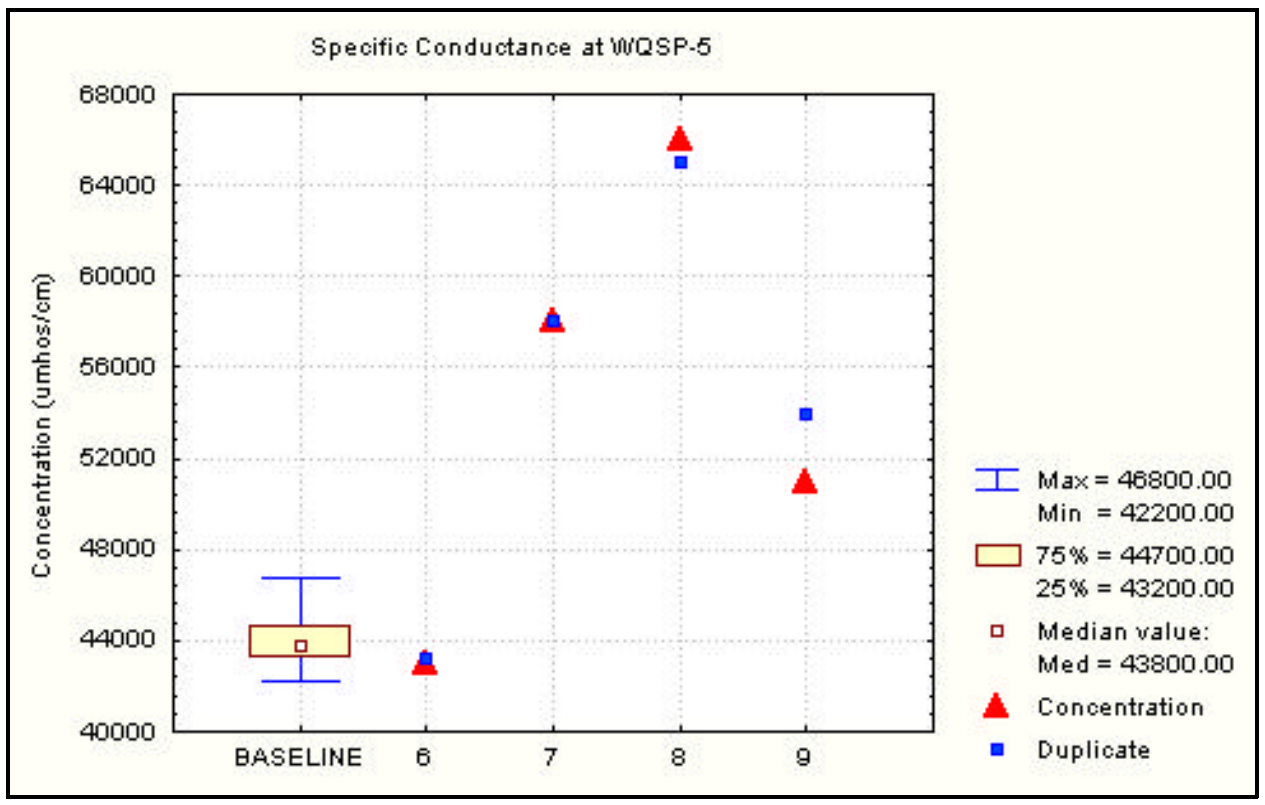

Figure 6.85 Time Trend Plot for Specific Conductance at WQSP-5

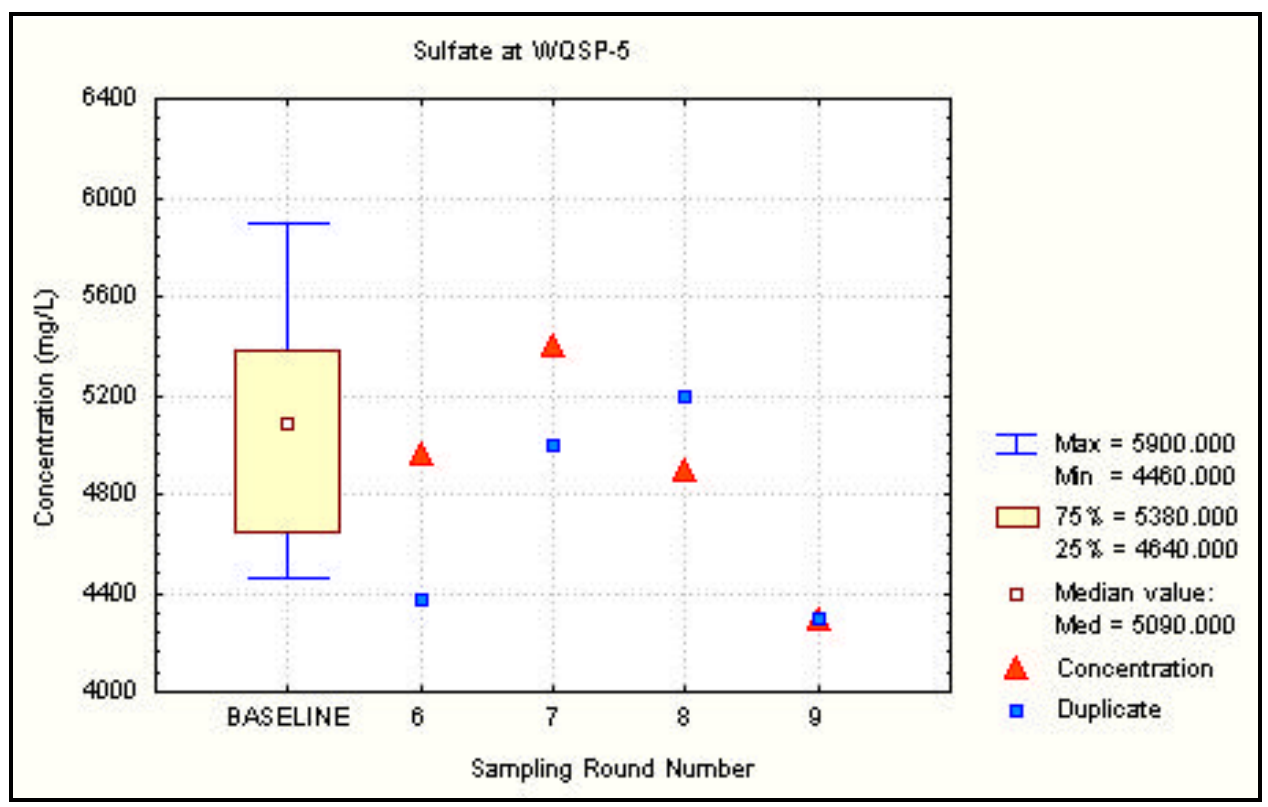

Figure 6.86 Time Trend Plot for Sulfate at WQSP-5 


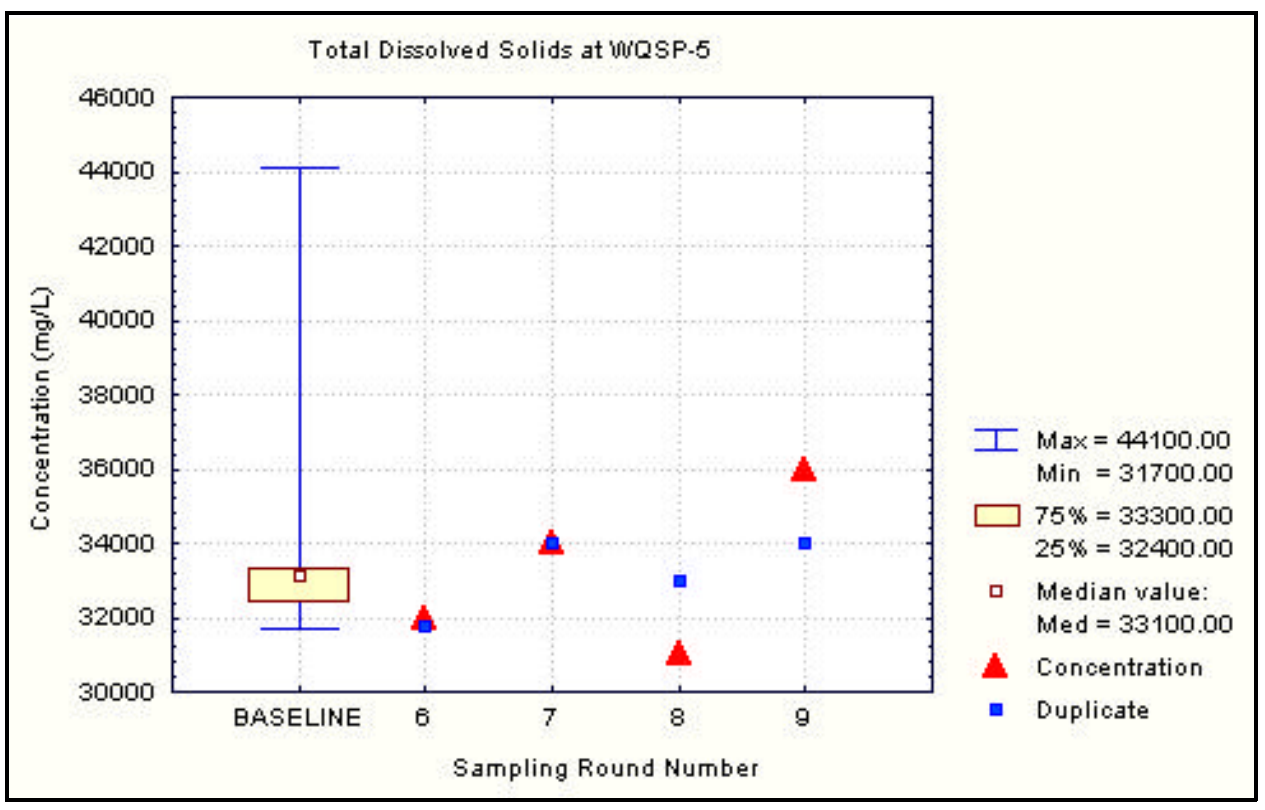

Figure 6.87 Time Trend Plot for Total Dissolved Solids at WQSP-5

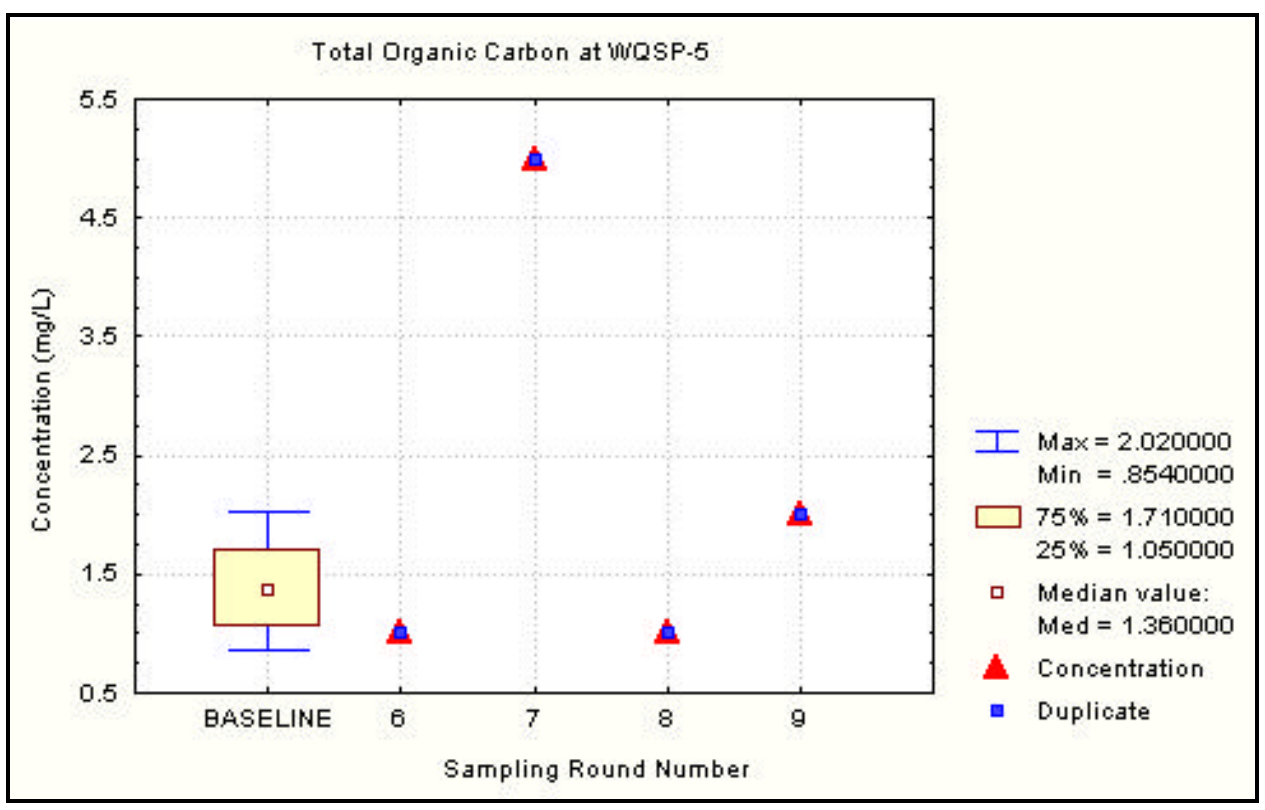

Figure 6.88 Time Trend Plot for Total Organic Carbon at WQSP-5 


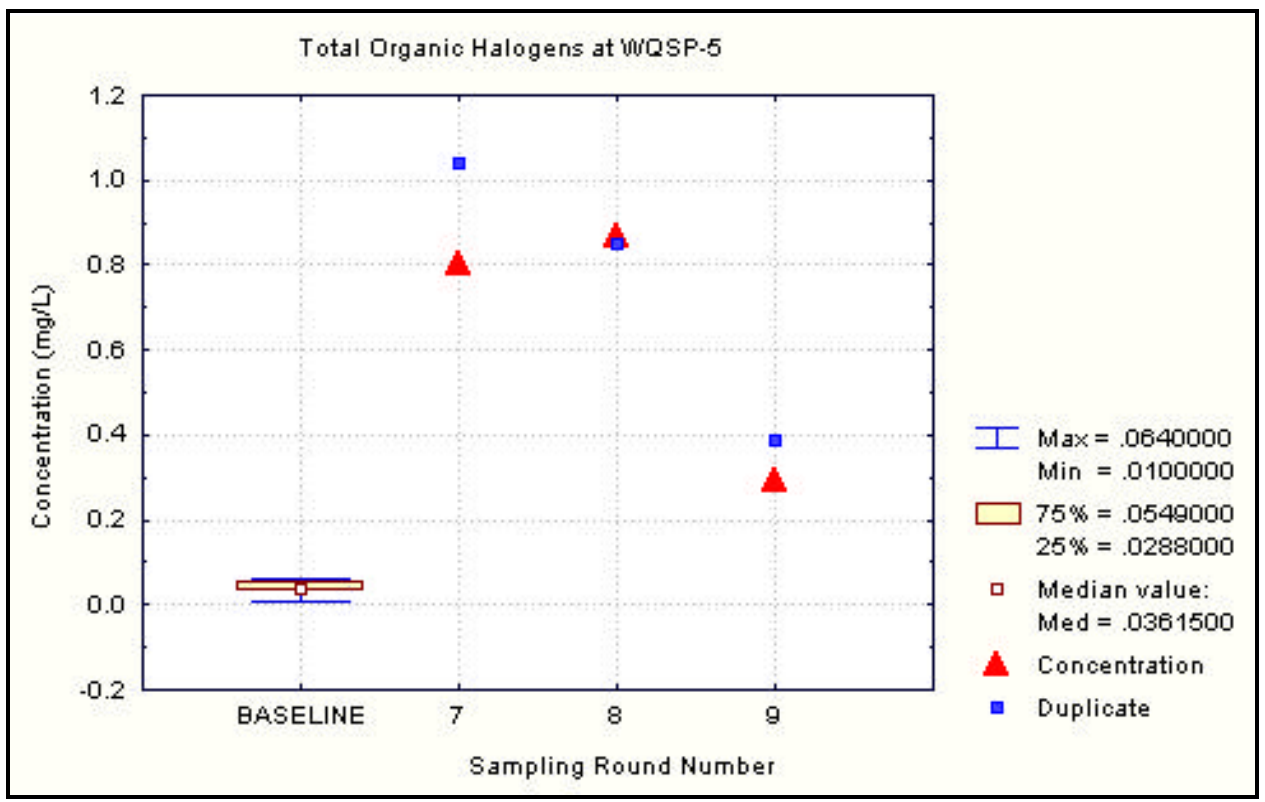

Figure 6.89 Time Trend Plot for Total Organic Halogens at WQSP-5

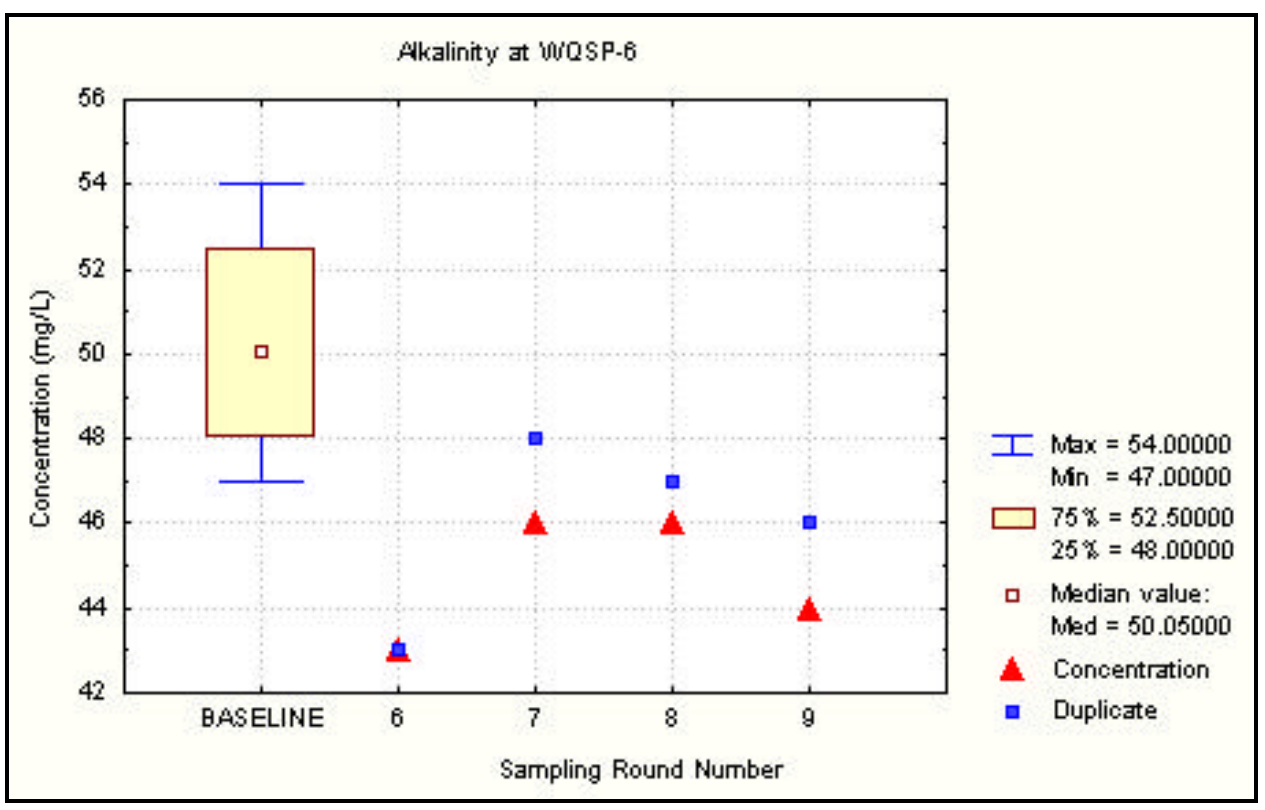

Figure 6.90 Time Trend Plot for Alkalinity at WQSP-6 


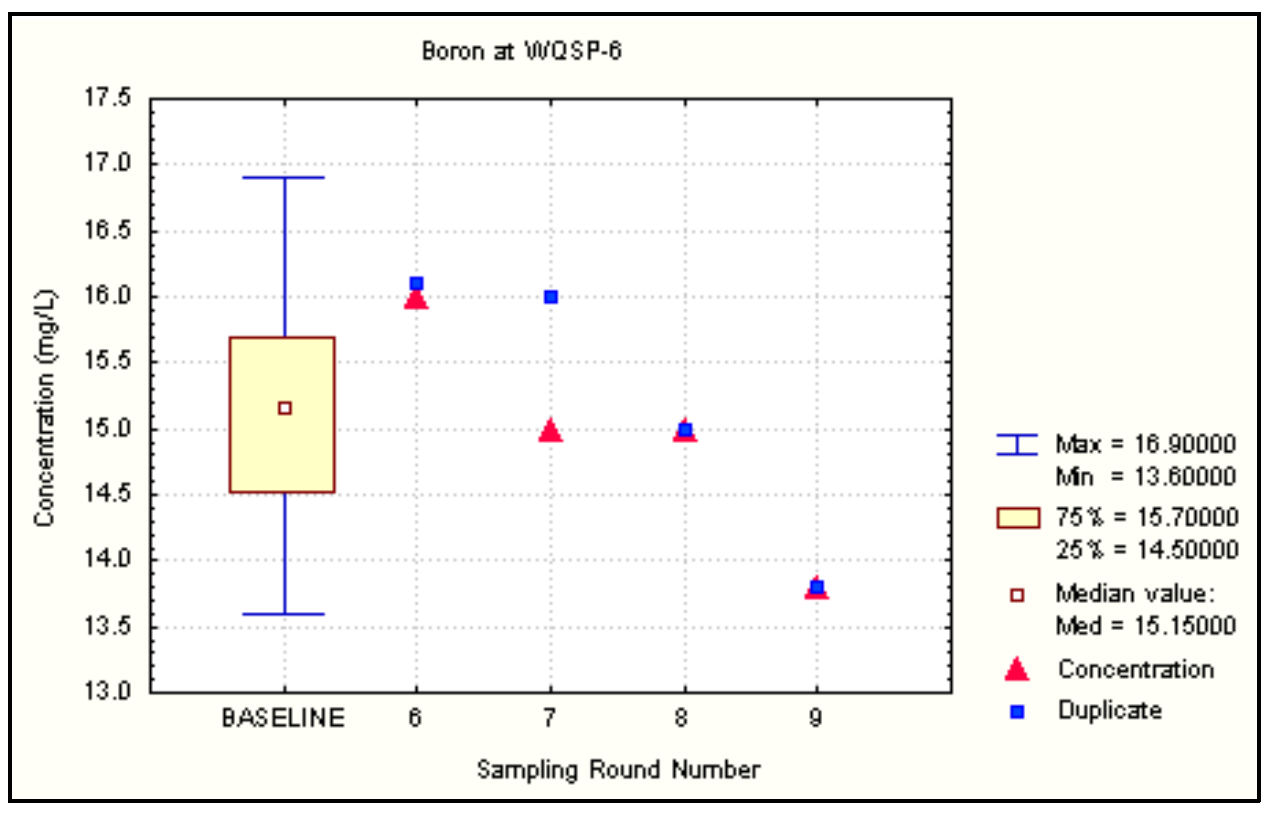

Figure 6.91 Time Trend Plot for Boron at WQSP-6

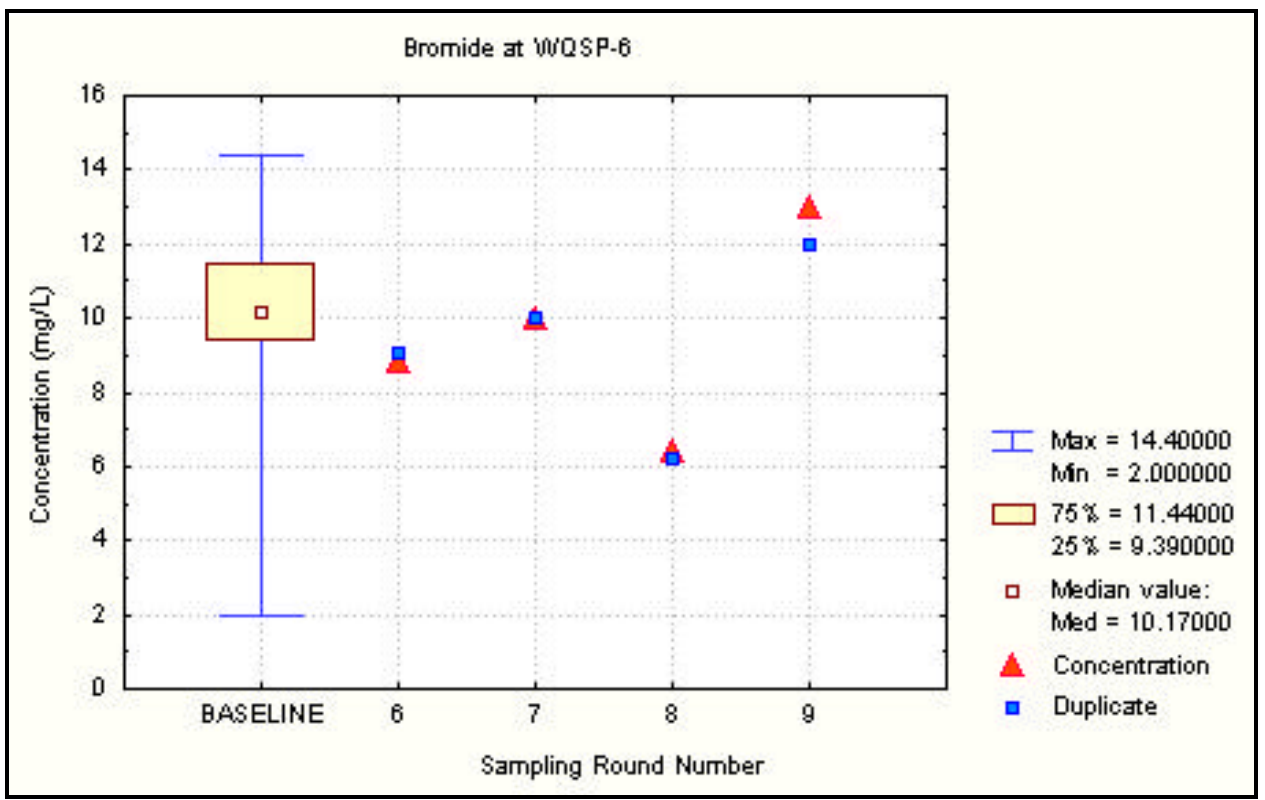

Figure 6.92 Time Trend Plot for Bromide at WQSP-6 


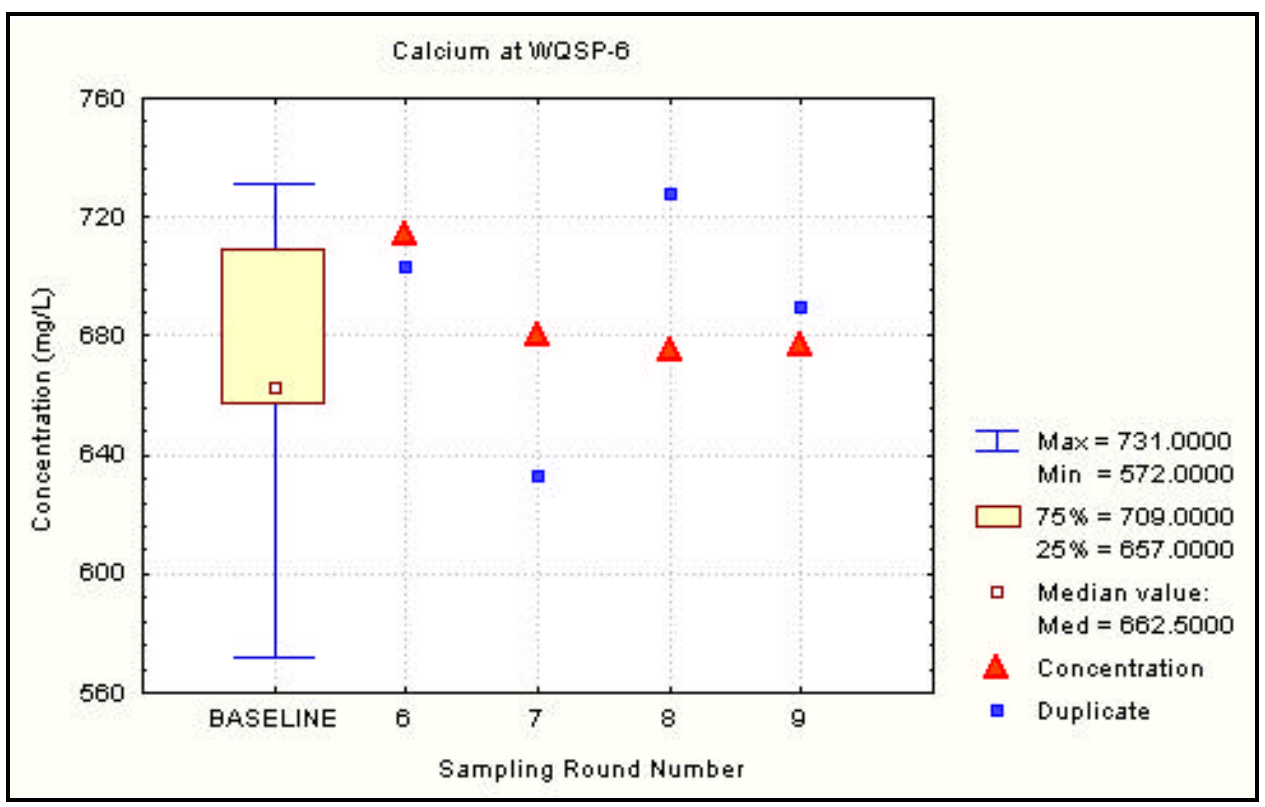

Figure 6.93 Time Trend Plot for Calcium at WQSP-6

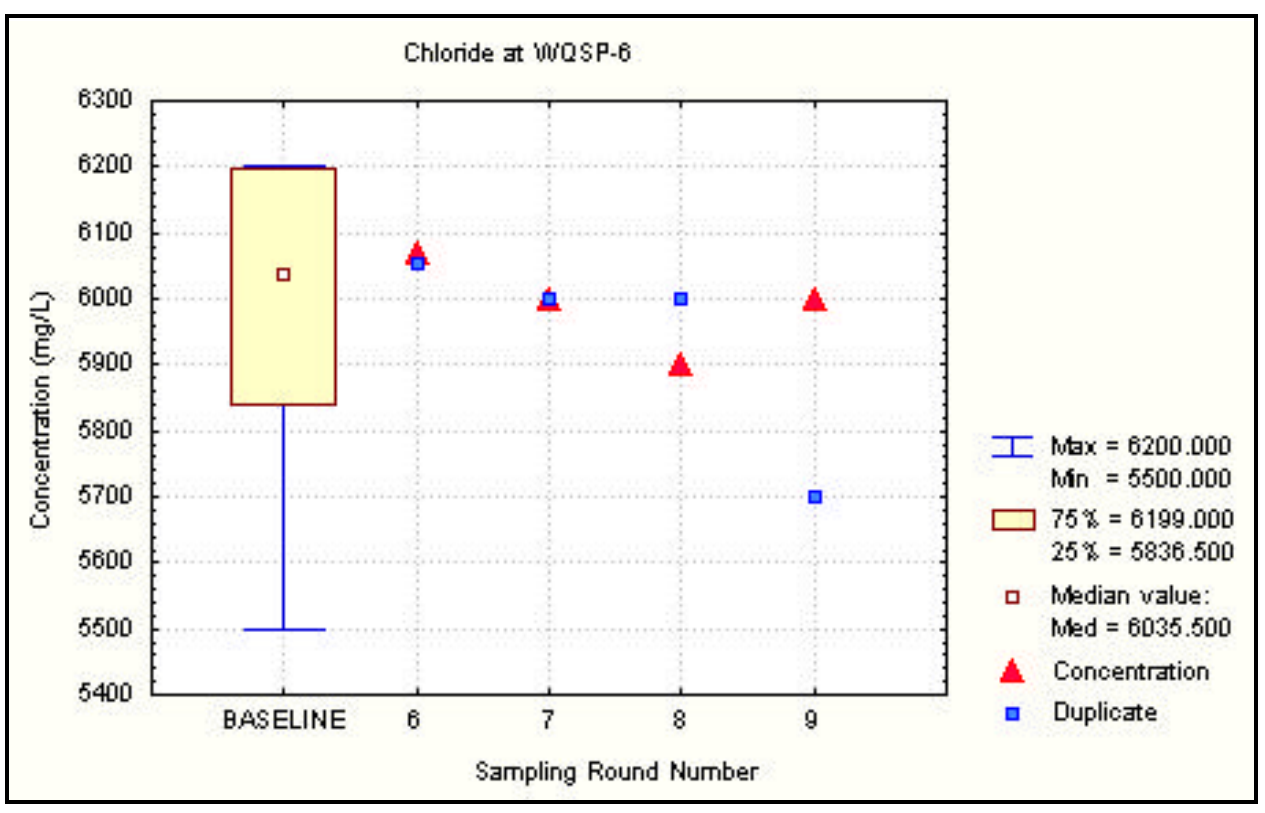

Figure 6.94 Time Trend Plot for Chloride at WQSP-6 


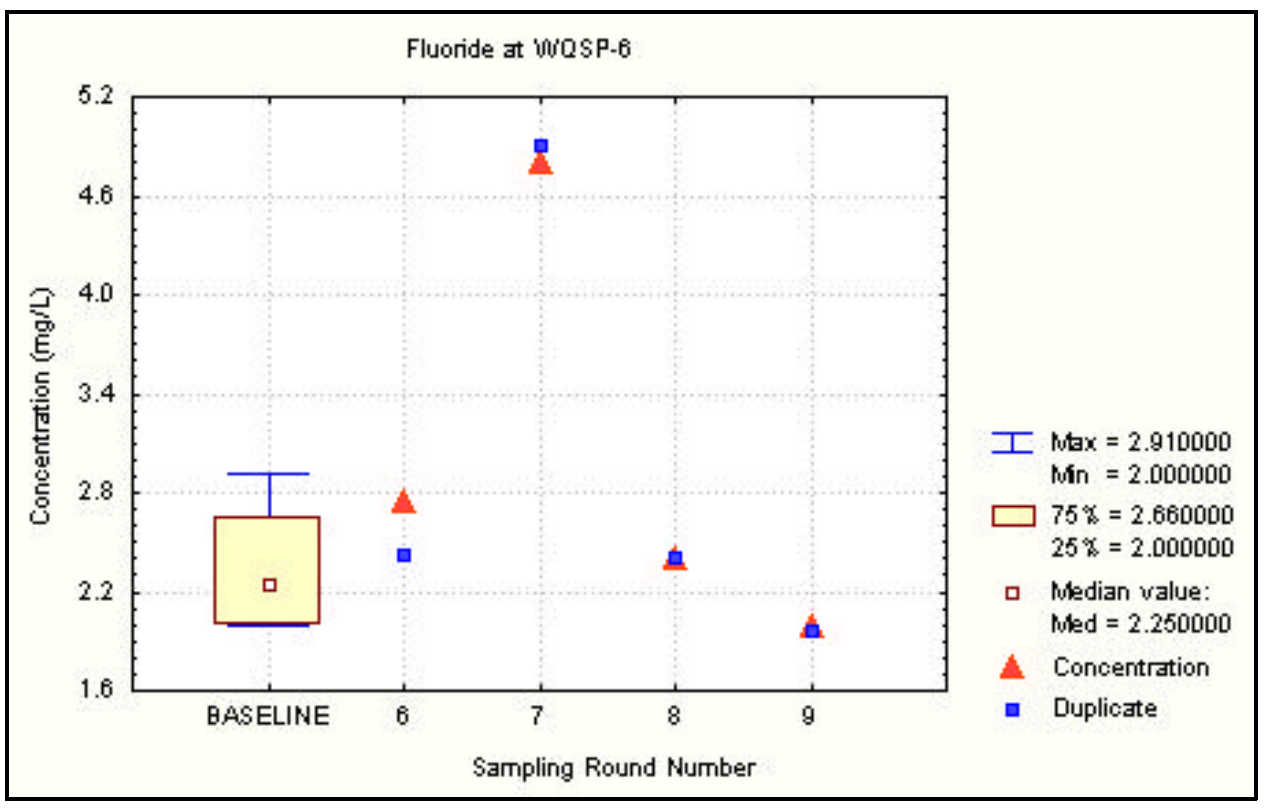

Figure 6.95 Time Trend Plot for Fluoride at WQSP-6

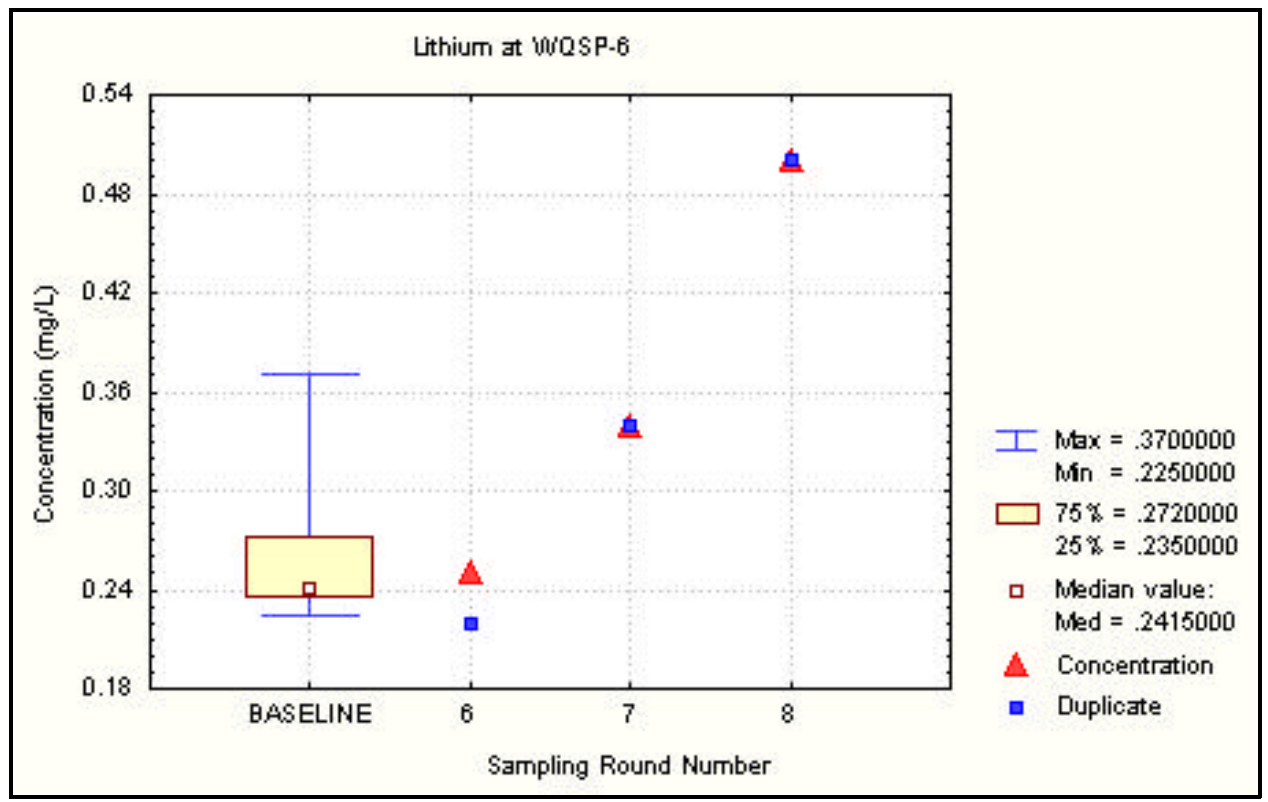

Figure 6.96 Time Trend Plot for Lithium at WQSP-6 


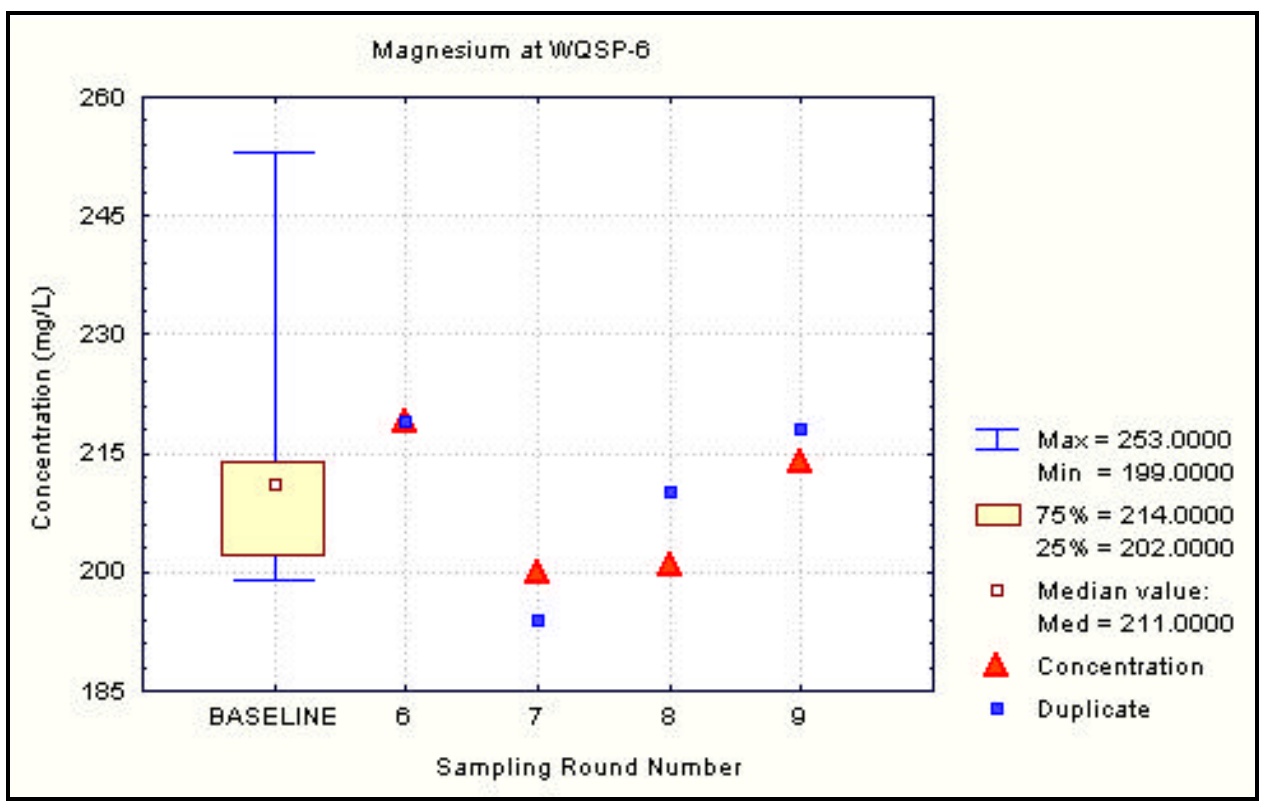

Figure 6.97 Time Trend Plot for Magnesium at WQSP-6

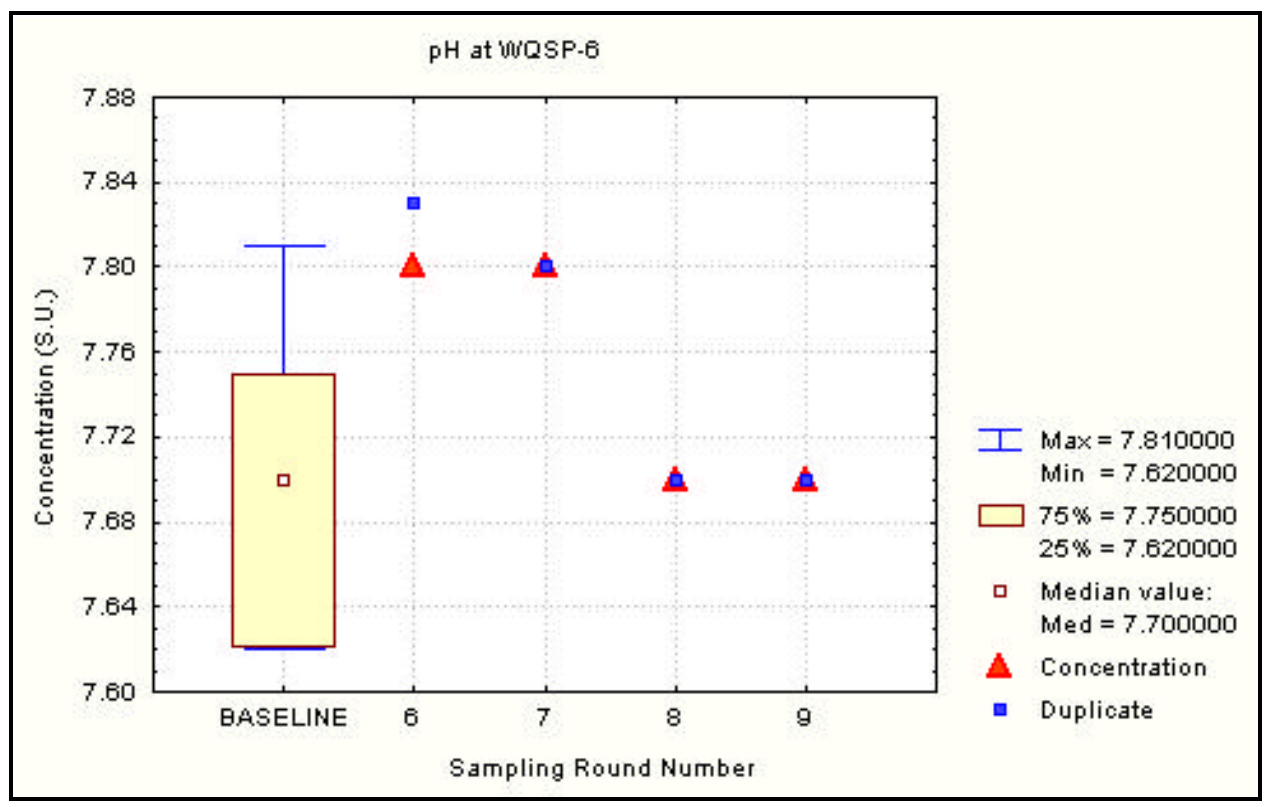

Figure 6.98 Time Trend Plot for $\mathrm{pH}$ at WQSP-6 


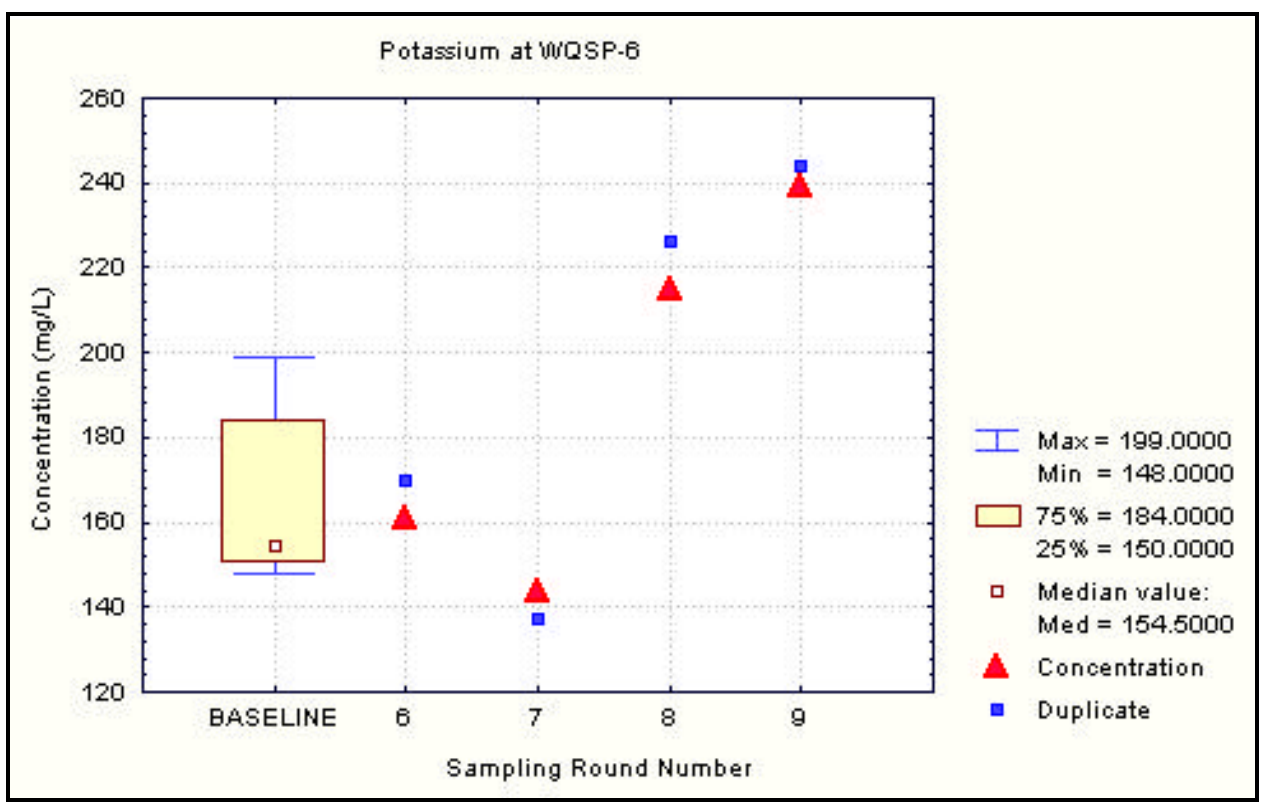

Figure 6.99 Time Trend Plot for Potassium at WQSP-6

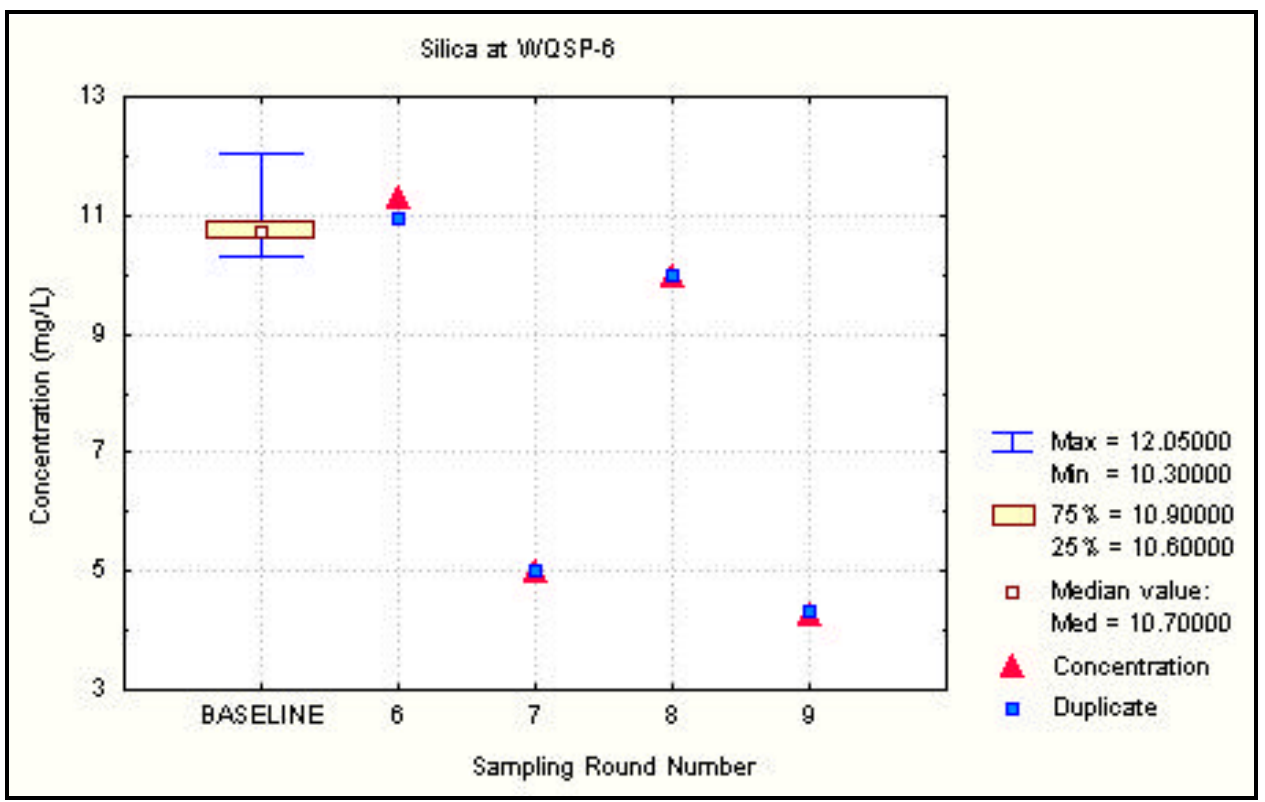

Figure 6.100 Time Trend Plot for Silica at WQSP-6 


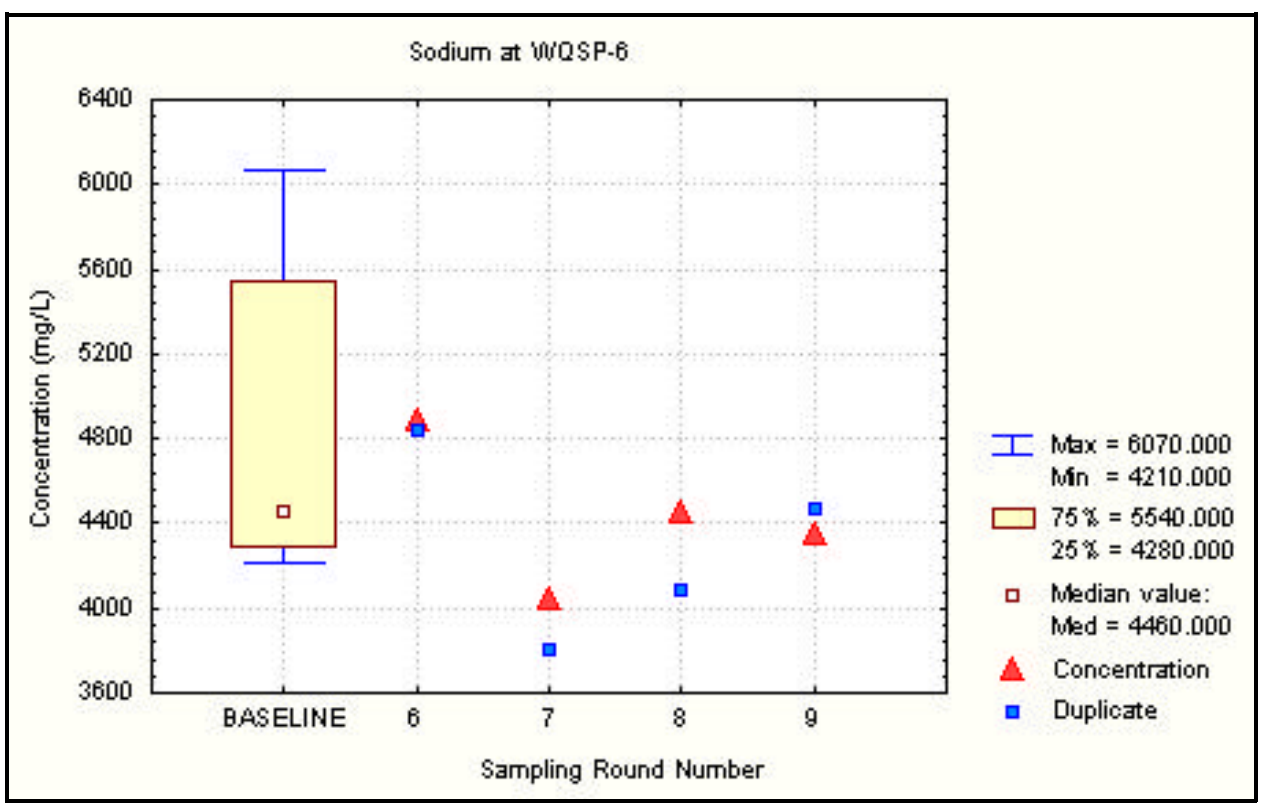

Figure 6.101 Time Trend Plot for Sodium at WQSP-6

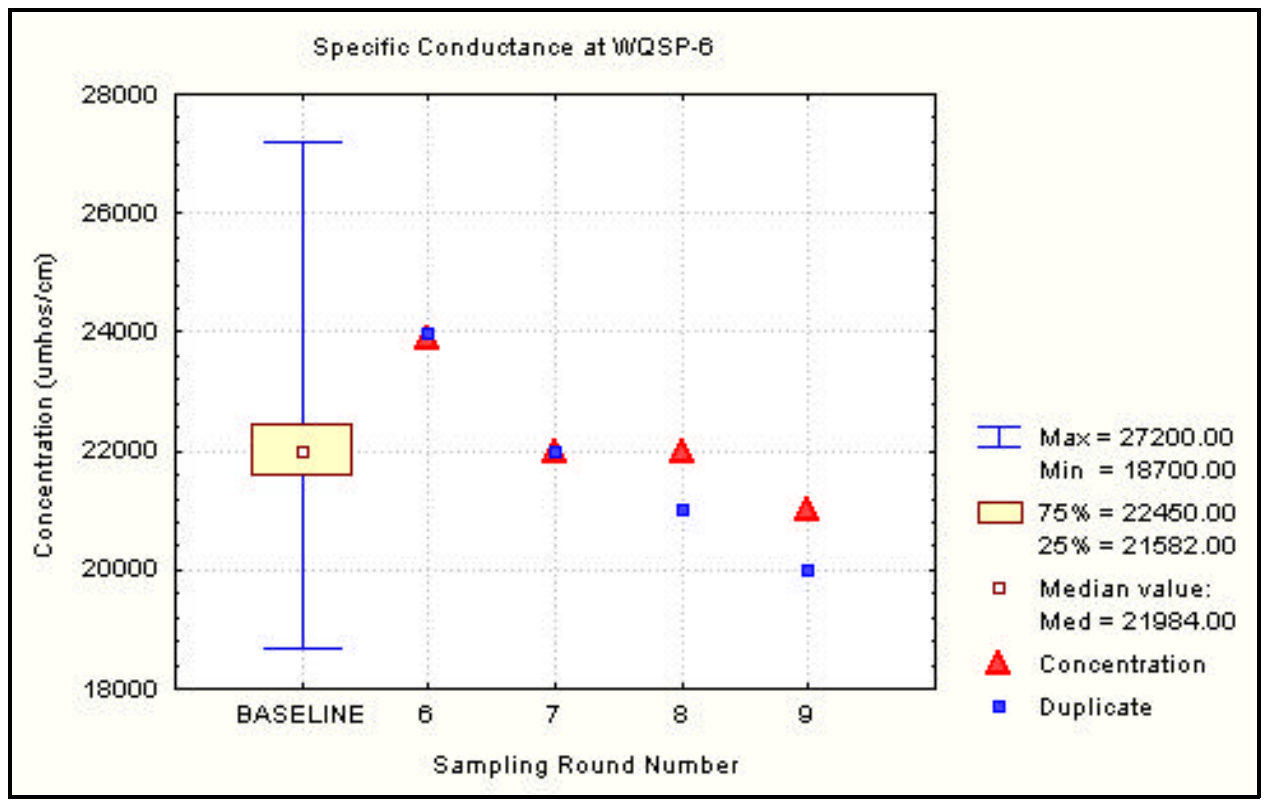

Figure 6.102 Time Trend Plot for Specific Conductance at WQSP-6 


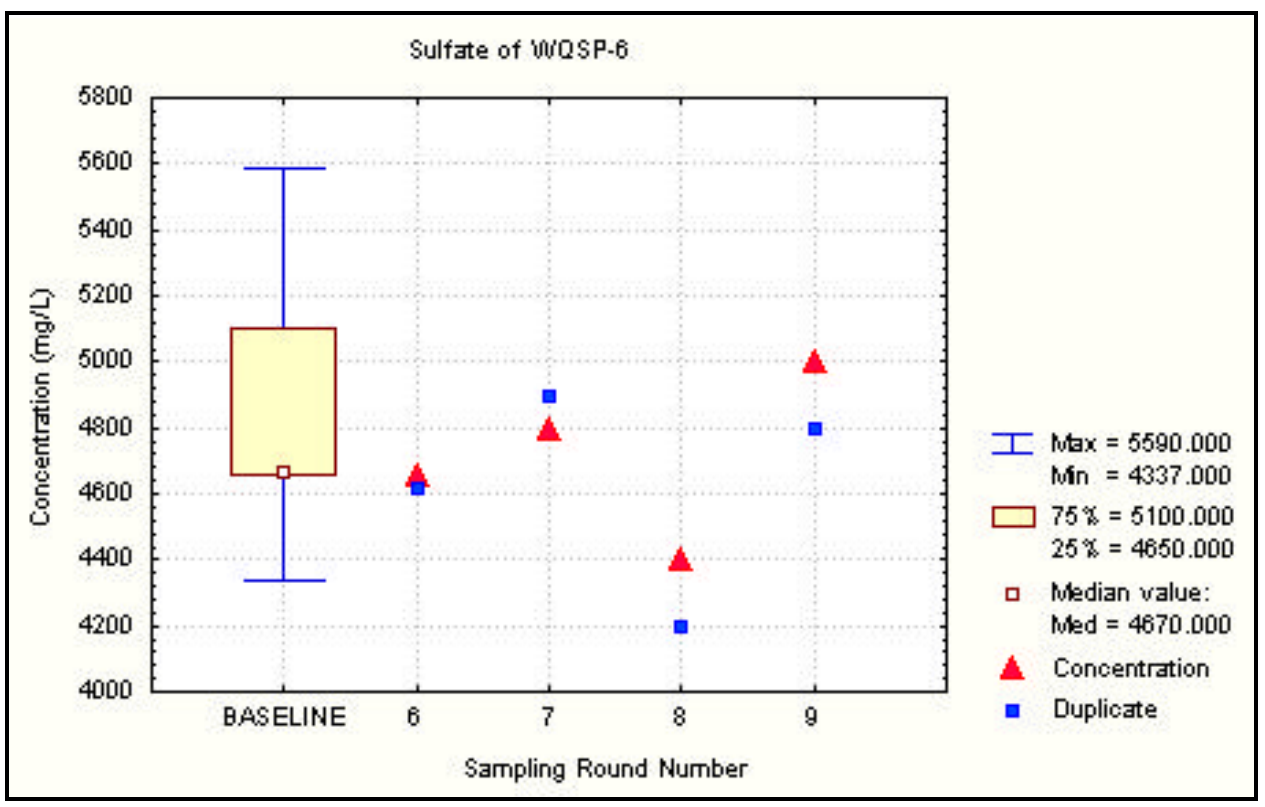

Figure 6.103 Time Trend Plot for Sulfate at WQSP-6

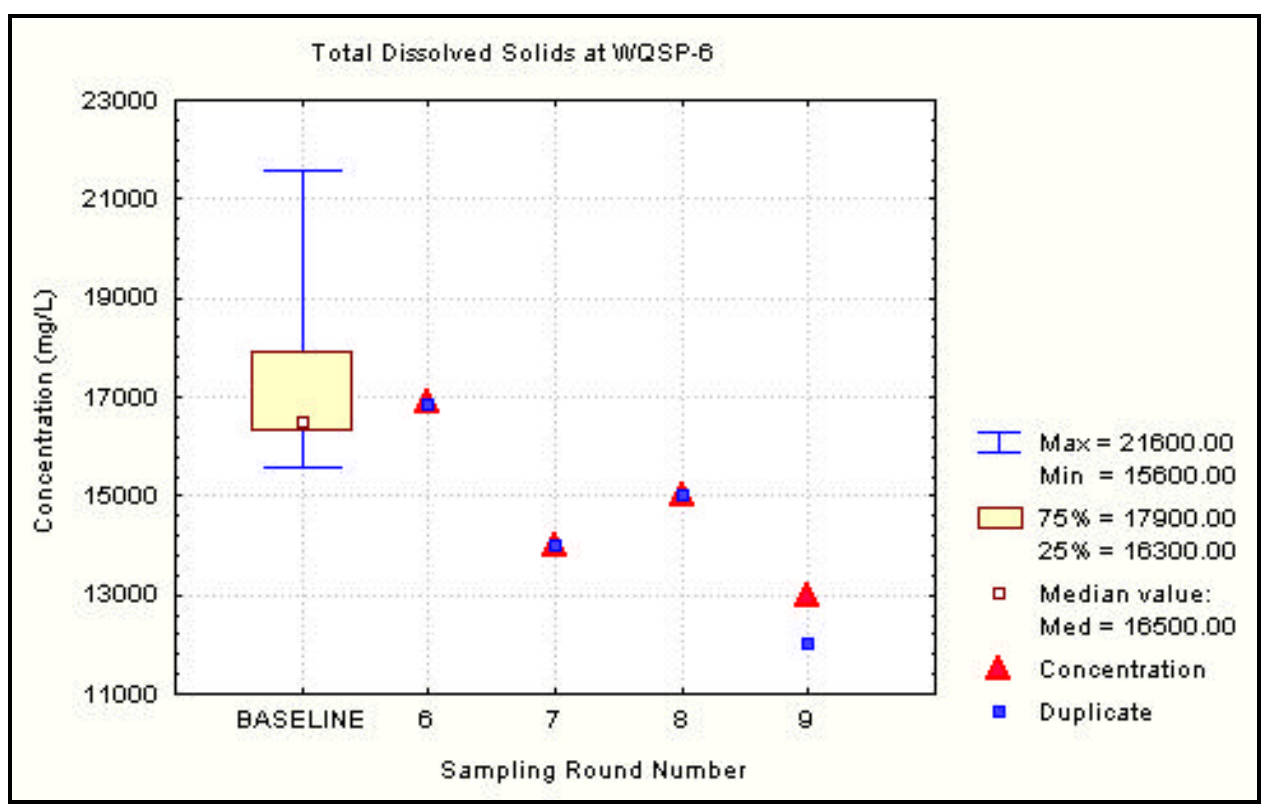

Figure 6.104 Time Trend Plot for Total Dissolved Solids at WQSP-6 


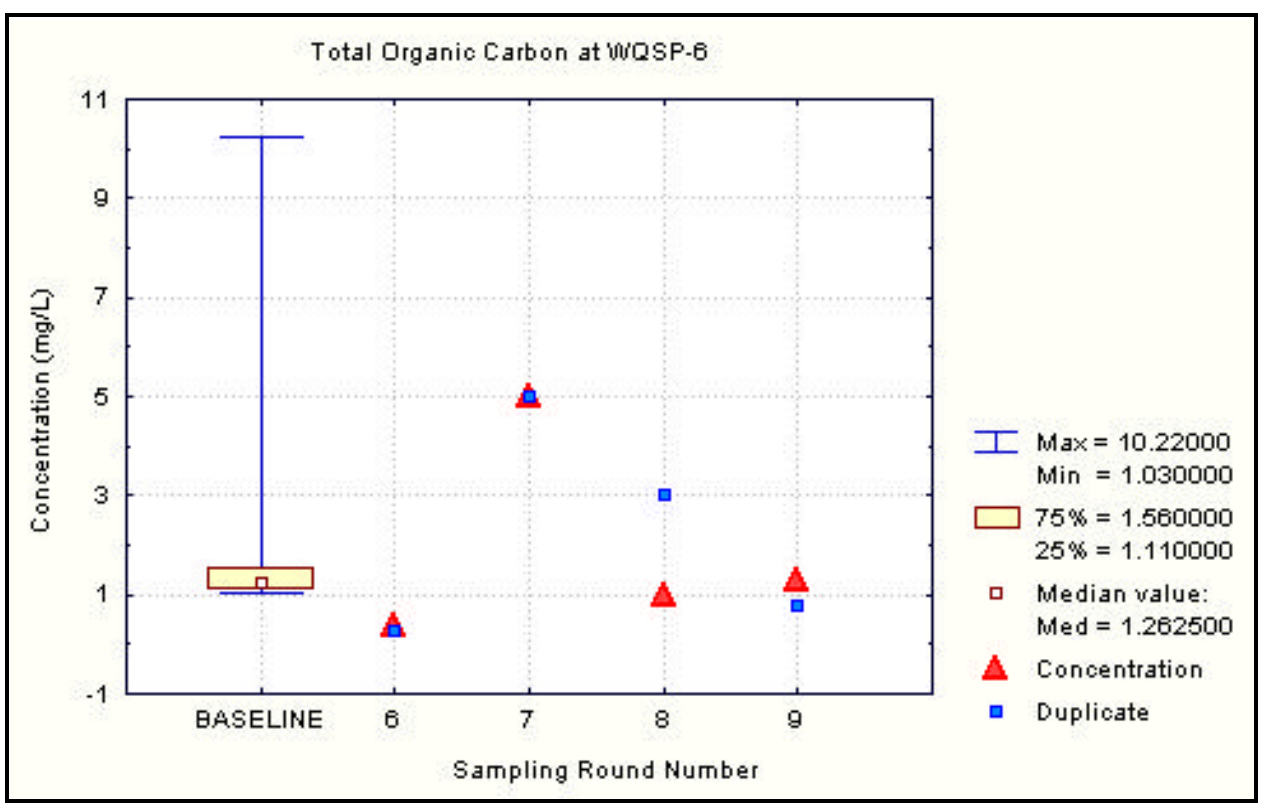

Figure 6.105 Time Trend Plot for Total Organic Carbon at WQSP-6

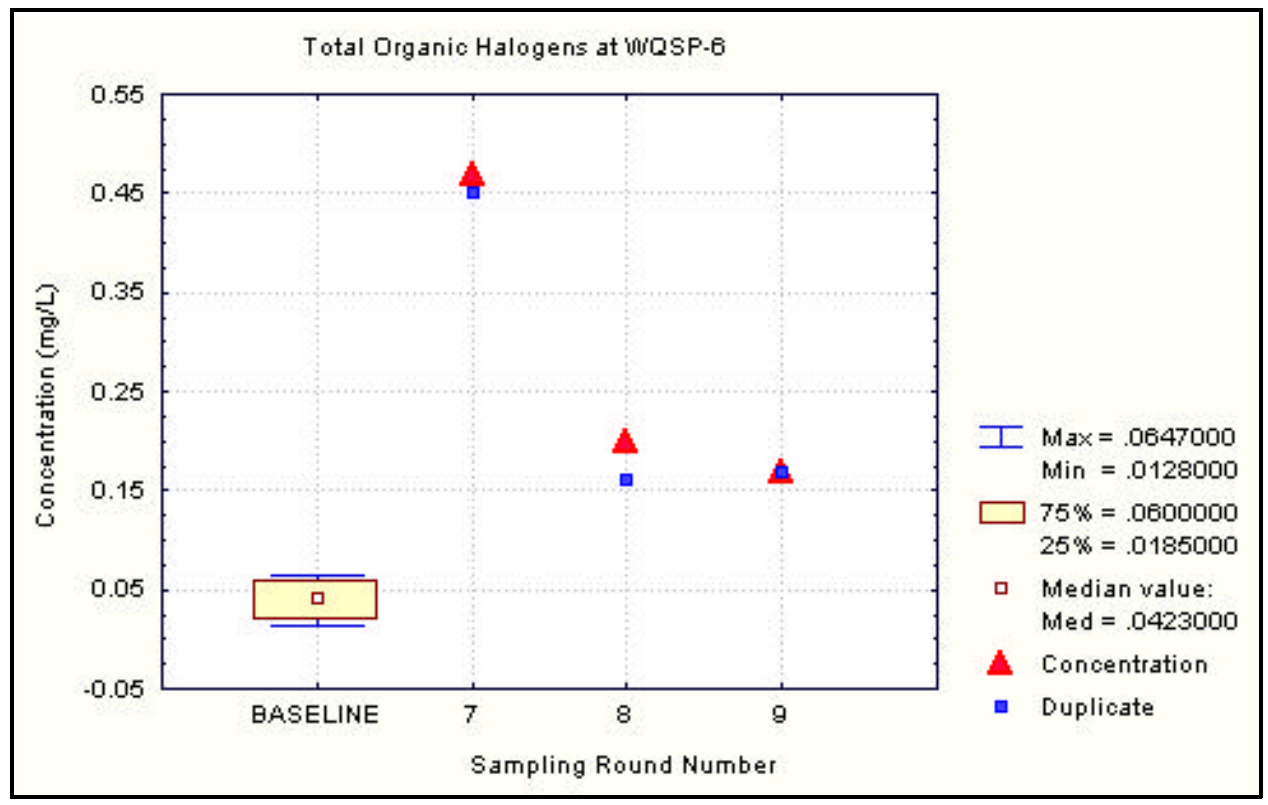

Figure 6.106 Time Trend Plot for Total Organic Halogens at WQSP-6 


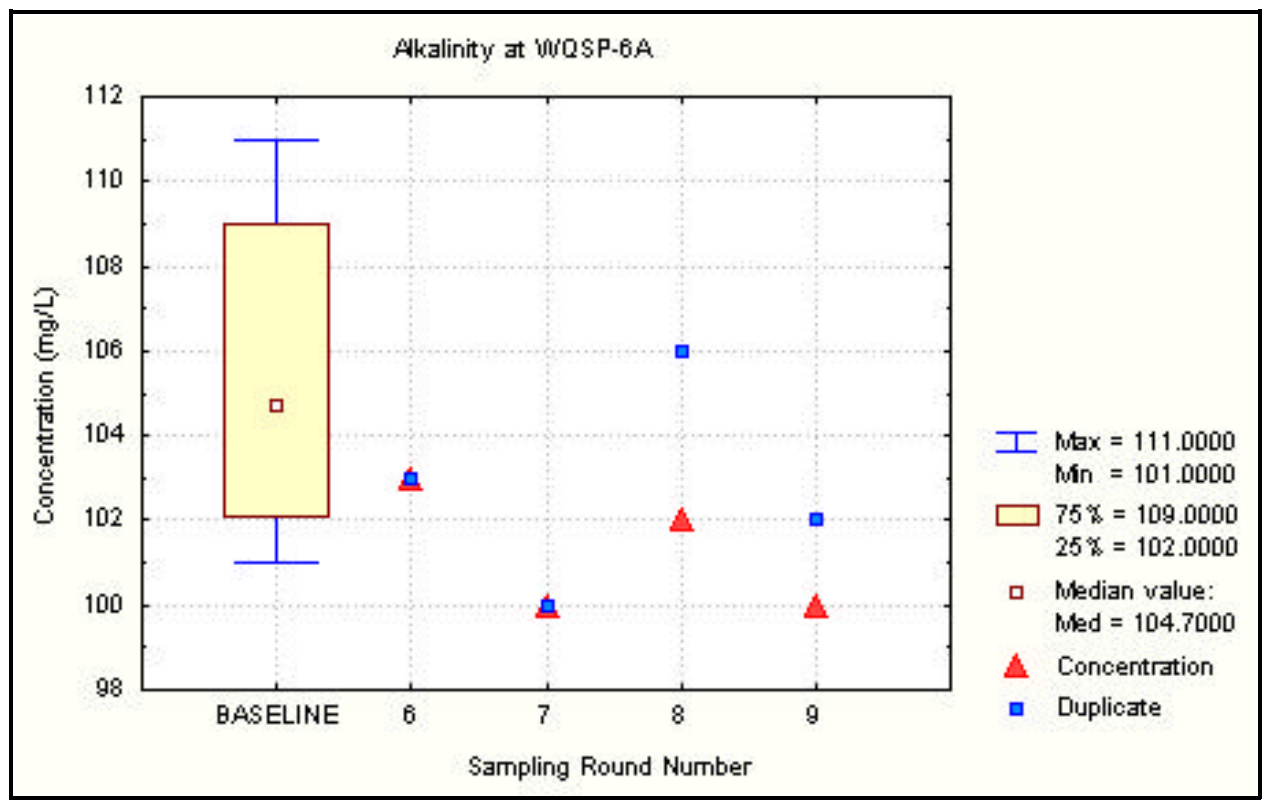

Figure 6.107 Time Trend Plot for Alkalinity at WQSP-6A

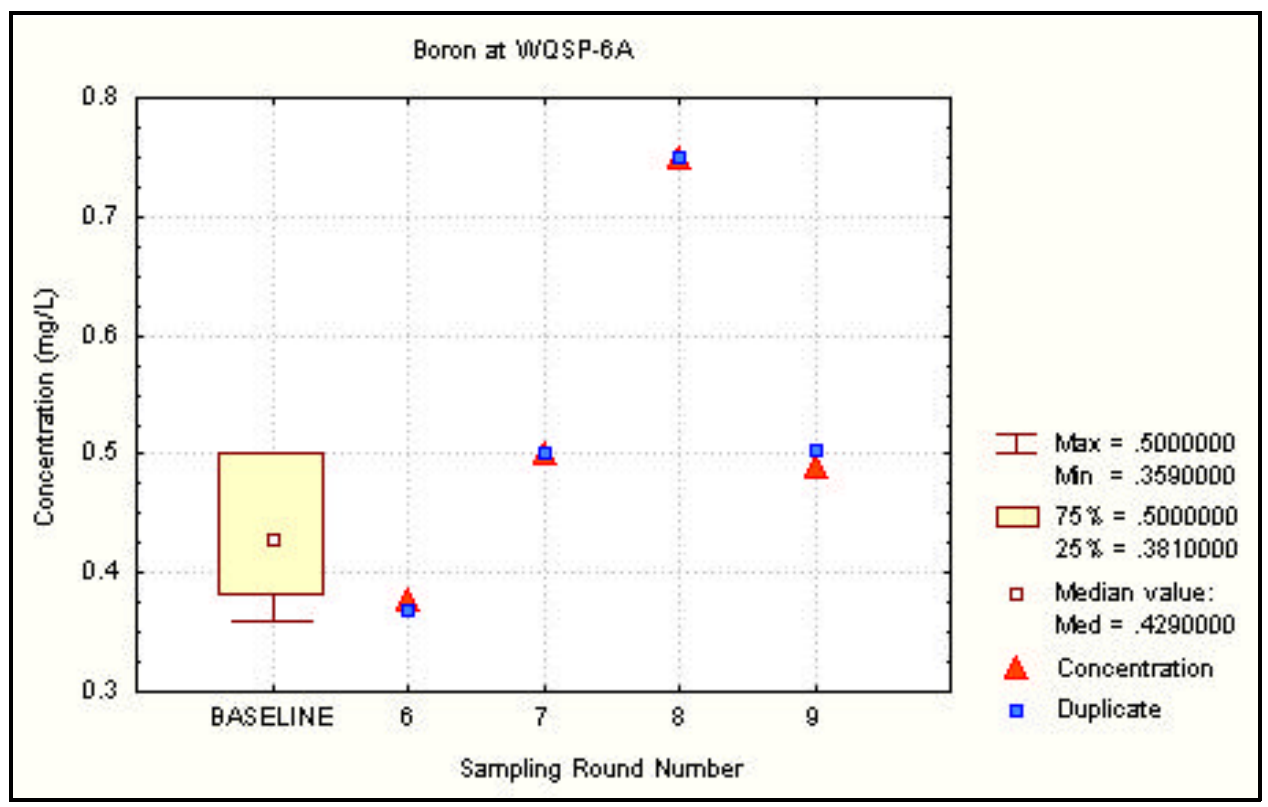

Figure 6.108 Time Trend Plot for Boron at WQSP-6A 


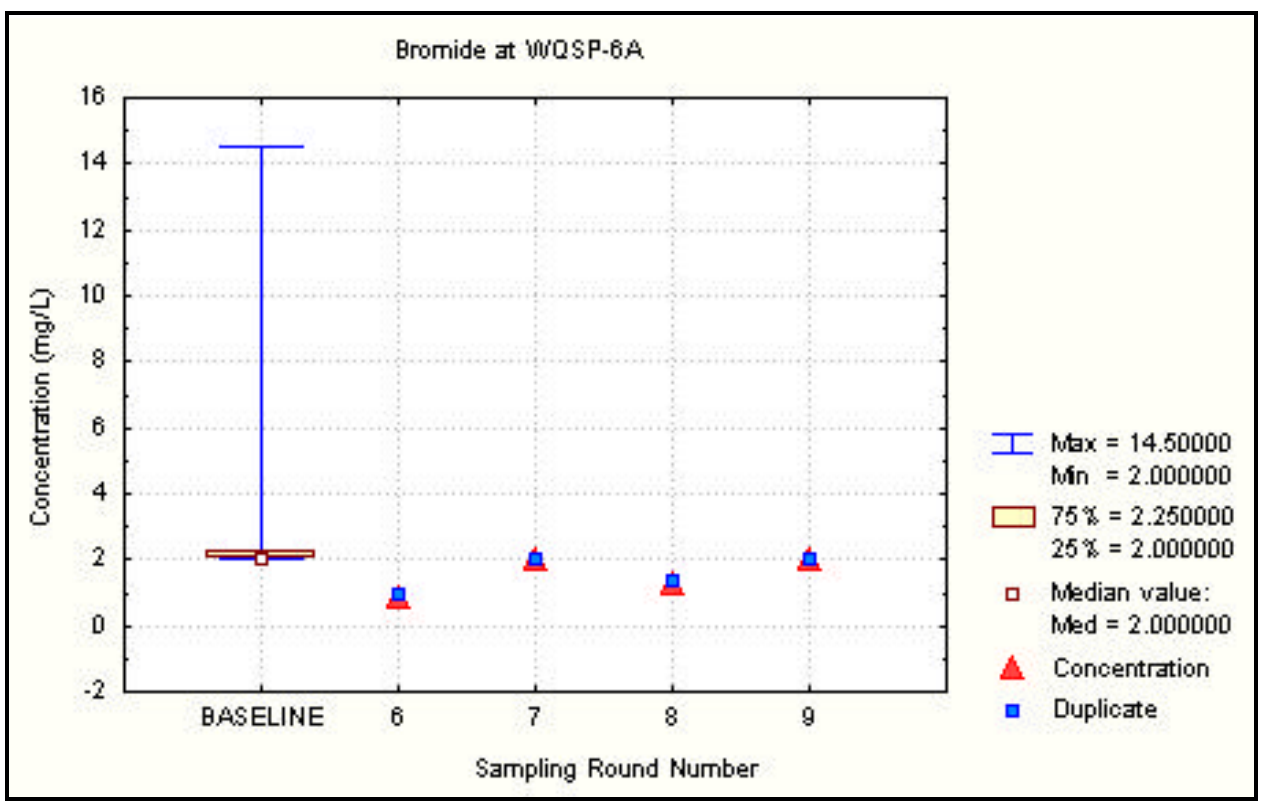

Figure 6.109 Time Trend Plot for Bromide at WQSP-6A

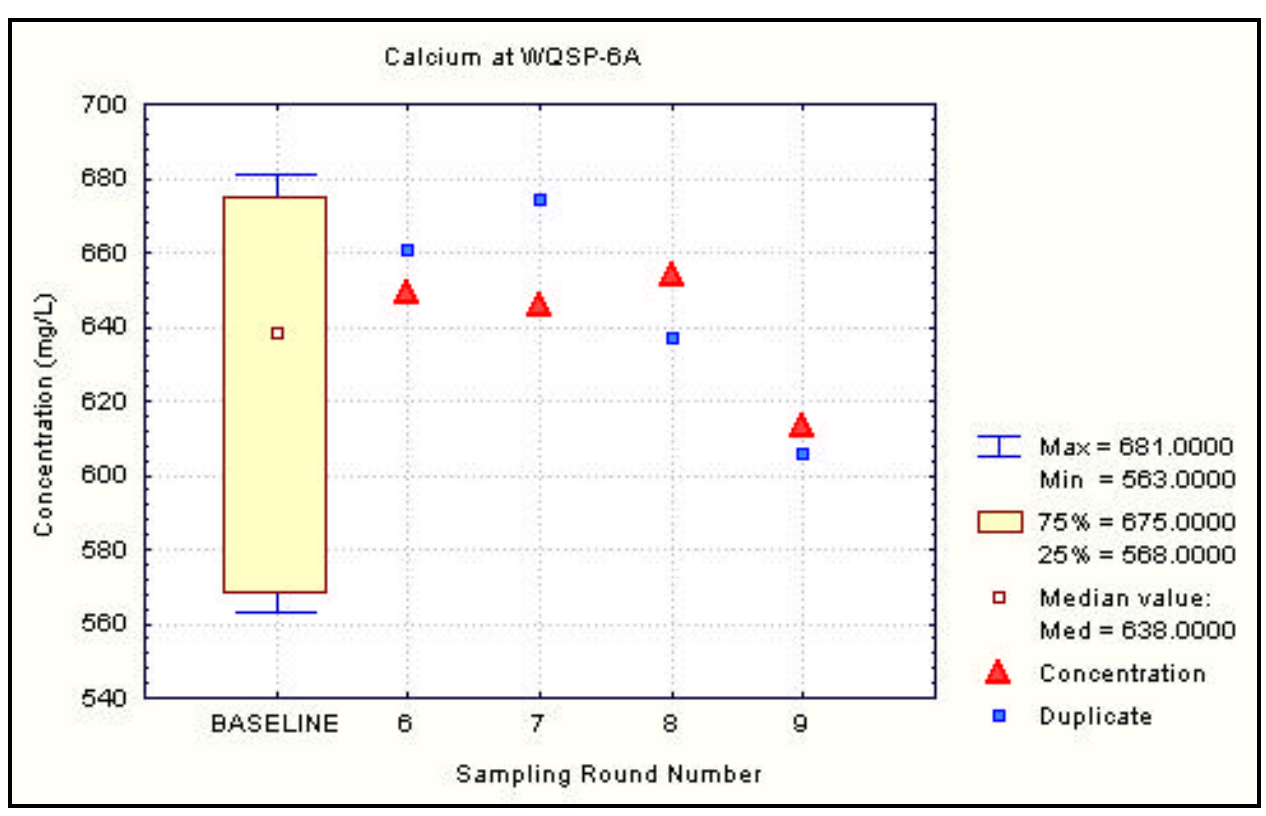

Figure 6.110 Time Trend Plot for Calcium at WQSP-6A 


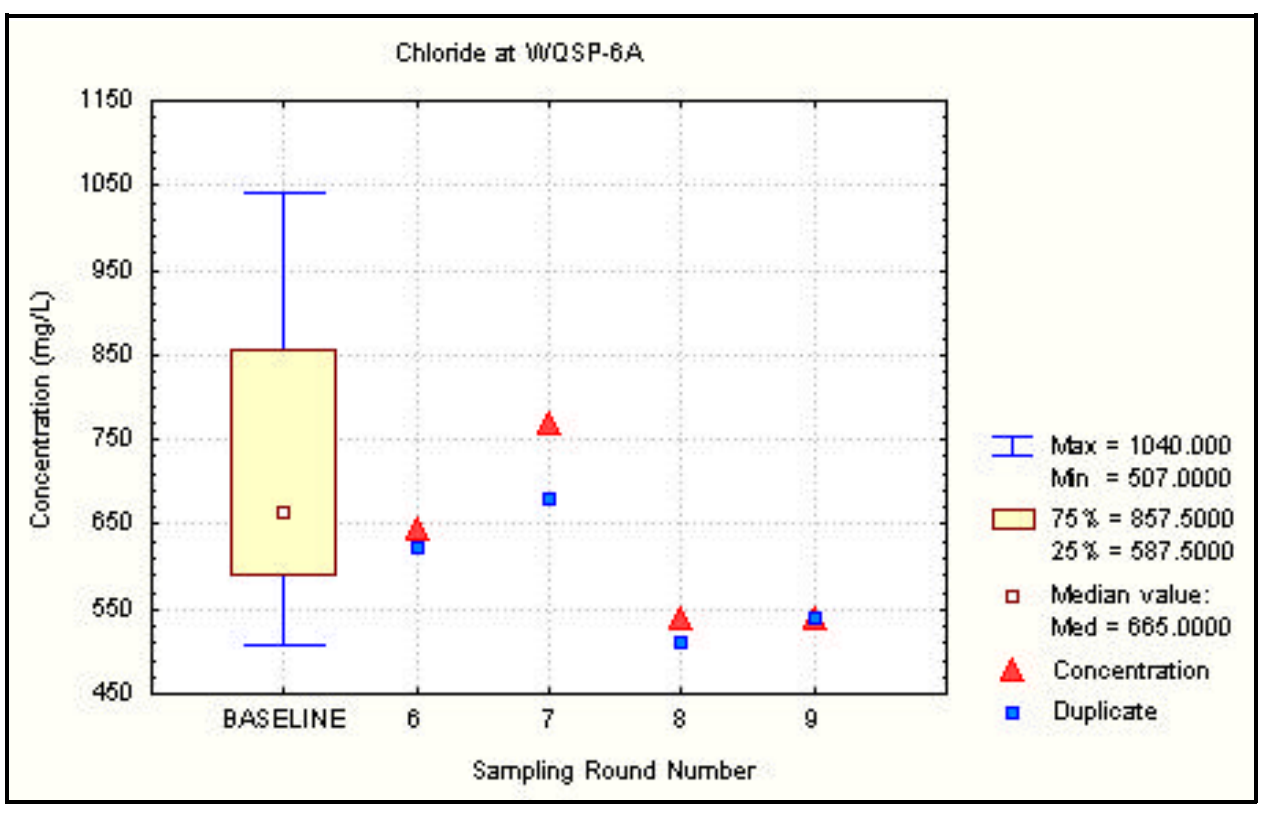

Figure 6.111 Time Trend Plot for Chloride at WQSP-6A

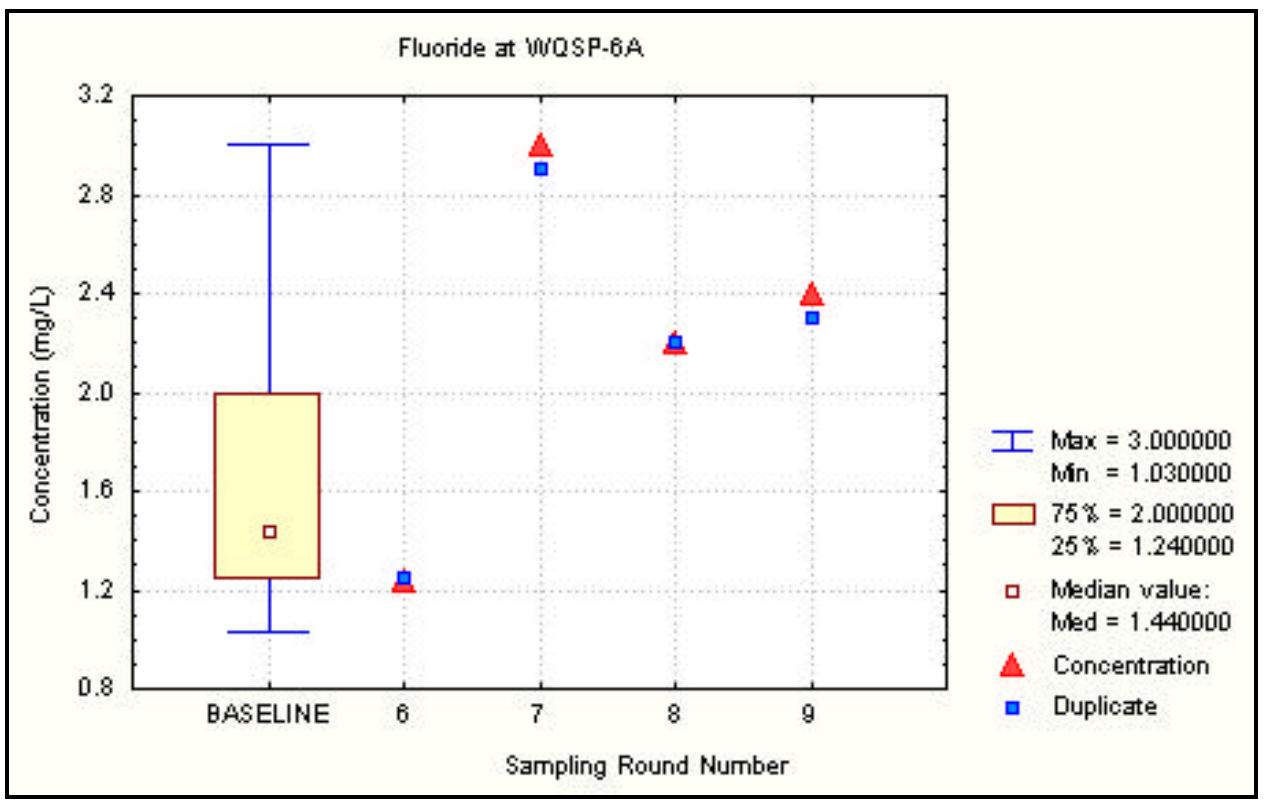

Figure 6.112 Time Trend Plot for Fluoride at WQSP-6A 


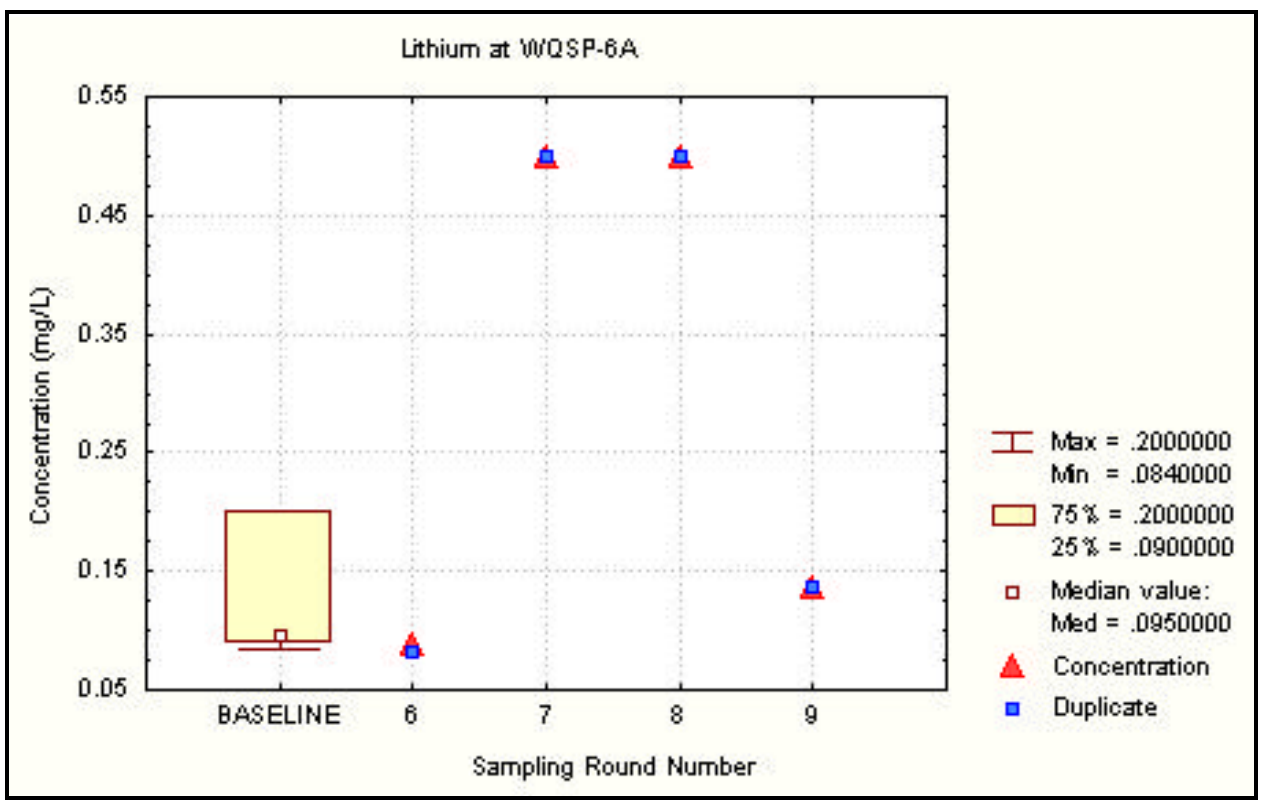

Figure 6.113 Time Trend Plot for Lithium at WQSP-6A

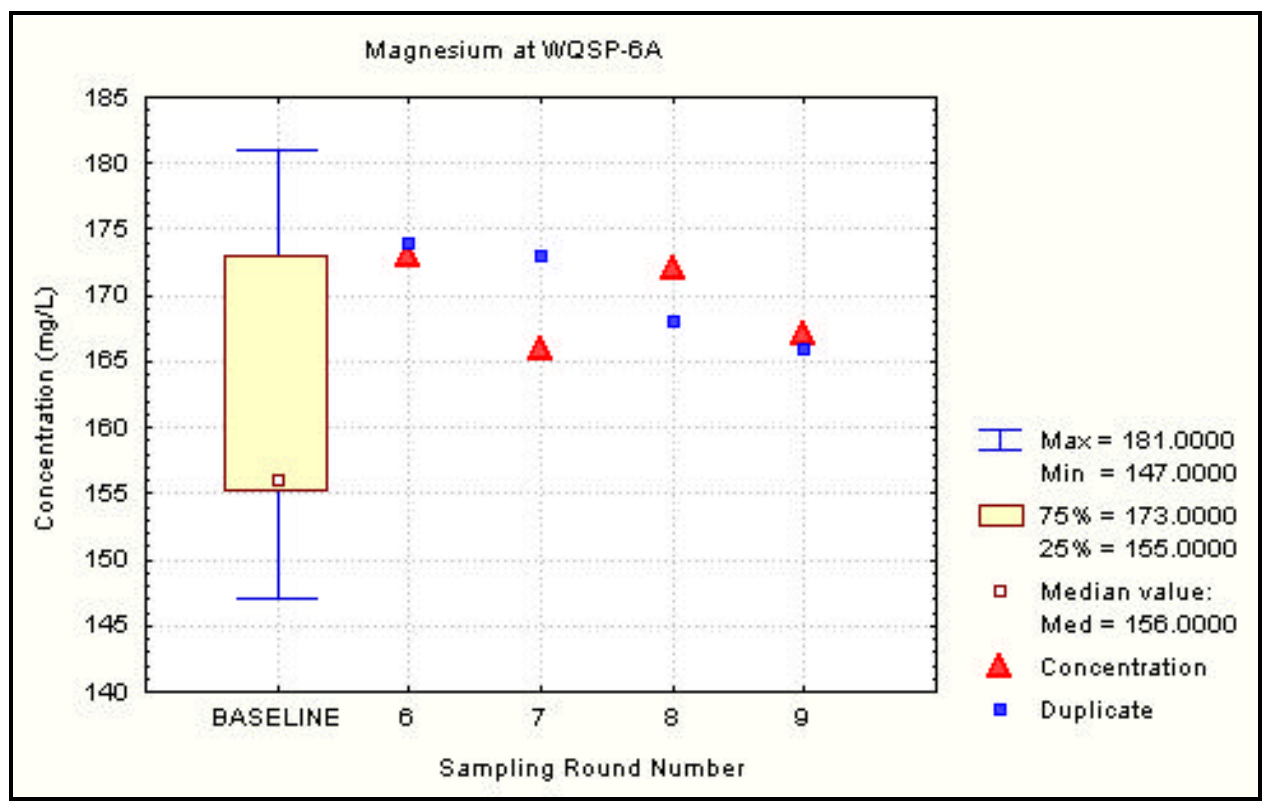

Figure 6.114 Time Trend Plot for Magnesium at WQSP-6A 


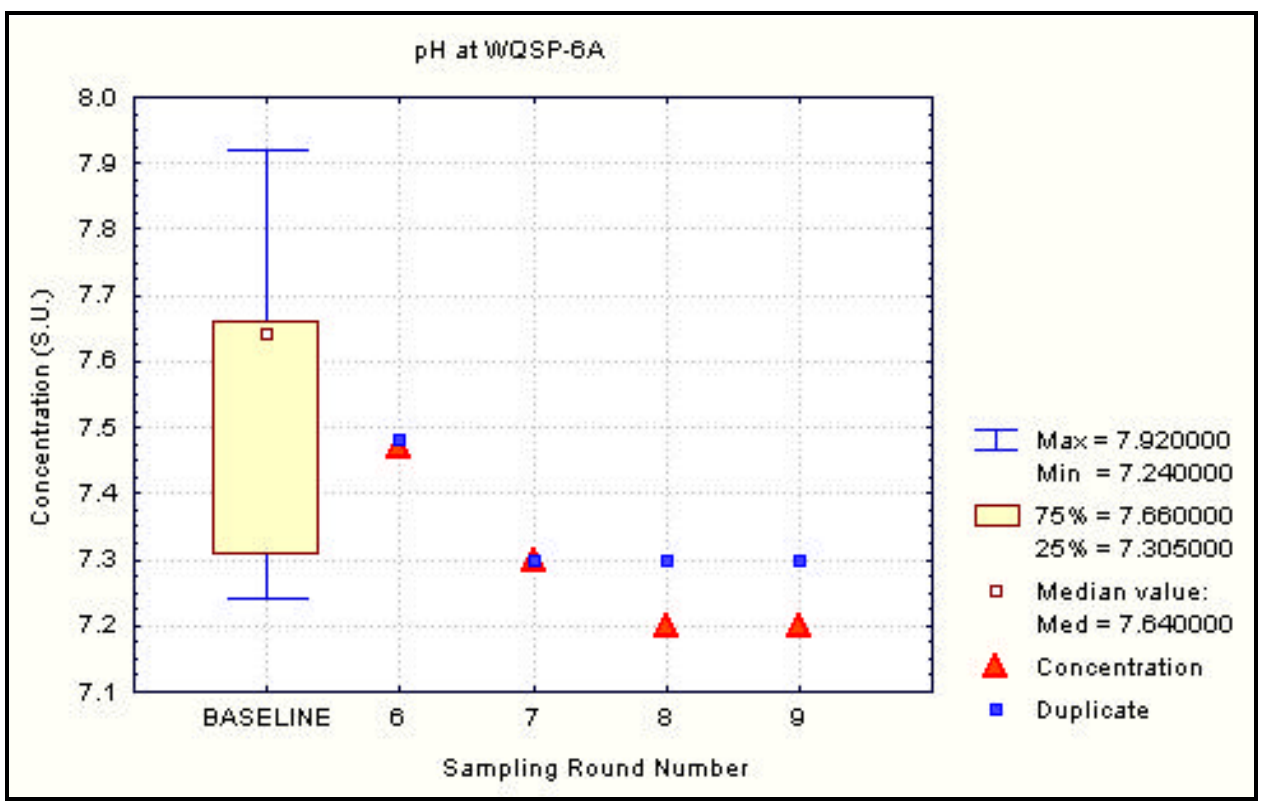

Figure 6.115 Time Trend Plot for $\mathrm{pH}$ at WQSP-6A

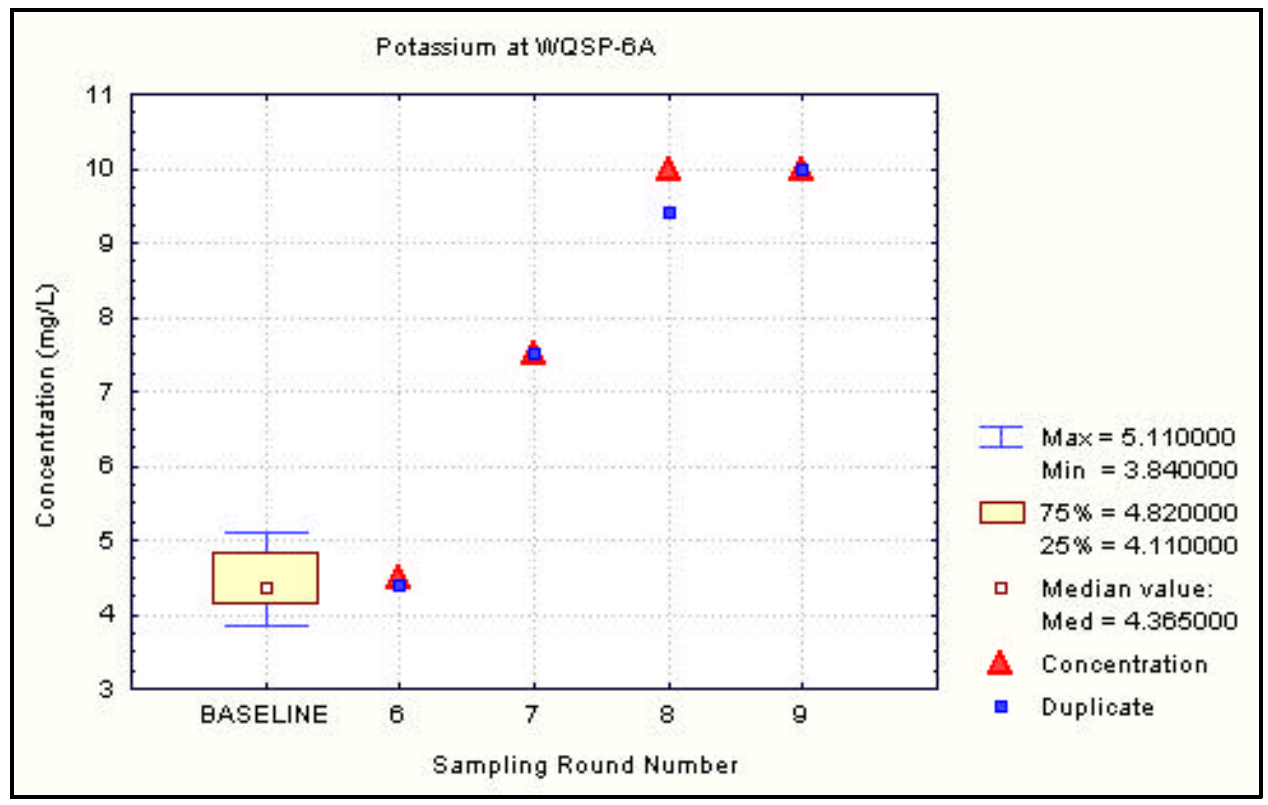

Figure 6.116 Time Trend Plot for Potassium at WQSP-6A 


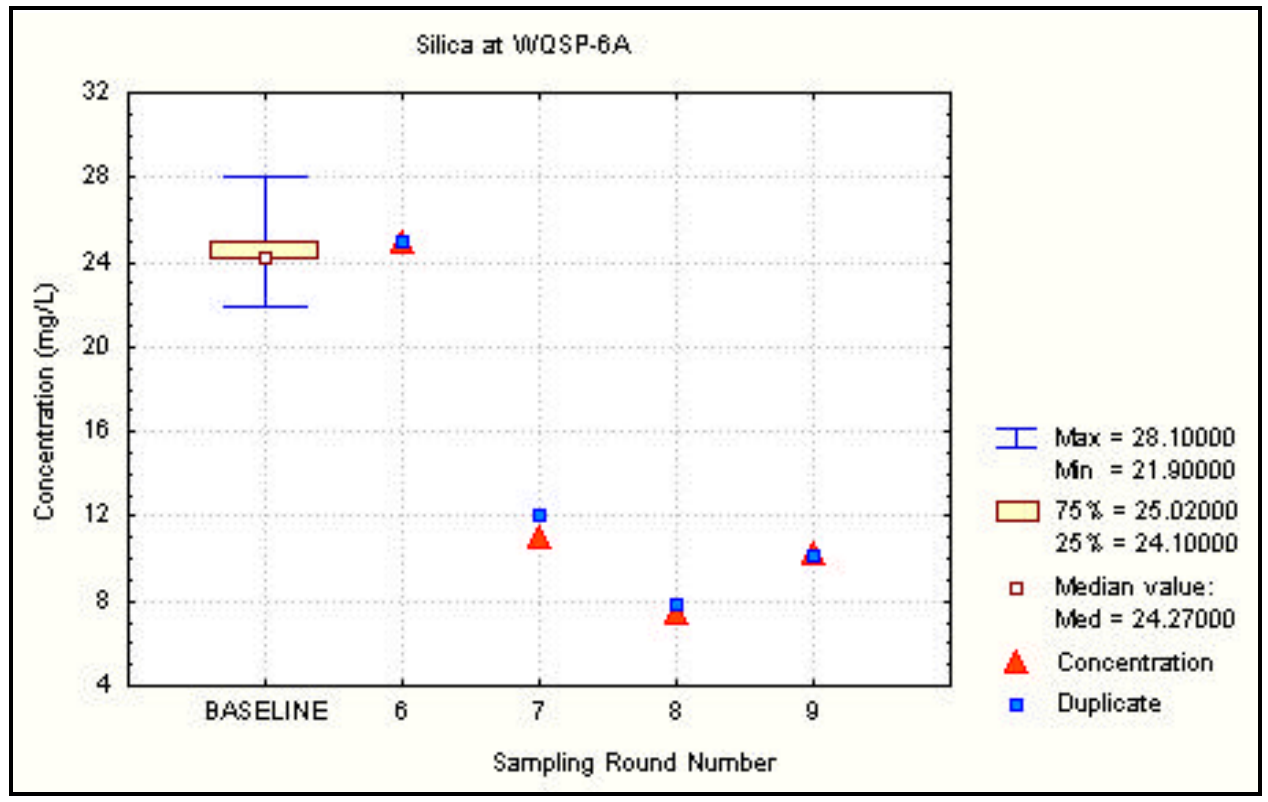

Figure 6.117 Time Trend Plot for Silica at WQSP-6A

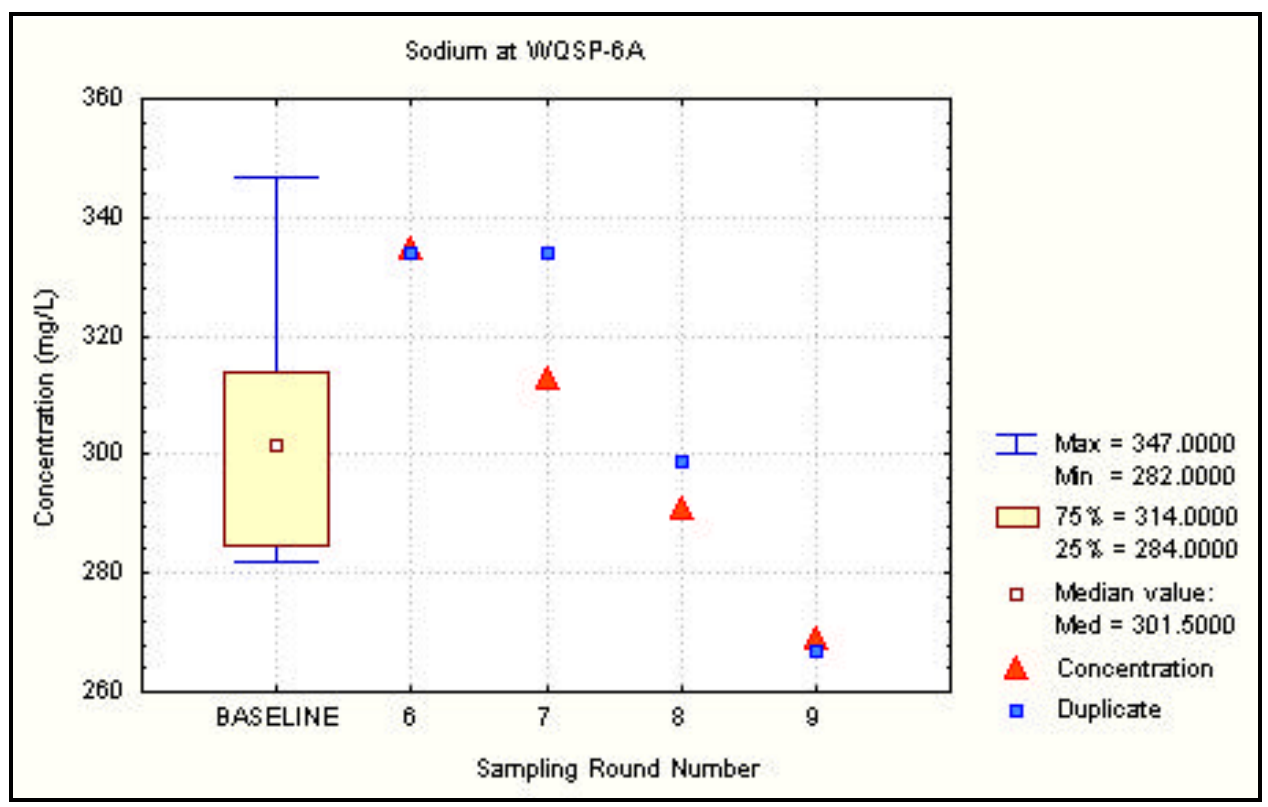

Figure 6.118 Time Trend Plot for Sodium at WQSP-6A 


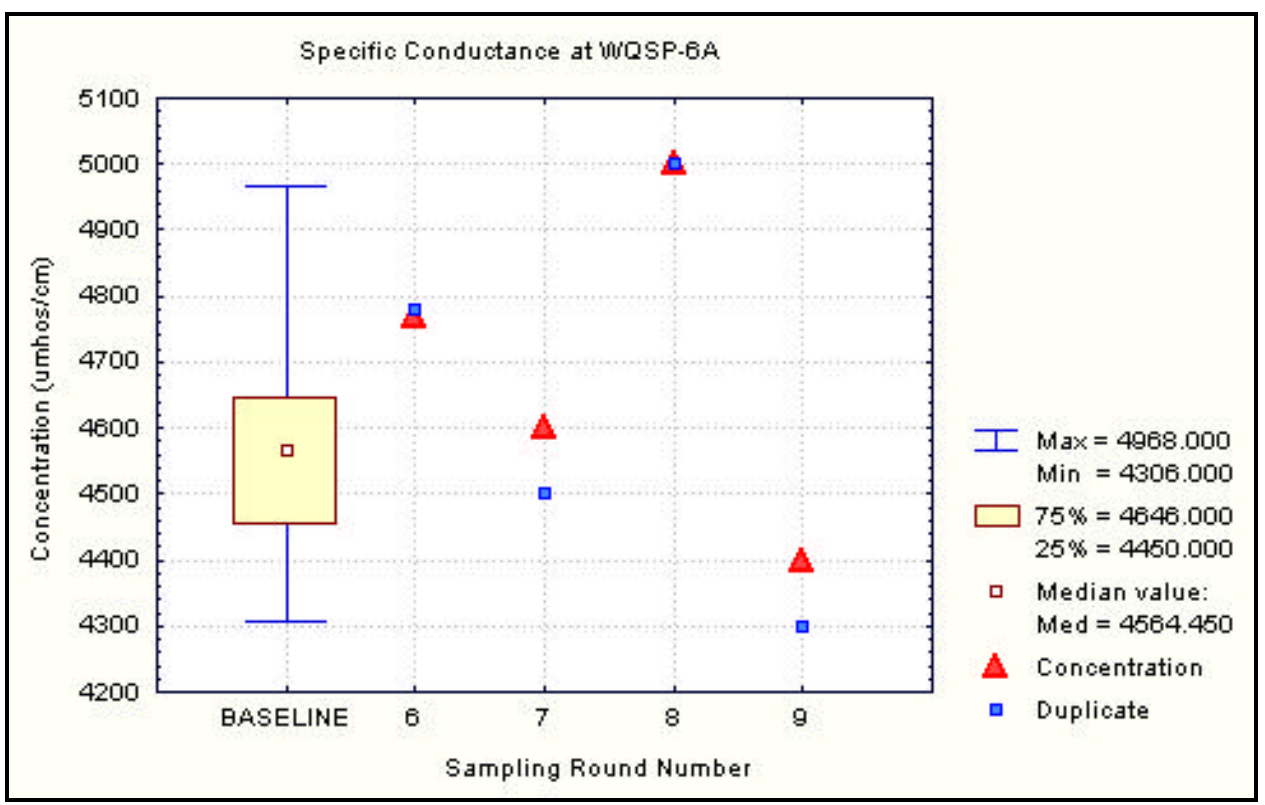

Figure 6.119 Time Trend Plot for Specific Conductance at WQSP-6A

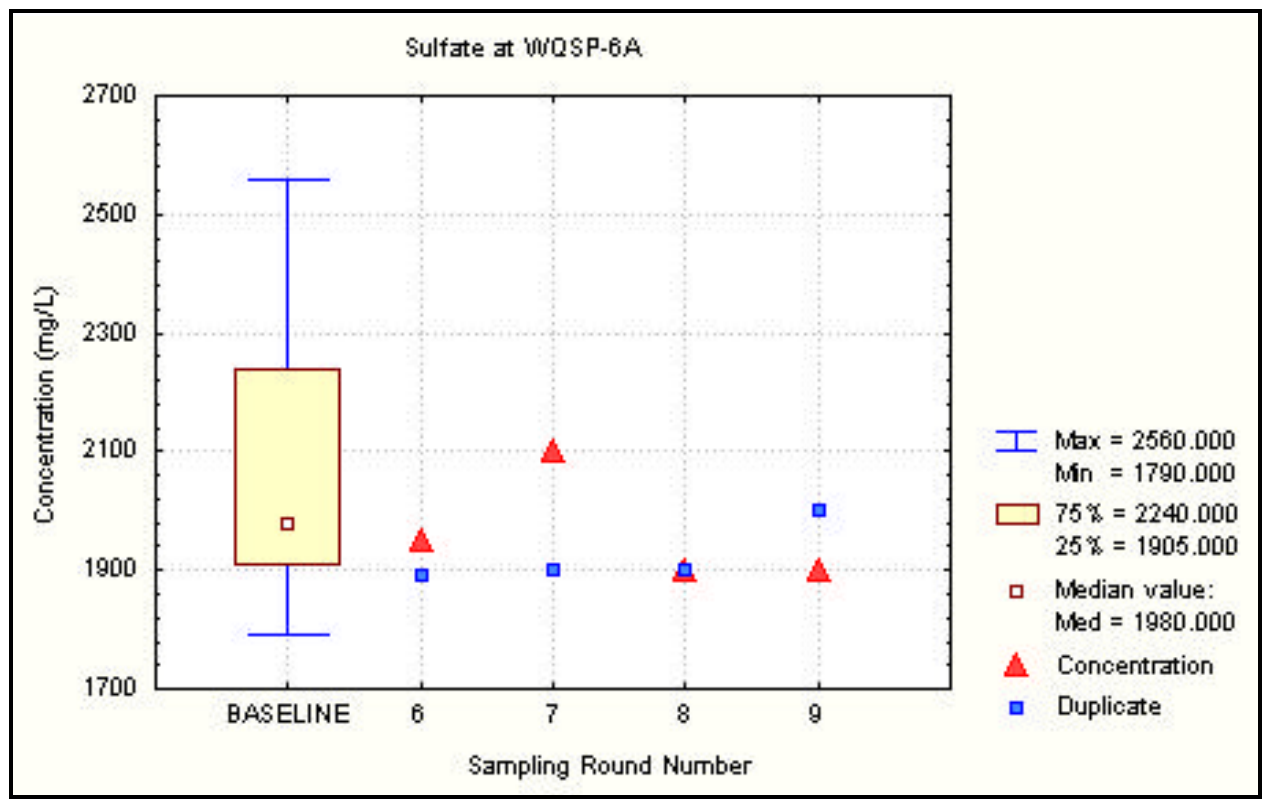

Figure 6.120 Time Trend Plot for Sulfate at WQSP-6A 


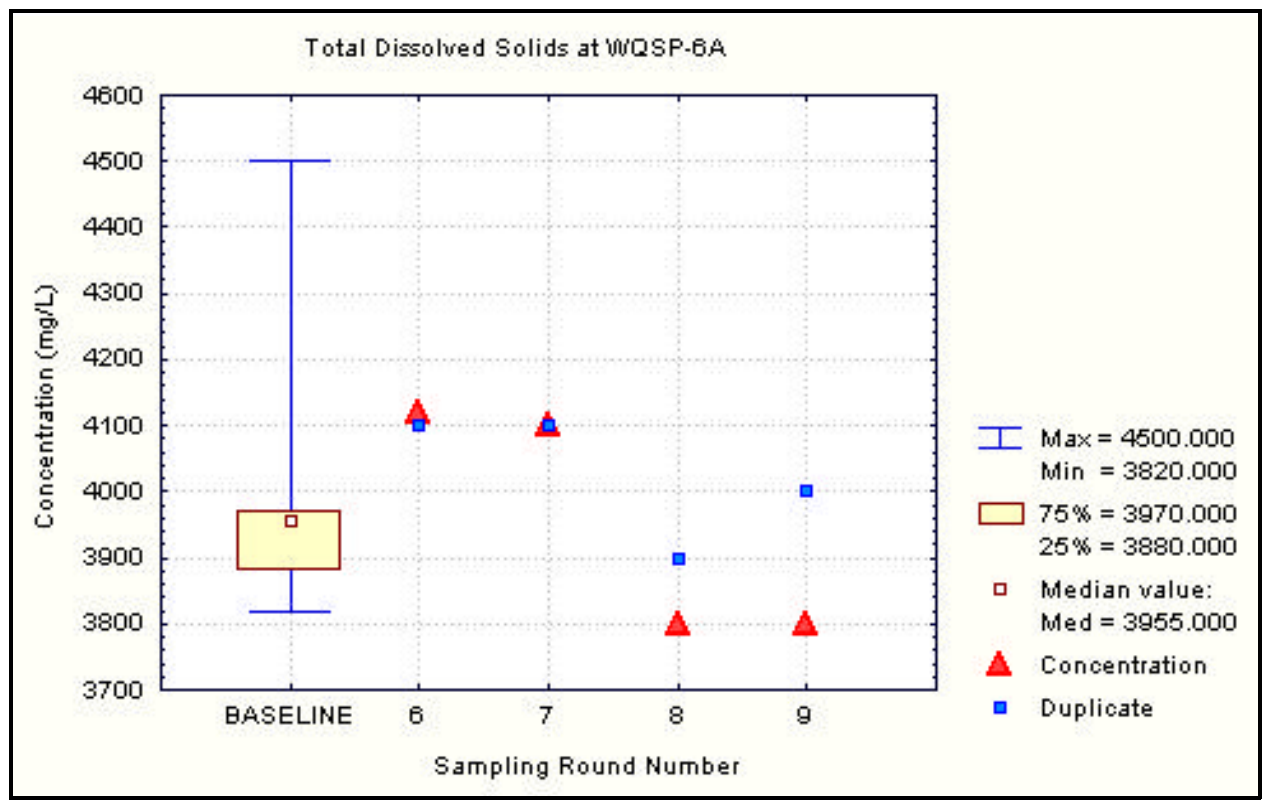

Figure 6.121 Time Trend Plot for Total Dissolved Solids at WQSP-6A

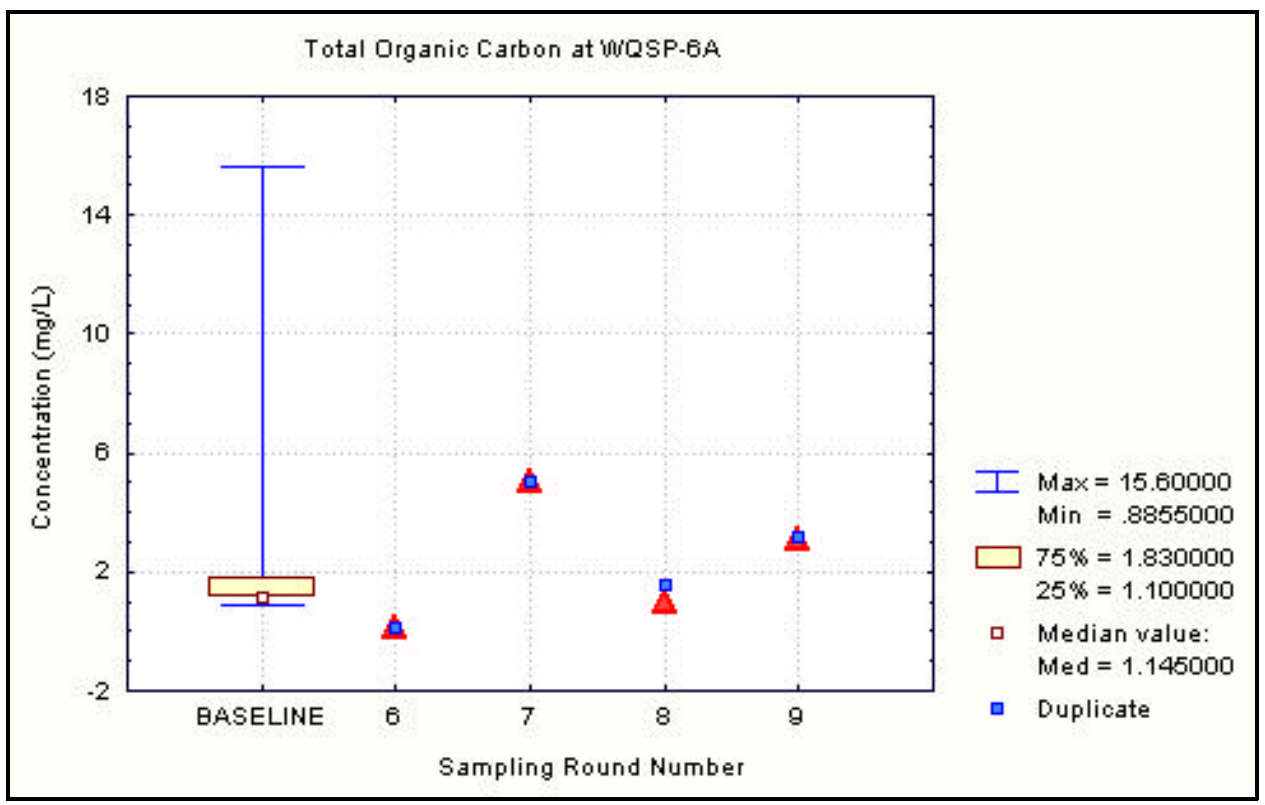

Figure 6.122 Time Trend Plot for Total Organic Carbon at WQSP-6A 


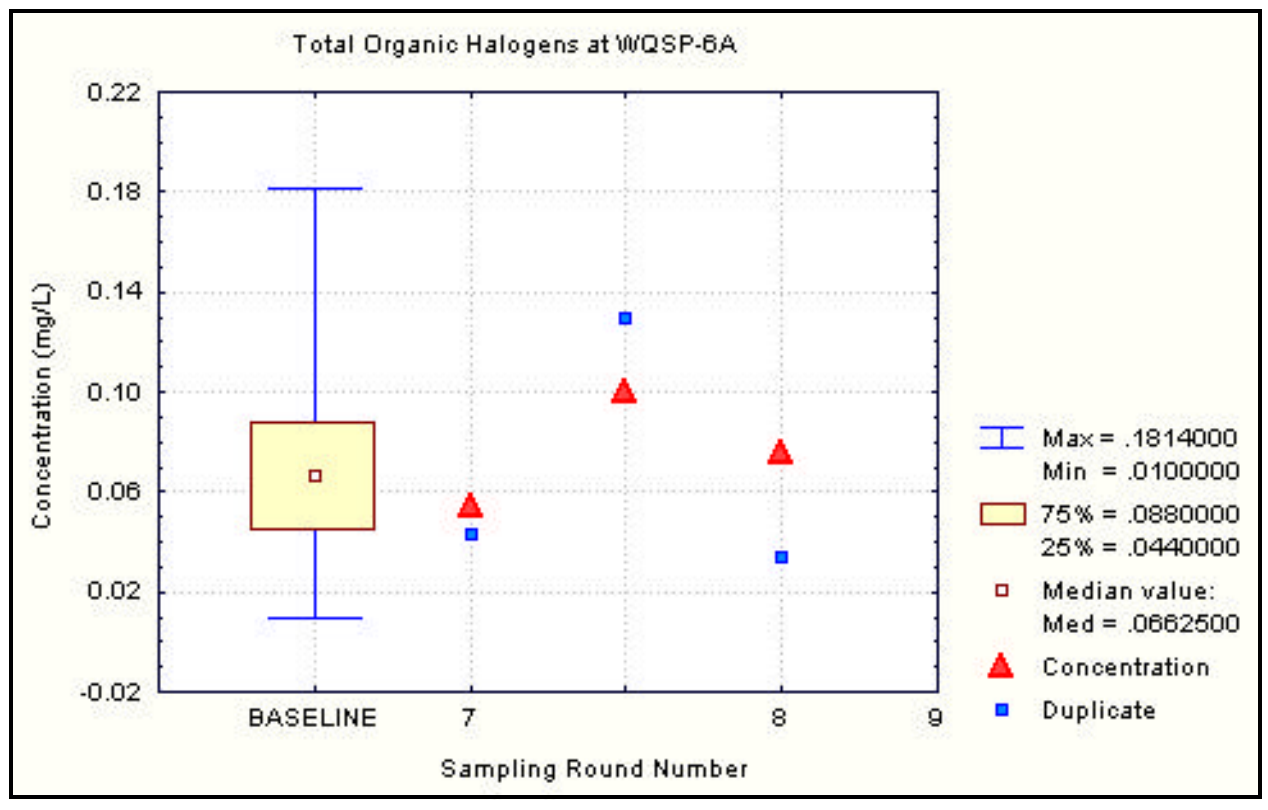

Figure 6.123 Time Trend Plot for Total Organic Halogens at WQSP-6A 


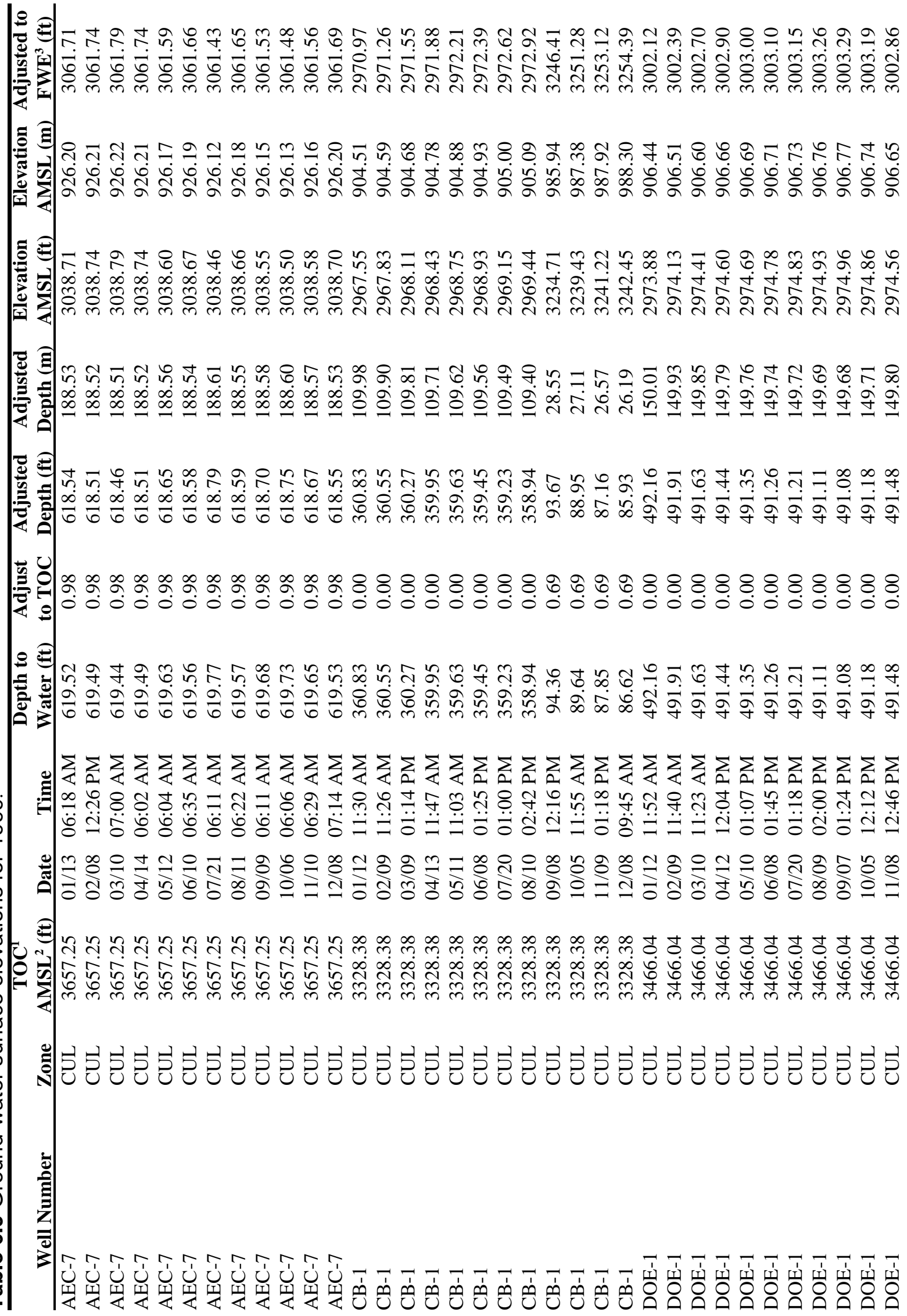




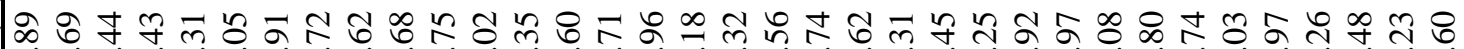

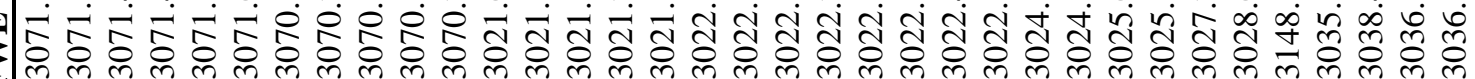

궁 సু

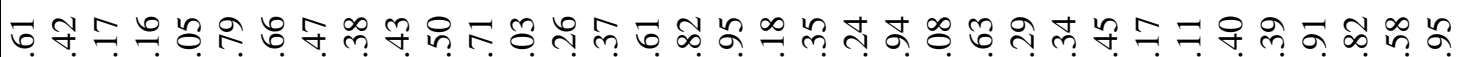

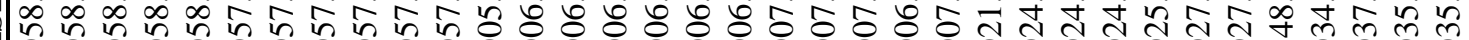

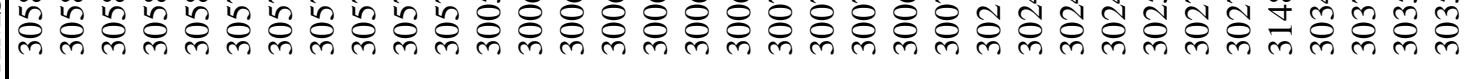

๓

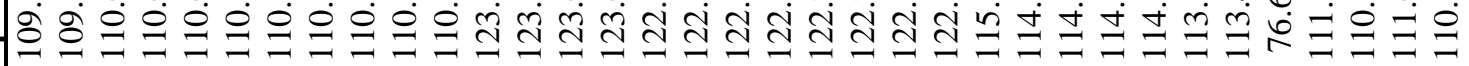

† 遖

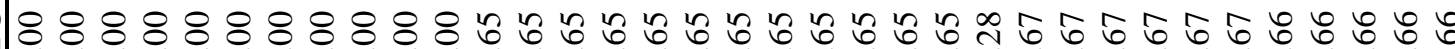

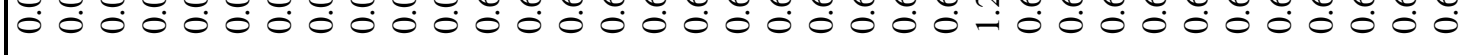

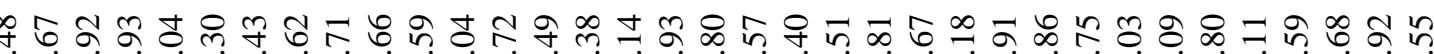
宛

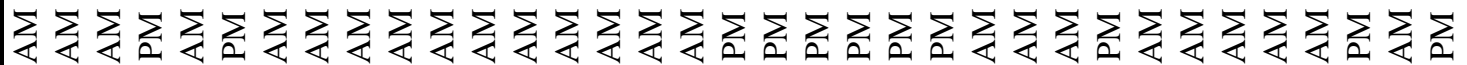
키음

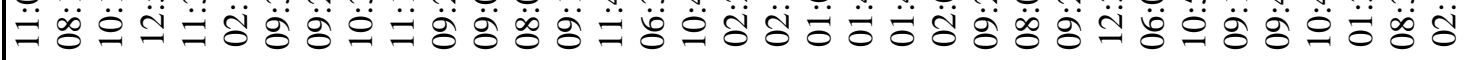

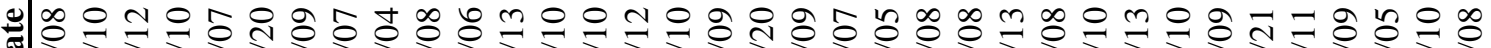

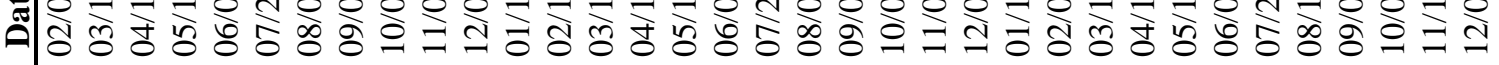

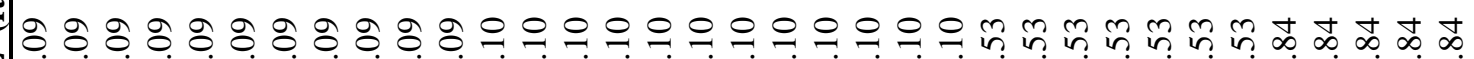

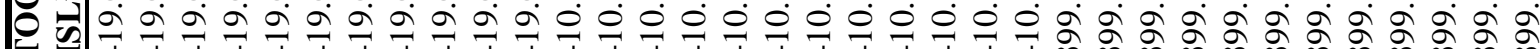

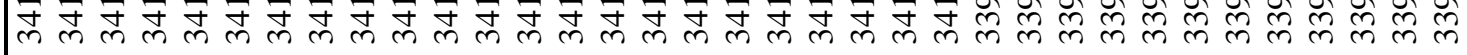

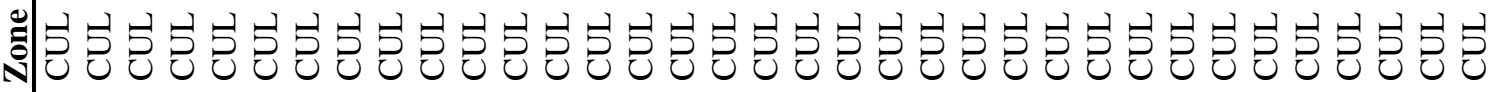




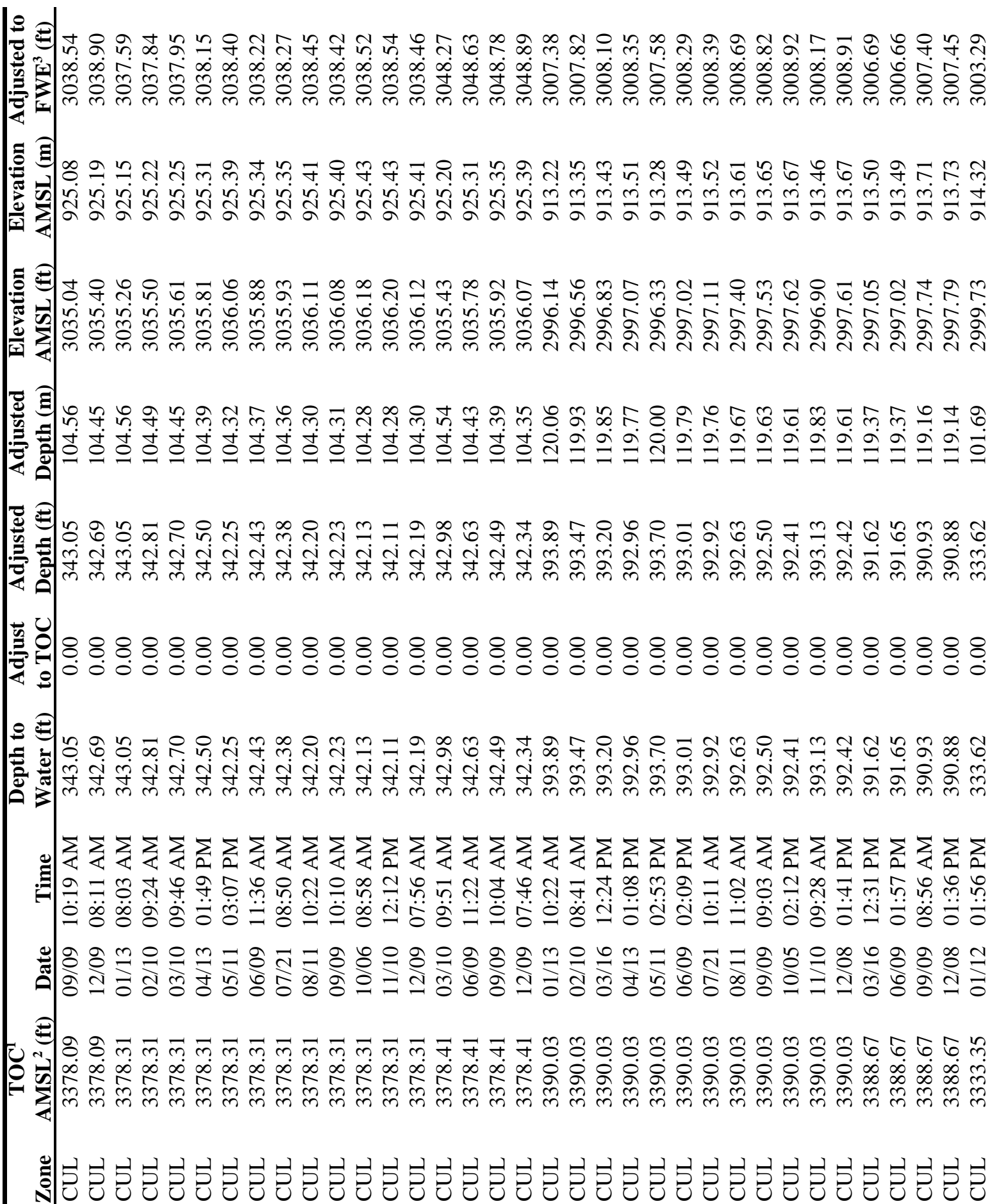




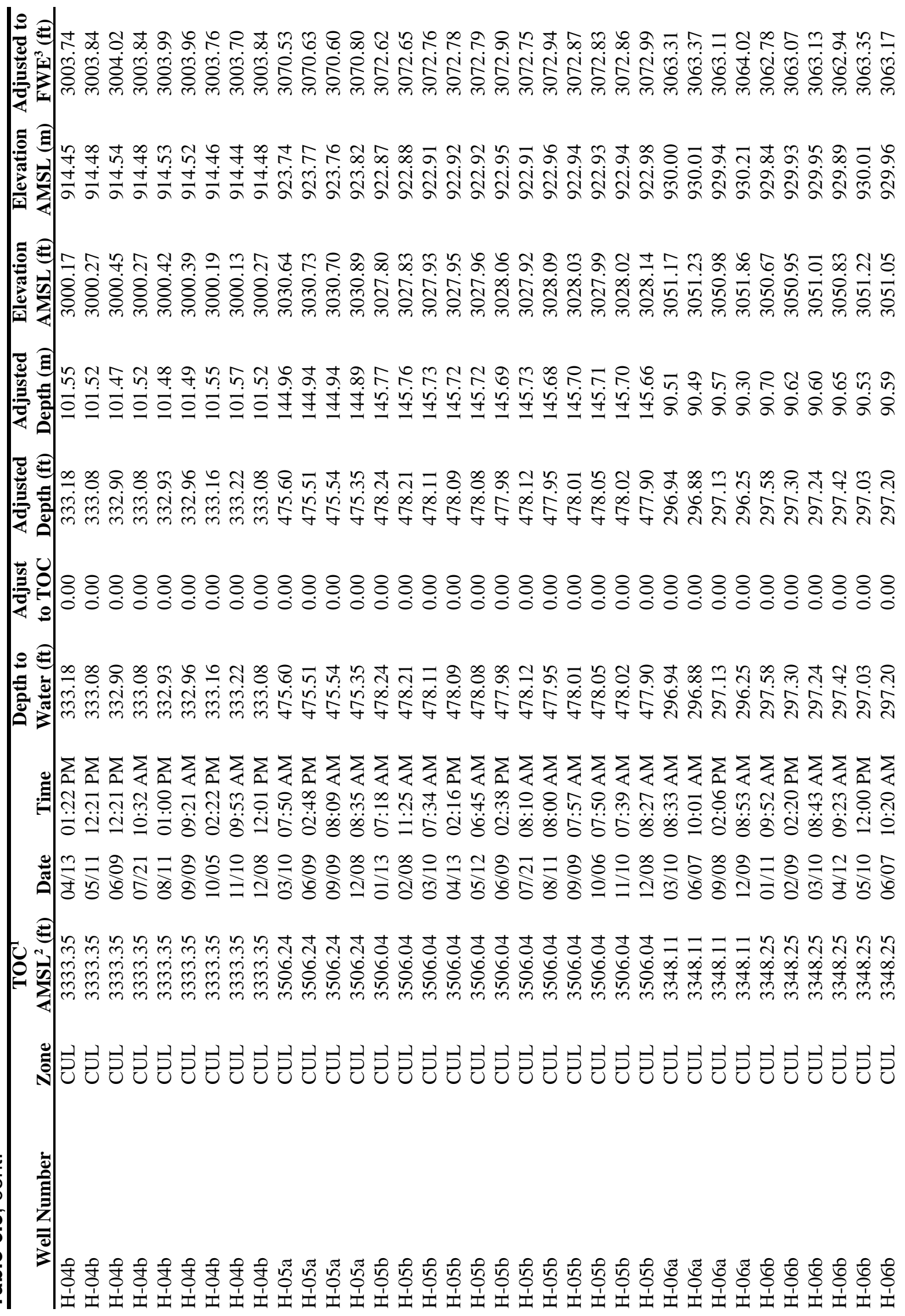




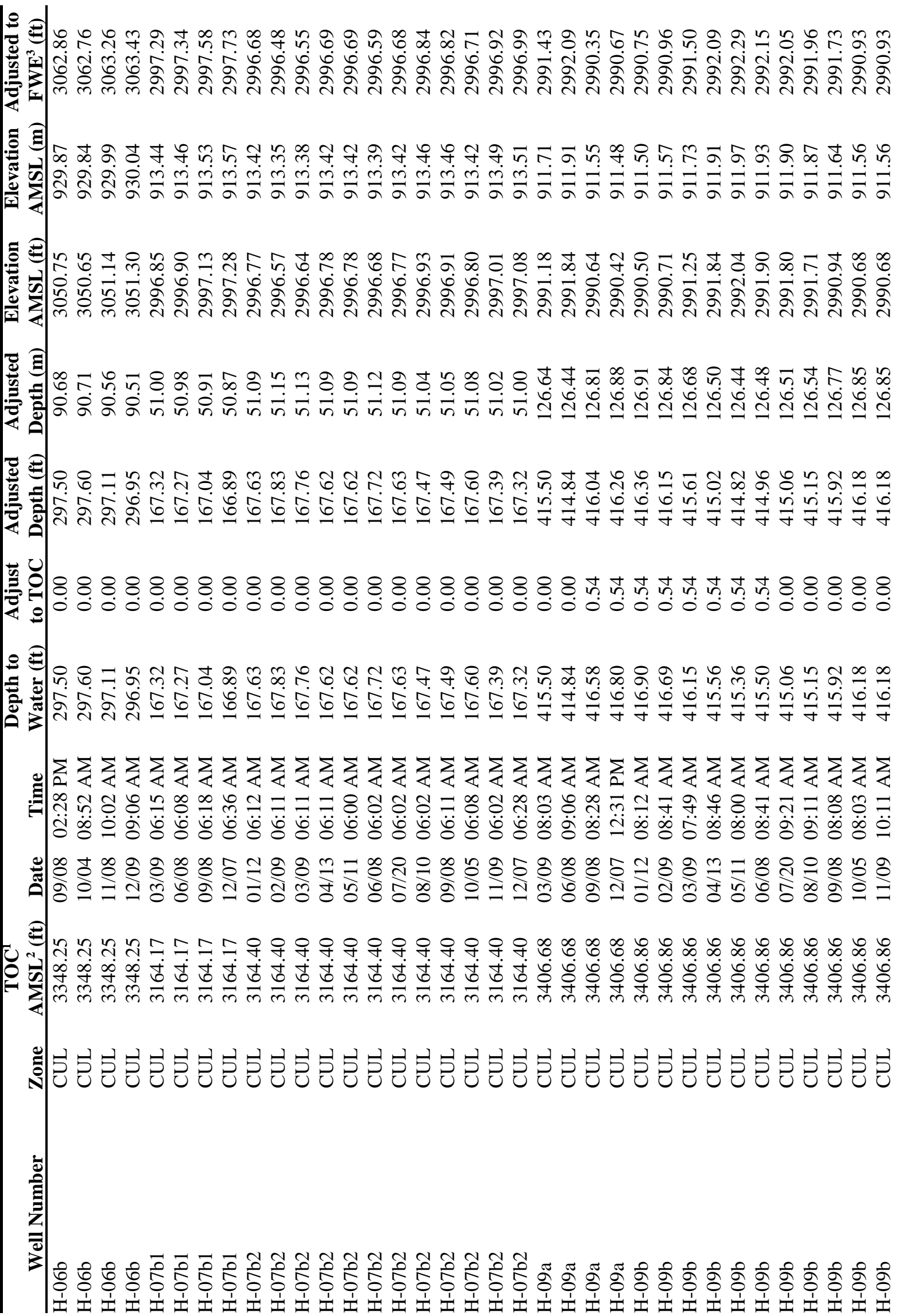




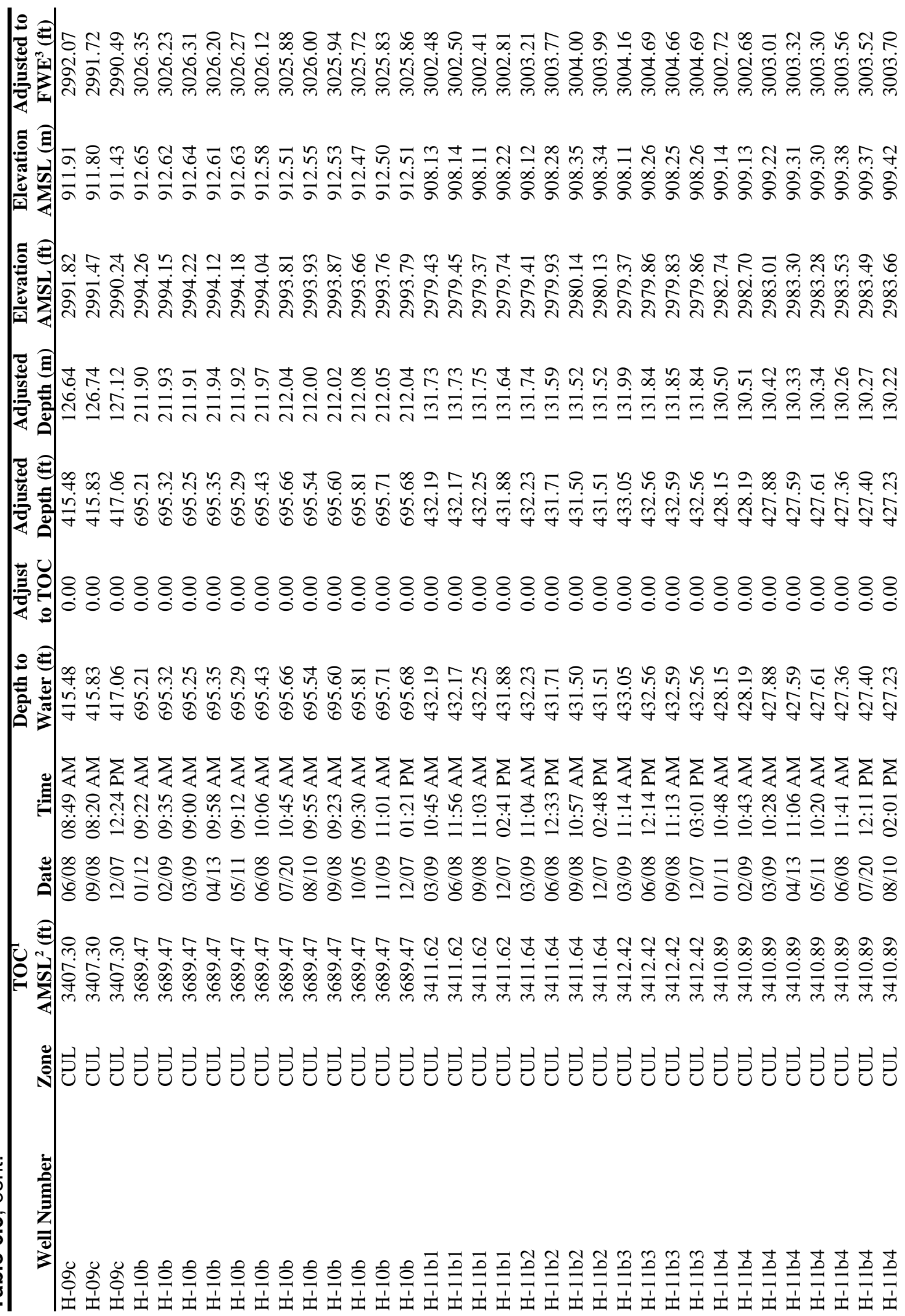




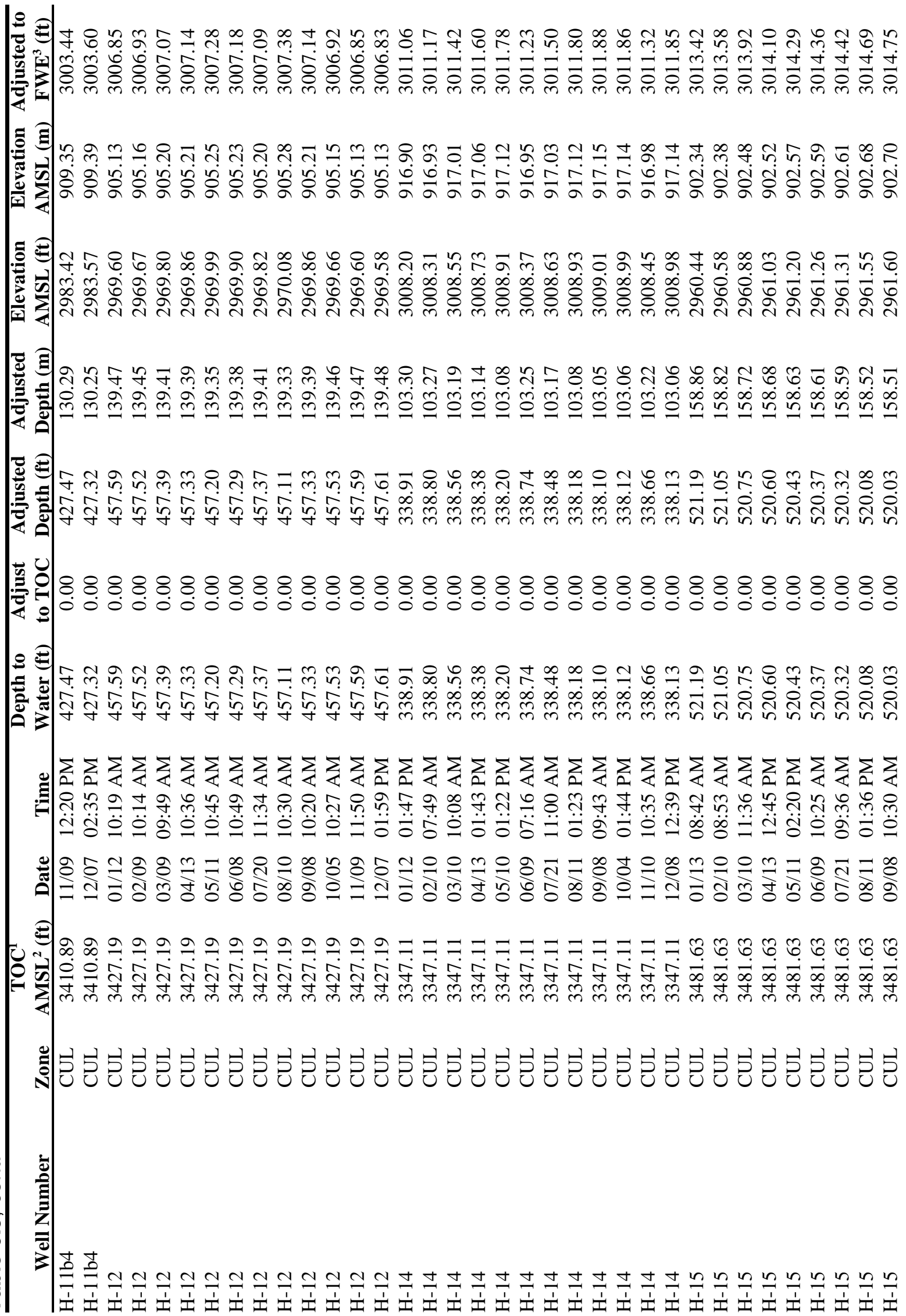




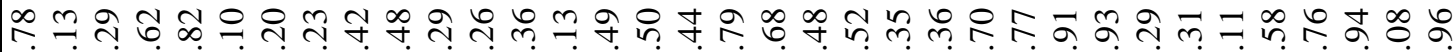

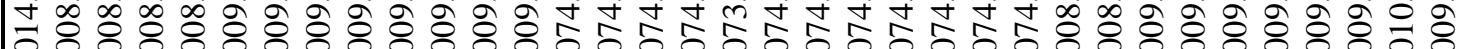

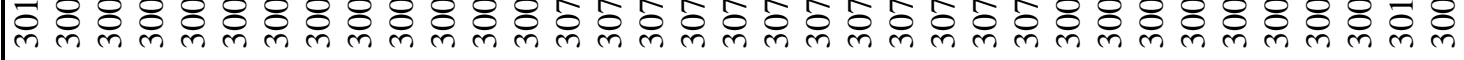

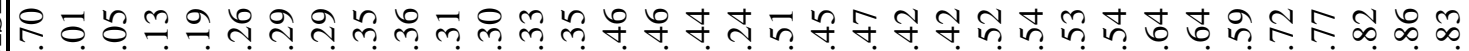

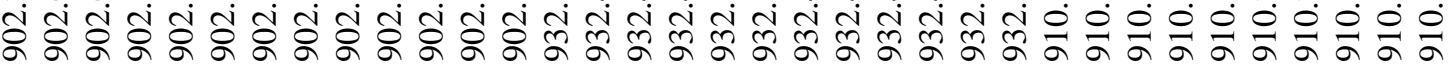

닝

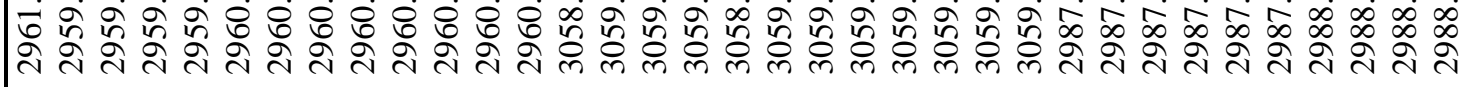

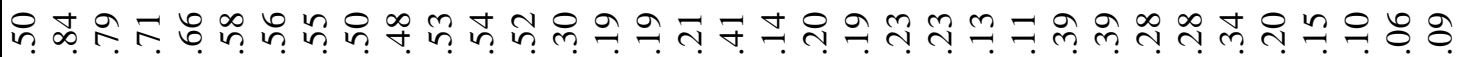

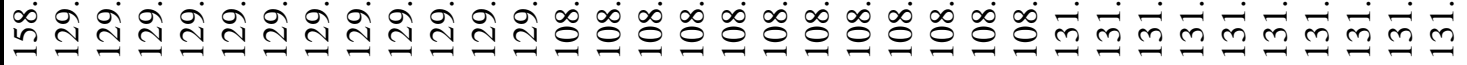

후

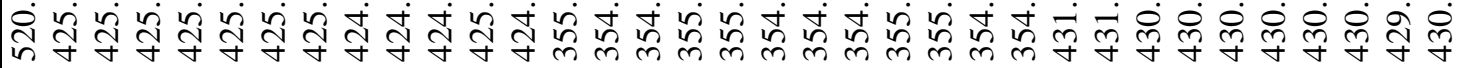

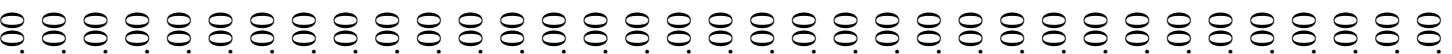

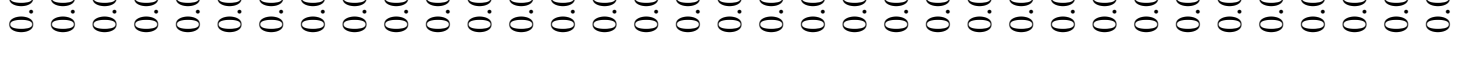

б.

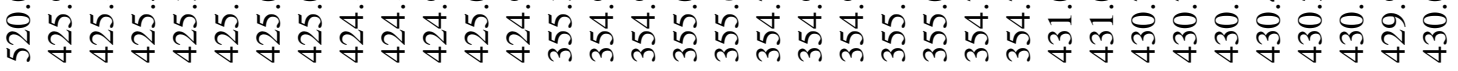

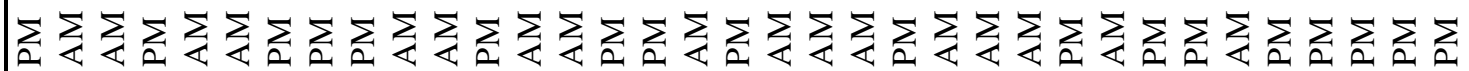
壮 8 n 过宅

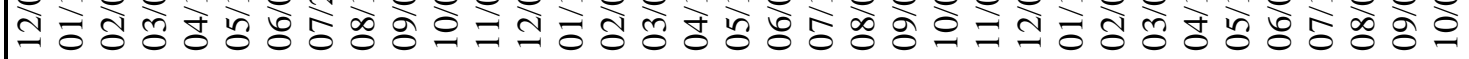

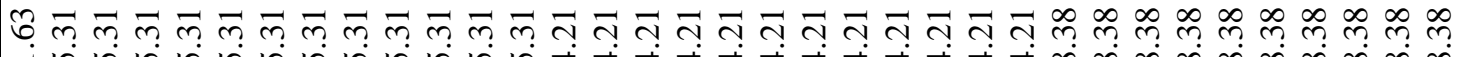

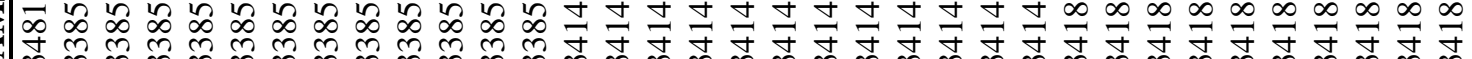

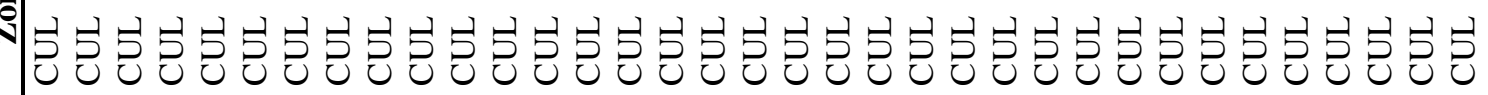

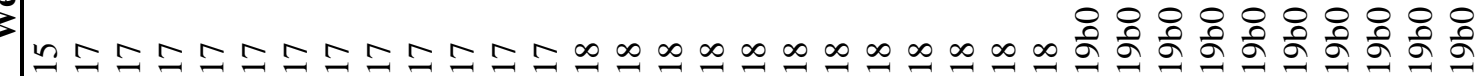

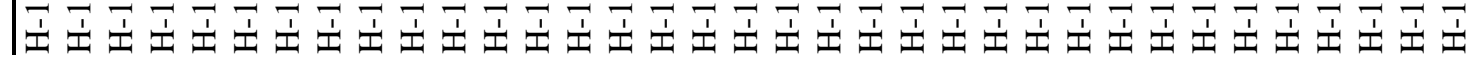




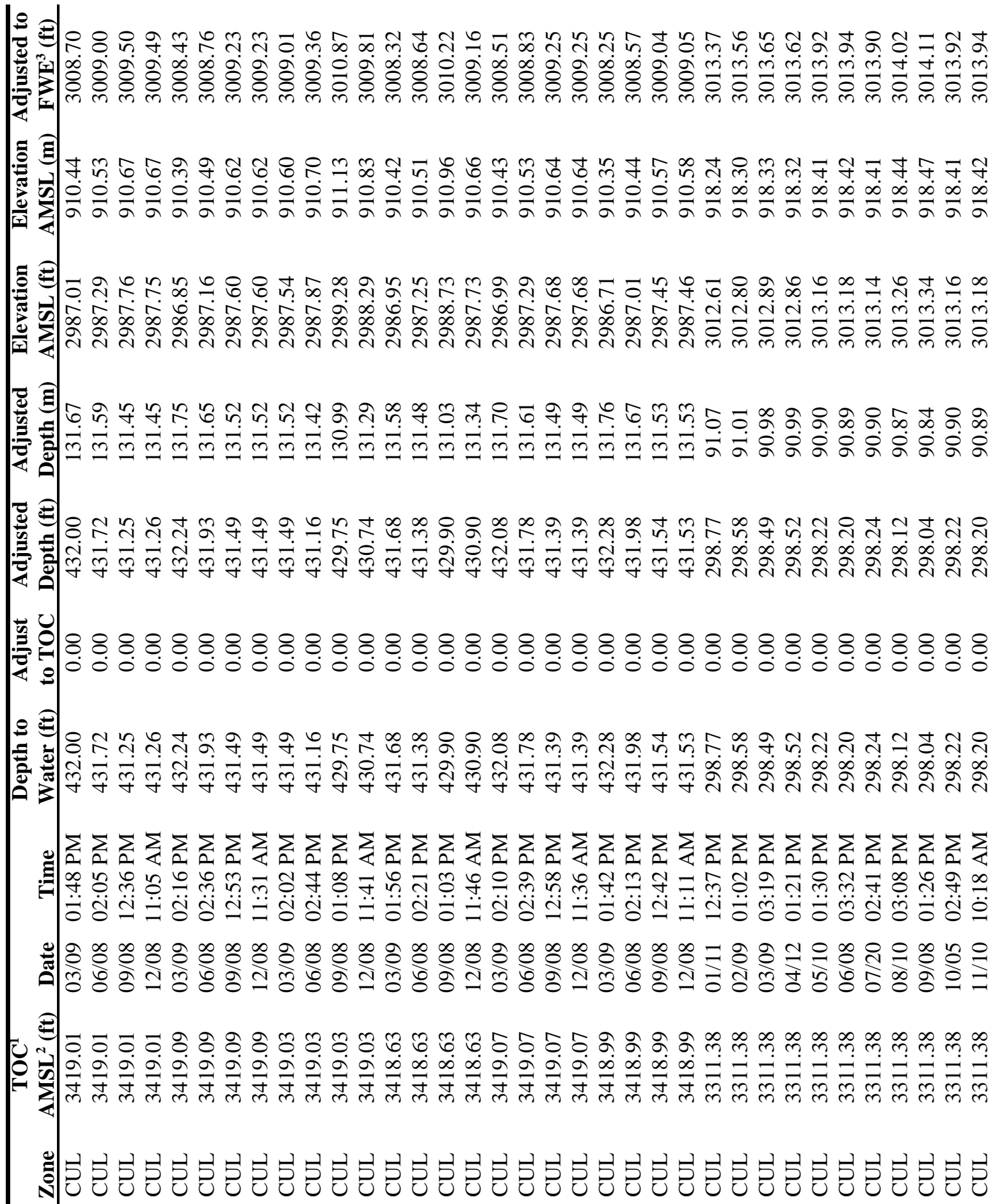




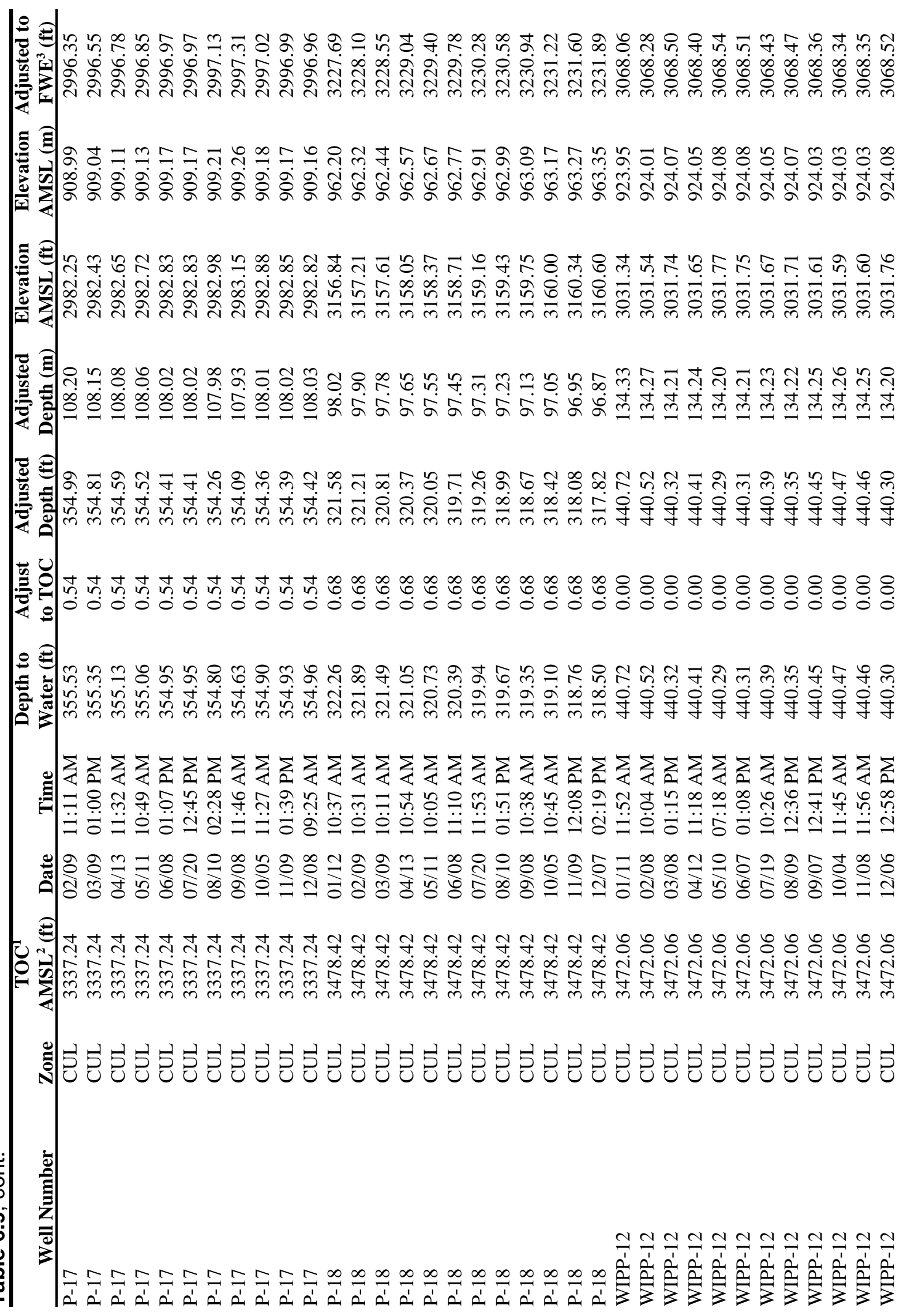




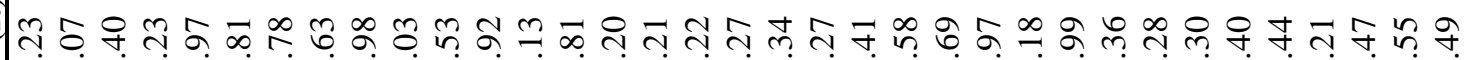
第

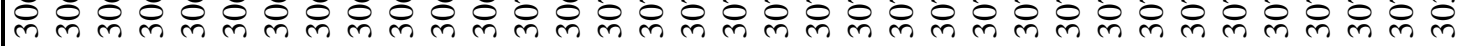

ㅊำกำำ

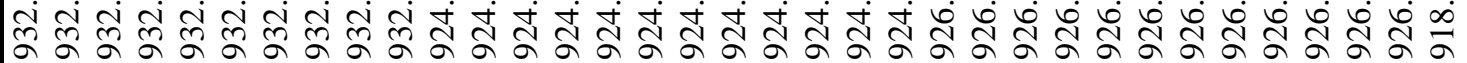

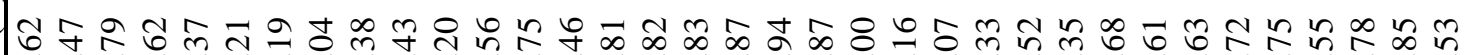

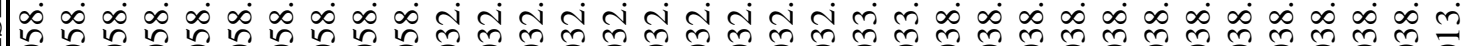

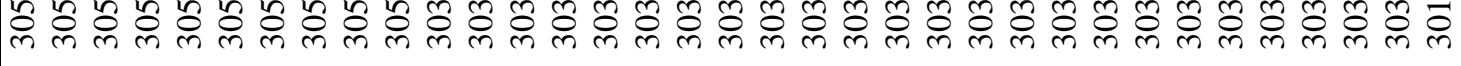

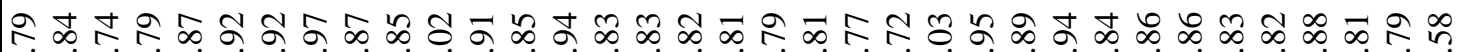

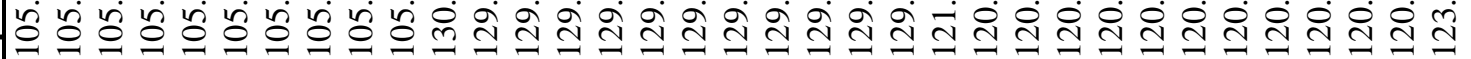

oิt

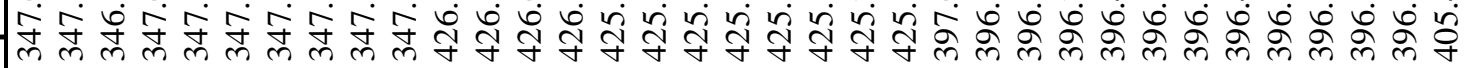

t t t t t t t t t t

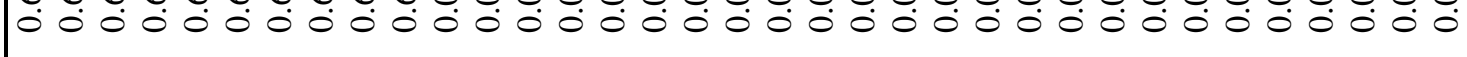

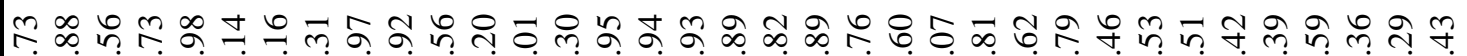

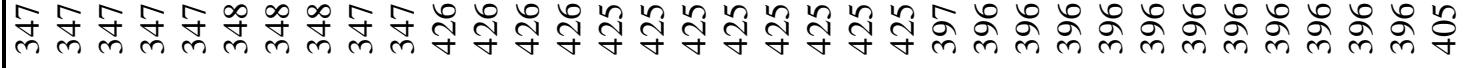

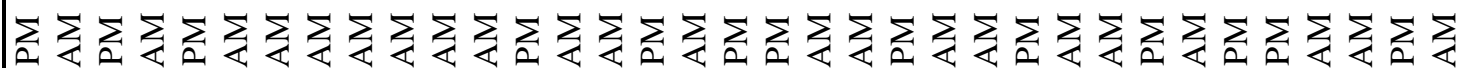
\# 깅

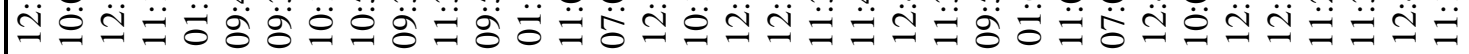

뉭윙

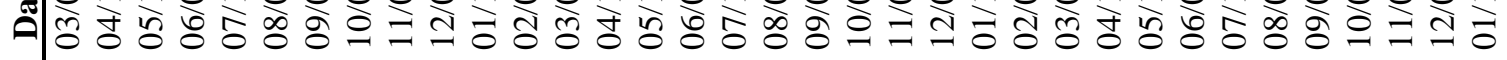

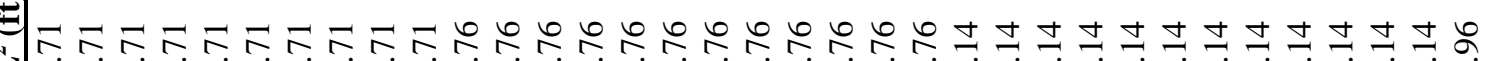

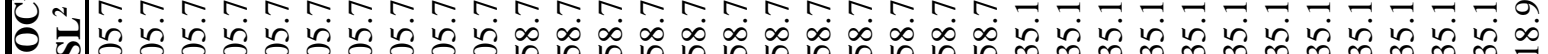

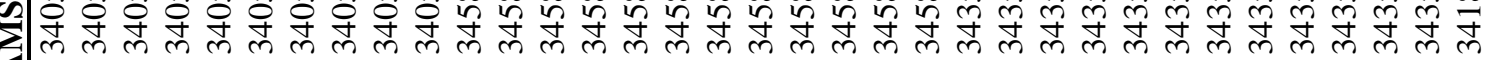

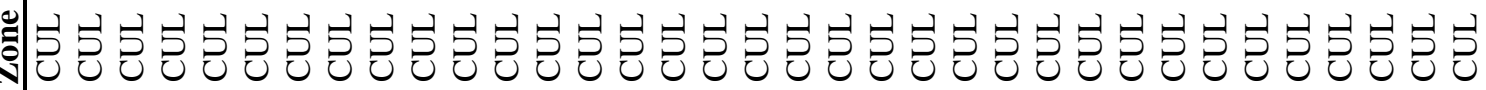

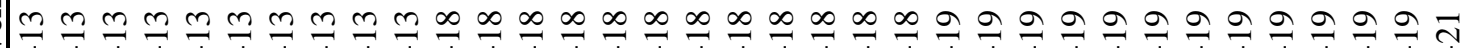

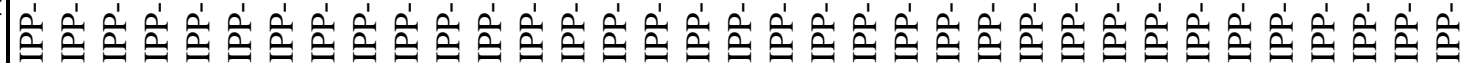

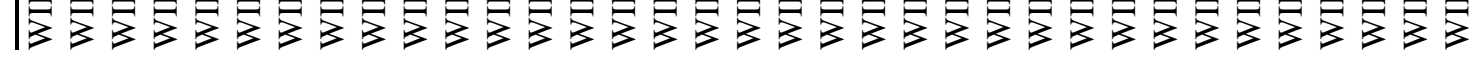




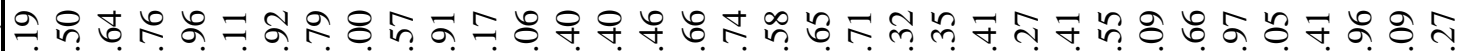
屯्ञ

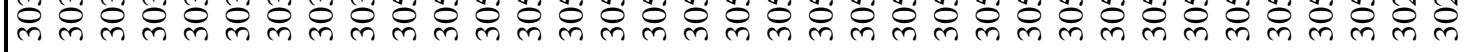

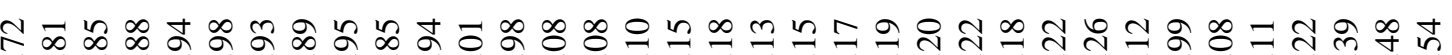

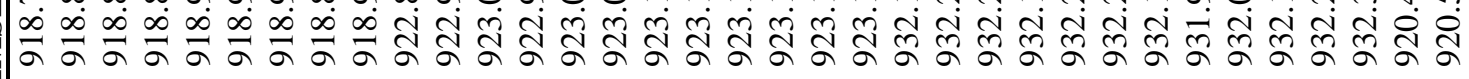

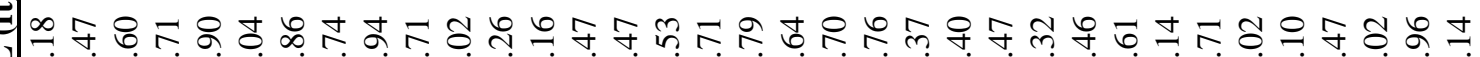

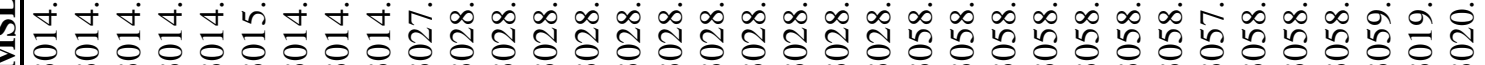

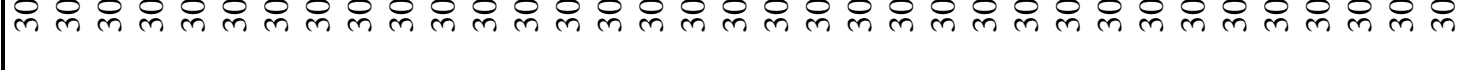

$\infty$ กิ กิ่

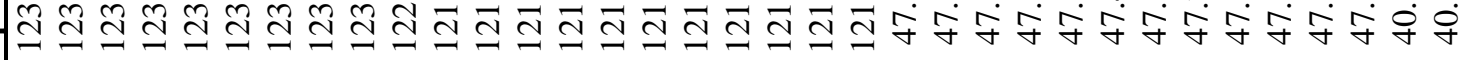

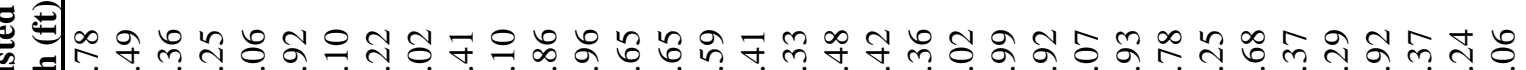

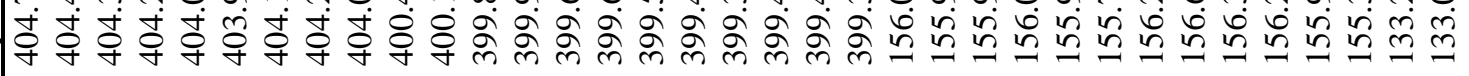

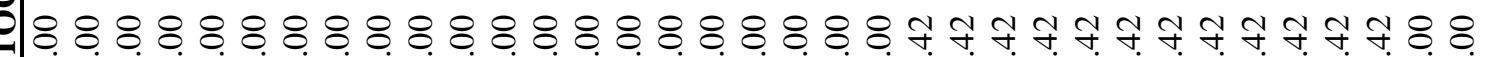

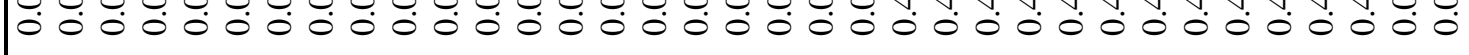

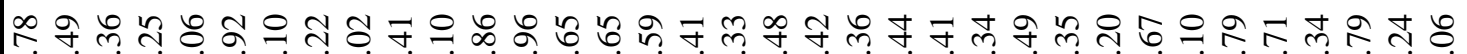

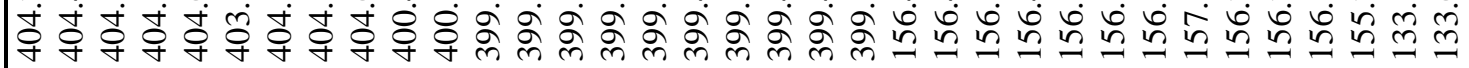

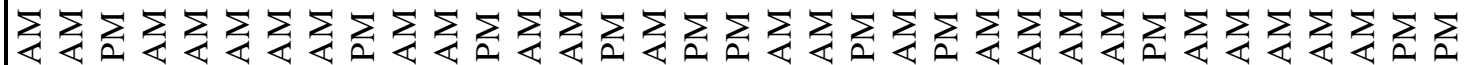
키웍워

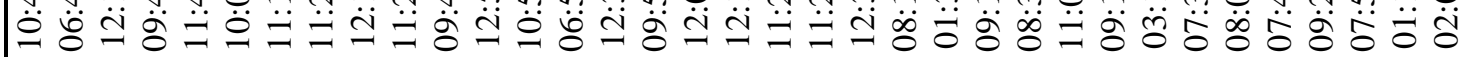

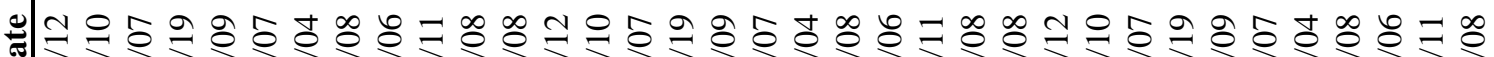

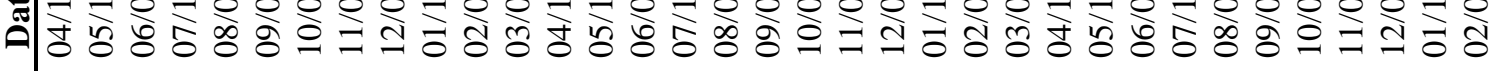

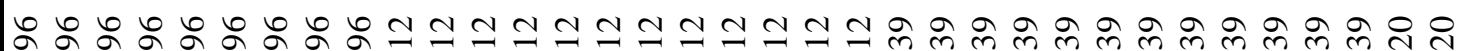

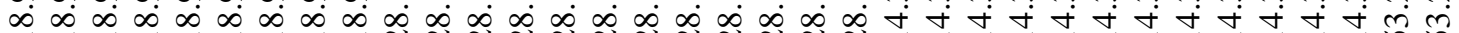

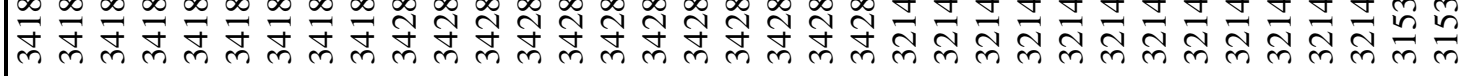

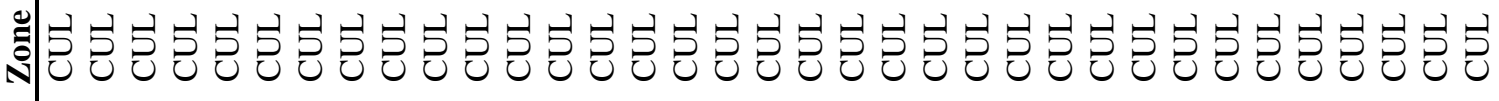

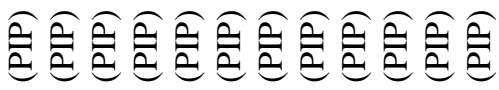

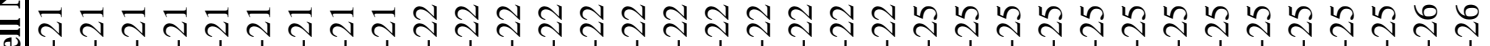

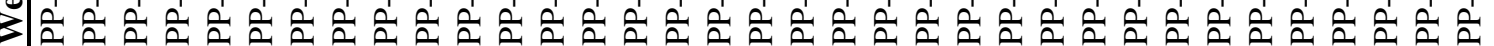

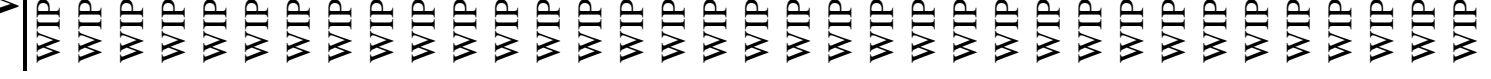




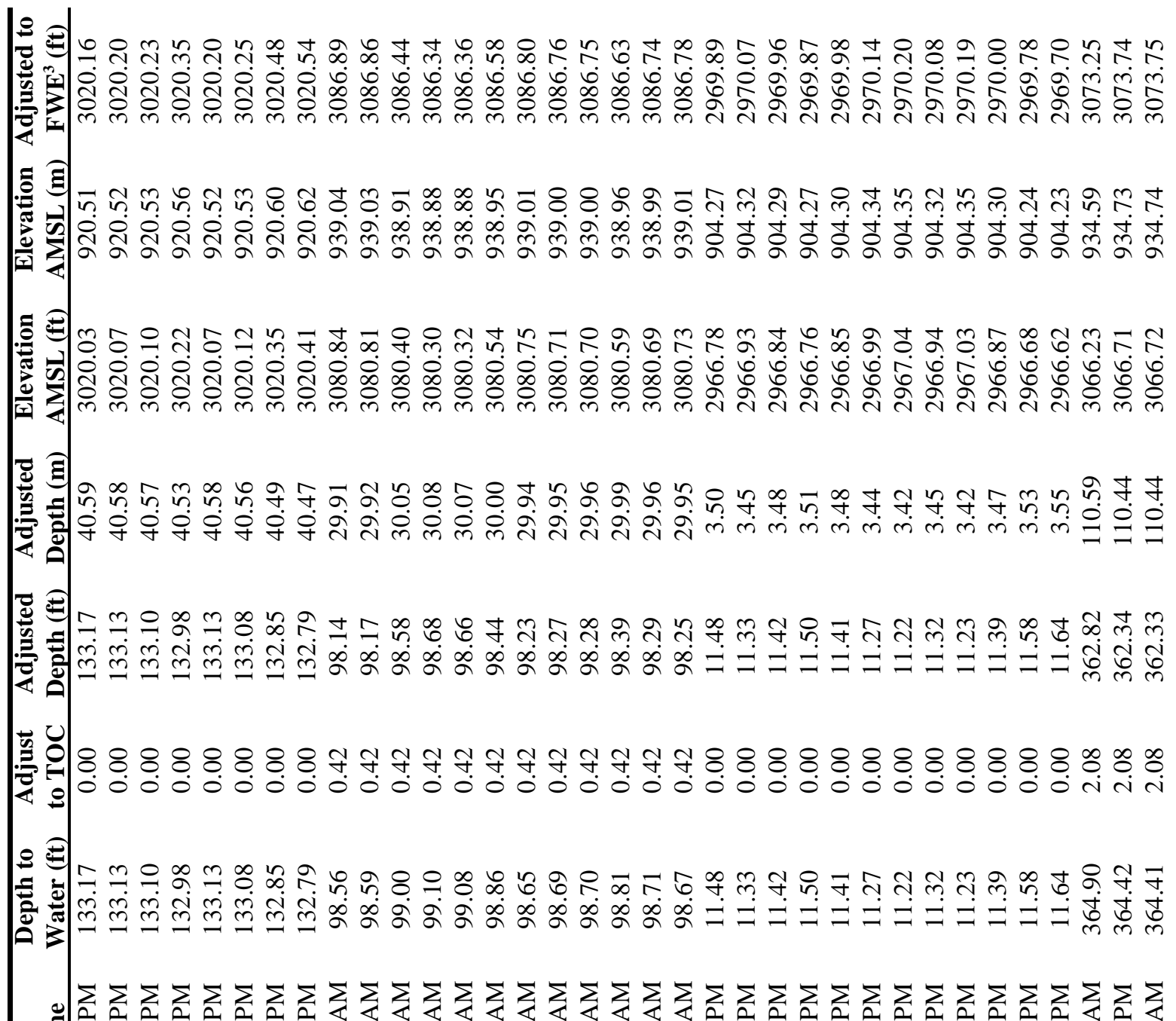
킥ำ 宁

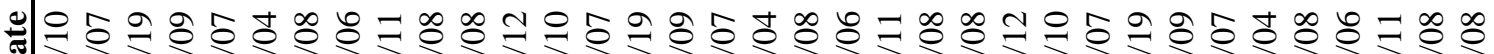

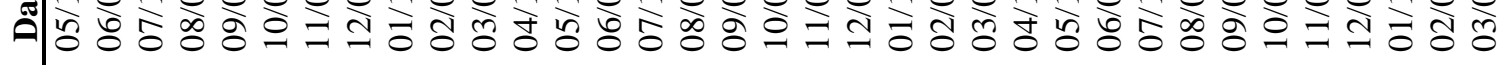

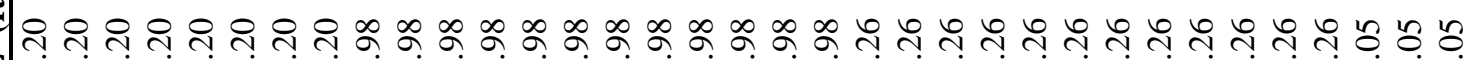

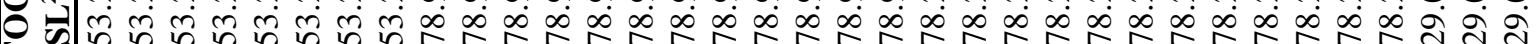

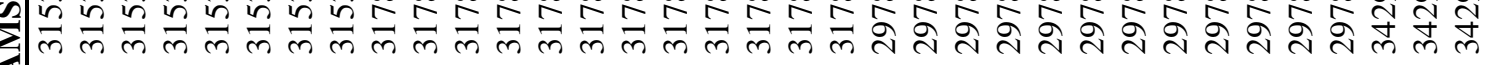

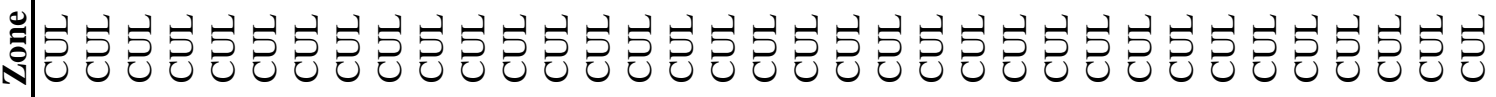

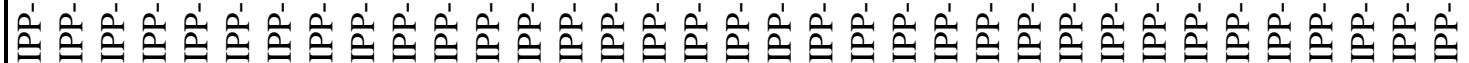

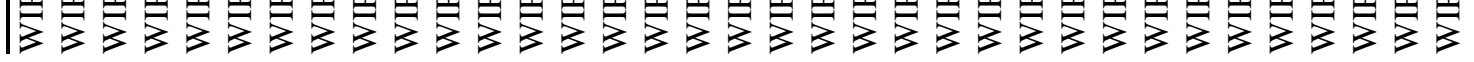




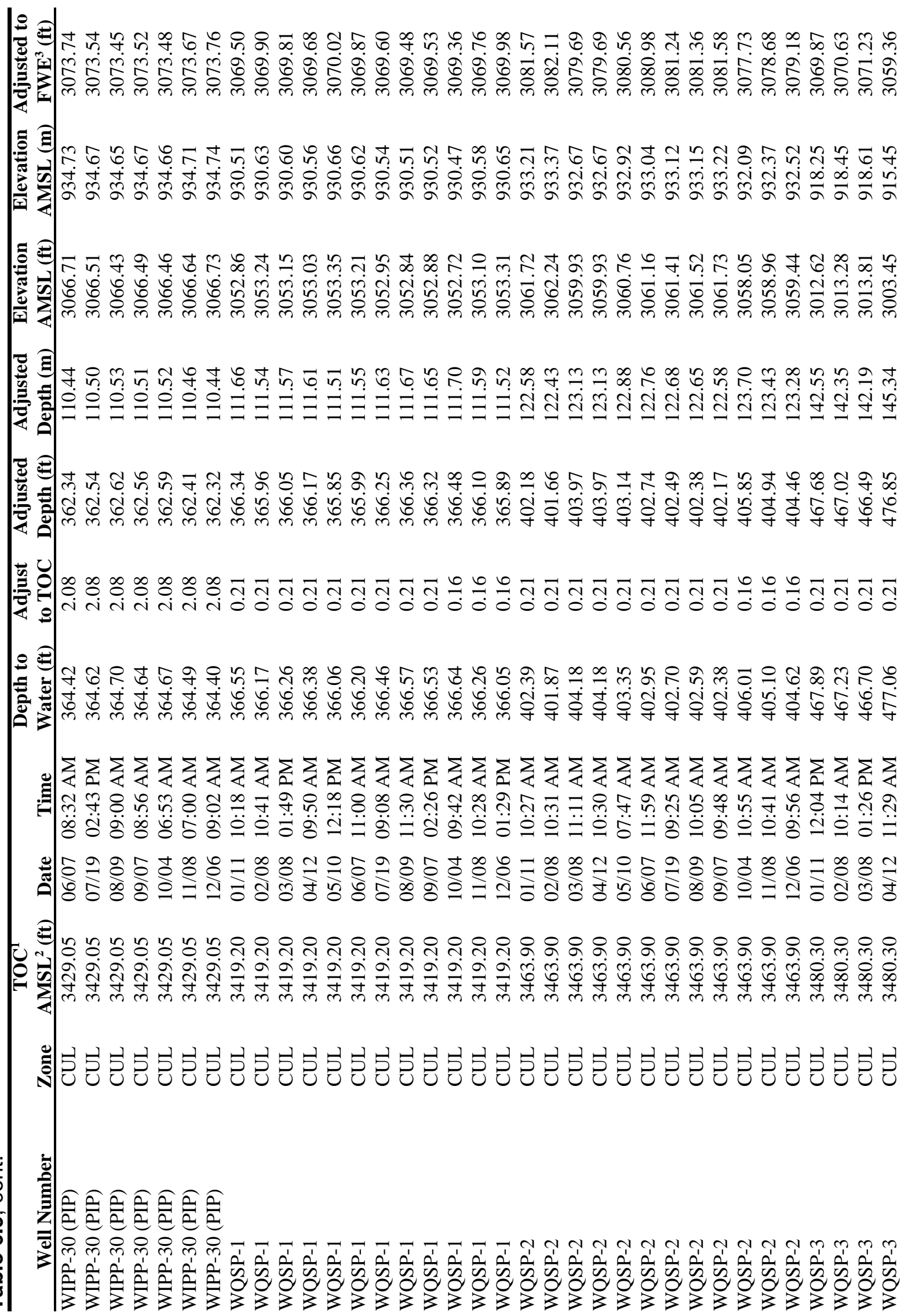




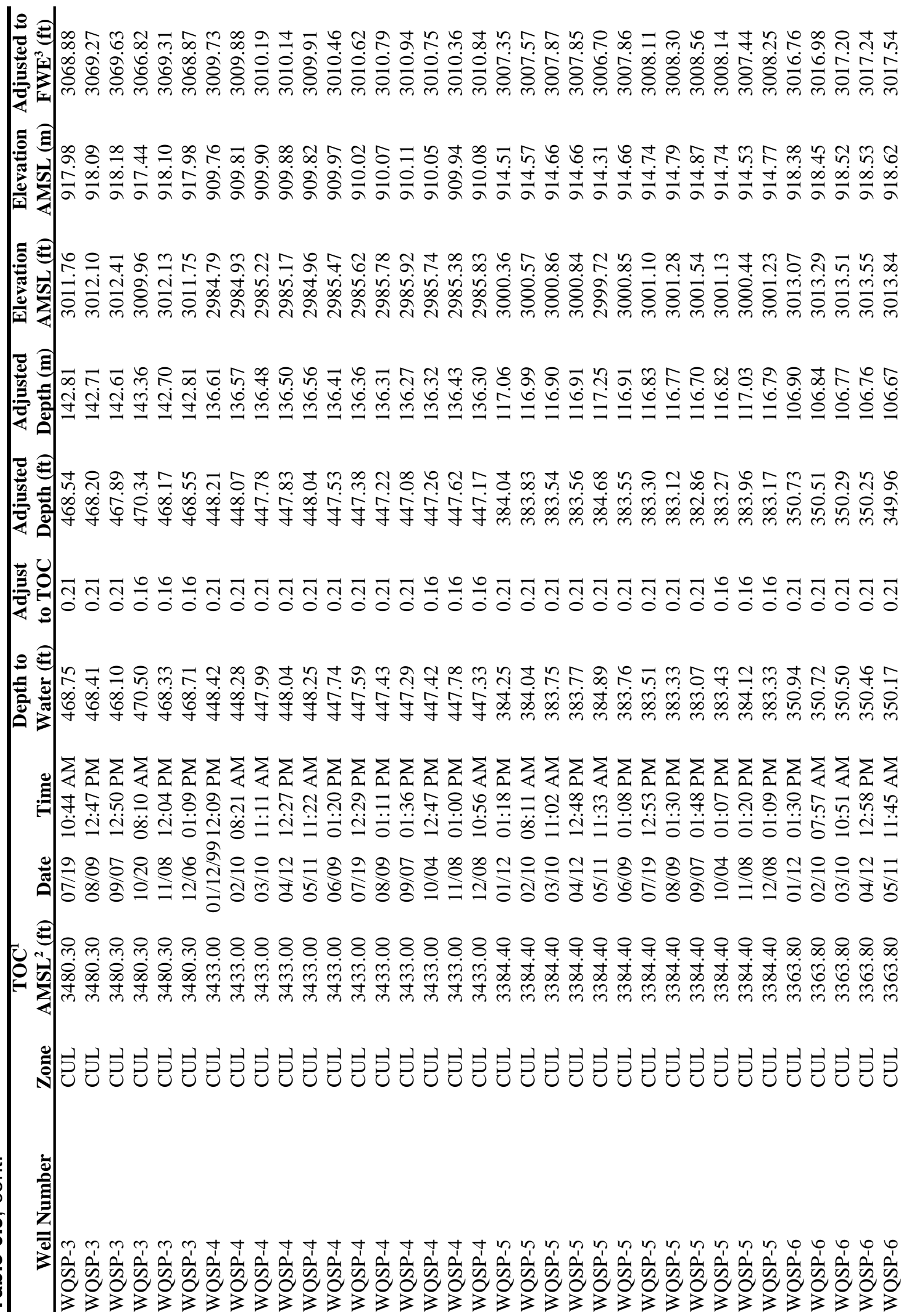




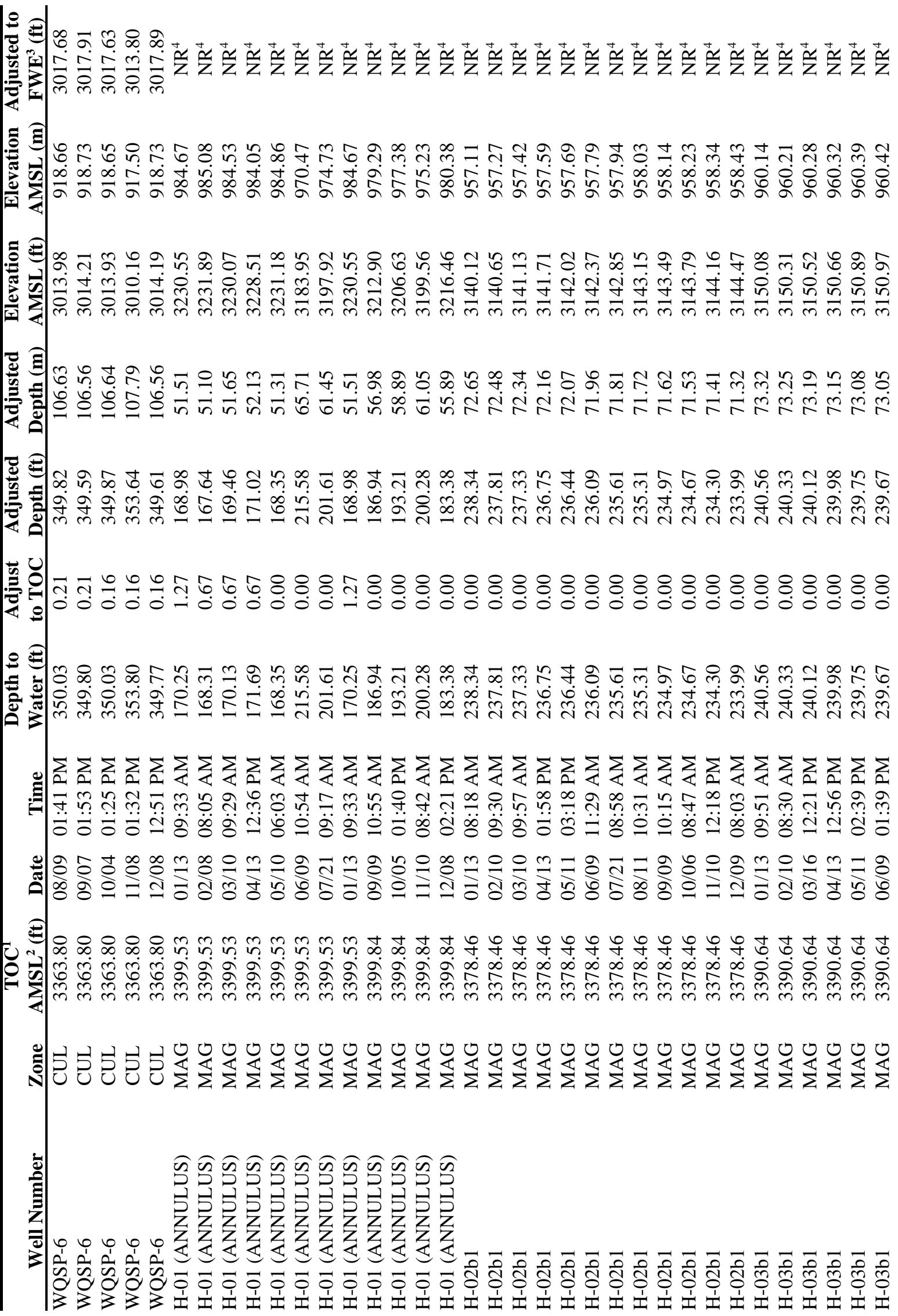




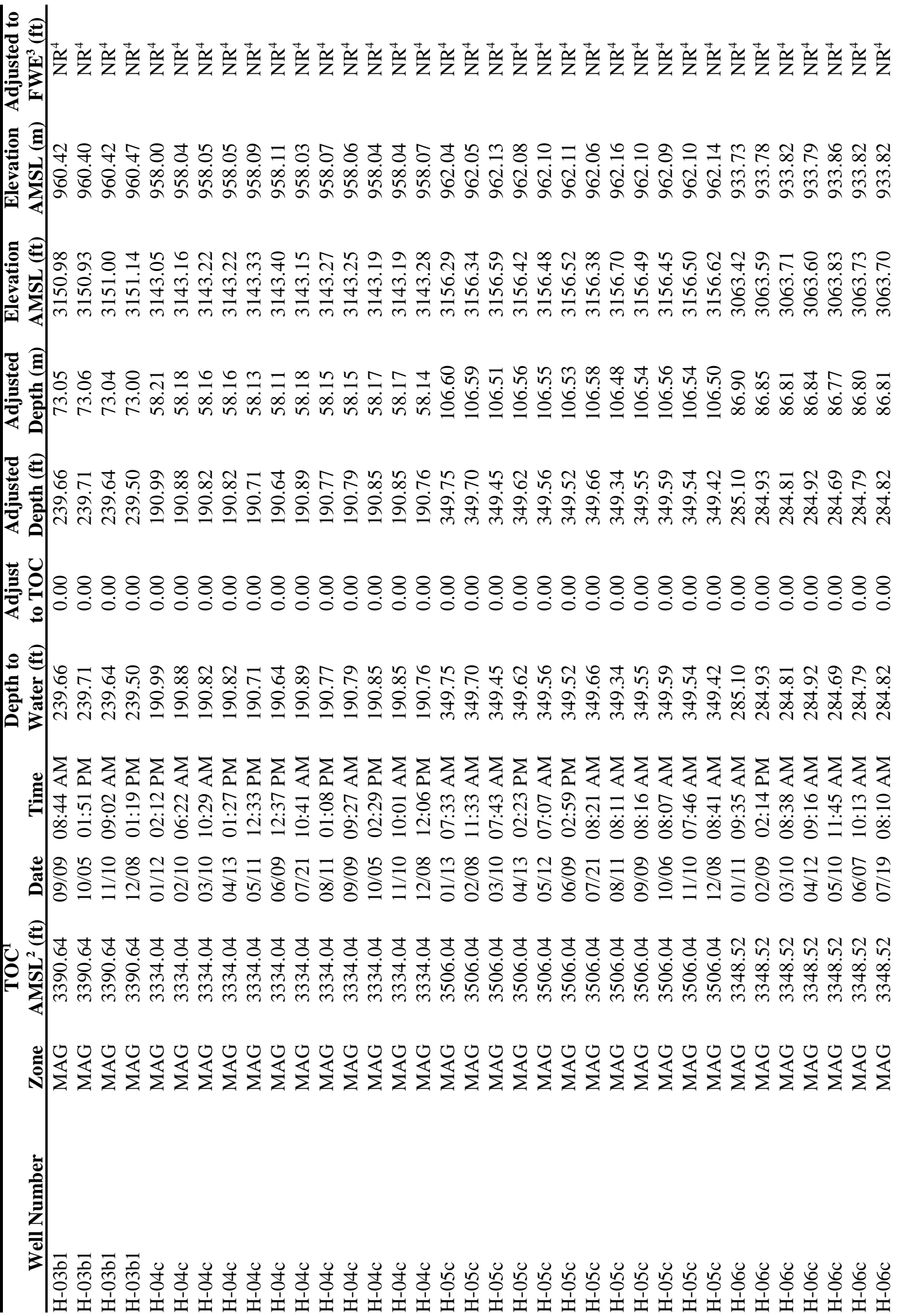




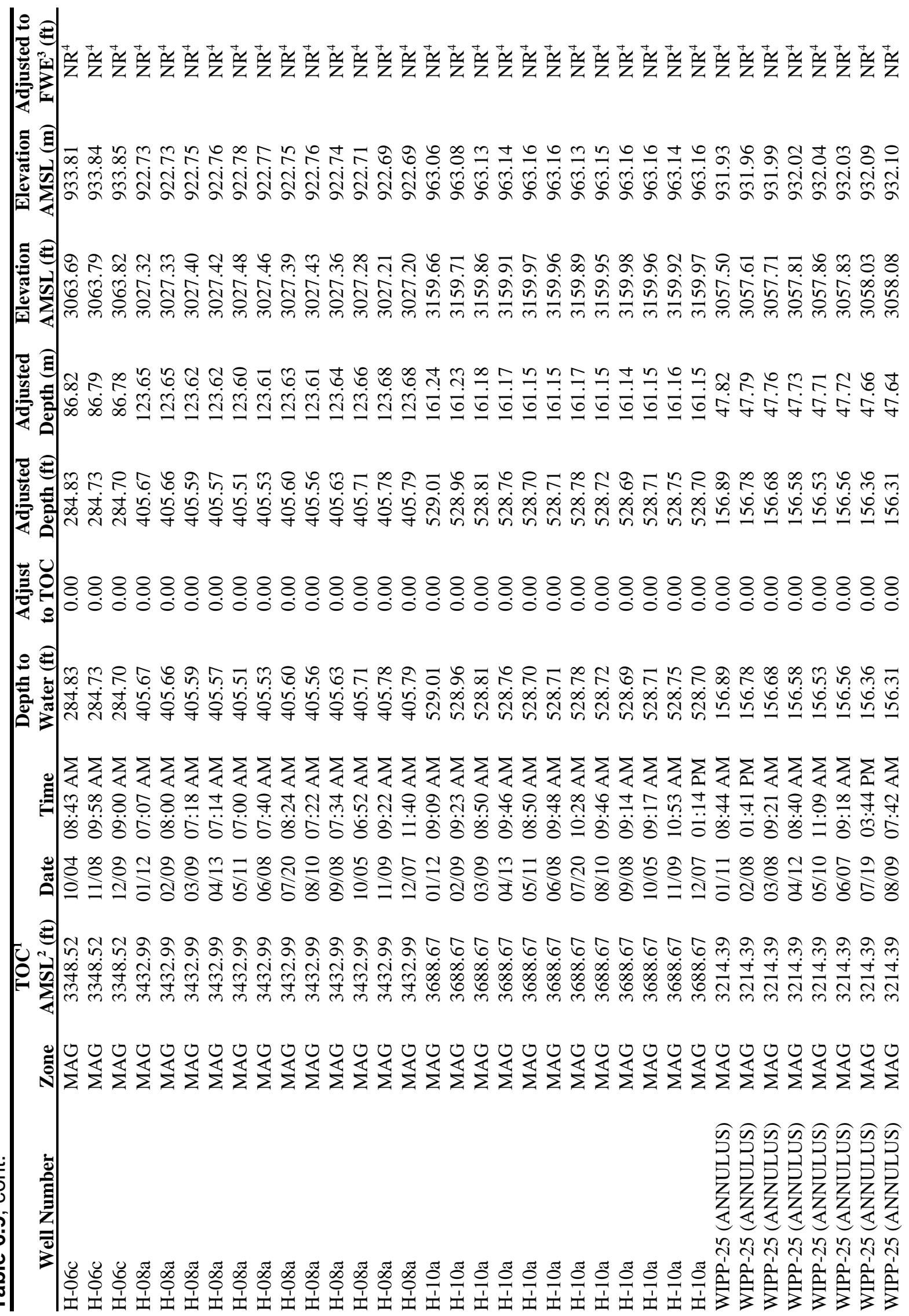




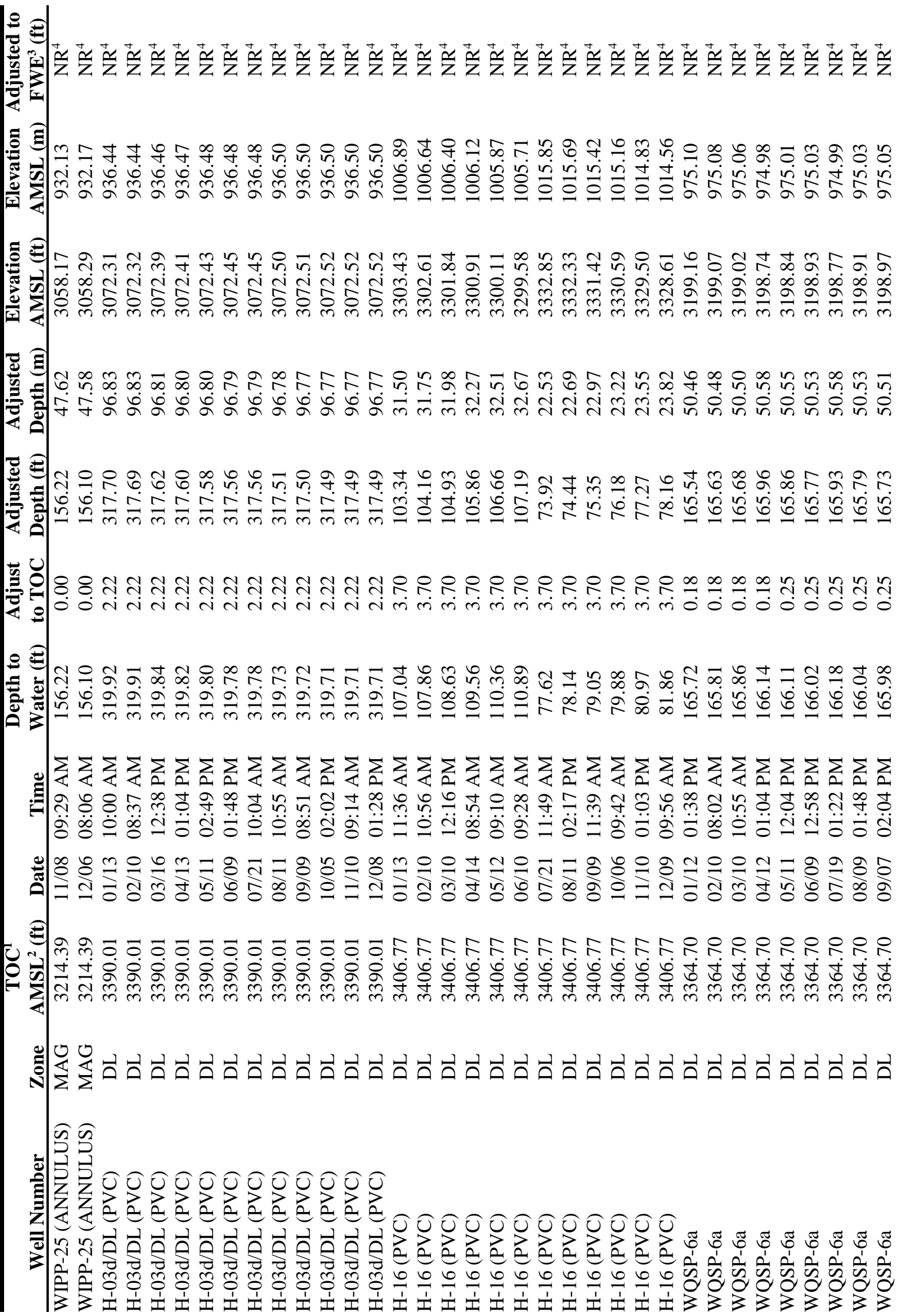




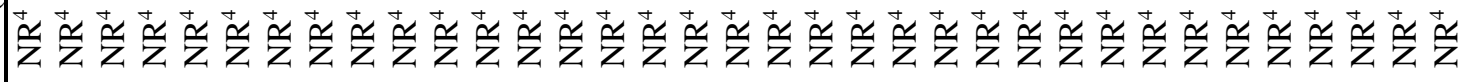

โระ ำง 人

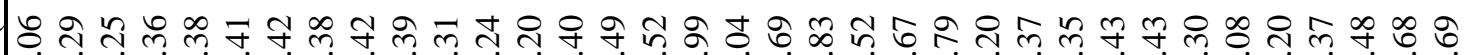

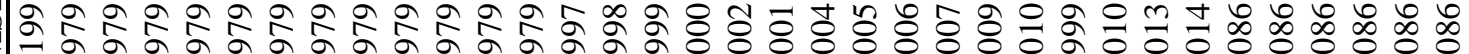

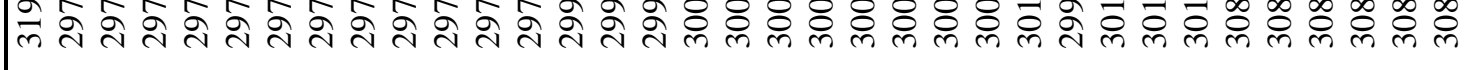

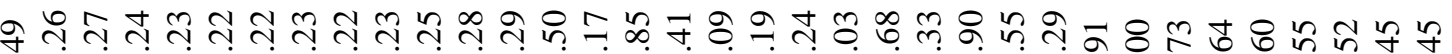

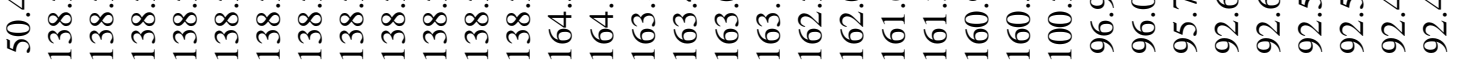

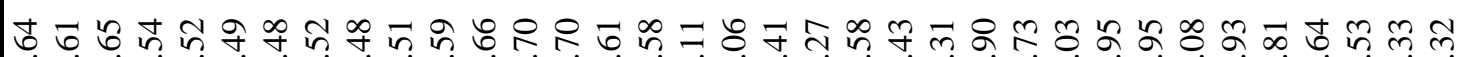

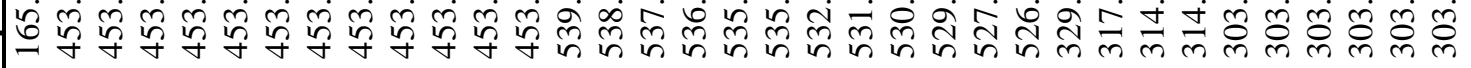

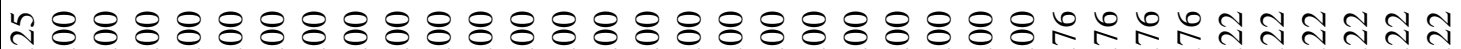

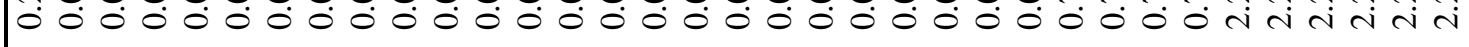

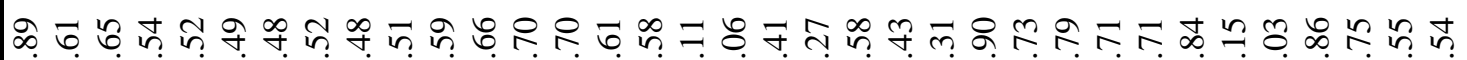

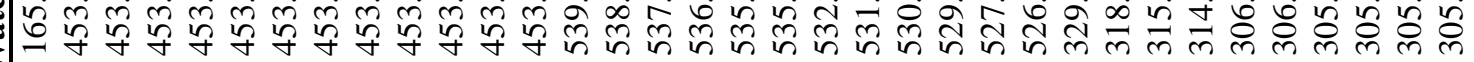

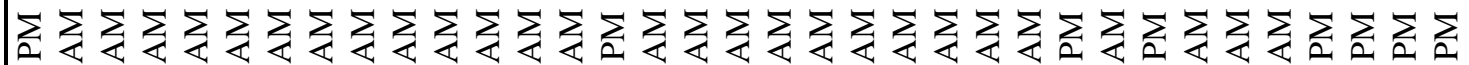
:

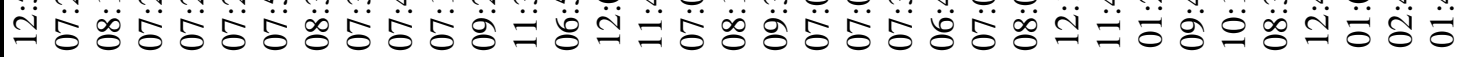

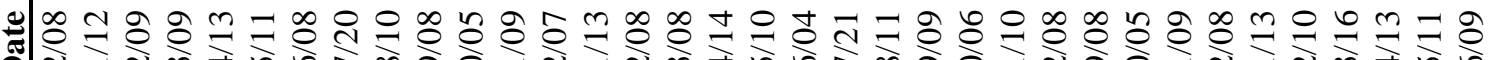

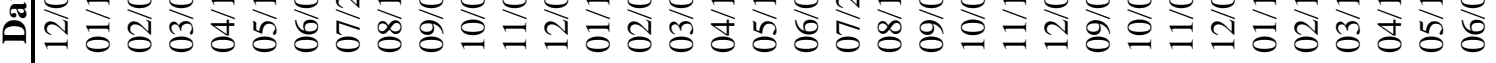

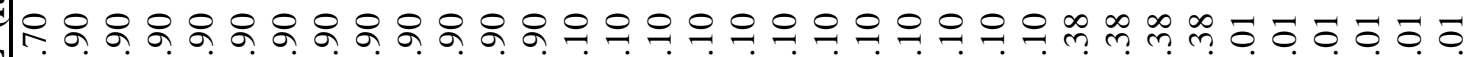

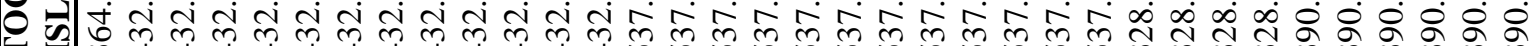

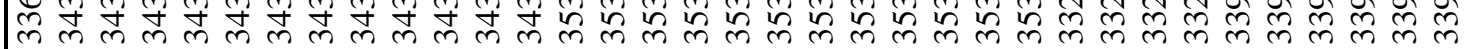

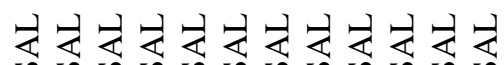

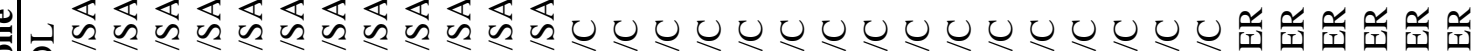

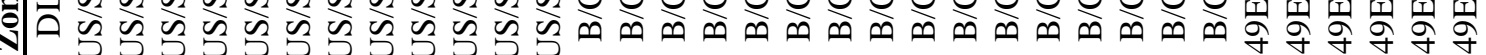

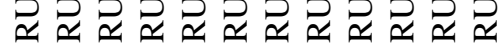




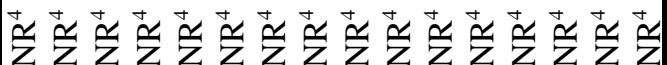
宅

$\Xi$

๓

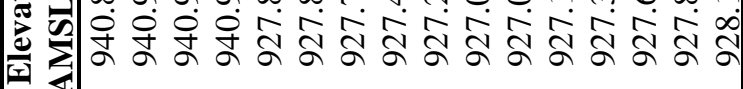

$$
\text { 告 }
$$

氙

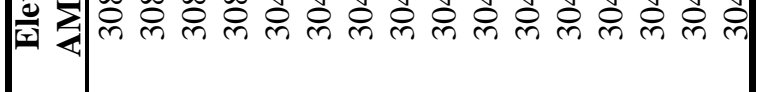

छ

匀

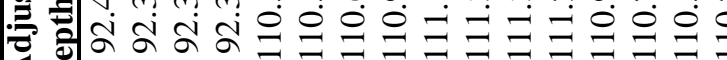

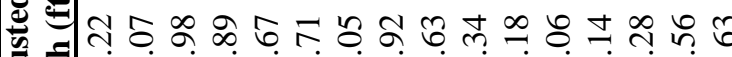
产

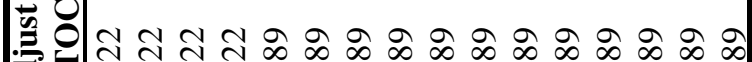

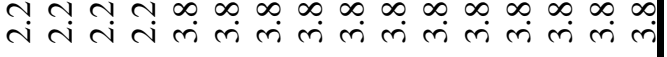

8 의

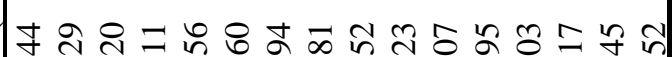

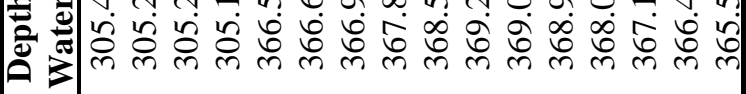

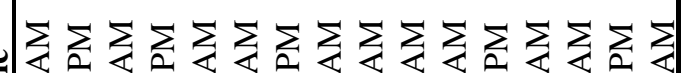

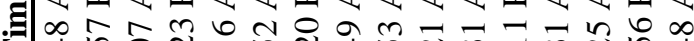

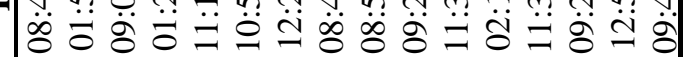

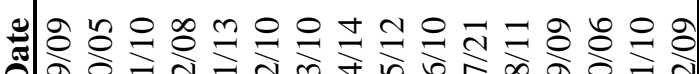

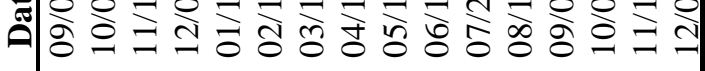

ت

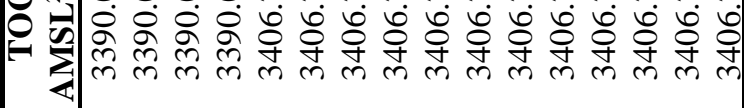

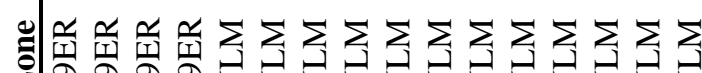

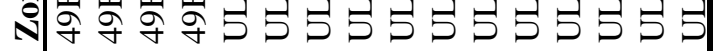

¿े

क)

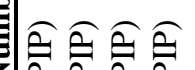

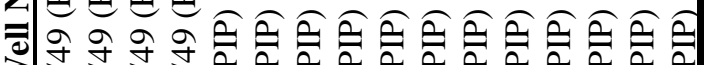

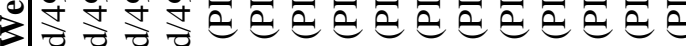
m

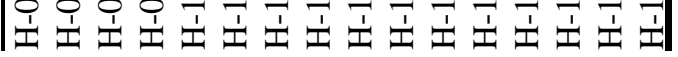

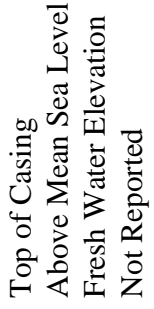




\section{Chapter 7 \\ Radiological Dose Assessment}

It is the policy of DOE “. . . to conduct its operations in an environmentally safe and sound manner. Protection of the environment and the public are responsibilities of paramount importance and concern to DOE" (DOE Order 5400.1). "It is also a DOE objective that potential exposures to members of the public be as far below the limits as is reasonably achievable. .." (DOE Order 5400.5).

Chapter 4 of this report summarized the amount of radioactivity in various media sampled in the WIPP environment in 1999. It is the purpose of this chapter to summarize what those levels mean in regards to the potential dose from WIPP operations.

Specifically, this chapter summarizes:

- introductory information on human radiation dose limits and risks from radiation,

- the national average dose from naturallyoccurring sources of radiation,

- the estimated dose from air emissions from WIPP,

- the total potential dose from WIPP operations, and

- potential doses to non-human biota from radioactivity measured near WIPP.

\subsection{Introduction and Dose Limits}

In this chapter, the term "dose" will refer to the committed effective dose equivalent unless another term is specifically stated. Dose was calculated by summing the committed dose equivalents to organs, each multiplied by a weighting factor proportional to each organ's sensitivity to radiation. Additional methods for calculating dose are discussed in the following sections on specific pathways.
For more than 50 years, extensive research has been conducted on the effects of radiation on humans and the environment. Much of this research used standard epidemiological and toxicological approaches to characterize the response of populations and individuals to high radiation doses. From this, a good understanding of the risks associated with high radiation doses was achieved. However, there is still uncertainty as to what risks are incurred from low radiation doses and dose rates. Because of the low rate of cancer incidence at low levels of radiation exposure, and the large sample sizes needed to study this relationship, risks due to low levels of radiation exposure are difficult to obtain; therefore, models have been used to predict risks from low radiation doses (Figure 7.1).

Regulatory dose limits are set well below levels where measurable health effects have been observed. Environmental radiation protection standards for the management and disposal of TRU radioactive wastes set limits on the total radiation dose to members of the public at 0.25 $\mathrm{mSv} / \mathrm{y}(25 \mathrm{mrem} / \mathrm{y})$ to the whole body and 0.75 $\mathrm{mSv} / \mathrm{y}(75 \mathrm{mrem} / \mathrm{y})$ to any critical organ $(40 \mathrm{CFR}$ $\S 191.03)$. National standards for emissions of radionuclides from DOE facilities state that the maximum dose to any member of the public from air emissions must be no greater than $0.1 \mathrm{mSv} / \mathrm{y}$ (10 mrem/y) (40 CFR \& 61.92). The Safe Drinking Water Act (40 CFR $\S 141.16$ ) states that average annual concentrations of beta- and gamma-emitting human-made radionuclides in drinking water shall not result in a dose greater than $0.04 \mathrm{mSv} / \mathrm{y}(4 \mathrm{mrem} / \mathrm{y})$. It is important to note that all of these dose limits are set for radionuclides released to the environment from DOE operations. They do not include, but are limits in addition to, doses from natural background radiation or from medical procedures. 


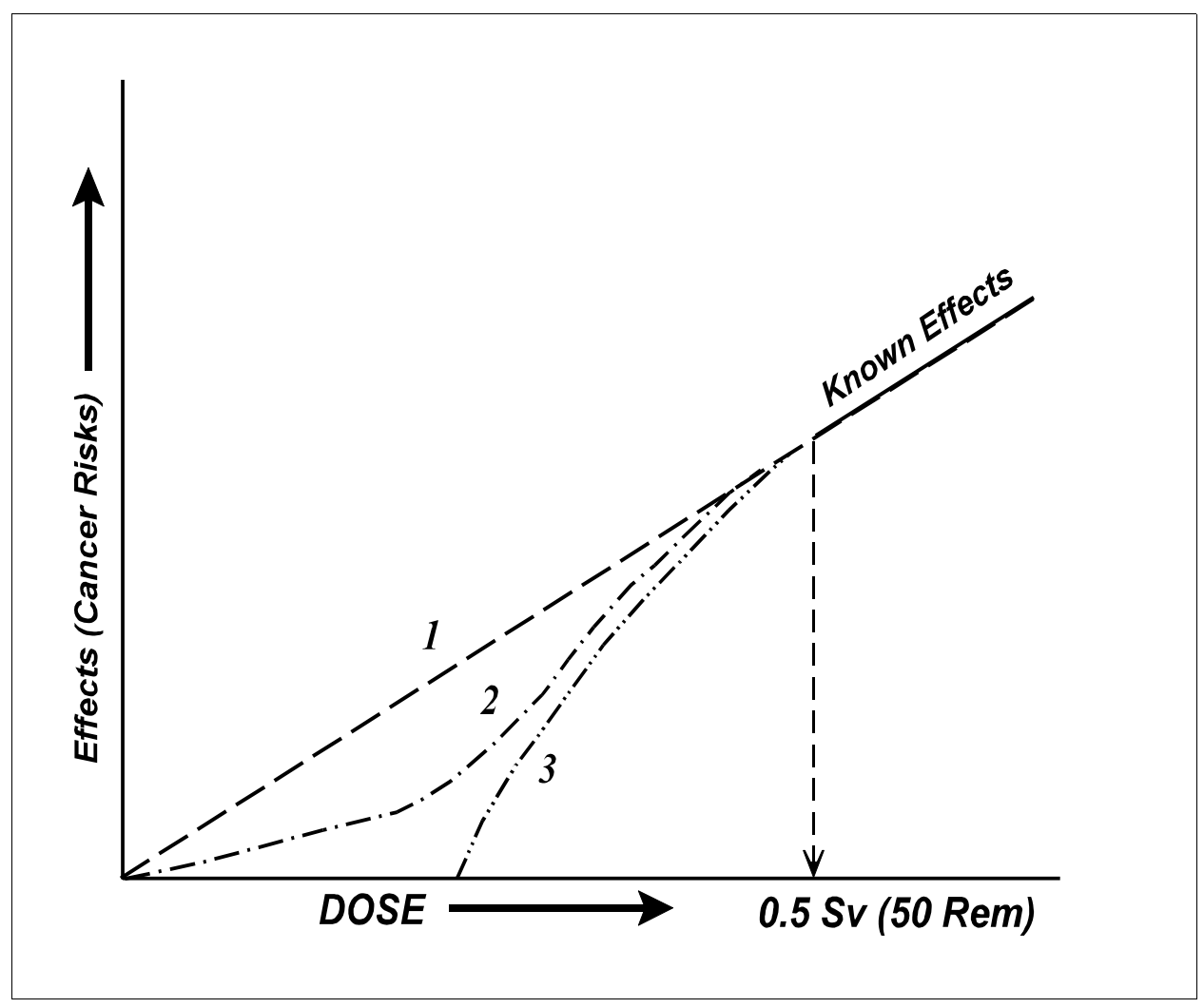

Figure 7.1 Three general models used to predict risk from radiation dose. Models are used because scientists have yet to reliably detect changes in cancer incidence following low doses of radiation. Risks from radiation are primarily based on effects observed from persons receiving high doses (e.g., Hiroshima and Nagasaki atomic bomb survivors). Regulatory dose limits are set well below levels where any health effects have been observed (Figure adapted from NRC 1999).

\subsection{Background Radiation}

Radiation is a naturally-occurring phenomenon that has been in the environment since the beginning of time. There are several sources of natural radiation: cosmic and cosmogenic radiation (from outer space and the earth's atmosphere), terrestrial radiation (from the earth's crust), and internal radiation (naturallyoccurring radiation in our bodies, such as ${ }^{40} \mathrm{~K}$ ). The most common sources of terrestrial radiation are uranium, thorium, and their decay products. Potassium-40 is another source of terrestrial radiation. While not a major radiation source, ${ }^{40} \mathrm{~K}$ may be enhanced in the southeastern New Mexico environment due to local potash mining. Radon gas, a decay product of uranium, is the most widely known naturally-occurring terrestrial radionuclide. In addition to natural radioactivity, small amounts of radioactivity from above-ground nuclear weapons tests that occurred from 1945 through 1980 and the 1986 Chernobyl nuclear accident are also present in the environment. Together, these sources of radiation are called "background" radiation. Every human is constantly exposed to background radiation. Exposure to radioactivity from weapons testing fallout is quite small compared to natural radioactivity and continually gets smaller as radionuclides decay.

Naturally-occurring radiation in our environment can deliver both internal and external doses. Internal dose is received as a result of the 
Table 7.1 Annual estimated average radiation dose received by a member of the population of the United States from naturally-occurring radiation sources (adapted from NCRP-1987).

Average Annual Effective Dose Equivalent

\begin{tabular}{lcc}
\multicolumn{1}{c}{ Source } & $(\mathbf{m S v})$ & $(\mathbf{m r e m})$ \\
\hline Inhaled (Radon and Decay Products) & 2 & 200 \\
Internal Radionuclides & 0.39 & 39 \\
Terrestrial Radiation & 0.28 & 28 \\
Cosmic Radiation & 0.27 & 27 \\
Cosmogenic Radioactivity & 0.01 & 1
\end{tabular}

intake of radionuclides. The major routes of intake of radionuclides for members of the public are ingestion and inhalation. Ingestion includes the intake of the radionuclides from eating and drinking contaminated food and drink. Inhalation includes the intake of radionuclides through breathing dust particles containing radioactive materials. External dose can occur from submersion in contaminated air or deposition of contaminants on surfaces. The average annual dose received by a member of the public from naturally-occurring radionuclides is about $3 \mathrm{mSv}$ (300 mrem) (Table 7.1).

\subsection{Dose from Air Emissions}

The National Emission Standards for Hazardous Air Pollutants issued by the EPA set limits for radionuclide emissions to air ( 40 § CFR 61). Compliance procedures for DOE facilities [40 § CFR 61.93(a)] require the use of CAP88 or AIRDOS-PC computer models, or an equivalent, to calculate dose to members of the public. For the determination of the radiation dose received by members of the public, WIPP used the computer model CAP88-PC, version 2.0. Source term input for the program was determined by radiochemical analyses of periodic air samples taken from the effluent Stations A, B, and C (see Section 4.1). Air samples were analyzed for ${ }^{241} \mathrm{Am},{ }^{239+240} \mathrm{Pu}$, and ${ }^{238} \mathrm{Pu}$ because they constitute over 98 percent of the dose potential for contacthandled waste. Measured activity values greater than the MDA were used as a part of the source term for the air emission pathway and, for measured results less than the MDA, the MDA value was used as part of the source term (see Table 4.1). CAP88 dose calculations are based on the assumption that exposed persons remain at home during the entire year and all vegetables, milk, and meat consumed are home produced. Thus, this dose calculation is a maximum potential dose which encompasses dose from inhalation, submersion, deposition, and ingestion of air emitted radionuclides.

\subsubsection{Maximally Exposed Individual from Air Emission Pathway}

For 1999, the CAP88 model predicted the highest dose to someone residing near WIPP to be at the Smith Ranch approximately $4 \mathrm{~km}(2.5 \mathrm{mi})$ northwest of WIPP. Results showed the whole body dose potentially received by someone residing at this location to be about $2.2 \times 10^{-8} \mathrm{mSv}$ $\left(2.2 \times 10^{-6} \mathrm{mrem}\right)$ per year. The critical organ dose was less than $3.9 \times 10^{-7} \mathrm{mSv}\left(3.9 \times 10^{-5} \mathrm{mrem}\right)$ per year. This potential whole body dose is $2.2 \times 10^{-5}$ percent of the whole body dose limits of $0.1 \mathrm{mSv}$ (10 mrem) per year specified in 40 § CFR 61.92. The dose to a hypothetical person residing year- 
round at the WIPP fence line was estimated to be $3.1 \times 10^{-7} \mathrm{mSv}\left(3.1 \times 10^{-5} \mathrm{mrem}\right)$ per year whole body and $5.3 \times 10^{-6} \mathrm{mSv}\left(5.3 \times 10^{-4} \mathrm{mrem}\right)$ per year to the critical organ.

\subsection{Total Potential Dose from WIPP Operations}

The radiation dose received by members of the public as a result of the management and storage of TRU radioactive wastes at any disposal facility operated by DOE is regulated under $40 \S$ CFR 191 Subpart A. Specific standards state that the combined annual dose to any member of the public in the general environment shall not exceed $0.25 \mathrm{mSv}$ ( $25 \mathrm{mrem}$ ) to the whole body and 0.75 $\mathrm{mSv}(75 \mathrm{mrem})$ to any critical organ. Section 7.3 discussed the potential dose received from radionuclides released to the air from WIPP. The following sections discuss the potential dose through other pathways and the total potential dose a member of the public may have received from WIPP operations during 1999.

\subsubsection{Potential Dose from Water Ingestion Pathway}

The potential dose to individuals from the ingestion of WIPP-related radionuclides transported in water is estimated to be nonexistent for several reasons. Drinking water for communities near WIPP comes from groundwater sources which are not expected to be affected by potential WIPP contaminants (based on current radionuclide transport scenarios summarized in the WIPP Safety Analysis Report [DOE/WIPP 95-2065, Rev. 3]). The only credible pathway for contaminants from WIPP to accessible ground water is through the Culebra member of the Rustler Formation and the Dewey Lake Formation (DOE/CAO 96-2184). Water from the Culebra is naturally not potable due to high levels of TDS. Water from the Dewey Lake Formation is suitable for livestock consumption having TDS values below 10,000 mg/L. Groundwater and surface water samples collected around WIPP during 1999 did not contain radionuclide concentrations discernable from those in samples collected prior to WIPP receiving waste.

\subsubsection{Potential Dose From Wild Game In- gestion}

Game animals sampled during 1999 were mule deer, quail, and catfish. No radionuclides were detected in quail and those detected in deer and catfish were not different from background levels measured prior to commencement of waste shipments to WIPP. Therefore, no dose from WIPP related radionuclides is estimated to have been received by any individual from this pathway during 1999.

\subsubsection{Total Potential Dose From All Path- ways}

The only pathway for which a dose could be estimated was that of air emissions. Air emissions from WIPP were not considered above background ambient air levels. Estimated concentrations of radionuclides in air emissions accounted for the calculable dose from WIPP operations during 1999. The dose potentially received by someone residing $4 \mathrm{~km}(2.5 \mathrm{mi})$ northwest of WIPP was calculated to be $2.2 \times 10^{-8}$ $\mathrm{mSv}\left(2.2 \times 10^{-6} \mathrm{mrem}\right)$ per year, whole body, and $3.9 \times 10^{-7} \mathrm{mSv}\left(3.9 \times 10^{-5} \mathrm{mrem}\right)$ per year to the critical organ. This is $8.8 \times 10^{-6}$ percent of the whole body dose limits of $0.25 \mathrm{mSv}$ ( $25 \mathrm{mrem})$ per year whole body dose and $5.2 \times 10^{-5}$ percent of the dose limit of $0.75 \mathrm{mSv}$ (75 mrem) per year specified in 40 § CFR 191.03(b). The dose to a hypothetical person residing year-round at the WIPP fence line was estimated to be $3.1 \times 10^{-7}$ $\mathrm{mSv}\left(3.1 \times 10^{-5} \mathrm{mrem}\right)$ per year whole body and $5.3 \times 10^{-6} \mathrm{mSv}\left(5.3 \times 10^{-4} \mathrm{mrem}\right)$ per year to the critical organ. This is $1.2 \times 10^{-4}$ percent of the whole body dose limits of $0.25 \mathrm{mSv}$ ( $25 \mathrm{mrem}$ ) per year whole body dose and $7.1 \times 10^{-4}$ percent of the dose limit of $0.75 \mathrm{mSv}$ (75 mrem) per year specified in 40 § CFR 191.03(b).

\subsection{Dose to non-human Biota}

DOE Order 5400.5 lists the environmental radiation protection requirements that WIPP must meet to protect aquatic animals. In addition, dose limits below which no deleterious effects on populations of aquatic and terrestrial organisms have been observed have been discussed by the 
National Council on Radiation Protection and Measurements (NCRP-109) and the International Atomic Energy Agency (IAEA Technical Report Series No. 332). Those dose limits are:

- $\quad$ Aquatic Animals - $10 \mathrm{mGy} / \mathrm{d}(1 \mathrm{rad} / \mathrm{d})$

- Terrestrial Plants - $10 \mathrm{mGy} / \mathrm{d}(1 \mathrm{rad} / \mathrm{d})$

- Terrestrial Animals - $1 \mathrm{mGy} / \mathrm{d}(0.1 \mathrm{rad} / \mathrm{d})$

DOE has considered proposing these dose standards for aquatic and terrestrial biota under proposed rule 10 CFR $\S 834$, "Radiation protection of the public and the environment" but has delayed until guidance for demonstrating compliance was developed. The Interim Technical Standard, DOE-STD-XXXX-00, A Graded Approach for Evaluating Radiation Doses to Aquatic and Terrestrial Biota, was developed to meet this need. Although the proposed rule has not been implemented, DOE requires discussion of radiation doses to non-human biota in the Annual Site Environmental Report using the Interim Technical Standard.

The Interim Technical Standard uses a multiphase approach, including an initial screening phase with conservative assumptions. Software is provided with the Interim Technical Standard to conduct the screening evaluation. In the initial screen, Biota Concentration Guides (BCG) are derived using very conservative assumptions for a variety of generic organisms. Maximum concentrations of radionuclides detected in soil, sediment, and water during environmental monitoring are divided by the BCGs and the results are summed for each organism (DOESTD-XXXX-00). If the sum of these fractions is less than 1 , the site is deemed to have passed the screen and no further action is required. This screening evaluation is intended to provide a very conservative evaluation of whether the site is in compliance with the recommended limits.

This guidance was used to screen radionuclide concentrations observed around WIPP during 1999 using the maximum radionuclide concentrations listed in Table 7.2. The sum of fractions was less than one for all media, demonstrating compliance with the proposed rule. Radiation in the environment surrounding WIPP does not have a deleterious effect on populations of plants and animals.

Table 7.2 General screening results for potential radiation dose to non-human biota from radionuclide concentrations in surface water $(\mathrm{Bq} / \mathrm{L})$, sediment $(\mathrm{Bq} / \mathrm{g})$, and soil $(\mathrm{Bq} / \mathrm{g})$ near the WIPP site. Maximum observed concentrations were compared with Biota Concentration Guide $^{1}$ (BCG) values to assess potential dose to biota. As long as the sum of the ratios between observed maximum concentrations and the associated BCG is below 1.0, no adverse effects on plant or animal populations are expected (DOE-STD-XXXX-00).

\begin{tabular}{|c|c|c|c|c|}
\hline Organism/Medium & Radionuclide & $\begin{array}{c}\text { Maximum } \\
\text { observed } \\
\text { concentration }\end{array}$ & $\begin{array}{c}\text { BCG } \\
(\mathrm{Bq} / \mathrm{g})\end{array}$ & $\begin{array}{c}\text { Concentration/ } \\
\text { BCG }\end{array}$ \\
\hline \multicolumn{5}{|c|}{ Aquatic plants and animals ${ }^{2}$} \\
\hline \multirow[t]{6}{*}{ Sediment } & ${ }^{90} \mathrm{Sr}$ & $3.40 \mathrm{E}-02$ & $1.30 \mathrm{E}+03$ & $2.61 \mathrm{E}-05$ \\
\hline & ${ }^{137} \mathrm{Cs}$ & $1.90 \mathrm{E}-02$ & $1.83 \mathrm{E}+03$ & $1.04 \mathrm{E}-05$ \\
\hline & ${ }^{233+234} \mathrm{U}^{3}$ & $6.30 \mathrm{E}-02$ & $1.14 \mathrm{E}+05$ & $5.52 \mathrm{E}-07$ \\
\hline & ${ }^{235} \mathrm{U}$ & $2.30 \mathrm{E}-03$ & $3.88 \mathrm{E}+03$ & $5.92 \mathrm{E}-07$ \\
\hline & ${ }^{238} \mathrm{U}$ & $5.20 \mathrm{E}-02$ & $1.59 \mathrm{E}+03$ & $3.28 \mathrm{E}-05$ \\
\hline & ${ }^{241} \mathrm{Am}$ & $2.20 \mathrm{E}-03$ & $2.61 \mathrm{E}+04$ & 8.44E-08 \\
\hline
\end{tabular}


Table 7.2, cont.

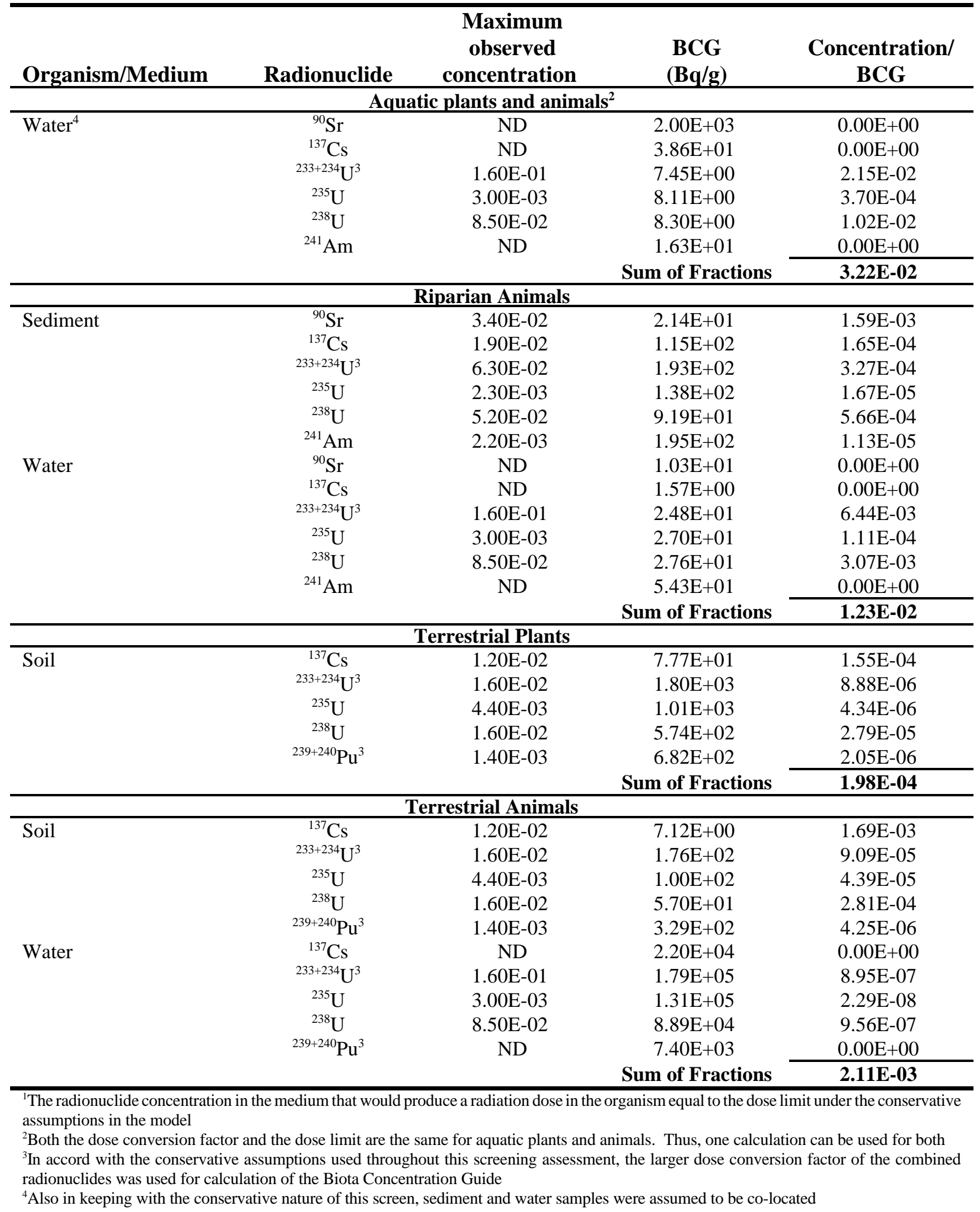




\section{Chapter 8 \\ Quality Assurance}

The fundamental objective of a QA program is to ensure high-quality measurements are produced and reported from the analytical laboratory. The defensibility of data generated by laboratories must be based on sound scientific principles, method evaluations, and data verification and validation. Thermo NuTech, in Albuquerque, New Mexico; Air Toxics, LTD, in Folsom, California; and Trace Analysis, in Lubbock, Texas, were the contract laboratories that performed the radiological and nonradiological analyses for WIPP environmental samples. The WIPP laboratory performed the gross alpha and beta analyses on weekly air particulate samples.

The laboratories were required to have documented QA programs and standard procedures to perform the work, and to participate in some comparison programs with the National Institute of Standards and Technology (NIST), the Environmental Monitoring Laboratory, the DOE Environmental Measurements Laboratory Quality Assurance Program (QAP), the Environmental Resource Associates interlaboratory assessment, and/or any other reputable intercomparison program. Elements of the requirements outlined in the following documents were included in each contract laboratory's QA program.

- ASME NQA-1-1994, Quality Assurance Program Requirements for Nuclear Facilities

- 10 CFR 50, Appendix B, Quality Assurance Criteria for Nuclear Power Plants and Fuel Reprocessing Plants

- EPA/600 14-83-004, QAMS-005/80, Interim Guidelines and Specification for Preparing Quality Assurance Project Plans
- NRC Regulatory Guide 4.15, Rev. 1, Quality Assurance for Radiological Monitoring Program-Effluent Streams and the Environment

- HPS N13.30 ANSI, Performance Criteria for Radiobioassay

- Proposed ANSI/ASQC-E4, Quality Assurance Program Requirements for Environmental Programs

The WID Environmental Monitoring Section performed assessments and audits to ensure the quality of the systems, processes, and deliverables were maintained or improved. Along with these regulatory requirements, the Environmental Monitoring Section also implements DOE Order 414.1A, Quality Assurance. The parameters for performance evaluations are completeness, reproducibility, accuracy, comparability, and representativeness.

\subsection{Completeness}

The completeness parameter was calculated as the ratio of the number of valid results to the total number of samples collected and analyzed. The gross alpha/beta analyses were 97 percent complete for 1999. Surface water samples were 93 percent complete, and air particulate samples were 98 percent complete. Measurements of radionuclides in ground water, soil, sediment, and animal and plant tissues were 100 percent complete. The data quality objective established for the environmental program is 98 percent complete. The Environmental Monitoring Program achieved the overall data quality objective of 98 percent completeness for environmental samples. Samples having analysis recoveries outside the range of 50 to 120 percent were reanalyzed. 


\subsection{Reproducibility}

The reproducibility of the measurements was validated through analyses of duplicate samples. A low-volume air sampler was rotated in each quarter from location to location, and sampled along with routine samples. The results of these duplicate comparisons are shown in Tables 8.1, $8.2,8.3$, and 8.4 for the four quarters of 1999 . The duplicate samples for other matrices were collected at the same time, same place, and under similar conditions as routine samples. These samples were analyzed in the same analytical batch and/or sample delivery group using similar methods for radiochemical separation and counting as the original samples.

Reproducibility is partially influenced by statistical counting uncertainty, so variances were expected between samples with very low activities (environmental levels). The reproducibility was evaluated with the RER:

$$
R E R=\frac{\mid(\text { Mean Activity })_{o r i}-(\text { Mean Activity })_{\text {dup }} \mid}{\sqrt{(2 \times S D)_{\text {ori }}^{2}+(2 \times S D)_{\text {dup }}^{2}}}
$$

Where:

$$
\begin{aligned}
& (\text { Mean Activity })_{\text {ori }}=\text { Mean Activity of Original } \\
& (\text { Mean Activity })_{\text {dup }}=\text { Mean Activity of Dupli- } \\
& \text { cate Sample } \\
& \mathrm{SD}=\text { Standard Deviation of Original and Dupli- } \\
& \text { cate Samples }
\end{aligned}
$$

RER results equal or less than one are acceptable and considered to demonstrate reproducibility.

\subsection{Accuracy and Comparability}

The accuracy of the analyses were assured/controlled by using NIST-traceable standards for instrument calibration. Internal quality control is performed by using spiked laboratory control samples. Intercomparisons were performed with the DOE Environmental Measurements Laboratory (EML) to ensure the reliability of radiochemical separation methods and counting instruments. Accuracy, expressed as percent bias, was calculated by:

$$
\% B I A S=\left[\frac{A_{m}-A_{k}}{A_{k}}\right] * 100
$$

Where:

$$
\begin{array}{cl}
\% \text { BIAS } & =\text { Percent Bias } \\
\mathrm{A}_{\mathrm{m}} & =\text { Measured Sample Activity } \\
\mathrm{A}_{\mathrm{k}} & =\text { Known Sample Activity }
\end{array}
$$

The DOE EML QAP prepares quality control samples containing various alpha-, beta-, and gamma-emitting nuclides in water, soil, air filter, vegetation, and tissue media and distributes them to numerous DOE contractor laboratories. The program is an interlaboratory comparison in that results from the participants are compared with the experimentally determined results of EML. Also, EML assesses the results as acceptable or not within a range of bias from the EML result. The Thermo NuTech contract laboratory participated in this program; the results are provided in Tables 8.5, 8.6, 8.7, and 8.8 for air, soil, vegetation, and water, respectively. The contract laboratory's percent bias in evaluating air filters was not acceptable for ${ }^{54} \mathrm{Mn},{ }^{239} \mathrm{Pu},{ }^{90} \mathrm{Sr}$, and ${ }^{238} \mathrm{U}$ in this intercomparison program. The gross alpha/beta analyses for air filters were not acceptable.

The reported values for ${ }^{214} \mathrm{Bi},{ }^{214} \mathrm{~Pb},{ }^{212} \mathrm{~Pb}$, ${ }^{239} \mathrm{Pu}$, and ${ }^{234} \mathrm{Th}$ in the soil matrix were not acceptable. All the reported values for radionuclides in the vegetation samples were acceptable, and all but one of the reported values for radionuclides in the water samples were acceptable. The ${ }^{234} \mathrm{U}$ reported value had a negative bias of 24.3 percent. ThermoNuTech's failure of these laboratory intercomparisons is of concern. However, because of the low values being measured and the large uncertainties associated with them, the conclusion that WIPP has not released radioactivity into the environment is still valid. 


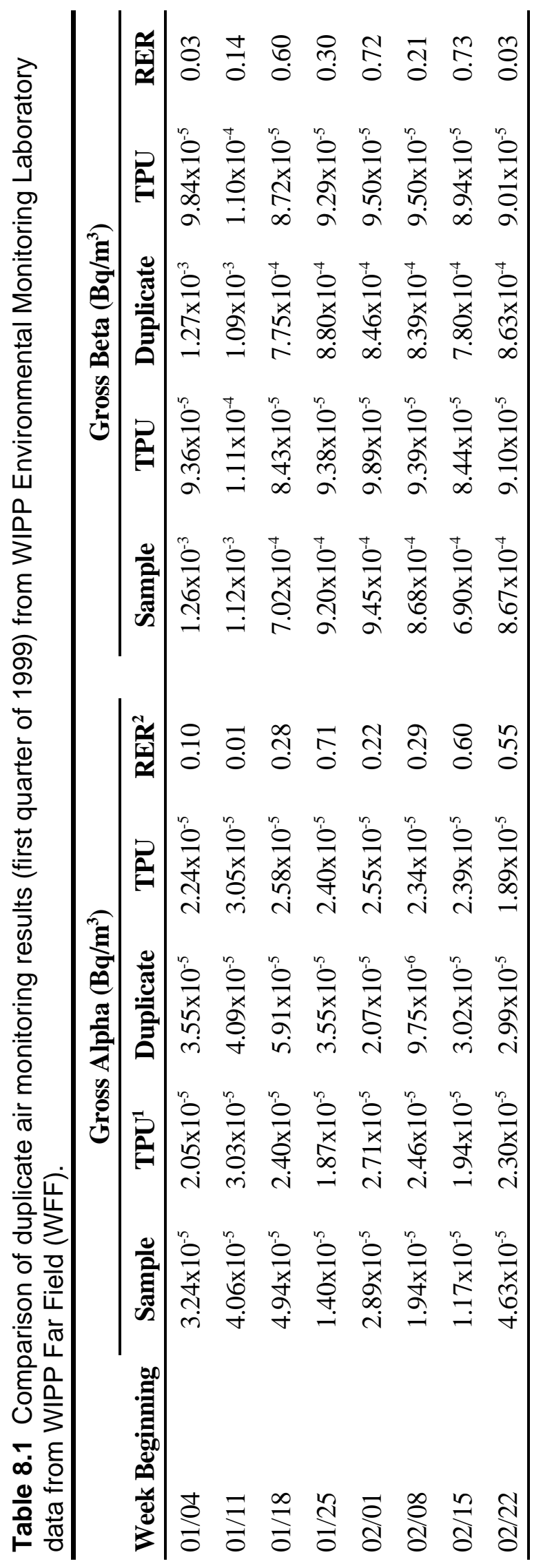




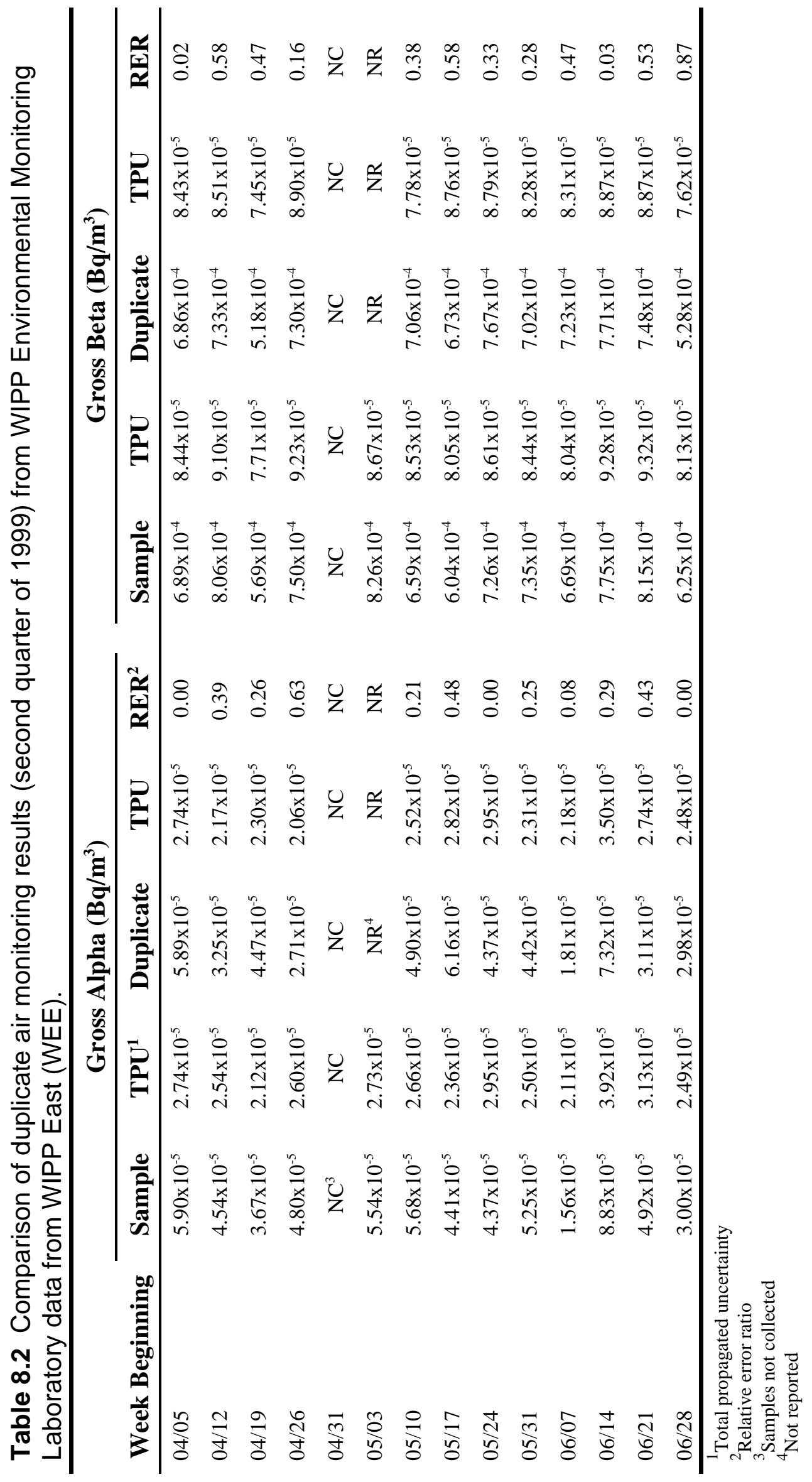




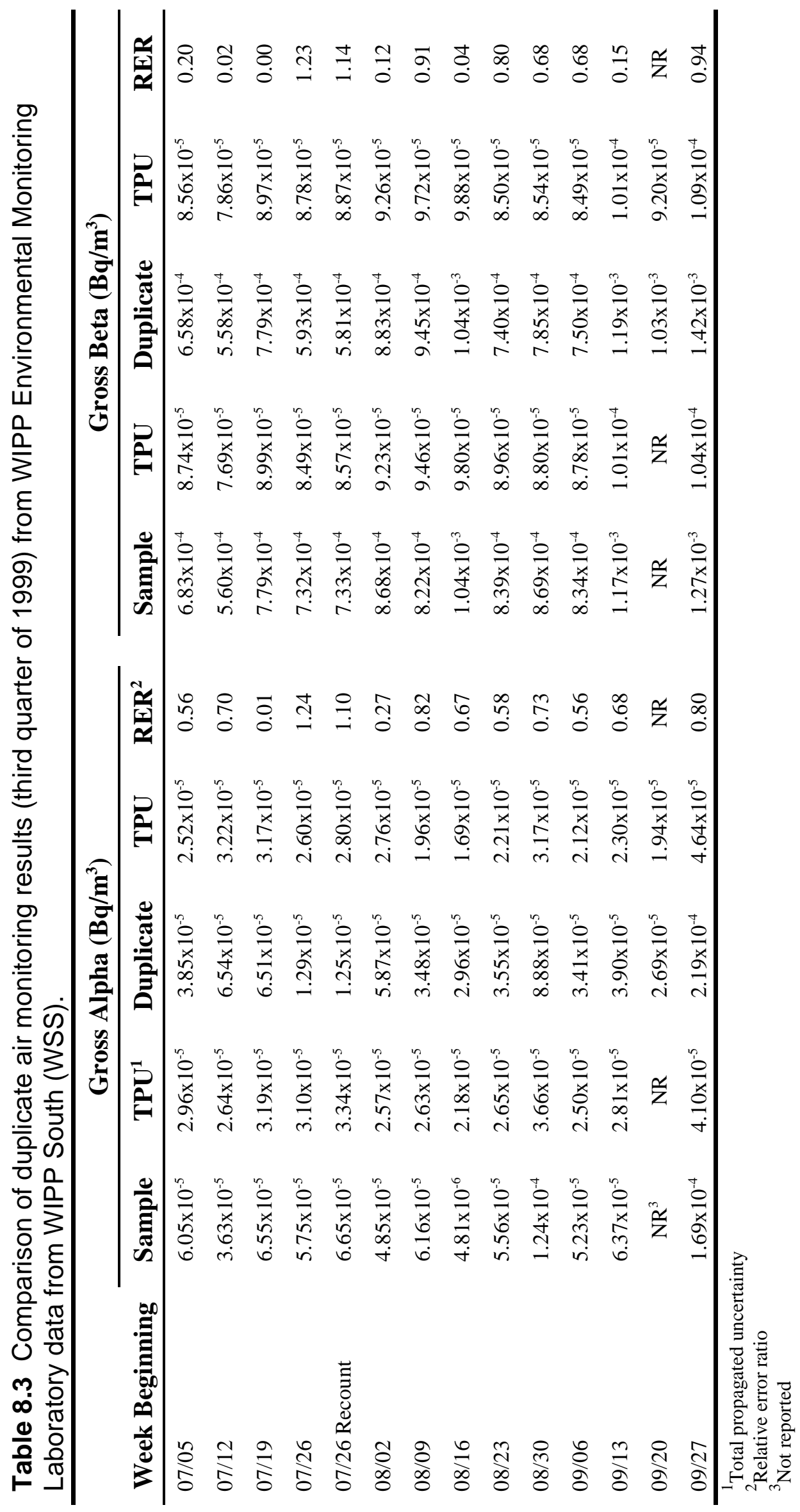




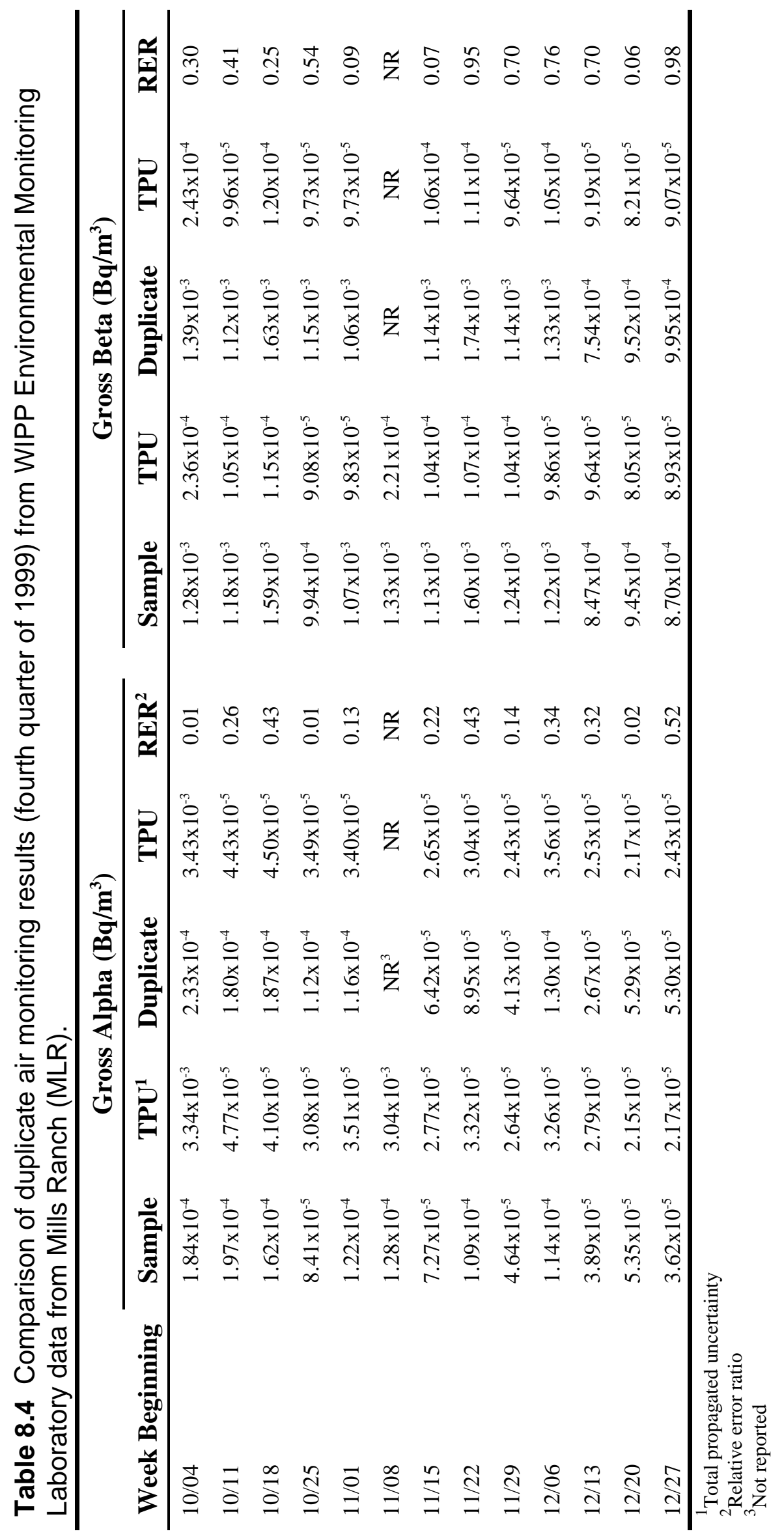


Table 8.5 Environmental Measurements Laboratory evaluation of Thermo NuTech (air).

\begin{tabular}{lccccc} 
& \multicolumn{2}{c}{ Air (Bq/filter) } & & \\
Radionuclide & $\begin{array}{c}\text { Reported } \\
\text { Value }\end{array}$ & $\begin{array}{c}\text { Reported } \\
\text { Error }\end{array}$ & $\begin{array}{c}\text { EML } \\
\text { Value }\end{array}$ & $\begin{array}{c}\text { EML } \\
\text { Error }\end{array}$ & \% Bias \\
\hline${ }^{241} \mathrm{Am}$ & 0.104 & 0.016 & 0.127 & 0.010 & -18.1 \\
${ }^{57} \mathrm{Co}$ & 5.310 & 0.100 & 7.730 & 0.033 & -31.3 \\
${ }^{60} \mathrm{Co}$ & 4.910 & 0.200 & 6.350 & 0.410 & -22.7 \\
${ }^{137} \mathrm{Cs}$ & 4.900 & 0.190 & 6.430 & 0.420 & -23.8 \\
${ }^{\mathrm{Gross}}$ & 1.260 & 0.350 & 2.77 & 0.260 & -54.5 \\
$\mathrm{Gross}$ beta & 1.010 & 0.220 & 2.660 & 0.260 & -62.0 \\
${ }^{54} \mathrm{Mn}$ & 5.830 & 0.210 & 7.910 & 0.450 & -26.3 \\
${ }^{238} \mathrm{Pu}$ & 0.093 & 0.015 & 0.097 & 0.007 & -3.9 \\
${ }^{239} \mathrm{Pu}$ & 0.091 & 0.012 & 0.136 & 0.011 & -33.1 \\
${ }^{106} \mathrm{Ru}$ & 5.810 & 1.300 & 5.500 & 1.760 & 5.6 \\
${ }^{90} \mathrm{Sr}$ & 2.790 & 0.850 & 0.336 & 0.014 & 730.0 \\
${ }^{234} \mathrm{U}$ & 0.059 & 0.011 & 0.066 & 0.003 & -10.3 \\
${ }^{238} \mathrm{U}$ & 0.053 & 0.010 & 0.065 & 0.005 & -18.0 \\
${ }^{\mathrm{TOT}} \mathrm{U}(\mu \mathrm{gg})$ & 5.190 & 0.530 & 5.230 & 0.290 & 0.8 \\
\hline
\end{tabular}

${ }^{1}$ Environmental Measurements Laboratory

Table 8.6 Environmental Measurement Laboratory evaluation of Thermo NuTech (soil).

Soil (Bq/kg)

\begin{tabular}{lrrrrc} 
Radionuclide & $\begin{array}{c}\text { Reported } \\
\text { Value }\end{array}$ & $\begin{array}{c}\text { Reported } \\
\text { Error }\end{array}$ & $\begin{array}{r}\text { EML } \\
\text { Value }\end{array}$ & $\begin{array}{c}\text { EML } \\
\text { Error }\end{array}$ & \% Bias \\
\hline${ }^{228} \mathrm{Ac}$ & 173.120 & 16.000 & 124.000 & 4.800 & 39.6 \\
${ }^{241} \mathrm{Am}$ & 2.520 & 1.040 & 1.440 & 0.190 & 75.0 \\
${ }^{214} \mathrm{Bi}$ & 99.400 & 8.300 & 69.500 & 1.800 & 43.0 \\
${ }^{137} \mathrm{Cs}$ & 250.180 & 5.500 & 204.000 & 5.000 & 22.6 \\
${ }^{40} \mathrm{~K}$ & 931.660 & 61.200 & 780.000 & 27.000 & 19.4 \\
${ }^{212} \mathrm{~Pb}$ & 174.790 & 5.500 & 127.000 & 4.800 & -37.6 \\
${ }^{214} \mathrm{~Pb}$ & 107.360 & 8.300 & 72.000 & 0.420 & 49.1 \\
${ }^{239} \mathrm{Pu}$ & 1.960 & 1.040 & 3.200 & 0.500 & 38.7 \\
${ }^{234} \mathrm{Th}$ & 379.030 & 32.200 & 198.000 & 5.600 & 91.4 \\
${ }^{234} \mathrm{U}$ & 192.070 & 19.900 & 190.000 & 5.200 & 1.1 \\
${ }^{238} \mathrm{U}$ & 195.380 & 20.200 & 202.000 & 7.200 & -3.3 \\
${ }^{\mathrm{TOT}} \mathrm{U}(\mu \mathrm{gg})$ & 17.600 & 2.430 & 16.300 & 0.300 & 8.0 \\
\hline
\end{tabular}

${ }^{1}$ Environmental Measurements Laboratory 
Table 8.7 Environmental Measurement Laboratory evaluation of Thermo NuTech (vegetation).

Vegetation $(\mathrm{Bq} / \mathrm{kg})$

\begin{tabular}{lccccc} 
Radionuclide & $\begin{array}{c}\text { Reported } \\
\text { Value }\end{array}$ & $\begin{array}{c}\text { Reported } \\
\text { Error }\end{array}$ & $\begin{array}{c}\text { EML }^{\mathbf{1}} \\
\text { Value }\end{array}$ & $\begin{array}{c}\text { EML } \\
\text { Error }\end{array}$ & \% Bias \\
\hline${ }^{241} \mathrm{Am}$ & 2.740 & 0.480 & 2.880 & 0.220 & -4.9 \\
${ }^{244} \mathrm{Cm}$ & 1.000 & 0.260 & 1.610 & 0.360 & -37.9 \\
${ }^{60} \mathrm{Co}$ & 18.830 & 2.760 & 17.600 & 1.000 & 7.0 \\
${ }^{137} \mathrm{Cs}$ & 496.170 & 5.400 & 440.000 & 20.000 & 12.8 \\
${ }^{40} \mathrm{~K}$ & 512.800 & 37.100 & 513.000 & 20.000 & 0.0 \\
${ }^{239} \mathrm{Pu}$ & 4.660 & 0.670 & 4.300 & 0.460 & 8.4 \\
${ }^{90} \mathrm{Sr}$ & 573.240 & 64.800 & 595.000 & 29.000 & -3.7 \\
\hline
\end{tabular}

${ }^{1}$ Environmental Measurements Laboratory

Table 8.8 Environmental Measurements Laboratory evaluation of Thermo NuTech (water).

\section{$\underline{\text { Water }(\mathbf{B q} / \mathbf{L})}$}

\begin{tabular}{lccccc} 
Radionuclide & $\begin{array}{c}\text { Reported } \\
\text { Value }\end{array}$ & $\begin{array}{c}\text { Reported } \\
\text { Error }\end{array}$ & $\begin{array}{c}\text { EML } \\
\text { Value }\end{array}$ & $\begin{array}{c}\text { EML } \\
\text { Error }\end{array}$ & \% Bias \\
\hline${ }^{241} \mathrm{Am}$ & 0.910 & 0.120 & 0.850 & 0.100 & 7.1 \\
${ }^{60} \mathrm{Co}$ & 56.480 & 0.740 & 52.400 & 2.200 & 7.8 \\
${ }^{137} \mathrm{Cs}$ & 85.400 & 0.770 & 76.000 & 3.400 & 12.4 \\
$\mathrm{Gross}$ Alpha & 1703.000 & 191.000 & 1580.000 & 20.000 & 7.8 \\
$\mathrm{Gross}$ Beta & 605.000 & 48.000 & 740.000 & 40.000 & -18.2 \\
${ }^{238} \mathrm{Pu}$ & 0.820 & 0.130 & 0.790 & 0.080 & 3.8 \\
${ }^{239} \mathrm{Pu}$ & 0.830 & 0.130 & 0.870 & 0.100 & -4.6 \\
${ }^{90} \mathrm{Sr}$ & 1.330 & 0.340 & 1.720 & 0.100 & -22.7 \\
${ }^{234} \mathrm{U}$ & 0.280 & 0.050 & 0.370 & 0.020 & -24.3 \\
${ }^{238} \mathrm{U}$ & 0.300 & 0.050 & 0.360 & 0.020 & -16.7 \\
${ }^{\mathrm{T}} \mathrm{T}$ & $0.033(\mu \mathrm{g})$ & 0.000 & 0.030 & 0.010 & 10.0 \\
\hline
\end{tabular}

${ }^{1}$ Environmental Measurements Laboratory 


\subsection{Representativeness}

The primary objective of environmental monitoring has been to protect the health and safety of the population surrounding the WIPP facility. The quality objective of representativeness was based on potential radiation exposure of the population through inhalation and ingestion. Samples of ambient air, surface water, sediment, ground water, and biota were collected from areas representative of potential pathways for intake.

The samples were collected using generally accepted methodologies for environmental sampling and approved procedures, ensuring they were representative of the media sampled. These samples were analyzed for natural radioactivity, fallout radioactivity from nuclear weapons tests, and other anthropogenic radionuclides. The reported concentrations at various locations were representative of the baseline information for radionuclides of interest at the WIPP facility.

Environmental Resource Associates provides an interlaboratory assessment of the analysis for volatile organics. Air Toxics participated in this assessment and received a score of 100 percent and an overall assessment of excellent. Air Toxics' results for that test are shown in Table 8.9.

Environmental Resource Associates also provides an interlaboratory assessment of the analysis for water pollutants. Trace Analysis participated in this assessment and received a score of 80.8 percent and an overall assessment of good. Trace Analysis results for that test are shown in Table 8.10.

Table 8.9 Environmental Resource Associates assessment of air toxics-volatiles-WP-49.

\begin{tabular}{lccc}
\hline \multicolumn{1}{c}{ Parameter } & $\begin{array}{c}\text { Reported Value } \\
(\mu \mathbf{g} / \mathbf{L})\end{array}$ & $\begin{array}{c}\text { ERA Certified Value } \\
(\mu \mathbf{g} / \mathbf{L})\end{array}$ & $\begin{array}{c}\text { Acceptance Limits } \\
(\mu \mathbf{g} / \mathbf{L})\end{array}$ \\
\hline Benzene & 37.0 & 35.6 & $25.5-46.0$ \\
Bromodichloromethane & 60.3 & 55.1 & $39.1-71.7$ \\
Bromoform & 41.2 & 35.6 & $22.8-48.8$ \\
Carbon tetrachloride & 47.6 & 45.8 & $28.4-64.6$ \\
Chlorobenzene & 21.5 & 19.9 & $14.5-25.2$ \\
Chlorodibromomethane & 31.2 & 27.8 & $18.3-36.9$ \\
Chloroform & 47.7 & 44.2 & $30.7-56.7$ \\
1,2-Dichlorobenzene & 29.2 & 26.8 & $18.7-34.3$ \\
1,3-Dichlorobenzene & 24.3 & 22.7 & $15.8-28.6$ \\
1,4 -Dichlorobenzene & 46.1 & 42.9 & $29.5-55.4$ \\
1,2 -Dichloroethane & 62.2 & 58.2 & $40.2-77.4$ \\
1,1-Dichloroethylene & 81.6 & 73.5 & $36.8-105$ \\
Trans-1,2-Dichloroethylene & 49.3 & 45.9 & $25.0-64.8$ \\
Ethylbenzene & 75.2 & 69.7 & $46.3-91.3$ \\
Methylene chloride & 42.7 & 38.4 & $24.3-53.1$ \\
4-Methyl-2pentanone (MIBK) & 64.5 & 61.7 & $23.6-96.3$ \\
Tetrachloroethylene & 61.5 & 58.8 & $38.9-75.2$ \\
Toluene & 22.5 & 21.1 & $14.9-26.8$ \\
1,1,1-Trichloroethane & 57.1 & 52.1 & $33.7-68.8$ \\
1,1,2-Trichloroethane & 68.2 & 63.5 & $40.5-87.6$ \\
Trichloroethylene & 51.8 & 48.3 & $31.4-62.4$ \\
\hline & & & \\
\hline
\end{tabular}


Table 8.10 Environmental Resource Associates assessment of trace analysis-InterLaB WatR ${ }^{\mathrm{TM}}$ Pollution WP-51.

\begin{tabular}{|c|c|c|c|}
\hline Parameter & $\begin{array}{c}\text { Reported Value } \\
(\mu \mathrm{g} / \mathrm{L})\end{array}$ & $\begin{array}{c}\text { ERA Certified Value } \\
(\mu \mathrm{g} / \mathrm{L})\end{array}$ & $\begin{array}{c}\text { Acceptance Limits } \\
(\mu \mathrm{g} / \mathrm{L})\end{array}$ \\
\hline Mercury & 12.5 & 12.4 & $9.28-15.5$ \\
\hline $\mathrm{pH}$ & 9.27 & 9.40 & $9.11-9.68$ \\
\hline BOD & 112 & 118 & $59.8-177$ \\
\hline COD & 187 & 191 & $148-217$ \\
\hline TOC & 74.4 & 75.6 & $63.2-86.9$ \\
\hline Total phosphorus as $\mathrm{P}$ & 6.47 & 7.65 & $5.82-8.94$ \\
\hline Total kjeldahl nitrogen as $\mathrm{N}$ & 4.20 & 2.96 & $1.86-4.09$ \\
\hline Total suspended solids & 36.0 & 31.0 & $22.4-32.9$ \\
\hline Calcium & 17.7 & 17.4 & $15.2-20.0$ \\
\hline Magnesium & 30.3 & 30.5 & $26.6-34.1$ \\
\hline Calcium hardness as $\mathrm{CaCO} 3$ & 44.2 & 43.4 & $34.3-52.5$ \\
\hline Total hardness as $\mathrm{CaCO} 3$ & 169 & 169 & $153-185$ \\
\hline Total dissolved solids at $180^{\circ} \mathrm{C}$ & 325 & 357 & $265-449$ \\
\hline Conductivity at $25^{\circ} \mathrm{C}$ ( $\mu$ mhos $)$ & 421 & 420 & $387-452$ \\
\hline Alkalinity as $\mathrm{CaCO} 3$ & 114 & 112 & $102-121$ \\
\hline Chloride & 56.9 & 58.2 & $52.1-63.9$ \\
\hline Fluoride & 2.49 & 2.71 & $2.36-3.02$ \\
\hline Sulfate & 4.89 & 5.48 & $3.28-7.61$ \\
\hline Potassium & 10.5 & 10.0 & $8.45-11.7$ \\
\hline Sodium & 83.5 & 89.4 & $80.8-97.8$ \\
\hline Grease and oil (gravimetric) & 28.3 & 30.4 & $19.3-35.7$ \\
\hline Ammonia as $\mathrm{N}$ & 17.1 & 18.5 & $14.4-22.3$ \\
\hline Nitrate as $\mathrm{N}$ & 1.28 & 0.918 & $0.686-1.13$ \\
\hline Ortho-phophate as P & 3.62 & 3.43 & $2.93-3.97$ \\
\hline Aluminum & 1950 & 2170 & $1870-2460$ \\
\hline Antimony & 269 & 247 & $166-301$ \\
\hline Arsenic & 588 & 575 & $483-674$ \\
\hline Barium & 1050 & 983 & $717-1250$ \\
\hline Beryllium & 54.0 & 57.8 & $47.9-65.5$ \\
\hline Boron & 815 & 917 & $669-1160$ \\
\hline Cadmium & 214 & 200 & $170-229$ \\
\hline Chromium & 952 & 952 & $831-1080$ \\
\hline Cobalt & 448 & 441 & $387-495$ \\
\hline Copper & 61.0 & 70.3 & $60.4-80.3$ \\
\hline Iron & 1000 & 957 & $846-1080$ \\
\hline Lead & 715 & 677 & $591-759$ \\
\hline Manganese & 1830 & 1870 & $1680-2080$ \\
\hline Molybdenum & 173 & 177 & $150-204$ \\
\hline Nickel & 2660 & 2600 & $2360-2900$ \\
\hline
\end{tabular}


Table 8.10, cont.

\begin{tabular}{|c|c|c|c|}
\hline Parameter & $\begin{array}{c}\text { Reported Value } \\
(\mu \mathrm{g} / \mathrm{L})\end{array}$ & $\begin{array}{c}\text { ERA Certified Value } \\
(\mu \mathrm{g} / \mathrm{L})\end{array}$ & $\begin{array}{c}\text { Acceptance Limits } \\
(\mu \mathrm{g} / \mathrm{L})\end{array}$ \\
\hline Selenium & 497 & 486 & $384-563$ \\
\hline Silver & 598 & 559 & $480-640$ \\
\hline Strontium & 206 & 204 & $174-234$ \\
\hline Thallium & 774 & 709 & $572-822$ \\
\hline Vanadium & 455 & 487 & $437-534$ \\
\hline Zinc & 2010 & 1980 & $1760-2220$ \\
\hline Total residual chlorine & 0.570 & 0.609 & $0.436-0.782$ \\
\hline Cyanide, total & 0.337 & 0.340 & $0.232-0.441$ \\
\hline Phenolics, total & 0.192 & 0.123 & $0.0596-0.186$ \\
\hline Aroclor 1016 & 2.60 & 1.92 & $1.05-2.32$ \\
\hline Aroclor 1260 & 14.0 & 15.9 & $3.06-22.9$ \\
\hline Aroclor 1254 & 30.0 & 32.6 & $4.39-48.5$ \\
\hline Aroclor 1254 & 2.50 & 2.00 & $0.797-2.88$ \\
\hline Benzene & 21.7 & 21.0 & $14.9-27.4$ \\
\hline Bromodichloromethane & 45.3 & 41.1 & $29.1-53.5$ \\
\hline Bromoform & 42.6 & 34.2 & $21.9-46.9$ \\
\hline Carbon tetrachloride & 59.4 & 53.5 & $33.1-75.5$ \\
\hline Chloroobenzene & 25.0 & 21.2 & $15.4-26.8$ \\
\hline Chlorodibromomethane & 50.0 & 41.0 & $27.1-54.4$ \\
\hline Chloroform & 25.8 & 24.9 & $17.5-32.1$ \\
\hline 1,2-Dichlorobenzene & 51.9 & 43.9 & $30.9-55.6$ \\
\hline 1,3-Dichlorobenzene & 38.3 & 27.5 & $19.3-34.5$ \\
\hline 1,4-Dichlorobenzene & 31.4 & 31.7 & $21.7-41.1$ \\
\hline 1,2-Dichloroethane & 42.2 & 38.8 & $26.9-51.8$ \\
\hline Ethylbenzene & 30.2 & 25.6 & $17.3-33.3$ \\
\hline Methylene chloride & 30.9 & 35.8 & $22.6-49.6$ \\
\hline 4-Methyl-2-pentanone (MIBK) & 16.6 & 20.4 & $7.79-31.8$ \\
\hline Styrene & 28.3 & 25.5 & $14.4-34.3$ \\
\hline 1,1,1,2-Tetrachloroethane & 80.3 & 66.1 & $40.4-90.7$ \\
\hline Tetrachloroethylene & 26.0 & 23.6 & $15.6-30.6$ \\
\hline Toluene & 41.1 & 38.4 & $27.5-48.1$ \\
\hline 1,1,1-Trichloroethane & 44.4 & 42.6 & $27.6-56.2$ \\
\hline Trichloroethylene & 55.3 & 55.3 & $35.9-71.5$ \\
\hline Anthracene & 81.0 & 97.0 & $28.9-130$ \\
\hline Benzo(k)fluorantene & 21.0 & 28.8 & $4.09-42.7$ \\
\hline Benzo(a)pyrene & 22.0 & 30.6 & $8.47-44.9$ \\
\hline Chrysene & 33.0 & 31.2 & $8.47-44.2$ \\
\hline Dibenzofuran & 65.0 & 96.5 & $30.6-122$ \\
\hline 1,3-Dechlorobenzene & 76.0 & 124 & D.L - 176 \\
\hline 2,4-Dinitrotoluene & 70.0 & 113 & $26.5-151$ \\
\hline Bis(2-Ethylhexyl)phthalate & 71.0 & 41.7 & $7.72-62.3$ \\
\hline
\end{tabular}


Table 8.10, cont.

\begin{tabular}{lccc}
\hline \multicolumn{1}{c}{ Parameter } & $\begin{array}{c}\text { Reported Value } \\
(\mu \mathbf{g} / \mathbf{L})\end{array}$ & $\begin{array}{c}\text { ERA Certified Value } \\
(\mu \mathbf{g} / \mathbf{L})\end{array}$ & $\begin{array}{c}\text { Acceptance Limits } \\
(\mu \mathbf{g} / \mathbf{L})\end{array}$ \\
\hline Fluoranthene & 37.0 & 49.2 & $13.4-70.9$ \\
Hexachloroethane & 18.0 & 29.0 & $5.41-42.6$ \\
Isophorone & 96.0 & 121 & $29.2-153$ \\
2-Methylnaphthalene & 60.0 & 94.6 & $10.2-131$ \\
Naphtalene & 27.0 & 39.9 & $6.32-53.3$ \\
Pyrene & 76.0 & 69.7 & $19.5-97.8$ \\
1,2,4-Trichlorobenzene & 67.0 & 103 & $8.30-139$ \\
2-Chlorophenol & 130 & 145 & $33.7-189$ \\
2,4-Dichlorophenol & 93.0 & 112 & $28.6-142$ \\
2-Methylphenol & 49.0 & 64.2 & $6.93-87.7$ \\
Pentachlorophenol & 14.0 & 44.6 & $3.34-66.6$ \\
Phenol & 22.0 & 59.5 & D.L. - 92.0 \\
2,4,5-Trichlorophenol & 37.0 & 51.8 & $10.5-69.7$ \\
2,4,6-Trichlorophenol & 22.0 & 30.4 & $7.70-40.3$ \\
Acenaphthene & 2.00 & 2.59 & $1.19-3.22$ \\
Benzo(a)pyrene & 4.00 & 8.93 & $3.81-12.2$ \\
Naphthalene & 21.0 & 25.1 & $7.52-34.0$ \\
\hline
\end{tabular}




\section{References}

10 CFR § 50, Appendix B. Quality Assurance Criteria for Nuclear Power Plants and Fuel Reprocessing Plants. Code of Federal Regulations. Office of the Federal Register, National Archives and Records Administration, Washington D.C.

10 CFR $\S 61$. Licensing Requirements For Land Disposal of Radioactive Waste. Code of Federal Regulations. Office of the Federal Register, National Archives and Records Administration, Washington D.C.

10 CFR $\S 71$. Packaging and Transportation of Radioactive Material. Code of Federal Regulations. Office of the Federal Register, National Archives and Records Administration, Washington D.C.

10 CFR $\S 834$. Radiation Protection of the Public and the Environment; Proposed Rule. Code of Federal Regulations. Office of the Federal Register, National Archives and Records Administration, Washington D.C.

10 CFR $\S 835$. Occupational Radiation Protection. Code of Federal Regulations. Office of the Federal Register, National Archives and Records Administration, Washington D.C.

10 CFR $\S 1021$. National Environmental Policy Act Implementing Procedures. Code of Federal Regulations. Office of the Federal Register, National Archives and Records Administration, Washington D.C.

10 CFR § 1021.331. National Environmental Policy Act Implementing Procedures,
Mitigation action plans. Code of Federal Regulations. Office of the Federal Register, National Archives and Records Administration, Washington D.C.

40 CFR § 61. National Emission Standards for Hazardous Air Pollutants. Code of Federal Regulations. Office of the Federal Register, National Archives and Records Administration, Washington D.C.

40 CFR § 61.09. National Emission Standards for Hazardous Air Pollutants, Notification of startup. Code of Federal Regulations. Office of the Federal Register, National Archives and Records Administration, Washington D.C.

40 CFR $\S$ 61.92. National Emission Standards for Hazardous Air Pollutants, Standard. Code of Federal Regulations. Office of the Federal Register, National Archives and Records Administration, Washington D.C.

40 CFR § 61.93(a). National Emission Standards for Hazardous Air Pollutants, Emission monitoring and test procedures. Code of Federal Regulations. Office of the Federal Register, National Archives and Records Administration, Washington D.C.

40 CFR § 122. EPA Administered Permit Programs: the National Pollutant Discharge Elimination System. Code of Federal Regulations. Office of the Federal Register, National Archives and Records Administration, Washington D.C. 
40 CFR § 191. Environmental radiation protection standards for the management and disposal of spent nuclear fuel, highlevel and transuranic radioactive wastes. Code of Federal Regulations. Office of the Federal Register, National Archives and Records Administration, Washington D.C.

40 CFR $\S 194$. Criteria for the certification and re-certification of the Waste Isolation Pilot Plant's compliance with the 40 CFR Part 191 disposal regulations. Code of Federal Regulations. Office of the Federal Register, National Archives and Records Administration, Washington D.C.

40 CFR § 262. Standards Applicable to Generators of Hazardous Waste. Code of Federal Regulations. Office of the Federal Register, National Archives and Records Administration, Washington D.C.

40 CFR § 264. Standards for owners and operators of hazardous waste treatment, storage, and disposal facilities. Code of Federal Regulations. Office of the Federal Register, National Archives and Records Administration, Washington D.C.

40 CFR § 300. National Oil and Hazardous Substances Pollution Contingency Plan. Code of Federal Regulations. Office of the Federal Register, National Archives and Records Administration, Washington D.C.

40 CFR § 302. Designation, Reportable Quantities, and Notification. Code of Federal Regulations. Office of the Federal Register, National Archives and Records Administration, Washington D.C.

40 CFR $\$ \S$ 1500-1508. Council on Environmental Quality. Office of the Federal Register, National Archives and
Records Administration, Washington D.C.

49 CFR. Transportation. Code of Federal Regulations. Office of the Federal Register, National Archives and Records Administration, Washington D.C.

49 CFR $\S \S 106-179$. Transportation, Research and Special Programs Administration, Department of Transportation. Code of Federal Regulations. Office of the Federal Register, National Archives and Records Administration, Washington D.C.

20 NMAC 2. Air Quality. Title 20, New Mexico Administrative Code, Chapter 2. Sante Fe, NM.

20 NMAC 2.72. Construction Permits. Title 20, New Mexico Administrative Code, Chapter 2, Part 72. (Air Quality Control Regulation 702). Santa Fe, NM.

20 NMAC 4.1. Hazardous Waste Management. Title 20, New Mexico Administrative Code, Chapter 4, Part 1. Sante Fe, NM.

7 U.S.C. § 136-136y. Federal Insecticide, Fungicide, and Rodenticide Act, as amended. U.S. Government Printing Office. Washington, D.C.

15 U.S.C. § 2301 et seq. Toxic Substances Control Act. U.S. Government Printing Office. Washington, D.C.

16 U.S.C. § 1531-1544, 87 Stat. 884. Endangered Species Act of 1973. U.S. Government Printing Office. Washington, D.C.

16 U.S.C. $§ 470$ et seq. National Historic Preservation Act. U.S. Government Printing Office. Washington, D.C. 
33 U.S.C. § 1251-1376; Chapter 758; PL 845; 62 Stat. 1155. Federal Water Pollution Control Act of 1948 (Clean Water Act), Section 402. U.S. Government Printing Office. Washington, D.C.

42 U.S.C. § 2278a. Atomic Energy Act of 1954. U.S. Government Printing Office. Washington, D.C.

42 U.S.C. $\S 300 f$ et seq. Safe Drinking Water Act. U.S. Government Printing Office. Washington, D.C.

42 U.S.C. $§ 3251$ et seq. Resource Conservation and Recovery Act. U.S. Government Printing Office. Washington, D.C.

42 U.S.C. § 4321-4345. National Environmental Policy Act. U.S. Government Printing Office. Washington, D.C.

42 U.S.C. § 7112. Department of Energy Organization Act. U.S. Government Printing Office. Washington, D.C.

42 U.S.C. $§ 7401$ et seq. Clean Air Act. U.S. Government Printing Office. Washington, D.C.

42 U.S.C. § 9601 et seq. Comprehensive Environmental Response, Compensation, and Liability Act (including the Superfund Amendments and Reauthorization Act of 1986). U.S. Government Printing Office. Washington, D.C.

42 U.S.C. $§ 10101$ et seq. Nuclear Waste Policy Act of 1982. U.S. Government Printing Office. Washington, D.C.

43 U.S.C. $§ 1751$ et seq. Federal Land Policy and Management Act, 1976. U.S. Government Printing Office. Washington, D.C.

49 App. U.S.C. § 1801 et seq.; 49 CFR § 106-179. Hazardous Materials Transportation Act.
U.S. Government Printing Office. Washington, D.C.

310-M-2. 1993. Air Quality Permit. New Mexico Environment Department, Santa Fe.

ANSI/ASQC - E4. Proposed. Quality Assurance Program Requirements for Environmental Programs. American National Standards Institute/ American Society for Quality Control, Washington, DC.

HPS N13.30. 1996. Performance Criteria for Radiobioassay. Health Physics Society, Washington, DC.

NQA-1-1994. 1994. Quality Assurance Program Requirements for Nuclear Facilities. American National Standards Institute, Washington, DC.

Dawson, J.W., S.C. Tygielski, and A.P. Hocker. 2000. Waste Isolation Pilot Plant WIPP Raptor Program 1999 Annual Report. Sonora Environmental Consultants, Inc.

DOE/CAO 96-2184. 1996. Compliance Certification Application, October 1996. U.S. Department of Energy, Carlsbad Area Office. Carlsbad, NM.

DOE/EH-0173T. 1991. Environmental Regulatory Guide for Radiological Effluent Monitoring and Environmental Surveillance. U.S. Department of Energy, Washington, D.C.

DOE/EIS-0026. 1980. Final Environmental Impact Statement, Waste Isolation Pilot Plant, Volumes 1 and 2. U.S. Department of Energy, Washington, D.C.

DOE/EIS-0026-FS. 1990. Final Supplemental Environmental Impact Statement (SEISI), Volumes 1-3. U.S. Department of Energy, Washington, D.C. 
DOE/EIS-0026-S-2. 1997. Waste Isolation Pilot Plant Disposal Phase Final Supplemental Environmental Impact Statement (SEISII), Volumes 1-3. U.S. Department of Energy, Washington, D.C.

DOE Order 151.1. 1996. Comprehensive Emergency Management System. U.S. Department of Energy, Washington, D.C.

DOE Order 225.1A. 1997. Accident Investigation. U.S. Department of Energy, Washington, D.C.

DOE Order 231.1. 1996. Environmental, Safety, and Health Reporting. U.S. Department of Energy, Washington, D.C.

DOE Order 414.1. 1998. Quality Assurance. U.S. Department of Energy, Washington, D.C.

DOE Order 430.1. 1995. Life-Cycle Assessment Management. U.S. Department of Energy, Washington, D.C.

DOE Order 435.1. 1999. Radioactive Waste Management. U.S. Department of Energy, Washington, D.C.

DOE Order 451.1A. 1995. National Environmental Compliance Policy Act Compliance Program. U.S. Department of Energy, Washington, D.C.

DOE Order 460.1A. 1996. Packaging and Transportation Safety. U.S. Department of Energy, Washington, D.C.

DOE Order 5400.1. 1990. General Environmental Protection Programs. U.S. Department of Energy, Washington, D.C.

DOE Order 5400.5. 1988. Radiation Protection of the Public and the Environment. U.S. Department of Energy, Washington, D.C.
DOE Order 5480.23. 1994. Nuclear Safety Analysis Reports. U.S. Department of Energy, Washington, D.C.

DOE Order 5484.1. 1987. Environmental Protection, Safety, and Health Protection Information Reporting Requirements. U.S. Department of Energy, Washington, D.C.

DOE-STD-XXXX-00 (Proposed). 2000. A Graded Approach for Evaluating Radiation Doses to Aquatic and Terrestrial Biota. National Technical Information Service, Washington, D.C.

DOE/WIPP 91-005. 1997. Resource Conservation and Recovery Act Part B Permit Application, Revision 6.5. Waste Isolation Pilot Plant, Carlsbad, NM.

DOE/WIPP-93-004. 1993. Waste Isolation Pilot Plant Land Management Plan. Waste Isolation Pilot Plant, Carlsbad, NM.

DOE/WIPP 95-2065, Rev. 3. 1998. WIPP Safety Analysis Report. Waste Isolation Pilot Plant, Carlsbad, NM.

DOE/WIPP 96-2199. 1996. Environmental Protection Implementation Plan for the Waste Isolation Pilot Plant. Waste Isolation Pilot Plant, Carlsbad, NM.

DOE/WIPP 98-2171. 1998. WIPP Biennial Environmental Compliance Report. Waste Isolation Pilot Plant, Carlsbad, NM.

DOE/WIPP 98-2285. 1998. Waste Isolation Pilot Plant RCRA Background Groundwater Quality Baseline Report. Waste Isolation Pilot Plant, Carlsbad, NM. 
DOE/WIPP 99-2194. 1999. WIPP Environmental Monitoring Plan. Waste Isolation Pilot Plant, Carlsbad, NM.

DP-831. 1997. WIPP Sewage System Discharge Plan. New Mexico Environment Department. Santa Fe.

Executive Order 13101, Greening the Government Through Waste Prevention, Recycling, and Federal Acquisition. Office of the President. Washington, D.C.

IAEA Technical Report Series No. 332. 1992. Effects of Ionizing Radiation on Plants and Animals at Levels Implied by Current Radiation Protection Standards. International Atomic Energy Agency. Vienna, Austria.

ISO 14001. Environmental Management System Standards. International Standards Organization. Geneva, Switzerland.

NCRP-94. 1987. Exposure of the Population in the United States and Canada from Natural Background. National Council on Radiation Protection and Measurements. Bethesda, MD.

NCRP-109. 1991. Effects of Ionizing Radiation on Aquatic Organisms. National Council on Radiation Protection and Measurements. Bethesda, MD.

NEPA ID \# WIP:99:001. 1999. 1998 Annual Mitigation Report for the Waste Isolation Pilot Plant. Waste Isolation Pilot Plant, Carlsbad, NM.

NM4890139088-TSDF. 1999. Waste Isolation Pilot Plant Hazardous Waste Permit. New Mexico Environment Department, Santa Fe.
NMED/DOE/AIP 94/1. 1994. Resource Conservation and Recovery Act Facility Assessment. New Mexico Environment Department, Santa Fe.

NMR05A225. 1998. New Mexico NPDES Multi-Sector General Permit. New Mexico Environment Department, Santa Fe.

NMSA $1978 \S 17-2-37$ to 17-2-46. Wildlife Conservation Act. New Mexico Statutes Annotated 1978. State of New Mexico, Santa Fe.

NMSA $1978 \S 74-2$. Air Quality Control Act. New Mexico Statutes Annotated 1978. State of New Mexico, Santa Fe.

NMSA 1978 § 74-6. Water Quality Act. New Mexico Statutes Annotated 1978. State of New Mexico, Santa Fe.

Public Law 96-164. National Security and Military Applications of Nuclear Energy Authorization Act of 1980.

Public Law 102-579, 106 stat. 4777. Waste Isolation Pilot Plant Land Withdrawal act. October 1992, as amended October 1996 by Public Law 104-201.

PPOA 99-02. 1999. Pollution Prevention Opportunity Assessment, CRC Lectra Motive Replacement. Waste Isolation Pilot Plant, Carlsbad, NM.

QAMS-005/80. 1980. Interim Guidelines and Specifications for Preparing Quality Assurance Project Plans. U.S. Environmental Protection Agency, Washington, D.C.

Regulatory Guide 4.15, Rev. 1. 1979. Quality Assurance for Radiological Monitoring Programs-Effluent Streams and the Environment. U.S. Nuclear Regulatory Commission, Washington, D.C. 
TO-14A. 1997. Compendium of Methods for the Determination of Toxic Organic Compounds in Ambient Air. U.S. Environmental Protection Agency, Washington, D.C.

U.S. Department of Energy. 1986. Environmental Policy Statement, Secretary Herrington. U.S. Department of Energy. Washington, D.C.

U.S. Nuclear Regulatory Commission. 1999. The Biological Effects of Radiation, $\mathrm{W}$ e b - p a g e . <http://www.nrc.gov/NRC/EDUCATE/ REACTOR/06-BIO/fig05.html>

VCAAO 1.0. 1994. Volatile Organics Analysis of Ambient Air in Canisters. U.S. Environmental Protection Agency, Washington, D.C.

WP 02-EC.0, Rev. 3. 1999. Environmental Management System Implementation Document. Waste Isolation Pilot Plant, Carlsbad, NM.
WP 02-EC.07. 1999. Affirmative Procurement Program Plan. Waste Isolation Pilot Plant, Carlsbad, NM.

WP 02-EM 3004, Rev. 0. 1998. Radiological Data Verification and Validation. Waste Isolation Pilot Plant, Carlsbad, NM.

WP02-1, Rev. 5. 1999. Groundwater Surveillance Program Plan. Waste Isolation Pilot Plant, Carlsbad, NM.

WP 12-VC.01, Rev. 2. 1999. Confirmatory Volatile Organic Compound Monitoring Plan. Waste Isolation Pilot Plant, Carlsbad, NM. 


\title{
Appendix A Acronyms, Abbreviations, and Symbols
}

\author{
A \\ ac \\ ACAA \\ AMSL \\ ANOVA \\ ANSI \\ AOC \\ ASME \\ ASTM \\ acre \\ Accelerated Corrective Action Approach \\ Above Mean Sea Level \\ Analysis of Variance \\ American National Standards Institute \\ Area Of Concern \\ American Society of Mechanical Engineers \\ American Society for Testing and Materials \\ B \\ BLM \\ $\mathrm{Bq}$ \\ $\mathrm{Bq} / \mathrm{L}$ \\ $\mathrm{Bq} / \mathrm{m}^{3}$ \\ United States Department of the Interior, Bureau of Land Management \\ Becquerel \\ Becquerel per liter \\ Becquerel per cubic meter \\ C \\ $\mathrm{C}$ of $\mathrm{C} \quad$ Certificate of Compliance \\ CAO Carlsbad Area Office \\ CERCLA Comprehensive Environmental Response, Compensation and Liability Act \\ CFR \\ $\mathrm{Ci}$ \\ Code of Federal Regulations \\ Curie \\ $\mathrm{cm}$ \\ centimeter \\ CMS Corrective Measures Study \\ CTAC CAO Technical Assistance Contractors \\ D \\ d \\ DLA \\ day \\ DOE \\ Decision Level Activity \\ United States Department of Energy \\ DOT \\ United States Department of Transportation \\ E \\ EA \\ EEG \\ Eh \\ EIS \\ EML \\ EMP \\ EMS \\ Environmental Assessment \\ Environmental Evaluation Group \\ Intensity factor \\ Environmental Impact Statement \\ Environmental Measurements Laboratory \\ WIPP Environmental Monitoring Plan \\ Environmental Management System \\ EPA \\ United States Environmental Protection Agency
}




\begin{tabular}{|c|c|}
\hline \multicolumn{2}{|l|}{$\mathrm{F}$} \\
\hline $\mathrm{ft}$ & foot \\
\hline $\mathrm{ft}^{3}$ & cubic foot \\
\hline FEIS & Final Environmental Impact Statement \\
\hline FR & Federal Register \\
\hline FWE & Fresh Water Elevation \\
\hline \multicolumn{2}{|l|}{ G } \\
\hline g & gram \\
\hline gal & gallon \\
\hline GOCO & Government-Owned, Contractor-Operated \\
\hline \multicolumn{2}{|l|}{$\mathrm{H}$} \\
\hline ha & hectare \\
\hline HalfPACT & Short Transuranic Package Transporter \\
\hline HAP & Hazardous Air Pollutant \\
\hline \multicolumn{2}{|l|}{ I } \\
\hline ISO & International Organization for Standards \\
\hline \multicolumn{2}{|l|}{ K } \\
\hline $\mathrm{kg}$ & kilogram \\
\hline $\mathrm{km}$ & kilometer \\
\hline $\mathrm{km}^{2}$ & square kilometers \\
\hline \multicolumn{2}{|l|}{$\mathrm{L}$} \\
\hline $\mathrm{L}$ & liter \\
\hline LMP & Land Management Plan \\
\hline LUR & Land Use Request \\
\hline \multicolumn{2}{|l|}{ M } \\
\hline $\mathrm{m}^{3}$ & cubic meters \\
\hline $\mathrm{mBq}$ & millibecquerel \\
\hline MDA & Minimum Detectable Activity \\
\hline MDC & Minimum Detectable Concentration \\
\hline MDL & Method Detection Limit \\
\hline $\mathrm{mg}$ & milligram \\
\hline $\mathrm{mg} / \mathrm{L}$ & milligram per liter \\
\hline $\mathrm{mi}$ & mile \\
\hline $\mathrm{mi}^{2}$ & square miles \\
\hline $\mathrm{ml}$ & milliliter \\
\hline MOU & Memorandum Of Understanding \\
\hline mrem & millirem \\
\hline $\mathrm{mrem} / \mathrm{yr}$ & millirem per year \\
\hline $\mathrm{mSv}$ & millisievert \\
\hline $\mathrm{mSv} / \mathrm{yr}$ & millisievert per year \\
\hline & metric tons \\
\hline
\end{tabular}


$\mathrm{N}$

N/A

NA

$\mathrm{NC}$

NCRP

NEPA

NESHAP

NHPA

NIST

NMAC

NMDG\&F

NMED

NMIMT

NOI

NPDES

NQA

NR

NRC

O

$\mathrm{OZ}$

$\mathrm{P}$

$\mathrm{P} 2$

P.L.

pCi

$\mathrm{pCi} / \mathrm{L}$

ppbv

PPOA

Q

QA

QAP

QC

qt

$\mathrm{R}$

RCRA Resource Conservation and Recovery Act

rem

RER

RFA

RFI

RFI/CMS

RL

ROD
Not Applicable

Not Available

Not Collected

National Council for Radiation Protection

National Environmental Policy Act

National Emission Standards for Hazardous Air Pollutants

National Historic Preservation Act

National Institute of Standards and Technology

New Mexico Administrative Codes

New Mexico Department of Game and Fish

New Mexico Environment Department

New Mexico Institute of Mining Technology

Notice of Intent

National Pollutant Discharge Elimination System

Nuclear Quality Assurance

Not Reported

Nuclear Regulatory Commission

ounce

Pollution Prevention

Public Law

picocuries

picocuries per liter

parts per billion by volume

Pollution Prevention Opportunity Assessment

Quality Assurance

Quality Assurance Program

Quality Control

quart

Roentgen equivalent man

Relative Error Ratio

RCRA Facility Assessment

RCRA Facility Investigation

RCRA Facility Investigation/Corrective Measures Study

Reporting Limit

Record of Decision 
$\mathrm{S}$

SAP

SARA

SARP

SD

SD

SDWA

SEIS-I

SEIS-II

SI

SMA

SNL

SS

SU

SWMU

$\mathrm{Sv}$

$\mathrm{T}$

TCLP

TDS

TENORM

TOC

TPU

TRANSCOM

TRU

TRUPACT-II

U

U.S.C.

USF\&WS

USGS

UTLV

$\mathrm{V}$

VOC

W

WID

WIPP

WQSP

WRP

Y

y
Sampling and Analysis Plan

Superfund Amendments and Reauthorization Act

Safety Analysis Report for Packaging

Soil Deep

Standard Deviation

Safe Drinking Water Act

First Supplemental Environmental Impact Statement

Second Supplemental Environmental Impact Statement

Soil Intermediate

Special Management Area

Sandia National Laboratories

Soil Surface

Standard Unit

Solid Waste Management Unit

Sievert

Toxicity Characteristic Leaching Procedure

Total Dissolved Solid

Technologically enhanced naturally occurring radioactive materials

Top of Casing

Total Propagated Uncertainty

Transportation Tracking and Communications (system)

Transuranic (waste)

Transuranic Package Transporter Model II

United States Code

United States Department of the Interior, Fish and Wildlife Service

United States Geological Survey

Upper Tolerance Limit Value

Volatile Organic Compound

Waste Isolation Division

Waste Isolation Pilot Plant

WIPP Groundwater Quality Sampling Program

WIPP Raptor Program

year 


\section{Symbols}

$\sigma \quad$ sigma

${ }^{\circ} \mathrm{C} \quad$ Degrees Celsius

${ }^{\circ} \mathrm{F} \quad$ Degrees Fahrenheit

$\mu \mathrm{Ci}$ microcurie

$\mu \mathrm{g} \quad$ microgram

$\mu$ mhos micromhos

$\% \quad$ Percent 


\section{Appendix B Location Codes}

Table B.1 Codes used to identify the sites from which samples were collected.

\begin{tabular}{llll}
\hline Code & \multicolumn{1}{c}{ Location } & Code & \multicolumn{1}{c}{ Location } \\
BHT & Bottom of the Hill Tank & RCP & Rainwater Catchment Pond \\
BRA & Brantley Lake & RED & Red Tank \\
CBD & Carlsbad & RNS & Rinse Aid Blank \\
COW & Coyote Well (deionized water blank) & SE1 & South East 1 \\
COY & Coyote (surface water duplicate) & SE2 & South East 2 \\
CT1 & Control 1 & SEC & South East Control \\
CT2 & Control 2 & SMR & Smith Ranch \\
FWT & Fresh Water Tank & SOO & Sample Of Opportunity \\
HIL & HillTank & SWL & Sewage Lagoons \\
IDN & Indian Tank & TUT & Tut Tank \\
LAG & Laguna Grande del Sol & UPR & Upper Pecos River \\
LST & Lost Tank & WAB & WIPP Air Blank \\
MLR & Mills Ranch & WE1 & WIPP East 1 \\
NOY & Noya Tank & WEE & WIPP East \\
NW1 & NorthWest1 & WIP & WIPP 16 Sections \\
NW2 & NorthWest2 & WFF & WIPP Far Field \\
PCN & Pierce Canyon & WQSP & Water Quality Sample Program \\
PEC & Pecos River & WSS & WIPP South \\
PKT & Poker Trap & & \\
\hline
\end{tabular}




\section{Appendix C}

\section{Concentrations of Alpha and Beta Activities in Air Particulate}

Table C.1 Results of gross alpha and gross beta analyses in air.

\begin{tabular}{|c|c|c|c|c|c|}
\hline \multirow[b]{2}{*}{$\begin{array}{c}\text { Sample } \\
\text { Week }\end{array}$} & \multirow[b]{2}{*}{ Sample ID } & \multicolumn{2}{|c|}{ Alpha $\left(\mathrm{Bq} / \mathbf{m}^{3}\right)$} & \multicolumn{2}{|c|}{ Beta $\left(\mathrm{Bq} / \mathbf{m}^{3}\right)$} \\
\hline & & Concentration & $2 \times \mathrm{TPU}^{1}$ & Concentration & $2 \times$ TPU \\
\hline \multicolumn{6}{|c|}{ Carlsbad (CBD) } \\
\hline 1 & AL-CBD-199901061.1 & $4.84 \times 10^{-5}$ & $2.43 \times 10^{-5}$ & $1.16 \times 10^{-3}$ & $9.28 \times 10^{-5}$ \\
\hline 2 & AL-CBD-199901131.1 & $6.20 \times 10^{-5}$ & $3.66 \times 10^{-5}$ & $1.17 \times 10^{-3}$ & $1.20 \times 10^{-4}$ \\
\hline 3 & AL-CBD-199901201.1 & $2.65 \times 10^{-5}$ & $1.80 \times 10^{-5}$ & $7.50 \times 10^{-4}$ & $8.41 \times 10^{-5}$ \\
\hline 4 & AL-CBD-199901271.1 & $3.85 \times 10^{-5}$ & $2.48 \times 10^{-5}$ & $1.07 \times 10^{-3}$ & $1.02 \times 10^{-4}$ \\
\hline 5 & AL-CBD-199902031.1 & $3.92 \times 10^{-5}$ & $3.02 \times 10^{-5}$ & $9.94 \times 10^{-4}$ & $1.04 \times 10^{-4}$ \\
\hline 6 & AL-CBD-199902101.1 & $3.87 \times 10^{-5}$ & $2.90 \times 10^{-5}$ & $9.43 \times 10^{-4}$ & $9.92 \times 10^{-5}$ \\
\hline 7 & AL-CBD-199902171.1 & $2.98 \times 10^{-5}$ & $2.37 \times 10^{-5}$ & $6.65 \times 10^{-4}$ & $8.34 \times 10^{-5}$ \\
\hline 8 & AL-CBD-199902241.1 & $4.08 \times 10^{-5}$ & $2.15 \times 10^{-5}$ & $8.44 \times 10^{-4}$ & $8.91 \times 10^{-5}$ \\
\hline 9 & AL-CBD-199903031.1 & $4.96 \times 10^{-5}$ & $2.69 \times 10^{-5}$ & $8.03 \times 10^{-4}$ & $8.74 \times 10^{-5}$ \\
\hline 10 & AL-CBD-199903101.1 & $2.24 \times 10^{-5}$ & $2.71 \times 10^{-5}$ & $8.02 \times 10^{-4}$ & $8.60 \times 10^{-5}$ \\
\hline 11 & AL-CBD-199903171.1 & $2.07 \times 10^{-5}$ & $2.09 \times 10^{-5}$ & $6.45 \times 10^{-4}$ & $7.08 \times 10^{-5}$ \\
\hline 12 & AL-CBD-199903241.1 & $9.27 \times 10^{-5}$ & $3.44 \times 10^{-5}$ & $7.60 \times 10^{-4}$ & $1.02 \times 10^{-4}$ \\
\hline 13 & AL-CBD-199903311.1 & $6.95 \times 10^{-5}$ & $3.00 \times 10^{-5}$ & $6.59 \times 10^{-4}$ & $8.25 \times 10^{-5}$ \\
\hline 14 & AL-CBD-199904071.1 & $3.05 \times 10^{-5}$ & $2.21 \times 10^{-5}$ & $8.16 \times 10^{-4}$ & $9.29 \times 10^{-5}$ \\
\hline 15 & AL-CBD-199904141.1 & $2.18 \times 10^{-5}$ & $1.95 \times 10^{-5}$ & $8.04 \times 10^{-4}$ & $9.07 \times 10^{-5}$ \\
\hline 16 & AL-CBD-199904211.1 & $6.91 \times 10^{-5}$ & $2.68 \times 10^{-5}$ & $5.62 \times 10^{-4}$ & $7.34 \times 10^{-5}$ \\
\hline 17 & AL-CBD-199904281.1 & $5.34 \times 10^{-5}$ & $2.62 \times 10^{-5}$ & $8.07 \times 10^{-4}$ & $9.17 \times 10^{-5}$ \\
\hline 18 & AL-CBD-199905051.1 & $5.11 \times 10^{-5}$ & $2.58 \times 10^{-5}$ & $8.23 \times 10^{-4}$ & $8.48 \times 10^{-5}$ \\
\hline 19 & AL-CBD-199905121.1 & $7.82 \times 10^{-5}$ & $3.11 \times 10^{-5}$ & $6.74 \times 10^{-4}$ & $8.80 \times 10^{-5}$ \\
\hline 20 & AL-CBD-199905191.1 & $6.20 \times 10^{-5}$ & $2.63 \times 10^{-5}$ & $6.62 \times 10^{-4}$ & $8.05 \times 10^{-5}$ \\
\hline 21 & AL-CBD-199905261.1 & $5.87 \times 10^{-5}$ & $3.35 \times 10^{-5}$ & $8.37 \times 10^{-4}$ & $9.44 \times 10^{-5}$ \\
\hline 22 & AL-CBD-199906021.1 & $5.01 \times 10^{-5}$ & $2.45 \times 10^{-5}$ & $8.01 \times 10^{-4}$ & $8.75 \times 10^{-5}$ \\
\hline 23 & AL-CBD-199906091.1 & $4.32 \times 10^{-5}$ & $2.77 \times 10^{-5}$ & $6.61 \times 10^{-4}$ & $8.22 \times 10^{-5}$ \\
\hline 24 & AL-CBD-199906161.1 & $4.62 \times 10^{-5}$ & $3.01 \times 10^{-5}$ & $7.62 \times 10^{-4}$ & $8.77 \times 10^{-5}$ \\
\hline 25 & AL-CBD-199906231.1 & $8.14 \times 10^{-5}$ & $3.78 \times 10^{-5}$ & $8.51 \times 10^{-4}$ & $9.76 \times 10^{-5}$ \\
\hline 26 & AL-CBD-199906301.1 & $4.45 \times 10^{-5}$ & $2.80 \times 10^{-5}$ & $6.23 \times 10^{-4}$ & $8.17 \times 10^{-5}$ \\
\hline 27 & AL-CBD-199907071.1 & $1.36 \times 10^{-5}$ & $1.90 \times 10^{-5}$ & $6.87 \times 10^{-4}$ & $8.56 \times 10^{-5}$ \\
\hline 28 & AL-CBD-199907141.1 & $1.28 \times 10^{-5}$ & $2.15 \times 10^{-5}$ & $5.60 \times 10^{-4}$ & $7.74 \times 10^{-5}$ \\
\hline 29 & AL-CBD-199907211.1 & $4.82 \times 10^{-5}$ & $2.98 \times 10^{-5}$ & $8.10 \times 10^{-4}$ & $9.41 \times 10^{-5}$ \\
\hline 30 & AL-CBD-199907281.1 & $4.42 \times 10^{-5}$ & $2.80 \times 10^{-5}$ & $7.67 \times 10^{-4}$ & $8.29 \times 10^{-5}$ \\
\hline 31 & AL-CBD-199908041.1 & $5.64 \times 10^{-5}$ & $2.79 \times 10^{-5}$ & $8.70 \times 10^{-4}$ & $9.47 \times 10^{-5}$ \\
\hline 32 & AL-CBD-199908111.1 & $\mathrm{NR}^{2}$ & NR & NR & NR \\
\hline 33 & AL-CBD-199908181.1 & $6.03 \times 10^{-5}$ & $2.54 \times 10^{-5}$ & $1.13 \times 10^{-3}$ & $1.06 \times 10^{-4}$ \\
\hline 34 & AL-CBD-199908251.1 & $4.73 \times 10^{-5}$ & $2.49 \times 10^{-5}$ & $9.39 \times 10^{-4}$ & $9.39 \times 10^{-5}$ \\
\hline 35 & AL-CBD-199909011.1 & $9.86 \times 10^{-5}$ & $3.26 \times 10^{-5}$ & $8.11 \times 10^{-4}$ & $8.48 \times 10^{-5}$ \\
\hline 36 & AL-CBD-199909081.1 & $4.30 \times 10^{-5}$ & $2.25 \times 10^{-5}$ & $8.99 \times 10^{-4}$ & $8.87 \times 10^{-5}$ \\
\hline 37 & AL-CBD-199909151.1 & $8.42 \times 10^{-5}$ & $3.39 \times 10^{-5}$ & $1.34 \times 10^{-3}$ & $1.15 \times 10^{-4}$ \\
\hline 38 & AL-CBD-199909221.1 & $3.04 \times 10^{-5}$ & $2.06 \times 10^{-5}$ & $1.00 \times 10^{-3}$ & $9.28 \times 10^{-5}$ \\
\hline
\end{tabular}


Table C.1, cont.

\begin{tabular}{|c|c|c|c|c|c|}
\hline \multirow[b]{2}{*}{$\begin{array}{c}\text { Sample } \\
\text { Week } \\
\end{array}$} & \multirow[b]{2}{*}{ Sample ID } & \multicolumn{2}{|c|}{ Alpha $\left(\mathrm{Bq} / \mathrm{m}^{3}\right)$} & \multicolumn{2}{|c|}{$\operatorname{Beta}\left(\mathrm{Bq} / \mathbf{m}^{3}\right)$} \\
\hline & & Concentration & $2 \times$ TPU $^{1}$ & Concentration & $2 \times$ TPU \\
\hline \multicolumn{6}{|c|}{ Carlsbad (CBD), cont. } \\
\hline 39 & AL-CBD-199909291.1 & $2.09 \times 10^{-4}$ & $4.54 \times 10^{-5}$ & $1.37 \times 10^{-3}$ & $1.08 \times 10^{-4}$ \\
\hline 40 & AL-CBD-199910061.1 & $2.03 \times 10^{-4}$ & $3.31 \times 10^{-3}$ & $1.23 \times 10^{-3}$ & $2.33 \times 10^{-4}$ \\
\hline 41 & AL-CBD-199910131.1 & $1.77 \times 10^{-4}$ & $4.49 \times 10^{-5}$ & $1.23 \times 10^{-3}$ & $1.06 \times 10^{-4}$ \\
\hline 42 & AL-CBD-199910201.1 & $2.09 \times 10^{-4}$ & $4.61 \times 10^{-5}$ & $1.64 \times 10^{-3}$ & $1.17 \times 10^{-4}$ \\
\hline 43 & AL-CBD-199910271.1 & $1.03 \times 10^{-4}$ & $3.44 \times 10^{-5}$ & $1.19 \times 10^{-3}$ & $1.01 \times 10^{-4}$ \\
\hline 44 & AL-CBD-199911031.1 & $7.43 \times 10^{-5}$ & $2.78 \times 10^{-5}$ & $1.30 \times 10^{-3}$ & $1.08 \times 10^{-4}$ \\
\hline 45 & AL-CBD-199911101.1 & $8.30 \times 10^{-5}$ & $3.06 \times 10^{-3}$ & $1.66 \times 10^{-3}$ & $2.28 \times 10^{-4}$ \\
\hline 46 & AL-CBD-199911171.1 & $8.16 \times 10^{-5}$ & $3.16 \times 10^{-5}$ & $1.26 \times 10^{-3}$ & $1.19 \times 10^{-4}$ \\
\hline 47 & AL-CBD-199911241.1 & $7.43 \times 10^{-5}$ & $2.93 \times 10^{-5}$ & $1.61 \times 10^{-3}$ & $1.11 \times 10^{-4}$ \\
\hline 49 & AL-CBD-199912081.1 & $1.23 \times 10^{-4}$ & $3.54 \times 10^{-5}$ & $1.57 \times 10^{-3}$ & $1.16 \times 10^{-4}$ \\
\hline 50 & AL-CBD-199912151.1 & $3.74 \times 10^{-5}$ & $2.84 \times 10^{-5}$ & $7.77 \times 10^{-4}$ & $9.54 \times 10^{-5}$ \\
\hline 51 & AL-CBD-199912221.1 & $6.90 \times 10^{-5}$ & $2.52 \times 10^{-5}$ & $1.09 \times 10^{-3}$ & $8.98 \times 10^{-5}$ \\
\hline 52 & AL-CBD-199912291.1 & $3.46 \times 10^{-5}$ & $2.08 \times 10^{-5}$ & $8.20 \times 10^{-4}$ & $8.49 \times 10^{-5}$ \\
\hline
\end{tabular}

Mills Ranch (MLR)

\begin{tabular}{|c|c|c|c|c|c|}
\hline 1 & AL-MLR-199901061.1 & $3.46 \times 10^{-5}$ & $2.08 \times 10^{-5}$ & $1.18 \times 10^{-3}$ & $9.03 \times 10^{-5}$ \\
\hline 2 & AL-MLR-199901131.1 & $1.16 \times 10^{-5}$ & $2.56 \times 10^{-5}$ & $1.07 \times 10^{-3}$ & $1.13 \times 10^{-4}$ \\
\hline 3 & AL-MLR-199901201.1 & $3.73 \times 10^{-5}$ & $2.07 \times 10^{-5}$ & $6.29 \times 10^{-4}$ & $7.85 \times 10^{-5}$ \\
\hline 4 & AL-MLR-199901271.1 & $2.98 \times 10^{-5}$ & $2.26 \times 10^{-5}$ & $9.28 \times 10^{-4}$ & $9.47 \times 10^{-5}$ \\
\hline 5 & AL-MLR-199902031.1 & $2.07 \times 10^{-5}$ & $2.55 \times 10^{-5}$ & $8.27 \times 10^{-4}$ & $9.40 \times 10^{-5}$ \\
\hline 6 & AL-MLR-199902101.1 & $-3.78 \times 10^{-6}$ & $1.88 \times 10^{-5}$ & $7.80 \times 10^{-4}$ & $8.87 \times 10^{-5}$ \\
\hline 7 & AL-MLR-199902171.1 & $2.37 \times 10^{-5}$ & $2.14 \times 10^{-5}$ & $6.33 \times 10^{-4}$ & $7.90 \times 10^{-5}$ \\
\hline 8 & AL-MLR-199902241.1 & $3.25 \times 10^{-5}$ & $1.94 \times 10^{-5}$ & $8.05 \times 10^{-4}$ & $8.67 \times 10^{-5}$ \\
\hline 9 & AL-MLR-199903031.1 & $4.70 \times 10^{-5}$ & $2.65 \times 10^{-5}$ & $8.22 \times 10^{-4}$ & $8.87 \times 10^{-5}$ \\
\hline 10 & AL-MLR-199903101.1 & $1.51 \times 10^{-5}$ & $2.64 \times 10^{-5}$ & $8.43 \times 10^{-4}$ & $8.94 \times 10^{-5}$ \\
\hline 11 & AL-MLR-199903171.1 & $2.49 \times 10^{-5}$ & $2.50 \times 10^{-5}$ & $6.04 \times 10^{-4}$ & $7.75 \times 10^{-5}$ \\
\hline 12 & AL-MLR-199903241.1 & $8.55 \times 10^{-5}$ & $2.97 \times 10^{-5}$ & $7.07 \times 10^{-4}$ & $8.68 \times 10^{-5}$ \\
\hline 13 & AL-MLR-199903311.1 & $6.48 \times 10^{-5}$ & $3.01 \times 10^{-5}$ & $7.37 \times 10^{-4}$ & $8.87 \times 10^{-5}$ \\
\hline 14 & AL-MLR-199904071.1 & $4.90 \times 10^{-5}$ & $2.59 \times 10^{-5}$ & $4.89 \times 10^{-4}$ & $7.57 \times 10^{-5}$ \\
\hline 15 & AL-MLR-199904141.1 & $4.88 \times 10^{-5}$ & $2.53 \times 10^{-5}$ & $7.97 \times 10^{-4}$ & $8.78 \times 10^{-5}$ \\
\hline 16 & AL-MLR-199904211.1 & $4.52 \times 10^{-5}$ & $2.33 \times 10^{-5}$ & $5.09 \times 10^{-4}$ & $7.46 \times 10^{-5}$ \\
\hline 17 & AL-MLR-199904281.1 & $4.67 \times 10^{-5}$ & $2.43 \times 10^{-5}$ & $8.32 \times 10^{-4}$ & $9.06 \times 10^{-5}$ \\
\hline 18 & AL-MLR-199905051.1 & $4.05 \times 10^{-5}$ & $2.35 \times 10^{-5}$ & $7.24 \times 10^{-4}$ & $7.97 \times 10^{-5}$ \\
\hline 19 & AL-MLR-199905121.1 & $6.33 \times 10^{-5}$ & $2.83 \times 10^{-5}$ & $6.50 \times 10^{-4}$ & $8.63 \times 10^{-5}$ \\
\hline 20 & AL-MLR-199905191.1 & NR & NR & NR & NR \\
\hline 21 & AL-MLR-199905261.1 & $3.98 \times 10^{-5}$ & $2.94 \times 10^{-5}$ & $7.18 \times 10^{-4}$ & $8.71 \times 10^{-5}$ \\
\hline 22 & AL-MLR-199906021.1 & $4.42 \times 10^{-5}$ & $2.31 \times 10^{-5}$ & $6.99 \times 10^{-4}$ & $8.27 \times 10^{-5}$ \\
\hline 23 & AL-MLR-199906091.1 & $2.91 \times 10^{-5}$ & $2.47 \times 10^{-5}$ & $6.13 \times 10^{-4}$ & $7.95 \times 10^{-5}$ \\
\hline 24 & AL-MLR-199906161.1 & $1.14 \times 10^{-5}$ & $2.28 \times 10^{-5}$ & $5.88 \times 10^{-4}$ & $7.91 \times 10^{-5}$ \\
\hline 25 & AL-MLR-199906231.1 & $4.56 \times 10^{-5}$ & $3.02 \times 10^{-5}$ & $7.68 \times 10^{-4}$ & $8.99 \times 10^{-5}$ \\
\hline 26 & AL-MLR-199906301.1 & $3.65 \times 10^{-5}$ & $2.67 \times 10^{-5}$ & $5.41 \times 10^{-4}$ & $7.82 \times 10^{-5}$ \\
\hline 27 & AL-MLR-199907071.1 & $1.34 \times 10^{-5}$ & $1.88 \times 10^{-5}$ & $6.64 \times 10^{-4}$ & $8.40 \times 10^{-5}$ \\
\hline 28 & AL-MLR-199907141.1 & $2.48 \times 10^{-5}$ & $2.49 \times 10^{-5}$ & $5.41 \times 10^{-4}$ & $7.82 \times 10^{-5}$ \\
\hline 29 & AL-MLR-199907211.1 & $5.04 \times 10^{-5}$ & $2.90 \times 10^{-5}$ & $7.35 \times 10^{-4}$ & $8.72 \times 10^{-5}$ \\
\hline 30 & AL-MLR-199907281.1 & $4.43 \times 10^{-5}$ & $2.96 \times 10^{-5}$ & $4.94 \times 10^{-4}$ & $7.37 \times 10^{-5}$ \\
\hline 31 & AL-MLR-199908041.1 & $4.02 \times 10^{-5}$ & $2.39 \times 10^{-5}$ & $8.34 \times 10^{-4}$ & $9.06 \times 10^{-5}$ \\
\hline 32 & AL-MLR-199908111.1 & $6.45 \times 10^{-5}$ & $3.26 \times 10^{-5}$ & $1.12 \times 10^{-3}$ & $1.34 \times 10^{-4}$ \\
\hline 33 & AL-MLR-199908181.1 & $3.33 \times 10^{-5}$ & $1.83 \times 10^{-5}$ & $1.04 \times 10^{-3}$ & $1.01 \times 10^{-4}$ \\
\hline
\end{tabular}


Table C.1, cont.

\begin{tabular}{|c|c|c|c|c|c|}
\hline \multirow[b]{2}{*}{$\begin{array}{c}\text { Sample } \\
\text { Week }\end{array}$} & \multirow[b]{2}{*}{ Sample ID } & \multicolumn{2}{|c|}{ Alpha $\left(\mathrm{Bq} / \mathrm{m}^{3}\right)$} & \multicolumn{2}{|c|}{ Beta $\left(\mathrm{Bq} / \mathrm{m}^{3}\right)$} \\
\hline & & Concentration & $2 \times \mathrm{TPU}^{1}$ & Concentration & $2 \times$ TPU \\
\hline \multicolumn{6}{|c|}{ Mills Ranch (MLR), cont. } \\
\hline$\overline{34}$ & AL-MLR-199908251.1 & $4.70 \times 10^{-5}$ & $2.47 \times 10^{-5}$ & $8.70 \times 10^{-4}$ & $9.06 \times 10^{-5}$ \\
\hline 35 & AL-MLR-199909011.1 & $1.14 \times 10^{-4}$ & $3.50 \times 10^{-5}$ & $9.21 \times 10^{-4}$ & $8.94 \times 10^{-5}$ \\
\hline 36 & AL-MLR-199909081.1 & $4.43 \times 10^{-5}$ & $2.32 \times 10^{-5}$ & $8.63 \times 10^{-4}$ & $8.88 \times 10^{-5}$ \\
\hline 37 & AL-MLR-199909151.1 & $5.68 \times 10^{-5}$ & $2.64 \times 10^{-5}$ & $1.25 \times 10^{-3}$ & $1.02 \times 10^{-4}$ \\
\hline 38 & AL-MLR-199909221.1 & $7.53 \times 10^{-5}$ & $2.98 \times 10^{-5}$ & $1.06 \times 10^{-3}$ & $9.59 \times 10^{-5}$ \\
\hline 39 & AL-MLR-199909291.1 & $2.22 \times 10^{-4}$ & $4.68 \times 10^{-5}$ & $1.35 \times 10^{-3}$ & $1.07 \times 10^{-4}$ \\
\hline 40 & AL-MLR-199910061.2 & $1.84 \times 10^{-4}$ & $3.34 \times 10^{-3}$ & $1.28 \times 10^{-3}$ & $2.36 \times 10^{-4}$ \\
\hline 40 & AL-MLR-199910062.2 & $2.33 \times 10^{-4}$ & $3.43 \times 10^{-3}$ & $1.39 \times 10^{-3}$ & $2.43 \times 10^{-4}$ \\
\hline 41 & AL-MLR-199910131.2 & $1.97 \times 10^{-4}$ & $4.77 \times 10^{-5}$ & $1.18 \times 10^{-3}$ & $1.05 \times 10^{-4}$ \\
\hline 41 & AL-MLR-199910132.2 & $1.80 \times 10^{-4}$ & $4.43 \times 10^{-5}$ & $1.12 \times 10^{-3}$ & $9.96 \times 10^{-5}$ \\
\hline 42 & AL-MLR-199910201.2 & $1.62 \times 10^{-4}$ & $4.10 \times 10^{-5}$ & $1.59 \times 10^{-3}$ & $1.15 \times 10^{-4}$ \\
\hline 42 & AL-MLR-199910202.2 & $1.87 \times 10^{-4}$ & $4.50 \times 10^{-5}$ & $1.63 \times 10^{-3}$ & $1.20 \times 10^{-4}$ \\
\hline 43 & AL-MLR-199910271.2 & $8.41 \times 10^{-5}$ & $3.08 \times 10^{-5}$ & $9.94 \times 10^{-4}$ & $9.08 \times 10^{-5}$ \\
\hline 43 & AL-MLR-199910272.2 & $1.12 \times 10^{-4}$ & $3.49 \times 10^{-5}$ & $1.15 \times 10^{-3}$ & $9.73 \times 10^{-5}$ \\
\hline 44 & AL-MLR-199911031.2 & $1.22 \times 10^{-4}$ & $3.51 \times 10^{-5}$ & $1.07 \times 10^{-3}$ & $9.83 \times 10^{-5}$ \\
\hline 44 & AL-MLR-199911032.2 & $1.16 \times 10^{-4}$ & $3.40 \times 10^{-5}$ & $1.06 \times 10^{-3}$ & $9.73 \times 10^{-5}$ \\
\hline 45 & AL-MLR-199911101.2 & $1.28 \times 10^{-4}$ & $3.04 \times 10^{-3}$ & $1.33 \times 10^{-3}$ & $2.21 \times 10^{-4}$ \\
\hline 46 & AL-MLR-199911171.2 & $7.27 \times 10^{-5}$ & $2.77 \times 10^{-5}$ & $1.13 \times 10^{-3}$ & $1.04 \times 10^{-4}$ \\
\hline 46 & AL-MLR-199911172.2 & $6.42 \times 10^{-5}$ & $2.65 \times 10^{-5}$ & $1.14 \times 10^{-3}$ & $1.06 \times 10^{-4}$ \\
\hline 47 & AL-MLR-199911241.2 & $1.09 \times 10^{-4}$ & $3.32 \times 10^{-5}$ & $1.60 \times 10^{-3}$ & $1.07 \times 10^{-4}$ \\
\hline 47 & AL-MLR-199911242.2 & $8.95 \times 10^{-5}$ & $3.04 \times 10^{-5}$ & $1.74 \times 10^{-3}$ & $1.11 \times 10^{-4}$ \\
\hline 49 & AL-MLR-199912081.2 & $1.14 \times 10^{-4}$ & $3.26 \times 10^{-5}$ & $1.22 \times 10^{-3}$ & $9.86 \times 10^{-5}$ \\
\hline 49 & AL-MLR-199912082.2 & $1.30 \times 10^{-4}$ & $3.56 \times 10^{-5}$ & $1.33 \times 10^{-3}$ & $1.05 \times 10^{-4}$ \\
\hline 50 & AL-MLR-199912151.2 & $3.89 \times 10^{-5}$ & $2.79 \times 10^{-5}$ & $8.47 \times 10^{-4}$ & $9.64 \times 10^{-5}$ \\
\hline 50 & AL-MLR-199912152.2 & $2.67 \times 10^{-5}$ & $2.53 \times 10^{-5}$ & $7.54 \times 10^{-4}$ & $9.19 \times 10^{-5}$ \\
\hline 51 & AL-MLR-199912221.2 & $5.35 \times 10^{-5}$ & $2.15 \times 10^{-5}$ & $9.45 \times 10^{-4}$ & $8.05 \times 10^{-5}$ \\
\hline 51 & AL-MLR-199912222.2 & $5.29 \times 10^{-5}$ & $2.17 \times 10^{-5}$ & $9.52 \times 10^{-4}$ & $8.21 \times 10^{-5}$ \\
\hline 52 & AL-MLR-199912291.2 & $3.62 \times 10^{-5}$ & $2.17 \times 10^{-5}$ & $8.70 \times 10^{-4}$ & $8.93 \times 10^{-5}$ \\
\hline 53 & AL-MLR-199912292.2 & $5.30 \times 10^{-5}$ & $2.43 \times 10^{-5}$ & $9.95 \times 10^{-4}$ & $9.07 \times 10^{-5}$ \\
\hline
\end{tabular}

South East Control (SEC)

\begin{tabular}{llllll}
\hline 1 & AL-SEC-199901061.1 & $4.91 \times 10^{-5}$ & $2.34 \times 10^{-5}$ & $1.31 \times 10^{-3}$ & $9.50 \times 10^{-5}$ \\
2 & AL-SEC-199901131.1 & $2.48 \times 10^{-5}$ & $2.92 \times 10^{-5}$ & $1.17 \times 10^{-3}$ & $1.19 \times 10^{-4}$ \\
3 & AL-SEC-199901201.1 & $3.91 \times 10^{-5}$ & $2.10 \times 10^{-5}$ & $8.07 \times 10^{-4}$ & $8.62 \times 10^{-5}$ \\
4 & AL-SEC-199901271.1 & $2.09 \times 10^{-5}$ & $2.15 \times 10^{-5}$ & $1.00 \times 10^{-3}$ & $1.01 \times 10^{-4}$ \\
5 & AL-SEC-199902031.1 & $3.27 \times 10^{-5}$ & $2.71 \times 10^{-5}$ & $1.03 \times 10^{-3}$ & $1.00 \times 10^{-4}$ \\
6 & AL-SEC-199902101.1 & $3.64 \times 10^{-5}$ & $2.73 \times 10^{-5}$ & $7.77 \times 10^{-4}$ & $8.87 \times 10^{-5}$ \\
7 & AL-SEC-199902171.1 & $2.33 \times 10^{-5}$ & $2.26 \times 10^{-5}$ & $6.26 \times 10^{-4}$ & $8.26 \times 10^{-5}$ \\
8 & AL-SEC-199902241.1 & $5.10 \times 10^{-5}$ & $2.38 \times 10^{-5}$ & $8.18 \times 10^{-4}$ & $8.80 \times 10^{-5}$ \\
9 & AL-SEC-199903031.1 & $7.71 \times 10^{-5}$ & $3.13 \times 10^{-5}$ & $8.78 \times 10^{-4}$ & $8.98 \times 10^{-5}$ \\
10 & AL-SEC-199903101.1 & $2.33 \times 10^{-5}$ & $2.82 \times 10^{-5}$ & $9.19 \times 10^{-4}$ & $9.30 \times 10^{-5}$ \\
11 & AL-SEC-199903171.1 & $1.66 \times 10^{-5}$ & $2.53 \times 10^{-5}$ & $6.70 \times 10^{-4}$ & $8.54 \times 10^{-5}$ \\
12 & AL-SEC-199903241.1 & $8.27 \times 10^{-5}$ & $2.98 \times 10^{-5}$ & $7.10 \times 10^{-4}$ & $8.90 \times 10^{-5}$ \\
13 & AL-SEC-199903311.1 & $7.29 \times 10^{-5}$ & $3.14 \times 10^{-5}$ & $8.02 \times 10^{-4}$ & $9.16 \times 10^{-5}$ \\
14 & AL-SEC-199904071.1 & $5.85 \times 10^{-5}$ & $2.74 \times 10^{-5}$ & $8.69 \times 10^{-4}$ & $9.28 \times 10^{-5}$ \\
15 & AL-SEC-199904141.1 & $3.70 \times 10^{-5}$ & $2.26 \times 10^{-5}$ & $8.86 \times 10^{-4}$ & $9.14 \times 10^{-5}$ \\
16 & AL-SEC-199904211.1 & $5.48 \times 10^{-5}$ & $2.57 \times 10^{-5}$ & $7.14 \times 10^{-4}$ & $8.62 \times 10^{-5}$ \\
17 & AL-SEC-199904281.1 & $4.08 \times 10^{-5}$ & $2.29 \times 10^{-5}$ & $8.78 \times 10^{-4}$ & $9.19 \times 10^{-5}$ \\
18 & AL-SEC-199905051.1 & $6.01 \times 10^{-5}$ & $2.79 \times 10^{-5}$ & $9.31 \times 10^{-4}$ & $9.04 \times 10^{-5}$
\end{tabular}


Table C.1, cont.

\begin{tabular}{|c|c|c|c|c|c|}
\hline \multirow[b]{2}{*}{ Sample } & \multirow[b]{2}{*}{ Samnle ID } & Alpha (B & $\left.q / m^{3}\right)$ & \multicolumn{2}{|c|}{ Beta $\left(\mathrm{Bq} / \mathrm{m}^{3}\right)$} \\
\hline & & Concentration & $2 \times$ TPU $^{1}$ & Concentration & $2 \times \mathrm{TPU}$ \\
\hline
\end{tabular}

South East Control (SEC), cont

\begin{tabular}{|c|c|c|c|c|c|}
\hline 19 & AL-SEC-199905121.1 & $7.93 \times 10^{-5}$ & $2.98 \times 10^{-5}$ & $7.52 \times 10^{-4}$ & $8.66 \times 10^{-5}$ \\
\hline 20 & AL-SEC-199905191.1 & $4.55 \times 10^{-5}$ & $2.34 \times 10^{-5}$ & $7.29 \times 10^{-4}$ & $8.43 \times 10^{-5}$ \\
\hline 21 & AL-SEC-199905261.1 & $4.23 \times 10^{-5}$ & $2.98 \times 10^{-5}$ & $7.72 \times 10^{-4}$ & $8.95 \times 10^{-5}$ \\
\hline 22 & AL-SEC-199906021.1 & $5.04 \times 10^{-5}$ & $2.40 \times 10^{-5}$ & $8.39 \times 10^{-4}$ & $8.70 \times 10^{-5}$ \\
\hline 23 & AL-SEC-199906091.1 & $4.08 \times 10^{-5}$ & $2.72 \times 10^{-5}$ & $6.02 \times 10^{-4}$ & $7.94 \times 10^{-5}$ \\
\hline 24 & AL-SEC-199906161.1 & $1.87 \times 10^{-5}$ & $2.30 \times 10^{-5}$ & $7.79 \times 10^{-4}$ & $8.48 \times 10^{-5}$ \\
\hline 25 & AL-SEC-199906231.1 & $3.32 \times 10^{-5}$ & $3.12 \times 10^{-5}$ & $8.80 \times 10^{-4}$ & $1.04 \times 10^{-4}$ \\
\hline 26 & AL-SEC-199906301.1 & $3.71 \times 10^{-5}$ & $2.71 \times 10^{-5}$ & $6.96 \times 10^{-4}$ & $8.66 \times 10^{-5}$ \\
\hline 27 & AL-SEC-199907071.1 & $2.39 \times 10^{-5}$ & $2.15 \times 10^{-5}$ & $7.24 \times 10^{-4}$ & $8.72 \times 10^{-5}$ \\
\hline 28 & AL-SEC-199907141.1 & $1.83 \times 10^{-5}$ & $2.27 \times 10^{-5}$ & $5.95 \times 10^{-4}$ & $7.89 \times 10^{-5}$ \\
\hline 29 & AL-SEC-199907211.1 & $3.43 \times 10^{-5}$ & $2.62 \times 10^{-5}$ & $9.29 \times 10^{-4}$ & $9.70 \times 10^{-5}$ \\
\hline 30 & AL-SEC-199907281.1 & $4.86 \times 10^{-5}$ & $3.08 \times 10^{-5}$ & $8.19 \times 10^{-4}$ & $9.01 \times 10^{-5}$ \\
\hline 31 & AL-SEC-199908041.1 & $5.34 \times 10^{-5}$ & $2.65 \times 10^{-5}$ & $9.60 \times 10^{-4}$ & $9.53 \times 10^{-5}$ \\
\hline 32 & AL-SEC-199908111.1 & $4.63 \times 10^{-5}$ & $2.27 \times 10^{-5}$ & $1.03 \times 10^{-3}$ & $1.02 \times 10^{-4}$ \\
\hline 33 & AL-SEC-199908181.1 & $3.43 \times 10^{-5}$ & $1.81 \times 10^{-5}$ & $1.18 \times 10^{-3}$ & $1.02 \times 10^{-4}$ \\
\hline 34 & AL-SEC-199908251.1 & $4.35 \times 10^{-5}$ & $2.38 \times 10^{-5}$ & $9.75 \times 10^{-4}$ & $9.46 \times 10^{-5}$ \\
\hline 35 & AL-SEC-199909011.1 & $1.00 \times 10^{-4}$ & $3.27 \times 10^{-5}$ & $9.56 \times 10^{-4}$ & $9.03 \times 10^{-5}$ \\
\hline 36 & AL-SEC-199909081.1 & $3.84 \times 10^{-5}$ & $2.10 \times 10^{-5}$ & $9.07 \times 10^{-4}$ & $8.71 \times 10^{-5}$ \\
\hline 37 & AL-SEC-199909151.1 & $4.31 \times 10^{-5}$ & $2.26 \times 10^{-5}$ & $1.21 \times 10^{-3}$ & $9.70 \times 10^{-5}$ \\
\hline 38 & AL-SEC-199909221.1 & $4.14 \times 10^{-5}$ & $2.25 \times 10^{-5}$ & $1.10 \times 10^{-3}$ & $9.41 \times 10^{-5}$ \\
\hline 39 & AL-SEC-199909291.1 & $2.66 \times 10^{-4}$ & $5.14 \times 10^{-5}$ & $1.32 \times 10^{-3}$ & $1.06 \times 10^{-4}$ \\
\hline 40 & AL-SEC-19991006 & \multicolumn{4}{|c|}{$\mathrm{NC}^{3}$} \\
\hline 41 & AL-SEC-199910131.1 & $1.61 \times 10^{-4}$ & $4.22 \times 10^{-5}$ & $1.06 \times 10^{-3}$ & $9.78 \times 10^{-5}$ \\
\hline 42 & AL-SEC-199910201.1 & $2.39 \times 10^{-4}$ & $5.06 \times 10^{-5}$ & $1.73 \times 10^{-3}$ & $1.23 \times 10^{-4}$ \\
\hline 43 & AL-SEC-199910271.1 & $1.48 \times 10^{-4}$ & $3.93 \times 10^{-5}$ & $9.63 \times 10^{-4}$ & $8.95 \times 10^{-5}$ \\
\hline 44 & AL-SEC-199911031.1 & $1.11 \times 10^{-4}$ & $3.37 \times 10^{-5}$ & $1.15 \times 10^{-3}$ & $1.02 \times 10^{-4}$ \\
\hline 45 & AL-SEC-199911101.1 & $1.26 \times 10^{-4}$ & $2.88 \times 10^{-3}$ & $1.60 \times 10^{-3}$ & $2.16 \times 10^{-4}$ \\
\hline 46 & AL-SEC-199911171.1 & $9.42 \times 10^{-5}$ & $3.29 \times 10^{-5}$ & $1.33 \times 10^{-3}$ & $1.18 \times 10^{-4}$ \\
\hline 47 & AL-SEC-199911241.1 & $7.48 \times 10^{-5}$ & $2.71 \times 10^{-5}$ & $1.78 \times 10^{-3}$ & $1.08 \times 10^{-4}$ \\
\hline 49 & AL-SEC-199912081.1 & $1.42 \times 10^{-4}$ & $3.71 \times 10^{-5}$ & $1.38 \times 10^{-3}$ & $1.06 \times 10^{-4}$ \\
\hline 50 & AL-SEC-199912151.1 & $2.53 \times 10^{-5}$ & $2.39 \times 10^{-5}$ & $7.23 \times 10^{-4}$ & $8.75 \times 10^{-5}$ \\
\hline 51 & AL-SEC-199912221.1 & $6.84 \times 10^{-5}$ & $2.50 \times 10^{-5}$ & $1.13 \times 10^{-3}$ & $9.08 \times 10^{-5}$ \\
\hline 52 & AL-SEC-199912291.1 & $3.44 \times 10^{-5}$ & $2.07 \times 10^{-5}$ & $9.75 \times 10^{-4}$ & $9.13 \times 10^{-5}$ \\
\hline
\end{tabular}

Smith Ranch (SMR)

\begin{tabular}{llllll}
\hline 1 & AL-SMR-199901061.1 & $2.11 \times 10^{-5}$ & $1.86 \times 10^{-5}$ & $1.03 \times 10^{-3}$ & $8.70 \times 10^{-5}$ \\
2 & AL-SMR-199901131.1 & $1.54 \times 10^{-5}$ & $2.80 \times 10^{-5}$ & $9.75 \times 10^{-4}$ & $1.13 \times 10^{-4}$ \\
3 & AL-SMR-199901201.1 & $3.23 \times 10^{-5}$ & $1.89 \times 10^{-5}$ & $7.10 \times 10^{-4}$ & $7.96 \times 10^{-5}$ \\
4 & AL-SMR-199901271.1 & $9.42 \times 10^{-6}$ & $1.75 \times 10^{-5}$ & $9.66 \times 10^{-4}$ & $9.63 \times 10^{-5}$ \\
5 & AL-SMR-199902031.1 & $1.82 \times 10^{-5}$ & $2.49 \times 10^{-5}$ & $8.07 \times 10^{-4}$ & $9.30 \times 10^{-5}$ \\
6 & AL-SMR-199902101.1 & $5.59 \times 10^{-5}$ & $3.24 \times 10^{-5}$ & $8.71 \times 10^{-4}$ & $9.75 \times 10^{-5}$ \\
7 & AL-SMR-199902171.1 & $4.76 \times 10^{-5}$ & $2.68 \times 10^{-5}$ & $6.43 \times 10^{-4}$ & $8.13 \times 10^{-5}$ \\
8 & AL-SMR-199902241.1 & $3.63 \times 10^{-5}$ & $2.08 \times 10^{-5}$ & $7.20 \times 10^{-4}$ & $8.51 \times 10^{-5}$ \\
9 & AL-SMR-199903031.1 & $5.36 \times 10^{-5}$ & $2.72 \times 10^{-5}$ & $7.04 \times 10^{-4}$ & $8.21 \times 10^{-5}$ \\
10 & AL-SMR-199903101.1 & $4.51 \times 10^{-5}$ & $3.20 \times 10^{-5}$ & $9.60 \times 10^{-4}$ & $9.48 \times 10^{-5}$ \\
11 & AL-SMR-199903171.1 & $2.57 \times 10^{-5}$ & $2.58 \times 10^{-5}$ & $6.97 \times 10^{-4}$ & $8.33 \times 10^{-5}$ \\
12 & AL-SMR-199903241.1 & $1.02 \times 10^{-4}$ & $3.18 \times 10^{-5}$ & $7.01 \times 10^{-4}$ & $8.43 \times 10^{-5}$ \\
13 & AL-SMR-199903311.1 & $8.21 \times 10^{-5}$ & $3.50 \times 10^{-5}$ & $6.41 \times 10^{-4}$ & $8.43 \times 10^{-5}$ \\
14 & AL-SMR-199904071.1 & $7.23 \times 10^{-5}$ & $2.99 \times 10^{-5}$ & $6.78 \times 10^{-4}$ & $8.42 \times 10^{-5}$
\end{tabular}


Table C.1, cont.

\begin{tabular}{llll} 
& & Alpha $\left(\mathrm{Bq} / \mathrm{m}^{3}\right)$ & \\
\cline { 3 - 3 } $\begin{array}{c}\text { Sample } \\
\text { Week }\end{array}$ & Sample ID & Concentration $2 \times$ TPU $^{1}$ & Concentration $2 \times$ XPU \\
\hline
\end{tabular}

Smith Ranch (SMR), cont.

\begin{tabular}{|c|c|c|c|c|c|}
\hline 15 & AL-SMR-199904141.1 & $5.06 \times 10^{-5}$ & $2.65 \times 10^{-5}$ & $7.89 \times 10^{-4}$ & $9.00 \times 10^{-5}$ \\
\hline 16 & AL-SMR-199904211.1 & $5.90 \times 10^{-5}$ & $2.62 \times 10^{-5}$ & $5.96 \times 10^{-4}$ & $7.92 \times 10^{-5}$ \\
\hline 17 & AL-SMR-199904281.1 & $3.80 \times 10^{-5}$ & $2.33 \times 10^{-5}$ & $7.55 \times 10^{-4}$ & $9.05 \times 10^{-5}$ \\
\hline 18 & AL-SMR-199905051.1 & \multicolumn{4}{|c|}{ Sample Aborted } \\
\hline 19 & AL-SMR-199905121.1 & $8.28 \times 10^{-5}$ & $3.11 \times 10^{-5}$ & $6.91 \times 10^{-4}$ & $8.63 \times 10^{-5}$ \\
\hline 20 & AL-SMR-199905191.1 & $6.33 \times 10^{-5}$ & $2.74 \times 10^{-5}$ & $6.82 \times 10^{-4}$ & $8.44 \times 10^{-5}$ \\
\hline 21 & AL-SMR-199905261.1 & $3.90 \times 10^{-5}$ & $2.88 \times 10^{-5}$ & $7.70 \times 10^{-4}$ & $8.84 \times 10^{-5}$ \\
\hline 22 & AL-SMR-199906021.1 & $4.45 \times 10^{-5}$ & $2.33 \times 10^{-5}$ & $7.32 \times 10^{-4}$ & $8.46 \times 10^{-5}$ \\
\hline 23 & AL-SMR-199906091.1 & $1.66 \times 10^{-5}$ & $2.24 \times 10^{-5}$ & $6.46 \times 10^{-4}$ & $8.23 \times 10^{-5}$ \\
\hline 24 & AL-SMR-199906161.1 & $1.79 \times 10^{-5}$ & $2.49 \times 10^{-5}$ & $8.20 \times 10^{-4}$ & $9.19 \times 10^{-5}$ \\
\hline 25 & AL-SMR-199906231.1 & $4.86 \times 10^{-5}$ & $3.10 \times 10^{-5}$ & $8.28 \times 10^{-4}$ & $9.31 \times 10^{-5}$ \\
\hline 26 & AL-SMR-199906301.1 & $4.01 \times 10^{-5}$ & $2.79 \times 10^{-5}$ & $6.17 \times 10^{-4}$ & $8.33 \times 10^{-5}$ \\
\hline 27 & AL-SMR-199907071.1 & $3.29 \times 10^{-5}$ & $2.41 \times 10^{-5}$ & $6.59 \times 10^{-4}$ & $8.59 \times 10^{-5}$ \\
\hline 28 & AL-SMR-199907141.1 & $2.40 \times 10^{-5}$ & $2.41 \times 10^{-5}$ & $5.95 \times 10^{-4}$ & $7.92 \times 10^{-5}$ \\
\hline 29 & AL-SMR-199907211.1 & $4.69 \times 10^{-5}$ & $2.90 \times 10^{-5}$ & $6.99 \times 10^{-4}$ & $8.72 \times 10^{-5}$ \\
\hline 30 & AL-SMR-199907281.1 & $5.48 \times 10^{-5}$ & $3.24 \times 10^{-5}$ & $6.72 \times 10^{-4}$ & $8.49 \times 10^{-5}$ \\
\hline 31 & AL-SMR-199908041.1 & $4.40 \times 10^{-5}$ & $2.52 \times 10^{-5}$ & $8.81 \times 10^{-4}$ & $9.43 \times 10^{-5}$ \\
\hline 32 & AL-SMR-199908111.1 & $5.97 \times 10^{-5}$ & $2.55 \times 10^{-5}$ & $1.01 \times 10^{-3}$ & $1.00 \times 10^{-4}$ \\
\hline 33 & AL-SMR-199908181.1 & $6.70 \times 10^{-5}$ & $2.58 \times 10^{-5}$ & $9.96 \times 10^{-4}$ & $9.59 \times 10^{-5}$ \\
\hline 34 & AL-SMR-199908251.1 & $4.57 \times 10^{-5}$ & $2.51 \times 10^{-5}$ & $8.25 \times 10^{-4}$ & $9.11 \times 10^{-5}$ \\
\hline 35 & AL-SMR-199909011.1 & $7.88 \times 10^{-5}$ & $2.91 \times 10^{-5}$ & $8.30 \times 10^{-4}$ & $8.46 \times 10^{-5}$ \\
\hline 36 & AL-SMR-199909081.1 & $4.07 \times 10^{-5}$ & $2.23 \times 10^{-5}$ & $7.76 \times 10^{-4}$ & $8.45 \times 10^{-5}$ \\
\hline 37 & AL-SMR-199909151.1 & $5.15 \times 10^{-5}$ & $2.61 \times 10^{-5}$ & $1.17 \times 10^{-3}$ & $1.02 \times 10^{-4}$ \\
\hline 38 & AL-SMR-199909221.1 & $5.54 \times 10^{-5}$ & $2.57 \times 10^{-5}$ & $9.92 \times 10^{-4}$ & $9.18 \times 10^{-5}$ \\
\hline 39 & AL-SMR-199909291.1 & $2.31 \times 10^{-4}$ & $4.78 \times 10^{-5}$ & $1.24 \times 10^{-3}$ & $1.03 \times 10^{-4}$ \\
\hline 40 & AL-SMR-199910061.1 & $2.13 \times 10^{-4}$ & $3.39 \times 10^{-3}$ & $1.26 \times 10^{-3}$ & $2.38 \times 10^{-4}$ \\
\hline 41 & AL-SMR-199910131.1 & $1.55 \times 10^{-4}$ & $4.18 \times 10^{-5}$ & $1.18 \times 10^{-3}$ & $1.03 \times 10^{-4}$ \\
\hline 42 & AL-SMR-199910201.1 & $1.56 \times 10^{-4}$ & $4.11 \times 10^{-5}$ & $1.53 \times 10^{-3}$ & $1.15 \times 10^{-4}$ \\
\hline 43 & AL-SMR-199910271.1 & $8.50 \times 10^{-5}$ & $3.11 \times 10^{-5}$ & $9.77 \times 10^{-4}$ & $9.06 \times 10^{-5}$ \\
\hline 44 & AL-SMR-199911031.1 & $9.85 \times 10^{-5}$ & $3.20 \times 10^{-5}$ & $1.11 \times 10^{-3}$ & $1.01 \times 10^{-4}$ \\
\hline 45 & AL-SMR-199911101.1 & $8.63 \times 10^{-5}$ & $2.82 \times 10^{-3}$ & $1.48 \times 10^{-3}$ & $2.09 \times 10^{-4}$ \\
\hline 46 & AL-SMR-199911171.1 & $5.45 \times 10^{-5}$ & $2.48 \times 10^{-5}$ & $1.08 \times 10^{-3}$ & $1.05 \times 10^{-4}$ \\
\hline 47 & AL-SMR-199911241.1 & $7.35 \times 10^{-5}$ & $2.84 \times 10^{-5}$ & $1.56 \times 10^{-3}$ & $1.07 \times 10^{-4}$ \\
\hline 49 & AL-SMR-199912081.1 & $6.74 \times 10^{-5}$ & $2.66 \times 10^{-5}$ & $1.14 \times 10^{-3}$ & $1.01 \times 10^{-4}$ \\
\hline 50 & AL-SMR-199912151.1 & $2.92 \times 10^{-5}$ & $2.55 \times 10^{-5}$ & $7.06 \times 10^{-4}$ & $8.85 \times 10^{-5}$ \\
\hline 51 & AL-SMR-199912221.1 & $4.22 \times 10^{-5}$ & $2.07 \times 10^{-5}$ & $1.02 \times 10^{-3}$ & $8.91 \times 10^{-5}$ \\
\hline 52 & AL-SMR-199912291.1 & $3.66 \times 10^{-5}$ & $2.19 \times 10^{-5}$ & $8.24 \times 10^{-4}$ & $8.77 \times 10^{-5}$ \\
\hline
\end{tabular}

WIPP Air Blank (WAB)

\begin{tabular}{llllll}
\hline 1 & AL-WAB-199901061.1 & $4.56 \times 10^{-3}$ & $7.30 \times 10^{-3}$ & $7.93 \times 10^{-3}$ & $1.72 \times 10^{-2}$ \\
2 & AL-WAB-199901131.1 & $9.17 \times 10^{-3}$ & $7.87 \times 10^{-3}$ & $4.17 \times 10^{-2}$ & $1.84 \times 10^{-2}$ \\
3 & AL-WAB-199901201.1 & $1.37 \times 10^{-3}$ & $4.00 \times 10^{-3}$ & $3.35 \times 10^{-2}$ & $1.80 \times 10^{-2}$ \\
4 & AL-WAB-199901271.1 & $4.57 \times 10^{-3}$ & $6.75 \times 10^{-3}$ & $4.16 \times 10^{-2}$ & $1.73 \times 10^{-2}$ \\
5 & AL-WAB-199902031.1 & $1.06 \times 10^{-2}$ & $8.38 \times 10^{-3}$ & $4.74 \times 10^{-2}$ & $1.94 \times 10^{-2}$ \\
6 & AL-WAB-199902101.1 & $1.06 \times 10^{-2}$ & $9.01 \times 10^{-3}$ & $6.44 \times 10^{-2}$ & $2.03 \times 10^{-2}$ \\
7 & AL-WAB-199902171.1 & $5.82 \times 10^{-3}$ & $7.17 \times 10^{-3}$ & $3.56 \times 10^{-2}$ & $1.88 \times 10^{-2}$ \\
8 & AL-WAB-199902241.1 & $0.00 \times 10^{0}$ & $4.40 \times 10^{-3}$ & $3.80 \times 10^{-2}$ & $1.84 \times 10^{-2}$ \\
9 & AL-WAB-199903031.1 & $4.55 \times 10^{-3}$ & $6.71 \times 10^{-3}$ & $4.29 \times 10^{-2}$ & $1.80 \times 10^{-2}$ \\
10 & AL-WAB-199903101.1 & $1.36 \times 10^{-2}$ & $9.90 \times 10^{-3}$ & $4.16 \times 10^{-2}$ & $1.79 \times 10^{-2}$
\end{tabular}


Table C.1, cont.

\begin{tabular}{|c|c|c|c|}
\hline & & Alpha $\left(\mathrm{Bq} / \mathbf{m}^{3}\right)$ & $\operatorname{Beta}\left(\mathrm{Bq} / \mathbf{m}^{3}\right)$ \\
\hline $\begin{array}{c}\text { Sample } \\
\text { Week }\end{array}$ & Sample ID & Concentration $2 \times$ TPU $^{1}$ & Concentration \\
\hline
\end{tabular}

WIPP Air Blank (WAB), cont.

\begin{tabular}{|c|c|c|c|c|c|}
\hline \\
\hline 11 & AL-WAB-199903171.1 & $1.05 \times 10^{-2}$ & $8.91 \times 10^{-3}$ & $5.18 \times 10^{-2}$ & $1.91 \times 10^{-2}$ \\
\hline 12 & AL-WAB-199903241.1 & $0.00 \times 10^{0}$ & $0.00 \times 10^{0}$ & $5.66 \times 10^{-2}$ & $1.93 \times 10^{-2}$ \\
\hline 13 & AL-WAB-199903311.1 & $5.98 \times 10^{-3}$ & $5.94 \times 10^{-3}$ & $5.41 \times 10^{-2}$ & $1.90 \times 10^{-2}$ \\
\hline 14 & AL-WAB-199904071.1 & $3.15 \times 10^{-3}$ & $5.10 \times 10^{-3}$ & $4.72 \times 10^{-2}$ & $1.73 \times 10^{-2}$ \\
\hline 15 & AL-WAB-19990414 1.1 & $3.22 \times 10^{-3}$ & $4.36 \times 10^{-3}$ & $2.83 \times 10^{-2}$ & $1.56 \times 10^{-2}$ \\
\hline 16 & AL-WAB-199904211.1 & $1.35 \times 10^{-3}$ & $3.93 \times 10^{-3}$ & $3.87 \times 10^{-2}$ & $1.76 \times 10^{-2}$ \\
\hline 17 & AL-WAB-199904281.1 & $1.36 \times 10^{-3}$ & $5.83 \times 10^{-3}$ & $5.16 \times 10^{-2}$ & $1.86 \times 10^{-2}$ \\
\hline 18 & AL-WAB-199905051.1 & $3.25 \times 10^{-3}$ & $6.21 \times 10^{-3}$ & $2.96 \times 10^{-2}$ & $1.65 \times 10^{-2}$ \\
\hline 19 & AL-WAB-199905121.1 & $3.16 \times 10^{-3}$ & $4.28 \times 10^{-3}$ & $5.86 \times 10^{-2}$ & $1.95 \times 10^{-2}$ \\
\hline 20 & AL-WAB-199905191.1 & $3.16 \times 10^{-3}$ & $4.28 \times 10^{-3}$ & $5.51 \times 10^{-2}$ & $1.91 \times 10^{-2}$ \\
\hline 21 & AL-WAB-199905261.1 & $9.24 \times 10^{-3}$ & $8.59 \times 10^{-3}$ & $4.59 \times 10^{-2}$ & $1.92 \times 10^{-2}$ \\
\hline 22 & AL-WAB-199906021.1 & $0.00 \times 10^{0}$ & $4.37 \times 10^{-3}$ & $2.94 \times 10^{-2}$ & $1.73 \times 10^{-2}$ \\
\hline 23 & AL-WAB-199906091.1 & $7.91 \times 10^{-3}$ & $7.44 \times 10^{-3}$ & $4.52 \times 10^{-2}$ & $1.86 \times 10^{-2}$ \\
\hline 24 & AL-WAB-199906161.1 & $9.32 \times 10^{-3}$ & $7.46 \times 10^{-3}$ & $3.08 \times 10^{-2}$ & $1.60 \times 10^{-2}$ \\
\hline 25 & AL-WAB-199906231.1 & $1.07 \times 10^{-2}$ & $8.00 \times 10^{-3}$ & $5.26 \times 10^{-2}$ & $1.87 \times 10^{-2}$ \\
\hline 26 & AL-WAB-199906301.1 & $7.93 \times 10^{-3}$ & $6.88 \times 10^{-3}$ & $4.57 \times 10^{-2}$ & $1.79 \times 10^{-2}$ \\
\hline 27 & AL-WAB-199907071.1 & $4.55 \times 10^{-3}$ & $6.71 \times 10^{-3}$ & $5.77 \times 10^{-2}$ & $1.94 \times 10^{-2}$ \\
\hline 28 & AL-WAB-199907141.1 & $7.80 \times 10^{-3}$ & $8.04 \times 10^{-3}$ & $5.30 \times 10^{-2}$ & $1.76 \times 10^{-2}$ \\
\hline 29 & AL-WAB-199907211.1 & $5.98 \times 10^{-3}$ & $7.36 \times 10^{-3}$ & $3.60 \times 10^{-2}$ & $1.78 \times 10^{-2}$ \\
\hline 30 & AL-WAB-199907281.1 & $8.92 \times 10^{-3}$ & $9.17 \times 10^{-3}$ & $5.41 \times 10^{-2}$ & $1.74 \times 10^{-2}$ \\
\hline 31 & AL-WAB-199908041.1 & $1.34 \times 10^{-3}$ & $6.38 \times 10^{-3}$ & $5.54 \times 10^{-2}$ & $1.76 \times 10^{-2}$ \\
\hline 32 & AL-WAB-199908111.1 & $-4.50 \times 10^{-2}$ & $5.81 \times 10^{-3}$ & $5.79 \times 10^{-2}$ & $1.99 \times 10^{-2}$ \\
\hline 33 & AL-WAB-199908181.1 & $-5.86 \times 10^{-3}$ & $5.10 \times 10^{-3}$ & $3.52 \times 10^{-2}$ & $1.73 \times 10^{-2}$ \\
\hline 34 & AL-WAB-199908251.1 & $1.37 \times 10^{-3}$ & $5.18 \times 10^{-3}$ & $3.32 \times 10^{-2}$ & $1.84 \times 10^{-2}$ \\
\hline 35 & AL-WAB-199909011.1 & $-1.50 \times 10^{-3}$ & $5.81 \times 10^{-3}$ & $3.48 \times 10^{-2}$ & $1.59 \times 10^{-2}$ \\
\hline 36 & AL-WAB-199909081.1 & $1.34 \times 10^{-3}$ & $4.98 \times 10^{-3}$ & $3.42 \times 10^{-2}$ & $1.70 \times 10^{-2}$ \\
\hline 37 & AL-WAB-199909151.1 & $1.49 \times 10^{-3}$ & $5.89 \times 10^{-3}$ & $4.23 \times 10^{-2}$ & $1.77 \times 10^{-2}$ \\
\hline 38 & AL-WAB-199909221.1 & $1.49 \times 10^{-3}$ & $5.89 \times 10^{-3}$ & $4.45 \times 10^{-2}$ & $1.79 \times 10^{-2}$ \\
\hline 39 & AL-WAB-199909291.1 & $-2.98 \times 10^{-5}$ & $2.83 \times 10^{-3}$ & $2.40 \times 10^{-2}$ & $1.55 \times 10^{-2}$ \\
\hline 40 & AL-WAB-199910061.1 & $0.00 \times 10^{0}$ & $1.68 \times 10^{0}$ & $0.00 \times 10^{0}$ & $1.06 \times 10^{-1}$ \\
\hline 41 & AL-WAB-199910131.1 & $5.78 \times 10^{-3}$ & $6.37 \times 10^{-3}$ & $3.98 \times 10^{-2}$ & $1.76 \times 10^{-2}$ \\
\hline 42 & AL-WAB-199910201.1 & $2.87 \times 10^{-3}$ & $4.92 \times 10^{-3}$ & $3.42 \times 10^{-2}$ & $1.69 \times 10^{-2}$ \\
\hline 43 & AL-WAB-199910271.1 & $4.38 \times 10^{-3}$ & $5.76 \times 10^{-3}$ & $2.63 \times 10^{-2}$ & $1.53 \times 10^{-2}$ \\
\hline 44 & AL-WAB-199911031.1 & $0.00 \times 10^{0}$ & $2.89 \times 10^{-3}$ & $3.80 \times 10^{-2}$ & $1.69 \times 10^{-2}$ \\
\hline 45 & AL-WAB-199911101.1 & $2.89 \times 10^{-3}$ & $1.69 \times 10^{0}$ & $4.48 \times 10^{-2}$ & $1.09 \times 10^{-1}$ \\
\hline 46 & AL-WAB-199911171.1 & $-6.87 \times 10^{-5}$ & $2.82 \times 10^{-3}$ & $4.95 \times 10^{-2}$ & $1.83 \times 10^{-2}$ \\
\hline 47 & AL-WAB-199911241.1 & $4.36 \times 10^{-3}$ & $6.41 \times 10^{-3}$ & $2.90 \times 10^{-2}$ & $1.60 \times 10^{-2}$ \\
\hline 49 & AL-WAB-199912081.1 & $-4.47 \times 10^{-5}$ & $2.86 \times 10^{-3}$ & $3.96 \times 10^{-2}$ & $1.69 \times 10^{-2}$ \\
\hline 50 & AL-WAB-199912151.1 & $5.89 \times 10^{-3}$ & $6.48 \times 10^{-3}$ & $3.26 \times 10^{-2}$ & $1.59 \times 10^{-2}$ \\
\hline 51 & AL-WAB-199912221.1 & $1.43 \times 10^{-3}$ & $4.08 \times 10^{-3}$ & $4.29 \times 10^{-2}$ & $1.73 \times 10^{-2}$ \\
\hline 52 & AL-WAB-199912291.1 & $1.46 \times 10^{-3}$ & $5.00 \times 10^{-3}$ & $2.61 \times 10^{-2}$ & $1.63 \times 10^{-2}$ \\
\hline \multicolumn{6}{|c|}{ WIPP East (WEE) } \\
\hline 1 & AL-WEE-199901061.1 & $3.94 \times 10^{-5}$ & $2.28 \times 10^{-5}$ & $1.33 \times 10^{-3}$ & $9.93 \times 10^{-5}$ \\
\hline 2 & AL-WEE-199901131.1 & $2.25 \times 10^{-5}$ & $2.66 \times 10^{-5}$ & $1.10 \times 10^{-3}$ & $1.10 \times 10^{-4}$ \\
\hline 3 & AL-WEE-199901201.1 & $3.44 \times 10^{-5}$ & $2.09 \times 10^{-5}$ & $6.31 \times 10^{-4}$ & $8.23 \times 10^{-5}$ \\
\hline 4 & AL-WEE-199901271.1 & $2.27 \times 10^{-5}$ & $2.15 \times 10^{-5}$ & $9.34 \times 10^{-4}$ & $9.67 \times 10^{-5}$ \\
\hline 5 & AL-WEE-199902031.1 & $1.82 \times 10^{-5}$ & $2.50 \times 10^{-5}$ & $9.36 \times 10^{-4}$ & $9.89 \times 10^{-5}$ \\
\hline 6 & AL-WEE-199902101.1 & $2.04 \times 10^{-5}$ & $2.58 \times 10^{-5}$ & $7.98 \times 10^{-4}$ & $9.38 \times 10^{-5}$ \\
\hline
\end{tabular}


Table C.1, cont.

\begin{tabular}{|c|c|c|c|c|c|}
\hline \multirow[b]{2}{*}{$\begin{array}{c}\text { Sample } \\
\text { Week }\end{array}$} & \multirow[b]{2}{*}{ Sample ID } & \multicolumn{2}{|c|}{ Alpha $\left(\mathrm{Bq} / \mathrm{m}^{3}\right)$} & \multicolumn{2}{|c|}{ Beta $\left(\mathrm{Bq} / \mathrm{m}^{3}\right)$} \\
\hline & & Concentration & $2 \times \mathrm{TPU}^{1}$ & Concentration & $2 \times$ TPU \\
\hline \multicolumn{6}{|c|}{ WIPP East (WEE), cont. } \\
\hline 7 & AL-WEE-199902171.1 & $3.12 \times 10^{-5}$ & $2.48 \times 10^{-5}$ & $7.56 \times 10^{-4}$ & $9.02 \times 10^{-5}$ \\
\hline 8 & AL-WEE-199902241.1 & $5.03 \times 10^{-5}$ & $2.35 \times 10^{-5}$ & $8.08 \times 10^{-4}$ & $8.69 \times 10^{-5}$ \\
\hline 9 & AL-WEE-199903031.1 & $3.67 \times 10^{-5}$ & $2.44 \times 10^{-5}$ & $8.39 \times 10^{-4}$ & $8.94 \times 10^{-5}$ \\
\hline 10 & AL-WEE-199903101.1 & $3.22 \times 10^{-5}$ & $2.87 \times 10^{-5}$ & $1.01 \times 10^{-3}$ & $9.40 \times 10^{-5}$ \\
\hline 11 & AL-WEE-199903171.1 & $4.01 \times 10^{-5}$ & $2.79 \times 10^{-5}$ & $6.51 \times 10^{-4}$ & $7.97 \times 10^{-5}$ \\
\hline 12 & AL-WEE-199903241.1 & $1.02 \times 10^{-4}$ & $3.31 \times 10^{-5}$ & $7.76 \times 10^{-4}$ & $9.20 \times 10^{-5}$ \\
\hline 13 & AL-WEE-199903311.1 & $7.31 \times 10^{-5}$ & $3.22 \times 10^{-5}$ & $6.55 \times 10^{-4}$ & $8.69 \times 10^{-5}$ \\
\hline 14 & AL-WEE-199904071.2 & $5.90 \times 10^{-5}$ & $2.74 \times 10^{-5}$ & $6.89 \times 10^{-4}$ & $8.44 \times 10^{-5}$ \\
\hline 14 & AL-WEE-199904072.2 & $5.89 \times 10^{-5}$ & $2.74 \times 10^{-5}$ & $6.86 \times 10^{-4}$ & $8.43 \times 10^{-5}$ \\
\hline 15 & AL-WEE-199904141.2 & $4.54 \times 10^{-5}$ & $2.54 \times 10^{-5}$ & $8.06 \times 10^{-4}$ & $9.10 \times 10^{-5}$ \\
\hline 15 & AL-WEE-199904142.2 & $3.25 \times 10^{-5}$ & $2.17 \times 10^{-5}$ & $7.33 \times 10^{-4}$ & $8.51 \times 10^{-5}$ \\
\hline 16 & AL-WEE-199904211.2 & $3.67 \times 10^{-5}$ & $2.12 \times 10^{-5}$ & $5.69 \times 10^{-4}$ & $7.71 \times 10^{-5}$ \\
\hline 16 & AL-WEE-199904212.2 & $4.47 \times 10^{-5}$ & $2.30 \times 10^{-5}$ & $5.18 \times 10^{-4}$ & $7.45 \times 10^{-5}$ \\
\hline 17 & AL-WEE-199904281.2 & $4.80 \times 10^{-5}$ & $2.60 \times 10^{-5}$ & $7.50 \times 10^{-4}$ & $9.23 \times 10^{-5}$ \\
\hline 17 & AL-WEE-199904282.2 & $2.71 \times 10^{-5}$ & $2.06 \times 10^{-5}$ & $7.30 \times 10^{-4}$ & $8.90 \times 10^{-5}$ \\
\hline 18 & AL-WEE-199905051.2 & $5.54 \times 10^{-5}$ & $2.73 \times 10^{-5}$ & $8.26 \times 10^{-4}$ & $8.67 \times 10^{-5}$ \\
\hline 18 & AL-WEE-199905052.2 & \multicolumn{4}{|c|}{ Sample Aborted } \\
\hline 19 & AL-WEE-199905121.2 & $5.68 \times 10^{-5}$ & $2.66 \times 10^{-5}$ & $6.59 \times 10^{-4}$ & $8.53 \times 10^{-5}$ \\
\hline 19 & AL-WEE-199905122.2 & $4.90 \times 10^{-5}$ & $2.52 \times 10^{-5}$ & $7.06 \times 10^{-4}$ & $8.78 \times 10^{-5}$ \\
\hline 20 & AL-WEE-199905191.2 & $4.41 \times 10^{-5}$ & $2.36 \times 10^{-5}$ & $6.04 \times 10^{-4}$ & $8.05 \times 10^{-5}$ \\
\hline 20 & AL-WEE-199905192.2 & $6.16 \times 10^{-5}$ & $2.82 \times 10^{-5}$ & $6.73 \times 10^{-4}$ & $8.76 \times 10^{-5}$ \\
\hline 21 & AL-WEE-199905261.2 & $4.37 \times 10^{-5}$ & $2.95 \times 10^{-5}$ & $7.26 \times 10^{-4}$ & $8.61 \times 10^{-5}$ \\
\hline 21 & AL-WEE-199905262.2 & $4.37 \times 10^{-5}$ & $2.95 \times 10^{-5}$ & $7.67 \times 10^{-4}$ & $8.79 \times 10^{-5}$ \\
\hline 22 & AL-WEE-199906021.2 & $5.25 \times 10^{-5}$ & $2.50 \times 10^{-5}$ & $7.35 \times 10^{-4}$ & $8.44 \times 10^{-5}$ \\
\hline 22 & AL-WEE-199906022.2 & $4.42 \times 10^{-5}$ & $2.31 \times 10^{-5}$ & $7.02 \times 10^{-4}$ & $8.28 \times 10^{-5}$ \\
\hline 23 & AL-WEE-199906091.2 & $1.56 \times 10^{-5}$ & $2.11 \times 10^{-5}$ & $6.69 \times 10^{-4}$ & $8.04 \times 10^{-5}$ \\
\hline 23 & AL-WEE-199906092.2 & $1.81 \times 10^{-5}$ & $2.18 \times 10^{-5}$ & $7.23 \times 10^{-4}$ & $8.31 \times 10^{-5}$ \\
\hline 24 & AL-WEE-199906161.2 & $8.83 \times 10^{-5}$ & $3.92 \times 10^{-5}$ & $7.75 \times 10^{-4}$ & $9.28 \times 10^{-5}$ \\
\hline 24 & AL-WEE-199906162.2 & $7.32 \times 10^{-5}$ & $3.50 \times 10^{-5}$ & $7.71 \times 10^{-4}$ & $8.87 \times 10^{-5}$ \\
\hline 25 & AL-WEE-199906231.2 & $4.92 \times 10^{-5}$ & $3.13 \times 10^{-5}$ & $8.15 \times 10^{-4}$ & $9.32 \times 10^{-5}$ \\
\hline 25 & AL-WEE-199906232.2 & $3.11 \times 10^{-5}$ & $2.74 \times 10^{-5}$ & $7.48 \times 10^{-4}$ & $8.87 \times 10^{-5}$ \\
\hline 26 & AL-WEE-199906301.2 & $3.00 \times 10^{-5}$ & $2.49 \times 10^{-5}$ & $6.25 \times 10^{-4}$ & $8.13 \times 10^{-5}$ \\
\hline 26 & AL-WEE-199906302.2 & $2.98 \times 10^{-5}$ & $2.48 \times 10^{-5}$ & $5.28 \times 10^{-4}$ & $7.62 \times 10^{-5}$ \\
\hline 27 & AL-WEE-199907071.1 & $8.10 \times 10^{-5}$ & $3.33 \times 10^{-5}$ & $6.64 \times 10^{-4}$ & $8.69 \times 10^{-5}$ \\
\hline 28 & AL-WEE-199907141.1 & $4.05 \times 10^{-5}$ & $2.76 \times 10^{-5}$ & $5.66 \times 10^{-4}$ & $7.84 \times 10^{-5}$ \\
\hline 29 & AL-WEE-199907211.1 & $6.23 \times 10^{-5}$ & $3.12 \times 10^{-5}$ & $7.71 \times 10^{-4}$ & $8.90 \times 10^{-5}$ \\
\hline 30 & AL-WEE-199907281.1 & $5.19 \times 10^{-5}$ & $3.18 \times 10^{-5}$ & $7.33 \times 10^{-4}$ & $8.73 \times 10^{-5}$ \\
\hline 31 & AL-WEE-199908041.1 & $4.53 \times 10^{-5}$ & $2.48 \times 10^{-5}$ & $9.58 \times 10^{-4}$ & $9.51 \times 10^{-5}$ \\
\hline 32 & AL-WEE-199908111.1 & $5.85 \times 10^{-5}$ & $2.50 \times 10^{-5}$ & $9.33 \times 10^{-4}$ & $9.61 \times 10^{-5}$ \\
\hline 33 & AL-WEE-199908181.1 & $5.00 \times 10^{-5}$ & $2.27 \times 10^{-5}$ & $1.04 \times 10^{-3}$ & $1.00 \times 10^{-4}$ \\
\hline 34 & AL-WEE-199908251.1 & $6.85 \times 10^{-5}$ & $2.90 \times 10^{-5}$ & $8.67 \times 10^{-4}$ & $9.06 \times 10^{-5}$ \\
\hline 35 & AL-WEE-199909011.1 & $1.01 \times 10^{-4}$ & $3.33 \times 10^{-5}$ & $8.40 \times 10^{-4}$ & $8.70 \times 10^{-5}$ \\
\hline 36 & AL-WEE-199909081.1 & $6.42 \times 10^{-5}$ & $2.71 \times 10^{-5}$ & $8.56 \times 10^{-4}$ & $8.83 \times 10^{-5}$ \\
\hline 37 & AL-WEE-199909151.1 & $3.96 \times 10^{-5}$ & $2.24 \times 10^{-5}$ & $1.28 \times 10^{-3}$ & $1.01 \times 10^{-4}$ \\
\hline 38 & AL-WEE-199909221.1 & $5.24 \times 10^{-5}$ & $2.58 \times 10^{-5}$ & $1.10 \times 10^{-3}$ & $9.81 \times 10^{-5}$ \\
\hline 39 & AL-WEE-199909291.1 & $2.48 \times 10^{-4}$ & $4.98 \times 10^{-5}$ & $1.25 \times 10^{-3}$ & $1.04 \times 10^{-4}$ \\
\hline 40 & AL-WEE-199910061.1 & $2.17 \times 10^{-4}$ & $3.44 \times 10^{-3}$ & $1.20 \times 10^{-3}$ & $2.40 \times 10^{-4}$ \\
\hline 41 & AL-WEE-199910131.1 & $1.65 \times 10^{-4}$ & $4.23 \times 10^{-5}$ & $1.14 \times 10^{-3}$ & $9.98 \times 10^{-5}$ \\
\hline 42 & AL-WEE-199910201.1 & $1.83 \times 10^{-4}$ & $4.46 \times 10^{-5}$ & $1.54 \times 10^{-3}$ & $1.17 \times 10^{-4}$ \\
\hline
\end{tabular}


Table C.1, cont.

\begin{tabular}{|c|c|c|c|c|c|}
\hline \multirow[b]{2}{*}{$\begin{array}{c}\text { Sample } \\
\text { Week }\end{array}$} & \multirow[b]{2}{*}{ Sample ID } & \multicolumn{2}{|c|}{ Alpha $\left(\mathrm{Bq} / \mathrm{m}^{3}\right)$} & \multicolumn{2}{|c|}{ Beta $\left(\mathrm{Bq} / \mathrm{m}^{3}\right)$} \\
\hline & & Concentration & $2 \times \mathbf{T P U}^{1}$ & Concentration & $2 \times$ TPU \\
\hline \multicolumn{6}{|c|}{ WIPP East (WEE), cont. } \\
\hline 43 & AL-WEE-199910271.1 & $1.29 \times 10^{-4}$ & $3.76 \times 10^{-5}$ & $1.18 \times 10^{-3}$ & $9.94 \times 10^{-5}$ \\
\hline 44 & AL-WEE-199911031.1 & $9.38 \times 10^{-5}$ & $3.13 \times 10^{-5}$ & $1.14 \times 10^{-3}$ & $1.03 \times 10^{-4}$ \\
\hline 45 & AL-WEE-199911101.1 & $1.22 \times 10^{-4}$ & $3.09 \times 10^{-3}$ & $1.55 \times 10^{-3}$ & $2.28 \times 10^{-4}$ \\
\hline 46 & AL-WEE-199911171.1 & $7.66 \times 10^{-5}$ & $2.92 \times 10^{-5}$ & $1.24 \times 10^{-3}$ & $1.12 \times 10^{-4}$ \\
\hline 47 & AL-WEE-199911241.1 & $9.18 \times 10^{-5}$ & $3.11 \times 10^{-5}$ & $1.57 \times 10^{-3}$ & $1.07 \times 10^{-4}$ \\
\hline 49 & AL-WEE-199912081.1 & $1.23 \times 10^{-4}$ & $3.39 \times 10^{-5}$ & $1.45 \times 10^{-3}$ & $1.06 \times 10^{-4}$ \\
\hline 50 & AL-WEE-199912151.1 & $4.80 \times 10^{-5}$ & $2.75 \times 10^{-5}$ & $8.29 \times 10^{-4}$ & $8.90 \times 10^{-5}$ \\
\hline 51 & AL-WEE-199912221.1 & $4.66 \times 10^{-5}$ & $2.16 \times 10^{-5}$ & $1.11 \times 10^{-3}$ & $9.26 \times 10^{-5}$ \\
\hline 52 & AL-WEE-199912291.1 & $5.08 \times 10^{-5}$ & $2.45 \times 10^{-5}$ & $8.07 \times 10^{-4}$ & $8.54 \times 10^{-5}$ \\
\hline
\end{tabular}

\section{WIPP Far Field (WFF)}

\begin{tabular}{|c|c|c|c|c|c|}
\hline 1 & AL-WFF-199901061.2 & $3.24 \times 10^{-5}$ & $2.05 \times 10^{-5}$ & $1.26 \times 10^{-3}$ & $9.36 \times 10^{-5}$ \\
\hline 1 & AL-WFF-199901062.2 & $3.55 \times 10^{-5}$ & $2.24 \times 10^{-5}$ & $1.27 \times 10^{-3}$ & $9.84 \times 10^{-5}$ \\
\hline 2 & AL-WFF-199901131.2 & $4.06 \times 10^{-5}$ & $3.03 \times 10^{-5}$ & $1.12 \times 10^{-3}$ & $1.11 \times 10^{-4}$ \\
\hline 2 & AL-WFF-199901132.2 & $4.09 \times 10^{-5}$ & $3.05 \times 10^{-5}$ & $1.09 \times 10^{-3}$ & $1.10 \times 10^{-4}$ \\
\hline 3 & AL-WFF-199901201.2 & $4.94 \times 10^{-5}$ & $2.40 \times 10^{-5}$ & $7.02 \times 10^{-4}$ & $8.43 \times 10^{-5}$ \\
\hline 3 & AL-WFF-199901202.2 & $5.91 \times 10^{-5}$ & $2.58 \times 10^{-5}$ & $7.75 \times 10^{-4}$ & $8.72 \times 10^{-5}$ \\
\hline 4 & AL-WFF-199901271.2 & $1.40 \times 10^{-5}$ & $1.87 \times 10^{-5}$ & $9.20 \times 10^{-4}$ & $9.38 \times 10^{-5}$ \\
\hline 4 & AL-WFF-199901272.2 & $3.55 \times 10^{-5}$ & $2.40 \times 10^{-5}$ & $8.80 \times 10^{-4}$ & $9.29 \times 10^{-5}$ \\
\hline 5 & AL-WFF-199902031.2 & $2.89 \times 10^{-5}$ & $2.71 \times 10^{-5}$ & $9.45 \times 10^{-4}$ & $9.89 \times 10^{-5}$ \\
\hline 5 & AL-WFF-199902032.2 & $2.07 \times 10^{-5}$ & $2.55 \times 10^{-5}$ & $8.46 \times 10^{-4}$ & $9.50 \times 10^{-5}$ \\
\hline 6 & AL-WFF-199902101.2 & $1.94 \times 10^{-5}$ & $2.46 \times 10^{-5}$ & $8.68 \times 10^{-4}$ & $9.39 \times 10^{-5}$ \\
\hline 6 & AL-WFF-199902102.2 & $9.75 \times 10^{-6}$ & $2.34 \times 10^{-5}$ & $8.39 \times 10^{-4}$ & $9.53 \times 10^{-5}$ \\
\hline 7 & AL-WFF-199902171.2 & $1.17 \times 10^{-5}$ & $1.94 \times 10^{-5}$ & $6.90 \times 10^{-4}$ & $8.44 \times 10^{-5}$ \\
\hline 7 & AL-WFF-199902172.2 & $3.02 \times 10^{-5}$ & $2.39 \times 10^{-5}$ & $7.80 \times 10^{-4}$ & $8.94 \times 10^{-5}$ \\
\hline 8 & AL-WFF-199902241.2 & $4.63 \times 10^{-5}$ & $2.30 \times 10^{-5}$ & $8.67 \times 10^{-4}$ & $9.10 \times 10^{-5}$ \\
\hline 8 & AL-WFF-199902242.2 & $2.99 \times 10^{-5}$ & $1.89 \times 10^{-5}$ & $8.63 \times 10^{-4}$ & $9.01 \times 10^{-5}$ \\
\hline 9 & AL-WFF-199903031.2 & $6.57 \times 10^{-5}$ & $2.97 \times 10^{-5}$ & $7.89 \times 10^{-4}$ & $8.69 \times 10^{-5}$ \\
\hline 9 & AL-WFF-199903032.2 & $6.00 \times 10^{-5}$ & $2.94 \times 10^{-5}$ & $7.59 \times 10^{-4}$ & $8.75 \times 10^{-5}$ \\
\hline 10 & AL-WFF-199903101.2 & $2.30 \times 10^{-5}$ & $2.79 \times 10^{-5}$ & $9.40 \times 10^{-4}$ & $9.33 \times 10^{-5}$ \\
\hline 10 & AL-WFF-199903102.2 & $3.66 \times 10^{-5}$ & $3.02 \times 10^{-5}$ & $9.30 \times 10^{-4}$ & $9.28 \times 10^{-5}$ \\
\hline 11 & AL-WFF-199903171.2 & $1.86 \times 10^{-5}$ & $2.28 \times 10^{-5}$ & $6.99 \times 10^{-4}$ & $7.92 \times 10^{-5}$ \\
\hline 11 & AL-WFF-199903172.2 & $2.73 \times 10^{-5}$ & $2.56 \times 10^{-5}$ & $7.63 \times 10^{-4}$ & $8.48 \times 10^{-5}$ \\
\hline 12 & AL-WFF-199903241.2 & $7.19 \times 10^{-5}$ & $2.68 \times 10^{-5}$ & $7.40 \times 10^{-4}$ & $8.67 \times 10^{-5}$ \\
\hline 12 & AL-WFF-199903242.2 & $8.22 \times 10^{-5}$ & $2.91 \times 10^{-5}$ & $8.06 \times 10^{-4}$ & $9.13 \times 10^{-5}$ \\
\hline 13 & AL-WFF-199903311.2 & $6.69 \times 10^{-5}$ & $2.95 \times 10^{-5}$ & $6.84 \times 10^{-4}$ & $8.35 \times 10^{-5}$ \\
\hline 13 & AL-WFF-199903312.2 & $1.28 \times 10^{-4}$ & $3.97 \times 10^{-5}$ & $6.92 \times 10^{-4}$ & $8.68 \times 10^{-5}$ \\
\hline 14 & AL-WFF-199904071.1 & $4.42 \times 10^{-5}$ & $2.41 \times 10^{-5}$ & $7.55 \times 10^{-4}$ & $8.63 \times 10^{-5}$ \\
\hline 15 & AL-WFF-199904141.1 & $5.12 \times 10^{-5}$ & $2.58 \times 10^{-5}$ & $8.52 \times 10^{-4}$ & $9.01 \times 10^{-5}$ \\
\hline 16 & AL-WFF-199904211.1 & $3.46 \times 10^{-5}$ & $2.08 \times 10^{-5}$ & $5.48 \times 10^{-4}$ & $7.65 \times 10^{-5}$ \\
\hline 17 & AL-WFF-199904281.1 & $5.91 \times 10^{-5}$ & $2.67 \times 10^{-5}$ & $9.39 \times 10^{-4}$ & $9.51 \times 10^{-5}$ \\
\hline 18 & AL-WFF-199905051.1 & $6.12 \times 10^{-5}$ & $2.84 \times 10^{-5}$ & $8.39 \times 10^{-4}$ & $8.74 \times 10^{-5}$ \\
\hline 19 & AL-WFF-199905121.1 & $8.45 \times 10^{-5}$ & $3.06 \times 10^{-5}$ & $7.55 \times 10^{-4}$ & $8.66 \times 10^{-5}$ \\
\hline 20 & AL-WFF-199905191.1 & $7.50 \times 10^{-5}$ & $2.87 \times 10^{-5}$ & $6.04 \times 10^{-4}$ & $7.81 \times 10^{-5}$ \\
\hline 21 & AL-WFF-199905261.1 & $2.27 \times 10^{-5}$ & $2.58 \times 10^{-5}$ & $8.35 \times 10^{-4}$ & $9.19 \times 10^{-5}$ \\
\hline 22 & AL-WFF-199906021.1 & $2.99 \times 10^{-5}$ & $1.92 \times 10^{-5}$ & $7.52 \times 10^{-4}$ & $8.37 \times 10^{-5}$ \\
\hline 23 & AL-WFF-199906091.1 & $2.15 \times 10^{-5}$ & $2.35 \times 10^{-5}$ & $6.80 \times 10^{-4}$ & $8.38 \times 10^{-5}$ \\
\hline 24 & AL-WFF-199906161.1 & $2.72 \times 10^{-5}$ & $2.77 \times 10^{-5}$ & $5.84 \times 10^{-4}$ & $8.23 \times 10^{-5}$ \\
\hline 25 & AL-WFF-199906231.1 & $5.41 \times 10^{-5}$ & $3.17 \times 10^{-5}$ & $8.14 \times 10^{-4}$ & $9.20 \times 10^{-5}$ \\
\hline
\end{tabular}


Table C.1, cont.

\begin{tabular}{llll} 
Sample & & $\operatorname{Alpha}\left(\mathrm{Bq} / \mathrm{m}^{3}\right)$ & $\frac{\operatorname{Beta}\left(\mathrm{Bq} / \mathrm{m}^{3}\right)}{n}$ \\
& & & \\
Week & Sample ID & Concentration $2 \times$ TPU $^{1}$ & Concentration $2 \times$ TPU \\
\hline
\end{tabular}

WIPP Far Field (WFF), cont.

\begin{tabular}{|c|c|c|c|c|c|}
\hline 26 & AL-WFF-199906301.1 & $4.60 \times 10^{-5}$ & $2.89 \times 10^{-5}$ & $6.01 \times 10^{-4}$ & $8.22 \times 10^{-5}$ \\
\hline 27 & AL-WFF-199907071.1 & $2.96 \times 10^{-5}$ & $2.29 \times 10^{-5}$ & $7.99 \times 10^{-4}$ & $9.06 \times 10^{-5}$ \\
\hline 28 & AL-WFF-199907141.1 & $2.66 \times 10^{-5}$ & $2.48 \times 10^{-5}$ & $5.96 \times 10^{-4}$ & $7.96 \times 10^{-5}$ \\
\hline 29 & AL-WFF-199907211.1 & $4.68 \times 10^{-5}$ & $2.79 \times 10^{-5}$ & $6.78 \times 10^{-4}$ & $8.34 \times 10^{-5}$ \\
\hline 30 & AL-WFF-199907281.1 & $2.11 \times 10^{-5}$ & $2.58 \times 10^{-5}$ & $7.51 \times 10^{-4}$ & $8.72 \times 10^{-5}$ \\
\hline 31 & AL-WFF-199908041.1 & $4.75 \times 10^{-5}$ & $2.52 \times 10^{-5}$ & $9.32 \times 10^{-4}$ & $9.38 \times 10^{-5}$ \\
\hline 32 & AL-WFF-199908111.1 & $5.60 \times 10^{-5}$ & $2.45 \times 10^{-5}$ & $9.28 \times 10^{-4}$ & $9.59 \times 10^{-5}$ \\
\hline 33 & AL-WFF-199908181.1 & $2.89 \times 10^{-5}$ & $1.65 \times 10^{-5}$ & $1.14 \times 10^{-3}$ & $1.01 \times 10^{-4}$ \\
\hline 34 & AL-WFF-199908251.1 & $6.19 \times 10^{-5}$ & $2.73 \times 10^{-5}$ & $8.00 \times 10^{-4}$ & $8.63 \times 10^{-5}$ \\
\hline 35 & AL-WFF-199909011.1 & $6.47 \times 10^{-5}$ & $2.70 \times 10^{-5}$ & $9.51 \times 10^{-4}$ & $9.06 \times 10^{-5}$ \\
\hline 36 & AL-WFF-199909081.1 & $5.90 \times 10^{-5}$ & $2.60 \times 10^{-5}$ & $8.04 \times 10^{-4}$ & $8.55 \times 10^{-5}$ \\
\hline 37 & AL-WFF-199909151.1 & $5.10 \times 10^{-5}$ & $2.44 \times 10^{-5}$ & $1.16 \times 10^{-3}$ & $9.59 \times 10^{-5}$ \\
\hline 38 & AL-WFF-199909221.1 & $5.47 \times 10^{-5}$ & $2.54 \times 10^{-5}$ & $1.13 \times 10^{-3}$ & $9.62 \times 10^{-5}$ \\
\hline 39 & AL-WFF-199909291.1 & $2.35 \times 10^{-4}$ & $4.82 \times 10^{-5}$ & $1.41 \times 10^{-3}$ & $1.09 \times 10^{-4}$ \\
\hline 40 & AL-WFF-199910061.1 & $2.18 \times 10^{-4}$ & $3.41 \times 10^{-3}$ & $1.27 \times 10^{-3}$ & $2.40 \times 10^{-4}$ \\
\hline 41 & AL-WFF-199910131.1 & $1.59 \times 10^{-4}$ & $4.11 \times 10^{-5}$ & $1.23 \times 10^{-3}$ & $1.02 \times 10^{-4}$ \\
\hline 42 & AL-WFF-199910201.1 & $2.34 \times 10^{-4}$ & $4.85 \times 10^{-5}$ & $1.79 \times 10^{-3}$ & $1.21 \times 10^{-4}$ \\
\hline 43 & AL-WFF-199910271.1 & $1.14 \times 10^{-4}$ & $3.59 \times 10^{-5}$ & $1.27 \times 10^{-3}$ & $1.04 \times 10^{-4}$ \\
\hline 44 & AL-WFF-199911031.1 & $8.78 \times 10^{-5}$ & $2.94 \times 10^{-5}$ & $1.18 \times 10^{-3}$ & $1.01 \times 10^{-4}$ \\
\hline 45 & AL-WFF-199911101.1 & $9.07 \times 10^{-5}$ & $2.88 \times 10^{-3}$ & $1.51 \times 10^{-3}$ & $2.14 \times 10^{-4}$ \\
\hline 46 & AL-WFF-199911171.1 & $6.97 \times 10^{-5}$ & $2.81 \times 10^{-5}$ & $1.22 \times 10^{-3}$ & $1.12 \times 10^{-4}$ \\
\hline 47 & AL-WFF-199911241.1 & $8.50 \times 10^{-5}$ & $3.02 \times 10^{-5}$ & $1.50 \times 10^{-3}$ & $1.05 \times 10^{-4}$ \\
\hline 49 & AL-WFF-199912081.1 & $1.38 \times 10^{-4}$ & $3.73 \times 10^{-5}$ & $1.58 \times 10^{-3}$ & $1.15 \times 10^{-4}$ \\
\hline 50 & AL-WFF-199912151.1 & $3.47 \times 10^{-5}$ & $2.36 \times 10^{-5}$ & $7.22 \times 10^{-4}$ & $8.07 \times 10^{-5}$ \\
\hline 51 & AL-WFF-199912221.1 & $4.84 \times 10^{-5}$ & $2.24 \times 10^{-5}$ & $1.05 \times 10^{-3}$ & $9.23 \times 10^{-5}$ \\
\hline 52 & AL-WFF-199912291.1 & $5.47 \times 10^{-5}$ & $2.50 \times 10^{-5}$ & $1.03 \times 10^{-3}$ & $9.39 \times 10^{-5}$ \\
\hline
\end{tabular}

\section{WIPP South (WSS)}

\begin{tabular}{llllll}
\hline 1 & AL-WSS-199901061.1 & $5.00 \times 10^{-5}$ & $2.45 \times 10^{-5}$ & $1.15 \times 10^{-3}$ & $9.20 \times 10^{-5}$ \\
2 & AL-WSS-199901131.1 & $3.29 \times 10^{-5}$ & $2.98 \times 10^{-5}$ & $1.10 \times 10^{-3}$ & $1.13 \times 10^{-4}$ \\
3 & AL-WSS-199901201.1 & $2.40 \times 10^{-5}$ & $1.72 \times 10^{-5}$ & $7.32 \times 10^{-4}$ & $8.27 \times 10^{-5}$ \\
4 & AL-WSS-199901271.1 & $3.11 \times 10^{-5}$ & $2.36 \times 10^{-5}$ & $9.23 \times 10^{-4}$ & $9.68 \times 10^{-5}$ \\
5 & AL-WSS-199902031.1 & $3.43 \times 10^{-5}$ & $2.79 \times 10^{-5}$ & $7.90 \times 10^{-4}$ & $9.16 \times 10^{-5}$ \\
6 & AL-WSS-199902101.1 & $1.41 \times 10^{-5}$ & $2.35 \times 10^{-5}$ & $8.64 \times 10^{-4}$ & $9.41 \times 10^{-5}$ \\
7 & AL-WSS-199902171.1 & $2.66 \times 10^{-5}$ & $2.24 \times 10^{-5}$ & $7.22 \times 10^{-4}$ & $8.44 \times 10^{-5}$ \\
8 & AL-WSS-199902241.1 & $4.03 \times 10^{-5}$ & $2.13 \times 10^{-5}$ & $7.34 \times 10^{-4}$ & $8.36 \times 10^{-5}$ \\
9 & AL-WSS-199903031.1 & $6.15 \times 10^{-5}$ & $2.94 \times 10^{-5}$ & $7.98 \times 10^{-4}$ & $8.85 \times 10^{-5}$ \\
10 & AL-WSS-199903101.1 & $1.03 \times 10^{-5}$ & $2.54 \times 10^{-5}$ & $9.33 \times 10^{-4}$ & $9.29 \times 10^{-5}$ \\
11 & AL-WSS-199903171.1 & $2.03 \times 10^{-5}$ & $2.48 \times 10^{-5}$ & $6.36 \times 10^{-4}$ & $8.06 \times 10^{-5}$ \\
12 & AL-WSS-199903241.1 & $9.95 \times 10^{-5}$ & $3.10 \times 10^{-5}$ & $7.13 \times 10^{-4}$ & $8.36 \times 10^{-5}$ \\
13 & AL-WSS-199903311.1 & $8.62 \times 10^{-5}$ & $3.40 \times 10^{-5}$ & $6.61 \times 10^{-4}$ & $8.64 \times 10^{-5}$ \\
14 & AL-WSS-199904071.1 & $6.58 \times 10^{-5}$ & $2.92 \times 10^{-5}$ & $6.16 \times 10^{-4}$ & $8.25 \times 10^{-5}$ \\
15 & AL-WSS-199904141.1 & $5.29 \times 10^{-5}$ & $2.59 \times 10^{-5}$ & $8.10 \times 10^{-4}$ & $8.74 \times 10^{-5}$ \\
16 & AL-WSS-199904211.1 & $3.44 \times 10^{-5}$ & $1.99 \times 10^{-5}$ & $5.74 \times 10^{-4}$ & $7.43 \times 10^{-5}$ \\
17 & AL-WSS-199904281.1 & $3.29 \times 10^{-5}$ & $2.20 \times 10^{-5}$ & $8.30 \times 10^{-4}$ & $9.35 \times 10^{-5}$ \\
18 & AL-WSS-199905051.1 & $6.39 \times 10^{-5}$ & $2.81 \times 10^{-5}$ & $8.62 \times 10^{-4}$ & $8.62 \times 10^{-5}$ \\
19 & AL-WSS-199905121.1 & $7.88 \times 10^{-5}$ & $3.01 \times 10^{-5}$ & $6.47 \times 10^{-4}$ & $8.31 \times 10^{-5}$ \\
20 & AL-WSS-199905191.1 & $9.22 \times 10^{-5}$ & $3.14 \times 10^{-5}$ & $6.57 \times 10^{-4}$ & $8.05 \times 10^{-5}$ \\
21 & AL-WSS-199905261.1 & $3.47 \times 10^{-5}$ & $2.74 \times 10^{-5}$ & $7.52 \times 10^{-4}$ & $8.62 \times 10^{-5}$
\end{tabular}


Table C.1, cont.

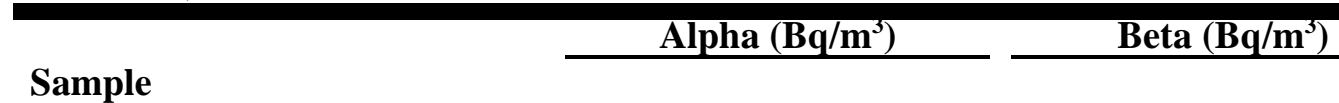

Week Sample ID $\quad$ Concentration $2 \times$ TPU $^{1}$ Concentration $2 \times$ TPU

WIPP South (WSS), cont.

\begin{tabular}{|c|c|c|c|c|c|}
\hline 22 & AL-WSS-199906021.1 & $4.14 \times 10^{-5}$ & $2.24 \times 10^{-5}$ & $7.01 \times 10^{-4}$ & $8.25 \times 10^{-5}$ \\
\hline 23 & AL-WSS-199906091.1 & $3.45 \times 10^{-5}$ & $2.71 \times 10^{-5}$ & $6.45 \times 10^{-4}$ & $8.43 \times 10^{-5}$ \\
\hline 24 & AL-WSS-199906161.1 & $4.59 \times 10^{-5}$ & $2.99 \times 10^{-5}$ & $6.03 \times 10^{-4}$ & $7.94 \times 10^{-5}$ \\
\hline 25 & AL-WSS-199906231.1 & $3.26 \times 10^{-5}$ & $2.87 \times 10^{-5}$ & $6.46 \times 10^{-4}$ & $8.66 \times 10^{-5}$ \\
\hline 26 & AL-WSS-199906301.1 & $2.17 \times 10^{-5}$ & $2.31 \times 10^{-5}$ & $6.09 \times 10^{-4}$ & $8.06 \times 10^{-5}$ \\
\hline 27 & AL-WSS-199907071.2 & $6.05 \times 10^{-5}$ & $2.96 \times 10^{-5}$ & $6.83 \times 10^{-4}$ & $8.74 \times 10^{-5}$ \\
\hline 27 & AL-WSS-199907072.2 & $3.85 \times 10^{-5}$ & $2.52 \times 10^{-5}$ & $6.58 \times 10^{-4}$ & $8.56 \times 10^{-5}$ \\
\hline 28 & AL-WSS-199907141.2 & $3.63 \times 10^{-5}$ & $2.64 \times 10^{-5}$ & $5.60 \times 10^{-4}$ & $7.69 \times 10^{-5}$ \\
\hline 28 & AL-WSS-199907142.2 & $6.54 \times 10^{-5}$ & $3.22 \times 10^{-5}$ & $5.58 \times 10^{-4}$ & $7.86 \times 10^{-5}$ \\
\hline 29 & AL-WSS-199907211.2 & $6.55 \times 10^{-5}$ & $3.19 \times 10^{-5}$ & $7.79 \times 10^{-4}$ & $8.99 \times 10^{-5}$ \\
\hline 29 & AL-WSS-199907212.2 & $6.51 \times 10^{-5}$ & $3.17 \times 10^{-5}$ & $7.79 \times 10^{-4}$ & $8.97 \times 10^{-5}$ \\
\hline 30 & AL-WSS-199907281.2 & $6.65 \times 10^{-5}$ & $3.34 \times 10^{-5}$ & $7.33 \times 10^{-4}$ & $8.57 \times 10^{-5}$ \\
\hline 30 & AL-WSS-199907282.2 & $1.25 \times 10^{-5}$ & $2.80 \times 10^{-5}$ & $5.81 \times 10^{-4}$ & $8.87 \times 10^{-5}$ \\
\hline 31 & AL-WSS-199908041.2 & $4.85 \times 10^{-5}$ & $2.57 \times 10^{-5}$ & $8.68 \times 10^{-4}$ & $9.23 \times 10^{-5}$ \\
\hline 31 & AL-WSS-199908042.2 & $5.87 \times 10^{-5}$ & $2.76 \times 10^{-5}$ & $8.83 \times 10^{-4}$ & $9.26 \times 10^{-5}$ \\
\hline 32 & AL-WSS-199908111.2 & $6.16 \times 10^{-5}$ & $2.63 \times 10^{-5}$ & $8.22 \times 10^{-4}$ & $9.46 \times 10^{-5}$ \\
\hline 32 & AL-WSS-199908112.2 & $3.48 \times 10^{-5}$ & $1.96 \times 10^{-5}$ & $9.45 \times 10^{-4}$ & $9.72 \times 10^{-5}$ \\
\hline 33 & AL-WSS-199908181.2 & $4.81 \times 10^{-6}$ & $2.18 \times 10^{-5}$ & $1.04 \times 10^{-3}$ & $9.80 \times 10^{-5}$ \\
\hline 33 & AL-WSS-199908182.2 & $2.96 \times 10^{-5}$ & $1.69 \times 10^{-5}$ & $1.04 \times 10^{-3}$ & $9.88 \times 10^{-5}$ \\
\hline 34 & AL-WSS-199908251.2 & $5.56 \times 10^{-5}$ & $2.65 \times 10^{-5}$ & $8.39 \times 10^{-4}$ & $8.96 \times 10^{-5}$ \\
\hline 34 & AL-WSS-199908252.2 & $3.55 \times 10^{-5}$ & $2.21 \times 10^{-5}$ & $7.40 \times 10^{-4}$ & $8.50 \times 10^{-5}$ \\
\hline 35 & AL-WSS-199909011.2 & $1.24 \times 10^{-4}$ & $3.66 \times 10^{-5}$ & $8.69 \times 10^{-4}$ & $8.80 \times 10^{-5}$ \\
\hline 35 & AL-WSS-199909012.2 & $8.88 \times 10^{-5}$ & $3.17 \times 10^{-5}$ & $7.85 \times 10^{-4}$ & $8.54 \times 10^{-5}$ \\
\hline 36 & AL-WSS-199909081.2 & $5.23 \times 10^{-5}$ & $2.50 \times 10^{-5}$ & $8.34 \times 10^{-4}$ & $8.78 \times 10^{-5}$ \\
\hline 36 & AL-WSS-199909082.2 & $3.41 \times 10^{-5}$ & $2.12 \times 10^{-5}$ & $7.50 \times 10^{-4}$ & $8.49 \times 10^{-5}$ \\
\hline 37 & AL-WSS-199909151.2 & $6.37 \times 10^{-5}$ & $2.81 \times 10^{-5}$ & $1.17 \times 10^{-3}$ & $1.01 \times 10^{-4}$ \\
\hline 37 & AL-WSS-199909152.2 & $3.90 \times 10^{-5}$ & $2.30 \times 10^{-5}$ & $1.19 \times 10^{-3}$ & $1.01 \times 10^{-4}$ \\
\hline 38 & AL-WSS-199909221.2 & NR & NR & NR & NR \\
\hline 38 & AL-WSS-199909222.2 & $2.69 \times 10^{-5}$ & $1.94 \times 10^{-5}$ & $1.03 \times 10^{-3}$ & $9.20 \times 10^{-5}$ \\
\hline 39 & AL-WSS-199909291.2 & $1.69 \times 10^{-4}$ & $4.10 \times 10^{-5}$ & $1.27 \times 10^{-3}$ & $1.04 \times 10^{-4}$ \\
\hline 39 & AL-WSS-199909292.2 & $2.19 \times 10^{-4}$ & $4.64 \times 10^{-5}$ & $1.42 \times 10^{-3}$ & $1.09 \times 10^{-4}$ \\
\hline 40 & AL-WSS-199910061.1 & $1.81 \times 10^{-4}$ & $3.45 \times 10^{-3}$ & $1.12 \times 10^{-3}$ & $2.39 \times 10^{-4}$ \\
\hline 41 & AL-WSS-199910131.1 & $1.57 \times 10^{-4}$ & $4.27 \times 10^{-5}$ & $9.86 \times 10^{-4}$ & $9.70 \times 10^{-5}$ \\
\hline 42 & AL-WSS-199910201.1 & $2.26 \times 10^{-4}$ & $4.87 \times 10^{-5}$ & $1.64 \times 10^{-3}$ & $1.19 \times 10^{-4}$ \\
\hline 43 & AL-WSS-199910271.1 & $1.25 \times 10^{-4}$ & $3.64 \times 10^{-5}$ & $9.78 \times 10^{-4}$ & $8.99 \times 10^{-5}$ \\
\hline 44 & AL-WSS-199911031.1 & $8.07 \times 10^{-5}$ & $2.91 \times 10^{-5}$ & $1.00 \times 10^{-3}$ & $9.71 \times 10^{-5}$ \\
\hline 45 & AL-WSS-199911101.1 & $1.31 \times 10^{-4}$ & $2.88 \times 10^{-3}$ & $1.49 \times 10^{-3}$ & $2.13 \times 10^{-4}$ \\
\hline 46 & AL-WSS-199911171.1 & $1.08 \times 10^{-4}$ & $3.50 \times 10^{-5}$ & $1.09 \times 10^{-3}$ & $1.08 \times 10^{-4}$ \\
\hline 47 & AL-WSS-199911241.1 & $6.64 \times 10^{-5}$ & $2.78 \times 10^{-5}$ & $1.51 \times 10^{-3}$ & $1.07 \times 10^{-4}$ \\
\hline 49 & AL-WSS-199912081.1 & $1.27 \times 10^{-4}$ & $3.57 \times 10^{-5}$ & $1.43 \times 10^{-3}$ & $1.10 \times 10^{-4}$ \\
\hline 50 & AL-WSS-199912151.1 & $3.86 \times 10^{-5}$ & $2.62 \times 10^{-5}$ & $6.77 \times 10^{-4}$ & $8.36 \times 10^{-5}$ \\
\hline 51 & AL-WSS-199912221.1 & $3.60 \times 10^{-5}$ & $1.89 \times 10^{-5}$ & $1.09 \times 10^{-3}$ & $8.98 \times 10^{-5}$ \\
\hline 52 & AL-WSS-199912291.1 & $3.62 \times 10^{-5}$ & $2.17 \times 10^{-5}$ & $9.07 \times 10^{-4}$ & $9.09 \times 10^{-5}$ \\
\hline
\end{tabular}

Quality Control

\begin{tabular}{|c|c|c|c|c|c|}
\hline 1 & QC\#1 & $4.59 \times 10^{-2}$ & $1.64 \times 10^{0}$ & NR & NR \\
\hline 2 & QC\#1 & $4.63 \times 10^{2}$ & $1.65 \times 10^{0}$ & NR & NR \\
\hline 3 & QC\#1 & $4.61 \times 10^{2}$ & $1.64 \times 10^{0}$ & NR & NR \\
\hline 4 & QC\#1 & $4.63 \times 10^{2}$ & $1.65 \times 10^{0}$ & NR & NR \\
\hline
\end{tabular}


Table C.1, cont.

\begin{tabular}{|c|c|c|c|c|c|}
\hline \multirow{2}{*}{$\begin{array}{c}\text { Sample } \\
\text { Week }\end{array}$} & \multirow[b]{2}{*}{ Sample ID } & \multicolumn{2}{|c|}{ Alpha $\left(\mathrm{Bq} / \mathbf{m}^{3}\right)$} & \multicolumn{2}{|c|}{$\operatorname{Beta}\left(\mathrm{Bq} / \mathrm{m}^{3}\right)$} \\
\hline & & Concentration & $2 \times$ TPU $^{1}$ & Concentration & $2 \times$ TPU \\
\hline \multicolumn{6}{|c|}{ Quality Control, cont. } \\
\hline 5 & QC\#1 & $4.66 \times 10^{2}$ & $1.66 \times 10^{0}$ & NR & NR \\
\hline 6 & QC\#1 & $4.72 \times 10^{2}$ & $1.67 \times 10^{0}$ & NR & NR \\
\hline 7 & QC\#1 & $4.53 \times 10^{2}$ & $1.61 \times 10^{0}$ & NR & NR \\
\hline 8 & QC\#1 & $4.69 \times 10^{2}$ & $1.67 \times 10^{0}$ & NR & NR \\
\hline 9 & QC\#1 & $4.56 \times 10^{2}$ & $1.63 \times 10^{0}$ & NR & NR \\
\hline 10 & QC\#1 & $5.17 \times 10^{2}$ & $1.74 \times 10^{0}$ & NR & NR \\
\hline 12 & QC\#1 & $4.64 \times 10^{2}$ & $1.65 \times 10^{0}$ & NR & NR \\
\hline 14 & QC\#1 & $4.54 \times 10^{2}$ & $1.62 \times 10^{0}$ & NR & NR \\
\hline 16 & QC\#1 & $4.52 \times 10^{2}$ & $1.61 \times 10^{0}$ & NR & NR \\
\hline 17 & QC\#1 & $4.54 \times 10^{2}$ & $1.62 \times 10^{0}$ & NR & NR \\
\hline 18 & QC\#1 & $4.68 \times 10^{2}$ & $1.67 \times 10^{0}$ & NR & NR \\
\hline 19 & QC\#1 & $4.53 \times 10^{2}$ & $1.62 \times 10^{0}$ & NR & NR \\
\hline 23 & QC\#1 & $4.65 \times 10^{2}$ & $1.66 \times 10^{0}$ & NR & NR \\
\hline 24 & QC\#1 & $4.65 \times 10^{2}$ & $1.67 \times 10^{0}$ & NR & NR \\
\hline 27 & QC\#1 & $4.54 \times 10^{2}$ & $1.63 \times 10^{0}$ & NR & NR \\
\hline 28 & QC\#1 & $4.60 \times 10^{2}$ & $1.64 \times 10^{0}$ & NR & NR \\
\hline 29 & QC\#1 & $4.58 \times 10^{2}$ & $1.64 \times 10^{0}$ & NR & NR \\
\hline 30 & QC\#1 & $4.57 \times 10^{2}$ & $1.61 \times 10^{0}$ & NR & NR \\
\hline 32 & QC\#1 & $4.60 \times 10^{2}$ & $1.63 \times 10^{0}$ & NR & NR \\
\hline 34 & QC\#1 & $4.67 \times 10^{2}$ & $1.65 \times 10^{0}$ & NR & NR \\
\hline 35 & QC\#1 & $4.58 \times 10^{2}$ & $1.61 \times 10^{0}$ & NR & NR \\
\hline 36 & QC\#1 & $4.56 \times 10^{2}$ & $1.62 \times 10^{0}$ & NR & NR \\
\hline 37 & QC\#1 & $4.65 \times 10^{2}$ & $1.64 \times 10^{0}$ & NR & NR \\
\hline 38 & QC\#1 & $4.61 \times 10^{2}$ & $1.63 \times 10^{0}$ & NR & NR \\
\hline 39 & QC\#1 & $4.50 \times 10^{2}$ & $1.59 \times 10^{0}$ & $1.57 \times 10^{0}$ & $8.39 \times 10^{-2}$ \\
\hline 42 & QC\#1 & $4.56 \times 10^{2}$ & $1.61 \times 10^{0}$ & $2.13 \times 10^{0}$ & $9.51 \times 10^{-2}$ \\
\hline 43 & QC\#1 & $4.54 \times 10^{2}$ & $1.60 \times 10^{0}$ & $2.48 \times 10^{0}$ & $1.05 \times 10^{-1}$ \\
\hline 47 & QC\#1 & $4.52 \times 10^{2}$ & $1.60 \times 10^{0}$ & $1.27 \times 10^{0}$ & $7.50 \times 10^{-2}$ \\
\hline 49 & QC\#1 & $4.58 \times 10^{2}$ & $1.61 \times 10^{0}$ & $2.52 \times 10^{0}$ & $1.05 \times 10^{-1}$ \\
\hline 52 & QC\#1 & $4.52 \times 10^{2}$ & $1.60 \times 10^{0}$ & $2.00 \times 10^{0}$ & $9.43 \times 10^{-2}$ \\
\hline 13 & QC\#2 & $5.28 \times 10^{2}$ & $1.76 \times 10^{0}$ & NR & NR \\
\hline 20 & QC\#2 & $5.03 \times 10^{2}$ & $1.71 \times 10^{0}$ & NR & NR \\
\hline 25 & QC\#2 & $5.28 \times 10^{2}$ & $1.78 \times 10^{0}$ & NR & NR \\
\hline 31 & QC\#2 & $5.15 \times 10^{2}$ & $1.72 \times 10^{0}$ & NR & NR \\
\hline 33 & QC\#2 & $5.13 \times 10^{2}$ & $1.72 \times 10^{0}$ & NR & NR \\
\hline 40 & QC\#2 & $5.03 \times 10^{2}$ & $1.68 \times 10^{0}$ & $2.48 \times 10^{0}$ & $1.05 \times 10^{-1}$ \\
\hline 43 & QC\#2 & $5.17 \times 10^{2}$ & $1.72 \times 10^{0}$ & $2.45 \times 10^{0}$ & $1.02 \times 10^{-1}$ \\
\hline 44 & QC\#2 & $5.12 \times 10^{2}$ & $1.70 \times 10^{0}$ & $3.10 \times 10^{0}$ & $1.18 \times 10^{-1}$ \\
\hline 50 & QC\#2 & $5.17 \times 10^{2}$ & $1.72 \times 10^{0}$ & $3.47 \times 10^{0}$ & $1.23 \times 10^{-1}$ \\
\hline 11 & QC\#3 & $5.03 \times 10^{2}$ & $1.71 \times 10^{0}$ & NR & NR \\
\hline 15 & QC\#3 & $5.13 \times 10^{2}$ & $1.74 \times 10^{0}$ & NR & NR \\
\hline 21 & QC\#3 & $5.11 \times 10^{2}$ & $1.74 \times 10^{0}$ & NR & NR \\
\hline 26 & QC\#3 & $5.16 \times 10^{2}$ & $1.76 \times 10^{0}$ & NR & NR \\
\hline 41 & QC\#3 & $5.01 \times 10^{2}$ & $1.68 \times 10^{0}$ & $1.91 \times 10^{0}$ & $9.22 \times 10^{-2}$ \\
\hline 45 & QC\#3 & $5.06 \times 10^{2}$ & $1.69 \times 10^{0}$ & $2.61 \times 10^{0}$ & $1.08 \times 10^{-1}$ \\
\hline 51 & QC\#3 & $5.05 \times 10^{2}$ & $1.70 \times 10^{0}$ & $2.88 \times 10^{0}$ & $1.12 \times 10^{-1}$ \\
\hline 22 & QC\#4 & $5.16 \times 10^{2}$ & $1.75 \times 10^{0}$ & NR & NR \\
\hline 42 & QC\#4 & $5.02 \times 10^{2}$ & $1.68 \times 10^{0}$ & $1.37 \times 10^{0}$ & $7.83 \times 10^{-2}$ \\
\hline 44 & QC\#4 & $5.18 \times 10^{2}$ & $1.72 \times 10^{0}$ & NR & NR \\
\hline
\end{tabular}


Table C.1, cont.

\begin{tabular}{|c|c|c|c|c|c|}
\hline \multirow{2}{*}{$\begin{array}{c}\text { Sample } \\
\text { Week }\end{array}$} & \multirow[b]{2}{*}{ Sample ID } & \multicolumn{2}{|c|}{ Alpha $\left(\mathrm{Bq} / \mathbf{m}^{3}\right)$} & \multicolumn{2}{|c|}{ Beta $\left(\mathrm{Bq} / \mathrm{m}^{3}\right)$} \\
\hline & & Concentration & $2 \times \mathbf{T P U}^{1}$ & Concentration & $2 \times \mathrm{TPU}$ \\
\hline \multicolumn{6}{|c|}{ Quality Control, cont. } \\
\hline 46 & QC\#4 & $5.10 \times 10^{2}$ & $1.70 \times 10^{0}$ & $2.83 \times 10^{0}$ & $1.12 \times 10^{-1}$ \\
\hline 1 & QC\#5 & NR & NR & $9.80 \times 10^{2}$ & $2.13 \times 10^{0}$ \\
\hline 2 & QC\#5 & NR & NR & $9.82 \times 10^{2}$ & $2.14 \times 10^{0}$ \\
\hline 3 & QC\#5 & NR & NR & $9.74 \times 10^{2}$ & $2.12 \times 10^{0}$ \\
\hline 4 & QC\#5 & NR & NR & $9.95 \times 10^{2}$ & $2.17 \times 10^{0}$ \\
\hline 5 & QC\#5 & NR & NR & $9.72 \times 10^{2}$ & $2.12 \times 10^{0}$ \\
\hline 6 & QC\#5 & NR & NR & $9.68 \times 10^{2}$ & $2.12 \times 10^{0}$ \\
\hline 7 & QC\#5 & NR & NR & $9.72 \times 10^{2}$ & $2.12 \times 10^{0}$ \\
\hline 8 & QC\#5 & NR & NR & $9.47 \times 10^{2}$ & $2.08 \times 10^{0}$ \\
\hline 9 & QC\#5 & NR & NR & $9.55 \times 10^{2}$ & $2.04 \times 10^{0}$ \\
\hline 10 & QC\#5 & NR & NR & $9.73 \times 10^{2}$ & $2.06 \times 10^{0}$ \\
\hline 12 & QC\#5 & NR & NR & $9.86 \times 10^{2}$ & $2.11 \times 10^{0}$ \\
\hline 14 & QC\#5 & NR & NR & $9.76 \times 10^{2}$ & $2.06 \times 10^{0}$ \\
\hline 16 & QC\#5 & NR & NR & $9.65 \times 10^{2}$ & $2.06 \times 10^{0}$ \\
\hline 17 & QC\#5 & NR & NR & $9.96 \times 10^{2}$ & $2.12 \times 10^{0}$ \\
\hline 18 & QC\#5 & NR & NR & $9.61 \times 10^{2}$ & $2.06 \times 10^{0}$ \\
\hline 19 & QC\#5 & NR & NR & $9.65 \times 10^{2}$ & $2.06 \times 10^{0}$ \\
\hline 23 & QC\#5 & NR & NR & $9.58 \times 10^{2}$ & $2.05 \times 10^{0}$ \\
\hline 24 & QC\#5 & NR & NR & $9.74 \times 10^{2}$ & $2.08 \times 10^{0}$ \\
\hline 27 & QC\#5 & NR & NR & $9.75 \times 10^{2}$ & $2.08 \times 10^{0}$ \\
\hline 28 & QC\#5 & NR & NR & $9.73 \times 10^{2}$ & $2.08 \times 10^{0}$ \\
\hline 29 & QC\#5 & NR & NR & $9.75 \times 10^{2}$ & $2.09 \times 10^{0}$ \\
\hline 30 & QC\#5 & NR & NR & $9.57 \times 10^{2}$ & $2.02 \times 10^{0}$ \\
\hline 32 & QC\#5 & NR & NR & $9.59 \times 10^{2}$ & $2.04 \times 10^{2}$ \\
\hline 34 & QC\#5 & NR & NR & $9.45 \times 10^{2}$ & $2.00 \times 10^{0}$ \\
\hline 35 & QC\#5 & NR & NR & $9.19 \times 10^{2}$ & $1.96 \times 10^{0}$ \\
\hline 36 & QC\#5 & NR & NR & $9.73 \times 10^{2}$ & $2.06 \times 10^{0}$ \\
\hline 37 & QC\#5 & NR & NR & $9.21 \times 10^{2}$ & $1.96 \times 10^{0}$ \\
\hline 38 & QC\#5 & NR & NR & $9.15 \times 10^{2}$ & $1.95 \times 10^{0}$ \\
\hline 39 & QC\#5 & $1.13 \times 10^{0}$ & $7.95 \times 10^{-2}$ & $9.66 \times 10^{2}$ & $2.06 \times 10^{0}$ \\
\hline 42 & QC\#5 & $3.79 \times 10^{-1}$ & $4.72 \times 10^{-2}$ & $9.17 \times 10^{2}$ & $1.95 \times 10^{0}$ \\
\hline 43 & QC\#5 & $7.81 \times 10^{-1}$ & $6.66 \times 10^{-2}$ & $9.74 \times 10^{2}$ & $2.08 \times 10^{0}$ \\
\hline 47 & QC\#5 & $1.07 \times 10^{0}$ & $7.77 \times 10^{-2}$ & $9.43 \times 10^{2}$ & $2.02 \times 10^{0}$ \\
\hline 49 & QC\#5 & $1.18 \times 10^{0}$ & $8.22 \times 10^{-2}$ & $9.51 \times 10^{2}$ & $2.03 \times 10^{0}$ \\
\hline 52 & QC\#5 & $8.01 \times 10^{-1}$ & $6.75 \times 10^{-2}$ & $9.58 \times 10^{2}$ & $2.04 \times 10^{0}$ \\
\hline 13 & QC\#6 & NR & NR & $1.00 \times 10^{3}$ & $2.13 \times 10^{0}$ \\
\hline 20 & QC\#6 & NR & NR & $9.97 \times 10^{2}$ & $2.10 \times 10^{0}$ \\
\hline 25 & QC\#6 & NR & NR & $9.84 \times 10^{2}$ & $2.09 \times 10^{0}$ \\
\hline 31 & QC\#6 & NR & NR & $9.67 \times 10^{2}$ & $2.03 \times 10^{0}$ \\
\hline 33 & QC\#6 & NR & NR & $1.00 \times 10^{3}$ & $2.08 \times 10^{0}$ \\
\hline 40 & QC\#6 & $1.40 \times 10^{0}$ & $8.87 \times 10^{-2}$ & $9.97 \times 10^{2}$ & $2.09 \times 10^{0}$ \\
\hline 43 & QC\#6 & $5.68 \times 10^{-1}$ & $5.75 \times 10^{-2}$ & $9.32 \times 10^{2}$ & $1.96 \times 10^{0}$ \\
\hline 44 & QC\#6 & $4.33 \times 10^{-1}$ & $4.96 \times 10^{-2}$ & $9.88 \times 10^{2}$ & $2.09 \times 10^{0}$ \\
\hline 50 & QC\#6 & $1.38 \times 10^{0}$ & $8.86 \times 10^{-2}$ & $9.62 \times 10^{2}$ & $2.04 \times 10^{0}$ \\
\hline 11 & QC\#7 & NR & NR & $9.70 \times 10^{2}$ & $2.06 \times 10^{0}$ \\
\hline 15 & QC\#7 & NR & NR & $1.01 \times 10^{3}$ & $2.13 \times 10^{0}$ \\
\hline 21 & QC\#7 & NR & NR & $9.55 \times 10^{2}$ & $2.03 \times 10^{0}$ \\
\hline 26 & QC\#7 & NR & NR & $9.85 \times 10^{2}$ & $2.09 \times 10^{0}$ \\
\hline 41 & QC\#7 & $1.41 \times 10^{0}$ & $8.88 \times 10^{-2}$ & $9.66 \times 10^{2}$ & $2.06 \times 10^{0}$ \\
\hline
\end{tabular}


Table C.1, cont.

\begin{tabular}{|c|c|c|c|c|c|}
\hline \multirow[b]{2}{*}{$\begin{array}{c}\text { Sample } \\
\text { Week }\end{array}$} & \multirow[b]{2}{*}{ Sample ID } & \multicolumn{2}{|c|}{ Alpha $\left(\mathrm{Bq} / \mathbf{m}^{3}\right)$} & \multicolumn{2}{|c|}{ Beta $\left(\mathrm{Bq} / \mathrm{m}^{3}\right)$} \\
\hline & & Concentration & $2 \times \mathrm{TPU}^{1}$ & Concentration & $2 \times$ TPU \\
\hline \multicolumn{6}{|c|}{ Quality Control, cont. } \\
\hline 45 & QC\#7 & $-9.23 \times 10^{-3}$ & NR & $9.74 \times 10^{2}$ & $2.08 \times 10^{0}$ \\
\hline 51 & QC\#7 & $1.33 \times 10^{0}$ & $8.69 \times 10^{-2}$ & $9.63 \times 10^{2}$ & $2.04 \times 10^{0}$ \\
\hline 22 & QC\#8 & NR & NR & $9.80 \times 10^{2}$ & $2.06 \times 10^{0}$ \\
\hline 42 & QC\#8 & $1.28 \times 10^{0}$ & $8.46 \times 10^{-2}$ & $9.88 \times 10^{2}$ & $2.08 \times 10^{0}$ \\
\hline 44 & QC\#8 & $7.49 \times 10^{-1}$ & $6.61 \times 10^{-2}$ & NR & NR \\
\hline 46 & OC\#8 & $7.73 \times 10^{-2}$ & $2.11 \times 10^{-2}$ & $1.01 \times 10^{3}$ & $2.11 \times 10^{0}$ \\
\hline
\end{tabular}




\section{Appendix D \\ Equations}

\section{Minimum Detectable Activity (MDA)}

MDA is equal to the mean of a distribution such that 95 percent of the measurements of the distribution will produce analytical results that have the activity above that of a blank. It is possible to achieve a very low level of detection by analyzing a large sample size and counting for a very long time.

The laboratory was advised to use the following equation for calculating the MDAs for each radionuclide in various sample matrices:

$$
M D A=\frac{4.65 S_{b}}{K_{0.05} T}+\frac{3}{K_{0.05} T}
$$

Where:

$$
\begin{array}{ll}
S_{b} & =\text { Standard deviation of the background } \\
K_{0.05} & =\text { Type I and Type II errors } \\
T & =\text { Counting time }
\end{array}
$$

For further evaluation of MDA, refer to HPS N13.30-1996, Performance Criteria for Bioassay.

\section{Total Propagated Uncertainty (TPU)}

Total propagated uncertainty for each data point must be reported at $2 \sigma$ level. The TPU was calculated by using the following equation:

$$
T P U_{1 \sigma}=\sigma_{A C T}=\frac{\sqrt{\sigma_{N C R}^{2}+(N C R)^{2} *\left(R E_{E F F}^{2}+R E_{A L I}^{2}+R E_{R}^{2}+\Sigma R E_{C F}^{2}\right)}}{2.22 * E F F * A L I * R * A B N_{S} * e^{-\lambda t} * C F}
$$

Where:

$$
\begin{array}{lllll}
\mathrm{EFF}= & \text { Detector Efficiency } & \\
\mathrm{ALI}= & \text { Sample Aliquot Volume or Mass } & & \\
\mathrm{R}= & \text { Sample Tracer/Carrier Recovery } & & \\
\mathrm{ABN}_{\mathrm{s}}= & \begin{array}{l}
\text { Abundance Fraction of the Emissions Used for } \\
\text { Identification/Quantification }
\end{array} & & \\
\sigma_{\mathrm{NCR}}^{2}= & \text { Variance of the Net Sample Count Rate } &
\end{array}
$$




\begin{tabular}{|c|c|c|}
\hline NCR & $=$ & Net Sample Count Rate \\
\hline $\mathrm{RE}_{\mathrm{EFF}}^{2}$ & $=$ & Square of the Relative Error of the Efficiency Term \\
\hline $\mathrm{RE}_{\mathrm{ALI}}^{2}$ & $=$ & Square of the Relative Error of the Aliquot \\
\hline $\mathrm{RE}_{\mathrm{R}}^{2}$ & $=$ & Square of the Relative Error of the Sample Recovery \\
\hline $\mathrm{RE}_{\mathrm{CF}}^{2}$ & $=$ & Square of the Relative Error of Other Correction Factors \\
\hline$\lambda$ & $=$ & $\begin{array}{l}\text { Analyte Decay Constant }=\ln 2 /(\text { half-life }) \text { [Same units as the half-life used } \\
\text { to compute } \lambda \text { ] }\end{array}$ \\
\hline $\mathrm{t}$ & $=$ & $\begin{array}{l}\text { Time from Sample Collection to Radionuclide Separation or Mid-Point of } \\
\text { Count Time (Same units as half-life) }\end{array}$ \\
\hline $\mathrm{CF}$ & $=$ & $\begin{array}{l}\text { Other Correction Factors as Appropriate (i.e., Ingrowth factor, self- } \\
\text { absorption factor, etc.) }\end{array}$ \\
\hline
\end{tabular}

\section{Relative Error Ratio (RER)}

The Relative Error Ratio is a method, similar to a t-test, with which to compare duplicate results (see Chapters 4 and 8; WP 02-EM 3004).

$$
R E R=\frac{\left|x_{A}-x_{B}\right|}{\sqrt{\left(2 \sigma_{A}\right)^{2}+\left(2 \sigma_{R}\right)^{2}}}
$$

Where:
$X_{A} \quad=$
Mean Activity of Population A
$X_{B} \quad=$
Mean Activity of Population B
$\sigma_{\mathrm{A}} \quad=$
Standard Deviation of Population A
$\sigma_{B} \quad=$
Standard Deviation of Population B 


\section{Appendix E \\ Air Sampling Data: Mass of Particulates and Volumes of Air Sampled}

Table E.1 Mass of air particulates $(\mathrm{mg})$ and volume of air $\left(\mathrm{m}^{3}\right)$ (first quarter of 1999).

\begin{tabular}{|c|c|c|c|c|c|c|c|c|}
\hline Week & Mass & Volume & Mass & Volume & Mass & Volume & Mass & Volume \\
\hline & \multicolumn{2}{|c|}{$\mathrm{CBD}^{1}$} & \multicolumn{2}{|c|}{ MLR } & \multicolumn{2}{|c|}{ SMR } & \multicolumn{2}{|c|}{ SEC } \\
\hline 1 & 24.9 & 678.978 & 14.8 & 724.093 & 19.8 & 692.281 & 12.8 & 723.692 \\
\hline 2 & 18.2 & 458.676 & 8.6 & 476.06 & 17.1 & 446.788 & 6.7 & 462.587 \\
\hline 3 & 21.6 & 601.524 & 13.5 & 599.764 & 25 & 635.168 & 13.7 & 606.196 \\
\hline 4 & 14.7 & 571.081 & 7.1 & 583.046 & 9.1 & 582.698 & 2.8 & 548.386 \\
\hline 5 & 13.2 & 527.383 & 5.9 & 554.491 & 11.5 & 556.375 & 6.8 & 575.886 \\
\hline 6 & 21.7 & 570.524 & 10.3 & 607.552 & 31.2 & 558.781 & 12.5 & 605.836 \\
\hline 7 & 18 & 570.864 & 8.9 & 604.771 & 24.5 & 582.974 & 9.1 & 558.115 \\
\hline 8 & 21.8 & 592.954 & 9.1 & 600.111 & 19.9 & 575.543 & 8.8 & 592.251 \\
\hline 9 & 24.9 & 574.943 & 15.2 & 570.524 & 21.4 & 585.89 & 18.5 & 583.79 \\
\hline 10 & 17.8 & 588.173 & 7.5 & 570.714 & 15.5 & 564.644 & 10.6 & 566.317 \\
\hline 11 & 19.8 & 723.264 & 9.6 & 602.62 & 22.7 & 584.162 & 9 & 548.682 \\
\hline 12 & 10.8 & 461.319 & 7.3 & 570.645 & 14.6 & 595.126 & 7.7 & 550.442 \\
\hline 13 & 50.6 & 589.086 & 23.1 & 560.962 & 27.1 & 560.628 & 28.1 & 561.966 \\
\hline \multirow[t]{2}{*}{ Total } & 278 & 7508.769 & 140.9 & 7625.353 & 259.4 & 7521.058 & 147.1 & 7484.146 \\
\hline & \multicolumn{2}{|c|}{ WEE } & \multicolumn{2}{|c|}{ WFF } & \multicolumn{2}{|c|}{ WFF Duplicate } & \multicolumn{2}{|c|}{ WSS } \\
\hline 1 & 12.3 & 671.45 & 11.1 & 717.284 & 9.8 & 654.995 & 11.5 & 683.448 \\
\hline 2 & 8.1 & 509.2 & 5.7 & 507.471 & 606 & 504.679 & 8.9 & 486.933 \\
\hline 3 & 10.8 & 556.592 & 8.8 & 573.035 & 10.4 & 578.737 & 9.7 & 607.97 \\
\hline 4 & 6.3 & 564.156 & 7.4 & 588.751 & 5.1 & 579.911 & 6.6 & 558.543 \\
\hline 5 & 6.1 & 553.507 & 5.5 & 556.375 & 5.8 & 553.507 & 6.3 & 562.111 \\
\hline 6 & 9.6 & 563.137 & 9.6 & 591.578 & 9.5 & 565.981 & 10 & 588.734 \\
\hline 7 & 9.2 & 544.903 & 8.8 & 573.243 & 9.1 & 564.644 & 9.4 & 590.44 \\
\hline 8 & 11.1 & 600.111 & 8.6 & 582.349 & 8.4 & 590.871 & 9.7 & 599.752 \\
\hline 9 & 15.6 & 570.524 & 14.3 & 574.06 & 13.4 & 553.738 & 14.6 & 561.632 \\
\hline 10 & 8.8 & 592.251 & 8.9 & 572.223 & 7.7 & 572.223 & 10.3 & 572.903 \\
\hline 11 & 9.4 & 600.834 & 10 & 634.791 & 10.3 & 600.478 & 7.3 & 583.321 \\
\hline 12 & 8.4 & 549.783 & 9.1 & 588.382 & 9 & 570.645 & 9.2 & 610.026 \\
\hline 13 & 19.7 & 541 & 22.6 & 591.548 & 20 & 559.289 & 21.4 & 549.572 \\
\hline Total & 135.4 & 7417.448 & 130.4 & 7651.09 & 724.5 & 7449.698 & 134.9 & 7555.385 \\
\hline
\end{tabular}


Table E.2 Mass of air particulates (mg) and volume of air $\left(\mathrm{m}^{3}\right)$ (second quarter of 1999).

\begin{tabular}{|c|c|c|c|c|c|c|c|c|}
\hline Week & Mass & Volume & Mass & Volume & Mass & Volume & Mass & Volume \\
\hline & \multicolumn{2}{|c|}{$\mathrm{CBD}^{1}$} & \multicolumn{2}{|c|}{ MLR } & \multicolumn{2}{|c|}{ SMR } & \multicolumn{2}{|c|}{ SEC } \\
\hline 14 & 39.1 & 531.536 & 21.4 & 542.642 & 39.4 & 554.397 & 46.5 & 554.397 \\
\hline 15 & 22.1 & 528.375 & 12.4 & 555.784 & 14 & 527.669 & 10.6 & 559.958 \\
\hline 16 & 31.9 & 604.045 & 28 & 555.716 & 35.5 & 554.727 & 35.5 & 540.43 \\
\hline 17 & 35.2 & 558.285 & 24.5 & 580.895 & 28.4 & 546.725 & 30.9 & 587.29 \\
\hline 18 & 28.2 & 599.05 & 18.6 & 606.884 & $\mathrm{NC}^{2}$ & $\mathrm{NC}$ & 22.6 & 586.94 \\
\hline 19 & 21.7 & 537.251 & 9.8 & 542.966 & 19.5 & 561.966 & 11.9 & 586.877 \\
\hline 20 & 19.7 & 604.771 & $\mathrm{NC}$ & $\mathrm{NC}$ & 15.6 & 571.544 & 10.8 & 595.488 \\
\hline 21 & 14.7 & 526.795 & 7.8 & 545.746 & 13.7 & 556.783 & 8.4 & 546.398 \\
\hline 22 & 25.3 & 553.179 & 11.9 & 554.163 & 21.7 & 549.987 & 17.2 & 576.792 \\
\hline 23 & 14.9 & 570.714 & 6.6 & 574.743 & 9.1 & 561.966 & 7.6 & 570.184 \\
\hline 24 & 9.8 & 534.329 & 4.5 & 533.418 & 7.2 & 519.542 & 5.6 & 574.857 \\
\hline 25 & 18.8 & 515.307 & 9.5 & 552.523 & 11.4 & 546.473 & 10.7 & 477.813 \\
\hline 26 & 21.4 & 555.267 & 9.5 & 548.588 & 15 & 534.696 & 11.9 & 540.707 \\
\hline \multirow[t]{2}{*}{ Total } & 302.8 & 7218.904 & 164.5 & 6694.068 & 230.5 & 6586.475 & 230.2 & 7298.131 \\
\hline & \multicolumn{2}{|c|}{ WEE } & \multicolumn{2}{|c|}{ WEE Duplicate } & \multicolumn{2}{|c|}{ WFF } & \multicolumn{2}{|c|}{ WSS } \\
\hline 14 & 33.5 & 557.586 & 33.4 & 557.918 & 27 & 570.714 & 31.1 & 540.751 \\
\hline 15 & 9.8 & 526.479 & 9.6 & 551.623 & 8.9 & 557.28 & 10.7 & 565.767 \\
\hline 16 & 30 & 562.777 & 27.7 & 562.111 & 22.8 & 557.034 & 28.3 & 599.749 \\
\hline 17 & 23.5 & 527.106 & 27.7 & 549.9 & 20.6 & 580.895 & 24.7 & 550.123 \\
\hline 18 & 19.8 & 577.378 & $\mathrm{NC}$ & NC & 16.9 & 576.323 & 21.1 & 602.234 \\
\hline 19 & 11.7 & 556.924 & 11.6 & 553.079 & 9.6 & 588.34 & 12.9 & 573.718 \\
\hline 20 & 7.5 & 574.06 & 9.1 & 535.144 & 8.1 & 602.62 & 15.6 & 602.62 \\
\hline 21 & 8.1 & 560.628 & 9.9 & 560.628 & 8.9 & 550.228 & 10.6 & 571.669 \\
\hline 22 & 13.4 & 553.942 & 14.6 & 554.273 & 14 & 570.864 & 14 & 557.586 \\
\hline 23 & 7.5 & 595.819 & 7.1 & 592.251 & 6.9 & 562.79 & 7.6 & 539.788 \\
\hline 24 & 4.2 & 491.274 & 6.6 & 528.452 & 5.1 & 520.818 & 9.3 & 538.039 \\
\hline 25 & 8.9 & 540.109 & 9.1 & 554.397 & 8.4 & 551.212 & 8.3 & 528.992 \\
\hline 26 & 10.6 & 559.958 & 10.6 & 562.464 & 9.5 & 537.57 & 10.9 & 559.623 \\
\hline Total & 188.5 & 7184.04 & 177 & 6662.24 & 166.7 & 7326.688 & 205.1 & 7330.659 \\
\hline
\end{tabular}

${ }^{1}$ See Appendix B for Location Codes

${ }^{2}$ Sample not collected 
Table E.3 Mass of air particulates (ma) and volume of air $\left(\mathrm{m}^{3}\right)$ (third quarter of 1999).

\begin{tabular}{|c|c|c|c|c|c|c|c|c|}
\hline Week & Mass & Volume & Mass & Volume & Mass & Volume & Mass & Volume \\
\hline & \multicolumn{2}{|c|}{$\mathrm{CBD}^{1}$} & \multicolumn{2}{|c|}{ MLR } & \multicolumn{2}{|c|}{ SMR } & \multicolumn{2}{|c|}{ SEC } \\
\hline 27 & 15.8 & 569.505 & 10.7 & 575.2 & 11.3 & 552.42 & 9.3 & 570.184 \\
\hline 28 & 13.8 & 575.767 & 6.2 & 555.386 & 10.1 & 574.743 & 8.2 & 577.602 \\
\hline 29 & 17.7 & 514.695 & 11.9 & 547.122 & 14.4 & 529.935 & 12.8 & 536.932 \\
\hline 30 & 18.2 & 605.488 & 7.3 & 563.305 & 14.5 & 536.932 & 9.7 & 550.556 \\
\hline 31 & 15.4 & 529.945 & 9.8 & 554.605 & 15.8 & 537.54 & 10.9 & 559.114 \\
\hline 32 & $\mathrm{NC}^{2}$ & $\mathrm{NC}$ & 11.7 & 370.263 & 22.5 & 551.037 & 13.5 & 544.58 \\
\hline 33 & 20.4 & 515.157 & 10.4 & 527.472 & 21.7 & 557.867 & 12.5 & 564.146 \\
\hline 34 & 20.9 & 550.884 & 9.5 & 554.397 & 14.7 & 530.588 & 10.6 & 557.782 \\
\hline 35 & 18.6 & 568.485 & 9.2 & 567.806 & 23.9 & 579.509 & 7 & 573.377 \\
\hline 36 & 16.4 & 592.954 & 9 & 575.084 & 11.3 & 581.151 & 9.7 & 617.267 \\
\hline 37 & 12.9 & 498.019 & 9.9 & 578.047 & 10.4 & 551.101 & 8 & 622.242 \\
\hline 38 & 19.3 & 585.832 & 9 & 576.109 & 16.9 & 593.699 & 11.4 & 611.552 \\
\hline 39 & 28.3 & 574.401 & 15.2 & 573.718 & 24.2 & 570.864 & 13.9 & 570.864 \\
\hline 40 & $\mathrm{NC}$ & $\mathrm{NC}$ & $\mathrm{NC}$ & $\mathrm{NC}$ & $\mathrm{NC}$ & $\mathrm{NC}$ & $\mathrm{NC}$ & $\mathrm{NC}$ \\
\hline \multirow[t]{2}{*}{ Total } & 217.7 & 6681.132 & 129.8 & 7118.514 & 211.7 & 7247.386 & 137.5 & 7456.198 \\
\hline & \multicolumn{2}{|c|}{ WEE } & \multicolumn{2}{|c|}{ WFF } & \multicolumn{2}{|c|}{ WSS } & \multicolumn{2}{|c|}{ WSS Duplicate } \\
\hline 27 & 7.8 & 544.851 & 8.2 & 568.961 & 10.7 & 548.916 & 9.7 & 554.936 \\
\hline 28 & 7.1 & 567.174 & 6.9 & 570.038 & 10.8 & 581.151 & 5.7 & 561.112 \\
\hline 29 & 11.3 & 546.149 & 10.1 & 559.78 & 12.5 & 540.751 & 11.4 & 543.612 \\
\hline 30 & 8.2 & 541.072 & 7.7 & 549.66 & 10.9 & 556.924 & 4.7 & 462.889 \\
\hline 31 & 10.9 & 560.628 & 9.3 & 563.137 & 10.9 & 551.76 & 10.1 & 554.605 \\
\hline 32 & 12.5 & 562.301 & 11.1 & 562.636 & 13.3 & 533.758 & 13 & 556.592 \\
\hline 33 & 11.2 & 531.852 & 11 & 561.297 & 14.5 & 552.749 & 14.2 & 547.051 \\
\hline 34 & 8.9 & 554.068 & 9.1 & 569.024 & 11.5 & 551.54 & 9.3 & 554.397 \\
\hline 35 & 7.4 & 556.783 & 7.4 & 568.146 & 9.1 & 559.289 & 8.6 & 547.933 \\
\hline 36 & 8.5 & 577.945 & 7.9 & 583.321 & 9.7 & 571.883 & 10.6 & 563.64 \\
\hline 37 & 10.3 & 600.828 & 9.6 & 615.065 & 9.3 & 563.137 & 10.2 & 572.011 \\
\hline 38 & 8.8 & 569.362 & 8.3 & 600.478 & $\mathrm{NC}$ & $\mathrm{NC}$ & 10.7 & 605.836 \\
\hline 39 & 14.2 & 565.864 & 13.3 & 572.563 & 13.3 & 571.883 & 15.1 & 575.084 \\
\hline 40 & $\mathrm{NC}$ & $\mathrm{NC}$ & $\mathrm{NC}$ & $\mathrm{NC}$ & $\mathrm{NC}$ & $\mathrm{NC}$ & $\mathrm{NC}$ & $\mathrm{NC}$ \\
\hline Total & 127.1 & 7278.877 & 119.9 & 7444.106 & 136.5 & 6683.741 & 133.3 & 7199.698 \\
\hline
\end{tabular}

${ }^{1}$ See Appendix B for Location Codes

${ }^{2}$ Sample not collected 
Table E.4 Mass of air particulates (ma) and volume of air $\left(\mathrm{m}^{3}\right)$ (fourth quarter of 1999).

\begin{tabular}{|c|c|c|c|c|c|c|c|c|}
\hline Week & Mass & Volume & Mass & Volume & Mass & Volume & Mass & Volume \\
\hline & \multicolumn{2}{|c|}{$\mathrm{CBD}^{1}$} & \multicolumn{2}{|c|}{ MLR } & \multicolumn{2}{|c|}{ MLR Duplicate } & \multicolumn{2}{|c|}{ SMR } \\
\hline 41 & 23 & 506.903 & 10 & 502.004 & 10 & 489.703 & 18.5 & 494.749 \\
\hline 42 & 18.7 & 555.451 & 11.2 & 543.877 & 12.2 & 578.047 & 19.6 & 569.024 \\
\hline 43 & 21.1 & 581.304 & 17.7 & 579.509 & 16.7 & 553.942 & 27.1 & 561.455 \\
\hline 44 & 28 & 577.133 & 17 & 603.689 & 18.8 & 597.939 & 41.4 & 597.586 \\
\hline 45 & 25.8 & 561.231 & 16.6 & 573.035 & 15.8 & 578.737 & 23.2 & 559.447 \\
\hline 46 & 27.9 & 553.079 & 15.6 & 556.261 & $\mathrm{NC}^{2}$ & $\mathrm{NC}$ & 25.3 & 600.121 \\
\hline 47 & 28.8 & 477.621 & 19.2 & 555.583 & 17.5 & 537.7 & 36.9 & 525.888 \\
\hline 48 & 32.2 & 613.59 & 16.6 & 647.615 & 17.6 & 654.373 & 26.1 & 640.034 \\
\hline 49 & 26.8 & 557.034 & 17.7 & 579.427 & 17 & 616.533 & 35.7 & 579.082 \\
\hline 50 & 25.6 & 569.62 & 14.2 & 619.019 & 15.5 & 596.553 & 48 & 561.297 \\
\hline 51 & 15.2 & 464.524 & 17.2 & 483.746 & 16.4 & 483.746 & 19.3 & 493.519 \\
\hline 52 & 13.9 & 675.954 & 22.6 & 734.061 & 22.9 & 714.132 & 19.5 & 649.873 \\
\hline 53 & 13.7 & 586.44 & 15.5 & 561.424 & 16.5 & 603.689 & 23 & 555.93 \\
\hline \multirow[t]{2}{*}{ Total } & 300.7 & 7279.884 & 211.1 & 7539.25 & 196.9 & 7005.094 & 363.6 & 7388.005 \\
\hline & \multicolumn{2}{|c|}{ SEC } & \multicolumn{2}{|c|}{ WEE } & \multicolumn{2}{|c|}{ WFF } & \multicolumn{2}{|c|}{ WSS } \\
\hline 41 & $\mathrm{NC}$ & $\mathrm{NC}$ & 9.1 & 487.661 & 9.1 & 492.092 & 9.8 & 487.314 \\
\hline 42 & 10.7 & 576.109 & 10.5 & 586.59 & 10.6 & 599.169 & 11.8 & 553.235 \\
\hline 43 & 12.6 & 550.96 & 8.4 & 551.76 & 9.3 & 586.24 & 10.9 & 562.801 \\
\hline 44 & 16.2 & 603.689 & 11.8 & 586.787 & 10.8 & 575.281 & 14.3 & 606.563 \\
\hline 45 & 11.7 & 563.975 & 15.6 & 555.93 & 10.4 & 592.638 & 12.6 & 555.93 \\
\hline 46 & 14 & 587.29 & 10.5 & 547.703 & 11.2 & 587.64 & 13.8 & 587.64 \\
\hline 47 & 15.3 & 506.057 & 16.9 & 526.473 & 11.9 & 516.275 & 15 & 511.005 \\
\hline 48 & 14.2 & 702.808 & 12.3 & 640.287 & 9.9 & 639.952 & 12.3 & 620.786 \\
\hline 49 & 13.4 & 585.832 & 11.7 & 396.139 & 10.8 & 595.843 & 14 & 599.05 \\
\hline 50 & 14.7 & 598.337 & 15.3 & 619.387 & 11.3 & 573.718 & 16.3 & 576.573 \\
\hline 51 & 7.1 & 510.621 & 9.9 & 545.583 & 7.8 & 584.728 & 11.2 & 527.723 \\
\hline 52 & 8.3 & 681.34 & 9.3 & 650.844 & 9 & 627.95 & 11.6 & 676.657 \\
\hline 53 & 9.7 & 587.64 & 18.1 & 574.17 & 6.9 & 585.54 & 10.4 & 560.293 \\
\hline Total & 1479 & 7054.658 & 159.4 & 7269.314 & 129 & 7557.066 & 164 & 7425.57 \\
\hline
\end{tabular}

${ }^{1}$ See Appendix B for Location Codes

${ }^{2}$ Sample not collected 


\section{Appendix F}

\section{Authors and Contributors}

\section{Executive Summary}

Amy Adams Luft (ed.)

Stewart B. Jones

Irene Joo

Wesley Nance

\section{Chapter 1 Introduction}

Amy Adams Luft (ed.)

Stewart B. Jones

Irene Joo

Wesley Nance

Chapter 2 Environmental Program Information

Amy Adams Luft (ed.)

Don L. Gilbert

Stewart B. Jones

Doug C. Lynn

Roger D. Simmons

\section{Chapter 3 Environmental}

\section{Compliance}

Timothy D. Reynolds, Ph.D. (ed.)

Rick Chavez

James R. Hollen

Irene Joo

Steve Kouba

Willie Most

Miriam Whatley

\section{Chapter 4 Environmental}

Radiological Program Information

Randall C. Morris, Ph.D. (ed.)

Balwan S. Hooda

Irene Joo

Wesley Nance

\section{Chapter 5 Environmental Non-} Radiological Program Information

Roy B. Evans, Ph.D. (ed.)

Tim W. Brown

Adela M. Cantu

Rey C. Carrasco

Chapter 6 Ground-water Monitoring

Timothy D. Reynolds, Ph.D. (ed.)

Melvin L. Balderrama

Mark Crawley

Butch S. Daszczyszak

William Foster

Irene Joo

Ron G. Richardson

Chapter 7 Radiological Dose Assessment

Ronald W. Warren (ed.)

Randall C. Morris, Ph.D.

Chapter 8 Quality Assurance

Don B. Martin (ed.)

\section{Appendices}

Timothy D. Reynolds, Ph.D. (ed)

\section{Administrative Support}

D. Katie Dimick

Melissa R. Harwood

Elizabeth Torrey

Mak Walker

\section{Data Entry}

Celeste Lamb

Margaret E. Winter 